José Eduardo Martinelli Filho

\title{
Variação temporal e crescimento do zooplâncton no litoral norte de São Paulo, com ênfase em estágios imaturos de copépodes
}

Tese apresentada ao Instituto
Oceanográfico da Universidade de São
Paulo, como parte dos requisitos para a
obtenção do título de Doutor em Ciências,
área de Oceanografia Biológica

Orientador:

Prof. Dr. Rubens Mendes Lopes

São Paulo

2013 
Universidade de São Paulo

Instituto Oceanográfico

Variação temporal e crescimento do zooplâncton no litoral norte do estado de São Paulo, com ênfase em estágios imaturos de copépodes

José Eduardo Martinelli Filho

Tese apresentada ao Instituto Oceanográfico da Universidade de São Paulo, como parte dos requisitos para a obtenção do título de doutor em Ciências, área de Oceanografia Biológica.

Julgada e aprovada em 02/12/2013

Prof. Dr. Rubens Mendes Lopes

Conceito

(Orientador)

Profa. Dra. Sigrid Neumann Leitão

Conceito

Profa. Dra. Betina Kozlowsky Suzuki

Conceito

Prof. Dr. Luiz Felipe Mendes de Gusmão

Conceito

Prof. Dr. Mário Katsuragawa

Conceito 
Dedico este trabalho a Deus e minha família: Rosiane e Mateus dos Santos Martinelli. 
Earth, stream and tree encircled by sea Waves sweep the sand from my island. My sunsets fade.

Field and glade wait only for rain Grain after grain love erodes my High weathered walls which fend off the tide

Cradle the wind

To my island.

(Peter J. Sinfield / Robert Fripp, 1973) 


\section{AGRADECIMENTOS}

Esta trilha com diversos obstáculos e sinuosidades finalmente chega ao fim. Seriam necessárias várias páginas para agradecer pessoalmente todos aqueles que, de uma maneira ou outra, estiveram envolvidos durante a caminhada.

Agradeço primeiramente ao prof. Dr. Rubens Mendes Lopes, pelas orientações, conselhos e amizade durante a última década de nossas vidas. Obrigado por ter me aceitado na equipe do Laboratório de Sistemas Pelágicos (LAPS) desde 2003, quando eu ainda era aluno de graduação.

Diversas instituições tornaram esse trabalho possível. Agradeço à Coordenação de Aperfeiçoamento de Pessoal de Nível Superior (CAPES), pela bolsa de doutorado concedida durante o primeiro ano deste trabalho. À Universidade de São Paulo, em especial ao Instituto Oceanográfico e Instituto de Biociências, a alma mater de minha formação como pesquisador e professor.

Agradecimentos especiais às equipes dos laboratórios de Ictioplâncton e de Produção Primária, coordenados pelos professores Mário Katsuragawa e Salvador Gaeta respectivamente, pelo apoio através de empréstimo de instrumentos de coleta e pelas análises laboratoriais de clorofila- $a$ e feopigmentos. Um muito obrigado especial ao prof. Mário, pela supervisão durante o estágio do programa de monitoria PAE, no primeiro semestre de 2009.

Inúmeros funcionários do IO foram vitais para este trabalho. Agradeço a todos os funcionários da base de apoio à pesquisa Clarimundo Jesus em Ubatuba, aos técnicos do departamento de Oceanografia Biológica, à seção de transporte, marcenaria e biblioteca. Ao amigo Wagner Pinheiro, por atender à todas as solicitações de literatura realizadas ao longo dos últimos cinco anos (não foram poucas...) meus mais sinceros agradecimentos

À equipe da secretaria de pós-graduação: Ana Paula, Silvana e Letícia, por solucionarem minhas dúvidas e pela paciência em cada telefonema nos quais eu explicava meus problemas. 
Aos companheiros de trabalho e pós-graduação do IO ao longo dos anos, especialmente: Márcio Okhawara, Mauro de Melo Júnior, Leonardo Myiashita, Cássia e Newton Aquino, Riguel Contente, Wellington Fernandez, Maíra Pombo, Fábio Hasue, Damian, Catarina Marcolin, Daniela Rimoldi, Adriana Crété, Lilian Oliveira, Túlia Martinez, Naira Juliana da Silva e muitos outros.

À Universidade Federal do Pará (UFPA), campus Altamira, em especial à coordenação do campus e Faculdade de Ciências Biológicas, por possibilitar à continuidade deste trabalho. À Faculdade de Oceanografia do Instituto de Geociências da UFPA, campus Guamá em Belém, pelo apoio durante o último ano de execução desta tese.

Diversos colegas contribuíram com críticas e sugestões durante a realização deste trabalho. Agradeço-os pelas produtivas discussões: Eduardo Tavares Paes, Nadson Ressyé Simões, Luiz Felipe Gusmão, James T. Lee, Leonardo Myiashita e Mauro de Melo Júnior.

Aos colegas e alunos que contribuíram durante as etapas de campo deste trabalho: Ronan Brito dos Santos, Naira J. da Silva, Márcia Yoshida (Pikachu), Aurélia Gabellini, Márcio e Caio Ribeiro. Às alunas Ondina Lilan do Couto, Aline Jéssica Pinho Flor, ao Jones Ribeiro e Ronan pelo auxílio com as fotografias dos experimentos. Aos alunos Bruno e Micaela na etapa final deste trabalho.

À república Estação 69, em especial pelos moradores Burcio, Caio Labor, Coelho e Juarez, pelo apoio logístico em São Paulo.

Por fim, agradeço especialmente minha família, pelo carinho e compreensão ao longo desses últimos cinco anos: minha mãe Anete e meu pai José Eduardo, meus irmãos Juliana, Paula e Marcos, minha sobrinha Stella, meus tios e primos. Agradeço minha tia Anelise pelo carinho, apoio e incentivo ao longo da minha pós-graduação. Agradeço especialmente minha sogra, Maria R. B. dos Santos por cuidar de meu filho durante tantos finais de semana dedicados a este trabalho.

A conclusão desta tese só foi possível pela dedicação, apoio e entusiasmo de minha esposa Rosiane dos Santos Martinelli. Obrigado por todo o amor e pelo nosso filho Mateus, nossa inspiração. 


\section{SUMÁRIO}

RESUMO

ABSTRACT

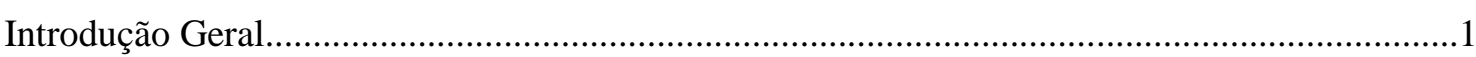

Capítulo 1. Estrutura e variação temporal do zooplâncton em uma estação fixa no litoral norte do estado de São Paulo, Brasil 10

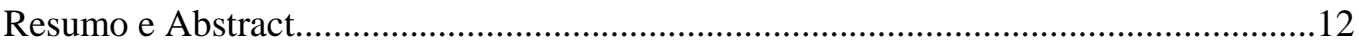

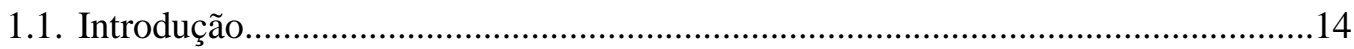

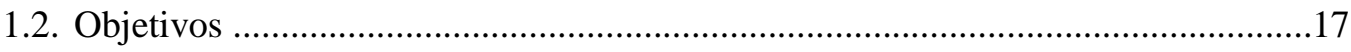

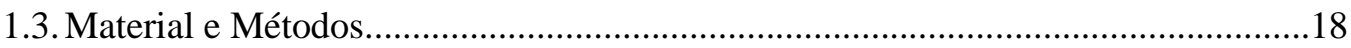

1.3.1. Obtenção de variáveis ambientais e coleta do plâncton..........................18

1.3.2. Clorofila- $a$ e feopigmentos (clorofila acidificada) .................................19

1.3.3. Análises qualitativa e quantitativa do zooplâncton ................................21

1.3.4. Densidade zooplanctônica e análises qualitativas..................................22

1.3.5. Tratamento dos dados e análises estatísticas .......................................23

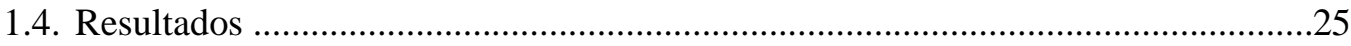

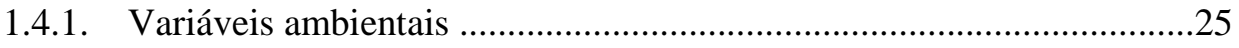

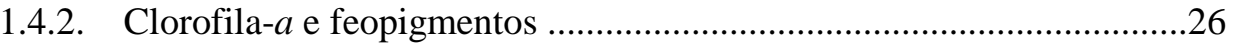

1.4.3. Estrutura e variação da comunidade .....................................................28

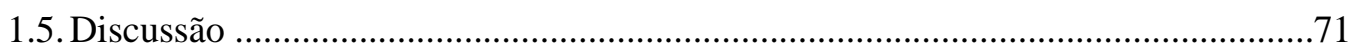

1.5.1. Variáveis ambientais e a comunidade zooplanctônica ..........................71

1.5.2. Variáveis ecológicas e principais grupos do zooplâncton ...........74

1.5.3. Densidade comparada entre os estágios de desenvolvimento de

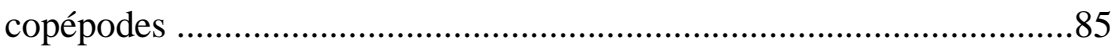

1.5.4. Fatores controladores da variabilidade temporal do zooplâncton .........87

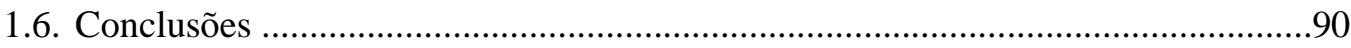

Capítulo 2. Crescimento e produção de copépodes pelágicos no litoral norte do estado de São

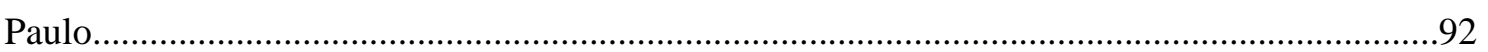

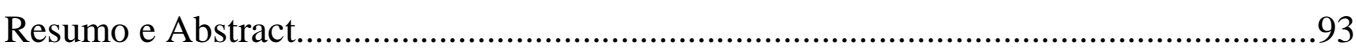

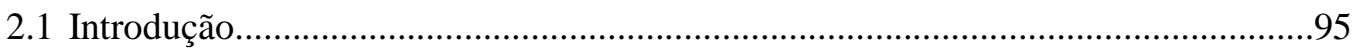

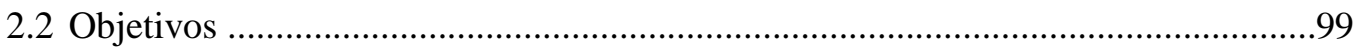

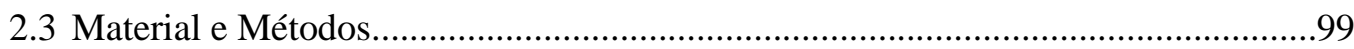

2.3.1 Obtenção das variáveis ambientais e do plâncton...................................99

2.3.2 Clorofila- $a$ e feopigmentos (clorofila acidificada)................................101 
2.3.3 Análise qualitativa dos copépodes......................................................102

2.3.4 Coortes artificiais e desenho experimental..........................................103

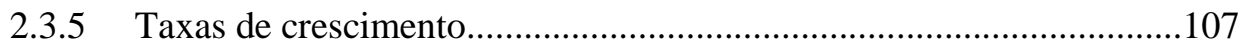

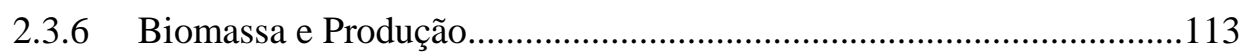

2.3.7 Tratamento de dados e análise estatística............................................114

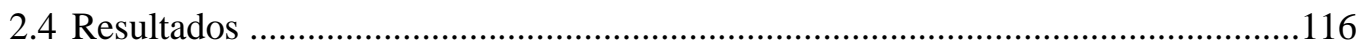

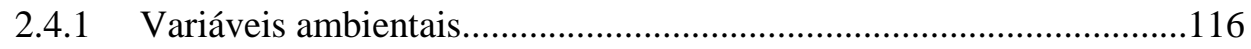

2.4.2 Fracionamento da comunidade de copépodes......................................118

2.4.3 Crescimento, biomassa e produção de juvenis de copépodes...............122

2.4.4 Comparação entre o crescimento medido e o estimado..........................159

2.4.5 Síntese das comparações das taxas de crescimento .............................162

2.4.6 Abundância, Biomassa e Produção das principais famílias..................164

2.4.7 Abundância, Biomassa e Produção das ordens Calanoida, Cyclopoida e

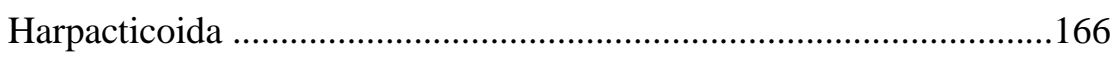

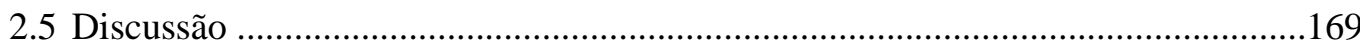

2.5.1 Crescimento, biomassa e produção de estágios juvenis de copépodes no

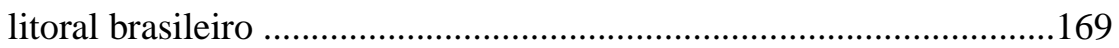

2.5.2 Considerações sobre o método empregado.........................................171

2.5.3 Interações entre as variáveis controladas dos experimentos e as taxas de

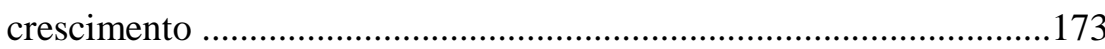

2.5.4 Aplicabilidade das equações globais da literatura ...............................177

2.5.5 Crescimento, biomasa e produção dos táxons considerados ...............179

Capítulo 3. Incidência do parasita Ellobiopsis sp. (Alveolata) sobre copépodes planctônicos de

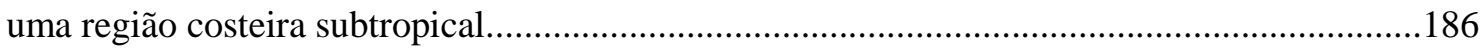

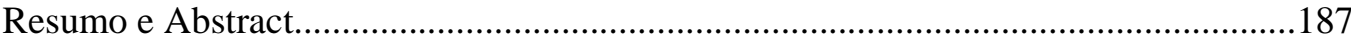

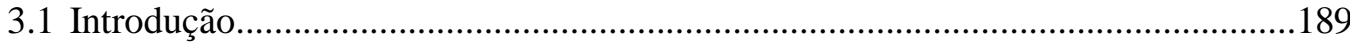

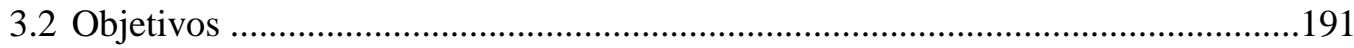

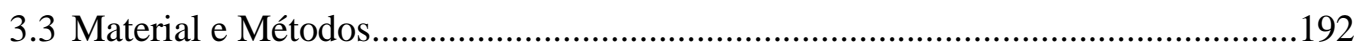

3.3.1 Obtenção das variáveis ambientais e zooplâncton ...............................192

3.3.2 Análises qualitativa e quantitativa do zooplâncton .............................194

3.3.3 Obtenção de imagens e dados morfométricos ....................................195

3.3.4 Análise de resultados e testes estatísticos ...........................................196

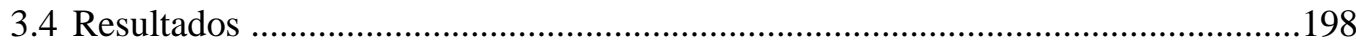

3.4.1 Frequência relativa e densidade de copépodes infectados ..................199

3.4.2 Comparações morfométricas entre animais normais e infectados .....201 
3.4.3 Quantidade de parasitas por hospedeiro e locais de adesão .................204

3.4.4 Características morfológicas e dimensões dos parasitas........................205

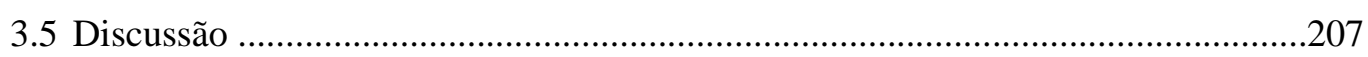

3.5.1 Ocorrência de elobiopsídeos em copépodes pelágicos.........................208

3.5.2 Padrões de distribuição de Ellobiopsis sp. sobre seus hospedeiros.....209

3.5.3 Distribuição e taxonomia do gênero Ellobiopsis...................................210

3.5.4 Consequências do parasitismo...............................................................212

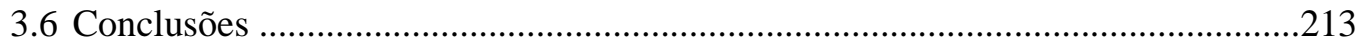

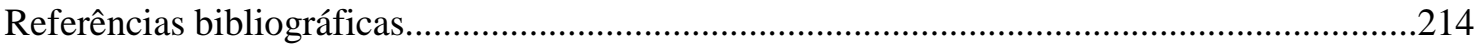

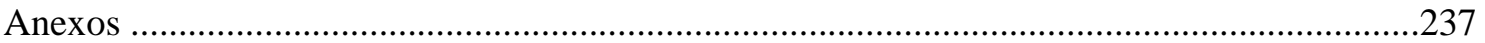




\section{ÍNDICE DE FIGURAS}

Figura 1: Localização das estações de coleta situada na plataforma interna ao largo de Ubatuba, litoral norte do estado de São Paulo. A: estação Ribeira; B: estação Boqueirão. .9

Figura1.1: Oscilação e amplitude da maré para cada um dos períodos amostrais durantes os anos de 2009 à 2011. Os círculos representam os momentos de coleta do zooplâncton,

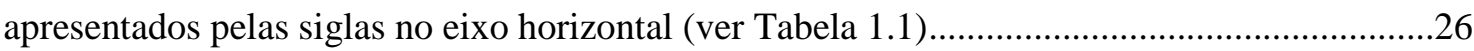

Figura 1.2: Variação da temperatura $\left({ }^{\circ} \mathrm{C}\right)$, salinidade e precipitação $(\mathrm{mm})$ durante cada um dos períodos de coleta em Ubatuba. As siglas dos períodos de coleta seguem como na Tabela 1.1. Notar diferentes escalas para precipitação entre o verão e o inverno.

Figura 1.3: Concentrações de clorofila- $a$ e feopigmentos em $\mathrm{mg} \cdot \mathrm{m}^{-3}$ de água da camada superficial para cada um dos períodos amostrais durante os anos de 2009 a 2011. Os números no eixo $x$ correspondem aos períodos amostrais (conforme Tabela 1.1). A concentração de feopigmentos para a primeira coleta não foi obtida. Notar escalas diferentes para o verão, em relação ao inverno...

28

Figura 1.4: Frequência de ocorrência para o zooplâncton (exceto copépodes) capturado pela rede de $20 \mu \mathrm{m}$. Os organismos raros foram agrupados e representados pela coluna rachurada..

Figura 1.5: Frequência de ocorrência dos copépodes e respectivos estágios de desenvolvimento para o zooplâncton capturado pela rede de $20 \mu \mathrm{m}$. Os organismos raros foram agrupados e representados pela coluna rachurada.. .35

Figura 1.6: Frequência de ocorrência dos táxons zooplanctônicos (exceto copépodes), capturados pela rede de $100 \mu \mathrm{m}$. Os organismos raros foram agrupados e representados pela coluna rachurada.

Figura 1.7: Frequência de ocorrência dos copépodes e respectivos estágios de desenvolvimento para o zooplâncton capturado pela rede de $100 \mu \mathrm{m}$. Os organismos raros foram agrupados e representados pela coluna rachurada. .36

Figura 1.8: Dados de densidade (org. $\mathrm{m}^{-3}$ ) para o holo- e meroplâncton capturados pela rede de 20 e $100 \mu \mathrm{m}$, durante os períodos de verão e inverno de 2009 a 2011. As siglas dos períodos de coleta seguem como na Tabela 1.1.

Figura 1.9: Densidade relativa dos principais grupos do meroplâncton, para as amostras da rede de $20 \mu \mathrm{m}$ durante o verão e inverno dos anos de 2009 a 2011. Sigla das amostras conforme a Tabela 1.1.....

Figura 1.10: Densidade relativa dos principais grupos do meroplâncton, para as amostras da rede de $100 \mu \mathrm{m}$, durante o verão e inverno dos anos de 2009 a 2011. Sigla das amostras conforme a Tabela 1.1. . .46

Figura 1.11: Densidade relativa dos principais grupos do holoplâncton, para as amostras da rede de $20 \mu \mathrm{m}$ durante o verão e inverno de 2009 a 2011. Sigla das amostras conforme a Tabela 1.1 . 
Figura 1.12: Densidade relativa dos principais grupos do holoplâncton, para as amostras da rede de $100 \mu \mathrm{m}$ durante o verão e inverno dos anos de 2009 a 2011. Sigla das amostras conforme a Tabela 1.1.

Figura 1.13: Análise de componentes principais utilizando as variáveis ambientais como fatores ativos e densidade dos principais grupos do zooplâncton como variáveis suplementares para a rede de $20 \mu \mathrm{m}$.

Figura 1.14: Análise de componentes principais utilizando as variáveis ambientais como fatores ativos e densidade dos principais grupos do zooplâncton como variáveis suplementares para a rede de $100 \mu \mathrm{m}$.

Figura 1.15: Distribuição das amostras de zooplâncton coletadas pela rede de $20 \mu \mathrm{m}$, através da análise de $M D S$. As amostras foram representadas para o fator estação do ano com duas categorias: verão e inverno. Legenda das amostras conforme Tabela 1.1.

Figura 1.16: Análises de $M D S$ para o zooplâncton da rede de $20 \mu \mathrm{m}$. Ordenação das amostras por fatores ambientais (A, B e C) e distribuição da densidade (D, E e F).Temperatura: ${ }^{\circ} \mathrm{C}$; Profundidade: $\mathrm{m}$; Densidade: org. $\mathrm{m}^{-3}$.

Figura 1.17: Análises de $M D S$ para o zooplâncton da rede de $20 \mu \mathrm{m}$. Distribuição da densidade para as famílias Paracalanidae, Temoridae, para o os quetognátos e para os cladóceros. Categorias de densidade em org. $\mathrm{m}^{-3}$. .66

Figura 1.18: Distribuição das amostras de zooplâncton coletadas pela rede de $100 \mu \mathrm{m}$, através da análise de $M D S$. As amostras foram representadas para o fator estação do ano com duas categorias: verão e inverno. Legenda das amostras conforme Tabela 1.1.

Figura 1.19: Análises de $M D S$ para o zooplâncton da rede de $100 \mu \mathrm{m}$. Ordenação das amostras por fatores ambientais (A, B e C) e distribuição da densidade (D, E e F). Temperatura: ${ }^{\circ} \mathrm{C}$; Profundidade: $\mathrm{m}$; Densidade: org. $\mathrm{m}^{-3}$. . .68

Figura 1.20: Análises de $M D S$ para o zooplâncton da rede de $100 \mu \mathrm{m}$. Distribuição da densidade para Euterpina acutifrons, quetognátos, apendiculários e o copépode Parvocalanus crassirostris. Categorias de densidade em org. $\mathrm{m}^{-3}$

Figura 2.1: Materiais utilizados para a elaboração dos experimentos de coortes artificiais. A: rede de plâncton cônica de $20 \mu \mathrm{m}$; B: rede cônica de plâncton de $100 \mu \mathrm{m}$; $\mathbf{C}$ : balde completamente cheio, contendo o zooplâncton após a coleta e revestido por um saco plástico preto para minimizar a radiação incidente; D: garrafas Nalgene completamente cheias e vedadas; E: roda de plâncton com diversas réplicas experimentais; F: kit de filtração de água do mar e G: zooplâncton removido das garrafas, após os períodos de incubação e fixados em formol $2 \%$ 104

Figura 2.2: Desenho experimental das coortes artificiais. Durante o período inicial (t0) foram filtradas três amostras de água para obtenção da concentração de clorofila- $a$ e feopigmentos, representada pelos filtros GF/F. Durante os períodos experimentais ( $t 1$ a $t 3$ ), foram incubadas três réplicas experimentais e três controles 106 
Figura 2.3: Exemplos de frequência de distribuição de peso dos organismos incubados. O peso em carbono é representado na escala logarítmica e a frequência em número de indivíduos de cada categoria ao longo dos períodos experimentais ( $t 0$ ao $t 3)$. 110

Figura 2.4: Exemplos da variação de peso em carbono (ln PC, eixo y) ao longo do tempo em horas (eixo x). A: exemplos onde a variação de peso foi linear, do período inicial até o terceiro dia de incubação. B: variação de peso e crescimento linear até o segundo dia de incubação, nesses casos o valor de $g$ para o terceiro dia foi descartado e $\mathbf{C}$ : casos onde $g$ não foi linear e geralmente adota-se o valor de $g$ para $t 24 h-t 0$. Notar as diferentes escalas em cada exemplo. Equação da reta considerando a média entre as três réplicas em cada período. 111

Figura 2.5: Concentração de clorofila- $a$ e feopigmentos $\left(\mathrm{mg} \mathrm{m}^{-3}\right)$ durante os experimentos de coortes artificiais (C-1 a C-8). C: réplicas de garrafas sem animais incubados (controle); Exp: réplicas experimentais. Cada ponto é representado pela média de três réplicas. Linha vermelha: nível de saturação do crescimento para copépodes dispersores juvenis estimado por Hirst \& Bunker (2003). Notar diferentes escalas no eixo y......

Figura 2.6: Taxas de crescimento para Acartia spp. ao longo do verão de 2009 até o verão de 2011. A: coortes menores, B: coortes maiores. $g$ mín.: mínimo; $g$ máx.: máximo e $g$ med.: mediana. Legendas do eixo x correspondem aos experimentos, conforme Tabela 2.1....

Figura 2.7: Box-plot com a variação de $g$ em cada um dos tamanhos de coortes analisados para o gênero Acartia. V: verão; I: inverno; 09,10 e 11: anos analisados.

Figura 2.8: Regressão linear e correlação de Spearman ( $\rho$ ) entre as variáveis controladas e $g$ para Acartia spp. nos experimentos de coortes artificiais. O eixo y é representado por $g$ e o eixo x pelo $\log _{10}$ da variável. Clorofila- $a(\mathrm{Cl}-a)$ e feopigmentos em $\mathrm{mg} \mathrm{m}^{-3}$; T: temperatura $\left({ }^{\circ} \mathrm{C}\right) ; \mathrm{N}$ : número de metazoários incubados. 124

Figura 2.9: Relação entre o crescimento medido experimentalmente (eixo x) e estimado para copépodes pelágicos em geral (Hirst \& Bunker 2003 I) e para juvenis de copépodes dispersores de ovos (Hirst \& Bunker 2003 II) em Acartia spp. Notar escalas diferentes no eixo y. Valores de $p$ do teste de Mann-Whitney. .125

Figura 2.10: Variação da biomassa (B), produção mediana ou média (P med.), mínima (P mín.) e máxima (P máx.) para Acartia spp. do verão de 2009 ao verão de 2011. Biomassa e produção no eixo y em escala logarítmica do PC $\left(\mathrm{mg} \mathrm{m}^{-3}\right)$. A: coortes menores e $\mathbf{B}$ : coortes maiores. Legendas do eixo x correspondem aos experimentos, conforme Tabela 2.1

Figura 2.11: Taxas de crescimento para Parvocalanus crassirostris ao longo do verão de 2009 até o verão de 2011. A: coortes menores, B: coortes maiores. $g$ mín.: mínimo; $g$ máx.: máximo e $g$ med.: mediana. Legendas do eixo x correspondem aos experimentos, conforme Tabela 2.1 . 127

Figura 2.12: Box-plot com a variação de $g$ para Parvocalanus crassirostris, coorte de 50-80 $\mu \mathrm{m}$. O número de experimentos para as demais coortes foi insuficiente para a representação por box-plot. V: verão; I: inverno; 09,10 e 11: anos.

Figura 2. 13: Regressão linear e correlação de Spearman ( $\rho$ ) entre as variáveis controladas e $g$ para Parvocalanus crassirostris nos experimentos de coortes artificiais. O eixo y é representado 
por $g$ e o eixo x pelo $\log _{10}$ da variável. Clorofila- $a(\mathrm{Cl}-a)$ e feopigmentos em $\mathrm{mg} \mathrm{m}^{-3} ; \mathrm{T}$ : temperatura $\left({ }^{\circ} \mathrm{C}\right) ; \mathrm{N}$ : número de metazoários incubados. 128

Figura 2.14: Relação entre o crescimento medido experimentalmente (eixo x) e estimado para copépodes pelágicos em geral (Hirst \& Bunker, 2003 I) e juvenis de copépodes dispersores de ovos (Hirst \& Bunker, 2003 II) em Parvocalanus crassirostris. Notar escalas diferentes no eixo y. Valores de $p$ do teste de Mann-Whitney.

Figura 2.15: Variação da biomassa (B), produção mediana ou média (P med.), mínima (P mín.) e máxima (P máx.) para Parvocalanus crassirostris do verão de 2009 ao verão de 2011. Biomassa e produção no eixo y em escala logarítmica do PC em $\mathrm{mg} \mathrm{m}^{-3}$. Sigla dos experimentos conforme tabela 2.1. A: coortes menores e B: coortes maiores. Legendas do eixo $\mathrm{x}$ correspondem aos experimentos, conforme Tabela 2.1.

Figura 2.16: Taxas de crescimento para Paracalanus spp. ao longo do verão de 2009 até o verão de 2011. A: coortes menores, B: coortes maiores. $g$ mín.: mínimo; $g$ máx.: máximo e $g$ med.: mediana. Legendas do eixo $\mathrm{x}$ correspondem aos experimentos, conforme Tabela 2.1 .

Figura 2.17: Box-plot com a variação de $g$ em cada um dos tamanhos de coortes analisados para Paracalanus spp. V: verão; I: inverno; 09,10 e 11: anos. 131

Figura 2.18: Regressão linear e correlação de Spearman ( $\rho)$ entre as variáveis controladas e $g$ para Paracalanus spp. nos experimentos de coortes artificiais. $\mathrm{O}$ eixo y é representado por $g$ e o eixo x pelo $\log _{10}$ da variável. Clorofila- $a(\mathrm{Cl}-a)$ e feopigmentos em $\mathrm{mg} \mathrm{m}^{-3}$; T: temperatura $\left({ }^{\circ} \mathrm{C}\right)$; $\mathrm{N}$ : número de metazoários incubados.

Figura 2.19: Relação entre o crescimento medido experimentalmente (eixo x) e estimado para copépodes pelágicos em geral (Hirst \& Bunker, 2003 I) e juvenis de copépodes dispersores de ovos (Hirst \& Bunker, 2003 II) em Paracalanus spp. Notar escalas diferentes no eixo y. Valores de $p$ do teste de Mann-Whitney. 133

Figura 2.20: Variação da biomassa (B), produção mediana ou média (P med.), mínima (P mín.) e máxima (P máx.) para Paracalanus spp. do verão de 2009 ao verão de 2011. Biomassa e produção no eixo y em escala logarítmica do PC $\left(\mathrm{mg} \mathrm{m}^{-3}\right)$. A: coortes menores e $\mathbf{B}$ : coortes maiores. Legendas do eixo x correspondem aos experimentos, conforme Tabela 2.1 133

Figura 2.21: Taxas de crescimento para Temora turbinata ao longo do verão de 2009 até o verão de 2011. A: coortes menores, B: coortes maiores. $g$ mín.: mínimo; $g$ máx.: máximo e $g$ med.: mediana. Legendas do eixo $\mathrm{x}$ correspondem aos experimentos, conforme Tabela 2.1 . 134

Figura 2.22: Relação entre o crescimento medido experimentalmente (eixo x) e estimado para copépodes pelágicos em geral (Hirst \& Bunker, 2003 I) e juvenis de copépodes dispersores de ovos (Hirst \& Bunker, 2003 II) em Temora turbinata Valores de $p$ do teste de MannWhitney. 134

Figura 2.23: Regressão linear e correlação de Spearman ( $\rho)$ entre as variáveis controladas e $g$ para Temora turbinata. nos experimentos de coortes artificiais. O eixo y é representado por $g$ e o eixo x pelo $\log _{10}$ da variável. Clorofila- $a(\mathrm{Cl}-a)$ e feopigmentos em mg.m ${ }^{-3}$; T: temperatura $\left({ }^{\circ} \mathrm{C}\right)$; N: número de metazoários incubados. 
Figura 2.24: Variação da biomassa (B), produção mediana ou média (P med.), mínima (P mín.) e máxima (P máx.) para Temora turbinata do verão de 2009 ao verão de 2011. Biomassa e produção no eixo y em escala logarítmica do $\mathrm{PC} \mathrm{em} \mathrm{mg} \mathrm{m}^{-3}$. Sigla dos experimentos conforme tabela 2.1. A: coortes menores e B: coortes maiores. Legendas do eixo x correspondem aos experimentos, conforme Tabela 2.1. 137

Figura 2.25: Taxas de crescimento para Temora stylifera ao longo do verão de 2009 até o inverno de 2010. $g$ mín.: mínimo; $g$ máx.: máximo e $g$ med.: mediana. Legendas do eixo $\mathrm{x}$ correspondem aos experimentos, conforme Tabela 2.1. .138

Figura 2.26: Variação da biomassa (B), produção mediana ou média (P med.), mínima (P mín.) e máxima (P máx.) para Temora stylifera do verão de 2009 ao verão de 2011.Biomassa e produção no eixo y em escala logarítmica do PC $\left(\mathrm{mg} \mathrm{m}^{-3}\right)$. Legendas do eixo x correspondem aos experimentos, conforme Tabela 2.1. 138

Figura 2.27: Relação entre o crescimento medido experimentalmente (eixo x) e estimado para copépodes pelágicos em geral (Hirst \& Bunker, 2003 I) e juvenis de copépodes dispersores de ovos (Hirst \& Bunker, 2003 II) em Temora stylifera. Notar escalas diferentes no eixo y. Valores de $p$ do teste de Mann-Whitney. 138

Figura 2.28: Regressão linear e correlação de Spearman ( $\rho)$ entre as variáveis controladas e $g$ para Temora stylifera nos experimentos de coortes artificiais. O eixo y é representado por $g$ e o eixo x pelo $\log _{10}$ da variável. Clorofila- $a(\mathrm{Cl}-a)$ e feopigmentos em $\mathrm{mg} \cdot \mathrm{m}^{-3}$; T: temperatura $\left({ }^{\circ} \mathrm{C}\right)$; $\mathrm{N}$ : número de metazoários incubados.

Figura 2.29: Taxas de crescimento ( $g$ médio) para Centropages velificatus durante o verão de 2010 e 2011. Legendas do eixo x correspondem aos experimentos, conforme Tabela 2.1.......140

Figura 2.30: Variação da biomassa (B), produção mediana ou média (P med.) para Centropages velificatus durante o verão de 2010 e 2011. Biomassa e produção no eixo y, em escala logarítmica do PC $\left(\mathrm{mg} \mathrm{m}^{-3}\right)$. Legendas do eixo x correspondem aos experimentos, conforme Tabela 2.1. 140

Figura 2.31: Taxas de crescimento para Pseudodiaptomus acutus durante o verão de 2009 e 2010. $g$ mín.: mínimo; $g$ máx.: máximo e $g$ med.: mediana. Legendas do eixo x correspondem aos experimentos, conforme Tabela 2.1

Figura 2.32: Variação da biomassa (B), produção mediana ou média (P med.), mínima (P mín.) e máxima (P máx.) para Pseudodiaptomus acutus durante o inverno de 2009 e verão de 2010. Biomassa e produção no eixo $\mathrm{y}$, em escala logarítmica de PC $\left(\mathrm{mg} \mathrm{m}^{-3}\right)$. Legendas do eixo $\mathrm{x}$ correspondem aos experimentos, conforme Tabela 2.1. . .141

Figura 2.33: Taxas de crescimento para Oithona spp. ao longo do verão de 2009 até o verão de 2011. A: coortes menores, B: coortes maiores. $g$ mín.: mínimo; $g$ máx.: máximo e $g$ med.: mediana. Legendas do eixo x correspondem aos experimentos, conforme Tabela 2.1

Figura 2.34: Box-plot com a variação de $g$ em cada um dos tamanhos de coortes analisados para Oithona spp. V: verão; I: inverno; 09,10 e 11: anos analisados. 143

Figura 2.35: Regressão linear e correlação de Spearman ( $\rho$ ) entre as variáveis controladas e $g$ para Oithona spp. nos experimentos de coortes artificiais. O eixo y é representado por $g$ e o eixo 
$\mathrm{x}$ pelo $\log _{10}$ da variável. Clorofila- $a(\mathrm{Cl}-a)$ e feopigmentos em $\mathrm{mg} \mathrm{m}^{-3}$; $\mathrm{T}$ : temperatura $\left({ }^{\circ} \mathrm{C}\right)$; $\mathrm{N}$ : número de metazoários incubados. 144

Figura 2.36: Relação entre o crescimento medido experimentalmente (eixo x) e estimado para copépodes pelágicos em geral (Hirst \& Bunker, 2003 I) e juvenis de copépodes dispersores de ovos (Hirst \& Bunker, 2003 II) em Oithona spp. Valores de $p$ do teste de Mann-Whitney.......145

Figura 2.37: Variação da biomassa (B), produção mediana ou média (P med.), mínima (P mín.) e máxima (P máx.) para Oithona spp. do verão de 2009 ao verão de 2011. A biomassa e produção são fornecidas no eixo y na escala logarítmica do PC $\left(\mathrm{mg} \mathrm{m}^{-3}\right)$. A: coortes menores e B: coortes maiores. Legendas do eixo $\mathrm{x}$ correspondem aos experimentos, conforme Tabela 2.1 .

Figura 2.38: Taxas de crescimento para Oithona plumifera ao longo do verão de 2009 até o verão de 2011. A: coortes menores, B: coortes maiores. $g$ mín.: mínimo; $g$ máx.: máximo e $g$ med.: mediana. Legendas do eixo $\mathrm{x}$ correspondem aos experimentos, conforme Tabela 2.1 . 147

Figura 2.39: Relação entre o crescimento medido experimentalmente (eixo x) e estimado para copépodes pelágicos em geral (Hirst \& Bunker, 2003 I) e juvenis de copépodes retentores de ovos (Hirst \& Bunker, 2003 II) em Oithona plumifera. Valores de $p$ do teste de MannWhitney.

Figura 2.40: Variação da biomassa (B), produção mediana ou média (P med.), mínima (P mín.) e máxima (P máx.) para Oithona plumifera do verão de 2009 ao verão de 2011. Biomassa e produção no eixo y em escala logarítmica do PC $\left(\mathrm{mg} \mathrm{m}^{-3}\right)$. A: coortes menores e B: coortes maiores. Legendas do eixo x correspondem aos experimentos, conforme Tabela 2.1 .148

Figura 2.41: Regressão linear e correlação de Spearman $(\rho)$ entre as variáveis controladas e $g$ para Oithona plumifera nos experimentos de coortes artificiais. O eixo y é representado por $g$ e o eixo x pelo $\log _{10}$ da variável. Clorofila- $a(\mathrm{Cl}-a)$ e feopigmentos em $\mathrm{mg} \mathrm{m}^{-3}$; $\mathrm{T}$ : temperatura $\left({ }^{\circ} \mathrm{C}\right)$; $\mathrm{N}$ : número de metazoários incubados. 149

Figura 2.42: Taxas de crescimento para Dioithona oculata ao longo do verão e inverno de 2009. $g$ mín.: mínimo; $g$ máx.: máximo e $g$ med.: mediana. Legendas do eixo x correspondem aos experimentos, conforme Tabela 2.1 . 150

Figura 2.43: Variação da biomassa (B), produção mediana ou média (P med.), mínima (P mín.) e máxima (P máx.) para Dioithona oculata durante o verão e o inverno de 2009. Biomassa e produção no eixo y em escala logarítmica do PC $\left(\mathrm{mg} \mathrm{m}^{-3}\right)$. Sigla dos experimentos conforme tabela 2.1. Legendas do eixo x correspondem aos experimentos, conforme Tabela 2.1 150

Figura 2.44: Relação entre o crescimento medido experimentalmente (eixo x) e estimado para copépodes pelágicos em geral (Hirst \& Bunker, 2003 I) e juvenis de copépodes retentores de ovos (Hirst \& Bunker, 2003 II) em Dioithona oculata. Valores de $p$ do teste de MannWhitney. 150

Figura 2.45: Regressão linear e correlação de Spearman $(\rho)$ entre as variáveis controladas e $g$ para Dioithona oculata nos experimentos de coortes artificiais. O eixo y é representado por $g$ e o eixo x pelo $\log _{10}$ da variável. Clorofila- $a(\mathrm{Cl}-a)$ e feopigmentos em $\mathrm{mg} \mathrm{m}^{-3}$; $\mathrm{T}$ : temperatura $\left({ }^{\circ} \mathrm{C}\right)$; $\mathrm{N}$ : número de metazoários incubados. 
Figura 2.46: Taxas de crescimento para copépodes da família Oncaeidae ao longo do verão de 2009 até o verão de 2011. A: coortes menores, B: coortes maiores. $g$ mín.: mínimo; $g$ máx.: máximo e $g$ med.: mediana. Legendas do eixo x correspondem aos experimentos, conforme Tabela 2.1.

Figura 2.47: Relação entre o crescimento medido experimentalmente (eixo x) e estimado para copépodes pelágicos em geral (Hirst \& Bunker, 2003 I) e juvenis de copépodes retentores de ovos (Hirst \& Bunker, 2003 II) em copépodes da família Oncaeidae. Valores de $p$ do teste de Mann-Whitney.

Figura 2.48: Regressão linear e correlação de Spearman ( $\rho)$ entre as variáveis controladas e $g$ para copépodes da família Oncaeidae nos experimentos de coortes artificiais. O eixo y é representado por $g$ e o eixo x pelo $\log _{10}$ da variável. Clorofila- $a(\mathrm{Cl}-a)$ e feopigmentos em $\mathrm{mg}$ $\mathrm{m}^{-3} ; \mathrm{T}$ : temperatura $\left({ }^{\circ} \mathrm{C}\right) ; \mathrm{N}$ : número de metazoários incubados. 154

Figura 2.49: Variação da biomassa (B), produção mediana ou média (P med.), mínima (P mín.) e máxima (P máx.) para copépodes da família Oncaeidae durante o verão e o inverno de 2009. A biomassa e produção são fornecidas no eixo y na escala logarítmica do $\mathrm{PC}\left(\mathrm{mg} \mathrm{m}^{-3}\right)$. A: coortes menores e B: coortes maiores. Legendas do eixo x correspondem aos experimentos, conforme Tabela 2.1. 155

Figura 2.50: Taxas de crescimento para Corycaeidae ao longo do verão de 2009 até o inverno de 2010. A: coortes menores, B: coortes maiores. $g$ mín.: mínimo; $g$ máx.: máximo e $g$ med.: mediana. Legendas do eixo x correspondem aos experimentos, conforme Tabela 2.1.... 156

Figura 2.51: Relação entre o crescimento medido experimentalmente (eixo x) e estimado para copépodes pelágicos em geral (Hirst \& Bunker, 2003 I) e juvenis de copépodes retentores de ovos (Hirst \& Bunker, 2003 II) em Corycaeidae. Valores de $p$ do teste de Mann-Whitney......156

Figura 2.52: Regressão linear e correlação de Spearman ( $\rho)$ entre as variáveis controladas e $g$ para copépodes da família Corycaeidae nos experimentos de coortes artificiais. O eixo y é representado por $g$ e o eixo x pelo $\log _{10}$ da variável. Clorofila- $a(\mathrm{Cl}-a)$ e feopigmentos em $\mathrm{mg}$ $\mathrm{m}^{-3}$; T: temperatura $\left({ }^{\circ} \mathrm{C}\right)$; $\mathrm{N}$ : número de metazoários incubados.

Figura 2.53: Variação da biomassa (B), produção mediana ou média (P med.), mínima (P mín.) e máxima (P máx.) para copépodes da família Corycaeidae durante o verão de 2009 ao inverno de 2010. A biomassa e produção são fornecidas no eixo y na escala logarítmica do $\mathrm{PC}\left(\mathrm{mg} \mathrm{m}^{-3}\right)$. A: coortes menores e B: coortes maiores. Legendas do eixo x correspondem aos experimentos, conforme Tabela 2.1. 158

Figura 2.54: Taxas de crescimento para Euterpina acutifrons ao longo do inverno de 2009 até o verão de 2011 e para Longipedia americana (*). $g$ mín.: mínimo; $g$ máx.: máximo e $g$ med.: mediana. Legendas do eixo $\mathrm{x}$ correspondem aos experimentos, conforme Tabela 2.1 ..... 160

Figura 2.55: Variação da biomassa (B), produção mediana ou média (P med.), mínima (P mín.) e máxima (P máx.) para Euterpina acutifrons do inverno de 2009 até o verão de 2011 e para Longipedia americana (*). A biomassa e produção são fornecidas no eixo y na escala logarítmica do PC $\left(\mathrm{mg} \mathrm{m}^{-3}\right)$. Legendas do eixo x correspondem aos experimentos, conforme Tabela 2.1. 160 
Figura 2.56: Relação entre o crescimento medido experimentalmente (eixo x) e estimado para copépodes pelágicos em geral (Hirst \& Bunker, 2003 I) e juvenis de copépodes retentores de ovos (Hirst \& Bunker, 2003 II) em Euterpina acutifrons. Valores de $p$ do teste de MannWhitney.

Figura 2.57: Regressão linear e correlação de Spearman ( $\rho$ ) entre as variáveis controladas e $g$ para Euterpina acutifrons. nos experimentos de coortes artificiais. O eixo y é representado por $g$ e o eixo x pelo $\log _{10}$ da variável. Clorofila- $a(\mathrm{Cl}-a)$ e feopigmentos em $\mathrm{mg} \mathrm{m}^{-3}$; T: temperatura $\left({ }^{\circ} \mathrm{C}\right)$; N: número de metazoários incubados. 161

Figura 2.58: Densidade em org. $\mathrm{m}^{-3}$ de juvenis das principais famílias de copépodes pelágicos ao longo do período estudado para os animais utilizados nas coortes menores (A; capturados com rede de $20 \mu \mathrm{m}$ ) e coortes maiores (B; capturados com rede de $100 \mu \mathrm{m}$ ). 167

Figura 2.59: Biomassa em $\mathrm{mg} \mathrm{C} \mathrm{m}^{-3}$ de juvenis das principais famílias de copépodes pelágicos ao longo do período estudado para os animais utilizados nas coortes menores (A; capturados com rede de $20 \mu \mathrm{m}$ ) e coortes maiores (B; capturados com rede de $100 \mu \mathrm{m}$ ). 167

Figura 2.60: Produção em $\mathrm{mg} \mathrm{C} \mathrm{m} \mathrm{m}^{-3} \cdot \mathrm{d}^{-1}$ de juvenis das principais famílias de copépodes pelágicos ao longo do período estudado para os animais utilizados nas coortes menores (A; capturados com rede de $20 \mu \mathrm{m}$ ) e coortes maiores (B; capturados com rede de $100 \mu \mathrm{m}$ ) 167

Figura 2.61: Densidade em org. $\mathrm{m}^{-3}$ de juvenis das três ordens de copépodes pelágicos ao longo do período estudado para os animais utilizados nas coortes menores (A; capturados com rede de $20 \mu \mathrm{m}$ ) e coortes maiores (B; capturados com rede de $100 \mu \mathrm{m}$ ). 168

Figura 2.62: Biomassa em $\mathrm{mg} \mathrm{C} \mathrm{m} \mathrm{m}^{-3}$ de juvenis das três ordens de copépodes pelágicos ao longo do período estudado para os animais utilizados nas coortes menores (A; capturados com rede de $20 \mu \mathrm{m}$ ) e coortes maiores (B; capturados com rede de $100 \mu \mathrm{m}$ )...... 168

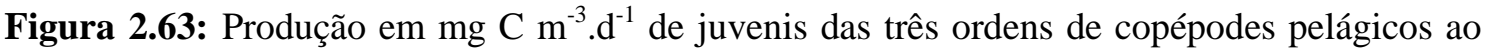
longo do período estudado para os animais utilizados nas coortes menores (A; capturados com rede de $20 \mu \mathrm{m}$ ) e coortes maiores (B; capturados com rede de $100 \mu \mathrm{m}$ ) 168

Figura 3.1: Copépodes da espécie Parvocalanus crassirostris. Um dos indivíduos encontra-se parasitado por Ellobiopsis sp. Em destaque o comprimento do prossomo, obtido utilizando o programa Image $J$. 196

Figura 3.2: Distribuição do volume $\left(\mu \mathrm{m}^{3}\right)$ dos copépodes da espécie Parvocalanus crassirostris parasitados, em relação ao volume de seus respectivos parasitas em escala logarítmica...... .202

Figura 3.3: Distribuição do volume $\left(\mu \mathrm{m}^{3}\right)$ dos copépodes do gênero Paracalanus parasitados, em relação ao volume de seus respectivos parasitas em escala logarítmica. .203

Figura 3.4: Diferentes hospedeiros parasitados por Ellobiopsis sp. A: Paracalanus quasimodo infectado por dois parasitas. B: Paracalanus sp. infectado por um Ellobiopsis sp. aderido a uma das peças bucais. C e D: Parvocalanus crassirostris com parasitas aderidos à antênula. A e B: escala $=200 \mu \mathrm{m} ; \mathrm{C}$ : escala $=80 \mu \mathrm{m}$ e D: escala $=60 \mu \mathrm{m}$. .206

Fígura 3.5: Relação entre o comprimento e largura de Ellobiopsis sp. encontrados em copépodes paracalanídeos. $n=118$. .206 


\section{ÍNDICE DE TABELAS}

Tabela 1.1: Sigla, data, horário, maré e profundidade local das coletas de plâncton. Coletas marcadas com * foram realizadas na estação Abrigada (Figura 1, introdução geral).

Tabela 1.2: Táxons de organismos zooplanctônicos (exceto copépodes) registrados entre os anos de 2009 a 2011 para ambas as classes de tamanho $(20$ e $100 \mu \mathrm{m})$. N.I.: organismos não identificados....

Tabela 1.3: Espécies de copépodes da ordem Calanoida registrados de 2009 a 2011 e os respectivos estágios do ciclo-de-vida capturados por cada malha. N: náuplios (NI - VI); CI-V: copepoditos I a V; CVI: copepodito VI ou adulto. *: casos em que o náuplio ou copepodito não foram classificados até o nível de espécie, sendo agrupados em gênero ou família...... .32

Tabela 1.4: Espécies de copépodes da ordem Cyclopoida registrados de 2009 a 2011 e os respectivos estágios do ciclo-de-vida capturados por cada malha. N: náuplios (NI - VI); CI-V: copepoditos I a V; CVI: copepodito VI ou adulto. *: casos em que o náuplio ou copepodito não foram classificados até o nível de espécie, sendo agrupados em gênero ou família.

Tabela 1.5: Espécies de copépodes das ordens Harpacticoida, Siphonostomatoida e Monstrilloida registrados de 2009 a 2011 e os respectivos estágios do ciclo-de-vida capturados por cada malha. N: náuplios (NI - VI); CI-V: copepoditos I a V; CVI: copepodito VI ou adulto. *: casos em que o náuplio ou copepodito não foram classificados até o nível de espécie, sendo agrupados em gênero ou família.

Tabela 1.6: Riqueza (R), Diversidade de Shannon (H') e Equitabilidade (J) para copépodes e cladóceros das amostras das redes de 20 e $100 \mu \mathrm{m}$ coletadas em Ubatuba, SP. Média e desviopadrão para o verão e o inverno dos três anos analisados.

Tabela 1.7: Valores de $p$ do teste de Mann-Whitney para comparação aos pares da densidade de diversos grupos zooplanctônicos entre a estação de verão e inverno. Dados obtidos para cada rede utilizada (20 e $100 \mu \mathrm{m}$ ) e anos de coleta (2009 a 2011). Em negrito: $p<0,05$; em itálico: $p$ $<0,001$

Tabela 1.8: Valores de $p$ do teste de Kruskal-Wallis para a comparação da densidade dos grupos do zooplâncton entre os anos de 2009 a 2011. No caso de diferença significativa, o teste de Student-Newman-Keuls foi aplicado para a comparação aos pares $(p<0,05)$. Em negrito: $p<$ 0,05; em itálico: $p<0,001$

Tabela 1.9: Média, desvio-padrão e mediana da densidade dos grupos do zooplâncton para as malhas de 20 e $100 \mu \mathrm{m}$. Valores de $p$ do teste de Mann-Whitney para comparação entre as malhas. Em negrito: $p<0,05$; em itálico: $p<0,001$

Tabela 1.10: Comparação entre as densidades dos estágios de desenvolvimento de Acartia spp. para as malhas de 20 e $100 \mu \mathrm{m}$, através do teste de significância de Student-Newman-Keuls entre os pares. Para as comparações foram utilizados os dados de densidade dos táxons (org. $\mathrm{m}^{-3}$ ) 
de todas as 46 amostras analisadas para cada rede. Em negrito: diferenças significativas. Em parênteses: densidade relativa de cada estágio de desenvolvimento (D.R., \%). .53

Tabela 1.11: Comparação entre as densidades dos estágios de desenvolvimento dos principais grupos taxonômicos de copépodes para as malhas de 20 e $100 \mu \mathrm{m}$, através do teste de significância de Student-Newman-Keuls entre os pares. Para as comparações foram utilizados os dados de densidade dos táxons (org. $\mathrm{m}^{-3}$ ) de todas as 46 amostras analisadas para cada rede. Em negrito: diferenças significativas. Em parênteses: densidade relativa de cada estágio de desenvolvimento (D.R., \%). .55

Tabela 1.12: Coeficientes de correlação de Spearman entre as variáveis ambientais e densidades dos principais grupos taxonômicos e funcionais para as amostras coletadas pela rede de $20 \mu \mathrm{m}$. Valores significativos para $p<0,05 \mathrm{em}$ negrito; $p<0,01$ em itálico.

.58

Tabela 1.13: Coeficientes de correlação de Spearman entre as variáveis ambientais e densidades dos principais grupos taxonômicos e funcionais para as amostras coletadas pela rede de $100 \mu \mathrm{m}$. Valores significativos para $p<0,05 \mathrm{em}$ negrito; $p<0,01 \mathrm{em}$ itálico... .59

Tabela 1.14: Valores de $p$ da análise de PERMANOVA e permutação de Monte Carlo entre os fatores selecionados. Est.: estação; M.: malha; d.f.: graus de liberdade; S.S.: soma dos quadrados; M.S.: média dos quadrados; $F$ : teste de Fisher.

Tabela 1.15: Valores de $p$ da análise de PERMANOVA e permutação de Monte Carlo para a interação entre as estações e ano de coleta. Resultados dos testes entre os níveis de estação (verão $\mathrm{x}$ inverno) para cada ano de coleta.

Tabela 1.16: Valores de $p$ da análise de PERMANOVA e permutação de Monte Carlo para a interação entre as estações e ano de coleta. Resultados dos testes entre os níveis do fator ano (2009 x 2010 x 2011) para cada estação analisada (verão e inverno)

Tabela 1.17: Abundância média, dissimilaridade média, razão dissimilaridade/desvio-padrão e contribuição (\%) das principais espécies responsáveis pela distinção entre as estações de verão e inverno da comunidade planctônica amostrada pela rede de $20 \mu \mathrm{m}$. D.R.: densidade relativa; $\delta i$ : dissimilaridade média; $\delta i$ /D.P.: razão dissimilaridade média pelo desvio padrão; Cr.: contribuição específica; Cumul.: contribuição cumulativa. Em negrito: espécies discriminantes. . .70

Tabela 1.18: Abundância média, similaridade média, razão similaridade/desvio-padrão e contribuição (\%) das principais espécies responsáveis pela distinção entre as estações de verão e inverno da comunidade planctônica amostrada pela rede de $100 \mu \mathrm{m}$. D.R.: densidade relativa; $\delta i$ : dissimilaridade média; $\delta i$ /D.P.: razão dissimilaridade média pelo desvio padrão; Cr.: contribuição específica; Cumul.: contribuição cumulativa. Em negrito: espécies discriminantes.

Tabela 1.19: Comparação entre as concentrações de clorofila- $a$ reportadas por diversos autores para Ubatuba ou águas adjacentes. A média é representada entre parênteses. *: médias calculadas através de dados fornecidos no estudo.

Tabela 1.20: Riqueza (S), diversidade (H), equitabilidade (J) e densidade média com o desvio padrão (D) da comunidade de copépodes para os estudos realizados no litoral norte do estado de São Paulo. N.F.: não fornecido. *: estimado através das representações gráficas. **: dados 
indisponíveis para o cálculo da média. Apenas trabalhos que avaliaram a comunidade total de copépodes.

Tabela 2.1: Data, horário e profundidade local das coletas de plâncton para os experimentos de coortes artificiais. Exp.: experimento, com o tamanho da coorte em $\mu \mathrm{m}$; Prof.: profundidade; *: coletas realizadas na estação abrigada.

101

Tabela 2.2: Temperatura ( $\mathrm{T}$ ), salinidade da água de superfície do local de coleta e concentrações iniciais de clorofila- $a$ e feopigmentos para cada um dos experimentos analisados. Em negrito: valores iniciais de clorofila- $a$ inferiores à $0,6 \mathrm{mg} \cdot \mathrm{m}^{-3}$. 105

Tabela 2.3: Equações de regressão utilizadas para obtenção do peso seco $(\mu \mathrm{g})$ a partir do comprimento do prossomo $(\mu \mathrm{m})$ para os estágios juvenis de copepoditos das espécies pelágicas coletadas em Ubatuba. Para os estágios naupliares o peso em carbono (ng) é obtido a partir do comprimento total dos indivíduos. N: náuplios; CD: copepoditos; PC: peso em carbono; PS: peso seco; PU: peso úmido, PU = 0,2 PS; CT: comprimento total; $\mathrm{CP}$ : comprimento do prossomo. 108

Tabela 2.4: Táxons analisados nos respectivos experimentos de coortes artificiais. Siglas e detalhes dos experimentos conforme Tabela 2.1 .....

Tabela 2.5: Comparação das concentrações de clorofila- $a$ e feopigmentos entre os tratamentos experimentais e controles em cada um dos experimentos ( $n=9$ para coortes isoladas e $n=18$

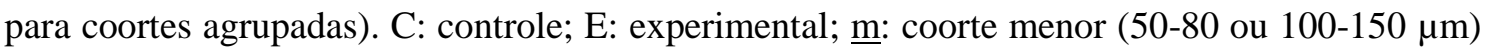
e $\underline{\mathrm{M}}$ : coorte maior $(80-100$ ou 150-200 $\mu \mathrm{m})$. Sigla dos experimentos conforme Tabela 2.1

Tabela 2.6: Principais táxons, seus respectivos estágios de desenvolvimento em categorias e dimensões durante o período inicial dos experimentos para cada classe de tamanho de coorte. C.: comprimento total para náuplios e comprimento do prossomo para copepoditos e adultos. L: largura máxima.

Tabela 2.7: valores de $p$ da regressão linear entre o crescimento medido e o estimado pelas equações de Hirst \& Bunker (2003). I: equações para copépodes em geral e II: equações para copépodes juvenis

Tabela 2.8: Comparações entre os valores médios de crescimento entre estações do ano agrupadas, entre os anos de coleta e entre os tamanhos de coortes. Teste de Kruskal-Wallis ou ANOVA para comparações múltiplas; ambos seguidos pelo teste de Student-Newman-Keuls de comparação entre grupos e teste $t$ ou teste de Mann-Whitney para comparação entre dois grupos. Coortes menores: 50-80 + 80-100; coortes maiores: 100-150 + 150-200; *: $p<0,05$ e **: $\mathrm{p}<$ 0,001 . 163

Tabela 2.9: Comparação dos valores de $g$ entre as classes de tamanho de coortes artificiais 163

Tabela 2.10: Taxas de crescimento para os táxons estudados, em cada uma das classes de tamanho de coortes artificiais. Entre parênteses, o número amostral de experimentos em cada classe de tamanho. 164 
Tabela 2.11: Taxas de crescimento de copépodes obtidas através do método de coorte artificial descrito por Kimmerer \& McKinnon (1987) para ambientes de águas tropicais e subtropicais. T: temperatura ambiental ou experimental de incubação. H: período de incubação em horas. Biomassa D: direta; ID: indireta.

Tabela 2.12: Comparação entre a produção média de copépodes pelágicos imaturos para Ubatuba e demais ecossistemas tropicais e subtropicais. Métodos utilizados para determinar o crescimento: CA: coortes artificiais; C.I.: crescimento instantâneo; Enz.: métodos enzimáticos; H\&B: modelos de Hirst \& Bunker (2003); H\&L: modelo de Hirst \& Lampitt (1998); H\&Lz: modelo de Huntley \& Lopez (1992). *: dados apenas para juvenis de Oithonidae, Oncaeidae e Calanoida de pequeno porte. N.F.: dados não fornecidos isoladamente para os estágios imaturos. **: produção total do zooplâncton capturado pela rede de $90 \mu \mathrm{m}$, contando com adultos. ***: dados convertidos para $\mathrm{mg} \mathrm{C} \mathrm{m}^{-3} \mathrm{~d}^{-1}$.

Tabela 3.1: Data, horário e profundidade local das coletas de zooplâncton. Prof.: profundidade; *: coletas realizadas na estação abrigada (Saco da Ribeira). 193

Tabela 3.2: Quantidade de exemplares observados e parasitados por categoria em Paracalanus spp. e Parvocalanus crassirostris e suas respectivas frequências relativas (F.R). T=total; CVI$\mathrm{M}=$ :machos; CVI-F= fêmeas; $\mathrm{CI}-\mathrm{V}=$ copepoditos.

Tabela 3.3: Quantidade de indivíduos parasitados por amostra qualitativa (amostra total) para Paracalanus spp., Parvocalanus crassirostris, Acartia lilljeborgii e Oithona spp. V: verão; I: inverno; 09 a 11: anos de 2009 a 2011 respectivamente.

Tabela 3.4: Estimativas da densidade de Parvocalanus crassirostris e Paracalanus spp. parasitados em org. $\mathrm{m}^{-3}$ nos respectivos períodos amostrais. $\mathrm{C}$ VI: adultos; $\mathrm{M}$. = macho; $\mathrm{F}=$ fêmea; $\mathrm{M}+\mathrm{F}=$ soma dos adultos; $\mathrm{CI}-\mathrm{V}=$ Copepoditos.

Tabela 3.5: Resultado do teste de comparação aos pares de Student-Newman-Keuls, entre a densidade de copépodes parasitados para os três anos de amostragens. .201

Tabela 3.6: Teste de Mann-Whitney para comparação entre os grupos (animais normais x parasitados) em machos, fêmeas e adultos de Parvocalanus crassirostris e Paracalanus spp. quanto ao comprimento do prossomo em $\mu \mathrm{m}$.

202

Tabela 3.7: Quantidade de parasitas por copépodes (Paracalanus spp. e Parvocalanus crassirostris) e suas respectivas frequências relativas (\%)...... .204

Tabela 3.8: Locais de adesão de Ellobiopsis sp. sobre os copépodes hospedeiros Parvocalanus crassirostris e Paracalanus spp. .204 


\section{RESUMO}

O objetivo desta tese foi o estudo da variabilidade temporal, crescimento e produção do zooplâncton metazoário, com ênfase sobre estágios imaturos de copépodes, na região costeira de Ubatuba (SP, Brasil). Para tal, a comunidade zooplanctônica foi estudada durante as estações de verão e inverno em regime de dias alternados, para os anos de 2009 a 2011, através de coletas realizadas com redes de malha de 20 e $100 \mu$ m. Índices ecológicos como densidade, diversidade e equitabilidade foram calculados. Os estágios imaturos de copépodes foram submetidos a experimentos de coortes artificiais em quatro classes de tamanho (50-80, 80-100, 100-150 e 150-200 $\mu \mathrm{m}$ ) para a determinação das taxas de crescimento de 14 táxons em diferentes estágios de desenvolvimento. A biomassa foi estimada através de equações de regressão comprimento-peso para o posterior cálculo da produção secundária. A incidência e possíveis efeitos de um protista alveolado parasita (Ellobiopsis sp.) sobre o crescimento de copépodes hospedeiros, com ênfase sobre a família Paracalanidae, também foi avaliada. A comunidade de copépodes esteve representada por 66 espécies e caracterizada por valores relativamente altos de diversidade e equitabilidade em relação aos demais trabalhos na plataforma interna da região sudeste do país. Os copépodes foram o grupo dominante, sendo que estágios naupliares foram os mais comuns para a rede de $20 \mu \mathrm{m}$, enquanto que copepoditos juvenis dominaram para a rede de $100 \mu \mathrm{m}$. A densidade do zooplâncton foi altamente variável, sendo os maiores valores registrados para o inverno de 2011 para a malha de $20 \mu \mathrm{m}\left(33.160 \pm 23.136\right.$ org. $\left.\mathrm{m}^{-3}\right)$ e os menores para o inverno de 2009 para a malha de $100 \mu \mathrm{m}\left(5.393 \pm 2.264 \mathrm{org} . \mathrm{m}^{-3}\right)$. As famílias dominantes de copépodes foram Oithonidae, Oncaeidae, Paracalanidae e Acartiidae, sendo a primeira dominante também em termos de biomassa. Os estágios juvenis dos copépodes representaram uma biomassa entre 1,06 a $3,47 \mathrm{mg} \mathrm{C} \mathrm{m}^{-3}$ para o inverno de 2010 e verão de 2009 respectivamente. Taxas de crescimento foram obtidas para sete táxons de Calanoida $\left(0,41 \pm 0,21 \mathrm{~d}^{-1}\right)$, cinco de Cyclopoida $\left(0,27 \pm 0,17 \mathrm{~d}^{-1}\right)$ e dois de Harpacticoida $\left(0,31 \pm 0,16 \mathrm{~d}^{-1}\right)$. Os valores de crescimento foram semelhantes entre as diferentes classes de tamanho e as estações do ano, mas foram substancialmente diferentes entre as ordens, sendo geralmente maiores para os Calanoida. A produção média estimada para os estágios imaturos dos táxons dominantes de copépodes foi igual a $0,45 \mathrm{mg} \mathrm{C} \mathrm{m}^{-3}$, valor conservativo por não contemplar as espécies de menor densidade e frequência. O crescimento de copépodes da família Paracalanidae, principalmente Parvocalanus crassirostris, foi afetado pelo protista parasita Ellobiopsis sp., uma vez que as fêmeas adultas infectadas foram significativamente menores do que as normais. Cerca de 5\% das fêmeas da espécie estiveram infectadas pelo parasita, que provavelmente afeta o crescimento somático e reprodutivo de $P$. crassirostris, com efeitos ainda desconhecidos em termos de biomassa e produção. As taxas calculadas de crescimento e a produção são semelhantes às de outros trabalhos em regiões tropicais. A abordagem experimental através de coortes artificiais forneceu os primeiros resultados sobre o crescimento de estágios juvenis de copépodes para uma região subtropical do Atlântico Sul Ocidental e demonstrou que a concentração da clorofila- $a$ não foi um fator limitante. Este é um dos poucos trabalhos a disponibilizar dados de crescimento, biomassa e produção de tais estágios em ecossistemas marinhos tropicais e que padroniza o método de coortes artificiais para obtenção do crescimento.

Descritores: microzooplâncton, coortes artificiais, produção secundária, costa brasileira, taxas de crescimento, parasitismo, Ellobiopsis. 


\begin{abstract}
This thesis aimed to evaluate the temporal variability of the metazoan zooplankton density, growth, and production, with emphasis on copepod immature stages in the coastal area of Ubatuba (São Paulo, Brazil). The zooplankton community was studied during summer and winter from 2009 to 2011, by means of sampling with 20 and 100 $\mu \mathrm{m}$ mesh-sized nets. Ecological indexes such as density, diversity and evenness were calculated. Growth rates for 14 taxa of copepod juvenile stages were determined by the artificial cohort method, in four size classes and different developmental stages (50-80, 80-100, 100-150 and 150-200 $\mu \mathrm{m}$ ). Biomass was estimated by the use of length-weight regressions followed by secondary production estimates. The incidence and possible effects of the alveolate parasite Ellobiopsis sp. on the growth of the copepod hosts was also investigated, with emphasis on the Paracalanidae family. The copepod assemblage was represented by 66 species and displayed relatively high diversity and evenness, in comparison to other studies in the inner shelf of the Brazilian southeastern coast. Copepod was the dominant group; nauplii in the $20 \mu \mathrm{m}$ net, and juvenile copepodids in the $100 \mu \mathrm{m}$ net. The zooplankton density was highly variable: the highest densities occurred during winter 2011 in the $20 \mu \mathrm{m}$ samples $\left(33,160 \pm 23,136\right.$ org. $\left.\mathrm{m}^{-3}\right)$ and the lowest for the winter 2009 in the $100 \mu \mathrm{m}$ samples $\left(5,393 \pm 2,264 \mathrm{org}^{-\mathrm{m}^{-3}}\right)$. The dominant copepod families were Oithonidae, Oncaeidae, Paracalanidae and Acartiidae, the former being the main taxa in terms of biomass as well. Juvenile copepod biomass varied between 1.06 and $3.47 \mathrm{mg} \mathrm{C} \mathrm{m}^{-3}$ in the winter 2010 and summer 2009, respectively. Growth rates were recorded for seven Calanoida $\left(0.41 \pm 0.21 \mathrm{~d}^{-1}\right)$, five Cyclopoida $\left(0.27 \pm 0.17 \mathrm{~d}^{-1}\right)$ and two Harpacticoida $\left(0.31 \pm 0.16 \mathrm{~d}^{-1}\right)$ taxa. Growth values were similar between the different size classes, seasons and years, but were substantially different between copepod orders (higher rates for the Calanoida). The mean production for all immature copepod stages was $0.45 \mathrm{mg} \mathrm{C} \mathrm{m}^{-3}$, a conservative value, since rare species were not accounted for. The growth of the Paracalanidae copepod Parvocalanus crassirostris, was affected by the parasite protist Ellobiopsis sp., since infected adult females were significantly smaller than normal individuals. About $5 \%$ of adult females were infected by the parasite, which probably reduced somatic and reproductive growth of $P$. crassirostris, with potential consequences for biomass accumulation and, consequently, production. Growth and production rates were similar to those found in other studies carried out in tropical regions. The artificial cohort method has been applied here for the first time on the tropical and subtropical Southwest Atlantic, where clorophyl- $a$ concentration was not considered a limiting factor for growth rates. This is one of the few studies providing data on growth, biomass and production for copepod juvenile stages in tropical marine ecosystems and standardizing the artificial cohort method to measure the growth rates.
\end{abstract}

Descriptors: microzooplankton, artificial cohorts, secondary production, Brazilian coast, growth rates, parasitism, Ellobiopsis. 
Introdução Geral 


\section{O microzooplâncton e estágios juvenis de copépodes}

O estudo sobre o microzooplâncton foi tradicionalmente subestimado em relação as maiores classes de tamanho como o meso- e macrozooplâncton, quanto a estrutura e dinâmica nos ecossistemas marinhos. Tal cenário é ainda mais crítico em ambientes de alta produtividade e em regiões tropicais (Calbet, 2008). As pesquisas realizadas com o zooplâncton na costa brasileira servem como exemplo didático da abordagem tangencial dada às menores frações de tamanho do plâncton (Lopes et al., 2006; Lopes, 2007).

Resumidamente, esta classe de tamanho é composta de predadores planctônicos de dimensões entre 20 a $200 \mu \mathrm{m}$ e que ocupam papel fundamental nas tramas tróficas marinhas. Formado por diversos grupos de protistas unicelulares heterotróficos a mixotróficos (flagelados, ciliados, dinoflagelados, foraminíferos, acantários, radiolários, ameboides) e por metazoários (como náuplios e copepoditos, rotíferos, larvas meroplanctônicas), o microzooplâncton é o principal consumidor primário na maioria dos ecossistemas marinhos, ultrapassando os copépodes adultos e outros táxons do meso- e macrozooplâncton (Schmoker et al., 2013).

Os estágios juvenis de copépodes (copepoditos I a V) e adultos de espécies pequenas geralmente são os organismos mais abundantes do mesozooplâncton, enquanto que os náuplios são os metazoários mais numerosos do microzooplâncton (Fryer, 1986). Aliada à dominância numérica dos estágios imaturos, as águas tropicais também são dominadas por copépodes de pequeno porte, prncipalmente das famílias Paracalanidae, Oithonidae e Oncaeidae (Paffenhöfer, 1993; Turner, 2004).

O uso de redes de plâncton de malhas inapropriadas para a coleta dos menores táxons resultou em uma defasagem quanto ao conhecimento real sobre sua ecologia (Galliene \& Robins, 2001). O histórico enfoque sobre o mesozooplâncton, amostrado por redes de $200 \mu \mathrm{m}$ ou malhas ainda maiores, subestimou a biomassa e produção não apenas dos estágios imaturos, mas também de adultos de espécies de pequeno porte.

Para as águas brasileiras, como resultado da pesquisa direcionada a classes de tamanho maiores, nenhum trabalho foi publicado sobre o crescimento dos estágios imaturos de copépodes exclusivamente. Miyashita et al. (2009) e Melo-Júnior (2009) abordaram parcialmente alguns estágios de copepoditos e mesmo de náuplios no litoral sudeste do Brasil, utilizando amostras coletadas por redes de 64 e $200 \mu \mathrm{m}$ 
respectivamente. Para ambos os casos, parte dos estágios juvenis foi perdida ou subestimada e o crescimento instantâneo foi estimado através dos modelos numéricos de Huntley \& Lopez (1992) e Hirst \& Bunker (2003).

Para o litoral do Rio Grande do Sul, Ávila et al. (2012) também determinaram o crescimento de copépodes, mas utilizando a concentração da enzima quitobiase como método principal. Estágios juvenis de espécies pequenas também foram subestimados, pois a malha utilizada para as coletas foi de $90 \mu \mathrm{m}$.

Estimar o crescimento, biomassa e produção zooplanctônicas tem sido um grande desafio para pesquisadores, tanto em ambientes marinhos, quando em águas continentais, desde a década de 1970 (Winberg, 1971; Downing \& Rigler, 1984; Harris et al., 2000, entre outros). A ausência de um método unificado para as diferentes escalas de tamanho dos metazoários pelágicos resultou nos estudos apenas das espécies numericamente importantes (Hirst et al., 2003).

O desenvolvimento dos copépodes segue dois padrões principais: o isocronal e o equiproporcional. O segundo padrão é o mais comum, sendo que o primeiro só ocorre para o gênero Acartia e algumas espécies de Oithona (Hart, 1990). O padrão isocronal postula que a duração dos estágios do ciclo de vida de uma espécie é igual, tanto para náuplios, quanto para copepoditos.

Em contrapartida, o padrão equiproporcional determina que o tempo de duração de um dado estágio é descrito por uma constante, proporcional ao tempo de desenvolvimento embrionário (Hart, 1990). Uma vez que o padrão equiproporcional é muito mais frequente que o isocronal, pode-se generalizar que a maioria dos copépodes possui um tempo de desenvolvimento maior durante os estágios de copepoditos, em relação aos estágios naupliares (Peterson, 2001). Portanto, as taxas de crescimento são mais elevadas em náuplios do que copepoditos, ou ainda, em estágios juvenis do que adultos.

Esta tese traz os primeiros resultados da obtenção de taxas de crescimento de juvenis de copépodes através de abordagem experimental pelo método de coortes artificiais. Resultados sobre a importância numérica dos estágios imaturos de copépodes e de atributos biológicos como densidade, biomassa e produção também são fornecidos. O termo microzooplâncton será evitado no decorrer da tese, como referência ao plâncton coletado pelas redes de 20 e $100 \mu \mathrm{m}$ neste estudo, uma vez que no material analisado também estiveram presentes organismos do mesozooplâncton. 
Para maior praticidade, o zooplâncton coletado pela rede de 20 e $100 \mu \mathrm{m}$ será denominado como frações menor e maior do zooplâncton, respectivamente.

\section{Métodos para obtenção do crescimento em copépodes}

Diversos métodos experimentais e matemáticos estão disponíveis atualmente para a estimativa das taxas de crescimento do zooplâncton. Independente do método, os experimentais, embora permitam avaliar o crescimento em relação a outras variáveis controladas ou observadas nos experimentos, são laboriosos e consumem tempo e dedicação consideráveis, justificando a utilização de modelos matemáticos globais de estimativa do crescimento.

Um dos primeiros modelos globais para copépodes levava em consideração apenas a temperatura como variável influenciando a estimativa do crescimento (Huntley \& Lopez, 1992). Posteriormente, dois novos modelos foram publicados, onde o tamanho do corpo foi a variável incorporada às equações (Hirst \& Sheader, 1997; Hirst \& Lampitt, 1998). O trabalho de Hirst \& Lampitt (1998) trouxe outro importante avanço: regressões específicas para copépodes dispersores e para os retentores de ovos, além da separação entre adultos e juvenis. O modelo de Hirst \& Bunker (2003) contou com uma quantidade robusta de dados da literatura sobre taxas de crescimento estimadas experimentalmente e gerou modelos com a adição da concentração de clorofila- $a$, como uma variável indicativa da disponibilidade de alimento. Atualmente é o modelo mais utilizado, embora sua aplicabilidade seja limitada (Liu \& Hopcroft, 2006 $a$ e $b$; entre outros).

Para o cálculo de crescimento de copépodes adultos através de abordagens experimentais, o método de produção de ovos é o mais antigo (Marshall \& Orr, 1955), de menor custo e tem sido utilizado sistematicamente desde o final da década de 1970 (e.g. Dagg, 1978). A técnica parte do pressuposto de que o crescimento somático em adultos é negligenciável, de maneira que o crescimento reprodutivo através da quantidade de ovos equivale à produção total das fêmeas adultas (Berggreen et al., 1988; Støttrup \& Cohen, 1990). O método também restringe o cálculo da produção às fêmeas adultas, ou seja, apenas uma parcela do ciclo de vida e da população de uma espécie de copépode pelágico (Poulet et al., 1995).

Embora amplamente empregado, o método de produção de ovos apresenta inconsistências como o pressuposto de que o peso de uma fêmea adulta é constante ao 
longo de um determinado período, o que resulta em propagação de erros, principalmente se o período de incubação for inferior ao período entre ninhadas (Hirst \& McKinnon, 2001). A disponibilidade e a qualidade de alimento também são variáveis que devem ser controladas para a determinação do crescimento reprodutivo pelo método (Saiz et al., 1998). Por fim, o crescimento de estágios juvenis provavelmente difere e deve ser maior do que o calculado pela produção de ovos para a maioria das espécies (e.g. McKinnon, 1996).

O método de produção de exúvias ou mudas é empregado para a determinação do crescimento dos estágios juvenis. A análise de exúvias foi proposta por Klein Breteler e colaboradores (1982) e utiliza a média de peso entre dois estágios consecutivos em determinado intervalo de tempo para o cálculo do crescimento. Embora largamente empregado (Burkill \& Kendal, 1982; McLaren et al., 1989; Peterson et al., 1991; Shreeve et al., 1998; Escribano et al., 2001; Muxagata et al., 2004; Jiménez-Melero et al., 2013; entre outros), o método tem sido criticado devido a dois fatores: o primeiro é a variação da duração entre sucessivos estágios do ciclo de vida de copépodes e o segundo a variação estágio-específica das taxas de crescimento (Hirst et al., 2005). Um método aprimorado para a taxa de mudas foi proposto por Hirst et al. (2005), embora resultados da aplicação do mesmo ainda não tenham sido publicados em artigos científicos até o momento.

Métodos enzimáticos da determinação do crescimento foram desenvolvidos durante as últimas duas décadas e podem ser classificados em dois tipos: i) a utilização de enzimas diretamente relacionadas à síntese de proteínas como a Aminoacil-tRNA sintetase (AARS, Yebra \& Hernández-León, 2004; Yebra et al., 2005) ou ii) de enzimas que degradam a quitina, como a quitobiase (Oosterhuis et al., 2000). Ambos os métodos foram aprimorados recentemente (Herrera et al., 2012 para AARS; Ávila et al., $2011 \mathrm{e}$ Suchy et al., 2013 para quitobiase) e já são utilizados satisfatoriamente em campo, a exemplo do trabalho de Sastri \& Dower (2006) para quitobiase e de Yebra et al. (2011) para $A A R S$. Acredita-se que tais metodologias serão utilizadas com maior frequência em um futuro próximo.

A razão RNA:DNA é outra ferramenta que tem sido utilizada para análise do crescimento do zooplâncton desde a década de 1970 (Dagg \& Littlepage, 1972). A técnica é consagrada para a estimativa do crescimento em diversos crustáceos e tem sido utilizada principalmente para estimativa de crescimento em adultos (Gusmão \& McKinnon 2009 a, entre outros), mas também é aplicável para o crescimento de juvenis 
ou concomitantemente com o método enzimático (Yebra et al., 2011). Uma importante crítica ao método, quando utilizado em copépodes adultos, é de que o crescimento medido através do RNA não está necessariamente correlacionado a viabilidade dos ovos produzidos. A produção de ovos pode estar diretamente relacionada aos índices de ácidos nucléicos, porém o mesmo não reflete na qualidade dos ovos (Hogfors et al., 2011). Entretanto, o próprio conteúdo de RNA é considerado uma referência do crescimento e estado nutricional em diversos invertebrados. Saiz et al. (1998) desenvolveram um protocolo de estimativa do crescimento para adultos do copépode Acartia grani e demostraram uma forte correlação entre a concentração de RNA e a produção de ovos. Outros autores aplicaram técnicas semelhantes para o estudo do crescimento de estágios naupliares (Wagner et al., 2001) e de copepoditos (Wagner et al., 1998).

Entre os métodos tradicionais, o de coortes artificiais é a principal alternativa à taxa de mudas para medir o crescimento de náuplios e copepoditos. O método foi descrito por Kimmerer \& McKinnon (1987), utilizando a espécie Acartia fanceri (classificada pelos autores como A. tantreri) como modelo e tem sido empregado com maior frequência nos últimos anos (McKinnon \& Duggan, 2003; McKinnon et al., 2005; Liu \& Hopcroft 2006 a,b; Gould \& Kimmerer, 2010 \& Lin et al., 2012). Uma grande vantagem do método é que permite a análise de diversos táxons e indivíduos em diferentes estágios de desenvolvimento concomitantemente. Porém, o método requer a incubação dos organismos e pode estar sujeito a eventuais erros e limitações causadas pelas condições laboratoriais, principalmente após as primeiras 24 horas de experimentação como o crescimento bacteriano e efeitos de cascata trófica (Kimmerer et al., 2007). Também não se pode avaliar possíveis consequências do manuseio dos animais, durante a coleta e a elaboração das coortes.

O método foi escolhido para a realização do presente estudo porque ainda apresenta outras vantagens em relação aos antes descritos como: i) é possível medir o crescimento de estágios imaturos isoladamente; ii) o tempo utilizado para a elaboração e manutenção dos experimentos é relativamente curto; iii) não requer identificação ou manipulação individual de cada organismo em campo; iv) não requer infraestrutura ou materiais de consumo de alto custo. 


\section{Postulado teórico e hipóteses}

O conhecimento sobre variações temporais na dinâmica e estrutura das populações zooplanctônicas é importante para compreender o funcionamento dos ecossistemas aquáticos, uma vez que estes organismos exercem papel central na teia alimentar pelágica. Além disso, as diferentes escalas temporais podem influenciar a interpretação de processos que atuam diretamente na estruturação do ecossistema subtropical estudado. Neste contexto, é de fundamental importância o estudo das interações entre os parâmetros climatológicos e hidrográficos locais com a densidade, crescimento e produção do zooplâncton, especialmente os copépodes, por sua dominância no mesozooplâncton e no microzooplâncton metazoário.

O principal objetivo da tese é avaliar as variáveis ecológicas dos metazoários do zooplâncton das frações de tamanho coletadas por redes de 20 e $100 \mu \mathrm{m}$, incluindo composição, densidade, diversidade e estrutura da comunidade em escala temporal, durante o verão e inverno, em três anos consecutivos. Ênfase foi dada aos estágios juvenis de copépodes, onde o crescimento foi determinado experimentalmente e a biomassa e produção estimadas.

Por fim, a incidência de copépodes infectados por um parasita alveolado (Ellobiopsis sp) foi estimada e o possível impacto do parasita sobre o crescimento de copépodes paracalanídeos foi avaliado. As seguintes hipóteses norteadoras foram formuladas e respondidas pelos estudos descritivos e experimentais desta tese:

1) A variação sazonal entre verão e inverno é significativa para explicar a variabilidade da diversidade, densidade, biomassa e produção do zooplâncton na região estudada? Capítulo 1,2.

2) A variação inter-anual é importante para a variabilidade dos fatores biológicos citados? Capítulo 1,2.

3) As variáveis ambientais analisadas foram importantes para explicar a variabilidade temporal da comunidade zooplanctônica? Capítulo 1,2.

4) As redes utilizadas foram eficientes na captura dos diversos estágios de desenvolvimento dos copépodes? Capítulo 1.

5) $\mathrm{O}$ crescimento obtido experimentalmente foi diferente do obtido pelo modelo matemático de Hirst \& Bunker (2003)? Capítulo 2. 
6) As taxas de crescimento foram afetadas pelas variáveis controladas dos experimentos de coortes artificiais? Capítulo 2.

7) As taxas de crescimento foram diferentes entre os níveis taxonômicos ou grupos funcionais abordados (tamanho e estratégia reprodutiva)? Capítulo 2.

8) Os valores de crescimento e produção são semelhantes aos de outras áreas tropicais? Capítulo 2.

9) Existe variabilidade temporal da frequência de infecção dos copépodes pelo parasita alveolado Ellobiopsis sp.? Capítulo 3.

10) O protista Ellobiopsis sp. influencia o crescimento dos copépodes parasitados? Capítulo 3.

\section{Área de estudo}

O plâncton costeiro foi coletado em uma estação fixa localizada nas coordenadas $23^{\circ} 31^{\prime} 27^{\prime}$ ' S e 45 $04^{\circ}$ '54' $\mathrm{O}$, próxima à base de pesquisa Clarimundo de Jesus, do Instituto Oceanográfico da USP, no município de Ubatuba (Figura 1), durante os anos de 2009 a 2011. Os experimentos de coortes artificiais foram realizados no Laboratório Integrado de Processos Oceanográficos (LIPO), na referida base de pesquisa.

O local onde a estação foi posicionada é conhecido popularmente como Boqueirão (B), uma depressão alongada em direção Sudoeste - Nordeste entre o continente e a Ilha Anchieta e de profundidade variável de 18 à $35 \mathrm{~m}$. Excepcionalmente, algumas amostragens foram realizadas em uma segunda estação mais abrigada, denominada Ribeira (sigla A, coordenadas $23^{\circ} 30^{\prime} 59^{\prime}$ ' S e $45^{\circ} 06^{\prime} 10^{\prime \prime}$ O), devido a dificuldades logísticas para realizar a coleta na estação Boqueirão em dias de muito vento.

A estação foi escolhida devido à sua heterogeneidade. Por ser próxima da costa, a presença de espécies costeiras é constante e por ser uma região que eventualmente recebe intrusões de águas neríticas durante o verão, espécies de distribuição mais neríticas são eventualmente capturadas. A intensidade do fluxo de maré pelo canal do Boqueirão também gera turbulência e homogeneização da coluna de água e fauna capturada na superfície é possivelmente semelhante a capturada no fundo. 
A plataforma interna na região de Ubatuba é influenciada por dois tipos de massas de água: Água Costeira (AC), recebendo aportes continentais (salinidade inferior a 35 e temperatura acima de $20^{\circ} \mathrm{C}$ ) e a Água Central do Atlântico Sul (ACAS), com temperatura menor que $18^{\circ} \mathrm{C}$ e salinidade entre 34,5 e 36,8 (Castro-Filho et al., 1987). O vento é a principal forçante ambiental nesta área, principalmente nas proximidades do continente, causando alterações nas camadas superficiais. Durante o verão o predomínio de ventos de leste e nordeste ocasionam o transporte da $\mathrm{AC} \mathrm{em}$ direção ao oceano, na camada de Ekman superficial, o qual é compensado pela inundação do fundo da plataforma pela ACAS.

As estações de coleta estão localizadas sobre o domínio interior da plataforma continental, definido por Castro Filho et al. (1987) como a plataforma limitada pela costa e isóbatas de 40 a $50 \mathrm{~m}$. Ainda segundo os autores, a ocorrência da ACAS é comum durante o verão, geralmente ocorrendo em profundidades abaixo de $20 \mathrm{~m}$. A ressurgência da ACAS é detectada em diversos pontos na plataforma externa e interna do sudeste como o sul da região de Cabo Frio, onde incide com maior intensidade. Tal mecanismo é responsável pela manutenção de uma área de elevada produtividade planctônica, favorecida pela estratificação da coluna de água e aporte de nutrientes (Valentin, 1984 b). Intrusões periódicas no setor interno da plataforma sudeste brasileira e especificamente na região de Ubatuba foram descritas por Pires-Vanin et al. (1993) e Castro et al. (2006), resultando no aumento da produtividade (e.g. MeloJúnior, 2009).

Durante a maior parte do ano, as águas são oligotróficas, devido à contribuição dispersa e pouco significante de pequenos estuários (Castro et al., 2006). Já em regiões mais próximas da costa, os processos de mistura causados pela baixa profundidade e vento são dominantes.

O sistema marinho da região de Ubatuba é considerado meso-oligotrófico e é caracterizado por temperaturas entre 14 a $28^{\circ} \mathrm{C}$ e salinidades entre 33 a 37 . O fito- e zooplâncton são dominados por espécies costeiras durante todo o ano (Gaeta et al., 1990; Aidar et al., 1993). Espécies oceânicas podem ser frequentes e abundantes durante os períodos de intrusão da ACAS e eventualmente transportadas para a plataforma interna (Valentin, $1984 a$ e $b$; Gianesella-Galvão \& Saldanha-Corrêa, 2008; Melo-Júnior, 2009). 


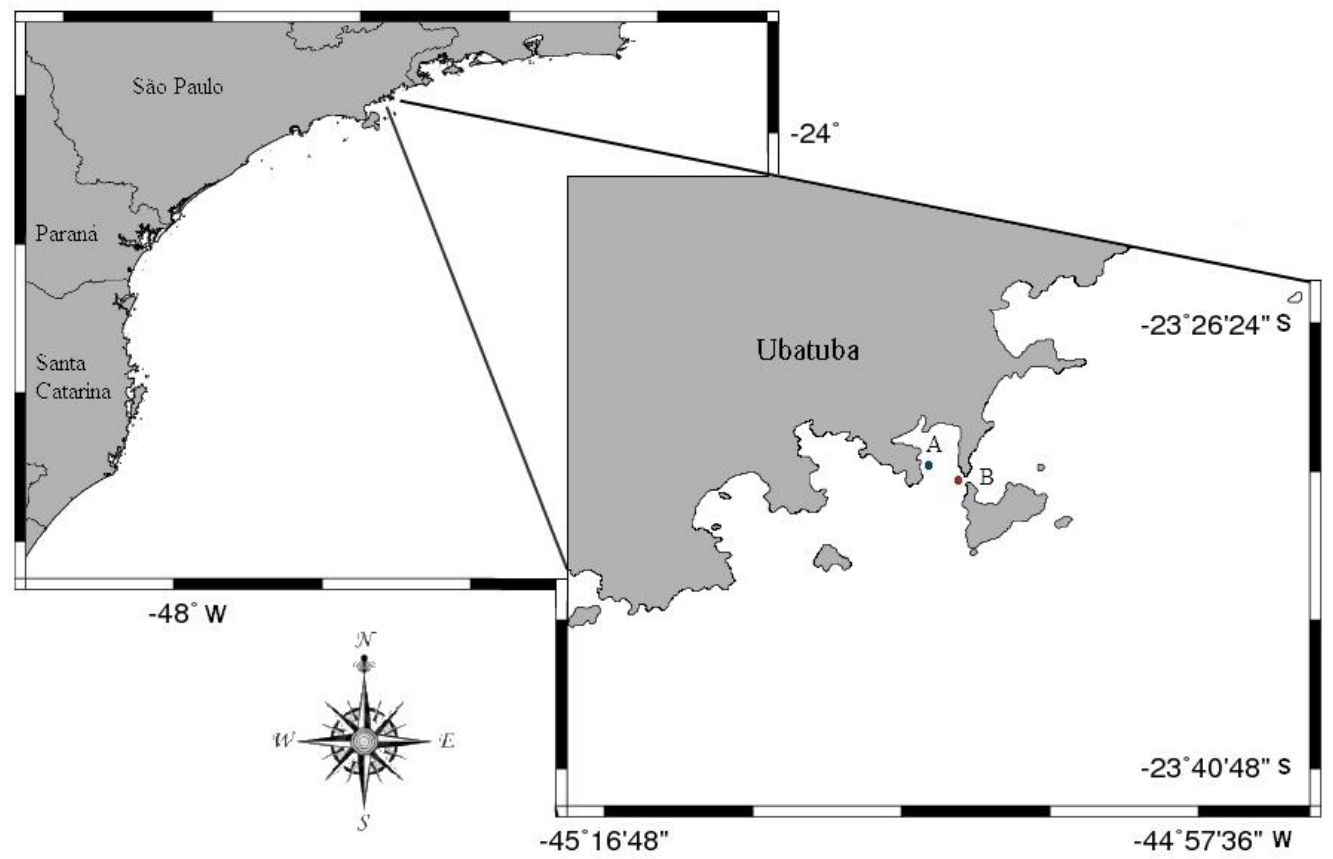

Figura 1: Localização das estações de coleta situada na plataforma interna ao largo de Ubatuba, litoral norte do estado de São Paulo. A: estação Ribeira; B: estação Boqueirão. 
Capítulo 1

Estrutura e variação temporal do zooplâncton em uma estação fixa no litoral norte do estado de São Paulo, Brasil 


\section{Capítulo 1. Estrutura e variação temporal do zooplâncton em uma estação fixa no litoral norte do estado de São Paulo, Brasil}

\section{Resumo}

A composição, abundância e estrutura do zooplâncton foram estudadas durante o verão e inverno dos anos de 2009 a 2011. A coleta foi realizada em águas superficiais, num ponto fixo no litoral de Ubatuba, região norte do estado de São Paulo. Variáveis como a temperatura, salinidade, precipitação, profundidade e concentrações de clorofila- $a$ e feopigmentos foram obtidas, juntamente com as amostras de plâncton utilizando duas redes de malha iguais a 20 e $100 \mu \mathrm{m}$. Um total de 92 amostras foi analisado, sendo 46 para cada rede. Foram realizadas oito amostragens em regime de dias alternados para cada verão e inverno (exceto durante o verão de 2011 com 6 amostragens). Cerca de 130 táxons foram contabilizados, sendo 66 espécies de copépodes. Valores de riqueza e diversidade mais elevados foram encontrados durante o verão e as amostras da rede de $20 \mu \mathrm{m}$ geralmente tiveram o dobro da densidade em relação a rede de $100 \mu \mathrm{m}$. Os copépodes foram o grupo dominante, sendo que estágios naupliares foram os mais comuns para a rede de $20 \mu \mathrm{m}$, enquanto que copepoditos juvenis dominaram para a rede de $100 \mu \mathrm{m}$. A densidade dos copépodes foi seguida pelos apendiculários, cladóceros e larvas meroplanctônicas de moluscos e poliquetos. Dentre os copépodes, as famílias Oithonidae, Oncaeidae e Paracalanidae foram as mais abundantes e frequentes para a amostragem de $20 \mu \mathrm{m}$, enquanto que para a rede de $100 \mu \mathrm{m}$ Oithonidae, Acartiidae e Paracalanidae foram as dominantes em ordem decrescente. A temperatura foi a principal variável ambiental responsável pela ordenação das amostras de plâncton através da análise de $P C A$ e $M D S$. Não foi observado um padrão de variação sazonal da comunidade zooplanctônica quanto à densidade, apesar de tal variação afetar a diversidade e equitabilidade da comunidade. Durante o inverno, as concentrações de clorofila- $a$ e feopigmentos foram maiores em relação ao verão. Uma vez que as amostragens foram em sub-superfície, é provável que tal resultado esteja relacionado à ressuspensão e ventos mais intensos durante esta estação do ano. Embora apenas três anos tenham sido analisados, a variação multianual foi mais acentuada do que a sazonal em relação à densidade da comunidade zooplanctônica.

Palavras-chave: zooplâncton, copepoditos, náuplios, Atlântico Sul, variação sazonal. 


\title{
Chapter 1. Microzooplankton structure and temporal variability at a fixed station on the north coast of São Paulo state, Brazil
}

\begin{abstract}
Zooplankton composition, abundance and structure were studied during summer and winter seasons for the years of 2009 to 2011. Sampling was performed on surface waters at a fixed coastal station near Ubatuba, north coast of São Paulo state. Environmental variables as temperature, salinity, rainfall, depth and clorophyll- $a$ and pheopigments concentration were obtained, along with plankton samples collected by 20 and $100 \mu \mathrm{m}$ mesh-sized plankton nets. Sampling was carried out on alternate days, totalling eight sampling periods per season, except only for the summer 2011 with six periods. A total of 92 plankton samples was analyzed, 46 for each mesh size. About 130 planktonic taxa were accounted, from which 66 were copepod species. Richness and diversity were higher during summer, while density of the zooplankton collected by $20 \mu \mathrm{m}$ net was about two times higher than the $100 \mu \mathrm{m}$ net. Copepods were the most abundant group, represented mainly by naupliar stages in the $20 \mu \mathrm{m}$ net and juvenile copepodids in the $100 \mu \mathrm{m}$ net samples. Other taxa such as appendicularians, cladocerans and the meroplanktonic larvae of mollusks and polychaets followed as abundant groups. The copepod families Oithonidae, Oncaeidae and Paracalanidae were dominant for the $20 \mu \mathrm{m}$ net samples, and Oithonidae, Acartiidae and Paracalanidae for the $100 \mu \mathrm{m}$ net samples. Temperature was the main environmental variable explaining the plankton samples ordination by the $P C A$ and $M D S$ analysis. Zooplankton density was not affected by seasonality in most cases, although diversity and eveness were affected. Inter-annual variability seemed more important than seasonal variability in this study. Chlorophyll- $a$ and pheopigments concentrations were higher during winter, probably as a result of stronger winds and ressuspension processes. Though only three years were analyzed, multiannual variation was higher than seasonal variation for the zooplankton density.
\end{abstract}

Keywords: zooplankton, copepodid, nauplii, South Atlantic, seasonal variaton 


\subsection{Introdução}

O zooplâncton é tradicionalmente descrito como o elo trófico entre os produtores primários e os consumidores secundários de níveis tróficos superiores. A composição e a disponibilidade do zooplâncton para os níveis tróficos superiores têm consequências diretas sobre os estoques de peixes pelágicos (Bakun, 1996), o que moldou a pesquisa sobre o zooplâncton em aspectos ecológicos e quantitativos como abundância, biomassa e produtividade (Wiebe \& Benfield, 2003). Além disso, o zooplâncton constitui compartimentos vitais nos ecossistemas marinhos, participando de processos oceanográficos como a bomba biológica, a trama trófica microbiana, reciclagem de nutrientes e de maneira geral nos ciclos biogeoquímicos.

Estudos quantitativos, de ecologia trófica e de predição dos estoques do zooplâncton são necessários e foram historicamente dominantes, com exceção apenas à taxonomia no período anterior ao final do século XIX. Em 1887, o trabalho pioneiro de Victor Hensen inicia a pesquisa sobre a variabilidade da comunidade zooplanctônica em resposta às diversas variáveis ambientais. Flutuações sazonais nos estoques planctônicos foram descritos pela primeira vez em águas temperadas (Hensen, 1887).

Atualmente, a pesquisa envolvendo o zooplâncton é muito mais diversificada: estudos sobre as interações ecológicas entre os táxons planctônicos como parasitismo (Théodoridès, 1989) simbiose (Decelle et al., 2012; Tang, 2005), utilização de organismos como bioindicadores de alterações climáticas e ambientais (Richardson, 2008), participação na regeneração de nutrientes (Giering et al., 2012) e mecanismos reguladores das populações fitoplanctônicas (Strom et al., 2007) e bacterianas (Turner \& Tester, 1992) são alguns dos exemplos.

O zooplâncton responde a uma diversidade de fatores abióticos e bióticos, possuindo inclusive a capacidade de modificar alguns desses fatores como a densidade de outros compartimentos do plâncton e a concentração de nutrientes dissolvidos (Bouvy et al., 2006, entre outros). Variações temporais e espaciais do zooplâncton foram extensivamente estudadas ao longo do século XX. Porém, estudos em ecossistemas tropicais eram de cunho taxonômico e estes ambientes só foram estudados quanto aos aspectos ecológicos e oceanográficos a partir dos anos 50 (FernándezÁlamo \& Färber-Lorda, 2006).

Diferente dos mares temperados, a abundância dos produtores primários e seus consumidores nas regiões tropicais não variam intensamente entre as estações do ano 
ou em função da variação da temperatura. Águas tropicais são caracterizadas por elevadas temperaturas nas camadas superiores e reduzida quantidade de nutrientes e matéria orgânica particulada durante o ano todo, exceto em áreas influenciadas por aporte continental ou mecanismos de ressurgência. A condição oligotrófica dominante nestas regiões molda a comunidade planctônica, sendo que a densidade do fito- e zooplâncton são baixas e processos regenerativos são importantes para a manutenção destas comunidades (Lalli \& Parsons, 1997).

O zooplâncton tropical de águas costeiras geralmente possui menor diversidade e é composto por espécies de menor porte, quando comparado ao zooplâncton de regiões oceânicas. Este padrão foi frequentemente documentado para as comunidades planctônicas em geral e para os copépodes, onde espécies pequenas são dominantes numericamente. Em diversos casos, a dominância também é refletida em termos de biomassa (Turner, 2004).

A maioria dos trabalhos sobre zooplâncton em regiões tropicais priorizaram as maiores classes de tamanho como o meso- e macrozooplâncton (Lopes, 2007). Para um adequado entendimento da comunidade zooplanctônica, esforços devem ser direcionados para classes de tamanho menores como o microzooplâncton, pois este provavelmente atua como o principal predador do fitoplâncton em águas oligotróficas (Calbet, 2008).

Tal cenário é visualizado para o litoral norte do estado de São Paulo, onde diversos trabalhos sobre oceanografia, ecologia e zoologia do plâncton já foram publicados, porém, apenas uma minoria inclui ou trata especificamente do microzooplâncton (Lopes et al., 2006 b). Embora o atual volume de trabalhos seja expressivo para o litoral paulista, quase todos focaram no meso- ou macrozooplâncton e a metodologia de coleta utilizada foram redes de malha igual ou superior a $100 \mu \mathrm{m}$, com exceção somente de Tundisi et al. (1978), Björnberg et al.(1998), De La Rocha (1998), Kuei \& Björnberg (2002), Rimoldi (2008) e Miyashita et al. (2009).

Tundisi et al. (1978) analisaram o micro- e mesozooplâncton utilizando uma malha de $50 \mu \mathrm{m}$. Estes autores, entretanto, realizaram apenas uma análise quantitativa em baixa resolução taxonômica. Já os trabalhos citados de Björnberg e colaboradores (1998) utilizaram redes de mesma malha para a captura de náuplios para descrição taxonômica: copépodes Harpacticoida da família Canuelidae em Björnberg et al. (1998) e Oncaea curta em Kuei \& Björnberg (2002). 
A dissertação de De La Rocha (1998) apresentou dados quantitativos da variação temporal do zooplâncton do canal de São Sebastião utilizando redes de malha iguais a 30 e $100 \mu \mathrm{m}$. A autora também determinou a biomassa de Acartia lilljeborgii e realizou estimativas da produção da espécie durante os anos de 1995 e 1996. O trabalho de Rimoldi (2008) é um dos poucos trabalhos que forneceram valores de biomassa, embora o mesmo tenha focado apenas nas espécies de Temora. A produção dos copépodes da plataforma adjacente a Santos foi estimada por Miyashita et al. (2009) utilizando redes de 64 e $300 \mu \mathrm{m}$, possibilitando a coleta de dados para náuplios e copepoditos componentes das frações menores do zooplâncton. Este estudo foi o único que estimou a biomassa e produção para uma ampla gama de copépodes com estágios de desenvolvimento pertencendo ao microzooplâncton metazoário para o litoral do estado de São Paulo.

Diversos organismos heterotróficos e mixotróficos com tamanho entre 20 e 200 $\mu \mathrm{m}$ compõem o microzooplâncton como, por exemplo, flagelados, ciliados, dinoflagelados, foraminíferos, larvas do meroplâncton e estágios juvenis de crustáceos, principalmente de copépodes. Tanto em águas costeiras quanto águas tropicais, o microzooplâncton é relativamente mais abundante do que em regiões oceânicas e temperadas, desempenhando papéis fundamentais para esses sistemas pelágicos, como bacterivoria e predação de nanoflagelados (Bouvy et al., 2006), como alimento para classes maiores do zooplâncton (Saiz \& Calbet, 2011) e contribuindo com a característica regenerativa desses sistemas pelo elevado metabolismo, liberação e assimilação de nutrientes (Calbet \& Landry, 2004).

De fato, processos importantes como o consumo de matéria orgânica particulada, mortalidade por predação, produção secundária e a colaboração para ciclos biogeoquímicos em geral são raramente abordados para o microzooplâncton e o papel deste compartimento nos ecossistemas pelágicos ainda é conhecido apenas superficialmente (Calbet, 2008). O conhecimento dos processos biológicos e ecológicos das menores frações de tamanho do zooplâncton, assim como a interação com os diversos compartimentos do ecossistema pelágico é necessário para uma futura compreensão dos ecossistemas de águas tropicais.

Neste trabalho, pretendeu-se avaliar a variabilidade temporal do zooplâncton em duas diferentes escalas: i) a sazonal, entre o verão e inverno e ii) a anual, entre os anos de 2009, 2010 e 2011. Para tal, foram utilizadas redes de plâncton de malhas equivalentes a 20 e $100 \mu \mathrm{m}$, as quais amostram as menores classes de tamanho do 
zooplâncton. As interações entre os fatores bióticos e abióticos como temperatura, salinidade, precipitação, profundidade, concentração de clorofila- $a$ e feopigmentos foram exploradas na tentativa de elucidar a variabilidade temporal do zooplâncton em uma estação fixa costeira no litoral norte do estado de São Paulo.

\subsection{Objetivos}

\subsubsection{Objetivo geral}

Analisar a composição, estrutura e variabilidade temporal do micro- e mesozooplâncton em uma estação fixa de coleta no litoral norte do estado de São Paulo durante o verão e inverno dos anos de 2009 a 2011.

\subsubsection{Objetivos específicos}

- Fornecer a composição taxonômica do zooplâncton metazoário, especialmente para os copépodes.

- Descrever a densidade numérica dos táxons do zooplâncton coletados pelas redes de 20 e $100 \mu \mathrm{m}$ ao longo do verão de 2009 ao inverno de 2011.

- Analisar a variabilidade temporal (sazonal e anual) do zooplâncton.

- Verificar as possíveis relações entre a estrutura da comunidade zooplanctônica e variáveis ambientais.

- Explorar a existência de padrões estruturais da comunidade zooplanctônica relacionados com as variáveis ambientais, temporais e classes de tamanho coletadas (20 e $100 \mu \mathrm{m})$.

- Analisar a eficiência de captura de diferentes estágios de desenvolvimento dos copépodes entre as redes de 20 e $100 \mu \mathrm{m}$. 


\subsection{Material e Métodos}

\subsubsection{Obtenção das variáveis ambientais e coleta do plâncton}

O plâncton costeiro foi coletado em duas estações fixas localizadas nas coordenadas $23^{\circ} 31^{\prime} 27^{\prime \prime}$ S e $45^{\circ} 04^{\prime} 54^{\prime \prime}$ O e $23^{\circ} 30^{\prime} 59^{\prime \prime} \mathrm{S}$ e $45^{\circ} 06^{\prime} 10^{\prime}$ ', próximas a base de pesquisa Clarimundo de Jesus, do Instituto Oceanográfico da USP, no município de Ubatuba (Figura 1, introdução geral). A amostragem foi realizada em dias alternados devido a realização dos experimentos de coortes artificiais, totalizando 8 coletas em cada verão e inverno dos anos de 2009 a 2011 (exceto pelo verão de 2011 com 6 coletas). O material foi coletado no período da manhã, ao redor das 9 horas, devido a logística da base de pesquisa.

De 46 amostragens, 39 foram realizadas na estação Boqueirão e apenas 7 na estação abrigada Ribeira. A data, horário, maré e profundidade local foram fornecidas na Tabela 1.1. Uma vez que as coletas foram padronizadas por horário, os dados de marés da estação meteorológica da base de pesquisa do Instituto Oceanográfico Clarimundo de Jesus foram obtidos para a confecção de gráficos de amplitude da maré. O momento de cada coleta foi plotado sobre o gráfico para visualização da altura, amplitude e condição de maré.

A profundidade local e a temperatura da água superficial foram medidas utilizando uma sonda portátil HawkEye modelo H22PX, sendo que a temperatura ainda foi aferida por um termômetro no momento da coleta. Os dados de precipitação foram obtidos da estação meteorológica da base Clarimundo de Jesus e registrados em milímetros. Para visualizar possíveis efeitos da precipitação sobre a comunidade zooplanctônica, foram utilizados dados a partir de sete dias anteriores aos períodos amostrais. A salinidade foi obtida utilizando um refratômetro e a água foi coletada em recipientes estéreis de 20 L para obtenção da clorofila- $a$ e feopigmentos.

As coletas de plâncton foram realizadas através de arrastos horizontas em subsuperfície, com redes de malhas equivalentes a 20 e $100 \mu \mathrm{m}$ respectivamente, equipadas com fluxômetro (General Oceanics) e poitas. A rede de $20 \mu \mathrm{m}$ mede 1,2 m de comprimento e $35 \mathrm{~cm}$ de diâmetro de abertura da boca, enquanto que a rede de 100 $\mu \mathrm{m}$ mede 2,6 $\mathrm{m}$ de comprimento e $50 \mathrm{~cm}$ de diâmetro de boca. A duração dos arrastos foi padronizada entre um a três minutos para a rede de $20 \mu \mathrm{m}$ e de um a cinco minutos para a rede de $100 \mu \mathrm{m}$ para evitar a colmatação das redes. A duração exata de cada 
arrasto dependeu da observação prévia de uma amostra de plâncton, anteriormente a coleta da amostra quantitativa, sendo o mais comum arrastos de cerca de dois minutos. As redes foram arrastadas lentamente e o zooplâncton transferido imediatamente para recipientes e preservados em solução de formaldeído neutralizado com tetraborato de sódio diluído em água do mar em concentração final equivalente a $4 \%$.

\subsubsection{Clorofila- $a$ e feopigmentos (clorofila acidificada)}

A clorofila- $a$ foi obtida através de filtragem a vácuo (pressão máxima de $10 \mathrm{~mm}$ $\mathrm{Hg}$ ) de um volume variável de água do mar (200 a $500 \mathrm{~mL}$ ) sobre membranas GF/F de 0,7 $\mu \mathrm{m}$ de porosidade (Whatman ${ }^{\circledR}$ ), realizada no laboratório ao abrigo da luz e imediatamente após as coletas. Antes da filtração, a amostra de água era homogeneizada e filtrada através de um filtro estéril de $37 \mu \mathrm{m}$ de porosidade, para a remoção do zooplâncton. Tais predadores podem conter clorofila- $a$ e feopigmentos resultantes da degradação da clorofila durante o processo de digestão do fitoplâncton ingerido.

A filtração também eliminou as espécies fitoplanctônicas de maior porte, contudo, tais células geralmente não são utilizadas pelos estágios juvenis de copépodes de pequeno tamanho e foram consideradas como uma fração de clorofila- $a$ não disponível para esses animais. As membranas foram armazenadas em congelador a -20 ${ }^{\circ} \mathrm{C}$ até o momento das análises. Os pigmentos foram extraídos utilizando acetona $90 \%$ por 24 horas e as concentrações obtidas por fluorimetria (Welschmeyer, 1994). O fluorímetro foi calibrado com clorofila- $a$ purificada para obtenção do limite de detecção. Foram realizadas 3 réplicas para cada período amostral para determinar essas concentrações no ambiente durante o período de coleta e os resultados foram expressos em $\mathrm{mg} \mathrm{m}^{-3}$.

A única exceção à metodologia mencionada ocorreu durante a primeira amostragem (sigla V 1, Tabela 1.1). Devido a problemas logísticos, a concentração de clorofila- $a$ foi estimada a partir de dados disponibilizados do satélite AQUA MODIS pelo sítio eletrônico Oceancolor (http://oceancolor.gsfc.nasa.gov) para águas superficiais. 
Tabela 1.1: Sigla, data, horário, maré e profundidade local das coletas de plâncton. Coletas marcadas com * foram realizadas na estação Abrigada (Figura 1, introdução geral).

\begin{tabular}{|c|c|c|c|c|c|}
\hline Campanha & Data & $\begin{array}{l}\text { Horário } \\
\text { (h) }\end{array}$ & Maré & $\begin{array}{c}\text { Local e } \\
\text { sigla }\end{array}$ & $\begin{array}{l}\text { Profundidade } \\
\text { local (m) }\end{array}$ \\
\hline \multirow{8}{*}{$\begin{array}{l}\text { verão de } \\
2009\end{array}$} & $16 / 01$ & $09: 45$ & Vazante & V 1 & 18 \\
\hline & $18 / 01$ & $10: 45$ & Vazante & $\mathrm{V} 2 *$ & 4 \\
\hline & $20 / 01$ & $10: 20$ & Alta & V $3 *$ & 5 \\
\hline & $24 / 01$ & 10:00 & Enchente & V $4 *$ & 3 \\
\hline & $26 / 01$ & $10: 20$ & Enchente & V 5* & 4 \\
\hline & $29 / 01$ & 11:00 & Enchente & V 6 & 18 \\
\hline & $30 / 01$ & $13: 15$ & Enchente & V 7 & 40 \\
\hline & $02 / 02$ & $10: 45$ & Vazante & V 8 & 18 \\
\hline \multirow{8}{*}{$\begin{array}{c}\text { inverno de } \\
2009\end{array}$} & $16 / 07$ & $10: 40$ & Vazante & I 1 & 20 \\
\hline & $18 / 07$ & 09:15 & Enchente & I $2 *$ & 3 \\
\hline & $20 / 07$ & 09:30 & Enchente & I 3 & 18 \\
\hline & $22 / 07$ & $15: 30$ & Enchente & I 4 & 18 \\
\hline & $24 / 07$ & $10: 30$ & Vazante & I 5 & 3 \\
\hline & $26 / 07$ & 09:30 & Vazante & I $6^{*}$ & 18 \\
\hline & $28 / 07$ & 11:00 & Vazante & I 7 & 29 \\
\hline & $30 / 07$ & $08: 45$ & Vazante & I 8 & 29 \\
\hline \multirow{8}{*}{$\begin{array}{l}\text { verão de } \\
2010\end{array}$} & $10 / 01$ & 09:00 & Enchente & V 9 & 25 \\
\hline & $12 / 01$ & 09:10 & Enchente & V 10 & 25 \\
\hline & $14 / 01$ & 09:20 & Enchente & V 11 & 25 \\
\hline & $16 / 01$ & $08: 45$ & Vazante & V 12 & 23 \\
\hline & $18 / 01$ & 09:20 & Vazante & V 13 & 23 \\
\hline & $20 / 01$ & 09:00 & Vazante & V 14 & 23 \\
\hline & $22 / 01$ & 09:00 & Vazante & V 15 & 23 \\
\hline & $24 / 01$ & 09:00 & Baixa & V 16 & 23 \\
\hline \multirow{8}{*}{$\begin{array}{l}\text { inverno de } \\
2010\end{array}$} & $16 / 07$ & $16: 00$ & Enchente & I 9* & 10 \\
\hline & $19 / 07$ & 09:00 & Baixa & I 10 & 25 \\
\hline & $21 / 07$ & $08: 45$ & Enchente & I 11 & 25 \\
\hline & $23 / 07$ & $08: 50$ & Enchente & I 12 & 20 \\
\hline & $26 / 07$ & $08: 45$ & Vazante & I 13 & 25 \\
\hline & $28 / 07$ & 08:40 & Vazante & I 14 & 20 \\
\hline & $30 / 07$ & $08: 40$ & Vazante & I 15 & 30 \\
\hline & $01 / 08$ & $08: 15$ & Vazante & I 16 & 28 \\
\hline \multirow{6}{*}{$\begin{array}{l}\text { verão de } \\
2011\end{array}$} & $13 / 01$ & $10: 05$ & Vazante & V 17 & 25 \\
\hline & $15 / 01$ & 08:00 & Enchente & V 18 & 29 \\
\hline & $17 / 01$ & $08: 45$ & Enchente & V 19 & 33 \\
\hline & $19 / 01$ & 08:30 & Vazante & V 20 & 33 \\
\hline & $21 / 01$ & 08:40 & Vazante & V 21 & 34 \\
\hline & $24 / 01$ & $08: 45$ & Vazante & V 22 & 34 \\
\hline \multirow{8}{*}{$\begin{array}{l}\text { inverno de } \\
2011\end{array}$} & $09 / 07$ & $08: 45$ & Alta & I 17 & 25 \\
\hline & $11 / 07$ & $08: 45$ & Enchente & I 18 & 32 \\
\hline & $13 / 07$ & $08: 40$ & Enchente & I 19 & 33 \\
\hline & $15 / 07$ & 09:05 & Baixa & I 20 & 31 \\
\hline & $17 / 07$ & 09:40 & Vazante & I 21 & 32 \\
\hline & $19 / 07$ & $09: 10$ & Vazante & I 22 & 33 \\
\hline & $21 / 07$ & 09:00 & Vazante & I 23 & 33 \\
\hline & $23 / 07$ & $08: 45$ & Vazante & I 24 & 33 \\
\hline
\end{tabular}




\subsubsection{Análise qualitativa e quantitativa do zooplâncton}

Os organismos zooplanctônicos foram contados e identificados em alíquotas das amostras totais de tamanho variável. A obtenção das alíquotas foi realizada utilizando um quarteador do tipo Motoda (Omori \& Ikeda, 1984).

Foram contadas frações de amostras de diversos tamanhos (1/8 a 1/256) para a contagem e identificação do zooplâncton. Numa fração de amostra, um mínimo de 30 indivíduos de cada táxon dominante foi contado, totalizando no mínimo 300 animais. Esse valor, estipulado por Frontier (1981), reduz a introdução de erros devido ao tamanho da subamostra, delimitando um número mínimo de organismos que deve ser contado para que o erro devido ao fracionamento da amostra não seja significativo. Para as espécies menos abundantes, uma alíquota maior (1/2 a 1/32 era analisada).

A identificação do plâncton foi feita em níveis taxonômicos diferentes. Os cladóceros e copépodes foram identificados até o nível de espécie sempre que possível. Para os copépodes, também foi feita a distinção dos estágios de desenvolvimento em náuplios (ortonáuplio e metanáuplio para algumas espécies), copepoditos juvenis (copepoditos I a V) e adultos (copepodito VI). Para fins do estudo da composição taxonômica, os estágios de desenvolvimento foram identificados ao menor nível possível (ver Tabela 1.2). Já para as análises quantitativas, estágios de desenvolvimento foram agrupados para alguns táxons, devido à ausência de descrição para estágios imaturos de algumas espécies e viabilizar a contagem de um número maior de amostras. Alguns dos agrupamentos selecionados foram os náuplios da família Oncaeidae, Paracalanidae (exceto Parvocalanus crassirostris) e Pontellidae, náuplios e copepoditos de Sapphirinidae e copepoditos dos estágios I a III da família Oithonidae.

Grupos que foram parcialmente identificados ao nível de espécie foram as medusas das classes Hydrozoa e Scyphozoa, os ctenóforos, quetognátos e apendiculários. Para os cnidários pelágicos, foram referências os trabalhos de Morandini et al.(2005), Bouillon (1999) e Miazan \& Cornelius (1999) e ctenóforos o de Oliveira et al. (2007). Para os quetognátos e apendiculários foram utilizados respectivamente os trabalhos de Casanova (1999) e Esnal (1999). Para a identificação dos cladóceros, utilizou-se a obra de Onbé (1999).

Diversas referências foram utilizadas para os copépodes, destacando os trabalhos de Björnberg (1967, 1972, 1981); Björnberg et al.(1994); Boxshall \& Halsey (2004) e Bradford-Grieve et al. (1999). 
Todas as espécies identificadas foram validadas e atualizadas quanto a nomenclatura e autoria através dos bancos de dados WoRMS (World Register of Marine Species; Appeltans et al., 2012), onde foi indexado o antigo banco de dados World of Copepods (Walter \& Boxshall, 2008) e Marine planktonic copepods (http://copepodes.obs-banylus.fr). Ainda para a subclasse Copepoda, foi adotada a classificação sistemática de Boxshall \& Halsey (2004).

\subsubsection{Densidade zooplanctônica e análises qualitativas}

A densidade do zooplâncton (org. $\mathrm{m}^{-3}$ ) foi obtida através do número de indivíduos presentes por amostra (estimado a partir das subamostras), dividido pelo volume de água filtrado pela rede $\left(\mathrm{m}^{3}\right)$. Tal volume foi estimado a partir da fórmula: $V$ $\left(m^{3}\right)=$ rotações (final - inicial) $x A \times C$; onde o número de rotações do fluxômetro é obtido pela subtração do valor final pelo inicial; $A$ representa a área da boca da rede; e $C$ o fator de calibração do fluxômetro utilizado.

A densidade relativa dos grupos zooplanctônicos foi calculada dividindo a densidade do grupo em questão pela densidade total do zooplâncton numa dada amostra e o resultado expressado em porcentagem. De maneira semelhante, a frequência de ocorrência foi obtida dividindo o número de amostras onde determinado táxon ocorre pelo total de amostras analisadas e multiplicando o resultado por 100 para demonstrar os dados em porcentagem. Os organismos foram classificados como raros $(\leq 25 \%)$, esporádicos $(25-50 \%)$, frequentes $(50-75 \%)$ ou muito frequentes $(>75 \%)$.

A partir dos dados de densidade foram feitos estimativas dos índices de diversidade específica e de equitabilidade. A diversidade específica ( $\mathrm{H}^{\prime}$; bits ind. $\left.{ }^{-1}\right)$ foi calculada através do índice de Shannon: $\mathrm{H}^{\prime}=-\sum$ pi* $\log _{2}$ pi; onde pi representa a abundância relativa do táxon i na amostra. Valores de $\mathrm{H}^{\prime}$ acima de 3 bits ind. ${ }^{-1}$ foram considerados elevados, entre 1 e 3 foram tidos como moderados e, abaixo de 1 bit ind $^{-1}$, a amostra foi considerada de baixa diversidade (Shannon, 1948). Com relação à equitabilidade $\left(J^{\prime}\right)$, foi aplicada a fórmula proposta por Pielou (1977): $J^{\prime}=\mathrm{H}^{\prime} * \log _{2} \mathrm{NE}^{-}$

1; onde NE representa o número de espécies identificadas na amostra. Este último índice varia entre 0 e 1, e indica como está a repartição de indivíduos entre as espécies na amostra (quanto mais próximo de 1, maior o equilíbrio da densidade entre as espécies). 
Dados de riqueza, diversidade e equitabilidade foram obtidos apenas para os copépodes e cladóceros, pois foram os únicos integralmente identificados ao nível específico.

\subsubsection{Tratamento dos dados e análises estatísticas}

As variáveis ambientais analisadas foram a temperatura $\left({ }^{\circ} \mathrm{C}\right)$, salinidade, precipitação $(\mathrm{mm})$, clorofila- $a$ e feopigmentos $\left(\mathrm{mg} \mathrm{m}^{-3}\right)$ da água de superfície. Já as variáveis bióticas da comunidade zooplanctônica estudadas foram a riqueza, diversidade, equitabilidade, densidade total, relativa e a frequência de ocorrência dos táxons. As variáveis ambientais e ecológicas foram tratadas como descritores ecológicos, enquanto que a sazonalidade (verão e inverno), anos de coleta (2009, 2010 e 2011) e malhas utilizadas (20 e $100 \mu \mathrm{m}$ ) foram considerados fatores das análises estatísticas multivariadas.

Todas as variáveis foram testadas quanto à normalidade e homocedasticidade através do teste de Lilliefors e Shappiro-Wilk respectivamente. Para as variáveis de distribuição não paramétrica, foram utilizados os testes de Mann-Whitney e KruskalWallis $(\alpha=0,05)$ para verificar a significância da variabilidade dos dados e entre as comparações em blocos (verão comparado ao inverno, comparação entre os anos de amostragem, malha de $20 \mu \mathrm{m}$ comparada a de $100 \mu \mathrm{m})$. Em seguida, o método de Student-Newman-Keuls foi realizado para as comparações aos pares. O teste de Dunn foi escolhido quando o tamanho entre as amostras era desigual e comparações com valores de $p \leq 0,05$ foram considerados significativos.

Análises de correlação de Spearman foram aplicadas para verificar possíveis associações entre a densidade do zooplâncton e as variáveis ambientais, todas transformadas anteriormente a analise. A abundância dos principais grupos como copépodes, cladóceros, apendiculários e meroplâncton foram analisados isoladamente e a correlação com as variáveis ambientais foram calculadas.

A análise de componentes principais $(P C A)$ foi empregada para visualizar a contribuição relativa dos fatores ambientas quanto à distribuição temporal da densidade dos principais táxons zooplanctônicos (táxons com frequência de ocorrência menor que $10 \%$ foram removidos). As variáveis ambientais (temperatura, salinidade, precipitação, 
concentração de clorofila- $a$, feopigmentos, profundidade e altura da maré) foram utilizadas como variáveis suplementares e normalizadas. A distância euclidiana foi utilizada para a execução desta análise (Clarke \& Gorley, 2001).

Para verificar a possível formação de grupos de amostras e a visualização da influência de variáveis ambientais sobre a abundância dos táxons do zooplâncton foi escolhidas a análise de MDS (Non-metric distance similarity, ordenação de escalonamento multidimensional não métrica). A análise de similaridade por aglomeração hierárquica (cluster) foi utilizada para verificar a formação de agrupamentos de táxons zooplanctônicos para ambas as classes de tamanho (20 e 100 $\mu \mathrm{m})$.

Para a realização das análises multivariadas, os dados das variáveis ambientais foram normalizados (valores subtraídos da média e divididos pelo desvio-padrão) enquanto que os dados de abundância dos táxons foram transformados por $\log _{10}(x+1)$, a fim de normalizar e homogeneizar as variáveis estudadas (Zar, 1999). As espécies com frequência de ocorrência menor que $15 \%$ removidas da análise. Foram utilizados apenas dados para os táxons Copepoda e Cladocera, pois somente os mesmos foram identificados ao nível de espécie. As matrizes de similaridade foram calculadas em modo "Q" pelo método de Bray-Curtis, a partir dos dados transformados de densidade dos táxons por amostra (Underwood, 1997). Os agrupamentos gerados pela análise de cluster com distância de ligação/distância máxima igual a $60 \%$ foram plotados sobre o $M D S$ para melhor visualização de padrões de distribuição dos dados. O nível de stress das análises foi considerada baixa quando $\leq 0,2$ (Clarke \& Warwick, 2001).

A análise de PERMANOVA (Permutional multivariate analysis of variance) foi executada para elucidar a interação entre os fatores do desenho amostral e a densidade das espécies de copépodes e cladóceros. Espécies com frequência de ocorrência menor que $5 \%$ foram removidas, sendo as demais espécies (um total de 63) consideradas como variáveis independentes da análise. O número de repetições por estação (verão e inverno) foi igual a seis, pois foi o mínimo para cada estação amostrada. Os dados de densidade foram transformados em $\log _{10}(\mathrm{x}+1)$ e a análise baseada na dissimilaridade de Bray-Curtis. Para a análise de PERMANOVA, o grau de liberdade escolhido foi igual a 0,01 (Anderson, 2005). 
A análise de Contribuição Específica para a dissimilaridade SIMPER (Similarity percentages - species contributions, análise do percentual de similaridade), que verifica a contribuição de cada táxon para a dissimilaridade média das amostras entre dois grupos também foi executada. Foram considerados táxons discriminantes para a comparação entre grupos (verão x inverno) aqueles onde a razão dissimilaridade média: desvio padrão ( $\delta i$ /D.P.) foi superior a 1,4 (Clarke \& Gorley, 2001).

Para a estatística descritiva e análises comparativas e de correlações o software Sigmaplot 11.0 (Systat software Inc., 2008) foi utilizado. As análises multivariadas foram calculadas através do software PRIMER 6.0 (Plymouth Routines in Multivariate Ecological Research, 2006) e STATISTICA 8.0 (Statsoft corporation). A análise de PERMANOVA (Anderson, 2001) foi calculada através do programa homônimo e detalhada no guia de usuário em Anderson (2005).

\subsection{Resultados}

\subsubsection{Variáveis Ambientais}

Devido à padronização das coletas de plâncton por horário, as condições de maré variaram durante as amostragens e dentro de cada estação do ano (Tabela 1.1). A Figura 1.1 contém o período, variação e amplitude da maré para cada uma das estações amostradas (verão e inverno dos anos de 2009 a 2011).

A temperatura superficial da água do mar esteve entre 19 e $29^{\circ} \mathrm{C}$ e a variação é nítida, quando comparados os valores obtidos durante os períodos de verão $(27,2 \pm 0,8$ ${ }^{\circ} \mathrm{C}$ ) e inverno $\left(21,4 \pm 0,9^{\circ} \mathrm{C}\right.$ ), sendo sempre superiores durante o verão (Figura 1.2). A diferença sazonal foi significativa em cada um dos três anos de amostragem (2009: $p=$ 0,001; 2010: $p<0,001$ e 2011: $p=0,002$; teste de Mann-Whitney), porém, diferenças não foram detectadas entre os verões ou invernos comparados isoladamente (verão 2009 x verão 2010, por exemplo).

A salinidade esteve geralmente entre 34 a 36, embora o valor mínimo tenha sido de 33 e o máximo de 37. Para o verão de 2011 ocorreram valores menores, entre 33 e 35 , enquanto que durante o inverno do mesmo ano foi constante e igual a 36. Variação entre as estações só ocorreu em 2011 ( $p<0,001$ teste de Mann-Whitney; Figura 1.2). 
A precipitação foi sempre maior durante os períodos de verão quando comparados ao inverno $(p<0,001)$ e geralmente foi baixa para todos os períodos amostrais. Em 2009 a precipitação durante o verão (9/01 a 02/02) foi de 5,2 $\pm 11 \mathrm{~mm}$, enquanto que durante o inverno (09 a 30/07) foi de 2,4 $\pm 7,6 \mathrm{~mm}(p=0,003)$. A variação entre as estações foi menor para 2010 (verão: 8,5 $\pm 35,8 \mathrm{~mm}$; inverno: 8,7 \pm $21,1 \mathrm{~mm}$ nos períodos de 2 a 24/01 e 9/07 a 1/08 respectivamente; $p=0,034) \mathrm{e}$ novamente mais acentuada em 2011 (verão: 8,6 $\pm 14,7 \mathrm{~mm}$; inverno: 3,9 $\pm 12,8 \mathrm{~mm}$ nos períodos de 6 a 24/01 e 2 a 23/07 respectivamente; $p=0,021$ ). A precipitação diária para as os períodos estudados está disponível na seção Anexos (Anexo A).

\subsubsection{Clorofila- $a$ e feopigmentos}

Os valores de clorofila- $a$ foram estatisticamente diferentes entre o verão e o inverno (Mann-Whitney, $p<0,001$ ), sendo que as menores concentrações foram encontradas para os períodos de verão, especialmente para o ano de $2011(0,28 \pm 0,1$ $\mathrm{mg} \mathrm{m}^{-3}$ ). Ainda para o verão, os valores de clorofila- $a$ raramente ultrapassaram $1 \mathrm{mg} \mathrm{m}^{-}$ ${ }^{3}$. Para o inverno, os maiores valores ocorreram em 2010 e raramente a clorofila- $a$ foi inferior a $1 \mathrm{mg} \mathrm{m}^{-3}$. Não houve diferença entre os três períodos de verão ou de inverno, quando testados aos pares.

Em relação aos feopigmentos, não houve variação entre as estações do ano, a média para os períodos de inverno foi de $0,51 \pm 0,31 \mathrm{mg} \mathrm{m}^{-3}$ e para o verão de $0,17 \pm$ $0,13 \mathrm{mg} \mathrm{m}^{-3}$. Os valores registrados corresponderam às médias de três réplicas em cada período de coleta (Figura 1.3). 

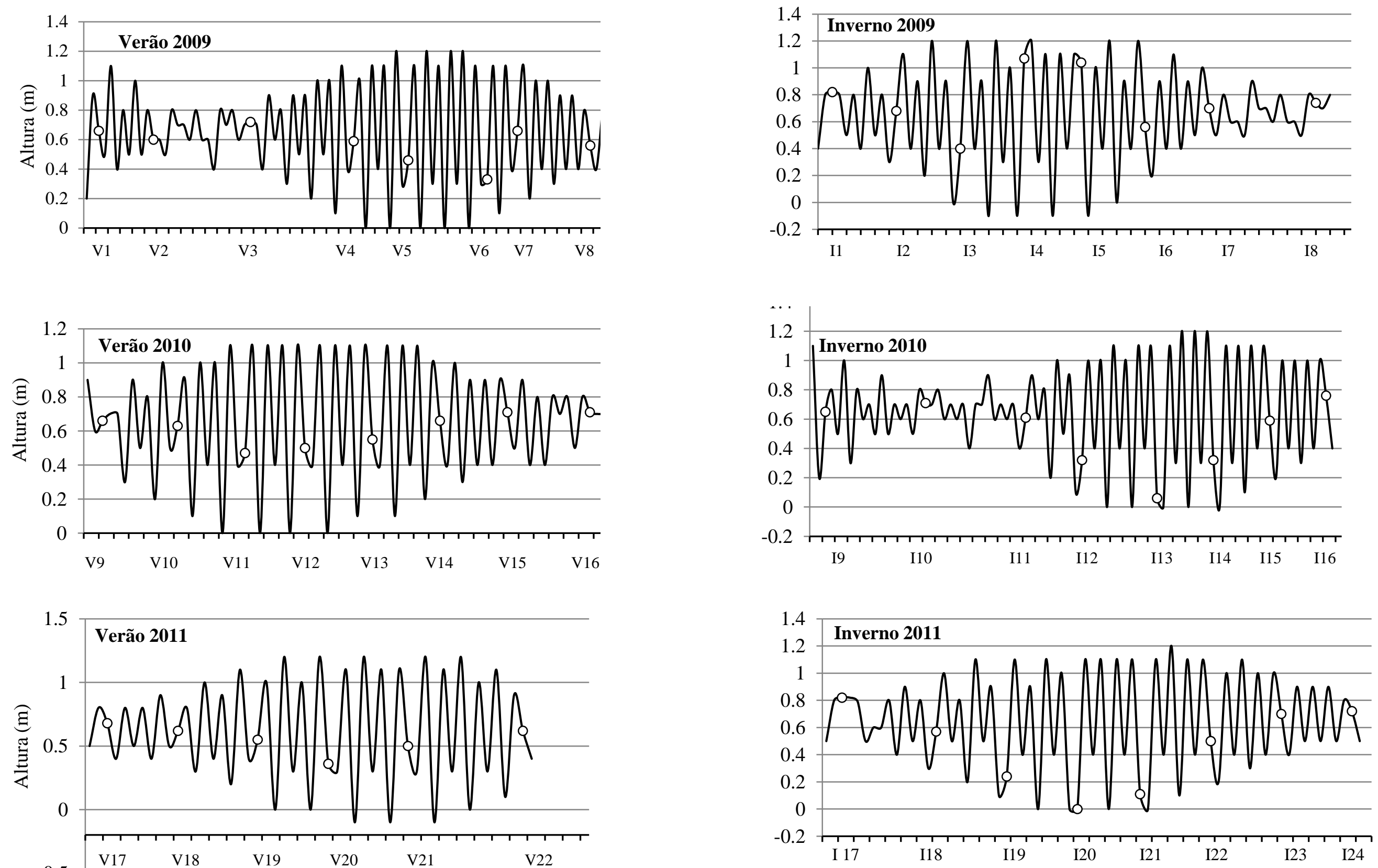

Figura 1.1: Oscilação e amplitude da maré para cada um dos períodos amostrais durantes os anos de 2009 a 2011. Os círculos representam os momentos de coleta de plâncton, apresentados pelas siglas no eixo horizontal (ver Tabela 1.1). 

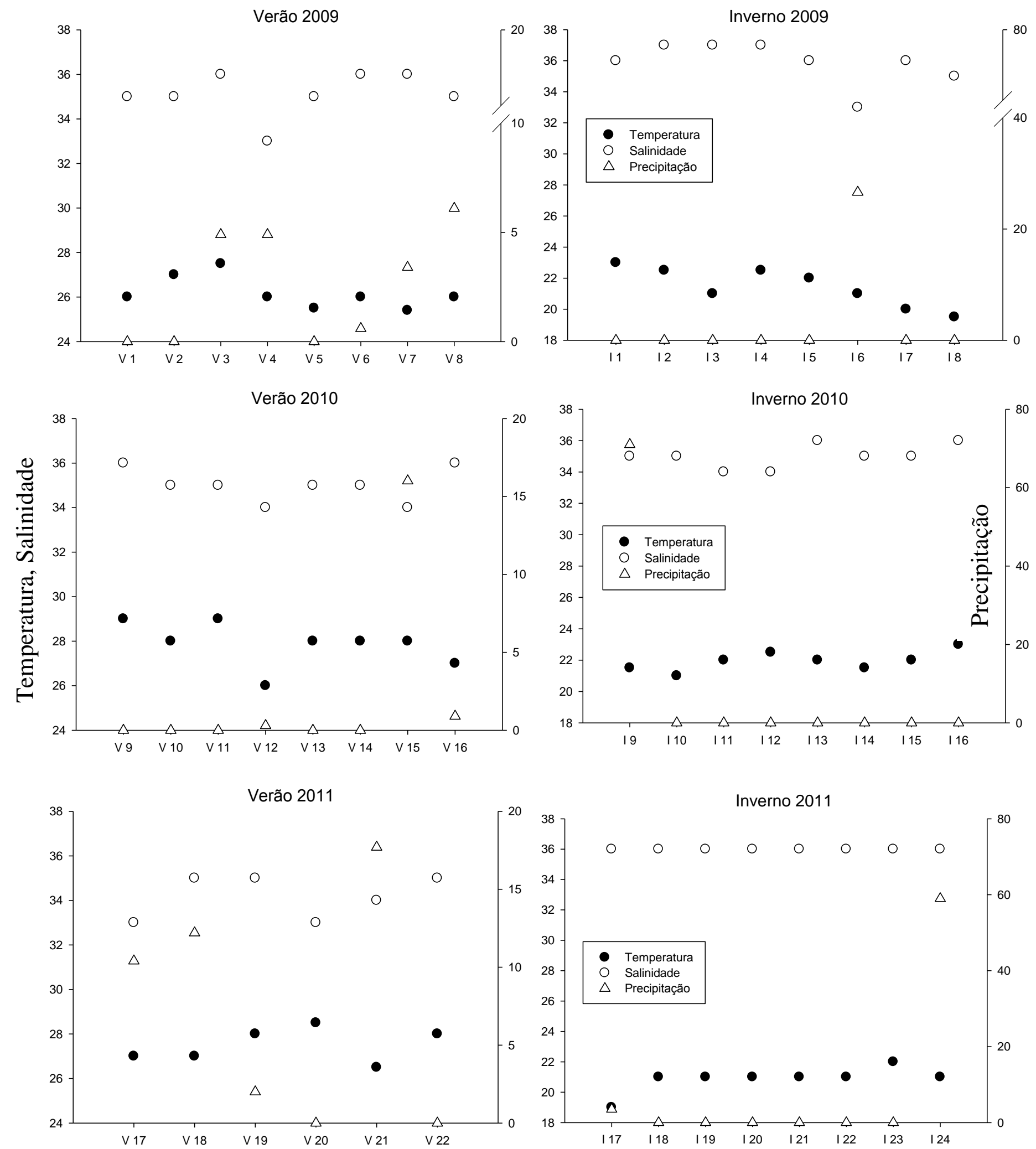

Figura 1.2: Variação da temperatura $\left({ }^{\circ} \mathrm{C}\right)$, salinidade e precipitação $(\mathrm{mm})$ durante cada um dos períodos de coleta em Ubatuba. As siglas dos períodos de coleta seguem como na Tabela 1.1. Notar diferentes escalas para precipitação entre o verão e o inverno. 

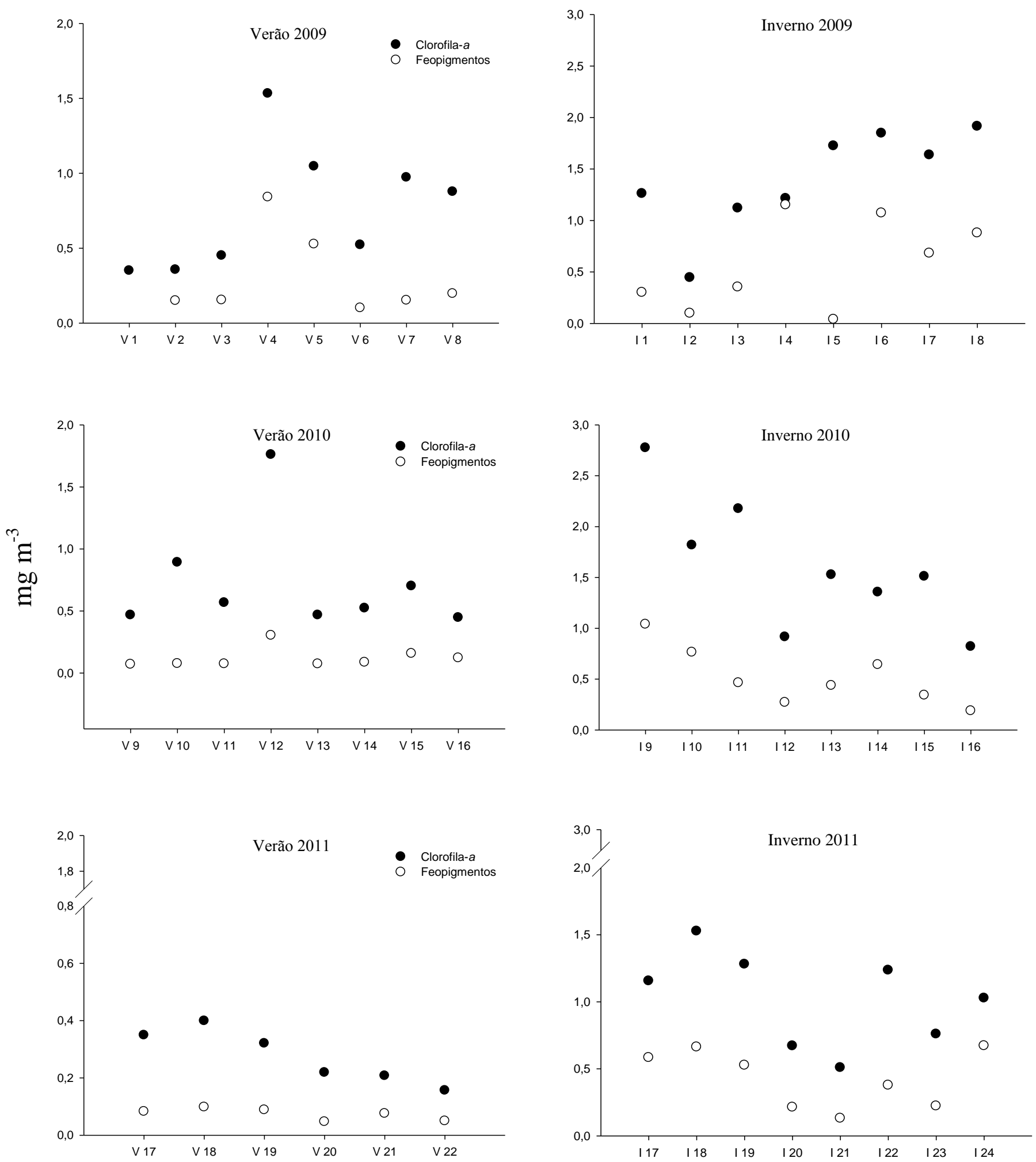

Figura 1.3: Concentrações de clorofila- $a$ e feopigmentos em mg. $\mathrm{m}^{-3}$ de água da camada superficial para cada um dos períodos amostrais durante os anos de 2009 a 2011. Os números no eixo $x$ correspondem aos períodos amostrais (conforme Tabela 1.1). A concentração de feopigmentos para a primeira coleta não foi obtida. Notar escalas diferentes para o verão, em relação ao inverno. 


\subsubsection{Estrutura e variação da comunidade}

\subsubsection{Composição do zooplâncton}

A composição taxonômica é apresentada na Tabela 1.2 para o zooplâncton em geral, exceto para a subclasse Copepoda, demonstrada nas Tabelas 1.3 a 1.5. O protozooplâncton não foi identificado em nível específico, sendo determinado apenas o gênero Noctiluca sp. Protistas autotróficos e mixotróficos não foram quantificados. Os Tintinnina foram os únicos protistas quantificados nas amostras, além de Noctiluca sp., devido a boa preservação dessas células tecadas em formol $4 \%$.

Os cnidários foram parcialmente identificados, sendo registradas quatro espécies de medusas da classe Hydrozoa e três de Scyphozoa. A cifomedusa Lychnorhiza lucerna foi capturada em 13 de julho de 2011, quando uma grande densidade dessas medusas atingiu a costa. Os animais alcançaram diâmetro da umbrela de até $23 \mathrm{~cm}$ e foram removidos da amostra quando capturados pelas redes. Quanto aos ctenóforos, apenas duas espécies foram coletadas (Tabela 1.2).

Os cladóceros e copépodes foram identificados a nível específico, totalizando quatro e 66 espécies respectivamente. As espécies Penilia avirostris, Pseudevadne tergestina, Evadne spinifera e Pleopis schmackeri representaram a diversidade de cladóceros. Os outros crustáceos foram classificados em grandes grupos, exceto para algumas espécies de Decapoda como o camarão holoplanctônico Lucifer faxoni e os comensais da medusa Lychnorhiza lucerna: Periclimenes paivai e Libinia ferreirae, registrados anteriormente para o litoral norte do estado de São Paulo (Martinelli-Filho et al., 2008).

Os apendiculários também foram parcialmente identificados e pelo menos cinco espécies foram encontradas, sendo o gênero Oikopleura de maior riqueza. O mesmo ocorreu com os quetognátos, onde seis espécies foram registradas, sendo três delas do gênero Parasagitta. A maioria dos indivíduos não foi identificada a nível específico, pois as malhas de 20 e $100 \mu \mathrm{m}$ capturaram uma elevada proporção de indivíduos juvenis (cerca de 90\%), onde alguns caracteres taxonômicos não puderam ser visualizados. 
Tabela 1.2: Táxons de organismos zooplanctônicos (exceto copépodes) registrados entre os anos de 2009 a 2011 para ambas as classes de tamanho $(20$ e $100 \mu \mathrm{m})$. N.I.: organismos não identificados.

\begin{tabular}{|c|c|}
\hline Táxon & Táxon \\
\hline Dinoflagellata & Peracarida \\
\hline Noctiluca sp. Suriray, 1836 & Mysidacea \\
\hline Foraminifera & Amphipoda \\
\hline Acantharia & Gammaridea N.I. \\
\hline Tintinnina & Hipperidea N.I. \\
\hline Cnidaria & Isopoda: Epicaridea N.I. \\
\hline Hydrozoa & Stomatopoda: antizoea \\
\hline Aglaura sp. Haeckel, 1879 & Decapoda \\
\hline Clytia spp. (Lamouroux 1812) & Náuplios N.I. \\
\hline Corymorpha gracilis (Brooks, 1822) & Dendrobranchiata: protozoea e mysis \\
\hline Liriope tetraphylla (Chamisso \& Eysenhardt, 1821) & $\begin{array}{l}\text { Sergestidea: larva elaphocaris } \\
\text { Lucifer faxoni Borradaile, } 1915\end{array}$ \\
\hline Hidromedusas N.I. & Caridea: zoea \\
\hline Siphonophora: N.I. & Periclimenes paivai Chace, 1969 \\
\hline Scyphozoa & Pleocyemata \\
\hline Aurelia sp. (Lammarck, 1816) & Brachyura: zoea \\
\hline Lychnorhiza lucerna (Haeckel, 1880) & Libinia ferreirae Brito Capello, 1871 \\
\hline Nausithoe aurea Silveira \& Morandini 1997 & Chaetognatha \\
\hline Ctenophora & Flaccisagitta enflata (Grassi, 1881) \\
\hline Beroe ovata Chamisso \& Eysenhardt, 1821 & Parasagitta spp. (Quoy \& Gaimard, 1827) \\
\hline Mnemiopsis leyidi Agassiz, 1865 & P. friderici (Ritter-Záhony, 1911) \\
\hline Turbellaria: Acoela N.I. & P. tenuis (Conant, 1896) \\
\hline NematodaN.I. & Pterosagitta draco (Krohn, 1853) \\
\hline Rotifera N.I. & Ectoprocta \\
\hline Mollusca & Larva cyphonauta \\
\hline Gastropoda: véliger & Phoronida \\
\hline Pteropoda: N.I. & Larva actinotrocha \\
\hline Pterotracheoidea: Pterotrachea sp.Förskal, 1775 & Echinodermata \\
\hline Bivalvia (véliger) & Asteroidea: bipinnaria \\
\hline Polychaeta N.I. (larvas) & Echinoidea: echinopluteus \\
\hline Tomopteris sp. Eschscholtz, 1825. & Ophiuroidea: ophiopluteus \\
\hline Crustacea & Urochordata \\
\hline Cladocera & Appendicularia \\
\hline Ctenopoda & Oikopleura dioica Fol, 1827 \\
\hline Penilia avirostris (Dana, 1852) & O. longicauda (Vogt, 1854) \\
\hline Onychopoda & O. fusiformis Aida, 1907 \\
\hline Evadne spinifera (Muller, 1867) & Oikopleura sp. Mertens, 1831 \\
\hline Pleopis schmackeri (Poppe, 1889) & Fritillaria spp. Quoy \& Gaimard, 1827 \\
\hline Pseudevadne tergestina (Claus, 1877) & Thaliacea \\
\hline Ostracoda N.I. & Thalia democratica (Förskal, 1775) \\
\hline Cirripedia & Doliolida N.I. \\
\hline Náuplios & Ascidiacea: larvas \\
\hline Cypris & Hemichordata: larvas \\
\hline & Vertebrata: Teleostei \\
\hline & Ovos \\
\hline & Larvas \\
\hline
\end{tabular}


Estágios larvais de gastrópodes (véliger) e bivalves representaram a maioria dos moluscos. Alguns gastrópodes holoplanctônicos foram registrados, como os Pteropoda do gênero Creseis e raramente os Heteropoda do gênero Pterotrachea.

Dentre os organismos do meroplâncton, foi comum a presença de larvas véliger de gastrópodes e larvas de bivalves, estágios larvais de diversas famílias de poliquetos (não identificados) e estágios de náuplios e cypris de cirripédios. Em menor frequência, foram coletadas diversas larvas de equinodermos (classes Asteroidea, Echinoidea e Ophiuroidea) e crustáceos da classe Malacostraca como a antizoea da ordem Stomatopoda, protozoea e mysis de camarões da subordem Dendrobranchiata, larva elaphocaris de camarões da superfamília Sergestoidea, zoea de camarões da infraordem Caridea e caranguejos da infraordem Brachyura. Outros componentes constituintes do meroplâncton encontrados esporadicamente foram as larvas dos filos Ectoprocta, Phoronida, Hemichordata e do subfilo Urochordata (larvas da classe Ascidiacea).

Os copépodes foram identificados ao nível de espécie sempre que possível, assim como os estágios de desenvolvimento encontrados (náuplios, copepoditos e adultos). Cinco ordens foram representadas, sendo que Calanoida contribuiu com maior riqueza, totalizando 36 espécies (Tabela 1.3). Em seguida, a ordem Cyclopoida foi representada por 20 espécies (Tabela 1.4), enquanto que os Harpacticoida, Monstrilloida e Siphonostomatoida contaram com sete, duas e uma espécie respectivamente (Tabela $1.5)$. 
Tabela 1.3: Espécies de copépodes da ordem Calanoida registrados de 2009 a 2011 e os respectivos estágios do ciclo-de-vida capturados por cada malha. N: náuplios (NI - VI); CI-V: copepoditos I a V; CVI: copepodito VI ou adulto. *: casos em que o náuplio ou copepodito não foram classificados até o nível de espécie, sendo agrupados em gênero ou família.

\begin{tabular}{|c|c|c|}
\hline Táxon & $20 \mu \mathrm{m}$ & $100 \mu \mathrm{m}$ \\
\hline Calanidae * (Dana, 1849$)$ & $\mathrm{N}$ & $\mathrm{N}$ \\
\hline Calanoides carinatus (Kröyer, 1849) & $\mathrm{N}$ & $\mathrm{N}, \mathrm{CI}-\mathrm{V}$ \\
\hline Nannocalanus minor (Claus, 1863) & $\mathrm{N}$ ? & $\mathrm{CI}-\mathrm{V}$ \\
\hline Undinula vulgaris (Dana, 1849) & - & CI-V \\
\hline Neocalanus sp. Sars, 1925 & - & $\mathrm{CI}-\mathrm{V}$ \\
\hline Paracalanidae Giesbrecht, 1892 & $\mathrm{~N}, \mathrm{CI}-\mathrm{V}$ & $\mathrm{N}, \mathrm{CI}-\mathrm{V}$ \\
\hline Acrocalanus sp. Giesbrecht, 1888 & - & CVI \\
\hline Bestiolina similis (Sewell, 1914) & - & CI-VI \\
\hline Calocalanus pavo (Dana, 1848) & - & CVI \\
\hline C. pavoninus Farran, 1936 & - & CVI \\
\hline Calocalanus sp. *Giesbrecht, 1888 & $\mathrm{CI}-\mathrm{V}$ & CI-VI \\
\hline Paracalanus aculeatus Giesbrecht, 1888 & - & CVI \\
\hline P. indicus Wolfenden, 1905 & - & CVI \\
\hline P. nanus Sars, 1925 & CVI & CVI \\
\hline P. quasimodo Bowman, 1971 & CVI & CVI \\
\hline Paracalanus sp. * Boeck, 1865 & $\mathrm{~N}, \mathrm{CI}-\mathrm{V}$ & $\mathrm{CI}-\mathrm{V}$ \\
\hline Parvocalanus crassirostris Andronov, 1970 & N, CI-VI & N, CI-VI \\
\hline \multicolumn{3}{|l|}{ Mecynoceridae Thompson, 1888} \\
\hline Mecynocera clausii Thompson, 1888 & CI-VI & CI-VI \\
\hline Eucalanidae Giesbrecht, 1892 & $\mathrm{~N}$ & $\mathrm{~N}$ \\
\hline Subeucalanus pileatus (Giesbrecht, 1888) & $\mathrm{N}, \mathrm{CI}-\mathrm{VI}$ & $\mathrm{N}, \mathrm{CI}-\mathrm{VI}$ \\
\hline S. crassus (Giesbrecht, 1888) & $\mathrm{N}$ & CI-V \\
\hline Clausocalanidae *Giesbrecht, 1892 & $\mathrm{~N}$ & $\mathrm{~N}$ \\
\hline Clausocalanus furcatus (Brady, 1883) & N, CI-VI & $\mathrm{N}, \mathrm{CI}-\mathrm{VI}$ \\
\hline Ctenocalanus heronae Vega-Pérez \& Bowman, 1992 & & CVI \\
\hline Ctenocalanus sp. (Giesbrecht, 1888) & $\mathrm{CI}-\mathrm{V}$ & $\mathrm{CI}-\mathrm{V}$ \\
\hline \multicolumn{3}{|l|}{ Euchaetidae Giesbrecht, 1892} \\
\hline Euchaeta marina (Prestandrea, 1883) & $\mathrm{N}$ & $\mathrm{N}, \mathrm{CI}-\mathrm{V}$ \\
\hline \multicolumn{3}{|l|}{ Scolecitrichidae Giesbrecht, 1892} \\
\hline Scolecithix sp. Brady, 1883 & - & $\mathrm{CI}-\mathrm{V}$ \\
\hline \multicolumn{3}{|l|}{ Metridinidae Sars, 1902} \\
\hline Pleurommama sp. Giesbrecht \& Schmeil, 1898 & $\mathrm{~N}$ & $\mathrm{CI}-\mathrm{V}$ \\
\hline \multicolumn{3}{|l|}{ Centropagidae Giesbrecht, 1892} \\
\hline Centropages velificatus Oliveira, 1946 & $\mathrm{~N}, \mathrm{CI}-\mathrm{VI}$ & $\mathrm{N}, \mathrm{CI}-\mathrm{VI}$ \\
\hline \multicolumn{3}{|l|}{ Pseudodiaptomidae Sars, 1902} \\
\hline Pseudodiaptomus acutus (F. Dahl, 1894) & $\mathrm{N}, \mathrm{CI}-\mathrm{VI}$ & $\mathrm{N}, \mathrm{CI}-\mathrm{VI}$ \\
\hline \multicolumn{3}{|l|}{ Temoridae Giesbrecht, 1893} \\
\hline Temora stylifera (Dana, 1849) & $\mathrm{N}, \mathrm{CI}-\mathrm{VI}$ & $\mathrm{N}, \mathrm{CI}-\mathrm{VI}$ \\
\hline T. turbinata (Dana, 1849) & $\mathrm{N}, \mathrm{CI}-\mathrm{VI}$ & $\mathrm{N}, \mathrm{CI}-\mathrm{VI}$ \\
\hline \multicolumn{3}{|l|}{ Candaciidae Giesbrecht, 1892} \\
\hline Candacia sp. Dana, 1846 & $\mathrm{~N}$ & $\mathrm{~N}, \mathrm{CI}-\mathrm{V}$ \\
\hline Pontellidae * Dana, 1853 & $\mathrm{~N}$ & $\mathrm{~N}$ \\
\hline Labidocera acutifrons (Dana, 1849) & $\mathrm{CI}-\mathrm{V}$ & CI-VI \\
\hline L. fluviatilis F. Dahl, 1894 & $\mathrm{CI}-\mathrm{V}$ & CI-VI \\
\hline Calanopia americana F. Dahl, 1894 & CI-VI & CI-VI \\
\hline Pontellopsis brevis (Giesbrecht, 1889) & $\mathrm{CI}-\mathrm{V}$ & $\mathrm{CI}-\mathrm{V}$ \\
\hline \multicolumn{3}{|l|}{ Acartiidae Sars, 1903} \\
\hline Acartia lilljeborgii Giesbrecht, 1889 & $\mathrm{~N}, \mathrm{CI}-\mathrm{VI}$ & $\mathrm{N}, \mathrm{CI}-\mathrm{VI}$ \\
\hline A. tonsa Dana, 1849 & $\mathrm{~N}, \mathrm{CI}-\mathrm{VI}$ & $\mathrm{N}, \mathrm{CI}-\mathrm{VI}$ \\
\hline
\end{tabular}


Tabela 1.4: Espécies de copépodes da ordem Cyclopoida registrados de 2009 a 2011 e os respectivos estágios do ciclo-de-vida capturados por cada malha. N: náuplios (NI - VI); CI-V: copepoditos I a V; CVI: copepodito VI ou adulto. *: casos em que o náuplio ou copepodito não foram classificados até o nível de espécie, sendo agrupados em gênero ou família.

\begin{tabular}{|c|c|c|}
\hline Táxon & $20 \mu \mathrm{m}$ & $100 \mu \mathrm{m}$ \\
\hline Oithonidae * Dana, 1853 & $\mathrm{~N}$ & $\mathrm{~N}$ \\
\hline Dioithona oculata (Farran, 1913) & $\mathrm{N}, \mathrm{CI}-\mathrm{VI}$ & $\mathrm{N}, \mathrm{CI}-\mathrm{VI}$ \\
\hline Oithona hebes (Giesbrecht, 1891) & $\mathrm{N}, \mathrm{CI}-\mathrm{VI}$ & $\mathrm{N}, \mathrm{CI}-\mathrm{VI}$ \\
\hline O. nana Giesbrecht, 1892 & $\mathrm{~N}, \mathrm{CI}-\mathrm{VI}$ & $\mathrm{N}, \mathrm{CI}-\mathrm{VI}$ \\
\hline O. plumifera Baird, 1843 & $\mathrm{~N}, \mathrm{CI}-\mathrm{VI}$ & $\mathrm{N}, \mathrm{CI}-\mathrm{VI}$ \\
\hline O. simplex (Farran, 1913) & $\mathrm{N}, \mathrm{CI}-\mathrm{VI}$ & $\mathrm{N}, \mathrm{CI}-\mathrm{VI}$ \\
\hline Oncaeidae * Giesbrecht, 1893 & $\mathrm{~N}$ & $\mathrm{~N}$ \\
\hline Oncaea mediterranea (Claus, 1863) & CI-V & CI-VI \\
\hline O. af curta Sars, 1916 & CI-VI & CI-VI \\
\hline O. venusta Philippi, 1843 & CI-VI & CI-VI \\
\hline Monothula subtilis (Giesbrecht, 1891) & CI-VI & CI-VI \\
\hline Triconia conifera (Giesbrecht, 1891) & CI-VI & CI-VI \\
\hline Sapphirinidae * Thorell, 1859 & $\mathrm{~N}, \mathrm{CI}-\mathrm{V}$ & $\mathrm{N}, \mathrm{CI}-\mathrm{V}$ \\
\hline Sapphirina nigromaculata Claus, 1863 & CVI & CVI \\
\hline Sapphirina sp. Thompson, 1829 & - & CVI \\
\hline Copilia miriabilis Dana, 1849 & - & CVI \\
\hline \multicolumn{3}{|l|}{ Corycaeidae * (Dana, 1852) } \\
\hline Corycaeus speciosus (Dana, 1842) & CI-VI & CI-VI \\
\hline Ditrichocorycaeus amazonicus (F. Dahl, 1894) & CI-VI & CI-VI \\
\hline Farranula gracilis (Dana, 1853) & CI-VI & CI-VI \\
\hline Onychocorycaeus giesbrechti (F. Dahl, 1894) & CI-VI & CI-VI \\
\hline \multicolumn{3}{|l|}{ Clausidiidae * Emblenton, 1901} \\
\hline Copepoditos & $\mathrm{CI}-\mathrm{V}$ & $\mathrm{CI}-\mathrm{V}$ \\
\hline Hemicyclops thalassius Vervoot \& Ramirez, 1966 & CVI & CVI \\
\hline
\end{tabular}

Tabela 1.5: Espécies de copépodes das ordens Harpacticoida, Siphonostomatoida e Monstrilloida registrados de 2009 a 2011 e os respectivos estágios do ciclo-de-vida capturados por cada malha. N: náuplios (NI - VI); CI-V: copepoditos I a V; CVI: copepodito VI ou adulto. *: casos em que o náuplio ou copepodito não foram classificados até o nível de espécie, sendo agrupados em gênero ou família.

\begin{tabular}{|c|c|c|}
\hline Táxon & $20 \mu \mathrm{m}$ & $100 \mu \mathrm{m}$ \\
\hline Ectinosomatidae Oloffson, 1917 & $\mathrm{~N}, \mathrm{CI}-\mathrm{V}$ & $\mathrm{N}, \mathrm{CI}-\mathrm{V}$ \\
\hline Microsetella novergica (Dana, 1847) & - & CVI \\
\hline M. rosea (Dana, 1847) & CVI & CVI \\
\hline Miraciidae Dana, 1846 & $\mathrm{~N}$ & $\mathrm{~N}$ \\
\hline Macrosetella gracilis (Dana, 1848) & CI-VI & CI-VI \\
\hline Euterpinidae Brian, 1921 & & \\
\hline $\begin{array}{l}\text { Euterpina acutifrons (Dana, 1852) } \\
\text { Clytemnestridae Scott, } 1909\end{array}$ & $\mathrm{~N}, \mathrm{CI}-\mathrm{VI}$ & $\mathrm{N}, \mathrm{CI}-\mathrm{VI}$ \\
\hline $\begin{array}{l}\text { Clytemnestra scutellata Dana, } 1848 \\
\text { Longipediidae Sars, } 1903\end{array}$ & $\mathrm{CI}-\mathrm{V}$ & $\mathrm{CI}-\mathrm{V}$ \\
\hline $\begin{array}{l}\text { Longipedia americana Wells, } 1980 \\
\text { Tisbidae Stebbing, } 1910\end{array}$ & $\mathrm{~N}, \mathrm{CI}-\mathrm{VI}$ & $\mathrm{N}, \mathrm{CI}-\mathrm{VI}$ \\
\hline Tisbe spp. Lilljeborg, 1853 & CI-VI & CI-VI \\
\hline Siphonostomatoida & & \\
\hline $\begin{array}{l}\text { Caligidae Burmeister, } 1835 \\
\text { Ergasilidae von Nordmann, } 1832\end{array}$ & $\begin{array}{c}\mathrm{CI}-\mathrm{V} \\
-\end{array}$ & $\begin{array}{l}\text { CI-VI } \\
\text { CVI }\end{array}$ \\
\hline Monstrilloida & & \\
\hline $\begin{array}{l}\text { Monstrillidae Dana, } 1849 \\
\text { Monstrilla sp. Dana, } 1849 \\
\text { Cymbasoma sp. Thompson, } 1888\end{array}$ & - & $\begin{array}{l}\text { CVI } \\
\text { CVI }\end{array}$ \\
\hline
\end{tabular}




\subsubsection{Frequência de ocorrência}

A frequência de ocorrência foi calculada para o zooplâncton total exceto os copépodes (Figuras 1.4 e 1.6) e somente para essa sublcasse (Figuras 1.5 e 1.7). Os táxons mais frequentes do plâncton coletado pela rede de $20 \mu \mathrm{m}$ foram Tintinnina, larvas de poliquetos, véliger de gastrópodes e bivalves, náuplios de copépodes e apendiculários (Figura 1.4).

Para os copépodes, o estágio de desenvolvimento mais frequente foi o de copepoditos juvenis, seguido pelos náuplios e os adultos. Os náuplios das famílias Paracalanidae e Clausocalanidae, copepoditos de Parvocalanus crassirostris, náuplios e copepoditos das famílias Oncaeidae e Oithonidae, náuplios de Acartia spp. e copepoditos de Temora turbinata foram os táxons mais frequentes. Destaca-se ainda a maior frequência de náuplios de Acartia spp. na rede de $20 \mu \mathrm{m}$ ( Figuras 1.5 e 1.7)

Para o zooplâncton da fração maior (exceto copépodes), os táxons mais frequentes foram as larvas véliger de gastrópodes e larvas de bivalves, urocordados como Oikopleura dioica e O. longicauda, larvas de poliquetos, náuplios de cirripédios e Tintinnina (Figuras 1.4 e 1.6). De maneira geral, a frequência dos cladóceros também foi maior para a rede de $100 \mu \mathrm{m}$.

As espécies Parvocalanus crassirostris (adultos e copepoditos), Temora turbinata (copepoditos), Paracalanus spp. (copepoditos), Onychocorycaeus giesbrechti (copepoditos e adultos) e copepoditos I ao III dos gêneros Acartia e Oithona foram os táxons mais frequentes para a rede de maior abertura (Figura 1.7). 


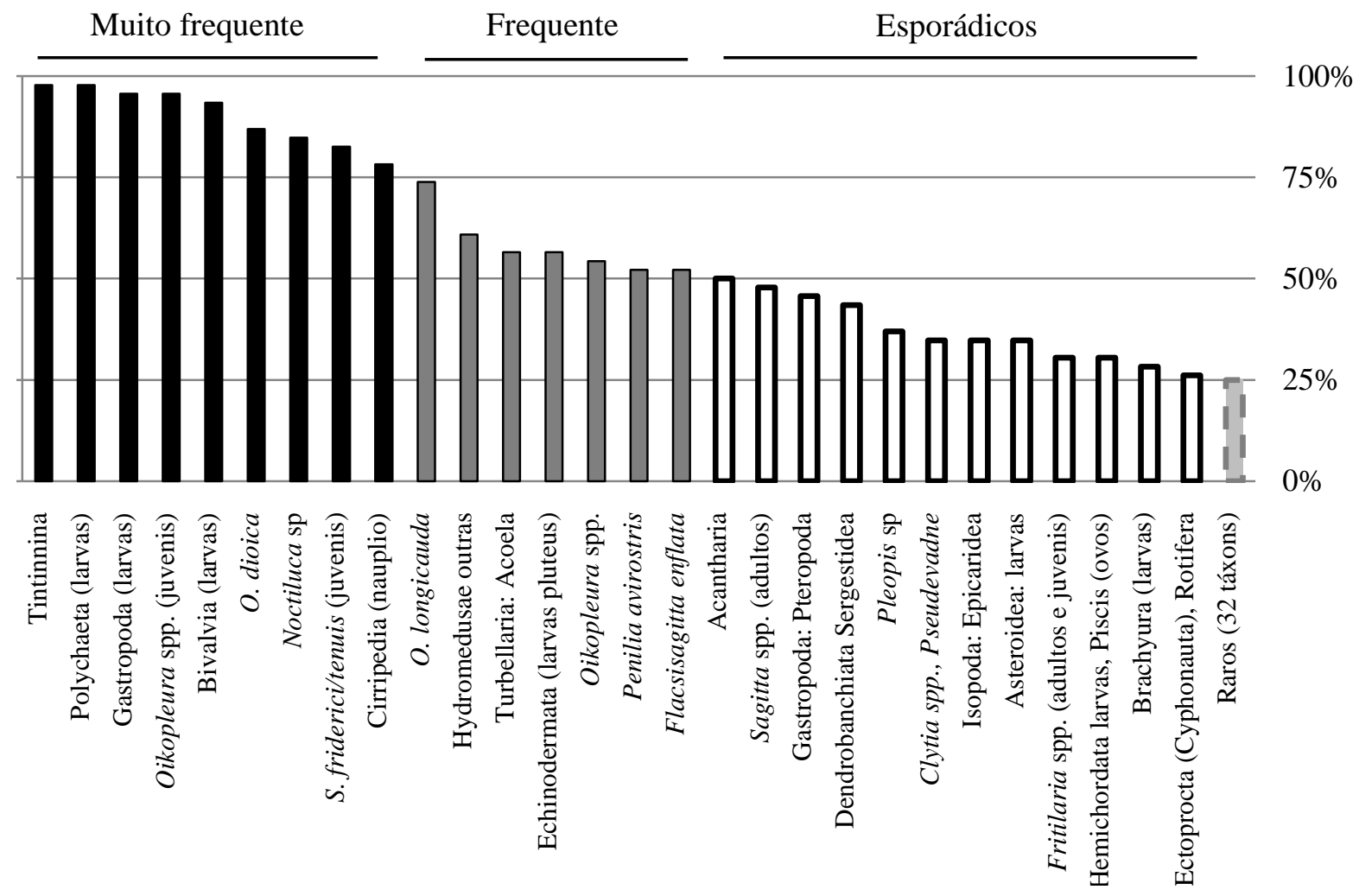

Figura 1.4: Frequência de ocorrência para o zooplâncton (exceto copépodes) capturado pela rede de 20 $\mu \mathrm{m}$. Os organismos raros foram agrupados e representados pela coluna rachurada.
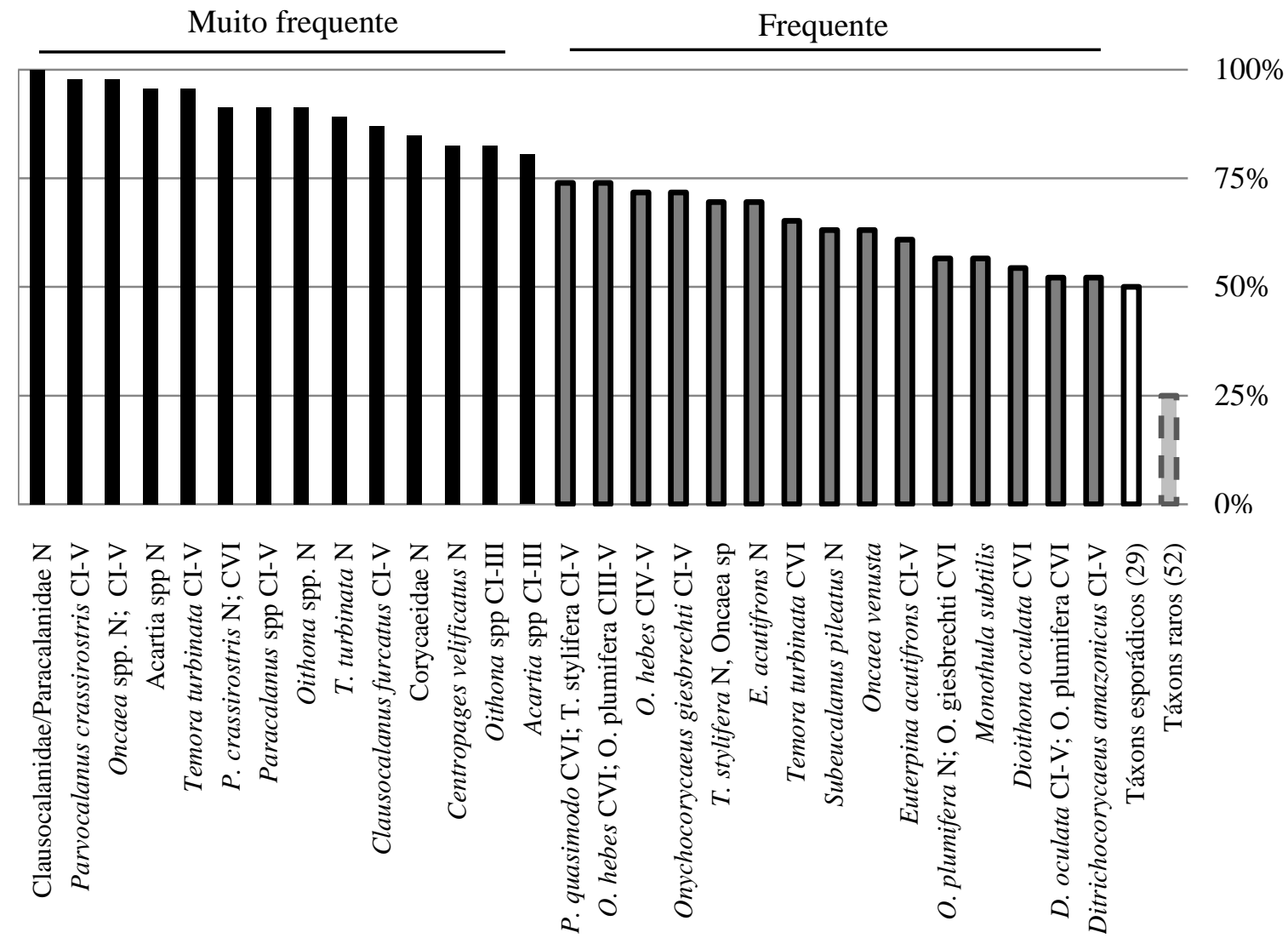

Figura 1.5: Frequência de ocorrência dos copépodes e respectivos estágios de desenvolvimento para o zooplâncton capturado pela rede de $20 \mu \mathrm{m}$. Os organismos raros foram agrupados e representados pela coluna rachurada. 

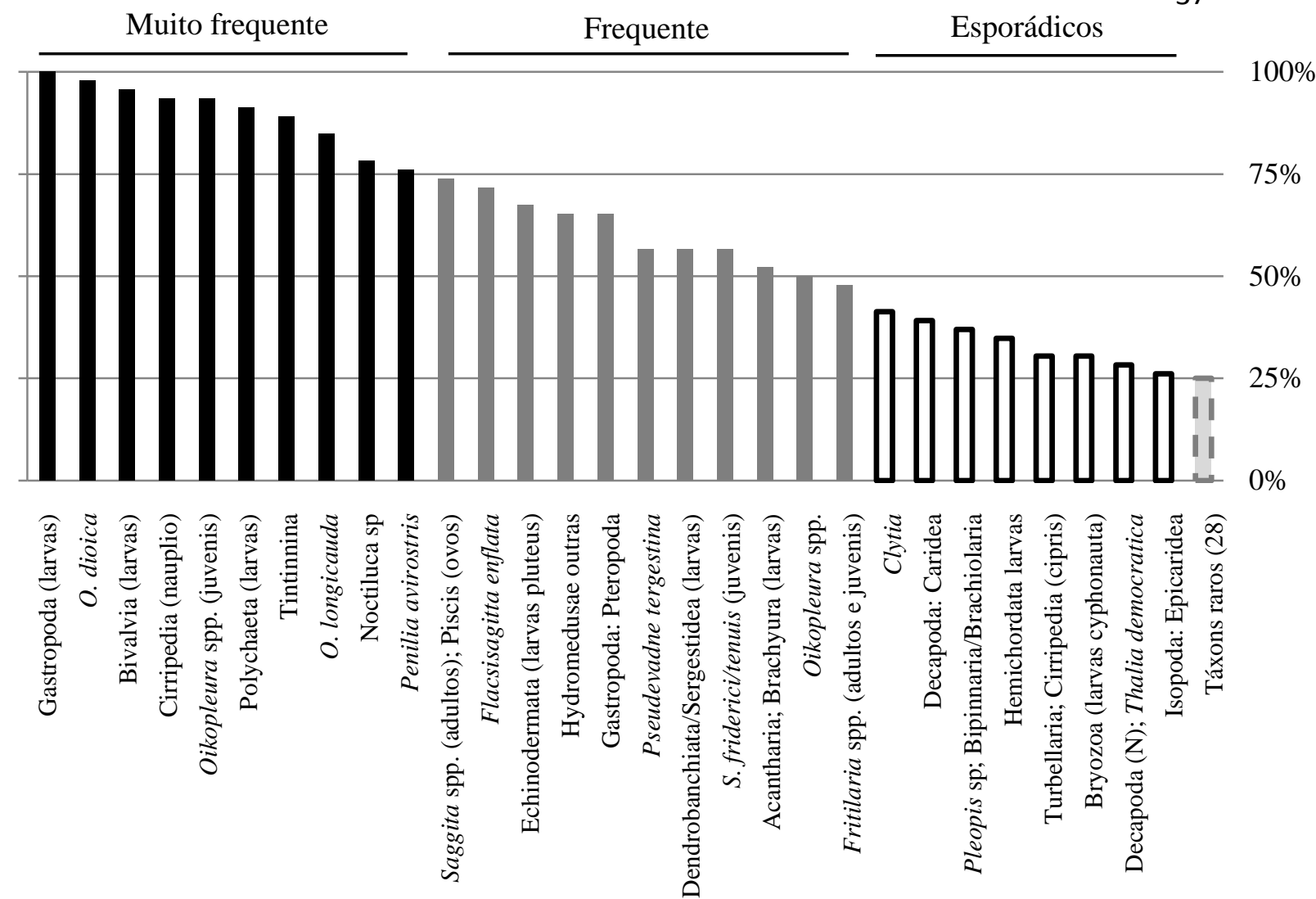

Figura 1.6: Frequência de ocorrência dos táxons zooplanctônicos (exceto copépodes), capturados pela rede de $100 \mu \mathrm{m}$. Os organismos raros foram agrupados e representados pela coluna rachurada.
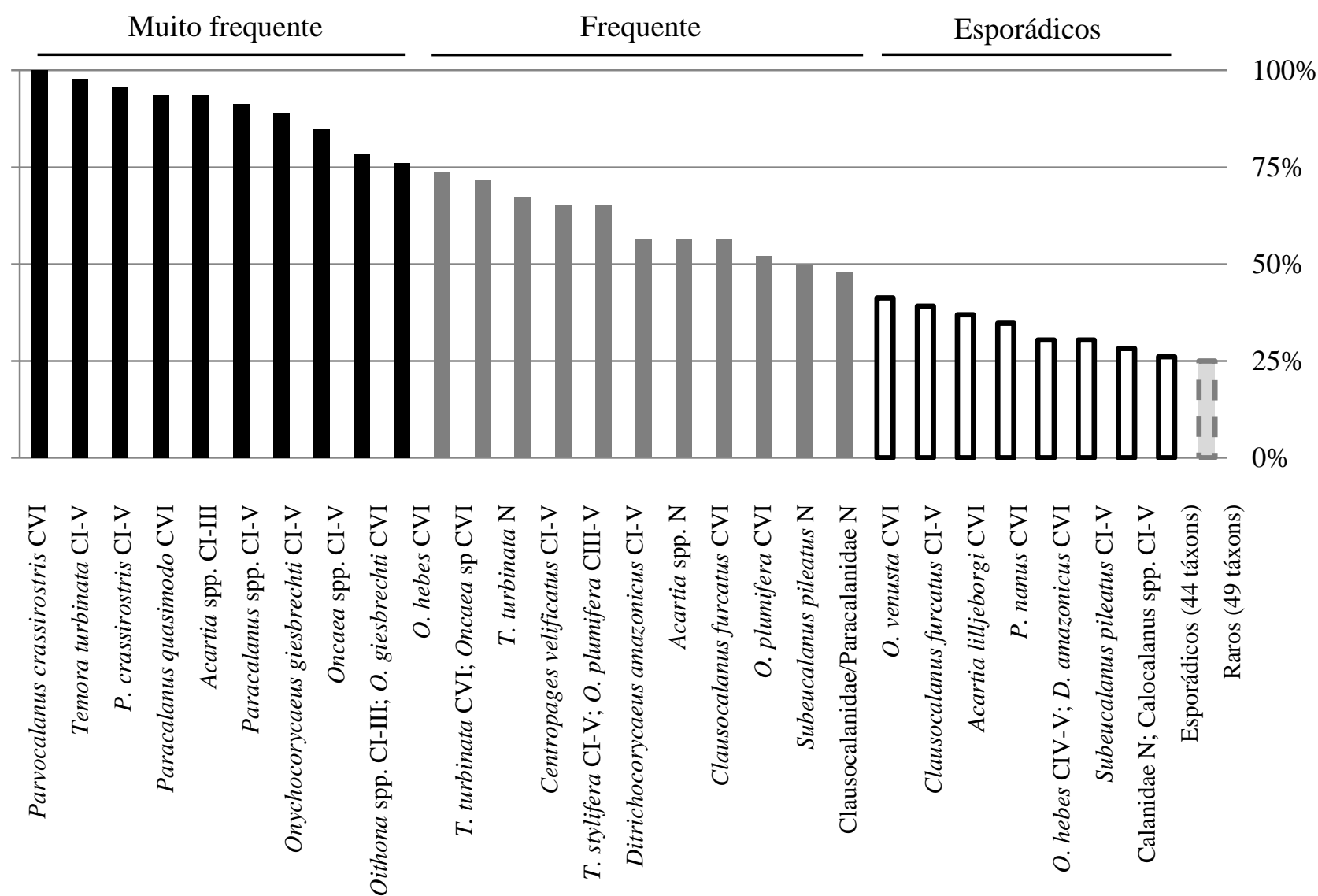

Figura 1.7: Frequência de ocorrência dos copépodes e respectivos estágios de desenvolvimento para o zooplâncton capturado pela rede de $100 \mu \mathrm{m}$. Os organismos raros foram agrupados e representados pela coluna rachurada. 


\subsubsection{Riqueza, Diversidade e Equitabilidade}

Variáveis ecológicas como a riqueza, diversidade e equitabilidade foram calculadas apenas para os cladóceros e copépodes, os quais foram identificados em nível de espécie sempre que possível. Um reduzido número de espécies de cladóceros está adaptado às águas marinhas, sendo encontradas aqui quatro das seis espécies registradas para o Atlântico sul. A riqueza do grupo não foi diferente entre as redes de 20 e $100 \mu \mathrm{m}(p=0,074)$, porém, foi maior nos períodos de verão, quando comparados ao inverno ( $p<0,001)$ para ambas as redes utilizadas (Tabela 1.6).

Para os copépodes, foram encontradas 66 espécies, sendo que a riqueza foi maior durante os períodos de verão ( $p<0,001$ para a rede de $20 \mu \mathrm{m}$ e $p=0,027$ para a rede de $100 \mu \mathrm{m})$. Os menores valores ocorreram no inverno de 2010. Entre as classes de tamanho, a riqueza foi superior para a rede de $100 \mu \mathrm{m}(p<0,001$; Tabela 1.6).

Para as análises de diversidade de Shannon e equitabilidade de Pielou foram considerados os dados de composição e densidade específica dos cladóceros e copépodes. Para a rede de $20 \mu \mathrm{m}, \mathrm{H}^{\prime}$ variou entre 2,73 a 4,06 durante o verão $(3,58 \pm$ 0,28 bits.ind $\left.^{-1}\right)$ e 2,73 a 4,1 (3,28 $\pm 0,35$ bits.ind $\left.^{-1}\right)$ durante o inverno, enquanto que para a rede de $100 \mu \mathrm{m}$ os valores estiveram entre 2,64 a 4,27 (3,62 $\pm 0,47$ bits.ind $\left.^{-1}\right)$ e 2,08 a 4,15 $\left(3,32 \pm 0,48\right.$ bits.ind $\left.^{-1}\right)$ para o verão e inverno respectivamente.

A equitabilidade teve baixa amplitude neste estudo. Para a malha de $20 \mu \mathrm{m}$ esteve entre 0,56 e 0,85 para todo o período amostral. A média durante o verão foi de $0,74 \pm 0,06$ e de $0,73 \pm 0,06$ para o inverno. Valores semelhantes foram obtidos para a rede de $100 \mu \mathrm{m}: 0,73 \pm 0,1$ durante o verão e $0,7 \pm 0,09$ durante o inverno.

A diversidade foi mais alta para o verão em comparação ao inverno ( $p=0,02 \mathrm{e}$ $p=0,036$ para redes de 20 e $100 \mu \mathrm{m}$ respectivamente). Diferenças entre as estações do ano não ocorreram quanto a equitabilidade. Também não houve diferença entre as redes de 20 e $100 \mu$ m para a diversidade e a equitabilidade (Tabela 1.6). 
Tabela 1.6: Riqueza (R), Diversidade de Shannon (H') e Equitabilidade (J) para copépodes e cladóceros das amostras das redes de 20 e $100 \mu \mathrm{m}$ coletadas em Ubatuba, SP. Média e desvio-padrão para o verão e o inverno dos três anos analisados.

\begin{tabular}{|c|c|c|c|c|c|c|}
\hline \multirow{2}{*}{$\begin{array}{c}\text { Ano } \\
\text { Estação }\end{array}$} & \multicolumn{2}{|c|}{2009} & \multicolumn{2}{|c|}{2010} & \multicolumn{2}{|c|}{2011} \\
\hline & Verão & Inverno & Verão & Inverno & Verão & Inverno \\
\hline $\mathbf{R}($ Copepoda $20 \mu \mathrm{m})$ & $27,8 \pm 2,4$ & $22,2 \pm 3,7$ & $24,9 \pm 2,1$ & $20,8 \pm 4,6$ & $28,2 \pm 4,4$ & $24,3 \pm 5$ \\
\hline$R($ Copepoda $100 \mu \mathrm{m})$ & $30,2 \pm 5,3$ & $28 \pm 4,5$ & $29,1 \pm 3,9$ & $24,2 \pm 2,5$ & $27,8 \pm 1,5$ & $27,1 \pm 3$ \\
\hline R $($ Cladocera $20 \mu \mathrm{m})$ & $2,1 \pm 0,8$ & $1,3 \pm 0,7$ & $2,3 \pm 1$ & $0,6 \pm 0,7$ & $2,2 \pm 1,2$ & 0 \\
\hline $\mathrm{R}($ Cladocera $100 \mu \mathrm{m})$ & $3 \pm 0,7$ & $1,3 \pm 1$ & $2,4 \pm 0,7$ & $1,6 \pm 1,2$ & $2,3 \pm 0,5$ & $0,4 \pm 0,5$ \\
\hline $\mathrm{H}^{\prime} 20 \mu \mathrm{m}$ & $3,6 \pm 0,4$ & $3,4 \pm 0,4$ & $3,6 \pm 0,2$ & $3,1 \pm 0,4$ & $3,6 \pm 0,2$ & $3,4 \pm 0,2$ \\
\hline $\mathrm{H}^{\prime} 100 \mu \mathrm{m}$ & $3,4 \pm 0,6$ & $3,6 \pm 0,1$ & $3,5 \pm 0,3$ & $3 \pm 0,6$ & $4 \pm 0,3$ & $3,3 \pm 0,2$ \\
\hline J $20 \mu \mathrm{m}$ & $0,7 \pm 0,08$ & $0,7 \pm 0,05$ & $0,7 \pm 0,05$ & $0,7 \pm 0,07$ & $0,7 \pm 0,04$ & $0,7 \pm 0,06$ \\
\hline J $100 \mu \mathrm{m}$ & $0,7 \pm 0,13$ & $0,7 \pm 0,06$ & $0,7 \pm 0,06$ & $0,6 \pm 0,13$ & $0,8 \pm 0,05$ & $0,7 \pm 0,04$ \\
\hline
\end{tabular}

\subsubsection{Densidade total e relativa do zooplâncton}

O plâncton foi analisado em grupos funcionais (holoplâncton, meroplâncton) e taxonômicos, quanto a densidade total e relativa de organismos nas diferentes estações e anos amostrados. Em relação aos estágios de maré, enchente e vazante, a densidade do zooplâncton total não foi diferente para ambas as classes de tamanho utilizadas. Também não houve diferença estatística para comparações entre as marés enchente e vazante para o inverno e para o verão isoladamente.

A maré não apresentou influências significantes para a densidade total do plâncton, mesmo nos períodos de maior amplitude. É possível que a maré tenha influenciado na densidade plâncton total ou de grupos isolados, porém, o desenho amostral adotado neste estudo não foi adequado para elucidar tais influências.

A densidade do holo- e meroplâncton para os verões de 2009 e 2010 foi pequena para a maioria das amostras. A grande variabilidade, porém, foi reflexo de valores muito elevados em poucas amostras como em V2 e V3 para o verão de 2009 e V14 para o verão de 2010. Esse mesmo padrão também foi observado para o inverno de 2010. Já o inverno de 2009 e ambas as estações do ano em 2011 foi notada uma dispersão ainda maior dos dados de densidade, principalmente para a malha de $20 \mu \mathrm{m}$ (Figura 1.8). 


\section{Fração menor do zooplâncton (rede de $20 \mu \mathrm{m}$ )}

A densidade total da fração menor do zooplâncton teve elevada variabilidade, sendo que para as coletas com a rede de $20 \mu \mathrm{m}$ esteve entre 1.178 a 65.819 org. $\mathrm{m}^{-3}$. Diferença estatística quanto a densidade do zooplâncton total foi encontrada entre o verão e o inverno em 2011 somente, sendo maior durante o inverno (Tabela 1.7). O holoplâncton foi mais abundante durante o ano de 2011 em relação aos demais anos ( $p$ =0,013, teste de Kruskall-Wallis).

O holoplâncton dominou numericamente sobre o meroplâncton em todas as amostras (Figura 1.8). A densidade do grupo foi de 1.034 a 65.819 org.m $\mathrm{m}^{-3}$ e em 2011 foi superior durante o inverno (Tabela 1.7). Os copépodes foram o grupo dominante do holoplâncton, salvo poucas exceções: as estações I10 e I13 onde os Tintinnina dominaram.

Em ordem decrescente, as famílias Oithonidae, Oncaeidae e Paracalanidae foram as mais importantes para a densidade relativa do plâncton da rede de $20 \mu \mathrm{m}$. Depois dos copépodes, os cladóceros e apendiculários foram os táxons mais abundantes (Tabela 1.6, Figuras 1.11 e 1.12). A densidade dos copépodes planctônicos variou entre 447 e 61.701 org. $\mathrm{m}^{-3}$.

Entre os estágios de desenvolvimento, os náuplios apresentaram as maiores densidades relativas, seguidos por copepoditos e posteriormente por adultos (42, 39 e 19\% respectivamente). As famílias Oithonidae, Oncaeidae, Acartiidae, Paracalanidae e Temoridae foram as que mais contribuíram em termos de densidade relativa para a classe de tamanho de $20 \mu \mathrm{m}$ (Figura 1.11), representando mais de $70 \%$ de todo o holoplâncton para a maioria das amostras. A família Oithonidae foi a principal contribuição para a densidade relativa, seguida pela família Paracalanidae. A contribuição numérica de Tintinnina e apendiculários também foi importante: os primeiros atingiram valores superiores a $25 \%$ para cinco amostras e apendiculários acima de $10 \%$ em 10 amostras.

Os Tintinnina foram abundantes em diversos períodos, com densidade máxima registrada de $4.224 \mathrm{org} . \mathrm{m}^{-3}$ durante o inverno de 2010. A densidade foi maior durante o verão, em relação ao inverno somente em 2011. Entre os anos, a diferença foi significativa, sendo a densidade mais elevada em 2010 (Tabela 1.8). Já o dinoflagelado Noctiluca sp. foi mais abundante durante os períodos de inverno. 
Penilia avirostris foi a espécie mais frequente e de maior densidade entre os cladóceros, seguida por Evadne spinifera. Exceto por Pleopis schmackeri, esses microcrustáceos foram mais numerosos durante os períodos de verão. A espécie $P$. schmackeri foi a menos abundante, embora tenha ocorrido com maior frequência nos períodos de inverno, em relação às espécies E. spinifera e $P$. tergestina.

Outros importantes componentes do holoplâncton em termos numéricos foram os urocordados da classe Appendicularia, com densidades de até 17.585 org. $\mathrm{m}^{-3} \mathrm{e}$ abundância menor para o ano de 2010. Ainda para o holoplâncton, foram detectadas seis espécies de quetognátos (quatro identificadas) e atingindo abundância de até 2.201 org. $\mathrm{m}^{-3}$, com densidades relativas geralmente maiores durante o verão.

O meroplâncton também apresentou elevada variação, entre 49 a 65.819 org.m ${ }^{-3}$ e diferença entre o verão e inverno apenas em 2011. Quanto a comparação multianual, a densidade foi maior em 2009. O mesmo resultado foi encontrado para as larvas de gastrópodes (Tabela 1.8). Os táxons dominantes do meroplâncton para a rede de $20 \mu \mathrm{m}$, tanto numericamente quanto em termos de densidade relativa, foram as larvas de poliquetos, seguidos por bivalves, véliger de gastrópodes e náuplios de cirripédios (Figura 1.9). Com exceção dos náuplios de cirripéidos cujas densidades mais elevadas ocorreram durante as estações de inverno, a maioria dos táxons do meroplâncton foi mais abundante durante o verão.

Tabela 1.7: Valores de $p$ do teste de Mann-Whitney para comparação aos pares da densidade de diversos grupos zooplanctônicos entre a estação de verão e inverno. Dados obtidos para cada rede utilizada (20 e $100 \mu \mathrm{m})$ e anos de coleta (2009 a 2011). Em negrito: $p<0,05$; em itálico: $p<0,001$.

\begin{tabular}{|c|c|c|c|c|c|c|}
\hline \multirow{2}{*}{ Grupo } & \multicolumn{3}{|c|}{$20 \mu \mathrm{m}$} & \multicolumn{3}{|c|}{$100 \mu \mathrm{m}$} \\
\hline & 2009 & 2010 & 2011 & 2009 & 2010 & 2011 \\
\hline Zooplâncton total & 0,195 & 0,328 & 0,013 & 0,13 & 0,721 & 0,662 \\
\hline Holoplâncton & 0,195 & 0,328 & 0,013 & 0,161 & 0,878 & 0,852 \\
\hline Copepoda total & 0,328 & 0,442 & $\underline{0,008}$ & 0,645 & 0,442 & 0,282 \\
\hline Náuplios & 0,798 & 0,875 & $\overline{0,02}$ & 0,574 & 0,505 & 0,852 \\
\hline Copepoditos & 0,195 & 0,234 & 0,02 & 0,721 & 0,798 & 0,181 \\
\hline Adultos & 0,328 & 0,505 & 0,02 & 0,105 & 0,574 & 0,491 \\
\hline Cladocera & $\leq 0,001$ & $\underline{0,007}$ & $\leq 0,001$ & $\underline{0,003}$ & 0,038 & $\leq 0,001$ \\
\hline Appendicularia & $\underline{0,002}$ & $\overline{0,234}$ & 0,059 & 0,234 & 0,279 & 0,181 \\
\hline Tintinnina & 0,721 & 0,959 & 0,043 & 0,13 & 0,574 & 0,414 \\
\hline Meroplâncton & 0,083 & 0,382 & 0,02 & 0,05 & 0,959 & 0,181 \\
\hline Gastropoda & $\underline{0,001}$ & 0,495 & 0,573 & $\leq 0,001$ & 0,083 & $\leq 0,001$ \\
\hline Bivalvia & $\overline{0,574}$ & 0,227 & $\underline{0,008}$ & $\overline{0,328}$ & 0,328 & 0,345 \\
\hline Polychaeta & 0,105 & 0,161 & $\leq 0,001$ & 0,05 & 0,645 & 0,573 \\
\hline
\end{tabular}




\section{Fração maior do zooplâncton (rede de $100 \mu \mathrm{m})$}

Para as amostras coletadas pela rede de $100 \mu \mathrm{m}$, a densidade zooplanctônica total variou entre 983 e 50.297 org. $\mathrm{m}^{-3}$ e diferenças não foram detectadas entre as estações do ano. O holoplâncton foi dominante sobre o meroplâncton em todas as amostras e a densidade esteve entre 661 a 48.368 org. $\mathrm{m}^{-3}$, sendo que não houve diferença entre as estações e anos amostrados.

As estações V1 e V2 foram as únicas onde os copépodes não foram numericamente dominantes, posição ocupada pelos cladóceros (Figura 1.12). A densidade do grupo variou entre 452 e 46.121 org.m ${ }^{-3}$. Dentre os estágios de desenvolvimento, os copepoditos juvenis (C I-V) representaram os metazoários numericamente mais expressivos, seguidos por adultos e posteriormente por náuplios (densidades relativas médias de 55, 36 e 9\% respectivamente). Apenas as densidades dos estágios de náuplios apresentaram diferença estatística entre os anos de coleta, a qual ocorreu em ambas as malhas (Tabela 1.8).

As famílias Paracalanidae, Oithonidae, Temoridae e Acartiidae foram as mais representativas em ordem decrescente. As quatro famílias representaram mais de $50 \%$ da densidade do holoplâncton em 22 das 46 amostras analisadas. Outros táxons tiveram densidades relativas pontualmente altas, como os cladóceros (três amostras acima de $25 \%$ para o verão de 2009, atingindo 52\%), apendiculários (17 amostras acima de 10\% e densidades próximas a 30\% para ambas as estações do ano de 2011), larvas de moluscos (4 amostras acima de 10\%) e larvas de cirripédios (55\% da densidade para a estação I 11).

A densidade total de cladóceros foi maior nos períodos de verão, quando comparados ao inverno (Tabela 1.7) para as quatro espécies registradas. De maneira geral, tais crustáceos foram menos abundantes e frequentes durante os períodos de inverno. A espécie Evadne spinifera, por exemplo, não ocorreu em nenhuma amostra dos períodos de inverno, enquanto que Pseudevadne tergestina esteve presente em apenas cinco amostras. Penilia avirostris foi a espécie mais abundante, atingindo densidade máxima durante o verão de 2009 (19.020 org. $\mathrm{m}^{-3}$ ) e seguida posteriormente por P. tergestina. 
Os apendiculários também tiveram densidades variadas e elevadas, de 4 a 4.370 org. $\mathrm{m}^{-3}$. A abundância do grupo foi menor para o ano de 2010. Dentre os quetognátos, outro importante grupo de animais vermiformes, a densidade alcançou a densidade máxima de 2.194 org. $\mathrm{m}^{-3}$ e seguiu o mesmo padrão descrito para a rede de $20 \mu \mathrm{m}$.

A densidade dos Tintinnina foi menor, cerca de 7 vezes inferior para a rede de $100 \mu \mathrm{m}$, quando comparada a rede de $20 \mu \mathrm{m}$. Densidade mais elevada foi detectada em 2010 em relação aos outros anos (Tabela 1.8).

Os dados de densidade do meroplâncton oscilaram entre 55 a 6.530 org. $\mathrm{m}^{-3} \mathrm{e}$ valores mais elevados foram encontrados preferencialmente para as coletas no verão (Figura 1.8). Apenas para o ano de 2009, a densidade foi superior em relação ao inverno (Tabela 1.7). Larvas de gastrópodes, náuplios de cirripédios, larvas de bivalves e de poliquetos foram os táxons mais expressivos. As larvas de bivalves foram mais abundantes para o ano de 2009, em relação a 2010 (Figura 1.10).

Em relação a variabilidade anual, alguns padrões mereceram destaque como a baixa contribuição dos Tintinnina e Temora turbinata e alta contribuição de Clausocalanus furcatus para 2009 em relação aos demais anos para a rede de $20 \mu \mathrm{m}$. Já para a rede de $100 \mu \mathrm{m}$, Acartia spp. e Euterpina acutifrons foram os táxons mais abundantes em 2009, em relação ao 2010 e 2011.

Tabela 1.8: Valores de $p$ do teste de Kruskal-Wallis para a comparação da densidade dos grupos do zooplâncton entre os anos de 2009 a 2011. No caso de diferença significativa, o teste de Student-NewmanKeuls foi aplicado para a comparação aos pares $(p<0,05)$. Em negrito: $p<0,05$; em itálico: $p<0,001$.

\begin{tabular}{|c|c|c|c|c|c|c|c|c|}
\hline \multirow{2}{*}{ Grupo } & \multirow{2}{*}{$\underset{\text { Krukal-Wallis }}{p}$} & \multicolumn{3}{|c|}{$20 \mu \mathrm{m}-$} & \multirow{2}{*}{ 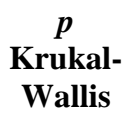 } & \multicolumn{3}{|c|}{$100 \mu \mathrm{m}$} \\
\hline & & 09x10 & 09x11 & $10 \times 11$ & & $09 \times 10$ & 09x11 & $10 \times 11$ \\
\hline Zooplâncton total & 0,166 & - & - & - & 0,297 & - & - & - \\
\hline Holoplâncton & 0,189 & - & - & - & 0,321 & - & - & - \\
\hline Copepoda total & 0,09 & - & - & - & 0,309 & - & - & - \\
\hline Náuplios & $\underline{0,008}$ & - & - & $<0,05$ & $\underline{0,009}$ & $<0,05$ & $<0,05$ & - \\
\hline Copepoditos & 0,164 & - & - & - & 0,151 & - & - & - \\
\hline Adultos & 0,2 & - & - & - & 0,298 & - & - & - \\
\hline Cladocera & 0,084 & - & - & - & 0,091 & - & - & - \\
\hline Appendicularia & $\leq 0,001$ & $<0,05$ & - & $<0,05$ & $\underline{0,008}$ & $<0,05$ & - & $<0,05$ \\
\hline Tintinnina & $\leq 0,001$ & $<0,05$ & - & - & $\leq 0,001$ & $<0,05$ & - & $<0,05$ \\
\hline Meroplâncton total & $\mathbf{0 , 0 2 8}$ & - & - & $<0,05$ & 0,286 & - & - & - \\
\hline Gastropoda & 0,04 & - & - & $<0,05$ & 0,455 & - & - & - \\
\hline Bivalvia & 0,267 & - & - & - & $\underline{0,008}$ & $<0,05$ & - & - \\
\hline Polychaeta & 0,018 & $<0,05$ & - & - & 0,464 & - & - & - \\
\hline
\end{tabular}



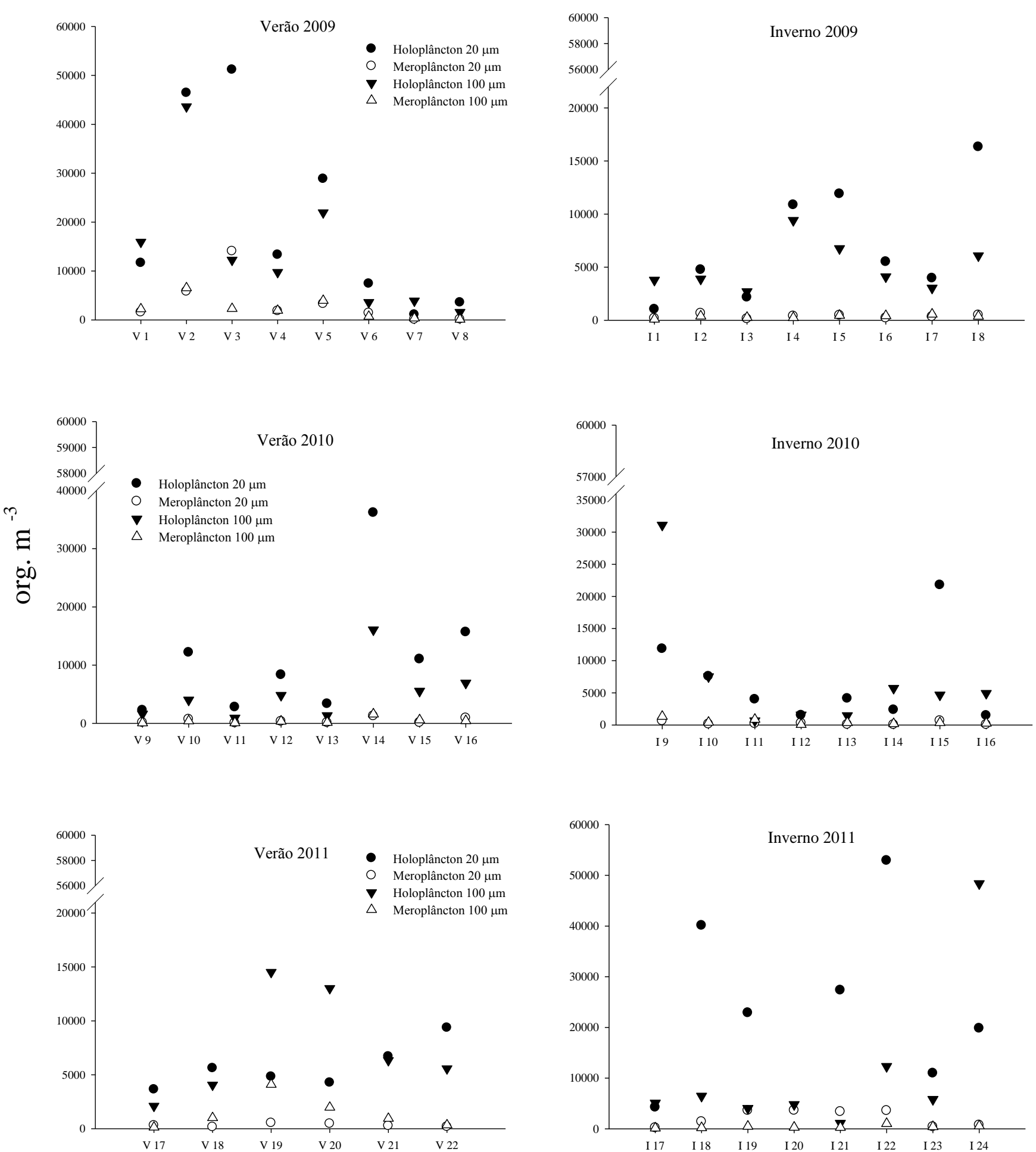

Figura 1.8: Dados de densidade (org. $\mathrm{m}^{-3}$ ) para o holo- e meroplâncton capturados pela rede de 20 e 100 $\mu \mathrm{m}$, durante os períodos de verão e inverno de 2009 a 2011. As siglas dos períodos de coleta seguem como na Tabela 1.1. 

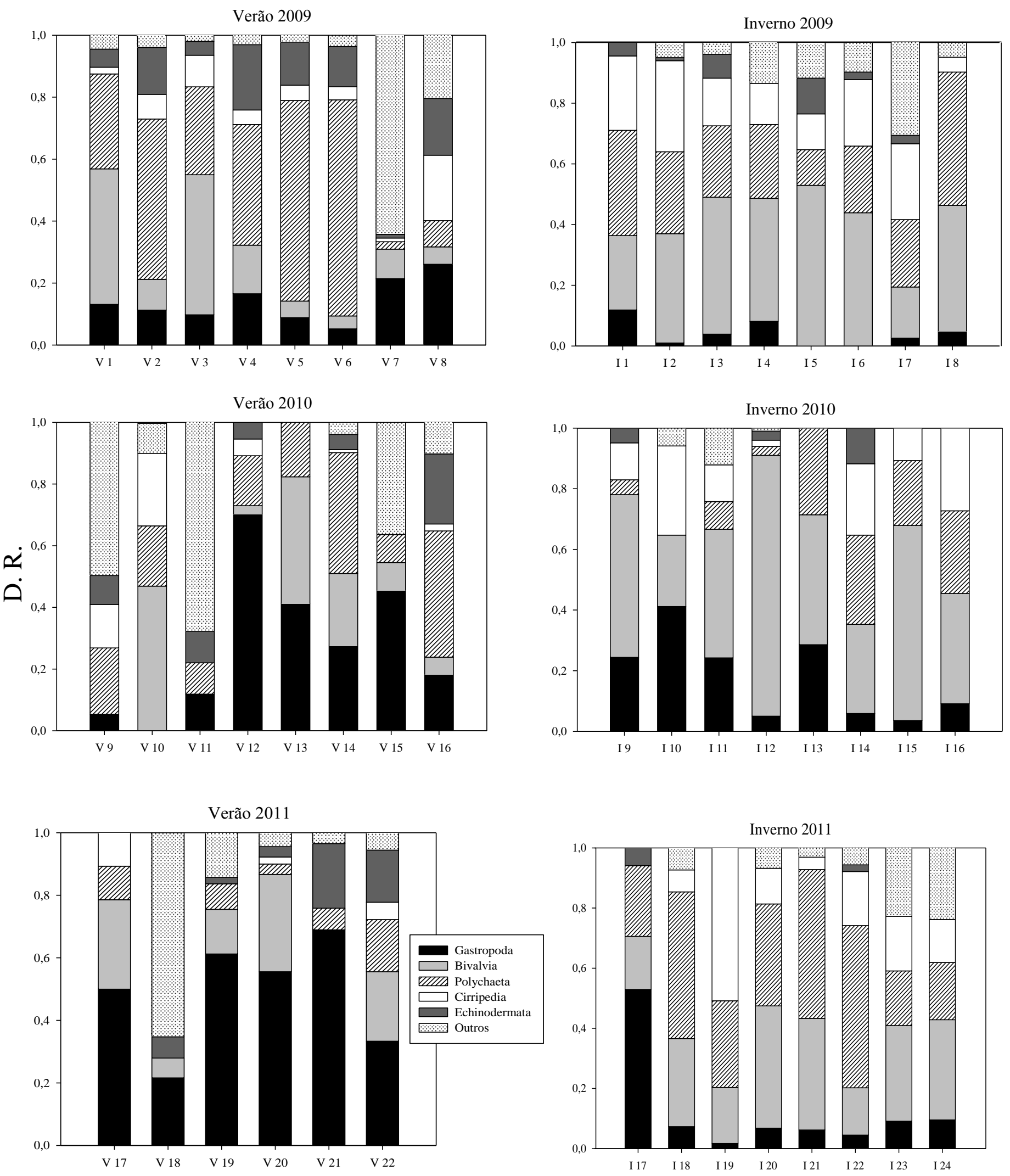

Figura 1.9: Densidade relativa dos principais grupos do meroplâncton, para as amostras da rede de 20 $\mu \mathrm{m}$ durante o verão e inverno dos anos de 2009 a 2011. Sigla das amostras conforme a Tabela 1.1. 
Verão 2009

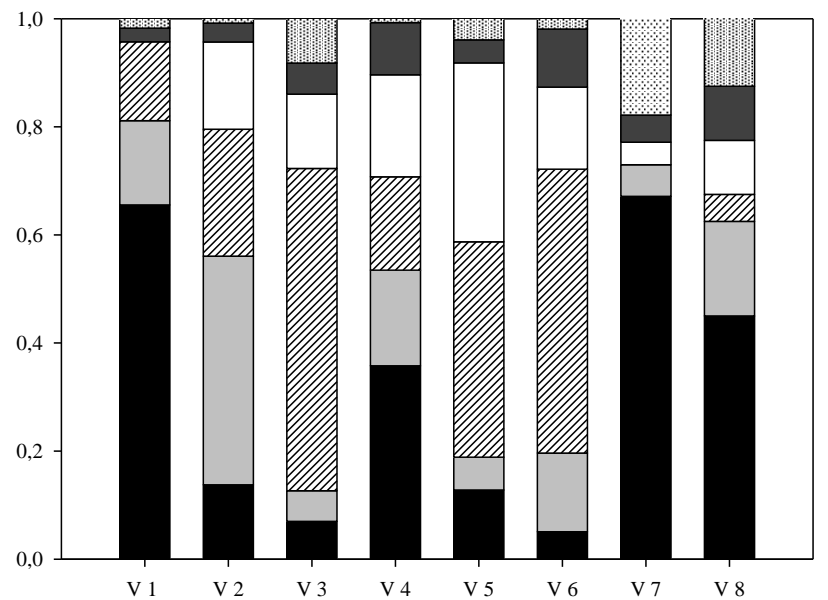

Verão 2010

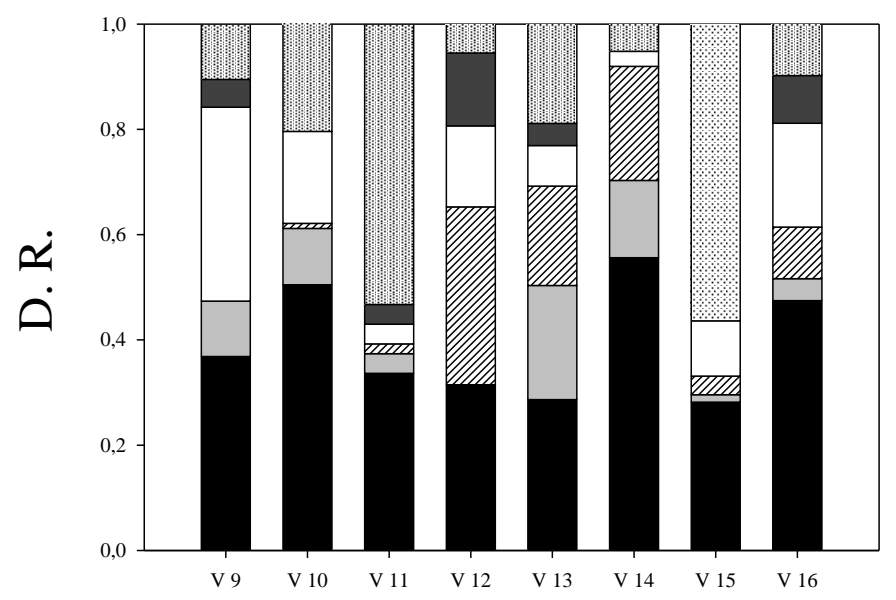

Verão 2011

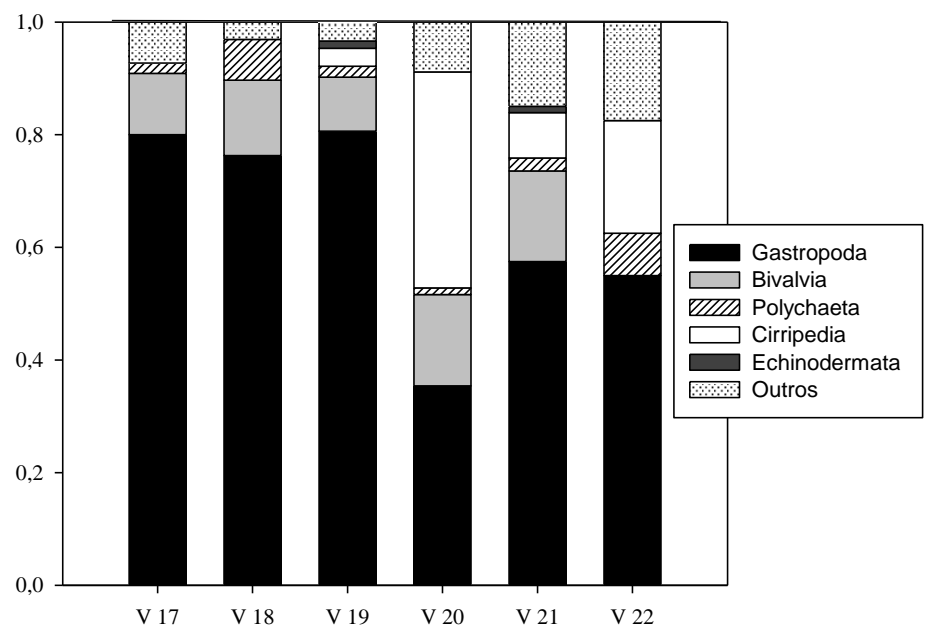

Inverno 2009

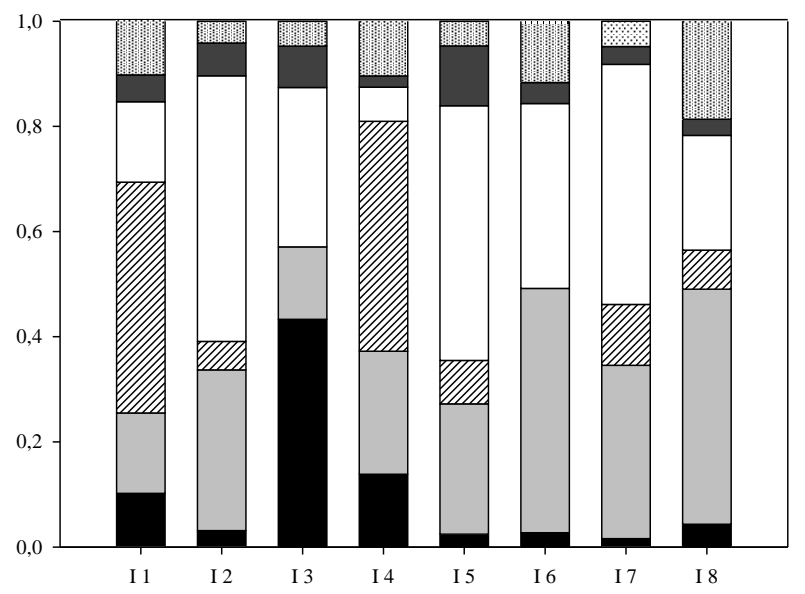

Inverno 2010

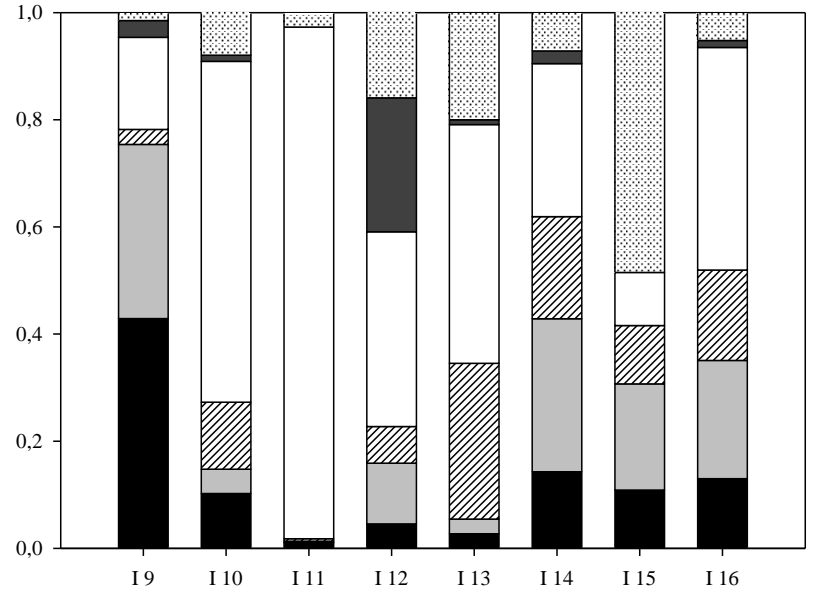

Inverno 2011

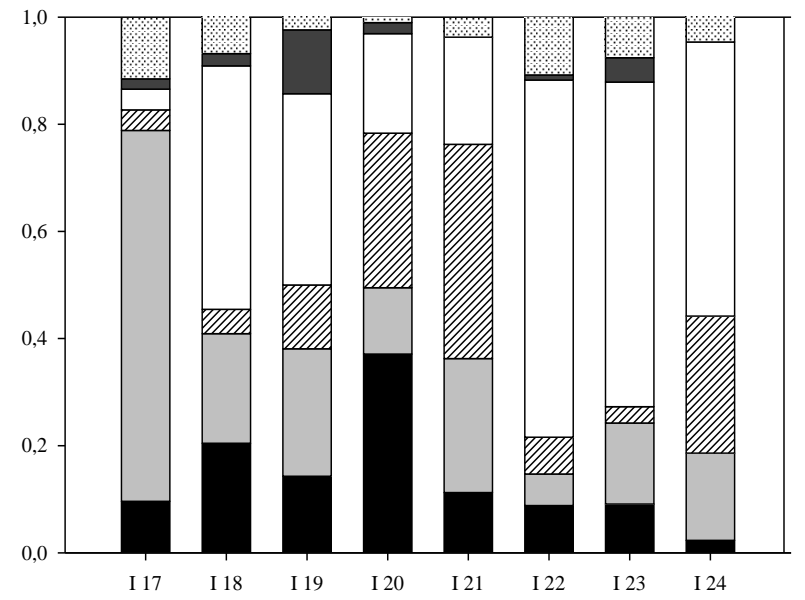

Figura 1.10: Densidade relativa dos principais grupos do meroplâncton, para as amostras da rede de 100 $\mu \mathrm{m}$, durante o verão e inverno dos anos de 2009 a 2011. Sigla das amostras conforme a Tabela 1.1. 

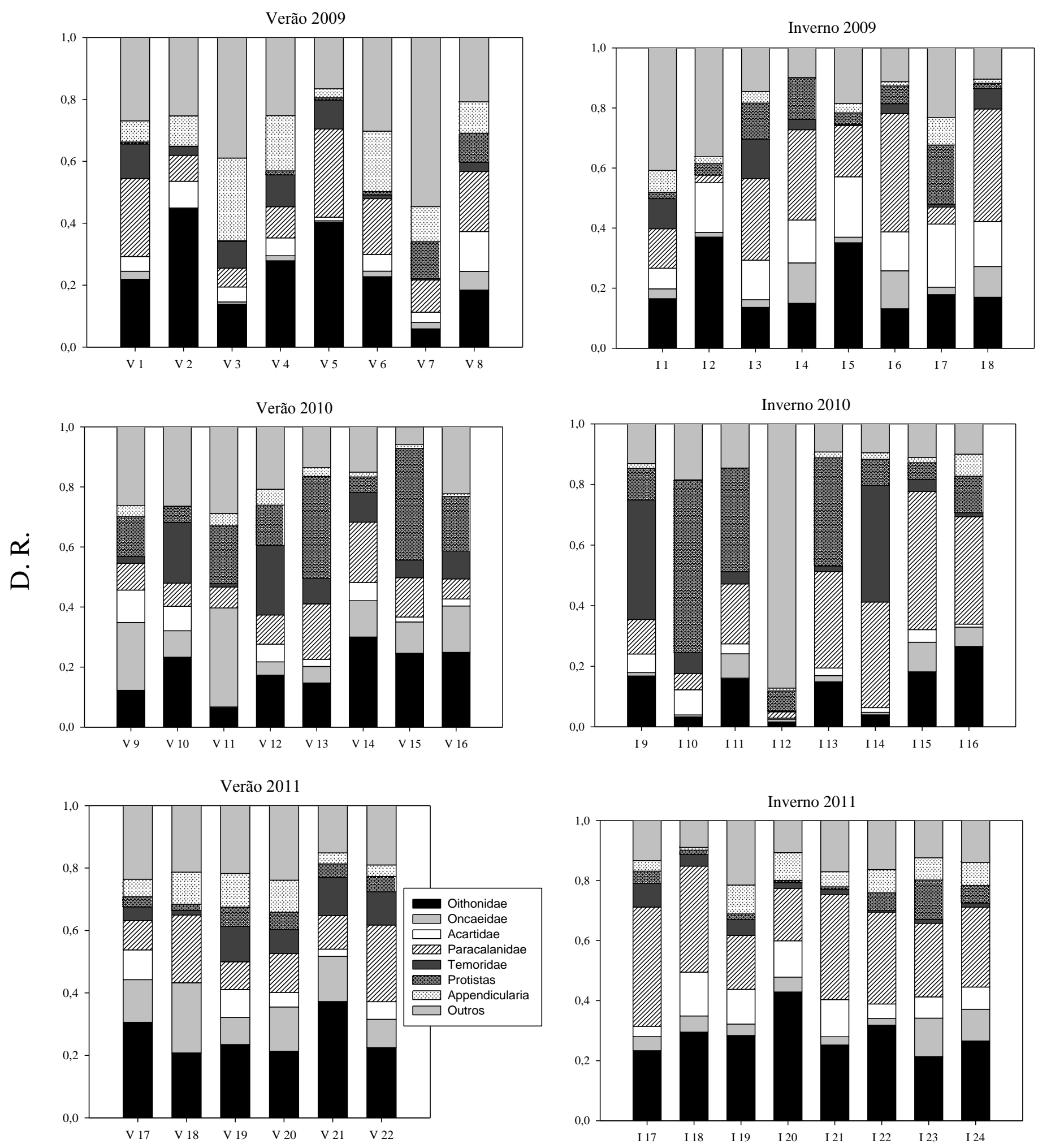

Figura 1.11: Densidade relativa dos principais grupos do holoplâncton, para as amostras da rede de 20 $\mu \mathrm{m}$ durante o verão e inverno de 2009 a 2011. Sigla das amostras conforme a Tabela 1.1. 

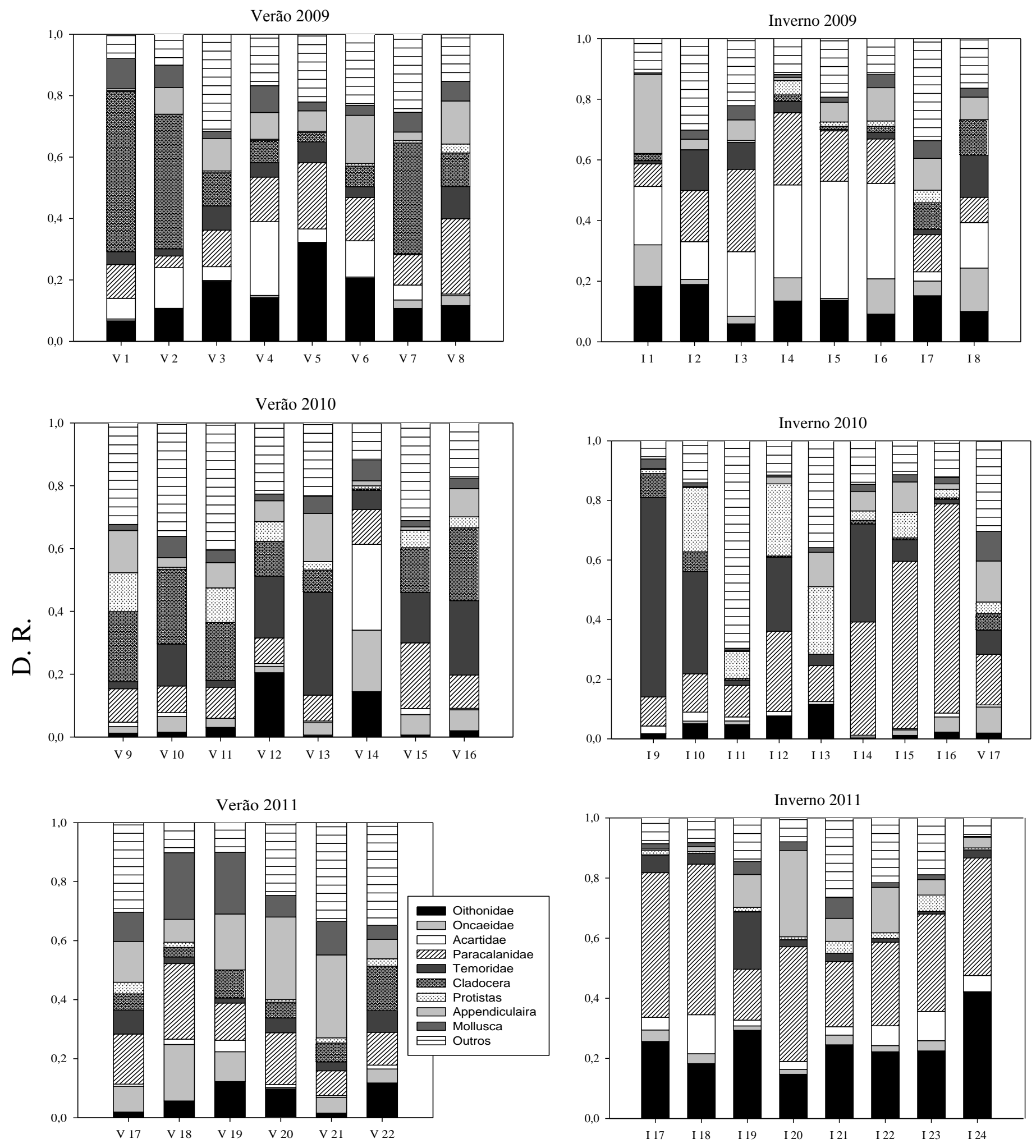

Figura 1.12: Densidade relativa dos principais grupos do holoplâncton, para as amostras da rede de $100 \mu \mathrm{m}$ durante o verão e inverno dos anos de 2009 a 2011. Sigla das amostras conforme a Tabela 1.1. 


\subsubsection{Comparação dos valores de densidade do zooplâncton e de estágios de desenvolvimento para as principais espécies de copépodes entre as malhas utilizadas}

Valores maiores de densidade foram registrados para a fração menor do zooplâncton, quando comparado à fração maior. Entretanto, diferenças entre as densidades do plâncton total, holo- e meroplâncton não foram detectadas entre as duas redes. Diferenças foram encontradas entre as densidades dos náuplios e entre os copépodes totais (soma de todos os estágios de desenvolvimento), sendo que a abundância foi mais elevada para a rede de $20 \mu \mathrm{m}$ em ambas as ocasiões (Tabela 1.9). A densidade dos estágios de copepoditos e adultos foram semelhantes entre as duas malhas.

As densidades totais para as espécies ou gêneros dominantes de copépodes foram registradas para todo o período amostral, através da média, desvio-padrão e mediana, obtidos durante as estações de verão e inverno dos anos de 2009 a 2011 e para ambas as redes utilizadas (Tabela 1.9). Os dados de densidade relativa por estágio de desenvolvimento (náuplios, copepoditos e adultos) também foram disponibilizados (Tabelas 1.10 e 1.11).

Tabela 1.9: Média (M), desvio-padrão (D.P.) e mediana da densidade dos grupos do zooplâncton para as malhas de 20 e $100 \mu \mathrm{m}$. Valores de $p$ do teste de Mann-Whitney para comparação entre as malhas. Em negrito: $p<0,05$; em itálico: $p<0,001$.

\begin{tabular}{|c|c|c|c|c|c|}
\hline Grupo & $\begin{array}{c}\text { M. e D.P. } \\
20 \mu \mathrm{m}\end{array}$ & $\begin{array}{c}\text { Mediana } \\
20 \mu \mathrm{m}\end{array}$ & $\begin{array}{c}\text { M. e D.P. } \\
100 \mu \mathrm{m}\end{array}$ & $\begin{array}{c}\text { Mediana } \\
100 \mu \mathrm{m}\end{array}$ & $p$ \\
\hline Zooplâncton total & $\overline{15.449 \pm 17.698}$ & 8.906 & $9.291 \pm 10.902$ & 5.209 & 0,099 \\
\hline Holoplâncton & $14.113 \pm 15.897$ & 7.960 & $8.365 \pm 10.026$ & 5.009 & 0,074 \\
\hline Meroplâncton & $1.210 \pm 2.320$ & 390 & $868 \pm 1.248$ & 405 & 0,812 \\
\hline Copepoda total & $11.562 \pm 13.435$ & 6.055 & $6065 \pm 8011$ & 3.675 & $\mathbf{0 , 0 2 9}$ \\
\hline Náuplios & $4.044 \pm 6201$ & 1.757 & $414 \pm 457$ & 215 & $\leq 0,001$ \\
\hline Copepoditos & $4.806 \pm 5783$ & 2390 & $3.821 \pm 6.327$ & 2.006 & 0,456 \\
\hline Adultos & $2.712 \pm 3.235$ & 1.262 & $1.830 \pm 1.806$ & 1.276 & 0,561 \\
\hline
\end{tabular}

A utilização de redes com abertura de malha pequena permitiu estimar a contribuição numérica dos copépodes de pequeno porte e seus respectivos estágios juvenis. As famílias Oithonidae e Paracalanidae foram as mais abundantes entre os copépodes na maioria das ocasiões e para ambas as classes de tamanho. Os táxons mais 
abundantes para a rede de $20 \mu \mathrm{m}$ foram Oithona spp., Parvocalanus crassirostris, Acartia spp., Temora turbinata e Oncaea spp. Os mesmos táxons também foram os mais abundantes para a rede de $100 \mu \mathrm{m}$, mas em ordem diferente: Oithona spp., $T$. turbinata, Acartia spp., P. crassirostris e Oncaea spp.

Para a família Oithonidae, diversas espécies foram importantes numericamente, embora a limitada distinção taxonômica entre os estágios imaturos impossibilitou a obtenção dos dados de densidade por estágio entre Oithona hebes, O. simplex e $O$. nana, as quais foram agrupadas. Para os adultos de $O$. hebes, o inverno de 2011 foi o período de maiores densidades, atingindo o máximo de 2.714 org. $\mathrm{m}^{-3}$ para a amostra I20, malha de $20 \mu \mathrm{m}$. O. simplex também foi mais abundante durante o inverno de 2011, enquanto que $O$. nana foi menos frequente e abundante, alcançando valores mais altos durante o verão de 2009. Todos os copépodes desta família foram mais abundantes nas amostras coletadas pela rede de $20 \mu \mathrm{m}$, em relação à rede de $100 \mu \mathrm{m}$ ( $p$ $<0,001$ ) devido principalmente a densidade dos estágios naupliares.

A densidade dos estágios de desenvolvimento foi diferente, sendo que a rede de $20 \mu \mathrm{m}$ capturou maiores proporções de náuplios, enquanto que copepoditos e adultos foram coletados em ambas as redes. Apenas os copepoditos foram mais abundantes para a malha de $100 \mu \mathrm{m}$. De maneira geral, a malha de $20 \mu \mathrm{m}$ selecionou os estágios naupliares e dos copepoditos I a II, enquanto que a de $100 \mu \mathrm{m}$ selecionou os copepoditos preferencialmente, com cerca de $70 \%$ da abundância relativa desses estágios (Tabelas 1.10 e 1.11).

A espécie Dioithona oculata foi a mais abundante da família Oithonidae durante o ano de 2009, com densidades de até 8.630 org. $\mathrm{m}^{-3}$, enquanto que Oithona plumifera não teve um padrão definido de distribuição temporal. Para Oithona spp., as amostras coletadas pela rede de $20 \mu \mathrm{m}$ abrigaram densidades mais elevadas dos estágios de náuplios e copepoditos imaturos, em relação à rede de $100 \mu \mathrm{m}$. Nenhuma diferença foi encontrada quanto a captura de indivíduos adultos entre as duas redes para Oithona spp. e entre os diferentes estágios de desenvolvimento para D. oculata (Tabela 1.11).

Para Oithona plumifera, a diferença entre as categorias de desenvolvimento foram significativas entre as redes $(p<0,001)$. A comparação entre os pares confirmou a diferença entre as densidades de náuplios para as duas malhas utilizadas, assim como para os copepoditos, ambas menores para a malha de $100 \mu \mathrm{m}$ (Tabela 1.11). A malha de $20 \mu \mathrm{m}$ foi mais eficiente na captura de náuplios e copepoditos e nenhuma das redes coletou adultos em proporções mais elevadas do que os copepoditos. 
Membros da família Paracalanidae também foram numericamente dominantes para o zooplâncton em ambas as classes de tamanho. Os dados para todas as espécies foram agrupados devido à baixa resolução taxonômica (para os estágios juvenis), com exceção para Parvocalanus crassirostris, onde os dados por categoria de desenvolvimento foram obtidos. Os Paracalanidae geralmente ocorreram em densidades superiores a 1.000 org. $\mathrm{m}^{-3}$ para todo o período amostral, atingindo um máximo de 16.143 org. $\mathrm{m}^{-3}$ e média igual a $7.286 \pm 2.248$ org. $\mathrm{m}^{-3}$ durante o inverno de 2011 para a rede de $20 \mu \mathrm{m}$. Padrão semelhante foi observado para $P$. crassirostris, com maiores densidades para o mesmo período e malha (média de $4.465 \pm 1.367$ e máximo de 10.850 org. $\left.\mathrm{m}^{-3}\right)$.

A abundância de náuplios e copepoditos imaturos foi maior para as amostras da rede de $20 \mu \mathrm{m}$, em relação à rede de $100 \mu \mathrm{m}$ ( $p<0,05)$, enquanto que os adultos foram mais abundantes para a rede de $100 \mu \mathrm{m}$ para os Paracalanidae exceto Parvocalanus crassirostris $(p<0,05)$. A rede de $20 \mu \mathrm{m}$ coletou preferencialmente náuplios e copepoditos, enquanto que a rede de $100 \mu \mathrm{m}$ coletou copepoditos e adultos, com exceção de $P$. crassirostris, onde não houve seletividade da captura para os adultos. Para esta espécie, apenas a malha de $20 \mu \mathrm{m}$ capturou com eficiência os estágios naupliares (Tabela 1.11).

A espécie Clausocalanus furcatus foi frequente durante os anos de 2009 a 2011 e geralmente em densidades superiores à 150 org. $\mathrm{m}^{-3}$, estando ausente apenas em duas e dez amostras para as redes de 20 e $100 \mu \mathrm{m}$ respectivamente. Os estágios naupliares foram mais abundantes apenas para a rede de $20 \mu \mathrm{m}$. Através do teste de comparação aos pares, a rede de $20 \mu \mathrm{m}$ possivelmente selecionou náuplios, enquanto que a rede de $100 \mu \mathrm{m}$ coletou copepoditos e adultos com maior eficiência.

Dentre os Temoridae, Temora turbinata foi numericamente dominante sobre $T$. stylifera em ambas as malhas utilizadas $(p<0,001)$. O copépode $T$. turbinata foi mais abundante durante o verão de 2009 (mediana de 1.254 org. $\mathrm{m}^{-3}$, rede de $20 \mu \mathrm{m}$ ), sendo os estágios de copepoditos os mais comuns. T. stylifera esteve presente em baixas densidades, geralmente inferior a 150 org. $\mathrm{m}^{-3}$ durante os três anos e diferenças não foram encontradas entre anos ou estações. Para ambas as espécies, a densidade não foi considerada diferente entre as malhas (Tabela 1.11).

Quanto aos estágios de desenvolvimento, a densidade de náuplios e copepoditos foi considerada semelhante em ambas as espécies de Temora para a rede de $20 \mu \mathrm{m}$. Já 
para T. turbinata na rede de $100 \mu \mathrm{m}$, a abundância relativa dos copepoditos foi maior do que de náuplios e menor do que de adultos.

As espécies Acartia tonsa e A. lilljeborgii coexistiram em 34 amostras para a rede de $20 \mu \mathrm{m}$ e em 25 para a rede de $100 \mu \mathrm{m}$, sendo que a segunda sempre foi mais abundante. Valores máximos encontrados para o gênero foram de 8.883 org. $\mathrm{m}^{-3}$ para a rede de $20 \mu \mathrm{m}$ (inverno de 2011) e 6.654 org. $\mathrm{m}^{-3}$ para a rede de $100 \mu \mathrm{m}$ (verão de 2009). Os indivíduos de Acartia spp. foram agrupados em copepoditos menores (CIIII), copepoditos maiores (C IV-V) e adultos (CVI) para a análise de seletividade pelas redes.

Para a rede de $20 \mu \mathrm{m}$, os estágios dominantes de Acartia spp. foram os náuplios $(p<0,001)$, sendo que os estágios de ortonáuplio (NI-II) ocorreram exclusivamente para esta malha. As densidades dos estágios naupliares foram estaticamente maiores para as duas malhas em relação aos copepoditos. Já as amostras da rede de $100 \mu \mathrm{m}$ foram dominadas pelos estágios de copepoditos (CI-III) e posteriormente por náuplios, sendo as densidades de adultos baixa ou mesmo inexistente em diversas amostras em ambas as redes utilizadas (Tabela 1.10).

Os estágios naupliares e copepoditos juvenis da família Oncaeidae também foram agrupados, sendo disponibilizada apenas a densidade em nível específico para os adultos. Os Oncaeidae estiveram presentes em todas as amostras da rede de $20 \mu \mathrm{m}$ e ausentes em apenas uma amostra da rede de $100 \mu \mathrm{m}$. As densidades mais elevadas para o grupo ocorreram para o verão de 2010 e inverno de 2011, ambos para a rede de 20 $\mu \mathrm{m}$. Ao contrário da maioria dos outros táxons, a contribuição de estágios adultos dos Oncaeidae foi estatiscamente maior do que de outros estágios para a rede de $100 \mu \mathrm{m}$. Ainda, esses copépodes foram mais abundantes para as amostras da rede de $20 \mu \mathrm{m}$, em relação à amostragem com rede de $100 \mu \mathrm{m}$. A utilização da malha de $20 \mu \mathrm{m}$ permitiu a captura desde náuplios à adultos em proporções semelhantes, enquanto que a rede de $100 \mu \mathrm{m}$ foi mais eficiente para a captura de adultos. Entre os adultos, as espécies $O$. venusta e $O$. curta foram as mais abundantes.

As espécies da família Corycaeidae foram identificadas em nível específico para adultos e copepoditos e agrupados para os náuplios. As espécies dominantes em ordem decrescente foram: Onychocorycaeus giesbrechti, Ditrichocorycaeus amazonicus, Farranula sp. e Corycaeus speciosus. Densidades mais elevadas foram registradas para o inverno de 2011. Adultos foram menos abundantes do que demais estágios para a rede de $20 \mu \mathrm{m}$, enquanto que os copepoditos foram dominantes para a rede de $100 \mu \mathrm{m}$. 
Os náuplios corresponderam a cerca de $50 \%$ da abundância relativa para ambas as malhas.

O Calanoida Centropages velificatus esteve presente em todas as estações dos três anos amostrados e na grande maioria das amostras, porém em baixas densidades (exceto para a amostra I 22, durante o inverno de 2011, com 1.325 org.m ${ }^{-3}$ ). Para a rede de $20 \mu \mathrm{m}$, a densidade de náuplios foi estaticamente maior do que dos outros estágios, sendo que para a rede de $100 \mu \mathrm{m}$ o estágio dominante foram os copepoditos. Para a rede de $20 \mu \mathrm{m}$, mais de $60 \%$ dos indivíduos foram representados por náuplios, enquanto que na rede de $100 \mu \mathrm{m}$ quase $70 \%$ dos indivíduos foram encontrados nos estágios juvenis de copepoditos.

Tabela 1.10: Comparação entre as densidades dos estágios de desenvolvimento de Acartia spp. para as malhas de 20 e $100 \mu \mathrm{m}$, através do teste de significância de Student-Newman-Keuls entre os pares. Para as comparações foram utilizados os dados de densidade dos táxons (org. $\mathrm{m}^{-3}$ ) de todas as 46 amostras analisadas para cada rede. Em negrito: diferenças significativas. Em parênteses: densidade relativa de cada estágio de desenvolvimento (D.R., \%).

\begin{tabular}{llllllll}
\hline & & & & CI -III- & CIV-V & \\
Estágio (D.R.\%) & MN-20 & MN-100 & CI-III-20 & $\mathbf{1 0 0}$ & $\mathbf{2 0}$ & CIV-V 100 & CVI-20 \\
\hline N-20 $(\mathbf{6 1 , 2})$ & - & - & - & - & - & - & - \\
N-100 (7,5) & $<\mathbf{0 , 0 5}$ & - & - & - & - & - & - \\
CI-III-20 $(\mathbf{2 9 , 1})$ & $<\mathbf{0 , 0 5}$ & $<\mathbf{0 , 0 5}$ & - & - & - & - & - \\
CI-III-100 (78,5) & $<\mathbf{0 , 0 5}$ & $<\mathbf{0 , 0 5}$ & $<\mathbf{0 , 0 5}$ & - & - & - & - \\
CIV-V-20 (6) & $<\mathbf{0 , 0 5}$ & $<\mathbf{0 , 0 5}$ & $<\mathbf{0 , 0 5}$ & $<\mathbf{0 , 0 5}$ & - & - & - \\
CIV-V-100 (6,7) & $<\mathbf{0 , 0 5}$ & $<\mathbf{0 , 0 5}$ & $<\mathbf{0 , 0 5}$ & $<\mathbf{0 , 0 5}$ & $>0,05$ & - & - \\
CVI-20 (3,7) & $<\mathbf{0 , 0 5}$ & $<\mathbf{0 , 0 5}$ & $<\mathbf{0 , 0 5}$ & $<\mathbf{0 , 0 5}$ & $>0,05$ & $>0,05$ & - \\
CVI-100 $(\mathbf{7 , 3})$ & $<\mathbf{0 , 0 5}$ & $>0,05$ & $<\mathbf{0 , 0 5}$ & $<\mathbf{0 , 0 5}$ & $<\mathbf{0 , 0 5}$ & $<\mathbf{0 , 0 5}$ & $<\mathbf{0 , 0 5}$ \\
\hline
\end{tabular}

Subeucalanus pileatus foi um dos maiores copépodes encontrados, além de espécies raras ou esporádicas como $S$. crassus, Nannocalanus minor, Undinula vulgaris ou Pontellopsis brevis. Não houve um padrão de distribuição temporal da densidade para $S$. pileatus A abundância foi geralmente baixa, sendo que a máxima chegou a 259 org. $\mathrm{m}^{-3}$ para a amostra I 15 (inverno de 2010). A grande maioria dos indivíduos capturados em ambas as redes ocorreram nos estágios naupliares, seguidos pelos copepoditos. Adultos foram coletados esporadicamente e principalmente pela rede de $100 \mu \mathrm{m}$. Os náuplios foram mais abundantes nas amostras da rede de $20 \mu \mathrm{m}$, quando comparado com a rede de $100 \mu \mathrm{m}$ (Tabela 1.11). Já os copepoditos foram mais comuns na rede de $100 \mu \mathrm{m}$, embora não tenham ultrapassado a densidade dos náuplios. 
Pseudodiaptomus acutus esteve distribuído de maneira desigual quanto aos anos estudados: esteve ausente na maioria das amostras para o inverno de 2010 e todo o ano de 2011. Densidade maior foi detectada para o ano de 2009 em relação aos demais anos e principalmente para o verão (máxima de 792 org. $\mathrm{m}^{-3}$ ), demonstrando maior ocorrência para a estação abrigada. A rede de $20 \mu \mathrm{m}$ coletou os náuplios com maior frequência, enquanto que a rede de $100 \mu \mathrm{m}$ capturou maiores quantidades de copepoditos. As comparações aos pares não foram realizadas devido ao elevado número de ausências da espécie durante o período amostral.

Euterpina acutifrons foi coletado em densidades relativamente baixas durante todo o período amostral, geralmente abaixo de $250 \mathrm{org} . \mathrm{m}^{-3}$. A densidade desta espécie foi maior para a rede de $20 \mu \mathrm{m}$, quando comparada à rede de $100 \mu \mathrm{m}(p<0,001)$. Os náuplios foram responsáveis por cerca de $50 \%$ da abundância relativa dos estágios de desenvolvimento para a malha de $20 \mu \mathrm{m}$ e a densidade foi significativamente superior aos outros estágios. Para a malha de $100 \mu \mathrm{m}$, a diferença entre a densidade de adultos e copepoditos não foi relevante (Tabela 1.11). 
Tabela 1.11: Comparação entre as densidades dos estágios de desenvolvimento dos principais grupos taxonômicos de copépodes para as malhas de 20 e $100 \mu \mathrm{m}$, através do teste de significância de Student-Newman-Keuls entre os pares. Para as comparações foram utilizados os dados de densidade dos táxons (org. $\mathrm{m}^{-3}$ ) de todas as 46 amostras analisadas para cada rede. Em negrito: diferenças significativas. Em parênteses: densidade relativa de cada estágio de desenvolvimento (D.R., \%).

\begin{tabular}{|c|c|c|c|c|c|c|}
\hline Táxon & D.R. & $\mathrm{N}-20$ & $\mathrm{~N}-100$ & CI-V-20 & CI-V-100 & CVI-20 \\
\hline \multirow{6}{*}{ Paracalanus spp. } & $\mathrm{N}-20(77,8)$ & - & - & - & - & - \\
\hline & N-100 $(47,4)$ & $<0,05$ & - & - & - & - \\
\hline & CI-V-20 $(18,4)$ & $<0,05$ & $<0,05$ & - & - & - \\
\hline & CI-V-100 $(35,8)$ & $<0,05$ & $>0,05$ & $<0,05$ & - & - \\
\hline & CVI-20 $(3,8)$ & $<0,05$ & $<0,05$ & $<0,05$ & $<0,05$ & - \\
\hline & CVI-100 (16,8) & $<0,05$ & $>0,05$ & $<0,05$ & $>0,05$ & $<0,05$ \\
\hline \multirow{6}{*}{$\begin{array}{l}\text { Parvocalanus } \\
\text { crassirostris }\end{array}$} & N-20 (34,1) & - & - & - & - & - \\
\hline & $\mathrm{N}-100(6,3)$ & $<0,05$ & - & - & - & - \\
\hline & CI-V -20 (38,7) & $>0,05$ & $<0,05$ & - & - & - \\
\hline & CI-V-100 (36,9) & $>0,05$ & $<0,05$ & $<0,05$ & - & - \\
\hline & CVI-20 $(27,2)$ & $>0,05$ & $<0,05$ & $>0,05$ & $>0,05$ & - \\
\hline & CVI-100 $(56,8)$ & $>0,05$ & $<0,05$ & $>0,05$ & $<0,05$ & $>0,05$ \\
\hline \multirow{6}{*}{$\begin{array}{l}\text { Clausocalanus } \\
\text { furcatus }\end{array}$} & N-20 $(73,2)$ & - & - & - & - & - \\
\hline & $\mathrm{N}-100(38,4)$ & $<0,05$ & - & - & - & - \\
\hline & CI-V-20 (23,9) & $<0,05$ & $<0,05$ & - & - & - \\
\hline & CI-V-100 $(41,8)$ & $<0,05$ & $>0,05$ & $<0,05$ & - & - \\
\hline & CVI-20 $(3,3)$ & $<0,05$ & $<0,05$ & $<0,05$ & $<0,05$ & - \\
\hline & CVI-100 (19,8) & $<0,05$ & $>0,05$ & $<0,05$ & $>0,05$ & $<0,05$ \\
\hline \multirow{6}{*}{$\begin{array}{l}\text { Subeucalanus } \\
\text { pileatus }\end{array}$} & $\mathrm{N}-20(85,4)$ & - & - & - & - & - \\
\hline & $\mathrm{N}-100(55,1)$ & $<0,05$ & - & - & - & - \\
\hline & CI-V-20 (12,6) & $<0,05$ & $<0,05$ & - & - & - \\
\hline & CI-V-100 $(37,6)$ & $<0,05$ & $<0,05$ & $<0,05$ & - & - \\
\hline & CVI-20 (2) & $<0,05$ & $<0,05$ & $<0,05$ & $<0,05$ & - \\
\hline & CVI-100 $(7,3)$ & $<0,05$ & $<0,05$ & $<0,05$ & $<0,05$ & $<0,05$ \\
\hline \multirow{6}{*}{ Temora turbinata } & N-20 $(46,1)$ & - & - & - & - & - \\
\hline & N-100 $(9,1)$ & $<0,05$ & - & - & - & - \\
\hline & CI-V-20 $(39,8)$ & $>0,05$ & $<0,05$ & - & - & - \\
\hline & CI-V-100 (81,9) & $>0,05$ & $<0,05$ & $>0,05$ & - & - \\
\hline & CVI-20 $(14,1)$ & $<0,05$ & $>0,05$ & $<0,05$ & $<0,05$ & - \\
\hline & CVI-100 (9) & $<0,05$ & $>0,05$ & $<0,05$ & $<0,05$ & $>0,05$ \\
\hline
\end{tabular}


Tabela 1.11 (continuação): Comparação entre as densidades dos estágios de desenvolvimento dos principais grupos taxonômicos de copépodes para as malhas de 20 e $100 \mu \mathrm{m}$, através do teste de significância de Student-Newman-Keuls entre os pares. Para as comparações foram utilizados os dados de densidade dos táxons (org. $\mathrm{m}^{-3}$ ) de todas as 46 amostras analisadas para cada rede. Em negrito: diferenças significativas. Em parênteses: densidade relativa de cada estágio de desenvolvimento (D.R., \%).

\begin{tabular}{|c|c|c|c|c|c|c|}
\hline Táxon & D.R. & $\mathrm{N}-20$ & $\mathrm{~N}-100$ & C I-V-20 & C I-V-100 & CVI-20 \\
\hline \multirow{6}{*}{ T. stylifera } & $\mathrm{N}-20(46,1)$ & - & - & - & - & - \\
\hline & $\mathrm{N}-100(15,6)$ & $<0,05$ & - & - & - & - \\
\hline & C I-V-20 $(39,8)$ & $>0,05$ & $<0,05$ & - & - & - \\
\hline & C I-V-100 (71) & $<0,05$ & $>0,05$ & $<0,05$ & - & - \\
\hline & CVI-20 $(14,1)$ & $<0,05$ & $>0,05$ & $<0,05$ & $>0,05$ & - \\
\hline & CVI-100 $(13,4)$ & $<0,05$ & $>0,05$ & $<0,05$ & $>0,05$ & $>0,05$ \\
\hline \multirow{6}{*}{$\begin{array}{l}\text { Centropages } \\
\text { velificatus }\end{array}$} & $\mathrm{N}-20(62,3)$ & - & - & - & - & - \\
\hline & N-100 $(14,9)$ & $<0,05$ & - & - & - & - \\
\hline & C I-V-20 $(7,1)$ & $<0,05$ & $>0,05$ & - & - & - \\
\hline & C I-V-100 (66,7) & $<0,05$ & $<0,05$ & $<0,05$ & - & - \\
\hline & CVI-20 (30,6) & $<0,05$ & $<0,05$ & $<0,05$ & $<0,05$ & - \\
\hline & CVI-100 $(18,4)$ & $<0,05$ & $>0,05$ & $>0,05$ & $<0,05$ & $<0,05$ \\
\hline \multirow{6}{*}{ Corycaeidae } & $\mathrm{N}-20(46,2)$ & - & - & - & - & - \\
\hline & N-100 $(5,1)$ & $<0,05$ & - & - & - & - \\
\hline & C I-V-20 $(39,4)$ & $>0,05$ & $<0,05$ & - & - & - \\
\hline & C I-V-100 (64) & $<0,05$ & $<0,05$ & $<0,05$ & - & - \\
\hline & CVI-20 $(14,5)$ & $<0,05$ & $<0,05$ & $<0,05$ & $<0,05$ & - \\
\hline & CVI-100 (30,9) & $>0,05$ & $<0,05$ & $>0,05$ & $<0,05$ & $<0,05$ \\
\hline \multirow{6}{*}{ Oncaeidae } & $\mathrm{N}-20(35,2)$ & - & - & - & - & - \\
\hline & N-100 $(1,5)$ & $<0,05$ & - & - & - & - \\
\hline & C I-V-20 (31,2) & $>0,05$ & $<0,05$ & - & - & - \\
\hline & C I-V-100 $(23,3)$ & $<0,05$ & $<0,05$ & $<0,05$ & - & - \\
\hline & CVI-20 $(33,6)$ & $>0,05$ & $<0,05$ & $>0,05$ & $<0,05$ & - \\
\hline & CVI-100 (75,3) & $>0,05$ & $>0,05$ & $>0,05$ & $>0,05$ & $>0,05$ \\
\hline \multirow{6}{*}{ Oithona spp. } & $\mathrm{N}-20(45,9)$ & - & - & - & - & - \\
\hline & $\mathrm{N}-100(2,9)$ & $<0,05$ & - & - & - & - \\
\hline & C I-V-20 $(38,5)$ & $>0,05$ & $<0,05$ & - & - & - \\
\hline & C I-V-100 $(68,7)$ & $<0,05$ & $<0,05$ & $<0,05$ & - & - \\
\hline & CVI-20 $(15,6)$ & $<0,05$ & $<0,05$ & $<0,05$ & $>0,05$ & - \\
\hline & CVI-100 $(28,4)$ & $<0,05$ & $<0,05$ & $<0,05$ & $>0,05$ & $>0,05$ \\
\hline
\end{tabular}


Tabela 1.11 (continuação): Comparação entre as densidades dos estágios de desenvolvimento dos principais grupos taxonômicos de copépodes para as malhas de 20 e $100 \mu \mathrm{m}$, através do teste de significância de Student-Newman-Keuls entre os pares. Para as comparações foram utilizados os dados de densidade dos táxons (org. $\mathrm{m}^{-3}$ ) de todas as 46 amostras analisadas para cada rede. Em negrito: diferenças significativas. Em parênteses: densidade relativa média de cada estágio de desenvolvimento (D.R., \%).

\begin{tabular}{|c|c|c|c|c|c|c|}
\hline Táxon & D.R. & $\mathrm{N}-20$ & $\mathrm{~N}-100$ & C I-V-20 & C I-V-100 & CVI-20 \\
\hline \multirow{6}{*}{ O. plumifera } & $\mathrm{N}-20(17,8)$ & - & - & - & - & - \\
\hline & $\mathrm{N}-100(13,2)$ & $<0,05$ & - & - & - & - \\
\hline & C I-V-20 (70,6) & $>0,05$ & $<0,05$ & - & - & - \\
\hline & C I-V-100 (59,2) & $>0,05$ & $<0,05$ & $<0,05$ & - & - \\
\hline & CVI-20 (11,5) & $>0,05$ & $<0,05$ & $>0,05$ & $>0,05$ & - \\
\hline & CVI-100 $(27,6)$ & $>0,05$ & $<0,05$ & $>0,05$ & $>0,05$ & $>0,05$ \\
\hline \multirow{6}{*}{$\begin{array}{l}\text { Euterpina } \\
\text { acutifrons }\end{array}$} & $\mathrm{N}-20(48,4)$ & - & - & - & - & - \\
\hline & N-100 (11) & $<0,05$ & - & - & - & - \\
\hline & C I-V-20 $(28,8)$ & $<0,05$ & $<0,05$ & - & - & - \\
\hline & C I-V-100 $(41,5)$ & $<0,05$ & $<0,05$ & $>0,05$ & - & - \\
\hline & CVI-20 (22,8) & $<0,05$ & $<0,05$ & $>0,05$ & $>0,05$ & - \\
\hline & CVI-100 $(47,4)$ & $>0,05$ & $<0,05$ & $>0,05$ & $>0,05$ & $>0,05$ \\
\hline
\end{tabular}

\subsubsection{Correlação entre variáveis bióticas e abióticas}

A correlação entre as variáveis ambientais estudadas (temperatura, salinidade, precipitação, concentração de clorofila- $a$ e feopigmentos) e a densidade de grupos funcionais ou taxonômicos do zooplâncton (meroplâncton, copépodes, cladóceros e apendiculários) foi obtida através do teste de Spearman. Os blocos de dados foram analisados isoladamente para cada uma das redes: 20 e $100 \mu \mathrm{m}$, uma vez que diferenças significativas foram notadas para esse fator (Tabelas 1.12 e 1.13).

A salinidade e a precipitação apresentaram correlação negativa durante o período amostrado. As correlações negativas entre a temperatura e concentrações de clorofila- $a$ e feopigmentos estiveram de acordo com os valores maiores desses pigmentos durante o inverno, em relação ao verão (Figuras 1.2 e 1.3).

Correlação positiva foi registrada entre as densidades de copépodes e meroplâncton. A densidade dos copépodes foi positivamente correlacionada com a 
concentração de feopigmentos, mas apenas para a rede de $100 \mu \mathrm{m}$. (Tabelas 1.12 e $1.13)$.

Os cladóceros estiveram positivamente correlacionados com a temperatura e negativamente correlacionados à salinidade em ambas as malhas. Para a rede de $20 \mu \mathrm{m}$, correlações negativas também foram detectadas entre a densidade de cladóceros e as concentrações de clorofila- $a$ e feopigmentos. Já as densidades de apendiculários foram positivamente correlacionadas com as densidades do meroplâncton e cladóceros nas duas malhas utilizadas (Tabelas 1.12 e 1.13).

Tabela 1.12: Coeficientes de correlação de Spearman entre as variáveis ambientais e densidades dos principais grupos taxonômicos e funcionais para as amostras coletadas pela rede de $\mathbf{2 0} \boldsymbol{\mu m}$. Valores significativos para $p<\mathbf{0 , 0 5} \mathbf{~ e m ~ n e g r i t o ; ~} p<0,01$ em itálico.

\begin{tabular}{|c|c|c|c|c|c|c|c|c|}
\hline Variáveis & 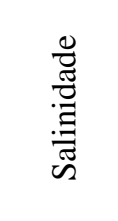 & 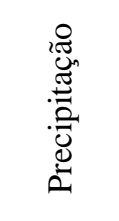 & 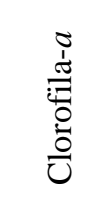 & 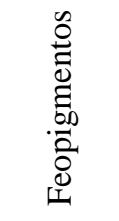 & 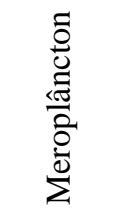 & 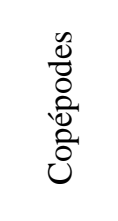 & 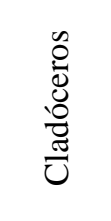 & 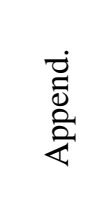 \\
\hline Temperatura & $-0,374$ & 0,121 & $\underline{-0,677}$ & $\underline{-0,793}$ & $-0,123$ & $-0,170$ & $\underline{0,683}$ & 0,005 \\
\hline Salinidade & - & $-0,296$ & 0,04 & 0,132 & 0,120 & 0,08 & $-0,339$ & 0,045 \\
\hline Precipitação & - & - & $-0,08$ & 0,044 & $-0,043$ & $-0,008$ & 0,274 & 0,153 \\
\hline Clorofila- $a$ & - & - & - & $\underline{0,867}$ & $-0,089$ & 0,005 & $-0,360$ & $-0,276$ \\
\hline Feopigmentos & - & - & - & - & 0,101 & 0,174 & $\underline{-0,425}$ & $-0,079$ \\
\hline Meroplâncton. & - & - & - & - & - & $\underline{0,838}$ & 0,131 & $\underline{0,740}$ \\
\hline Copépodes & - & - & - & - & - & - & 0,102 & $\underline{0,657}$ \\
\hline Cladóceros & - & - & - & - & - & - & - & 0,206 \\
\hline Apendiculários & - & - & - & - & - & - & - & - \\
\hline
\end{tabular}


Tabela 1.13: Coeficientes de correlação de Spearman entre as variáveis ambientais e densidades dos principais grupos taxonômicos e funcionais para as amostras coletadas pela rede de $\mathbf{1 0 0} \boldsymbol{\mu m}$. Valores significativos para $\boldsymbol{p}<\mathbf{0 , 0 5} \mathbf{~ e m}$ negrito; $\underline{p<0,01 \text { em itálico. }}$.

\begin{tabular}{|c|c|c|c|c|c|c|c|c|}
\hline Variáveis & 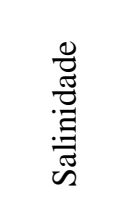 & 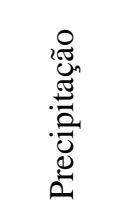 & 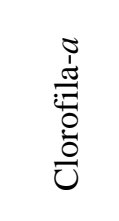 & 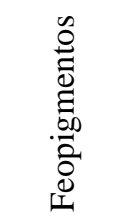 & 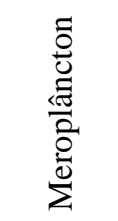 & 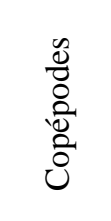 & 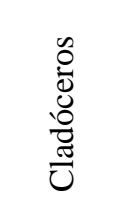 & 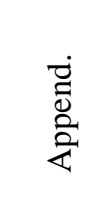 \\
\hline Temperatura & $-0,374$ & 0,121 & $\underline{-0,677}$ & $\underline{-0,793}$ & 0,144 & $-0,138$ & $\underline{0,564}$ & 0,124 \\
\hline Salinidade & - & $-0,296$ & 0,04 & 0,132 & $-0,225$ & 0,056 & $\underline{-0,416}$ & $-0,075$ \\
\hline Precipitação & - & - & $-0,08$ & 0,044 & 0,227 & 0,108 & 0,298 & 0,177 \\
\hline Clorofila- $a$ & - & - & - & $\underline{0,867}$ & $-0,119$ & 0,105 & $-0,252$ & $-0,231$ \\
\hline Feopigmentos & - & - & - & - & 0,039 & $\underline{0,387}$ & $-0,226$ & $-0,108$ \\
\hline Meroplâncton & - & - & - & - & - & $\underline{0,562}$ & $\underline{0,446}$ & $\underline{0,502}$ \\
\hline Copépodes & - & - & - & - & - & - & 0,206 & 0,345 \\
\hline Cladóceros & - & - & - & - & - & - & - & 0,198 \\
\hline Apendiculários & - & - & - & - & - & - & - & - \\
\hline
\end{tabular}

\subsubsection{Análises multivariadas}

\subsection{Análise de variância PERMANOVA}

Através da análise de PERMANOVA, utilizando a matriz de densidade das espécies de copépodes e cladóceros e como fatores da análise os anos de coleta, estações do ano e tamanho de malhas utilizadas. Resultados significativos foram encontrados apenas para a interação entre as estações e anos de coleta (Tabela 1.14). A interação entre os fatores estação e malha, não contribuiram para a variabilidade da densidade dos táxons analisados de copépodes e cladóceros. Apenas o fator ano resultou em valores de $p<0,01$ entre todos os anos analisados isoladamente (combinações 2009 x 2010; 2009 x 2011 e 2010 x 2011).

Os testes a posteriori para a interação estação x ano foram realizados, isolando as estações para verificar a variabilidade entre os anos (Tabela 1.15) e também isolando o fator ano para visualizar a variabilidade entre verão e inverno (Tabela 1.16). A variabilidade sazonal da densidade das espécies analisadas foi detectada em todos os anos $(p<0,01)$. Entre as estações de inverno, a variabilidade foi significativa para todas 
as combinações testadas. Já para as estações de verão, não foi detectada a variabilidade entre os anos de 2010 e 2011 (Tabela 1.16).

Tabela 1.14: Valores de $p$ da análise de PERMANOVA e permutação de Monte Carlo entre os fatores selecionados. Est.: estação; M.: malha; d.f.: graus de liberdade; S.S.: soma dos quadrados; M.S.: média dos quadrados; $F$ : teste de Fisher.

\begin{tabular}{lcccccc}
\hline \multicolumn{1}{c}{ Fatores } & d.f. & S.S. & M.S. & $\boldsymbol{F}$ & PERMANOVA & Monte Carlo \\
\hline Estação & 1 & $6.745,38$ & $6.745,38$ & 3,59 & $\mathbf{0 , 0 1 8 0}$ & $\underline{0,0054}$ \\
Malha & 1 & $3.748,13$ & $3.748,13$ & 3,92 & $\mathbf{0 , 0 3 4 0}$ & $\underline{0,0034}$ \\
Ano & 2 & $12.614,1$ & $6.307,05$ & 8,70 & $\underline{0,0002}$ & $\underline{0,0002}$ \\
Estação x Malha & 1 & 524,012 & 524,02 & 0,53 & 0,8166 & 0,8742 \\
Estação x Ano & 2 & $3.752,48$ & $1.876,24$ & 2,59 & $\underline{0,0002}$ & $\underline{0,0008}$ \\
Malha x Ano & 2 & $1.911,67$ & 955,83 & 1,32 & 0,1356 & 0,1532 \\
Estação x Malha x Ano & 2 & $1.993,34$ & 996,67 & 1,37 & 0,1004 & 0,1226 \\
\hline
\end{tabular}

Tabela 1.15: Valores de $p$ da análise de PERMANOVA e permutação de Monte Carlo para a interação entre as estações e ano de coleta. Resultados dos testes entre os níveis de estação (verão $\mathrm{x}$ inverno) para cada ano de coleta.

\begin{tabular}{lcc}
\hline Ano & $\boldsymbol{p}($ PERMANOVA) & $\boldsymbol{p}$ (Monte Carlo) \\
\hline $\mathbf{2 0 0 9}$ & 0,001 & 0,001 \\
$\mathbf{2 0 1 0}$ & 0,001 & 0,002 \\
$\mathbf{2 0 1 1}$ & 0,001 & 0,001 \\
\hline
\end{tabular}

Tabela 1.16: Valores de $p$ da análise de PERMANOVA e permutação de Monte Carlo para a interação entre as estações e ano de coleta. Resultados dos testes entre os níveis do fator ano (2009 x 2010 x 2011) para cada estação analisada.

\begin{tabular}{cccc}
\hline Estação & & $\boldsymbol{p}($ PERMANOVA) & $\boldsymbol{p}$ (Monte Carlo) \\
\hline \multirow{3}{*}{ Inverno } & $\mathbf{2 0 0 9} \times \mathbf{2 0 1 0}$ & 0,001 & 0,001 \\
& $\mathbf{2 0 0 9} \times \mathbf{2 0 1 1}$ & 0,001 & 0,001 \\
& $\mathbf{2 0 1 0} \times \mathbf{2 0 1 1}$ & 0,001 & 0,002 \\
\multirow{2}{*}{ Verã } & $\mathbf{2 0 0 9} \times \mathbf{2 0 1 0}$ & 0,001 & 0,001 \\
& $\mathbf{2 0 0 9} \times \mathbf{2 0 1 1}$ & 0,001 & 0,001 \\
& $\mathbf{2 0 1 0} \times \mathbf{2 0 1 1}$ & 0,063 & 0,105 \\
\hline
\end{tabular}

A variabilidade da distribuição dos microcrustáceos estudados parece estar fortemente relacionada com a variação temporal, principalmente com a interação entre os efeitos da variabilidade anual e sazonal (Tabelas 1.14 a 1.16). 


\subsection{Análise de componentes principais $(P C A)$}

Optou-se por executar a análise de componentes principais com as variáveis ambientais como ativas e a densidades dos grupos mais frequentes do zooplâncton como variáveis suplementares e para cada uma das redes empregadas separadamente. Os dois principais eixos da análise explicaram 55,5\% da contribuição relativa das variáveis ambientais para a distribuição temporal dos grupos zooplanctônicos.

A temperatura foi a principal variável afetando a estrutura temporal do plâncton e para os dois principais eixos da análise. O eixo 1 (36,2\%) é formado principalmente pelas contribuições principais das concentrações de clorofila- $a$ e feopigmentos, além da temperatura. Já o eixo 2 (19,3\%) é parcialmente formado pela precipitação e salinidade e menor grau pela temperatura (Figuras 1.13 e 1.14).

Os cladóceros e copépodes da família Paracalanidae (exceto Parvocalanus crassirostris) estiveram relacionados ao eixo 1, representado por maiores temperaturas e menores concentrações de clorofila- $a$ e feopigmentos. Já um grupo de organismos (medusas da classe Hydrozoa, Temora turbinata, T. stylifera e larvas de gastrópodes para a rede de $20 \mu \mathrm{m}$, com adição de Tintinnina, cladóceros e copépodes da ordem Harpacticoida para a fração maior do zooplâncton) esteve possivelmente relacionado ao eixo 2, apresentando maiores densidades em períodos de menores valores de salinidade e maior precipitação. 


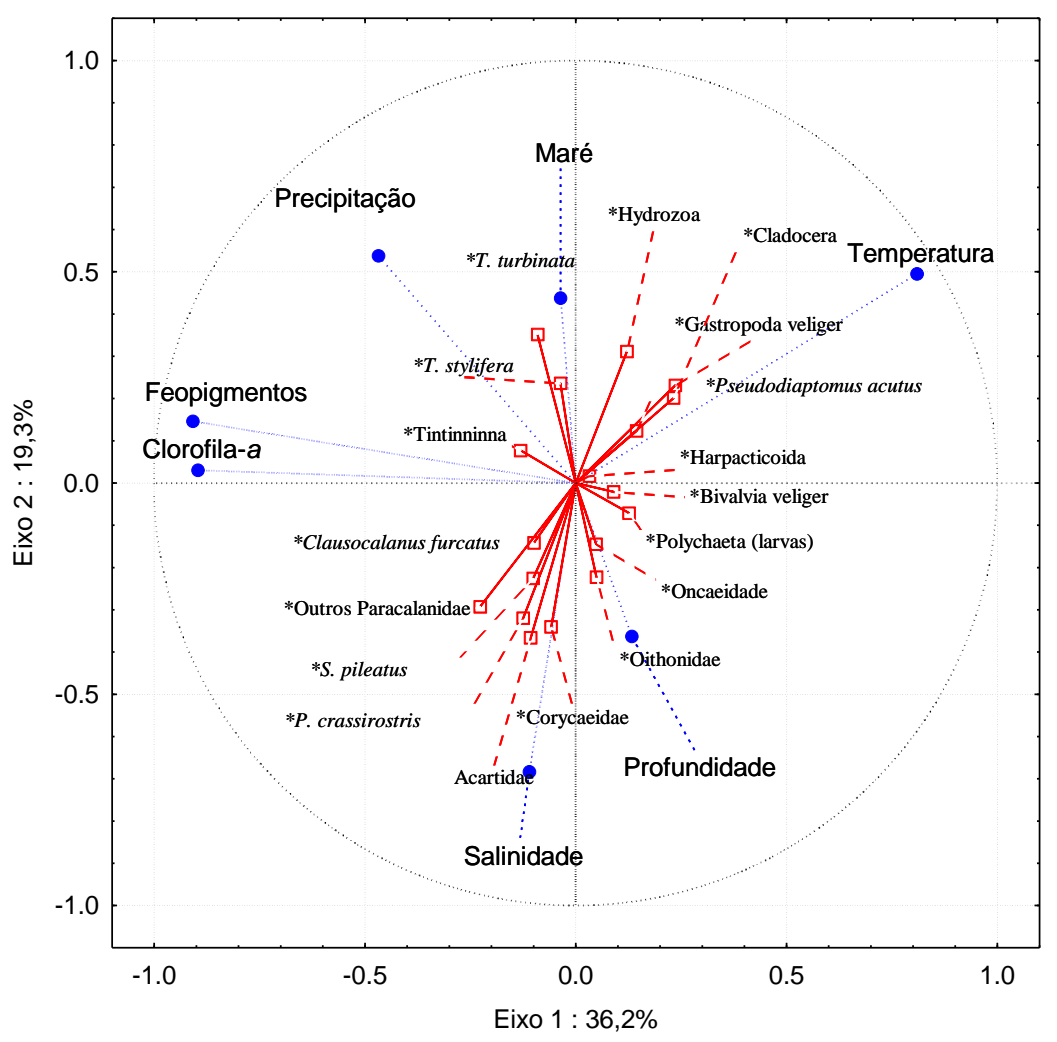

Figura 1.13: Análise de componentes principais utilizando as variáveis ambientais como fatores ativos e densidade dos principais grupos do zooplâncton como variáveis suplementares para a rede de $20 \mu \mathrm{m}$.

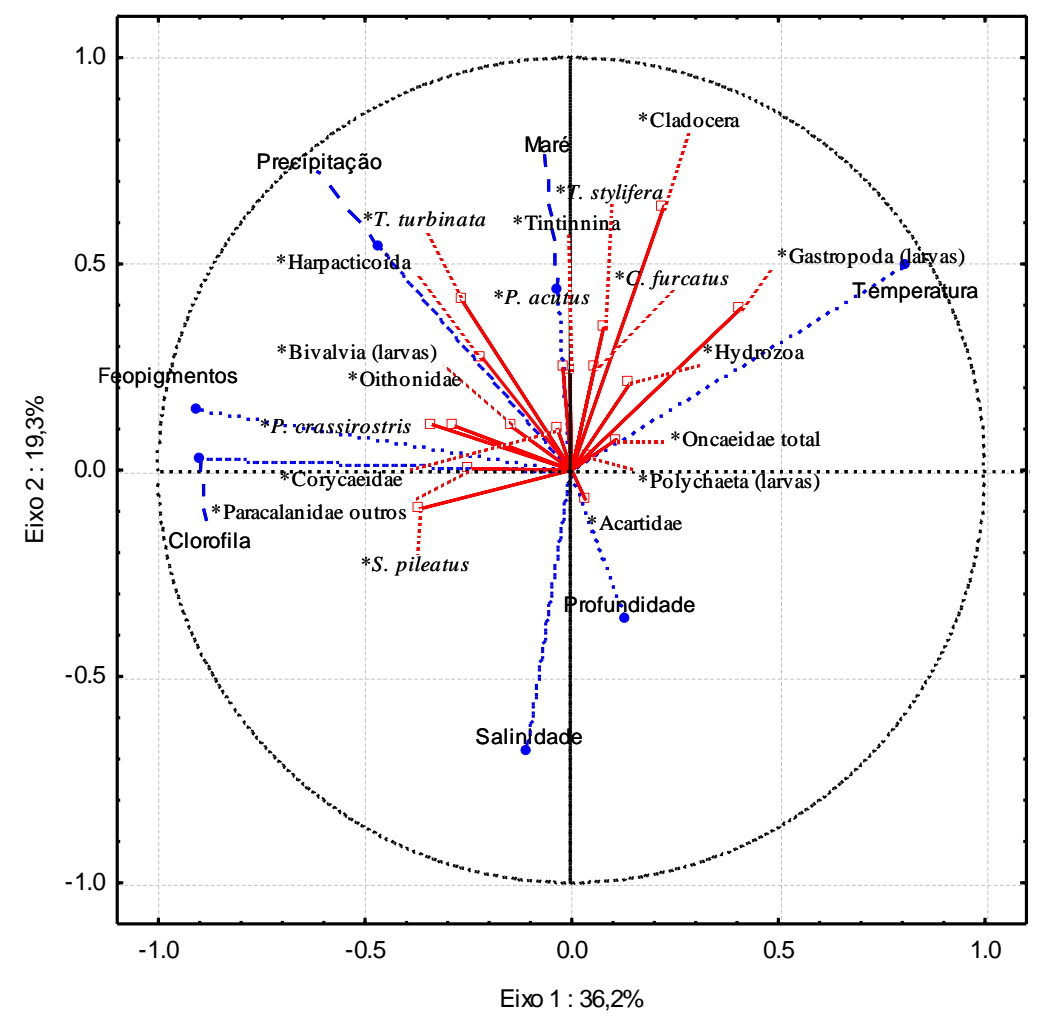

Figura 1.14: Análise de componentes principais utilizando as variáveis ambientais como fatores ativos e densidade dos principais grupos do zooplâncton como variáveis suplementares para a rede de $100 \mu \mathrm{m}$. 


\subsection{Ordenação de escalonamento multidimensional não métrico (MDS)}

As análises multivariadas $M D S$ e SIMPER foram realizadas separadamente para as duas classes de tamanho do plâncton estudadas: 20 e $100 \mu \mathrm{m}$. As análises de $M D S$ foram realizadas no espaço bidimensional. Para amostragem realizada pela rede de 20 $\mu \mathrm{m}$, o $M D S$ permitiu visualizar a distribuição das amostras em poucos grupos: as estações I 12, 14 e 16, o grupo V 9, 11 e 18, as amostras I 10 e V 07 isoladamente e todas as outras amostras em um grupo principal. Tais grupos foram formados pela análise de cluster e plotados sobre o MDS (linhas escuras).

Utilizando o fator estação do ano, o $M D S$ permitiu visualizar a separação entre as amostras do verão e inverno (Figuras 1.15 e 1.18). Vale ressaltar que essa mesma distribuição das amostras entre os grupos também esteve em concordância com a temperatura, fator dividido em duas categorias: menor que 25 e maior ou igual a $25^{\circ} \mathrm{C}$ (Figuras 1.16 a e 1.19 a).

Para os anos de coleta apenas o grupo composto por I 12, 14 e 16 correspondeu às amostras de um mesmo ano e período amostral, o inverno de 2010 (Figura 1.15). O grupo V 9, 11 e 18, da mesma maneira, é formado por temperaturas superiores a $25^{\circ} \mathrm{C}$, ou seja, durante o verão. A maioria dos fatores ambientais não permitiu a distinção de grupos entre as diferentes categorias. A profundidade, porém, mostrou um padrão: todas as amostras com profundidade inferior a 5 metros foram dispostas próximas umas das outras (Figuras $1.16 \mathrm{c}$ e $1.19 \mathrm{c}$ ).

As análises de cluster plotadas sobre o $M D S$ resultaram em dois grupos de amostras para o zooplâncton da rede de $100 \mu \mathrm{m}$. A separação dos grupos de amostras não foi evidente para a malha de $20 \mu \mathrm{m}$, separando apenas amostras do inverno de 2010, verão de 2010 e uma única amostra do verão de 2009 (V 7; Figuras 1.15 e 1.18).

A densidade do zooplâncton total foi plotada sobre a análise apenas para visualização do padrão geral de distribuição (Figura 1.14 d e 1.19 d). Embora diversos táxons tenham sido testados quanto a distribuição da densidade, apenas alguns foram selecionados como exemplos de distribuição.

Os copépodes das famílias Oithonidae e Paracalanidae foram abundantes durante todo o período amostral, porém valores maiores ocorreram em amostras do verão de 
2009, inverno de 2010 e 2011. As abundâncias elevadas dessas famílias refletiram no padrão de distribuição da densidade total da fração menor do zoplâncton, onde tais táxons foram dominantes (Figuras 1.16, 1.17, 1.19 e 1.20).

Já para alguns copépodes, como o gênero Temora, padrões temporais de distribuição foram ausentes (Figura 1.17). A densidade de predadores, como os quetognátos, esteve distribuída de maneira semelhante às famílias mais abundantes de copépodes (Figuras 1.17 e 1.19). Tintinnina foram mais abundantes nos anos de $2010 \mathrm{e}$ 2011, sem um padrão entre as estações do ano. Esses protistas estiveram distribuídos preferencialmente no grupo central de amostras para o plâncton da rede de $20 \mu \mathrm{m}$ (Figura 1.16).

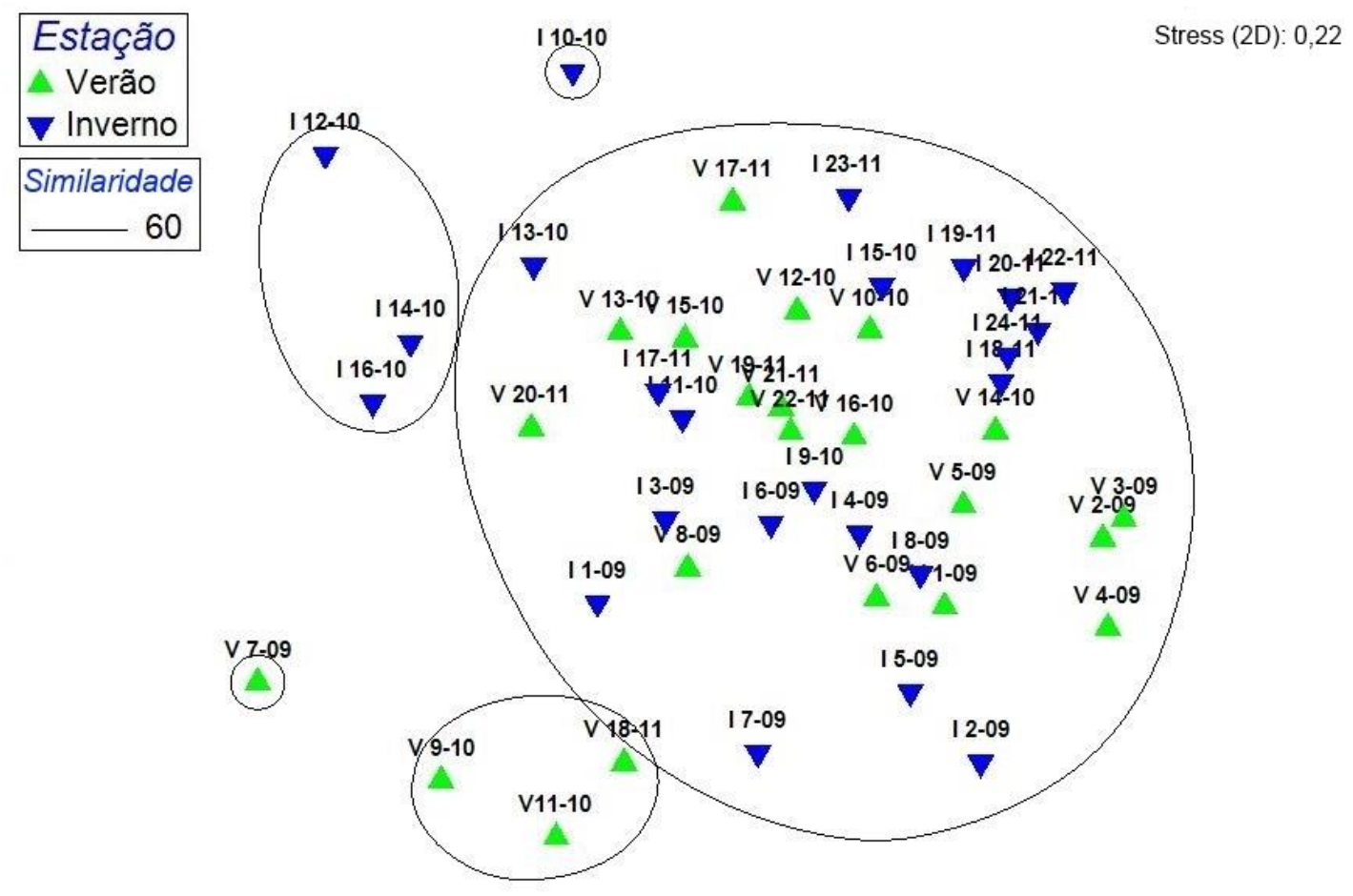

Figura 1.15: Distribuição das amostras de zooplâncton coletadas pela rede de $20 \mu \mathrm{m}$, através da análise de $M D S$. As amostras foram representadas para o fator estação do ano com duas categorias: verão e inverno. Legenda das amostras conforme Tabela 1.1. 

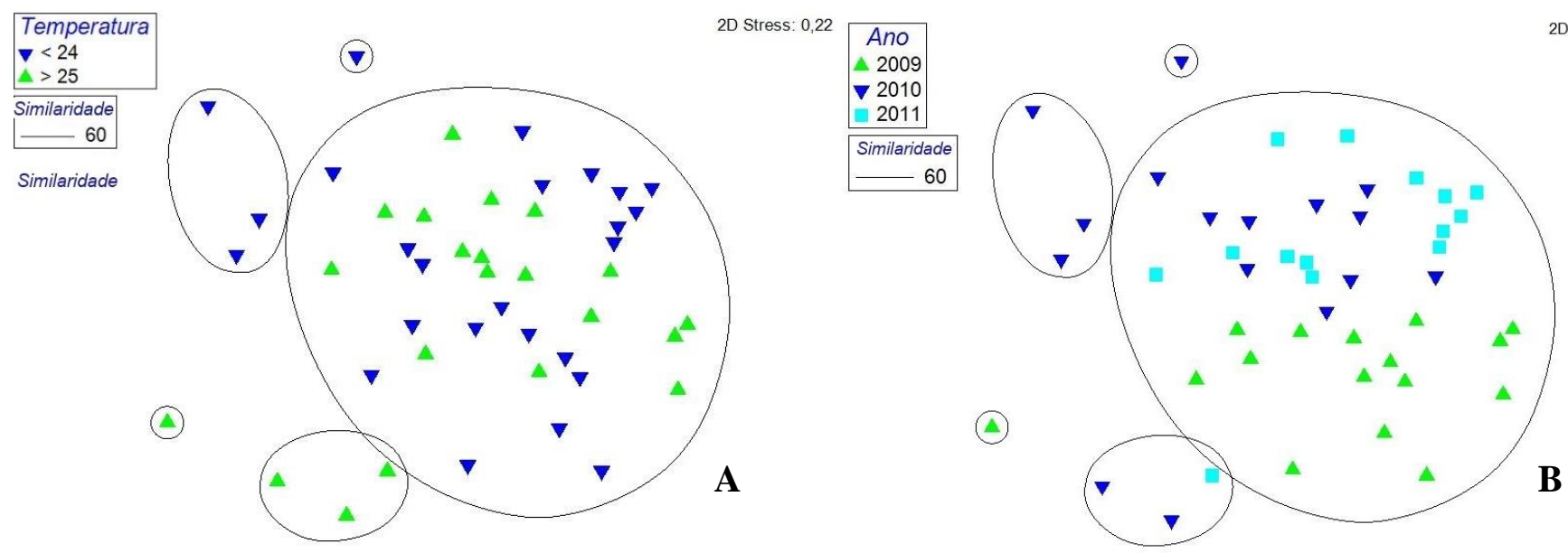

2D Stress: 0,22
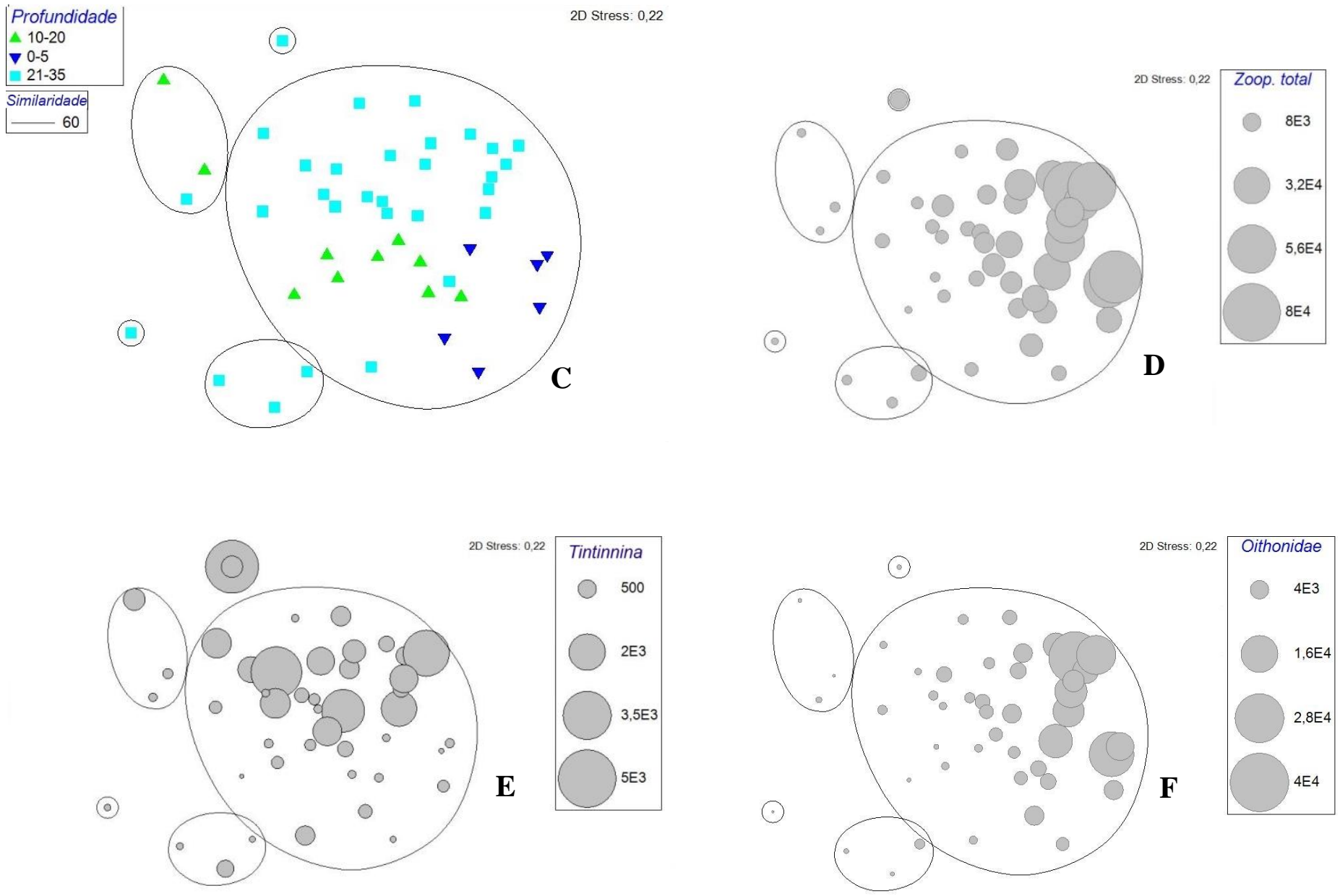

Figura 1.16: Análises de $M D S$ para o zooplâncton da rede de $20 \mu \mathrm{m}$. Ordenação das amostras por fatores ambientais (A, B e C) e distribuição da densidade (D, E e F).Temperatura: ${ }^{\circ} \mathrm{C}$; Profundidade: $\mathrm{m}$; Densidade: org. $\mathrm{m}^{-3}$. 

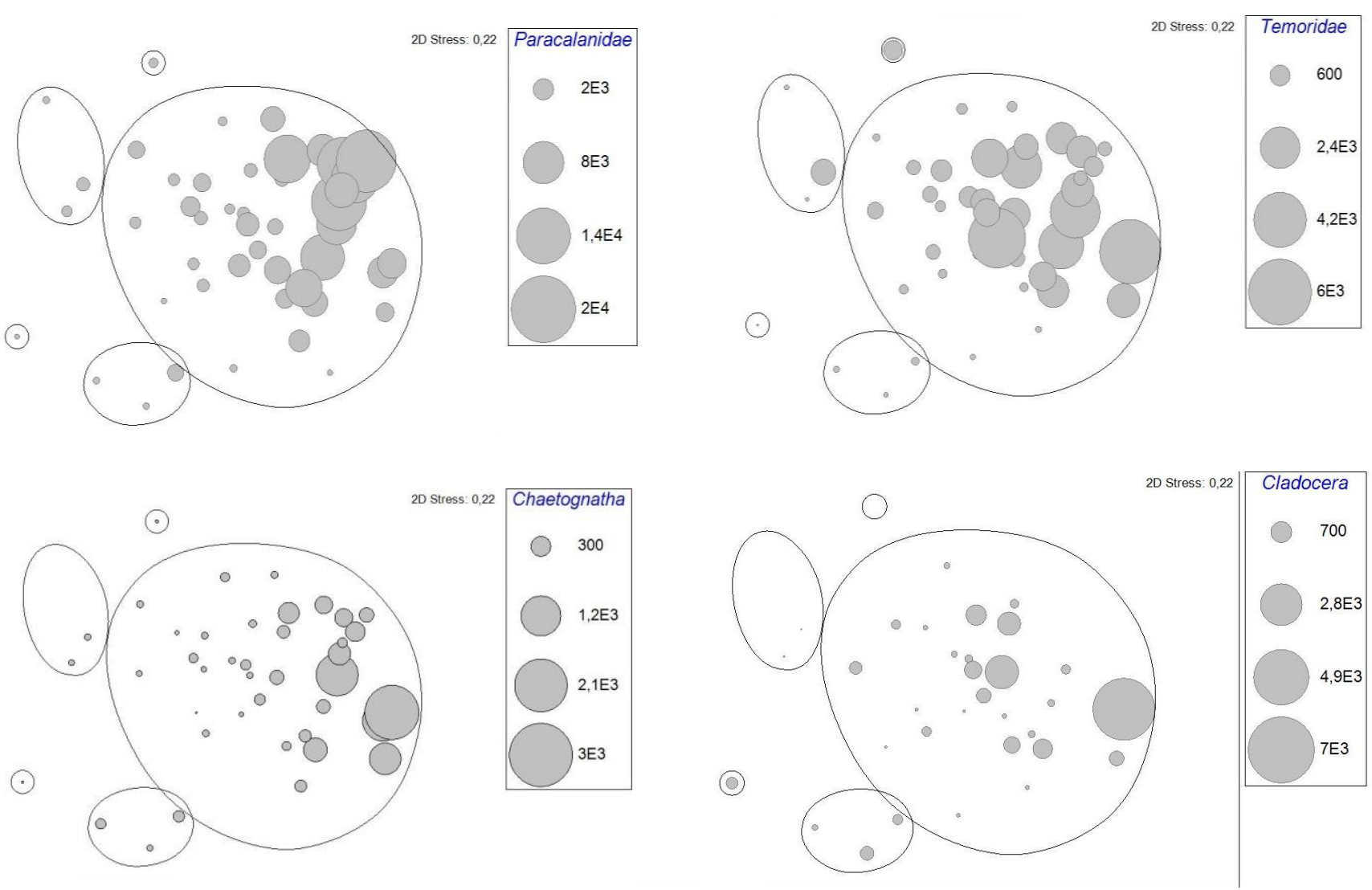

Figura 1.17: Análises de $M D S$ para o zooplâncton da rede de $20 \mu \mathrm{m}$. Distribuição da densidade para as famílias Paracalanidae, Temoridae, para o filo Chaetognatha e para os cladóceros. Categorias de densidade em org. $\mathrm{m}^{-3}$.

Uma ordenação mais concisa das amostras ocorreu para o zooplâncton da rede de $100 \mu \mathrm{m}$ através da análise de $M D S$, com a formação de dois grandes grupos. Algumas amostras pertenceram a ambos os grupos, todas correspondendo a períodos de inverno: I 1, I 4, I 7 a 9, I 18 e I 24. A separação das amostras entre o verão e o inverno e entre as categorias de temperatura foram idênticas, embora os agrupamentos formados pela análise de cluster não correspondam a esse padrão (Figuras 1.20 e 1.21 a).

O ano de coleta foi um fator importante na formação dos agrupamentos principais, pois o grupo à direita do gráfico é formado principalmente por amostras coletadas durante 2009 (Figura 1.19 b). Da mesma maneira, as amostras coletadas em profundidades rasas (inferior a 5m) também foram agrupadas em posições semelhantes (Figura 1.19 c) e correspondem, em sua maioria, às coletas realizadas em 2009. Ambos os fatores foram importantes para justificar a formação do grupo em questão, quanto a distribuição da densidade dos táxons zooplanctônicos.

Alguns táxons demonstraram maior abundância relativa durante as estações de verão, como os filtradores (cladóceros) e predadores como os quetognátos e cnidários 
pelágicos. Os táxons mais abundantes do trabalho foram responsáveis pelo padrão de distribuição do plâncton geral, exemplificado nos gráficos da rede de $20 \mu \mathrm{m}$ por Oithonidae e Paracalanidae e para a rede de $100 \mu \mathrm{m}$ por Parvocalanus crassirostris e apendiculários (Figuras 1.16 a 1.20).

Três padrões de distribuição temporal foram detectados para as espécies: i) espécies com densidades concentradas durante o ano de 2009 (Acartia spp.; Euterpina acutifrons, Dioithona oculata; Figuras 1.19 e e 1.20); ii) durante os períodos de verão (Penilia avirostris, larvas de poliquetos, quetognátos e cnidários pelágicos; Figura 1.20) e iii) táxons de distribuição esparsa (apendiculários, Parvocalanus crassirostris, Oithona hebes, O. plumifera, Temora stylifera e copépodes da família Corycaeidae e Oncaeidae; Figura 1.20).

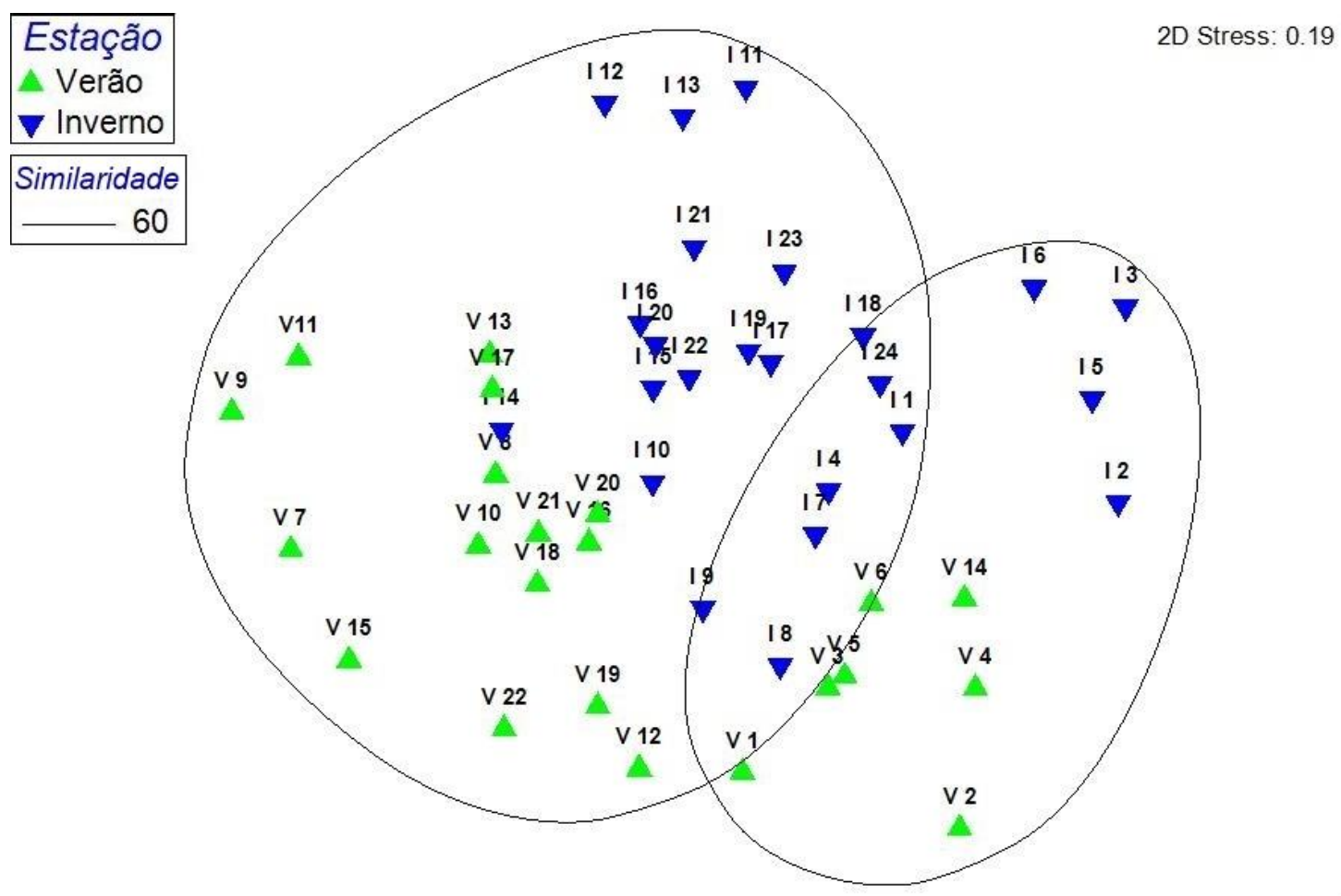

Figura 1.18: Distribuição das amostras de zooplâncton coletadas pela rede de $100 \mu \mathrm{m}$, através da análise de $M D S$. As amostras foram representadas para o fator estação do ano com duas categorias: verão e inverno. Legenda das amostras conforme Tabela 1.1. 

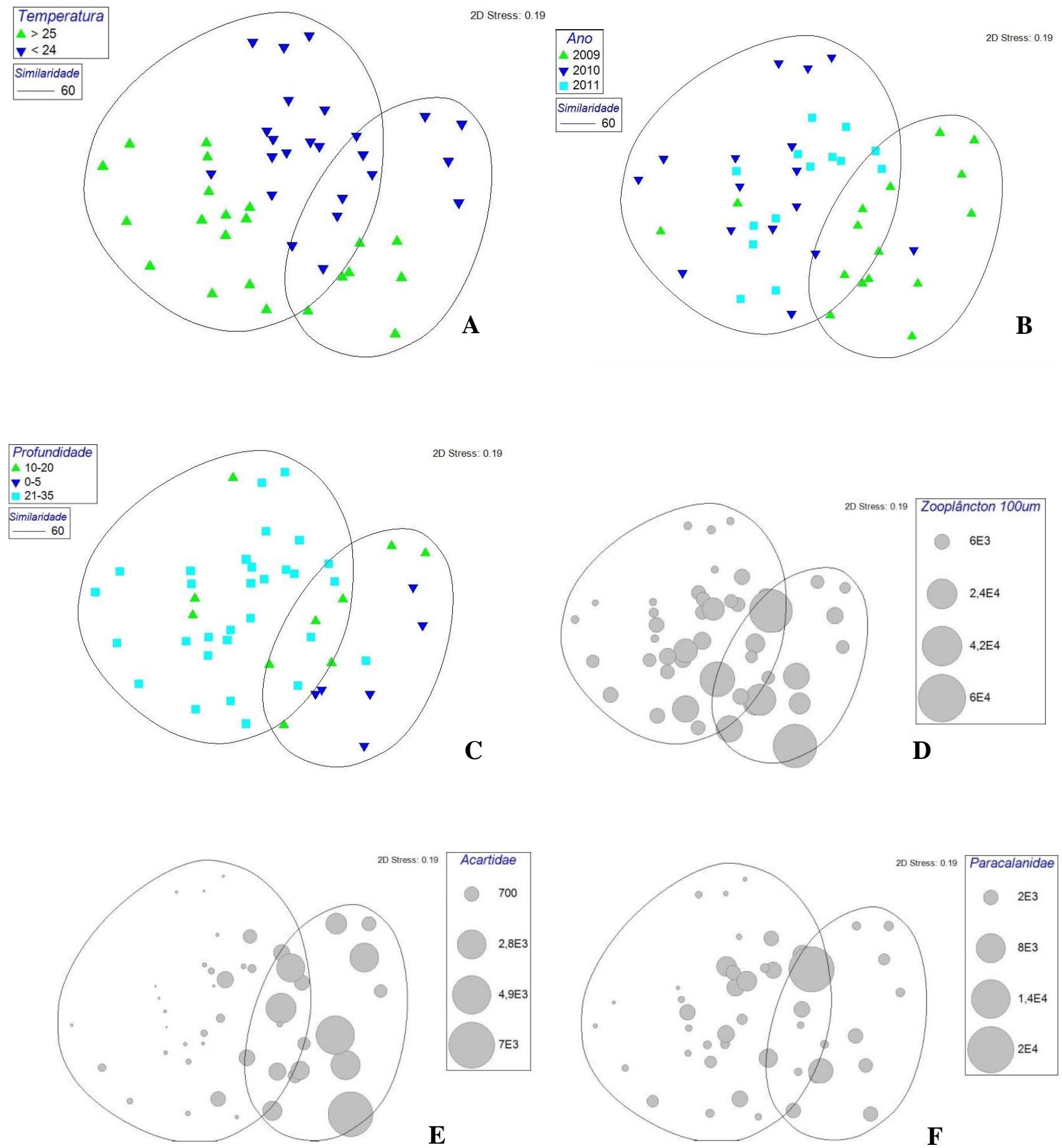

Figura 1.19: Análises de $M D S$ para o zooplâncton da rede de $100 \mu \mathrm{m}$. Ordenação das amostras por fatores ambientais (A, B e C) e distribuição da densidade (D, E e F). Temperatura: ${ }^{\circ} \mathrm{C}$; Profundidade: $\mathrm{m}$; Densidade: org. $\mathrm{m}^{-3}$. 

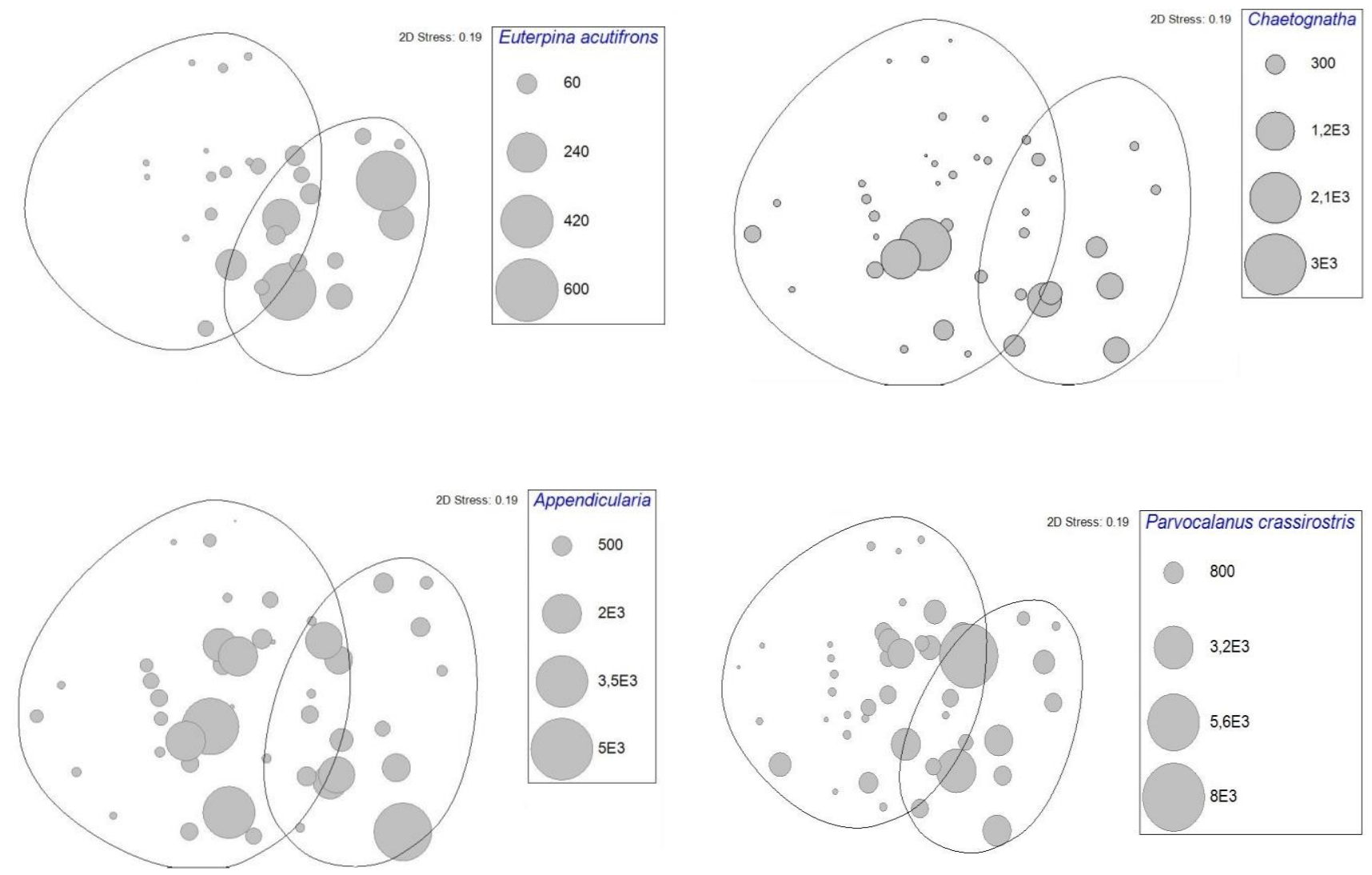

Figura 1.20: Análises de $M D S$ para o zooplâncton da rede de $100 \mu \mathrm{m}$. Distribuição da densidade para Euterpina acutifrons, o filo Chaetognatha, a classe Appendicularia e o copépode Parvocalanus crassirostris. Categorias de densidade em org. $\mathrm{m}^{-3}$.

\subsection{Contribuição específica para a dissimilaridade (SIMPER)}

A contribuição específica dos táxons para a dissimilaridade foi obtida pela análise de SIMPER. Cada teste foi realizado isoladamente para as duas classes de tamanho do zooplâncton para visualizar a contribuição dos táxons quanto a diferença entre o verão e o inverno.

As espécies que mais contribuíram para a dissimilaridade da comunidade entre o verão e inverno para a rede de $20 \mu \mathrm{m}$ (maiores contribuições específicas) foram Acartia tonsa, Penilia avirostris, Dioithona oculata e Oithona simplex (Tabela 1.17). Nenhuma espécie teve contribuição relativamente alta para a diferença entre as estações, sendo necessários 20 táxons para representar um valor superior a 50\% da contribuição 
cumulativa. Os únicos táxons considerados discriminantes $(\delta i / \mathrm{D} . \mathrm{P}>1,4)$ entre as estações do ano foram Penilia avirostris e as larvas de poliquetos para a rede de $20 \mu \mathrm{m}$.

Para a rede de $100 \mu \mathrm{m}$, os táxons responsáveis pela dissimilaridade entre as estações foram Pseudevadne tergestina, Penilia avirostris, Dioithona oculata, Oithona hebes, Clausocalanus furcatus e Temora stylifera (Tabela 1.18). Entretanto, as espécies de maior contribuição não representaram as espécies discriminantes necessariamente. Foi o caso das espécies D. oculata, O. hebes e $C$. furcatus, espécies com alta contribuição relativa e razão $\delta i$ /D.P. baixas; enquanto que Temora stylifera, Euterpina acutifrons e larvas de gastrópodes não foram táxons de maior contribuição, porém foram discriminantes ( $\delta i$ /D.P $>1,4)$.

Tabela 1.17: Abundância média, dissimilaridade média, razão dissimilaridade/desvio-padrão e contribuição (\%) das principais espécies responsáveis pela distinção entre as estações de verão e inverno da comunidade planctônica amostrada pela rede de $20 \mu \mathrm{m}$. D.R.: densidade relativa; $\delta i$ : dissimilaridade média; $\delta i$ /D.P.: razão dissimilaridade média pelo desvio padrão; Cr.: contribuição específica; Cumul.: contribuição cumulativa. Em negrito: espécies discriminantes.

\begin{tabular}{lcccccc}
\hline \multicolumn{1}{c}{ Espécie } & $\begin{array}{c}\text { D.R. } \\
\text { verão }\end{array}$ & $\begin{array}{c}\text { D.R. } \\
\text { inverno }\end{array}$ & $\boldsymbol{\delta i}$ & $\boldsymbol{\delta i}$ /D.P. & Cr. (\%) & $\begin{array}{c}\text { Cumul } \\
(\%)\end{array}$ \\
\hline Acartia tonsa & 2,03 & 4,22 & 1,41 & 1,39 & 3,64 & 3,64 \\
Penilia avirostris & 3,96 & 1,00 & 1,38 & $\mathbf{1 , 4 7}$ & 3,57 & 7,21 \\
Dioithona oculata & 3,94 & 3,56 & 1,27 & 1,34 & 3,29 & 10,5 \\
Oithona simplex & 2,69 & 1,58 & 1,18 & 0,98 & 3,05 & 13,55 \\
Outros Paracalanidae & 5,08 & 6,65 & 1,14 & 1,06 & 2,95 & 16,5 \\
Pseudevadne tergestina & 2,87 & 0 & 1,1 & 1,38 & 2,84 & 19,34 \\
Oithona plumifera & 5,34 & 4,66 & 1,02 & 1,2 & 2,65 & 21,99 \\
Pseudodiaptomus acutus & 2,64 & 1,79 & 0,98 & 1,2 & 2,54 & 24,54 \\
\hline Labidocera acutifrons & 1,87 & 1,79 & 0,97 & 1,01 & 2,52 & 27,05 \\
Ditrichocorycaeus amazonicus & 2,33 & 2,97 & 0,97 & 1,24 & 2,5 & 29,56 \\
Longipedia americana & 2,29 & 1,73 & 0,96 & 1,18 & 2,49 & 32,04 \\
Onychocorycaeus giesbrechti & 4,03 & 3,74 & 0,93 & 1,33 & 2,4 & 34,44 \\
Polychaeta (larvas) & 4,37 & 4,42 & 0,88 & $\mathbf{1 , 4}$ & 2,29 & 36,73 \\
Temora stylifera & 3,92 & 2,91 & 0,88 & 1,32 & 2,26 & 38,99 \\
Bivalvia (larvas) & 3,88 & 5 & 0,87 & 1,27 & 2,24 & 41,24 \\
Acartia lilljeborgii & 5,37 & 5,55 & 0,85 & 1,13 & 2,19 & 43,43 \\
Hydromedusae & 2,77 & 1,28 & 0,84 & 1,37 & 2,18 & 45,61 \\
Temora turbinata & 5,94 & 5,32 & 0,84 & 1,24 & 2,18 & 47,79 \\
Noctiluca sp. & 3,41 & 4,21 & 0,82 & 1,18 & 2,12 & 49,91 \\
Subeucalanus pileatus & 2,22 & 2,51 & 0,82 & 1,35 & 2,12 & 52,02 \\
Oithona hebes & 6,53 & 6,6 & 0,82 & 1,11 & 2,11 & 54,13 \\
Gastropoda (larvas) & 4,58 & 3,28 & 0,78 & 1,35 & 2,02 & 56,15 \\
\hline
\end{tabular}


Tabela 1.18: Abundância média, similaridade média, razão similaridade/desvio-padrão e contribuição (\%) das principais espécies responsáveis pela distinção entre as estações de verão e inverno da comunidade planctônica amostrada pela rede de $100 \mu \mathrm{m}$. D.R.: densidade relativa; $\delta i$ : dissimilaridade média; $\delta i$ /D.P.: razão dissimilaridade média pelo desvio padrão; Cr.: contribuição específica; Cumul.: contribuição cumulativa. Em negrito: espécies discriminantes.

\begin{tabular}{lcccccc}
\hline \multicolumn{1}{c}{ Espécie } & $\begin{array}{c}\text { D.R. } \\
\text { verão }\end{array}$ & $\begin{array}{c}\text { D.R. } \\
\text { inverno }\end{array}$ & $\boldsymbol{\delta} \boldsymbol{i}$ & $\boldsymbol{\delta i}$ /D.P. & Cr. (\%) & $\begin{array}{c}\text { Cumul } \\
\text { (\%) }\end{array}$ \\
\hline Pseudevadne tergestina & 5,15 & 0,81 & 1,9 & $\mathbf{2 , 1 5}$ & 4,85 & 4,85 \\
Penilia avirostris & 5,88 & 2,16 & 1,74 & $\mathbf{1 , 6 9}$ & 4,44 & 9,28 \\
Dioithona oculata & 2,7 & 2,93 & 1,3 & 1,26 & 3,32 & 12,61 \\
Oithona hebes & 4,45 & 5,67 & 1,13 & 1,15 & 2,87 & 15,48 \\
Clausocalanus furcatus & 4,47 & 3,60 & 1,12 & 1,26 & 2,85 & 18,33 \\
Temora stylifera & 3,92 & 2,73 & 1,06 & $\mathbf{1 , 4 2}$ & 2,7 & 21,03 \\
Euterpina acutifrons & 1,43 & 2,96 & 1,04 & $\mathbf{1 , 4 7}$ & 2,64 & 23,67 \\
Acartia spp. & 5,08 & 5,08 & 0,97 & 1,34 & 2,48 & 26,16 \\
Pseudodiaptomus acutus & 2,17 & 1,38 & 0,96 & 1,12 & 2,45 & 28,6 \\
Gastropoda (larvas) & 5,45 & 3,31 & 0,95 & $\mathbf{1 , 6 5}$ & 2,43 & 31,03 \\
Calocalanus spp. & 2,03 & 2,9 & 0,92 & 1,3 & 2,35 & 33,38 \\
Oithona plumifera & 3,77 & 3,69 & 0,92 & 1,31 & 2,35 & 35,74 \\
\hline Polychaeta (larvas) & 3,82 & 3,26 & 0,92 & 1,39 & 2,34 & 38,08 \\
Ctenocalanus spp. & 2,22 & 1,68 & 0,9 & 1,22 & 2,31 & 40,38 \\
Longipedia americana & 1,66 & 1,45 & 0,9 & 0,99 & 2,29 & 42,67 \\
Ditrichocorycaeus amazonicus & 2,7 & 3,54 & 0,88 & 1,22 & 2,25 & 44,92 \\
Gastropoda: Pteropoda & 2,5 & 1,69 & 0,86 & 1,34 & 2,2 & 47,12 \\
Noctiluca sp. & 2,53 & 3,6 & 0,86 & 1,29 & 2,2 & 49,32 \\
Farranula sp. & 2,13 & 0,94 & 0,83 & 1,27 & 2,12 & 51,44 \\
Labidocera fluviatilis & 1,34 & 2,11 & 0,82 & 1,38 & 2,08 & 53,52 \\
Corycaeus speciosus & 2,06 & 0,6 & 0,81 & 1,3 & 2,07 & 55,59 \\
Tintinnina & 3,63 & 3,28 & 0,81 & 1,36 & 2,06 & 57,65 \\
\hline
\end{tabular}

\section{Discussão}

\subsubsection{Variáveis ambientais e a comunidade zooplanctônica}

Os dados relativos às variáveis ambientais foram obtidos apenas para a água de superfície em uma estação fixa muito próxima da costa. Dessa maneira valores mais elevados de temperatura durante o verão refletiram a radiação mais elevada nesse período, aquecendo a camada superficial. Os dados de clorofila- $a$ e foram maiores durante os períodos de inverno, quando comparados ao verão. A concentração de clorofila- $a$ geralmente oscilou entre 0,3 a $2,3 \mathrm{mg} \mathrm{m}^{-3}$, resultado similar encontrado por Tundisi et al. (1978), onde essa concentração variou entre 1 a $2,5 \mathrm{mg} \mathrm{m}^{-3}$ em águas superficiais entre os anos de 1971 e 1972. Vale destacar que os valores de produção primária foram mais elevados durante o final do verão e início do outono (Tundisi et $a l ., 1978)$, representando a alta produtividade deste período em relação ao resto do ano. 
Em condições normais, a concentração de clorofila- $a$ na região parece oscilar entre 0,3 a $3,5 \mathrm{mg} \mathrm{m}^{-3}$, mas pode ser bastante elevada durante a ressurgência da ACAS em suas áreas de influência, chegando a 20,4 $\mathrm{mg} \mathrm{m}^{-3}$ (Metzler, 1991; Aidar et al., 1993; Gianesella-Galvão \& Saldanha-Corrêa, 1995). Ainda para a região costeira do litoral norte do estado de São Paulo, a concentração de clorofila- $a$ foi determinada pontualmente para as estações de verão e inverno, durante os anos de 1985 a 1988. A AC apresentou valores médios entre 0,31 a 0,82 e 0,53 a $1,07 \mathrm{mg} \mathrm{m}^{-3}$ no verão e inverno respectivamente (Aidar et al., 1993), valores semelhantes aos detectados aqui.

O litoral norte do estado de São Paulo não abriga rios e estuários de grande volume, sendo o aporte continental pouco significativo. Conclui-se que além da coleta ter sido realizada em águas superficiais neste estudo, a localização da estação fixa, muito próxima à costa, também foi responsável pelas concentrações baixas a moderadas de clorofila- $a$, em relação a áreas de influência de ressurgência (Tabela 1.19). Já os trabalhos de Metzler (1991), Aidar et al. (1993) e Miyashita et al. (2011) foram influenciados pela ressurgência, resultando em maiores produtividades primária ou secundária.

Vale destacar também que as concentrações de clorofila- $a$ foram maiores no inverno. Tal fenômeno pode estar relacionado a um possível efeito de ressuspensão devido ao vento. Durante o inverno, as forçantes dos ventos predominam de SW para $\mathrm{NE}$, com componentes paralelos à costa e frentes frias associadas aos períodos de ventos intensos (Castro et al., 1987). A camada superficial geralmente sofre transporte de mar aberto para a costa durante essa estação.

Durante o verão, a maior precipitação pode ter resultado em turbidez mais acentuada. A incidência de luz pode ter comprometido a produção primária em águas costeiras da plataforma interna, o que explicaria as maiores concentrações de clorofila$a$ durante o inverno.

A amplitude de salinidade relativamente baixa (34-36 em 96\% dos períodos de coleta) para a estação aqui estudada, provavelmente não foi a principal variável ambiental que afetou a densidade ou diversidade do plâncton, como demonstrado pelas análises estatísticas. A precipitação durante o período amostrado foi relativamente baixa para a região de Ubatuba, tanto para as estações de verão, quanto de inverno. $\mathrm{O}$ aporte de água doce na região costeira durante os períodos amostrados não esteve acima da média e a salinidade superficial raramente esteve abaixo de 34 . O período mais chuvoso ocorre durante o verão, como comprovado pelos dados obtidos da estação 
meteorológica. Entretanto, a quantidade de chuva foi coincidentemente baixa durante os períodos das coletas realizadas nos três anos estudados.

Tabela 1.19: Comparação entre as concentrações de clorofila- $a$ reportadas por diversos autores para Ubatuba ou águas adjacentes. A média é representada entre parênteses. *: médias calculadas através de dados fornecidos no estudo.

\begin{tabular}{|c|c|c|c|}
\hline Local & Estação do ano & Cla- $a\left(\mathrm{mg} \mathrm{m}^{-3}\right)$ & Fonte \\
\hline Plataforma interna & inverno, 1988 & $1,2-3,4(2,6)$ & \multirow{3}{*}{$\begin{array}{c}\text { Gianesella-Galvão \& } \\
\text { Saldanha-Corrêa } \\
\text { (1995) }\end{array}$} \\
\hline$(40 \mathrm{~m})$ & verão, 1989 & $7,8-15,9(12,9)$ & \\
\hline $\begin{array}{l}\text { Plataforma externa } \\
\qquad(70 \mathrm{~m})\end{array}$ & verão, 1989 & $6,6-9,7(7,7)$ & \\
\hline \multirow{3}{*}{$\begin{array}{l}\text { Plataforma interna } \\
\qquad(40 \mathrm{~m})\end{array}$} & $\begin{array}{l}\text { mensal (2005-2008) } \\
\text { col. não-estratificada }\end{array}$ & $0,3-2,5$ & \multirow{3}{*}{$\begin{array}{l}\text { Miyashita et al. } \\
\text { (2010) }\end{array}$} \\
\hline & mensal (2005-2008) & $0-10 \mathrm{~m}: 0,5-1,0$ & \\
\hline & coluna estratificada & <25m: 1,5 - 2,5 Máx.: 12,4 & \\
\hline \multirow{2}{*}{$\begin{array}{l}\text { Plataforma interna } \\
\qquad(50 \mathrm{~m})\end{array}$} & verão, 1994 & $1,3-2,6(1,7)$ & \multirow{2}{*}{$\begin{array}{l}\text { Saldanha-Corrêa \& } \\
\text { Gianesella (2008) }\end{array}$} \\
\hline & primavera, 1997 & $3,7-5,8$ & \\
\hline \multirow{6}{*}{$\begin{array}{l}\text { Boqueirão } \\
(0-30 \mathrm{~m})\end{array}$} & verão, 1988 , & $3,3-20,4(12,4)$ & \multirow{2}{*}{ Metzler (1991) } \\
\hline & inverno, 1988, & $2,9-8,2(4,8)$ & \\
\hline & verão, 1990 & $(3,5)$ & \multirow{2}{*}{ Abe (1993) } \\
\hline & inverno, 1990 & $(4,1)$ & \\
\hline & \multirow{2}{*}{ verão, 1988} & $(1,6)$ & \multirow{2}{*}{ Gaeta et al. (1999) } \\
\hline & & Máx.: 5,3 & \\
\hline \multirow{4}{*}{$\begin{array}{c}\text { Plataforma interna e } \\
\text { externa }\end{array}$} & \multirow{4}{*}{$\begin{array}{l}\text { verão 1985-1988 } \\
\text { inverno 1985-1988 } \\
\text { (estratificada) }\end{array}$} & AC: $(0,5)$ AT: $(0,15)$ & \multirow{4}{*}{ Aidar et al. (1993) } \\
\hline & & ACAS: $(0,87)$ & \\
\hline & & AC: $(0,73)$ AT: $(0,35)$ & \\
\hline & & ACAS: $(0,24)$ & \\
\hline \multirow{2}{*}{$\begin{array}{c}\text { Enseada Flamengo } \\
\text { (superfície) }\end{array}$} & mensal & verão $(1,4)$ & \multirow{2}{*}{ Tundisi (1978)* } \\
\hline & (08/1970 - 07/1971) & inverno $(1,5)$ & \\
\hline \multirow{2}{*}{$\begin{array}{l}\text { Boqueirão } \\
\text { (superfície) }\end{array}$} & verão 2009-2011 & $0,2-1,8(0,6)$ & \multirow{2}{*}{ Este estudo } \\
\hline & inverno 2009-2011 & $0,4-2,8(1,3)$ & \\
\hline
\end{tabular}

A variação nictemeral é um importante fator na densidade do zooplâncton, principalmente em regiões estuarinas (Marques et al., 2011; Menéndez et al., 2012). No presente estudo, as coletas foram padronizadas por horário, causando diferença no estágio de maré durante as amostragens. Contudo, não houve diferença da densidade microzooplanctônica total entre as coletas durante a maré vazante e maré enchente 
considerando todo o período amostral, ou entre vazante e enchente para as estações de verão e inverno isoladamente. $\mathrm{O}$ resultado poderia ser explicado pela moderada a baixa amplitude da maré semidiurna (máximo de $0,8 \mathrm{~m}$ de diferença entre as coletas, durante os períodos amostrais).

Embora o estudo apenas da camada superficial implique em limitações do real funcionamento do ecossistema, os resultados indicaram a variação sazonal das variáveis ambientais estudadas. Além disso, uma vez que a estação de coleta é situada próxima à costa em estação de baixa profundidade, os processos de turbulência e mistura da coluna de água favorece a homogeneização da mesma e a utilização dos dados de superfície como representativos de parte da coluna de água.

\subsubsection{Variáveis ecológicas e principais grupos do zooplâncton}

O zooplâncton costeiro é caracterizado pela dominância de poucas espécies e número elevado de táxons considerados raros (Mauchline, 1998). Tal padrão resulta em baixa equitabilidade, enquanto que o inverso costuma ocorrer para o zooplâncton oceânico, com baixas densidades distribuídas em diversas espécies (Longhurst, 2007). Já a densidade e biomassa dependem de uma gama de variáveis, entre elas a produção primária do sistema e mesmo os métodos empregados para a coleta e estimativas da biomassa.

Diferença entre as estações do ano só ocorreu para o zooplâncton da rede de 20 Mm durante 2011 (Tabela 1.7). A fração menor do zooplâncton foi mais abundante, quando comparado à fração maior. Tal resultado era esperado, uma vez que a densidade dos estágios naupliares e dos primeiros estágios de copepoditos são superiores à densidade dos últimos estágios de desenvolvimento. $\mathrm{O}$ mesmo padrão ocorre naturalmente para juvenis de outros metazoários planctônicos. A variabilidade temporal da densidade e os fatores relacionados são detalhados na seção 1.5.4.

É comum a dominância dos náuplios e primeiros copepoditos sobre a abundância do microzooplâncton metazoário (Hopcroft et al., 2001; Gallienne \& Robins, 2001; McManus et al., 2007; Monti et al., 2012). Porém, quando se considera o protozooplâncton (exceto pelos nanoflagelados e outros grupos que não podem ser fixados em soluções de formol ou álcool), os ciliados loricados da subordem Tintinnina são comumente os organismos mais abundantes do microplâncton (Monti et al., 2012). Os copépodes, seguidos pelos cladóceros e posteriormente por apendiculários e 
Tintinnina foram os táxons dominantes para ambas as redes nesta pesquisa. Situação semelhante foi descrita para os anos de 1971-72 em Ubatuba, onde a dominância de copépodes foi seguida pelas larvas meroplanctônicas e apendiculários (Tundisi et al., 1978) e indicando uma alta resiliência dos táxons do zooplâncton costeiro, após quarenta anos deste primeiro registro.

O trabalho de Tundisi et al. (1978) é o único realizado dentro da enseada do Flamengo sobre a estrutura e variação temporal da comunidade zooplanctônica, pois outros autores focaram seus estudos em uma única espécie (Milstein, 1979; Pinese, 1983). Embora a malha utilizada tenha sido a de $50 \mu \mathrm{m}$, comparações foram realizadas, uma vez que a estação fixa desses autores se encontra a cerca de quatro quilômetros da estação Boqueirão. Valor médio de densidade do zooplâncton de 72.420 org. $\mathrm{m}^{-3}$ foi encontrado pelos autores, sendo que náuplios e copepoditos (não houve distinção entre copepoditos juvenis e adultos) foram os metazoários dominantes, seguidos pelo agrupamento das larvas meroplanctônicas e posteriormente pelos apendiculários. Os valores médios descritos aqui foram consideravelmente menores para as duas malhas utilizadas.

Os demais trabalhos publicados sobre a ecologia do zooplâncton no litoral do estado de São Paulo utilizaram redes com malhas superiores a $100 \mu \mathrm{m}$, com exceção de Miyashita et al. (2009), onde rede de $64 \mu \mathrm{m}$ foi utilizada concomitantemente à rede de $300 \mu \mathrm{m}$, mas apenas os copépodes foram estudados. A mesma estratégia de utilização de redes complementares para amostrar diferentes classes de tamanho com redes de 64 e $300 \mu \mathrm{m}$ foi empregada por outros autores (Lopes, 1997; Crété, 2006 e Rimoldi, 2008). A preferência por utilização de redes com aberturas de malha superiores a 100 $\mu \mathrm{m}$ gerou como consequência a lacuna de conhecimento sobre as menores classes de tamanho do zooplâncton para a região.

A costa brasileira como um todo é carente quanto a pesquisas publicadas sobre a estrutura e diversidade do microzooplâncton metazoário. Raros exemplos são os estudos de Lopes (1997) no complexo estuarino de Paranaguá com rede de $64 \mu \mathrm{m}$, Neumann-Leitão \& Matsumura-Tundisi (1998) no porto de Suape, Penambuco, com rede de $65 \mu \mathrm{m}$, De La Rocha (1998) com redes de 30 e $100 \mu \mathrm{m}$, da Costa et al. (2011) utilizando rede de 120 m no estuário de Caeté, estado do Pará e de Martinez (2013) com malha equivalente a $64 \mu \mathrm{m}$ na bacia de Campos, Rio de Janeiro.

Nas últimas décadas, a comunidade microzooplanctônica foi investigada com menor frequência do que as maiores classes de tamanho do plâncton, principalmente 
devido às limitações metodológicas encontradas para estudos quantitativos de organismos pequenos, como a preservação apropriada das células atecadas (Calbet, 2008).

\subsubsection{Protistas}

O protozooplâncton é certamente um dos compartimentos do ecossistema pelágico com maiores lacunas de conhecimento. Protistas maiores em tamanho e/ou que possuem estruturas esqueléticas como os Foraminifera, Polycystinea, Phaeodarea, Acantharia e o agrupamento Heliozoa podem ser coletados com redes de plâncton e alguns preservados em formol ou álcool. Protistas de pequeno porte como zooflagelados e ciliados somente receberam atenção devida após a divulgação de sua importância ecológica na alça microbiana por Pomeroy (1974) e posteriormente na estruturação da trama trófica marinha (Azam et al., 1983; Sherr \& Sherr, 1991; entre outros).

Os métodos de coleta e preservação aqui utilizados não foram adequados para o estudo dos protistas, causando a perda de organismos de menor tamanho devido à utilização das redes, além da perda por fixação em formalina dos grupos atecados. Foram estimados aqui apenas os Tintinnina e o gênero Noctiluca. Outros táxons foram encontrados com menor frequência, mas não quantificados ou identificados, como os foraminíferos e radiolários.

Os Tintinnina foram numericamente importantes para as amostras da rede de 20 $\mu \mathrm{m}$. Esses protistas de dimensões entre 20 a $200 \mu \mathrm{m}$ são eficientes herbívoros, alimentando-se do nano- e microplâncton (Dolan et al., 2013). Ocasionalmente, sua atividade alimentar pode dominar o consumo do fitoplâncton (e.g. Karayanni et al., 2005), evidenciando a importância do grupo. Tais organismos foram subestimados pela rede de $100 \mu \mathrm{m}$, pois a densidade foi inferior quando comparado com a rede de $20 \mu \mathrm{m}$ ( $p<0,001)$. Tundisi et al. (1978) encontraram uma média de 63 org. $\mathrm{m}^{-3}$ e valores máximos de $234 \mathrm{org} . \mathrm{m}^{-3}$ em Ubatuba. Essas baixas densidades foram semelhantes aos encontrados aqui para a malha de $100 \mu \mathrm{m}$, o que leva ao indício de que apenas malhas inferiores a $50 \mu \mathrm{m}$ sejam eficazes para a estimativa da densidade dos Tintinnina.

Valores altos de abundância e biomassa também foram reportados para os Tintinnina em águas costeiras (Pompeu, 1998; Fernandes $2004 a$ e b; Monti et al., 2012) e oceânicas (Fernandes $2004 a$ e $b$; Martinez, 2013) do Brasil. Já o dinoflagelado do gênero Noctiluca mostrou densidades superiores durante os períodos de inverno para 
ambas as malhas. Valores pontuais elevados de abundância (1.132 org.m ${ }^{-3}$ durante o inverno de 2009) foram comuns, uma vez que estes organismos são encontrados em distintos padrões de agregação (Omori \& Hamner, 1982; Kirchner et al., 1996).

\subsubsection{Zooplâncton gelatinoso}

Os cnidários foram parcialmente identificados e a diversidade do filo certamente foi maior: apenas quatro táxons foram determinados neste estudo, porém mais de quinze espécies de medusas foram registradas para o litoral norte de São Paulo (Morandini et al., 2005; Tronolone, 2007). A diversidade do grupo também foi considerada baixa devido ao tamanho das malhas utilizadas, provavelmente muito pequenas para a captura desses organismos do macrozooplâncton.

As espécies aqui descritas são tipicamente distribuídas nas camadas superficiais da AC e ACAS, exceto por Corymorpha gracilis geralmente encontrada entre 50 e 100 m (Tronolone, 2007). Os hidrozoários da ordem Siphonophora foram raros neste estudo, ocorrendo em apenas cinco amostras da rede de $20 \mu \mathrm{m}$ e uma da rede de 100 $\mu \mathrm{m}$. Mais de 20 trabalhos já foram publicados sobre o grupo para a costa brasileira (Lopes, 2007), porém raros foram realizados com material coletado no litoral norte de São Paulo (Dias, 1994).

As medusas de cifozoários geralmente são de grande porte, invalidando o método aqui utilizado para estudos quantitativos do grupo. Entretanto, algumas exceções ocorreram: a espécie pequena Nausithoe aurea e indivíduos juvenis de Aurelia sp., anteriormente documentadas para o litoral norte do estado de São Paulo (Vannucci, 1957; Morandini \& Silveira, 2001; Morandini et al., 2005). A terceira espécie Lychnorhiza lucerna, foi acidentamente capturada pelas redes durante as amostragens em julho de 2010, provavelmente devido ao grande tamanho e distribuição esporádica.

Os ctenóforos não podem ser fixados em soluções rotineiras de formol ou álcool, por isto métodos inapropriados de fixação neste estudo podem ter causado subestimativa da densidade e riqueza. As redes utilizadas também não foram apropriadas para coleta dos ctenóforos, pois as espécies geralmente são classificadas como macrozooplâncton e devem ser coletados através de mergulho, pois são facilmente danificados por redes. As duas espécies encontradas aqui, Mnemiopsis leydi e Beroe ovata foram as mais comuns entre as sete documentadas para o canal de São Sebastião (Oliveira \& Migotto, 2006). 
A diversidade e abundância dos quetognátos neste estudo foi mais baixa em relação ao reportado por outros trabalhos no litoral do estado de São Paulo (Liang \& Vega-Pérez, 1994, 2002). Em São Sebastião foram determinadas sete espécies e

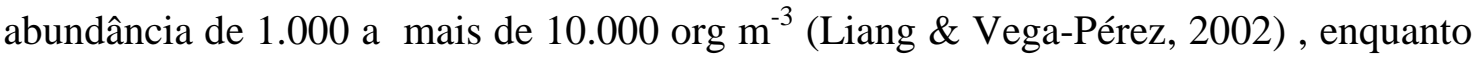
que para o verão de 1994 em Ubatuba foram registradas 10 espécies e valores de abundância entre 2.880 para o verão de 1985 a 20.230 para o inverno de 1986 (Liang \& Vega-Pérez, 1994), sendo que Parasagitta friderici atingiu densidades de até 14.000 org $\mathrm{m}^{3}$.

O tipo de coleta empregado pode explicar essa variabilidade, sendo que os autores citados utilizaram uma malha de $330 \mu \mathrm{m}$, mais apropriada para a captura de organismos do meso- e macrozooplâncton. A utilização das malhas de 20 e $100 \mu \mathrm{m}$ provavelmente foi menos eficientes para a captura dos quetognátos.

Oikopleura dioica foi a espécie dominante durante o período aqui amostrado. A espécie é comum e geralmente a dominante em estuários em águas costeiras na plataforma interna, adaptada à variações físico-químicas nesses ambientes (Teixeira et al., 1965; Tundisi, 1970). A proximidade da costa para a estação de coleta justifica a dominância de $O$. dioica ${ }_{s}$ em detrimento de espécies dominantes em regiões neríticas como O. longicauda e O. fusiformis (Forneris, 1965; Tundisi, 1970) neste estudo.

Vale ressaltar que as outras publicações sobre o grupo foram realizadas em estações com distância mínima de nove quilômetros da costa, cobrindo áreas maiores (Forneris 1965; Tundisi, 1970), fato que justificaria a dominância de O. longicauda sobre $O$. dioica e a maior riqueza, chegando a 19 espécies (Forneris, 1965). Também é importante destacar que em estudo pretérito (Miyashita \& Lopes, 2011), não houve correlação significativa entre $O$. dioica e variáveis ambientais como temperatura e salinidade. Os autores atribuíram o fato à adaptabilidade desta espécie a regiões costeiras.

Aspectos ecológicos como a biomassa, crescimento somático e produção de casas de muco foram estimadas por Miyashita \& Lopes (2011) para uma estação fixa, distante a cerca de 20 quilômetros da costa em Ubatuba, sendo que produção do grupo foi igual a $77 \%$ da produção dos copépodes para a mesma área. A abundância média foi de $245 \pm 197$ org. $\mathrm{m}^{-3}$, enquanto que no presente estudo os valores médios foram cerca de três a cinco vezes maiores. Tal diferença pode ser atribuída pela posição das estações de coleta e pelo tamanho da malha, sendo que Miyashita \& Lopes (2011) utilizaram uma rede de $200 \mu \mathrm{m}$. Com base nos valores de densidade encontrados aqui, é provável 
que a biomassa e produção secundária do táxon para a região costeira de Ubatuba seja maior do que o reportado por Miyashita \& Lopes (2011), uma vez que informação sobre as menores classes de tamanho não foram obtidas.

A temperatura como fator regulador da densidade deste grupo já foi relatada em diversos trabalhos (ver o exemplo de Acuña \& Anadón, 1992), porém a correlação não foi detectada neste estudo (Tabelas 1.12 e 1.13).

\subsubsection{Principais táxons meroplanctônicos: moluscos e poliquetos}

Os gastrópodes holoplanctônicos foram raros (Pterotrachea sp.) ou pouco frequentes (superordem Pteropoda), tais organismos são adaptados às águas oceânicas em sua maioria, justificando a baixa densidade dos mesmos em ambientes costeiros (Richter \& Seapy, 1999; Van der Spoel \& Dadon, 1999). As larvas véliger de gastrópodes e bivalves foram organismos frequentes do meroplâncton, sendo que as larvas de gastrópodes estiveram presentes em todas as amostras da rede de $100 \mu \mathrm{m}$, onde foi o táxon dominante do meroplâncton. Em algumas ocasiões, as larvas meroplanctônicas de moluscos foram mais abundantes no verão, em relação ao inverno (Tabela 1.7). Tal fato pode estar relacionado à maior produtividade do zoobentos durante o verão (Rocha et al., 2003) ou ao ciclo reprodutivo dos moluscos bentônicos da região estudada.

O filo Polychaeta foi representado por diferentes estágios larvais, desde a trocófora até formas juvenis. Com exceção do gênero Tomopteris, os demais organismos encontrados foram larvas meroplanctônicas de diversas famílias. O estoque larval de grupos como os gastrópodes, bivalves e poliquetos refletiu a importância desses organismos para os sistemas bentônicos em ambientes costeiros rasos no litoral norte do estado de São Paulo (Pires-Vanin et al., 2013).

\subsubsection{Cladóceros}

A densidade dos cladóceros foi mais elevada sempre durante o verão. Miyashita et al. (2010) encontraram densidades superiores para Penilia avirostris, além da ocorrência de outras espécies como Pleopis polyphaemoides e Podon intermedius (Miyashita et al., 2011) também durante o verão. Abundâncias mais elevadas encontradas por esses autores em relação a este estudo provavelmente é atribuída ao método de coleta, uma vez que foram utilizadas redes de $200 \mu \mathrm{m}$, mais apropriadas 
para a coleta de indivíduos adultos de $P$. avirostris. Outra variável importante é a estação de coleta, uma vez que os autores citados coletaram em uma estação cerca de $20 \mathrm{~km}$ distante do Boqueirão, área influenciada pela ressurgência da ACAS. O predomínio de $P$. avirostris durante o verão em áreas de ressurgência próximas a costa também pode ser notada em Cabo Frio (Valentin \& Monteiro-Ribas, 1993).

Os cladóceros marinhos são eficientes consumidores do nano- e microplâncton, sendo o espectro de tamanho de partículas ingeridas entre 1 a $20 \mu \mathrm{m}$, eventualmente predando organimos maiores como dinoflagelados e ciliados (Atienza et al., 2006). As diversificadas estratégias reprodutivas como a pedogênese (Egloff et al., 1997) e elevadas taxas de crescimento (Atienza et al., 2007) tornam esses organismos eficientes componentes do metazooplâncton e entre os que possuem respostas reprodutivas mais rápidas, de maneira que podem ultrapassar os copépodes em importância numérica em determinadas ocasiões (Grahame, 1976).

Segundo Atienza et al. (2006 e 2007), a capacidade de utilizar partículas do nanoplâncton confere vantagem adaptativa aos cladóceros durante o verão no Mediterrâneo, quando a estratificação da coluna de água resulta em condições oligotróficas das águas superficiais e em águas tropicais dominadas por produtores de pequeno porte.

As correlações negativas com a salinidade e positivas com a temperatura apresentadas pelos cladóceros também foram resultados da variação sazonal, uma vez que estes táxons foram mais abundantes para o verão. A distribuição sazonal também poderia explicar as correlações negativas entre esses microcrustáceos e os pigmentos para a rede de $20 \mu \mathrm{m}$.

\subsubsection{Copépodes}

A riqueza encontrada de 66 espécies foi moderada, porém dentro dos valores esperados para águas costeiras. Pesquisas realizadas na região de Ubatuba e outros pontos do litoral norte do estado de São Paulo registraram um número variável de espécies: entre 25 a 129, mas geralmente acima de 40 (Tabela 1.20). Uma exceção foi o estudo de Gianesella-Galvão et al. (1999), onde a baixa diversidade poderia ser explicada pela reduzida variabilidade temporal, pois os 20 pontos de coleta foram realizados durante um único cruzeiro em Outubro de 1991. Outro trabalho reportando baixa diversidade foi o pioneiro de Almeida-Prado (1962), com apenas 20 espécies registradas. $\mathrm{O}$ desenho amostral de baixa resolução espacial e temporal também pode 
explicar a baixa riqueza. É possível também que o material tenha sido parcialmente identificado, devido à falta de literatura apropriada para o Atlântico Sul na época.

Por outro lado, um número maior de espécies foi descrito por Vega-Pérez (1993), que registrou 129 espécies de copépodes para a plataforma de São Sebastião. Entretanto, as amostras de plâncton não foram restritas às estações costeiras, sendo amostrada também a plataforma externa, com estações dispostas após a isóbata de 100 m e resultaram na coleta de espécies costeiras e oceânicas.

Tabela 1.20: Riqueza (S), diversidade $(\mathrm{H})$, equitabilidade $(\mathrm{J})$ e densidade média com o desvio padrão (D) da comunidade de copépodes para os estudos realizados no litoral norte do estado de São Paulo. N.F.: não fornecido. *: estimado através das representações gráficas. **: dados indisponíveis para o cálculo da média. Apenas trabalhos que avaliaram a comunidade total de copépodes.

\begin{tabular}{|c|c|c|c|c|c|}
\hline $\mathbf{S}$ & $\mathbf{H}$ & $\mathbf{J}$ & D $\left(\right.$ org.m $\left.{ }^{-3}\right)$ & $\begin{array}{c}\text { Malha } \\
(\mu \mathrm{m})\end{array}$ & Fonte \\
\hline 20 & N. F. & N. F. & N. F. & $\sim 300$ e 500 & Almeida-Prado (1962) \\
\hline N. F. & N. F. & N. F. & $2.661 \pm 3.695$ & 50 & Tundisi et al. (1978) \\
\hline 41 & N. F. & N. F. & N. F. & 70 & Gaeta et al. (1990) \\
\hline 129 & N.F. & N. F. & $3.262 \pm 5.086$ & 200 & Vega-Pérez (1993) \\
\hline 73 & N. F. & N. F. & $11.393 \pm 8.947 *$ & 330 & $\begin{array}{c}\text { Gianesella-Galvão et al. } \\
\text { (1997) }\end{array}$ \\
\hline 25 & $\begin{array}{c}1,15-2,47 \\
(1,83 \pm 0,38)\end{array}$ & $\begin{array}{l}0,36-0,74 \\
(0,54 \pm 0,11)\end{array}$ & $5.173 \pm 4.191$ & 200 & $\begin{array}{c}\text { Gianesella-Galvão et al. } \\
\text { (1999) }\end{array}$ \\
\hline 53 & N. F. & N.F. & $86-2.958^{* *}$ & 200 & $\begin{array}{c}\text { Eskinazi-Sant'Anna \& } \\
\text { Björnberg (2006) }\end{array}$ \\
\hline 77 & N. F. & N. F. & $304-69.461 * *$ & 330 & Vega-Pérez (2008) \\
\hline 58 & N. F. & N. F. & $\begin{array}{c}17.928 \pm 14.777 \\
735 \pm 354\end{array}$ & $\begin{array}{c}64 \\
300\end{array}$ & Miyashita et al. (2009) \\
\hline 71 & $\begin{array}{c}1,83-3,63(2,91 \pm \\
0,38)\end{array}$ & $0,64 \pm 0,09$ & $4.726 \pm 3.711$ & 200 & Melo-Júnior (2009) \\
\hline 66 & $\begin{array}{c}2,73-4,1(3,43 \pm \\
0,35) \\
2,08-4,27(3,47 \pm \\
0,49)\end{array}$ & $\begin{array}{c}0,56-0,85 \\
(0,74 \pm 0,06) \\
0,44-0,88 \\
(0,71 \pm 0,1)\end{array}$ & $\begin{array}{c}11.562 \pm 13.435 \\
6.065 \pm 8.011\end{array}$ & $\begin{array}{c}20 \\
100\end{array}$ & Este estudo \\
\hline
\end{tabular}

A diversidade encontrada aqui foi relativamente alta, principalmente para o verão devido à ocorrência de copépodes neríticos. A intrusão de águas oceânicas sobre a plataforma interna é o mecanismo que explicou o incremento da diversidade em Melo-Júnior (2009). A presença de espécies costeiras durante todo do período amostral (Acartia lilljeborgii, Parvocalanus crassirostris, Temora turbinata) e de espécies 
oceânicas principalmente durante o verão, como Calanoides carinatus, Pleurommama sp., Scolecithrix sp. e membros da família Sapphirinidae, corroboraram tal variabilidade, tanto no trabalho de Melo-Júnior, quanto aqui. A diferença é que tais espécies ocorreram raramente e em menores densidades neste estudo, em relação ao registrado por Melo-Júnior (2009).

A diversidade e a equitabilidade foram um pouco maiores do que o registrado na literatura para o zooplâncton costeiro da região sudeste (Tabela 1.20), consequência também da heterogeneidade sazonal que a estação de coleta está submetida. Contudo, os trabalhos que descreveram as maiores riquezas não forneceram índices ecológicos (Vega-Pérez, 1993, 2008).

Dentre os trabalhos publicados para o litoral norte do estado de São Paulo, densidade média mais elevada do que o reportado aqui para a rede de $20 \mu \mathrm{m}$ só foram registradas por Tundisi et al. (1978) e Miyashita et al. (2009). Como esperado, redes de malha maior resultaram em densidades mais baixas, com exceção apenas para o estudo de Gianesella-Galvão et al. (1997) (Tabela 1.20).

A dominância entre as ordens Calanoida e Cyclopoida não foi evidente, sendo ambas principais componentes do zooplâncton. A ordem Cyclopoida, porém, destacouse em termos de biomassa e produção devido à família Oithonidae (ver capítulo 2). Os principais táxons de copépodes são abordados a seguir.

Copépodes de pequeno porte, usualmente pertencentes às famílias Paracalanidae, Oithonidae e Oncaeidae, são particularmente importantes desde os trópicos às águas polares (Paffenhöffer, 1993; Hopcroft \& Hoff, 2001; Turner, 2004). O uso de redes de plâncton de malhas inapropriadas para a coleta desses táxons resultou numa defasagem quanto ao conhecimento sobre a ecologia e função dos mesmos nos ecossistemas pelágicos, especialmente para áreas tropicais como a costa brasileira (Lopes, 2007).

Os grupos mais abundantes foram basicamente os mesmos relatados por MeloJúnior (2009) como dominantes para uma estação fixa na plataforma interna de Ubatuba, com exceção de Acartia spp. e do gênero Oncaea, o mais abundante no trabalho deste autor. Miyashita e colaboradores (2009) observaram que náuplios de diversas espécies e copepoditos de Parvocalanus crassirostris, Monothula subtilis e Oncaea waldemari foram dominantes numericamente. Diversos outros estudos publicados para a comunidade de copépodes tropicais também reportaram as famílias 
Paracalanidae, Oithonidae e Oncaeidae como dominantes (Hopcroft et al., 1998; entre outros).

Dentre a ordem Calanoida, os Paracalanidae constituem uma família diversificada, com mais de 80 espécies distribuídas em seis gêneros (Boxshall \& Halsey, 2004). Para o litoral brasileiro, pelo menos 15 espécies já foram registradas (Almeida-Prado \& Lansac-Tôha, 1984; Vega-Pérez, 1993, 2008; Dias \& Bonecker, 2008; Miyashita et al., 2012).

Parvocalanus crassirostris foi a espécie mais frequente e de maior densidade entre os Paracalanidae, atingindo um máximo de 10.850 e média de 1.723 org.m $\mathrm{m}^{-3}$ para a amostragem com rede de $20 \mu \mathrm{m}$. Representou também um dos menores copépodes (tanto nos estágios de náuplios como de copepoditos) durante este estudo, com machos adultos menores que $350 \mu \mathrm{m}$ de comprimento do prossomo. O táxon também foi o dominante para o plâncton do canal de São Sebastião (Eskinazi-Sant'Anna \& Björnberg, 2006), além de diversas outras regiões do atlântico sul ocidental (Sartori \& Lopes, 2000; Gómez-Erache et al., 2000; Artigas et al., 2003; Schwamborn et al., 2004) e outros oceanos ao redor do mundo (Mallin, 1991; McKinnon \& Ayukai, 1996; Calbet et al., 2000; Liu \& Wang, 2002; Lo et al., 2004).

Altas densidades em todos os períodos amostrados podem ser explicadas pelo hábito costeiro (Björnberg, 1963) e alimentar da espécie. Tais copépodes são onívoros e consumidores desde microalgas a ciliados heterotróficos, comumente disponíveis em águas costeiras (Eskinazi-Sant'Anna, 2000; McKinnon et al., 2003; Gorri, 2006; Chen et al., 2013). Outros membros da família como Paracalanus quasimodo e o Clausocalanidae Clausocalanus furcatus também foram frequentes e abundantes durante os três anos analisados aqui e constituem táxons dominantes do zooplâncton em diversas regiões tropicais e subtropicais (Calbet et al., 2001; Bi \& Benfield, 2003; Cornils et al., 2007; Leitão et al., 2008).

Oithona hebes é uma espécie típica de águas estuarinas, mas que ocorre na AC em menores densidades (Rocha, 1986). A espécie é adaptada a salinidades entre 6,3 e 30 (Tundisi \& Tundisi, 1968; identificada como O. ovalis), embora seja encontrada frequentemente em salinidades mais elevadas (Lopes et al., 1999). Outras espécies frequentes deste trabalho foram $O$. plumifera e Diothona oculata, ambas consideradas comuns em águas costeiras da região sudeste do Brasil (Dias \& Bonecker, 2008, entre outros). 
Copépodes da família Oncaeidae foram frequentes neste estudo e dominantes para alguns trabalhos realizados na costa brasileira (Sartori \& Lopes, 2000; Miyashita et al., 2009; Melo-Júnior, 2009). Tais copépodes possuem estratégias alimentares peculiares, atuando como consumidores de neve marinha, pelotas fecais ou como predadores de apendiculários e quetognátos (Go et al., 1998; Metz, 1998). A família é uma das principais entre copépodes em águas tropicais ao redor do globo, tanto em densidade (Melo-Júnior, 2009), quanto em diversidade (Nishibe et al., 2009).

A família Corycaeidae é composta por copépodes predadores e representada aqui principalmente por Onychocorycaeus giesbrechti, Ditrichocorycaeus. amazonicus e Corycaeus speciosus. A primeira espécie foi mais frequente e abundante desta família neste e em diversos trabalhos para o Atlântico Sul (e.g. Eskinazi-Sant'Anna \& Björnberg, 2006) e representa um dos copépodes mais frequentes de águas costeiras e oceânicas na costa brasileira (Dias \& Bonecker, 2008).

Euterpina acutifrons é o copépode mais comum da ordem Harpacticoida no zooplâncton costeiro e estuarino. A espécie foi frequente, porém pouco abundante durante o período amostrado. Diversos estudos foram publicados sobre a biologia e aspectos reprodutivos de E. acutifrons (Melo-Júnior et al., 2013 por exemplo). Moreira e colaboradores (1982) estudaram a variação sazonal da espécie no litoral norte de São Paulo e notaram drástica redução na abundância durante os meses de verão, resultados semelhantes aos registrados neste estudo.

A dominância de copépodes de pequeno porte provavelmente se deve às características intrínsecas destas espécies, como altas taxas reprodutivas, hábito e eficiência alimentar e ciclo de vida curto. O rápido ciclo de vida é explicado como função do tamanho reduzido e temperaturas mais elevadas em ambientes tropicais e subtropicais (Mauchline, 1998).

Ambas as espécies Temora turbinata e T. stylifera ocorrem em águas costeiras brasileiras e preferencialmente nos primeiros $20 \mathrm{~m}$ de profundidade. Segundo Rimoldi (2008), T. turbinata distribui-se preferencialmente em águas costeiras, onde é dominante sobre T. stylifera, sendo que o contrário acontece em águas oceânicas. Neste estudo, T. turbinata foi dominante sobre T. stylifera durante todo o período amostrado.

A ocorrência de T. turbinata como uma das espécies dominantes em diversas regiões estuarinas e costeiras é frequente (Ara, 2002; Kamisnki \& Montú, 2005; Gomes, 2007; Rimoldi, 2008). Aspectos específicos da biologia, hábito alimentar e 
ecologia desta espécie devem ser explorados a fim de explicar o sucesso do organismo como uma espécie invasora em diversas áreas costeiras do mundo (e.g. Silva, 2012).

A espécie Pseudodiaptomus acutus é encontrada frequentemente em estuários do estado de São Paulo e Paraná (Lopes, 1994; Martinelli-Filho, 2007; Bicalho, 2010; Miyashita et al., 2012), mas também é registrada para águas costeiras de Ubatuba (Melo-Junior, 2009). Neste estudo, o copépode foi encontrado em maior frequência e abundância em 2009. Tal distribuição não esteve relacionada com os valores de salinidade, uma vez que essa variável não foi menor para o ano em questão.

Subeucalanus pileatus foi um copépode frequente, porém pouco abundante. Embora a densidade seja relativamente baixa, a biomassa e produção foram consideradas elevadas para o litoral de São Paulo (Melo-Júnior, 2009; Miyashita et al., 2009). Os náuplios foram comumente encontrados em ambas as malhas aqui utilizadas, enquanto que os adultos foram raramente coletados.

Centropages velificatus também foi uma espécie comum, em densidades relativamente baixas, porém maiores que Subeucalanus pileatus. A espécie de médio porte apresentou altas taxas de produção de ovos para a região de Ubatuba, com as maiores médias de deposição de ovos por dia (Melo-Júnior, 2009), um indicativo de que o táxon é um importante contribuinte para a produção zooplanctônica.

O gênero Acartia foi representado por A. lilljeborgii e A. tonsa. A primeira espécie é associada à $\mathrm{AC}$ e frequentemente encontrada no plâncton costeiro (Pombo \& Martinelli-Filho, 2012), já a segunda é comumente encontrada em estuários (Miyashita et al., 2012). Ambas são comuns e abundantes em toda a plataforma interna do litoral brasileiro e apresentam altas taxas de produção (Muxagata et al., 2012; Magalhães et al., 2013), com exceção de A. tonsa que não ocorre no litoral do Nordeste do país. Elevadas taxas de crescimento somático (ver segundo capítulo) e reprodutivo (Kaminski \& Montú, 2005; Melo-Júnior, 2009) também foram descritas para o gênero, demonstrando a importância do mesmo para águas costeiras.

\subsubsection{Densidade comparada entre os estágios de desenvolvimento de copépodes}

A utilização de duas malhas pequenas e de tamanhos consideravelmente diferentes foi a estratégia adotada para gerar estimativas de densidade e amostrar a maior diversidade possível de estágios imaturos de desenvolvimento dos copépodes. Além disso, com exceção de De La Rocha (1998), nenhum trabalho foi publicado na 
costa brasileira utilizando redes inferiores a $50 \mu \mathrm{m}$ para o estudo quantitativo do microzooplâncton metazoário (ver Tabela 1.20), ressaltando a importância dos dados aqui fornecidos.

Os náuplios de copépodes são comumente o táxon dominante para o zooplâncton coletado com redes de $50 \mu \mathrm{m}$ ou inferiores. Tais organismos foram responsáveis pela maior densidade relativa do plâncton para a malha de $20 \mu \mathrm{m}$. Resultado semelhante foi observado por Thompson et al. (2001) utilizando rede de 30 $\mu \mathrm{m}$ e Lam-Hoai et al. (2006) com rede de $40 \mu \mathrm{m}$. Neste estudo, apenas $9 \%$ dos copépodes coletados eram adultos para a rede de $20 \mu \mathrm{m}$, e $19 \%$ para a rede de $100 \mu \mathrm{m}$, confirmando que estes tamanhos de malha favorecem a coleta dos estágios imaturos de desenvolvimento.

A comparação entre a eficiência das redes em coletar diferentes estágios de desenvolvimento dos copépodes resultou em três padrões principais de captura dos organismos. O primeiro padrão consistiu na presença dos três estágios principais (náuplios, copepoditos e adultos) em proporções semelhantes para a rede de $20 \mu \mathrm{m}$ e geralmente a exclusão ou proporções baixas de náuplios para a rede de $100 \mu \mathrm{m}$. As espécies de pequeno porte como Parvocalanus crassirostris, Oncaea spp., representantes da família Corycaeidae e Euterpina acutifrons apresentaram este padrão.

Outro grupo de espécies teve seus náuplios e copepoditos coletados pela malha de $20 \mu \mathrm{m}$, enquanto que copepoditos tardios e, em alguns casos, os adultos, foram coletados pela malha de $100 \mu \mathrm{m}$ (Acartia spp., Temora turbinata e T. stylifera, Centropages velificatus, Pseudodiaptomus acutus e todos as espécies de Oithonidae). Este agrupamento possui algumas variações importantes. Para os gêneros Acartia e Temora, por exemplo, nenhuma das redes coletou adultos com eficiência, porém os adultos de Oithonidae foram capturados em altas proporções pela rede de $100 \mu \mathrm{m}$.

O último padrão é representado por espécies onde apenas os náuplios foram devidamente capturados pelas duas redes. A maior parte dos organismos foi encontrada no estágio de náuplio para a rede de $20 \mu \mathrm{m}$. Para a rede de $100 \mu \mathrm{m}$, a dominância dos estágios naupliares ainda foi observada, porém proporções elevadas de copepoditos também foram registradas (Subeucalanus pileatus, Paracalanus spp., Clausocalanus spp.).

As mesmas espécies ocorreram em ambas as malhas na grande maioria das amostras. Conclui-se que as malhas empregadas selecionaram efetivamente os estágios de desenvolvimento, não havendo seleção quanto a composição taxonômica para os 
copépodes. A importância da rede de $20 \mu \mathrm{m}$ é destacada, como um tamanho de malha eficiente para a coleta das menores espécies de copépodes em quaisquer estágios do desenvolvimento.

Porém, foi notado que as malhas empregadas subestimaram o estágio adulto de diversas espécies, principalmente para aquelas classificadas no terceiro e algumas do segundo padrão de distribuição dos estágios. Acredita-se também que uma riqueza maior de copépodes poderia ser obtida utilizando uma malha de tamanho superior, pois as malhas empregadas possivelmente permitiram a evasão de animais maiores. Para a captura eficiente e estimativa precisa da abundância dos copépodes, desde náuplios a adultos, recomenda-se a utilização de duas redes: uma inferior e outra superior a 100 $\mu \mathrm{m}$, como a utilização das redes de 20 e 100, 50 e 150 ou 64 e $200 \mu$ m.

\subsubsection{Fatores controladores da variabilidade temporal do zooplâncton}

A comunidade zooplanctônica apresentou respostas temporais associadas às variáveis ambientais. Tais respostas, entretanto, são difíceis de serem interpretadas como consequência de variáveis isoladas, mas sim da interação entre diversos descritores ambientais e ecológicos. Para a visualização adequada de padrões de variabilidade, foram produzidas matrizes de correlação de Spearman e técnicas de estatística multivariada, frequentemente recomendada para estudos de comunidades (Valentin, $1984 a$ e $b$ ).

As concentrações de clorofila- $a$ e feopigmentos estiveram negativamente relacionadas à temperatura, sustentando o fato dessas concentrações terem sido mais elevadas durante o inverno. Os resultados das correlações de Spearman também indicaram a variação sazonal de algumas variáveis: a temperatura foi negativamente relacionada à salinidade, que por sua vez foi negativamente relacionada à precipitação (Tabelas 1.12 e 1.13). Em outras palavras, durante o verão, a temperatura é mais elevada, a precipitação é maior e, consequentemente, a salinidade diminui. O inverso ocorre durante o inverno, justificando a significância de tais relações.

A concentração de clorofila- $a$ não foi suficiente para explicar a variação da densidade dos grupos zooplanctônicos, uma vez que correlação foi encontrada apenas entre a concentração de clorofila- $a$ e a densidade de cladóceros para a malha de $20 \mu \mathrm{m}$. A concentração de feopigmentos, porém, foi positivamente correlacionada com a 
densidade dos copépodes para a malha de $100 \mu \mathrm{m}$. Tal relação poderia ser explicada pela herbivoria promovida pelos estágios de copepoditos, os animais dominantes nessas amostras. A atividade alimentar e a produção de pelotas fecais causam o aumento da concentração de feopigmentos, através da degradação da clorofila (Mackas \& Bohrer, 1976; Welschmeyer \& Lorenzen, 1985).

A interação entre os anos de coleta e a sazonalidade explicou a variabilidade da densidade das espécies analisadas. Considerando $\alpha=0,01$, apenas o fator ano foi diferente, o que indicou a importância da variabilidade interanual para a densidade zooplanctônica (Tabelas 1.14 a 1.16). Para uma melhor avaliação sobre a importância da escala anual sobre a comunidade planctônica, uma série temporal mais longa seria necessária.

A diferença entre as malhas não foi significativa entre as estações do ano ou anos de coleta. Tal resultado pode ser explicado pela existência de diferentes estágios de desenvolvimento dos copépodes, em proporções semelhantes de densidade para ambas as redes. A densidade total do zooplâncton para a rede de $20 \mu \mathrm{m}$ foi cerca de duas vezes superior à rede de $100 \mu \mathrm{m}$, porém, tal diferença raramente foi significativa.

A temperatura foi a principal variável que contribuiu para distribuição da densidade das espécies, através da análise de $P C A$, seguida pela clorofila- $a$ e feopigmentos. Ambos os grupos de espécies formados pelo PCA provavelmente estão relacionados à sazonalidade, estando presentes em maiores densidades durante o verão (cladóceros e copépodes da família Paracalanidae exceto Parvocalanus crassirostris e medusas, Temora spp. e larvas de gastrópodes). Já a grande maioria das espécies, não incluídas nos dois grupos citados nos resultados (larvas de bivalves e poliquetos, copépodes das famílias Acartidae, Oithonidae, Oncaeidae e Corycaeidae) parece possuir distribuição mais homogênea ao longo de todo o período amostrado. Para essas espécies, é possível que a variação interanual da densidade numérica tenha sido mais importante do que a sazonal.

Quanto à analise de $M D S$, o isolamento da amostra V 7 (Janeiro de 2009) pode ser explicado pela sua maior diversidade $(\mathrm{H}=3,84$ e 3,37 para as malhas de 20 e 100 $\mu \mathrm{m}$, respectivamente), pois foram observadas espécies típicas de águas oceânicas. A intrusão de águas oceânicas, mais frequentes durante o verão, pode ter sido mais intensa nesse período, ocasionando o transporte dessas espécies para águas próximas da costa, como reportado por Melo-Júnior (2009). A amostra I 10, correspondente à segunda coleta realizada durante o inverno de 2010, também ocorreu isoladamente dos demais 
grupos. Tal amostragem foi realizada após o dia de maior precipitação para o inverno de 2010, fato que possivelmente influenciou na composição zooplanctônica.

Para a malha de $100 \mu \mathrm{m}$, a visualização de dois grupos distintos foi explicada principalmente pelo ano de coleta. O grupo à direita do gráfico é formado em sua maioria por amostras coletadas em 2009, enquanto que o da esquerda é formado pelos demais anos. Também foi possível visualizar com clareza a distribuição das amostras do verão separadas do inverno, embora a sazonalidade não seja responsável pelos grupos formados pela análise de cluster (Figura 1.MDS4). A separação sazonal apresentou o mesmo padrão visualizado para a temperatura, reforçando a importância desta variável.

A profundidade da coleta também auxiliou na interpretação da formação dos grupos, pois todas as amostras coletadas em profundidades entre 3 a 5 metros foram representadas no agrupamento da direita. Estas profundidades mais rasas foram equivalentes às coletas realizadas no ponto denominado de Ribeira (Figura 1). Tais amostras tiveram um padrão de distribuição diferenciado, provavelmente porque o processo de mistura, mais intenso em baixas profundidades, deve ter afetado a estrutura do plâncton. Os dois pontos foram analisados em conjunto, uma vez que a maioria das coletas foi feita no Boqueirão. Entretanto, os resultados apontaram que diferenças na comunidade foram notáveis entre os dois pontos.

Aparentemente, existe uma diferença mais acentuada entre as estações para a fração maior do zooplâncton, quando comparado a menor, devido à contribuição de táxons dominantes durante o verão e raros ou pouco abundantes durante o inverno.

Os agrupamentos gerados no $P C A$ e $M D S$ foram menos nítidos para o zooplâncton da rede de $20 \mu \mathrm{m}$. Como comentado anteriormente, os náuplios foram os principais componentes desta fração de tamanho. Devido a taxonomia desses estágios ser laboriosa, a identificação foi realizada em categorias mais abrangentes (ex. náuplios de Oithona spp., náuplios de Oncaeidae), em relação aos copepoditos e adultos na malha de $100 \mu \mathrm{m}$. Uma menor resolução taxonômica pode ter mascarado padrões de distribuição do zooplâncton, o qual foi identificado em níveis taxonômicos mais refinados para a malha de $100 \mu \mathrm{m}$.

A contribuição relativamente baixa para a dissimilaridade da grande maioria dos táxons da comunidade da rede de $20 \mu \mathrm{m}$ também poderia explicar esse padrão. Foram necessários 20 táxons para alcançar um valor superior a 50\% da contribuição cumulativa pela análise de SIMPER. Tal padrão foi reflexo de uma baixa dominância, 
uma vez que os principais grupos em densidade relativa são basicamente os mesmos entre o verão e o inverno (Tabela 1.17).

Em linhas gerais, a comunidade zooplanctônica foi influenciada por variáveis ambientais com nítidas variações sazonais, embora a densidade total da comunidade não tenha sido relacionada à sazonalidade. Conclui-se que os efeitos da sazonalidade foram mais expressivos para a riqueza, diversidade e equitabilidade da comunidade, enquanto que a variação anual foi mais importante para a densidade planctônica.

A conhecida sazonalidade da produtividade do ecossistema marinho da plataforma da costa norte do estado de São Paulo, devido à ressurgências que ocorrem durante o verão não foram evidentes durante este estudo. É provável que o ponto de coleta esteja longe das áreas de influência da ressurgência e seus efeitos sobre o plâncton aqui estudo seja mínima. Maiores concentrações de clorofila- $a$, feopigmentos para o inverno dos três anos e maiores densidades do zooplâncton durante o inverno de 2011 corroboraram tal hipótese.

\subsection{Conclusões}

- A composição do zooplâncton foi dominada por espécies de águas costeiras, com ocorrência de táxons de águas oceânicas principalmente durante os períodos de verão. A riqueza, diversidade e equitabilidade foram em geral mais altas do que as registradas anteriormente para a região, possivelmente devido a heterogeneidade da estação de coleta.

- Os Tintinnina foram encontrados em altas densidades ao longo de todo o período amostral, destacando a importância do protozooplâncton na região. $\mathrm{O}$ microzooplâncton protista foi subestimado neste estudo e sua importância ecológica permanece pouco estudada na costa brasileira.

- O zooplâncton foi dominado principalmente por estágios juvenis de copépodes costeiros: náuplios para a rede de $20 \mu \mathrm{m}$ e copepoditos juvenis para a rede de $100 \mu \mathrm{m}$. A utilização das redes de 20 e $100 \mu \mathrm{m}$ foi satisfatória para a estimativa da densidade dos estágios imaturos de desenvolvimento da comunidade de copépodes, mas subestimou adultos de diversas espécies. 
- Não existe um padrão para os tamanhos de malhas utilizados para o estudo do zooplâncton no Brasil. Estudos são necessários para padronizar a seleção do tamanho das malhas, em relação aos compartimentos planctônicos a serem analisados.

- A densidade do zooplâncton apresentou alta variabilidade, tanto sazonal, quanto anual, sendo os maiores valores registrados para o inverno de 2011 para a malha de $20 \mu \mathrm{m}\left(33.160 \pm 23.136\right.$ org. $\left.\mathrm{m}^{-3}\right)$ e os menores para o inverno de 2009 para a malha de $100 \mu \mathrm{m}\left(5.393 \pm 2.264\right.$ org. $\left.\mathrm{m}^{-3}\right)$. A densidade do zooplâncton capturado pela rede de $20 \mu \mathrm{m}$ foi cerca de duas vezes maior do que o capturado pela rede de $100 \mu \mathrm{m}$.

- Variáveis ecológicas como a riqueza, diversidade e equitabilidade apresentaram respostas frente à variabilidade sazonal, enquanto que a densidade esteve mais relacionada à variabilidade interanual.

- A temperatura foi a principal variável ambiental atuando na ordenação das amostras, através das análises de PCA e $M D S$. As concentrações de clorofila- $a$ e feopigmentos, mais elevadas durante o inverno, também foram importantes para a estrutura do zooplâncton. A profundidade também foi um fator importante, uma vez que as amostras coletadas na estação abrigada mostraram-se separadas da maioria das amostradas coletadas no Boqueirão.

- A comunidade zooplanctônica foi mais homogênea durante o inverno. A maior heterogeneidade durante o verão deve-se a maior representatividade de cladóceros e a ocorrência esporádica de copépodes neríticos, característicos da plataforma externa. 
Capítulo 2

Crescimento e produção de copépodes pelágicos no litoral norte do estado de São Paulo 


\section{Capítulo 2. Crescimento e produção de copépodes pelágicos no litoral norte do estado de São Paulo}

\section{Resumo}

A produção zooplanctônica em águas tropicais e subtropicais do Atlântico Sul é pouco estudada e os raros trabalhos sobre o tema focaram os estágios adultos dos grupos de crustáceos dominantes no plâncton marinho, os copépodes. Sabe-se que estágios juvenis de desenvolvimento têm diferentes taxas de crescimento quando comparados aos adultos e que a abundância desses estágios é mais elevada. Conhecer o crescimento é crucial para estimar a produção do zooplâncton com maior acurácia para as águas tropicais. Neste trabalho foram realizados experimentos de coortes artificiais com diferentes faixas de tamanho (50-80, 80-100, 100-150 e 150-200 $\mu \mathrm{m})$ a fim de obter taxas de crescimento de diferentes espécies e estágios imaturos de copépodes durante o verão e inverno dos anos de 2009 e 2010 e verão de 2011, em Ubatuba, litoral sudeste do Brasil. Parâmetros ambientais como temperatura e salinidade, além das variáveis da comunidade planctônica como a concentração de clorofila- $a$ e feopigmentos foram controladas durante os experimentos e correlacionadas às taxas de crescimento. Os modelos globais para estimativa de crescimento de Hirst \& Bunker (2003) foram utilizados e o crescimento comparado com os resultados experimentais. A biomassa foi estimada a partir de equações de regressão comprimento-peso e a produção calculada em nível de família e ordem. Os valores de crescimento foram semelhantes entre as diferentes classes de tamanho, sendo a menor média para a coorte de 100-150 $\mu \mathrm{m}(0,27$ $\left.\pm 0,17 \mathrm{~d}^{-1}\right)$ e a maior na coorte de $50-80 \mu \mathrm{m}\left(0,34 \pm 0,22 \mathrm{~d}^{-1}\right)$ e foram substancialmente diferentes entre as ordens de copépodes, sendo que os Calanoida apresentaram valores mais elevados em relação aos Cyclopoida $\left(0,41 \pm 0,21 \mathrm{~d}^{-1}\right.$ e $0,27 \pm 0,17 \mathrm{~d}^{-1}$ respectivamente). As taxas de crescimento obtidas experimentalmente foram diferentes das obtidas por modelos matemáticos para a maioria dos táxons, sugerindo a aplicabilidade limitada dos mesmos para os copépodes estudados. A concentração de clorofila- $a$ não foi considerada limitante para o crescimento de estágios juvenis de copépodes nesta região subtropical. A produção média dos estágios juvenis de copépodes foi de $0,45 \mathrm{mg} \mathrm{C} \mathrm{m}^{-3}$, semelhante ao encontrado em outras áreas tropicais.

Palavras-chave: Atlântico sul, náuplios, copepoditos, coortes artificiais. 
Chapter 2: Growth and production of pelagic copepods from the north coast of the São Paulo state

\begin{abstract}
Zooplankton production in tropical and subtropical waters of the South Atlantic is overlooked and only a few studies are available, all focusing on adult stages of the dominant zooplanktonic taxa, the copepods. Immature stages are known to have different growth rates than the adults and higher abundances. Knowledge on growth is necessary to estimate zooplankton production with better accuracy. Artificial cohort experiments with different size classes (50-80, 80-100, 100-150 and 150-200 $\mu \mathrm{m})$ were performed in this study to determine growth rates of different taxa and immature copepod stages during 2009 and 2010 summer and winter seasons and summer 2011 in Ubatuba, southeast coast of Brazil. Environmental variables as temperature, salinity, chlorophyll- $a$ and pheopigments concentrations were controlled during the experiments and correlated with growth rates. The global models for growth estimates proposed by Hirst \& Bunker (2003) were compared with the experimental results. Biomass was estimated by length-weight regressions and production calculated at family and order taxonomic levels. Growth rates were similar between the different size classes, the lower occurring in the $100-150 \mu \mathrm{m}\left(0,27 \pm 0,17 \mathrm{~d}^{-1}\right)$ and the largest in the 50-80 $\mu \mathrm{m}$ $\left(0,34 \pm 0,22 \mathrm{~d}^{-1}\right)$ cohorts and were substantially different between the orders. Calanoid copepods showed higher growth rates than cyclopoids $\left(0,41 \pm 0,21 \mathrm{~d}^{-1}\right.$ e $0,27 \pm 0,17 \mathrm{~d}^{-1}$, respectively). Most experimental growth rates were different than model-derived estimates, suggesting a limited applicability of these equations for the copepods analyzed here. Chlorophyll- $a$ concentration was not considered a limiting factor on copepod growth in this subtropical region. Mean production of immature stages of copepods was $0.45 \mathrm{mg} \mathrm{C} \mathrm{m}^{-3}$, similar to other tropical areas.
\end{abstract}

Keywords: South Atlantic, nauplii, copepodites, artificial cohorts. 


\subsection{Introdução}

Os copépodes são os metazoários dominantes do mesozooplâncton marinho (organismos entre 200-2.000 $\mu^{1}$ ), sendo responsáveis por cerca de 50 a $95 \%$ da densidade zooplanctônica (Longhurst, 1985) e os maiores valores de abundância numérica e biomassa nos ecossistemas pelágicos marinhos. Estima-se que existam $1,3^{21}$ copépodes pelágicos marinhos, abundância três vezes maior do que o número estimado para os insetos terrestres (Boxshall, 1998). A biomassa, apenas para as espécies pelágicas, é estimada em $46,8.10^{9}$ t, ou 150 vezes a biomassa de seres humanos no planeta (Schminke, 2007).

Tais crustáceos desempenham papéis cruciais na predação de diversas classes de tamanho dos produtores primários (cianobactérias, dinoflagelados, diatomáceas), do nanoplâncton ao mesozooplâncton (bactérias heterotróficas, nanoflagelados, ciliados, náuplios, copepoditos e larvas meroplanctônicas), na regeneração de nutrientes e na formação das vias clássica e regenerada do sistema pelágico (Møller, 2007). A grande diversidade e densidade dos copépodes ainda os inserem em diversas interações ecológicas, por exemplo, com níveis tróficos superiores como principal recurso alimentar (Grahame, 1987), parasitas obrigatórios (Boxshall \& Halsey, 2004), predadores oportunistas (Go et al., 1998), consumidores da neve marinha (Green \& Dagg, 1997) e microhabitats para bactérias heterotróficas (Tang, et al., 2011). Copépodes juvenis representam a principal conexão entre a alça microbiana e compartimentos superiores como o macrozooplâncton e o nécton.

Os náuplios são provavelmente os metazoários mais abundantes dos ambientes aquáticos (Fryer, 1986). Durante o ciclo de vida da grande maioria dos copépodes, cinco ou seis estágios naupliares estão presentes. Tais estágios são predados por inúmeros organismos do zooplâncton e como consequência, os estágios de copepodito após a metamorfose são menos numerosos. Os copepoditos imaturos (C I a V) geralmente representam o compartimento mais abundante do mesozooplâncton, enquanto que os náuplios são os metazoários mais numerosos do microzooplâncton (Gallienne \& Robins, 2001).

Para poder entender a dinâmica populacional do zooplâncton e seu papel no

\footnotetext{
${ }^{1}$ Utilizando a classificação de tamanho de Dussart (1965), modificada por Omori \& Ikeda (1984).
} 
fluxo e transformação da matéria nos oceanos, é necessário estudar sua taxa de crescimento e produção (Hirst \& Lampitt, 1998). A produtividade de um metazoário em um dado intervalo de tempo equivale à taxa de síntese de biomassa, independente do destino dessa nova matéria (Hirst \& McKinnon, 2001). O levantamento da produção destes organismos permite conhecer o papel do zooplâncton na transferência de energia e matéria para os níveis tróficos superiores da teia alimentar marinha (Hirst \& Bunker, 2003).

As formas juvenis, copepoditos e náuplios, possuem diferentes taxas de crescimento por estágio de desenvolvimento, o que reflete nas estimativas da produção de uma comunidade. Diversos estudos demonstraram que para a maioria das espécies, as taxas de crescimento são as mais elevadas ou que o tempo de desenvolvimento é menor para os estágios naupliares do que para os copepoditos (Hart, 1990; Peterson, 2001; Almeda et al., 2010). Em águas costeiras tropicais, onde os microcrustáceos possuem ciclos de vida mais curtos quando comparados com espécies de águas temperadas, as taxas de crescimento são essenciais para uma estimativa mais realista da produção zooplanctônica. Soma-se a isso a ausência de dados como taxas de crescimento e produção para os estágios imaturos de copépodes na costa brasileira.

A estimativa da produção de copépodes pelágicos é comumente realizada através de quatro métodos: produção de ovos, coortes artificiais, produção de mudas e métodos enzimáticos. A produtividade zooplanctônica é variável e as estimativas estão sujeitas a erros metodológicos. A produção de ovos não se aplica para os estágios imaturos, enquanto que o método de produção de mudas tem sido criticado na literatura (Hirst et al., 2005).

Recentemente, o método enzimático da quitobiase apresentou resultados satisfatórios (Ávila et al., 2012), porém tal metodologia requer certo tempo de padronização, devido a produção de quitobiase por outras fontes além dos copépodes, como bactérias vibrionáceas e protistas. Essa interferência é ainda maior em águas costeiras ou rasas (Sastri \& Dower, 2006). Além disso, maior infraestrutura em laboratório é necessária. Entre os métodos disponíveis, a coorte artificial tem obtido boa parte dos resultados para os estágios juvenis (Kimmerer \& McKinnon, 1987; McKinnon \& Duggan, 2003; Liu \& Hopcroft, 2006 a e b; Kimmerer et al., 2007; Lin et al., 2012). 
Em águas costeiras tropicais do sudeste do Brasil, a comunidade de copépodes é dominada por espécies pequenas das ordens Calanoida e Cyclopoida, como Parvocalanus crassirostris, Paracalanus quasimodo, P. nanus, Oncaea spp., Oithona hebes e Dioithona oculata (Sartori \& Lopes, 2000; Lopes et al., 2006; Melo-Júnior, 2009). Esses juvenis são frações dominantes dos metazoários que compõem o meso- e microzooplâncton na região. O método de coortes artificiais é o mais prático quando se trabalha com organismos nessa fração de tamanho devido a reduzida dimensão e biomassa que dificulta trabalhar com indivíduos isoladamente.

Sabe-se também que as taxas de crescimento e, consequentemente, a produção sofrem variação ontogenética em diversos táxons zooplanctônicos (Hirst \& Bunker, 2003). A maioria dos trabalhos sobre produção do zooplâncton tem foco principal nos organismos adultos, gerando falhas no conhecimento da produção zooplanctônica total das populações (integrada). Essa informação é ainda mais importante em ecossistemas tropicais, onde as taxas de crescimento são geralmente mais elevadas, (Chisholm \& Roff, 1990; Hopcroft et al., 1998).

Diversos fatores físicos e ambientais também interagem e modelam a produção dos metazoários. Conhecer adequadamente a resposta do zooplâncton a esses fatores é crucial para conhecimento da ecologia dos organismos, o funcionamento e dinâmica do ecossistema pelágico, realizar predições sobre os estoques e avaliar o impacto de mudanças climáticas sobre essas comunidades (Dam, 2013). Entre os físicos, a temperatura é fortemente relacionada ao crescimento e produção. Vários estudos comprovam essa relação para os copépodes (Huntley \& Lopez, 1992; Hirst \& Sheader, 1997; Hopcroft et al., 1998; Hirst \& Lampitt, 1998). A temperatura atua diretamente em taxas metabólicas dos crustáceos, sendo o tempo de desenvolvimento de náuplios e copepoditos uma função monotônica inversa à temperatura (Hart, 1990).

A turbulência, em intensidade apropriada, promove maior encontro entre partículas, auxiliando a predação pelos animais e provavelmente reflete em valores maiores de produção (Miller, 2004). A advecção é outro fator físico que interfere no estudo da dinâmica zooplanctônica, principalmente em ambientes marinhos não confinados e deve ser levado em consideração quando se estima índices de biomassa e produtividade regionais (em pequenas escalas). Ainda, a mistura de camadas e processos de ressurgência, resultando na homogeneização ou fertilização da coluna de água, também favorece a produção secundária indiretamente, por promover maior 
produtividade primária (Melo-Júnior et al., 2013).

Entre as principais variáveis biológicas relacionadas ao crescimento e produção, destaca-se a disponibilidade e qualidade do alimento e o tamanho dos animais (Jónasdottir et al., 2000). Sabe-se que para regiões tropicais, os recursos alimentares podem limitar as taxas de crescimento e produção do zooplâncton (ver McKinnon \& Duggan, 2003). A predominância de sistemas dominados pela via regenerativa microbiana, principalmente durante o inverno na costa sudeste do Brasil, evidencia a condição oligotrófica das águas (Oliveira, 2000).

Diferentes espectros de tamanho do fitoplâncton são consumidos por predadores específicos e esses limitados pelos seus respectivos estoques. Em águas costeiras oligotróficas tropicais, dominadas por produtores de tamanho reduzido, o cenário favorece a dominância de copépodes de pequeno porte, como as famílias Oithonidae, Paracalanidae, Clausocalanidae e Euterpina acutifrons. Esses copépodes variam entre cerca de 350 a $1.000 \mu \mathrm{m}$ de comprimento total quando adultos (Bradford-Grieve et al., 1999). Seus náuplios e juvenis variam entre 60 e $600 \mu \mathrm{m}$. Em geral, táxons de menor porte também apresentam taxas de crescimento mais elevadas, quando comparadas com espécies maiores (Peterson et al., 1991; entre outros).

Para determinar a importância dos estágios juvenis dos copépodes em uma região costeira subtropical, a biomassa foi estimada através de modelos de regressão e o método de coortes artificiais foi utilizado para determinação de taxas de crescimento das espécies dominantes durante as estações de verão e inverno para os anos de 2009 e 2010 e verão de 2011 em Ubatuba, litoral norte do estado de São Paulo. 


\subsection{Objetivos}

\subsubsection{Objetivo geral}

Avaliar a importância de estágios imaturos dos copépodes em uma região costeira subtropical quanto a produção, através da determinação experimental das taxas de crescimento e estimativa da biomassa.

\subsubsection{Objetivos específicos}

- Estimar as taxas de crescimento dos estágios juvenis de copépodes pelágicos, através do método de coortes artificiais.

- Comparar os resultados obtidos experimentalmente com o principal modelo matemático de crescimento para copépodes na literatura.

- Verificar a influência de variáveis ambientais e variáveis controladas do experimento sobre as taxas de crescimento.

- Estimar a biomassa e produção dos táxons dominantes de copépodes presentes nos experimentos.

- Analisar a variabilidade temporal do crescimento, biomassa e produção ao longo do período estudado.

- Analisar a variabilidade do crescimento em relação a diferentes níveis taxonômicos (ordens e famílias).

- Comparar os valores de crescimento e produção deste trabalho com os fornecidos na literatura.

\subsection{Material e Métodos}

\subsubsection{Obtenção das variáveis ambientais e do plâncton}

O plâncton foi coletado em uma estação fixa localizada nas coordenadas $23^{\circ} 31^{\text {' }}$ 27' 'S e 45 04' 54', O, próxima a base de pesquisa Clarimundo de Jesus, do Instituto Oceanográfico da USP, no município de Ubatuba (Figura 1, introdução geral) durante 
os anos de 2009 a 2011. Os experimentos de coortes artificiais foram realizados no Laboratório Integrado de Processos Oceanográficos (LIPO), na referida base de pesquisa.

As coletas de zooplâncton e água foram geralmente realizadas em dias alternados, totalizando ao menos duas amostragens em cada estação de verão e inverno dos anos de 2009 e 2010 e durante o verão de 2011, preferencialmente no período da manhã devido a questões logísticas de uso da base de pesquisa. Em cada coleta, foi obtida uma amostra quantitativa de plâncton, fixada imediatamente após o arrasto e uma amostra qualitativa com animais vivos para experimentos de coortes artificiais em laboratório. De um total de 16 coletas, apenas 3 foram realizadas na estação interna abrigada $A$ (Tabela 2.1).

Um total de 31 experimentos foi conduzido em diferentes classes de tamanho de coortes: $50-80(n=10), 80-100(n=11), 100-150(n=11)$ e $150-200 \mu \mathrm{m}(n=12)$. As quatro classes de tamanho foram selecionadas para ampliar a diversidade de táxons e estágios de desenvolvimento presentes nas amostras de plâncton das redes de 20 e 100 $\mu \mathrm{m}$.

A temperatura e salinidade da água do mar foram obtidas por termômetro e refratômetro no momento de cada coleta. A água de superfície foi coletada em recipientes limpos de 20 L para obtenção de variáveis ecológicas do plâncton (clorofila$a$ e feopigmentos totais da água, filtrada a $40 \mu \mathrm{m})$. As coletas de plâncton foram realizadas através de arrastos horizontais em subsuperfície ou verticais curtos, com redes de malha equivalente a $20 \mu \mathrm{m}$ (para as coortes de 50-80 e 80-100 $\mu \mathrm{m}$ ) e $100 \mu \mathrm{m}$ (para as coortes de 100-150 e 150-200 $\mu \mathrm{m}$ ) equipadas com fluxômetro, poitas e copo fechado (Figura 2.1 A e B).

As redes foram arrastadas o mais lentamente possível e o plâncton transferido imediatamente para recipientes de $20 \mathrm{~L}$ de volume com água do mar da estação de coleta. O recipiente era transportado fechado, sem bolhas e envolto em saco plástico preto para redução da radiação incidente até o transporte para o laboratório (MeloJúnior, 2009). O saco plástico revestiu o balde internamente para as coletas realizadas durante 2009 (Figura 2.1 C) e externamente ao balde, durante as amostragens posteriores, a fim de evitar eventuais contaminantes que possam ser liberados do plástico. 
Tabela 2.1: Data, horário e profundidade local das coletas de plâncton para os experimentos de coortes artificiais. Exp.: experimento, com o tamanho da coorte em $\mu \mathrm{m}$; Prof.: profundidade; *: coletas realizadas na estação abrigada.

\begin{tabular}{|c|c|c|c|c|}
\hline Campanha & Data & Horário (h) & Exp. & Prof. (m) \\
\hline \multirow{4}{*}{ Verão de 2009} & $24 / 01$ & $10: 00$ & C-1*: 50-80; 80-100 & 3 \\
\hline & $26 / 01$ & $10: 20$ & C-2*: $100-150 ; 150-200$ & 4 \\
\hline & 29/01 & $11: 00$ & C-3: 100-150; 150-200 & 18 \\
\hline & $30 / 01$ & $13: 15$ & C-4: 50-80; 80-100 & 40 \\
\hline \multirow{3}{*}{ Inverno de 2009} & $16 / 07$ & $10: 40$ & C-5: 50-80; 80-100 & 20 \\
\hline & $18 / 07$ & $09: 15$ & C-6*: $100-150 ; 150-200$ & 3 \\
\hline & $24 / 07$ & $10: 30$ & C-7: $50-80 ; 80-100$ & 3 \\
\hline \multirow{2}{*}{ Verão de 2010} & $12 / 01$ & 09:10 & C-8: $100-150 ; 150-200$ & 25 \\
\hline & $22 / 01$ & 09:00 & C-9: $80-100$ & 23 \\
\hline \multirow{4}{*}{ Inverno de 2010} & $21 / 07$ & $08: 45$ & C-10: 100-150; 150-200 & 25 \\
\hline & $23 / 07$ & $08: 50$ & C-11: 50-80; 80-100 & 20 \\
\hline & $30 / 07$ & 08:40 & C-12: $100-150 ; 150-200$ & 30 \\
\hline & $01 / 08$ & 08:15 & C-13: 50-80; 80-100 & 28 \\
\hline \multirow{3}{*}{ Verão de 2011} & $17 / 01$ & $08: 45$ & C-14: $50-80 ; 80-100$ & 33 \\
\hline & $19 / 01$ & $08: 30$ & C-15: $100-150 ; 150-200$ & 33 \\
\hline & $24 / 01$ & $08: 45$ & C-16: 100-150; 150-200 & 34 \\
\hline
\end{tabular}

Um segundo arrasto, de maior velocidade e duração (entre 2 a 5 minutos) era realizado em cada ponto de coleta e o plâncton fixado em formol $4 \%$ neutralizado com Tetraborato de Sódio (amostra quantitativa). O tempo de arrasto foi determinado de acordo com a concentração aparente dos organismos, obtida pela inspeção visual das amostras coletadas anteriormente. Essas amostras foram utilizadas na determinação da composição, densidade e biomassa microzooplanctônica.

\subsubsection{Clorofila- $a$ e feopigmentos (clorofila acidificada)}

A clorofila- $a$ foi obtida através de filtragem a vácuo (pressão máxima de $10 \mathrm{~mm}$ $\mathrm{Hg}$ ) sobre membranas $\mathrm{GF} / \mathrm{F}$ de $0,7 \mu \mathrm{m}$ de porosidade (Whatman $\AA$ ), realizada no laboratório ao abrigo da luz e imediatamente após as coletas (Figura 2.1 F). Após cada intervalo experimental $(0,24,48$ e 72 horas), a água removida das garrafas de incubação foi filtrada a $37 \mu \mathrm{m}$, homogeneizada e uma alíquota de 100 a $250 \mathrm{~mL}$ filtrada. As membranas foram armazenadas em congelador à $-20^{\circ} \mathrm{C}$ até o momento das análises. Os pigmentos foram extraídos utilizando acetona $90 \%$ (Merck®) por 24 horas a $-10^{\circ} \mathrm{C}$ e as concentrações obtidas por fluorimetria (Parsons et al., 1984 modificado; Weslchmeyer, 1994). O fluorímetro foi calibrado com clorofila- $a$ purificada (Merck®) e o limite de detecção obtido anteriormente às análises.

Tanto para as amostras do tratamento controle, quanto do experimental, a água 
foi previamente filtrada a $37 \mu \mathrm{m}$ para a remoção do zooplâncton. Esta etapa também eliminou as espécies fitoplanctônicas de maior porte. Contudo, tais células não são utilizadas pelos estágios juvenis de copépodes, principalmente os tropicais de tamanho reduzido, sendo considerada como uma fração de clorofila- $a$ não disponível para esses animais. Foram determinadas três réplicas para cada coleta para obter as concentrações no ambiente durante o início e cada um dos períodos de incubação dos experimentos de coortes artificiais.

\subsubsection{Análise qualitativa dos copépodes}

Os copépodes foram identificados até o nível de espécie sempre que possível. Para as análises das amostras quantitativas e dos experimentos de coortes artificiais, os estágios de desenvolvimento foram agrupados em categorias: Ortonáuplio (NI-II) e Metanáuplio (NIII-VI), primeiros copepoditos (CI-III), copepoditos tardios (CIV-V) ou copepoditos imaturos (CI-V) e adultos (CVI). A divisão foi adotada devido à ausência de descrição para estágios imaturos de algumas espécies e a limitação do método de análise por imagens (item 2.3.5), dificultando a identificação por estágio de desenvolvimento.

Algumas espécies foram agrupadas em gêneros ou famílias, para possibilitar a análise das amostras provenientes dos experimentos, uma vez que as imagens limitaram a resolução taxonômica. Foi o caso para náuplios e copepoditos da família Corycaeidae, Oncaeidae, Paracalanidae (exceto Parvocalanus crassirostris), do gênero Acartia e naúplios e copepoditos dos estágios I à III da família Oithonidade (exceto para as espécies Oithona plumifera e Dioithona oculata).

Diversas referências foram utilizadas para os copépodes, destacando os trabalhos de Björnberg (1967, 1972, 1981); Björnberg et al.(1994); Bradford-Grieve et al. (1999) e Boxshall \& Halsey (2004). Todas as espécies identificadas foram validadas e atualizadas quanto à nomenclatura e autoria através dos bancos de dados WoRMS (World Register of Marine Species; Appeltans et al., 2012), onde fora indexado o antigo banco de dados World of Copepods (Walter \& Boxshall, 2008) e Marine planktonic copepods (http://copepodes.obs-banylus.fr). A classificação sistemática hierárquica de Boxshall \& Halsey (2004) foi adotada. 


\subsubsection{Coortes artificiais e Desenho experimental}

Quatro classes de tamanho de coortes artificiais foram selecionadas: 50-80, 80$100,100-150$ e 150-200 $\mu \mathrm{m}$. Os limites superiores e inferiores das coortes foram definidos de acordo com a largura de náuplios e copepoditos de águas costeiras tropicais (Björnberg, 1981; Bradford-Grieve et al., 1999). Coortes de pequena amplitude ( $\leq 50$ $\mu \mathrm{m})$ foram criadas, tornando-as mais homogêneas quanto a variação de tamanho e diversidade dos organismos (Kimmerer et al., 2007) e reduzindo a ocorrência de eventuais predadores.

O método selecionou os animais de acordo com a largura dos mesmos, através de uma série de filtrações inversas por malhas de nylon de diversos tamanhos $(50,80$, 100,150 e $200 \mu \mathrm{m}$ ), uma vez que o comprimento dos organismos incubados foi sempre maior. Os copépodes de vida livre, desde os estágios naupliares, já possuem o corpo alongado no eixo ântero-posterior (Huys \& Boxshall, 1991).

Primeiramente, a água do mar de superfície da estação de coleta, que serviu como meio de incubação, foi pré-filtrada em malha de $30 \mu \mathrm{m}$ para remoção do zooplâncton e eventuais predadores. A água filtrada foi adicionada às garrafas de policarbonato transparentes de dois litros (Nalgene) e mantidas em temperatura controlada em câmara de incubação (Figura 2.1 D). As malhas foram imersas em um recipiente contendo a água pré-filtrada e o zooplâncton cuidadosamente sifonado através dos filtros, utilizando uma mangueira de silicone. A água e animais que passam pelo sistema constituem a coorte utilizada nas incubações e os filtros representam os limites superiores de largura dos organismos nessas coortes.

O zooplâncton fracionado (coorte) foi então homogeneizado e alíquotas de volumes conhecidos adicionadas às garrafas de incubação. As garrafas foram preenchidas até a boca e fechadas com parafilme (SPI supplies) para evitar vazamentos e formação de bolhas. A quantidade de indivíduos incubados por garrafa sofreu variações, porém foi inspecionado se essa quantidade era apropriada para o volume de incubação, através da análise de uma alíquota das coortes ao estereomicroscópio, anteriormente ao início do experimento (50-500 org. $\left.\mathrm{L}^{-1}\right)$.

Para formação das coortes de 50-80 e 80-100 $\mu \mathrm{m}$, a amostra de zooplâncton coletada pela rede de $20 \mu \mathrm{m}$ foi diluída em água do mar filtrada e sifonada por um filtro elaborado de $100 \mu \mathrm{m}$ de malha para o interior de um balde limpo contendo água do mar filtrada, para reduzir possíveis impactos mecânicos sobre os animais. O plâncton que 
passou pela rede foi então novamente sifonado por um filtro de $80 \mu \mathrm{m}$. Os organismos retidos por essa rede constituem a coorte de $80-100 \mu \mathrm{m}$, a qual foi gentilmente transferida para um béquer e posteriormente replicada nas garrafas de cultivo. $\mathrm{O}$ zooplâncton que permaneceu no balde, constitui uma fração de tamanho entre 20 (limite da rede) e $80 \mu \mathrm{m}$ e foi sifonado novamente por uma malha de $50 \mu \mathrm{m}$, para a formação da coorte de $50-80 \mu \mathrm{m}$.

O mesmo procedimento foi repetido para as amostras de zooplâncton coletadas pela rede de $100 \mu \mathrm{m}$, utilizando filtros de tamanho equivalente a 150 e $200 \mu \mathrm{m}$, para formação das coortes de 100-150 e 150-200 $\mu \mathrm{m}$.
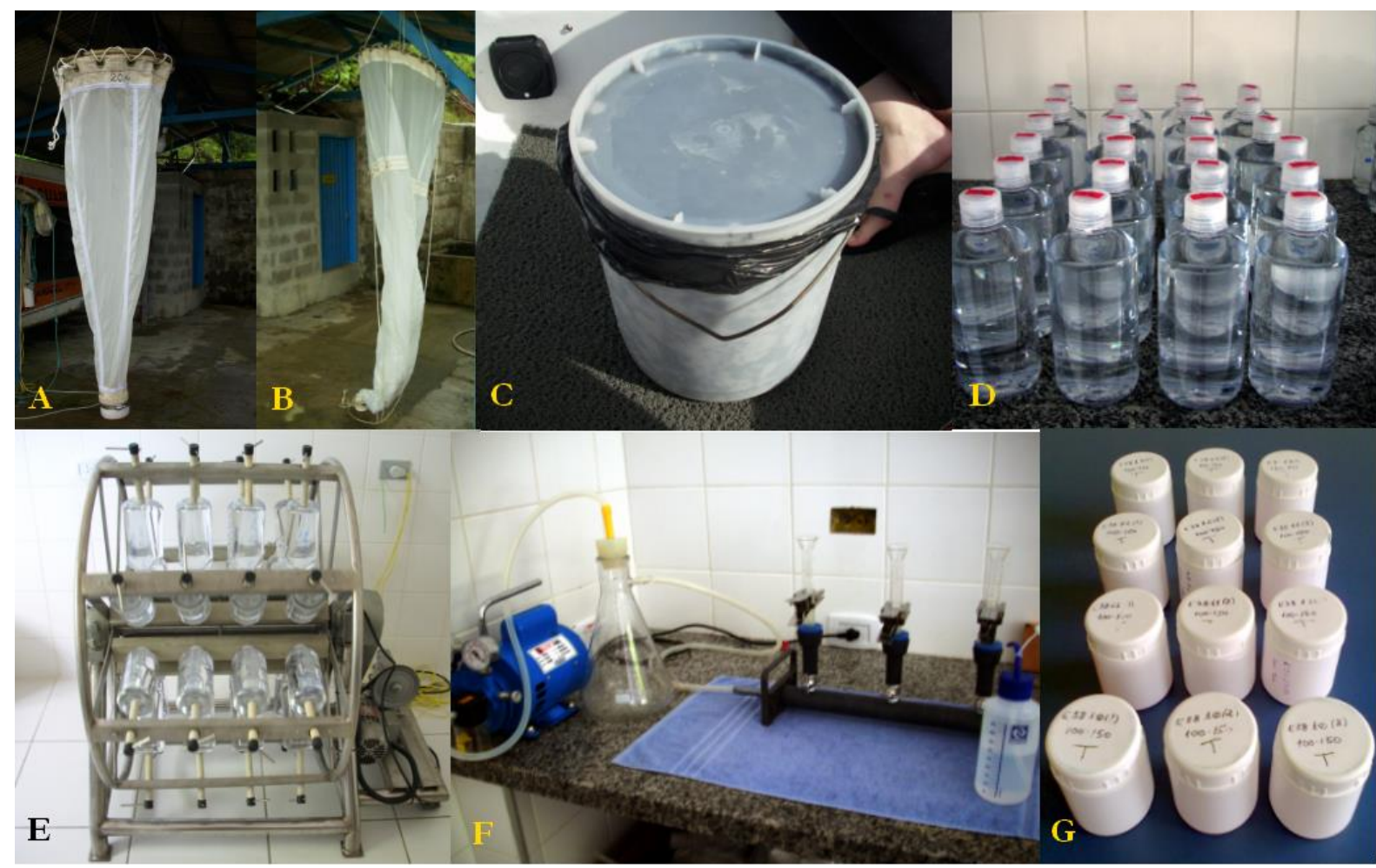

Figura 2.1: Materiais utilizados para a elaboração dos experimentos de coortes artificiais. A: rede de plâncton cônica de $20 \mu \mathrm{m}$; B: rede cônica de plâncton de $100 \mu \mathrm{m}$; $\mathbf{C}$ : balde completamente cheio, contendo o zooplâncton após a coleta e revestido por um saco plástico preto para minimizar a radiação incidente; D: garrafas Nalgene completamente cheias e vedadas; E: roda de plâncton com diversas réplicas experimentais; F: kit de filtração de água do mar e $\mathbf{G}$ : zooplâncton removido das garrafas, após os períodos de incubação e fixados em formol $2 \%$.

A elaboração e incubação das coortes foram realizadas em sala de temperatura controlada (Eletrolab®), sendo que diferentes valores foram testados $\left(18\right.$ a $\left.27^{\circ} \mathrm{C}\right)$ e que a variação de temperatura foi de $\pm 0,3^{\circ} \mathrm{C}$. Dados como a temperatura de incubação, salinidade, concentração inicial de clorofila- $a$ e feopigmentos e o número de 
metazoários incubados são fornecidos na tabela 2.2. A incidência luminosa e fotoperíodos naturais foram mantidas, sendo que as garrafas permaneceram no escuro ao anoitecer. Um agitador automático permaneceu ligado durante toda a incubação (roda de plâncton, Figura 2.1 E), a uma velocidade de 1,3 rpm e manteve os frascos homogeneizados durante todo o curso dos experimentos. A única exceção ocorreu durante o verão de 2009, quando as garrafas foram homogeneizadas manualmente em intervalos de uma a duas horas.

Foram montados dois experimentos consecutivos por dia, sendo que duas coortes foram incubadas simultaneamente (coortes de 50-80 e 80-100 ou coortes de 100-150 e 150-200, cada coorte equivale à um experimento).

Tabela 2.2: Temperatura (T) local no momento da coleta e de incubação (constante), salinidade (S), concentrações iniciais de clorofila- $a(\mathrm{Cl}-a)$ e feopigmentos (Feop.) da água de superfície do local de coleta e número médio da metazoários incubados no período inicial $(\mathrm{N})$ para cada um dos experimentos analisados (primeiro valor para coorte menor e segundo para a coorte maior). Em negrito: valores iniciais de clorofila- $a$ inferiores à $0,6 \mathrm{mg} \cdot \mathrm{m}^{-3}$, limiar determinado por Hirst \& Bunker (2003).

\begin{tabular}{lcccccc}
\hline \multicolumn{1}{c}{ Experimentos } & $\begin{array}{c}\text { T. } \\
\text { local }\end{array}$ & $\begin{array}{c}\text { T. } \\
\text { incubação }\end{array}$ & S & Cl-a & Feop. & N \\
\hline C-1: $50-80 ; 80-100$ & 26 & 25 & 35 & 1,53 & 0,84 & 102,118 \\
C-2: $100-150 ; 150-200$ & 25,5 & 26 & 35 & 1,05 & 0,53 & 103,288 \\
C-3: $100-150 ; 150-200$ & 26 & 25,5 & 36 & $\mathbf{0 , 5 2}$ & 0,10 & 46,88 \\
C-4: $50-80 ; 80-100$ & 25,5 & 25,5 & 36 & 0,97 & 0,15 & 103,200 \\
\hline C-5: $50-80 ; 80-100$ & 23 & 23 & 36 & 1,26 & 0,30 & 87,71 \\
C-6: $100-150 ; 150-200$ & 22,5 & 22,5 & 37 & $\mathbf{0 , 4 5}$ & 0,10 & 108,165 \\
C-7: $50-80 ; 80-100$ & 22 & 22 & 36 & 1,72 & 0,04 & 250,228 \\
\hline C-8: $100-150 ; 150-200$ & 28 & 27 & 35 & 0,89 & 0,08 & 578,423 \\
C-9: $80-100$ & 28 & 19 & 34 & 0,70 & 0,16 & 218 \\
\hline C-10: $100-150 ; 150-200$ & 22 & 22 & 34 & 2,18 & 0,46 & 128,204 \\
C-11: $50-80 ; 80-100$ & 22,5 & 22 & 34 & 0,92 & 0,27 & 54,74 \\
C-12: $100-150 ; 150-200$ & 22 & 18 & 35 & 1,51 & 0,34 & 225,314 \\
C-13: $50-80 ; 80-100$ & 23 & 18 & 36 & 0,82 & 0,19 & 38,94 \\
\hline C-14: $50-80 ; 80-100$ & 28 & 27,5 & 35 & $\mathbf{0 , 3 2}$ & 0,09 & 28,170 \\
C-15: $100-150 ; 150-200$ & 28,5 & 27,5 & 33 & $\mathbf{0 , 2 2}$ & 0,05 & 144,140 \\
C-16: $100-150 ; 150-200$ & 28 & 18 & 35 & $\mathbf{0 , 1 6}$ & 0,05 & 321,152 \\
\hline
\end{tabular}


Nove garrafas foram incubadas por experimento, de maneira que três réplicas são geradas para cada intervalo de tempo (24, 48 e 72 horas; siglas $t 1$, $t 2$ e $t 3$ respectivamente). $\mathrm{O}$ período inicial representado por $0 \mathrm{~h}$ consta de três réplicas do volume de zooplâncton adicionado às garrafas, fixadas durante o momento da incubação das coortes. Além disso, os controles "brancos" também foram obtidos em triplicata para cada período do experimento, para obtenção dos valores de clorofila- $a$ (Figura 2.2). As garrafas de controle continham apenas a água do mar filtrada a $30 \mu \mathrm{m}$ para obtenção da concentração de clorofila- $a$ e feopigmentos após o intervalo de incubação. A clorofila- $a$ total foi obtida juntamente com os tratamentos contendo as coortes. O número de réplicas é baseado em McKinnon \& Duggan (2003), McKinnon et al. (2005) e Kimmerer et al. (2007).

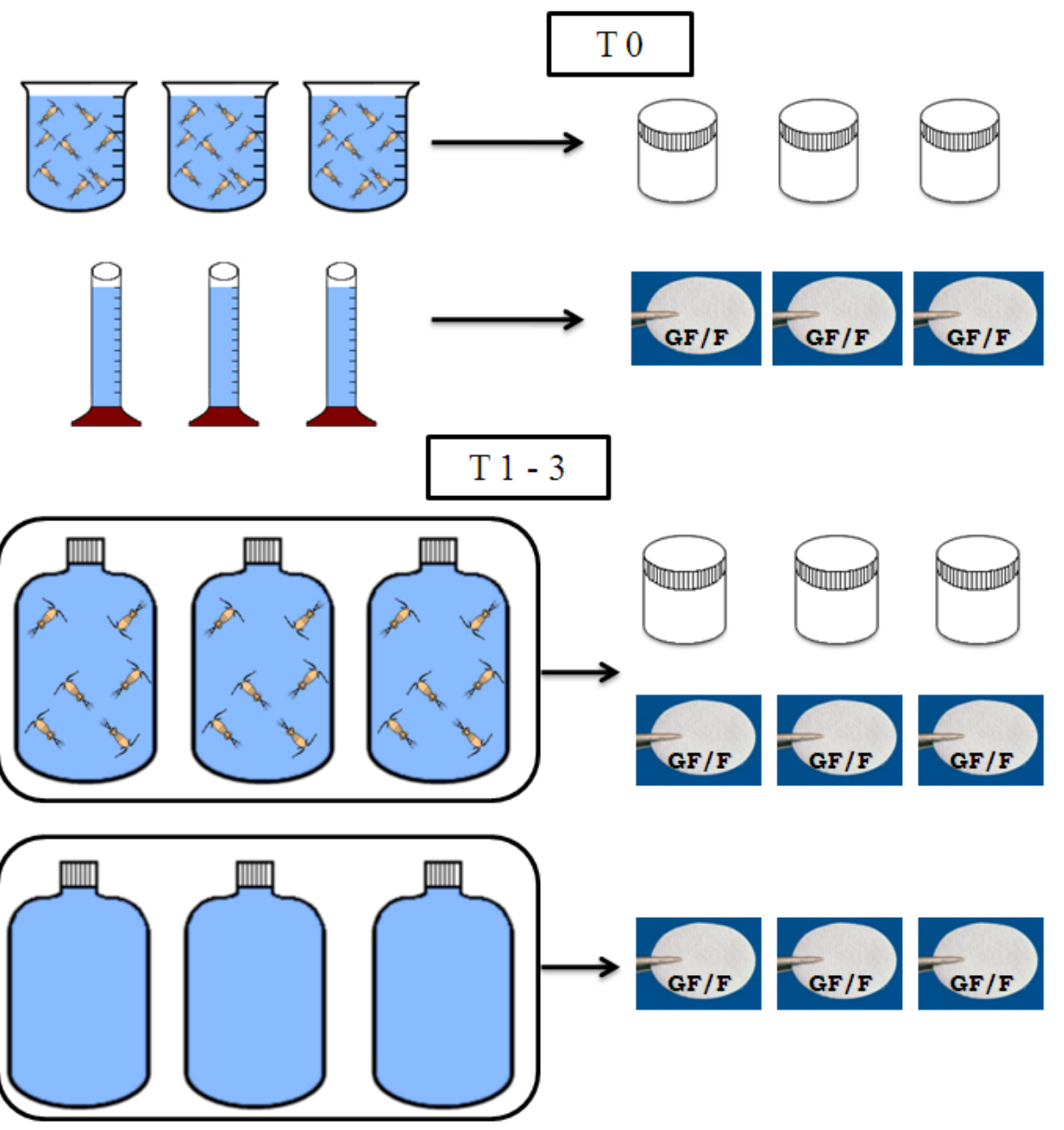

Figura 2.2: Desenho experimental das coortes artificiais. Durante o período inicial $(t 0)$ foram filtradas três amostras de água para obtenção da concentração de clorofila- $a$ e feopigmentos, representada pelos filtros GF/F. Durante os períodos experimentais $(t$ 1 a $t 3$ ), foram incubadas três réplicas experimentais e três controles. 
Três réplicas foram fixadas no momento inicial do experimento e após 24,48 e 72 horas, totalizando 12 amostras em cada experimento. Após a incubação, os organismos foram removidos das garrafas por filtração em malha de $40 \mu \mathrm{m}$ e fixados em formol 2\% neutralizado em Tetraborato de Sódio diluído em água do mar filtrada para posterior análise em estereomicroscópio (Figura $2.1 \mathrm{G}$ ). As amostras foram analisadas em um prazo inferior a um ano da data da coleta.

\subsubsection{Taxas de crescimento}

As amostras relativas aos experimentos de coortes artificiais foram fotografadas ao estereomicroscópio, utilizando uma máquina fotográfica digital SONY DSC W-220, 12.1 pixels de resolução. A máquina foi montada sobre um acoplador que possui uma lente ocular de 10x, uma das lentes oculares foi removida e o acoplador encaixado ao estereomicroscópio. As amostras foram previamente coradas com uma solução de rosa de bengala para aumentar o contraste dos náuplios e copepoditos.

Todas as amostras foram fotografadas na definição de 12 megapixels e aumento de 160x (ampliação de 40x do estereomicroscópio e zoom digital de 4x da máquina fotográfica). Todos os indivíduos da classe Copepoda foram contados e medidos (náuplios, copepoditos e eventuais adultos) para a análise do crescimento. O software livre Image $J$ (Rasband, W.) foi utilizado para obtenção das dimensões dos copépodes. Para calcular a escala de tamanho das imagens, utilizou-se uma lâmina micrometrada de um milímetro com subdivisões de até $10 \mu \mathrm{m}$, a qual foi fotografada e utilizada em um arquivo de calibração do programa (macro).

Através de uma série de transformações, o programa calcula medidas como comprimento, largura, perímetro e área de cada organismo desejado. No caso dos copepoditos, o urossomo foi removido manualmente das imagens para obtenção do comprimento do prossomo.

O comprimento total dos náuplios (CT) e comprimento do prossomo dos copepoditos (CP) foram utilizados em equações de regressão comprimento $\mathrm{x}$ peso publicadas na literatura, para gerar uma estimativa dos valores de peso seco (PS), peso seco livre de cinzas (PSLC) ou peso em carbono (PC) dos microcrustáceos. Diversas equações foram utilizadas, sendo que o critério de escolha foi a menor distância 
filogenética (equações de regressão espécie-específicas foram utilizadas sempre que possível) e posteriormente a localização geográfica das populações utilizadas para descrição das equações pelos autores (Tabela 2.3).

Para os náuplios de algumas espécies de copépodes da ordem Calanoida, as equações disponíveis na literatura (Båmstedt, 1986 e Bergreen et al., 1988) foram comparadas e as mais adequadas escolhidas. Para as equações que forneceram o peso seco livre de cinzas, o valor foi transformado em peso seco considerando PSLC $=0,89$ PS, o qual por sua vez foi convertido em peso em carbono, assumido que PC = 0,4 PS (Båmstedt, 1986). Os valores foram obtidos em peso em carbono como medida de padronização e comparação, uma vez que as equações de regressão para náuplios, e publicações atuais utilizam esta unidade (Bergreen et al., 1988; Almeda et al., 2010; Almeda et al., 2011; entre outros).

Tabela 2.3: Equações de regressão utilizadas para obtenção do peso seco $(\mu \mathrm{g})$ a partir do comprimento do prossomo $(\mu \mathrm{m})$ para os estágios juvenis de copepoditos das espécies pelágicas coletadas em Ubatuba. Para os estágios naupliares o peso em carbono (ng) é obtido a partir do comprimento total dos indivíduos. N: náuplios; CD: copepoditos; PC: peso em carbono; PS: peso seco; PU: peso úmido, $\mathrm{PU}=0,2 \mathrm{PS}$; $\mathrm{CT}$ : comprimento total; $\mathrm{CP}$ : comprimento do prossomo.

\begin{tabular}{|c|c|c|c|}
\hline Elaborada para... & Equação de regressão & Aplicada para... & Referência \\
\hline Acartia tonsa $(\mathrm{N})$ & $\mathrm{PC}=3,1810^{-6} \mathrm{CT}^{3,31}$ & Acartia spp., P. acutus & 1 \\
\hline A. tonsa $(\mathrm{C} \mathrm{I}-\mathrm{V})$ & $\mathrm{PC}=1,1110^{-5} \mathrm{CT}^{2,92}$ & Acartia spp. $(\mathrm{CI}-\mathrm{CV})$ & 1 \\
\hline Oithona davisae $(\mathrm{N})$ & $\mathrm{PC}=0,0021 \times \mathrm{CT}^{2,14}$ & $\begin{array}{l}\text { Cyclopoida }(\mathrm{N}), \text { Euterpina } \\
\text { acutifrons }(\mathrm{N}) ; \text { Oncaeidae }(\mathrm{N})\end{array}$ & 2 \\
\hline O. davisae (C I-V) & $\mathrm{PC}=0,0318 \times \mathrm{CT}^{1,61}$ & $\begin{array}{l}\text { Diothona oculata, Oithona spp. } \\
\text { (CI - CV) }\end{array}$ & 2 \\
\hline O. plumifera $(\mathrm{CI}-\mathrm{V})$ & $\operatorname{lnPS}=1,68 \operatorname{lnCP}-10,2$ & O. plumifera $(\mathrm{CI}-\mathrm{V})$ & 4 \\
\hline Centropages velificatus (C I-V) & $\ln P S=3,68 \ln C P-22,86$ & C. velificatus $(\mathrm{CI}-\mathrm{CV})$ & 3 \\
\hline Paracalanus spp. (CI-V) & $\ln P S=2,78 \times \ln C P-16,52$ & Paracalanidae $(\mathrm{CI}-\mathrm{CV})$ & 4 \\
\hline P. quasimodo $(\mathrm{C} \mathrm{I}-\mathrm{V})$ & $\mathrm{PS}=6,829 \times 10^{-11} \mathrm{CP}^{3,871}$ & $\begin{array}{c}\text { Parvocalanus crassirostris (CI } \\
-\mathrm{CV})\end{array}$ & 4 \\
\hline Clausocalanus furcatus (C I-V) & $\ln P S=3,25 \times \ln C P-19,65$ & Clausocalanidae $(\mathrm{CI}-\mathrm{CV})$ & 3 \\
\hline Corycaeidae (C I-V) & $\ln P S=1,70 \times \ln C P-9,92$ & Corycaeidae $(\mathrm{CI}-\mathrm{CV})$ & 3 \\
\hline Oncaea spp. (C I-V) & $\ln P S=2,1 x \ln C P-11,63$ & Oncaeidae $(\mathrm{CI}-\mathrm{CV})$ & 4 \\
\hline Temora turbinata $(\mathrm{CI}-\mathrm{V})$ & $\ln \mathrm{PS}=3,34 \mathrm{x} \ln \mathrm{CP}-19,59$ & T. turbinata $(\mathrm{CI}-\mathrm{CV})$ & 3 \\
\hline T. stylifera $(\mathrm{CI}-\mathrm{V})$ & $\log \mathrm{PU}=2,057 \log \mathrm{CP}-4,042$ & T. stylifera $(\mathrm{CI}-\mathrm{CV})$ & 6 \\
\hline Euterpina acutifrons $(\mathrm{CI}-\mathrm{V})$ & $\mathrm{PS}=8,148 \cdot 10^{-8} \mathrm{CP}^{2,736}$ & E. acutifrons $(\mathrm{CI}-\mathrm{CV})$ & 5 \\
\hline Náuplios & $\ln$ PSLC $=2,48 \ln$ CT $-15,7$ & $\begin{array}{c}\text { Temora spp., Paracalanus spp., } \\
\text { Parvocalanus crassirostris; } C . \\
\text { velificatus }\end{array}$ & 7 \\
\hline
\end{tabular}

Referências: 1. Bergreen et al. (1988); 2. Almeda et al. (2010); 3. Chisholm \&Roff (1990); 4. Webber \& Roff (1995); 5. Ara (2001 b); 6. Shmleva (1965); 7. Båmstedt (1986). 
A taxa de crescimento $\left(g, \mathrm{~d}^{-1}\right)$ foi determinada assumindo que o crescimento dos estágios imaturos de copépodes é exponencial em um intervalo de tempo e utilizando a fórmula:

$$
g=\frac{\ln P C_{t}-\ln P C_{0}}{t}
$$

onde PCt é o peso em carbono no tempo $t, \mathrm{PC}_{0}$ é o peso em carbono no período inicial do experimento e $t$ a diferença de tempo em dias (Hirst et al., 2003) entre o início e final das incubações. Os valores de PC dos diferentes estágios de desenvolvimento, náuplios e copepoditos, foram somados em cada intervalo e os valores médios utilizados para o cálculo de $g$.

A frequência de distribuição dos valores de $\ln P C$ foi testada para visualizar o aumento de peso ao longo dos experimentos. Já as taxas de crescimento ao longo dos períodos experimentais, do inicial ao terceiro dia de incubação, foram analisadas quanto à linearidade, através de regressão linear. O crescimento foi considerado log-linear quando $\mathrm{r}^{2} \geq 0,91$ para os dados de $g$ do tempo inicial até o $t 3$. Quando o valor de $r^{2}$ foi menor, a linearidade ainda foi testada do tempo inicial até o $t 2$. Nos casos onde a linearidade não foi comprovada, o valor de $g$ no $t l$ foi geralmente considerado.

Nos casos em que $g$ foi linear, a frequência de distribuição demonstrou um claro deslocamento das categorias de peso ao longo do tempo (Figura 2.3). Quando comprovada a linearidade do crescimento, ainda foram calculados os valores intermediários de $g$, resultando em seis valores pela diferença entre cada intervalo experimental: $t 1-t 0, t 2-t 0, t 3-t 0, t 3-t 1, t 3-t 2$ e $t 2-t 1$. Um valor mínimo, máximo e a mediana de $g$ entre os pontos acima foi obtido (Figura $2.4 a$ ). Em outras ocasiões, $g$ foi linear apenas até o segundo dia de incubação. Nesses casos foram considerados os valores de $g$ para $t 1-t 0, t 2-t 0$ e $t 2$ - $t 1$ (Figura $2.4 \mathrm{~b}$ ). Por fim, nos casos onde $g$ não foi linear, foi selecionado o valor mais próximo da linearidade: $t 1$ - $t 0$ ou $t 2-t 0$ (Figura $2.4 \mathrm{c}$ ) para o posterior cálculo da produção. 

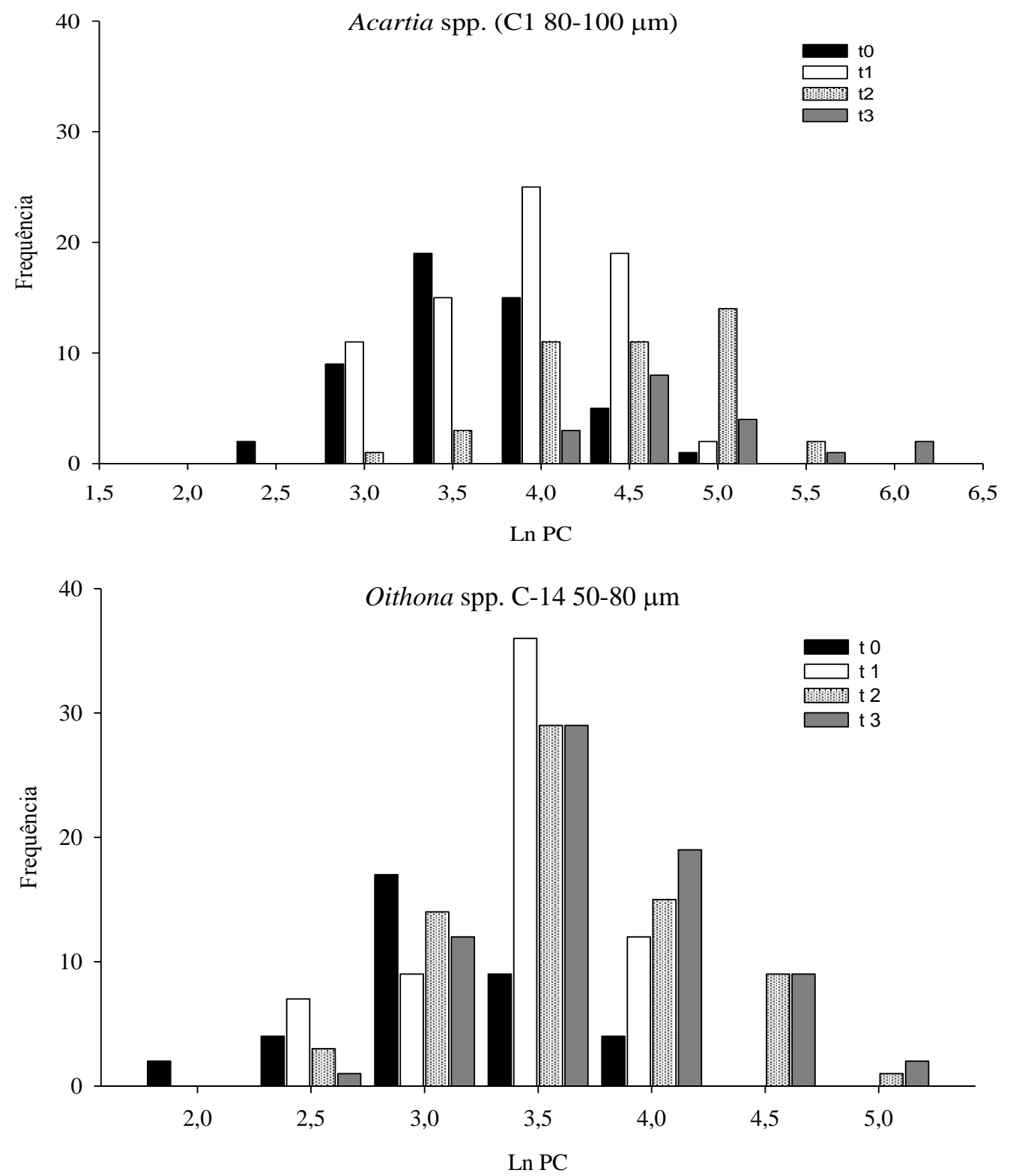

Figura 2.3: Exemplos de frequência de distribuição de peso dos organismos incubados. O peso em carbono é representado na escala logarítmica e a frequência em número de indivíduos de cada categoria ao longo dos períodos experimentais $(t 0$ ao $t 3)$. 
A
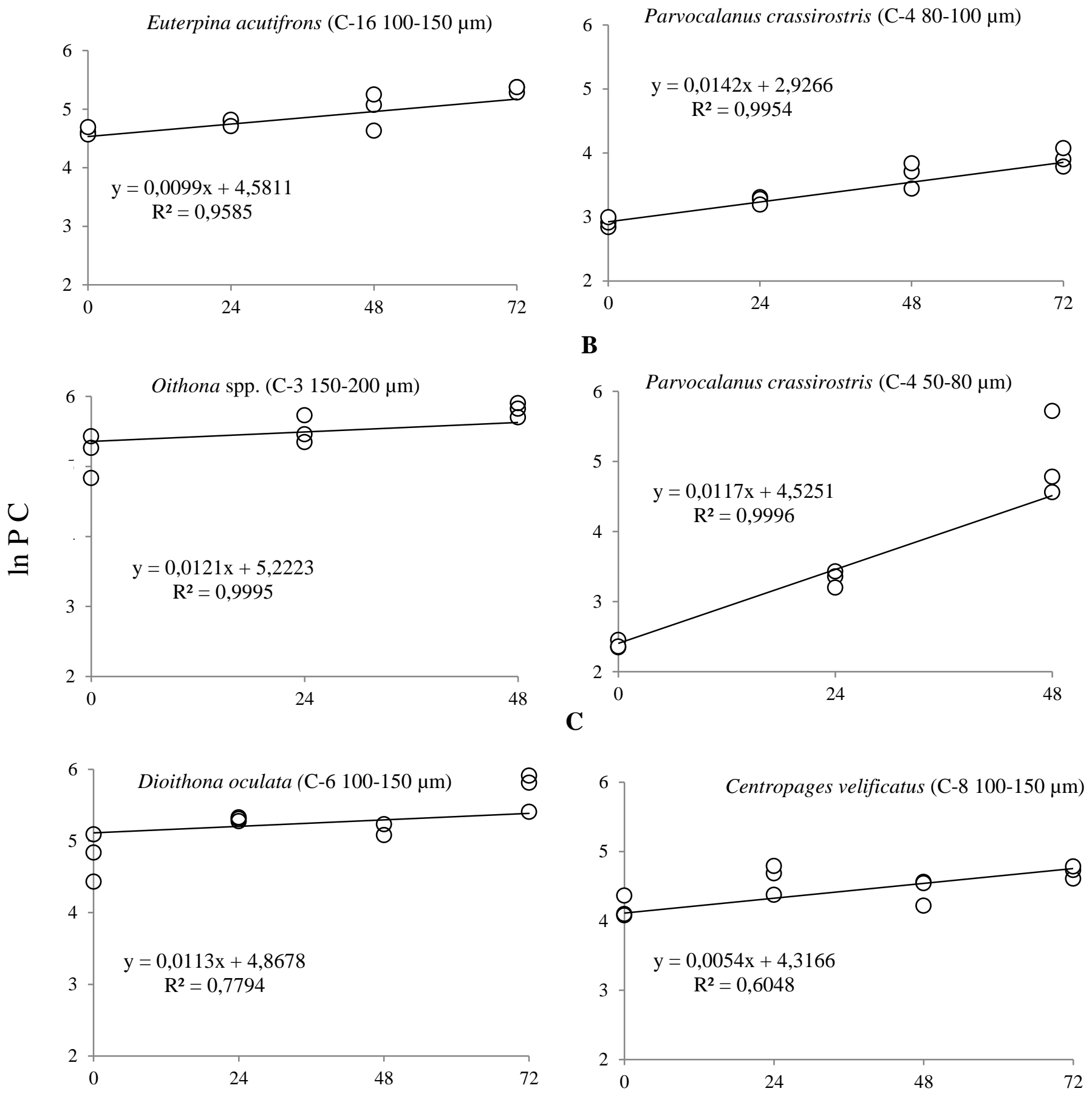

Figura 2.4: Exemplos da variação de peso em carbono (ln PC, eixo y) ao longo do tempo em horas (eixo x). A: exemplos onde a variação de peso foi linear, do período inicial até o terceiro dia de incubação. B: variação de peso e crescimento linear até o segundo dia de incubação, nesses casos o valor de $g$ para o terceiro dia foi descartado e $\mathbf{C}$ : casos onde $g$ não foi linear e geralmente adota-se o valor de $g$ para $t 1-t 0$ (24 h). Notar as diferentes escalas em cada exemplo. Equação da reta considerando a média entre as três réplicas em cada período. 
Os valores de crescimento obtidos experimentalmente ainda foram comparados com os modelos globais de crescimento de Hirst \& Bunker (2003), a fim de verificar se tais modelos se adequam aos juvenis de copépodes tropicais aqui utilizados. Para cada táxon, o crescimento experimental foi comparado com o obtido para a equação geral para copépodes pelágicos, chamada aqui de Hirst \& Bunker (2003) I:

$\log _{10} g=0,0186 \times \mathrm{T}-0,288 \times \log _{10} \mathrm{PC}+0,417 \log _{10} \mathrm{Cl}-a-1,209$

Para os estágios juvenis de copépodes que secretam sacos ovígeros (retentores), foi utilizada a equação:

$\log _{10} g=0,0333 \times \mathrm{T}-0,163 \times \log _{10}$ PC $-1,523$

Já para os juvenis de copépodes liberadores de ovos, a equação utilizada foi:

$$
\log _{10} g=-0,0143 \times \mathrm{T}-0,363 \times \log _{10} \mathrm{PC}+0,135 \log _{10} \mathrm{Cl}-a-0,105
$$

As equações para juvenis foram denominadas Hirst \& Bunker (2003) II. A temperatura foi fornecida em ${ }^{\circ} \mathrm{C}$, o Peso em carbono (PC) em $\mu \mathrm{g} \mathrm{C}$ ind $^{-1}$ e a clorofila- $a$ (Cl-a) em $\mu \mathrm{g} \mathrm{L}^{-1}$. Para as estimativas utilizando os modelos de Hirst \& Bunker (2003), foi utilizado o valor de $g$ entre os diferentes períodos experimentais quando aplicáveis ( $t 3-t 0 t 2-t 0 t 1$ - $t 0$, ver Figura 2.4). Os valores de $g$ foram registrados para as principais espécies ou agrupamentos de espécies que ocorreram nos experimentos. Foram estudados apenas os táxons que possuíram número amostral suficiente para a análise do crescimento, ou seja, ao menos dez indivíduos por período de tempo em cada experimento (Tabela 2.4).

A relação dos táxons nos experimentos cujas respectivas taxas de crescimento foram analisadas foi sumarizada na Tabela 2.4. Para cada táxon, foram registrados os valores médios de densidade para ambas as redes utilizadas $(20$ e $100 \mu \mathrm{m})$, as taxas de crescimento para cada experimento, organizadas em classes de tamanho: coortes menores $(50-80$ e 80-100 $\mu \mathrm{m})$ e coortes maiores $(100-150,150-200 \mu \mathrm{m})$ e o resultado de testes de comparação entre grupos (verão x inverno, 2009 x 2010 x 2011 e coortes menores x maiores) quando possível. A correlação entre $g$ e variáveis controladas, a comparação entre $g$ medido pelos experimentos e o estimado por modelos da literatura (Hirst \& Bunker, 2003) e finalmente os dados de biomassa e produção em cada período experimental também foram fornecidos para cada táxon. 
Tabela 2.4: Táxons analisados nos respectivos experimentos de coortes artificiais. Siglas e detalhes dos experimentos conforme Tabela 2.1 .

\begin{tabular}{|c|c|c|c|c|c|c|c|c|c|c|c|c|c|c|c|c|}
\hline \multirow{2}{*}{$\begin{array}{l}\text { Estação } \\
\text { Experimento }\end{array}$} & \multicolumn{4}{|c|}{ verão 2009} & \multicolumn{3}{|c|}{ inverno 2009} & \multicolumn{2}{|c|}{$\begin{array}{l}\text { verão } \\
2010\end{array}$} & \multicolumn{4}{|c|}{ inverno 2010} & \multicolumn{3}{|c|}{ verão 2011} \\
\hline & C1 & $\mathrm{C} 2$ & C3 & C4 & C5 & C6 & C7 & C8 & C9 & C10 & C11 & C12 & C13 & C14 & C15 & C16 \\
\hline Acartia spp. & $\mathrm{X}$ & - & $\mathrm{X}$ & $\mathrm{X}$ & $\mathrm{X}$ & $\mathrm{X}$ & $\mathrm{X}$ & $\mathrm{X}$ & $\mathrm{X}$ & $X$ & $\mathrm{X}$ & $\mathrm{X}$ & $\mathrm{X}$ & $\mathrm{X}$ & $\mathrm{X}$ & $\mathrm{X}$ \\
\hline P. crassirostris & $\mathrm{X}$ & $\mathrm{X}$ & - & $\mathrm{X}$ & $\mathrm{X}$ & $\mathrm{X}$ & $\mathrm{X}$ & - & $\mathrm{X}$ & $X$ & $\mathrm{X}$ & - & $\mathrm{X}$ & $\mathrm{X}$ & $\mathrm{X}$ & $\mathrm{X}$ \\
\hline Paracalanus spp. & $\mathrm{X}$ & $\mathrm{X}$ & $\mathrm{X}$ & $\mathrm{X}$ & $\mathrm{X}$ & $\mathrm{X}$ & $\mathrm{X}$ & $\mathrm{X}$ & $\mathrm{X}$ & $X$ & $\mathrm{X}$ & $\mathrm{X}$ & $\mathrm{X}$ & $\mathrm{X}$ & $\mathrm{X}$ & $\mathrm{X}$ \\
\hline C. velificatus & - & - & - & - & - & - & - & $\mathrm{X}$ & - & - & - & - & - & - & - & $\mathrm{X}$ \\
\hline P. acutus & - & - & - & - & - & $\mathrm{X}$ & - & - & $\mathrm{X}$ & - & - & - & - & - & - & - \\
\hline Temora turbinata & - & $\mathrm{X}$ & - & - & $\mathrm{X}$ & - & - & $\mathrm{X}$ & $\mathrm{X}$ & $\mathrm{X}$ & - & $\mathrm{X}$ & - & $\mathrm{X}$ & $\mathrm{X}$ & $\mathrm{X}$ \\
\hline T. stylifera & - & - & - & $\mathrm{X}$ & - & - & - & $\mathrm{X}$ & - & $X$ & - & $\mathrm{X}$ & - & - & - & - \\
\hline Dioithona oculata & $\mathrm{X}$ & $\mathrm{X}$ & - & - & - & $X$ & - & - & - & - & - & - & - & - & - & - \\
\hline Oithona spp. & $\mathrm{X}$ & $\mathrm{X}$ & $\mathrm{X}$ & $\mathrm{X}$ & $\mathrm{X}$ & $\mathrm{X}$ & $\mathrm{X}$ & $\mathrm{X}$ & $\mathrm{X}$ & $\mathrm{X}$ & $\mathrm{X}$ & $\mathrm{X}$ & $\mathrm{X}$ & $\mathrm{X}$ & $\mathrm{X}$ & $\mathrm{X}$ \\
\hline Oithona plumifera & - & - & - & $\mathrm{X}$ & - & - & - & $\mathrm{X}$ & $\mathrm{X}$ & - & - & $\mathrm{X}$ & - & $\mathrm{X}$ & $\mathrm{X}$ & - \\
\hline Oncaea spp. & $\mathrm{X}$ & - & - & $\mathrm{X}$ & $X$ & $\mathrm{X}$ & $\mathrm{X}$ & $\mathrm{X}$ & $\mathrm{X}$ & $\mathrm{X}$ & - & $\mathrm{X}$ & $\mathrm{X}$ & $X$ & $\mathrm{X}$ & $\mathrm{X}$ \\
\hline Corycaeus spp. & - & - & - & $\mathrm{X}$ & - & - & - & $\mathrm{X}$ & $\mathrm{X}$ & $\mathrm{X}$ & $\mathrm{X}$ & $\mathrm{X}$ & - & - & - & - \\
\hline L.. americana & $\mathrm{X}$ & - & - & - & - & - & - & - & - & - & - & - & - & - & - & - \\
\hline E.acutifrons & - & - & - & - & - & $\mathrm{X}$ & $\mathrm{X}$ & - & - & $\mathrm{X}$ & - & - & - & - & $\mathrm{X}$ & $\mathrm{X}$ \\
\hline
\end{tabular}

\subsubsection{Biomassa e Produção}

Neste estudo, não foi realizada a medição direta da biomassa devido ao peso reduzido dos náuplios e copepoditos da região como das famílias Paracalanidae, Oithonidae e Oncaeidae. A obtenção do peso seco por métodos analíticos depende de balanças de alta precisão e que um número elevado de indivíduos seja pesado em cada réplica (Bicalho, 2010), a fim de evitar erros associados à própria pesagem.

A biomassa foi obtida através das equações de regressão comprimento-peso (Tabela 2.3), aplicadas aos indivíduos medidos no to dos experimentos de coortes. Foram utilizadas as médias de tamanho (comprimento total para náuplios e comprimento do prossomo para copepoditos) dos indivíduos de cada táxon selecionado para o cálculo do peso. O valor de densidade foi obtido das amostras quantitativas, onde os organismos foram classificados quanto ao estágio de desenvolvimento em: ortonáuplio, metanáuplio, copepoditos CI à CIII, CIV a CV e adultos. 
A densidade dos organismos por $\mathrm{m}^{-3}$ foi calculada através da análise da amostra quantitativa, considerando as densidades das categorias de desenvolvimento descritas no item 2.3.3. A biomassa de cada táxon, em cada período de coleta é igual ao produto entre o peso médio e a densidade de indivíduos. A partir da taxa de crescimento e da biomassa a produção de copépodes $\left(\mathrm{P}, \mathrm{mg} \mathrm{C} \cdot \mathrm{m}^{-3} \cdot \mathrm{d}^{-1}\right)$ foi calculada pela equação abaixo: $\mathrm{P}=g \cdot \mathrm{B}$,

Onde $g=$ taxa de crescimento $\left(\mathrm{d}^{-1}\right) ; \mathrm{B}=$ biomassa $\left(\mathrm{mg} \mathrm{C} \mathrm{m} \mathrm{m}^{-3}\right)$ (Rigler \& Downing, 1984).

Os dados de produção dos estágios juvenis foram obtidos para diversos gêneros ou espécies e posteriormente incorporados em grupos funcionais (copépodes dispersores ou retentores dos ovos) ou categorias taxonômicas como as classes (Calanoida, Cyclopoida e Harpacticoida).

\subsubsection{Tratamento dos dados e análise estatística}

As variáveis independentes analisadas foram a temperatura $\left({ }^{\circ} \mathrm{C}\right)$, salinidade, concentração de clorofila- $a$ e feopigmentos $\left(\mathrm{mg} \cdot \mathrm{m}^{-3}\right)$ da água e número total de organismos zooplanctônicos incubados (N) durante o início da incubação e nos intervalos dos experimentos de coortes. A quantidade de metazoários planctônicos $(\mathrm{N})$ foi monitorada para verificar se houve mortalidade elevada ao longo dos experimentos e a possível consequência dessa variável sobre as concentrações de pigmentos.

Cada variável independente foi testada em análises de correlação de Spearman ( $\rho)$ em relação às taxas de crescimento dos táxons estudados, que foram tratadas como variáveis dependentes. Para tal, a normalidade e homocedasticidade dos dados foram testadas e as variáveis transformadas em $\log _{10} \mathrm{x}+1$, exceto por $g$, que é representado na escala logarítmica natural (ln). Gráficos de dispersão da relação das taxas de crescimento com cada variável foram produzidos para cada táxon, utilizando os valores de $g$ obtidos em todos os experimentos realizados e fornecendo a equação da reta, o valor de $\rho$ e seu respectivo valor de probabilidade $(p)$.

Os valores de crescimento foram testados quanto à diferença entre categorias temporais como as estações do ano (verão x inverno), entre os anos estudados ( $2009 \mathrm{x}$ 
2010 x 2011) e entre os diferentes tamanhos das coortes (coortes menores: 50-80 e 80$100 \mu \mathrm{m}$ x coortes maiores: 100-150 e 150-200 $\mu \mathrm{m}$ ). Foram escolhidos os teste- $t$ e ANOVA para conjuntos de dados com distribuição normal e Mann-Whitney ou KruskalWallis para dados de distribuição não paramétrica. O teste de comparação aos pares posterior ao resultado obtido por ANOVA ou Kruskal-Wallis utilizado foi o de StudentNewman-Keuls. Os valores de crescimento obtidos experimentalmente ainda foram comparados com os resultados de modelos matemáticos através de regressões lineares.

As concentrações de clorofila- $a$ e feopigmentos foram comparadas nos diferentes experimentos quanto à diferença de valores obtidos entre os tamanhos de coortes (50-80 x 80-100 $\mu \mathrm{m}$ ou 100-150 x 150-200 $\mu \mathrm{m})$. Quando $p \geq 0,05$, os valores de clorofila- $a$ das garrafas experimentais das duas coortes foram agrupadas e comparadas quanto à concentrações das garrafas controle (Figura 2.3). Os dados foram comparados isoladamente para cada tamanho de coorte quando $p<0,05$ (controle x 50-80 $\mu \mathrm{m}$; controle x 80-100 $\mu \mathrm{m}$; Tabela 2.5).

Para a estatística descritiva e análises comparativas e de correlações o software Sigmaplot 11.0 (Systat software Inc., 2008) e Microsoft Office Excel 2010 (Microsoft, 2010) foram utilizados. 


\subsection{Resultados}

\subsubsection{Variáveis Ambientais}

Os valores apresentados na Tabela 2.2 corresponderam às condições iniciais dos experimentos. A temperatura e a salinidade foram constantes ao longo da incubação, sendo as concentrações de clorofila- $a$, feopigmentos e a densidade de organismos zooplanctônicos incubados variáveis ao longo do tempo.

As concentrações de clorofila- $a$ e feopigmentos foram medidas em cada período experimental (Figura 2.5) e decresceram na maioria dos experimentos ao longo dos três dias de incubação, porém o inverso ocorreu nos experimentos C-3, C-7, C-11 e C-16.

As concentrações de clorofila- $a$ foram menores nos tratamentos experimentais para os experimentos $\mathrm{C}-1,8,9,12$ e 16, enquanto que valores maiores foram encontrados nos tratamentos experimentais em C-3, $11(80-100 \mu \mathrm{m})$ e 13. Nenhuma diferença significativa foi detectada entre as concentrações dos tratamentos controle e experimentais para o restante dos experimentos (Tabela 2.5).

Já para os feopigmentos, a diferença significativa entre as concentrações encontradas nas incubações e controles ocorreu em número ainda menor de experimentos, sendo que o tratamento controle foi maior que o experimental em quatro casos e menor em apenas dois (Tabela 2.5).

Não foram observados padrões de variação da concentração dos pigmentos, quando comparados os diferentes tamanhos de coortes artificiais. As menores (50-80 e 80-100 $\mu \mathrm{m})$ não foram significativamente diferentes das maiores (100-150 e 150-200 $\mu \mathrm{m})$ em relação à clorofila- $a$ e feopigmentos. Os diferentes períodos amostrais também não mostraram padrões exclusivos de variações nas concentrações de pigmentos (Figura 2.5). Embora a variabilidade tenha sido alta, diferenças não foram encontradas na maioria dos experimentos entre os tratamentos controle e experimental. 

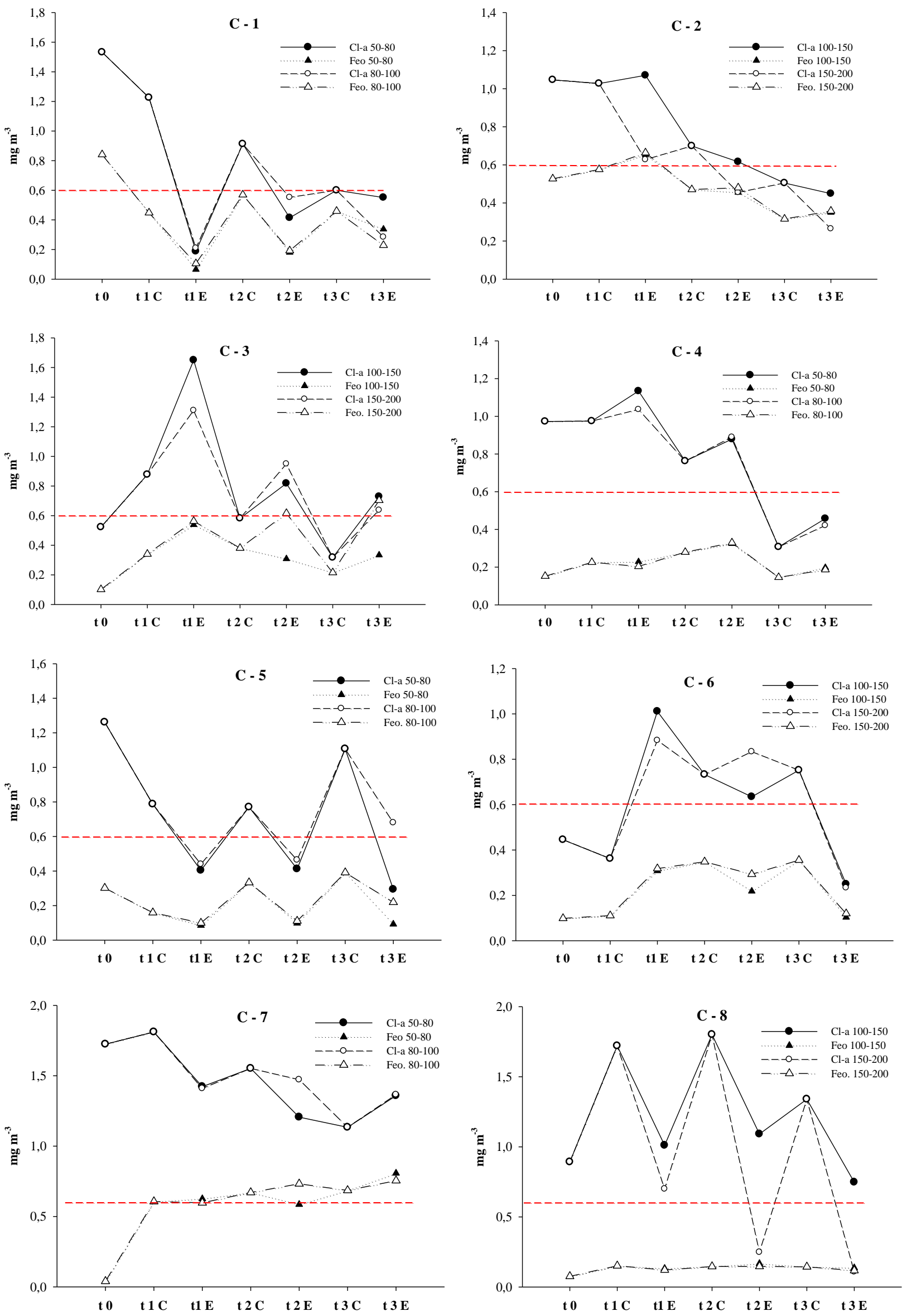

Figura 2.5: Concentração de clorofila- $a$ e feopigmentos $\left(\mathrm{mg} \mathrm{m}^{-3}\right)$ durante os experimentos de coortes artificiais (C-1 a C-8). C: réplicas de garrafas sem animais incubados (controle); Exp: réplicas experimentais. Cada ponto é representado pela média de três réplicas. Linha vermelha: nível de saturação do crescimento para copépodes dispersores juvenis estimado por Hirst \& Bunker (2003). Notar as diferentes escalas no eixo y. 

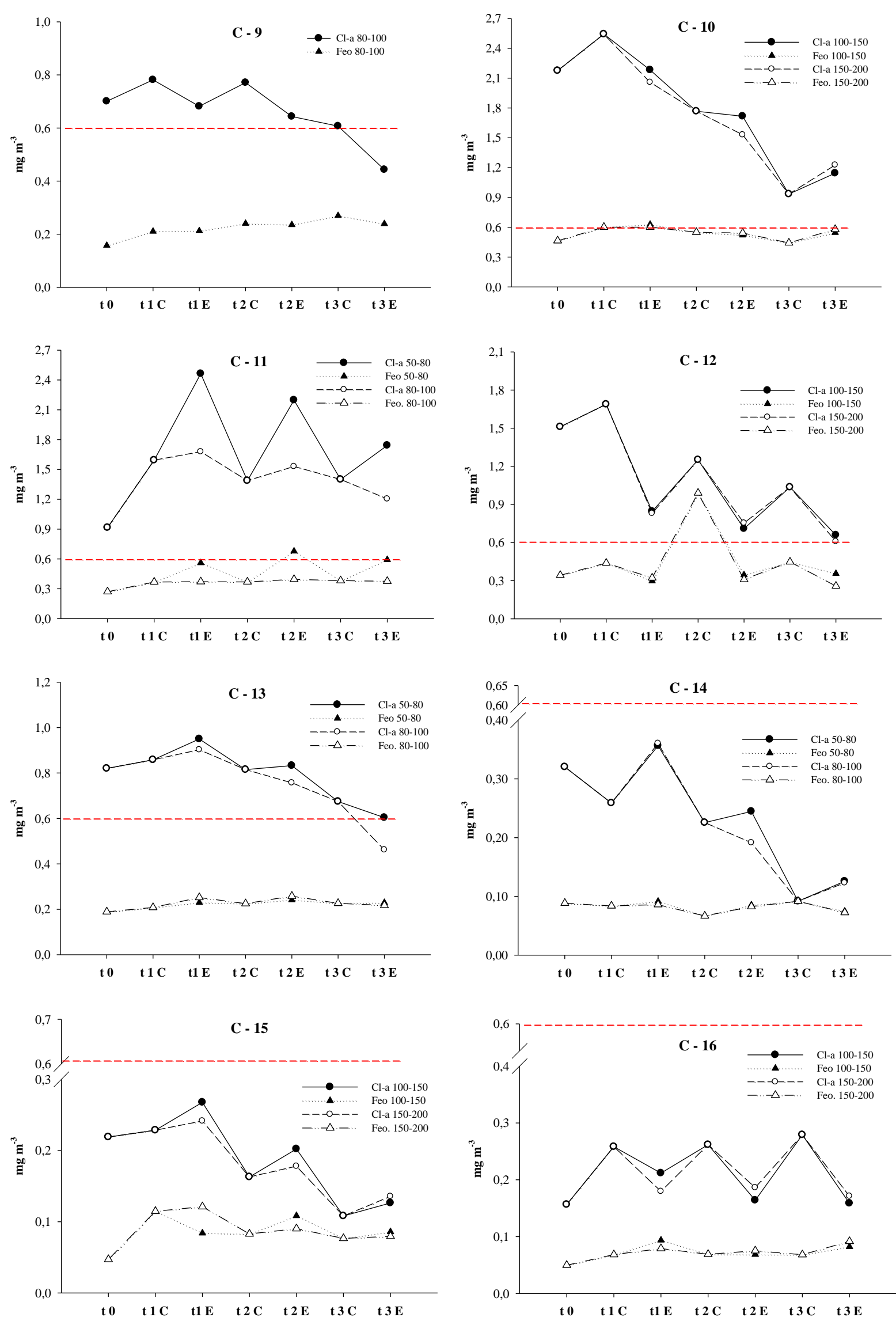

Figura 2.5 (Continuação): Concentração de clorofila- $a$ e feopigmentos $\left(\mathrm{mg} \mathrm{m}^{-3}\right)$ durante os experimentos de coortes artificiais (C-9 a C-16). C: réplicas de garrafas sem animais incubados (controle); Exp: réplicas experimentais. Cada ponto é representado pela média de três réplicas. Linha vermelha: nível de saturação do crescimento para copépodes dispersores juvenis estimado por Hirst \& Bunker (2003). Notar as diferentes escalas no eixo y. 
Tabela 2.5: Comparação das concentrações de clorofila- $a$ (Cla- $a$ ) e feopigmentos (Feop.) entre os tratamentos experimentais e controles em cada um dos experimentos ( $n=9$ para coortes isoladas e $n=18$ para coortes agrupadas). C: controle; E: experimental; $\underline{\mathrm{m}}$ : coorte

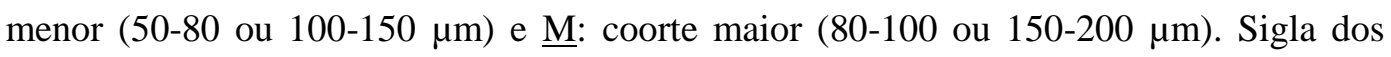
experimentos conforme Tabela 2.1 .

\begin{tabular}{|c|c|c|c|c|}
\hline Experimento & $\begin{array}{c}\text { Cla- } a \mathrm{~m} \\
\mathrm{C} \times \mathrm{E}\end{array}$ & $\underset{\text { Cla- } a \underline{\mathrm{M}}}{\operatorname{Co}}$ & $\underset{\text { Ceop, } \underline{\text { m }}}{\text { Fe }}$ & $\underset{\text { Ceop, } \underline{\mathbf{M}}}{\mathbf{E}}$ \\
\hline C-1 & \multicolumn{2}{|c|}{$>(p=0,006)$} & \multicolumn{2}{|c|}{$>(p=0,004)$} \\
\hline $\mathrm{C}-2$ & \multicolumn{2}{|c|}{$=(p=0,143)$} & \multicolumn{2}{|c|}{$=(p=0,554)$} \\
\hline C-3 & \multicolumn{2}{|c|}{$<(p=0,011)$} & $=(p=0,226)$ & $<(p<0,001)$ \\
\hline C- 4 & \multicolumn{2}{|c|}{$=(p=0,189)$} & \multicolumn{2}{|c|}{$=(p=0,297)$} \\
\hline C-5 & \multicolumn{2}{|c|}{$=(p=0,426)$} & \multicolumn{2}{|c|}{$=(p=0,888)$} \\
\hline C-6 & \multicolumn{2}{|c|}{$=(p=0,81)$} & \multicolumn{2}{|c|}{$=(p=0,406)$} \\
\hline $\mathrm{C}-7$ & \multicolumn{2}{|c|}{$=(p=0,396)$} & \multicolumn{2}{|c|}{$=(p=0,587)$} \\
\hline C- 8 & $>(p<0,001)$ & $>(p<0,001)$ & \multicolumn{2}{|c|}{$=(p=0,259)$} \\
\hline C-9 & $=(p=0,446)$ & $>(p=0,036)$ & \multirow{2}{*}{\multicolumn{2}{|c|}{$\begin{array}{l}=(p=0,24) \\
=(p=0,119)\end{array}$}} \\
\hline $\mathrm{C}-10$ & \multicolumn{2}{|c|}{$=(p=0,738)$} & & \\
\hline $\mathrm{C}-11$ & $<(p=0,002)$ & $=(p=0,25)$ & $<(p<0,001)$ & $=(p=0,513)$ \\
\hline C-12 & \multicolumn{2}{|c|}{$>(p<0,001)$} & $>(p<0,001)$ & $>(p<0,001)$ \\
\hline C-13 & \multicolumn{2}{|c|}{$<(p=0,028)$} & \multicolumn{2}{|c|}{$=(p=0,095)$} \\
\hline C-14 & \multicolumn{2}{|c|}{$\begin{array}{l}=(p=0,303) \\
=(p=0,19)\end{array}$} & \multicolumn{2}{|c|}{$=(p=0,662)$} \\
\hline $\mathrm{C}-15$ & \multirow{2}{*}{\multicolumn{2}{|c|}{$\begin{array}{c}=(p=0,19) \\
>(p<0,001)\end{array}$}} & \multicolumn{2}{|c|}{$=(p=0,738)$} \\
\hline C-16 & & & \multicolumn{2}{|c|}{$=(p=0,292)$} \\
\hline
\end{tabular}

\subsubsection{Fracionamento da comunidade de copépodes}

As quatro categorias de tamanho utilizadas foram previamente testadas quanto ao fracionamento da comunidade de copépodes em assembleias contendo táxons em estágios de desenvolvimento diferentes. Os organismos foram separados através da largura máxima do corpo, sendo que raramente o valor médio para a largura ultrapassou o limite superior da coorte (Tabela 2.6). As coortes de 50-80 e 80-100 $\mu \mathrm{m}$ abrigaram a maioria dos táxons estudados, porém as coortes maiores como as de 100-150 e 150-200 $\mu \mathrm{m}$ adicionaram estágios de desenvolvimento mais tardios como copepoditos.

A coorte de 50-80 $\mu \mathrm{m}$ foi a mais restritiva, abrigando apenas estágios naupliares, principalmente das famílias Acartiidae, Paracalanidae, Oithonidae, Oncaeidae e Euterpina acutifrons. As coortes maiores como a de 100-150 $\mu \mathrm{m}$ foram mais inclusivas, resultando na incubação de náuplios maiores como os da família Temoridae e Centropages velificatus. As coortes de 150-200 $\mu$ m incluíram copepoditos e até adultos de espécies pequenas como Parvocalanus crassirostris e da família Oithonidae (Tabela 2.6). A presença de adultos geralmente impediu o cálculo do crescimento desses táxons em tais coortes, uma vez que nessas ocasiões a biomassa estimada não corresponde necessariamente aos estágios juvenis. 
Tabela 2.6: Principais táxons, seus respectivos estágios de desenvolvimento em categorias e dimensões durante o período inicial dos experimentos para cada classe de tamanho de coorte. C.: comprimento total para náuplios e comprimento do prossomo para copepoditos e adultos. L: largura máxima.

\begin{tabular}{|c|c|c|c|c|}
\hline Coortes $(\mu \mathrm{m})$ & Táxon & Categoria & C. médio $(\mu \mathrm{m})$ & L. média $(\mu \mathrm{m})$ \\
\hline \multirow{8}{*}{$50-80$} & Acartia spp. & $\begin{array}{c}\text { N I-II } \\
\text { N III-VI }\end{array}$ & $\begin{array}{l}121,2 \pm 13,4 \\
165,6 \pm 15,5\end{array}$ & $\begin{array}{c}73,6 \pm 13 \\
81,1 \pm 13,2\end{array}$ \\
\hline & Paracalanidae & $\begin{array}{c}\text { N I-II } \\
\text { N III-VI }\end{array}$ & $\begin{array}{c}105,7 \pm 13,6 \\
138 \pm 16,8\end{array}$ & $\begin{array}{l}72,6 \pm 13,7 \\
78,3 \pm 13,1\end{array}$ \\
\hline & Parvocalanus crassirostris & $\begin{array}{c}\text { N I-II } \\
\text { N III-VI }\end{array}$ & $\begin{array}{c}87,9 \pm 9,9 \\
114,3 \pm 12,3\end{array}$ & $\begin{array}{c}60,9 \pm 13,23 \\
75,53 \pm 14,35\end{array}$ \\
\hline & Diothona oculata & $\begin{array}{c}\text { N I-II } \\
\text { N III-VI }\end{array}$ & $\begin{array}{l}123,5 \pm 17,2 \\
141,5 \pm 16,7\end{array}$ & $\begin{array}{l}79,3 \pm 13,7 \\
88,8 \pm 15,6\end{array}$ \\
\hline & Oithona spp. & $\begin{array}{c}\text { N I-II } \\
\text { N III-VI }\end{array}$ & $\begin{array}{c}94,4 \pm 18,3 \\
124,4 \pm 15,2\end{array}$ & $\begin{array}{l}58,2 \pm 13,1 \\
69,7 \pm 11,8\end{array}$ \\
\hline & O. plumifera & $\begin{array}{c}\text { N I-II } \\
\text { N III-VI }\end{array}$ & $\begin{array}{c}114,9 \pm 5,5 \\
129 \pm 6,6\end{array}$ & $\begin{array}{l}65,1 \pm 9,1 \\
61,1 \pm 6,1\end{array}$ \\
\hline & Oncaeidae & $\begin{array}{c}\text { N I-II } \\
\text { N III-VI } \\
\end{array}$ & $\begin{array}{c}100,5 \pm 17,8 \\
124,3 \pm 17 \\
\end{array}$ & $\begin{array}{l}54,6 \pm 12,5 \\
61,7 \pm 12,4 \\
\end{array}$ \\
\hline & Euterpina acutifrons & N I-II & $113 \pm 12,4$ & $78,5 \pm 13,9$ \\
\hline \multirow{13}{*}{$80-100$} & Acartia spp. & $\begin{array}{c}\text { N I-II } \\
\text { N III-VI } \\
\text { C I-V }\end{array}$ & $\begin{array}{l}128,2 \pm 16,6 \\
169,6 \pm 19,5 \\
254,4 \pm 35,1\end{array}$ & $\begin{array}{c}86,1 \pm 16,1 \\
97,1 \pm 19,9 \\
100,1 \pm 11,7\end{array}$ \\
\hline & Paracalanidae & $\begin{array}{c}\text { N I-II } \\
\text { N III-VI } \\
\text { C I-V }\end{array}$ & $\begin{array}{l}112,8 \pm 15,1 \\
159,3 \pm 24,8 \\
268,6 \pm 57,5\end{array}$ & $\begin{array}{c}81 \pm 14,4 \\
96,4 \pm 14,7 \\
114,9 \pm 23,3\end{array}$ \\
\hline & Parvocalanus crassirostris & $\begin{array}{c}\text { N I-II } \\
\text { N III-VI } \\
\text { C I-V }\end{array}$ & $\begin{array}{c}90,3 \pm 10,8 \\
119,8 \pm 16,1 \\
215 \pm 46,1\end{array}$ & $\begin{array}{c}67,2 \pm 13,5 \\
79,1 \pm 12,2 \\
98,9 \pm 20\end{array}$ \\
\hline & Pseudodiaptomus acutus & $\begin{array}{c}\text { N I-II } \\
\text { N III-VI }\end{array}$ & $\begin{array}{c}128,4 \pm 19 \\
160,5 \pm 14,2\end{array}$ & $\begin{array}{c}91,8 \pm 10,9 \\
94,4 \pm 8,8\end{array}$ \\
\hline & Temora turbinata & $\begin{array}{c}\text { N I-II } \\
\text { N III-VI }\end{array}$ & $\begin{array}{c}124 \pm 13,6 \\
159,6 \pm 14,5\end{array}$ & $\begin{array}{l}95,01 \pm 10,7 \\
102,5 \pm 11,4\end{array}$ \\
\hline & T. stylifera & N I-II & $119 \pm 13,4$ & $80,2 \pm 8,4$ \\
\hline & Dioithona oculata & N III-VI & $161,7 \pm 35,7$ & $98,1 \pm 30,6$ \\
\hline & Oithona spp. & $\begin{array}{c}\text { N I-II } \\
\text { N III-VI } \\
\text { C I-V }\end{array}$ & $\begin{array}{c}91,8 \pm 15,1 \\
134,1 \pm 23,3 \\
218,1 \pm 52,1\end{array}$ & $\begin{array}{l}62,7 \pm 12,8 \\
76,9 \pm 14,8 \\
95,7 \pm 17,9\end{array}$ \\
\hline & O. plumifera & $\begin{array}{c}\text { N III-VI } \\
\text { C I-V }\end{array}$ & $\begin{array}{c}166,3 \pm 41,9 \\
217,1 \pm 28\end{array}$ & $\begin{array}{l}76,3 \pm 18,6 \\
94,3 \pm 16,5\end{array}$ \\
\hline & Oncaeidae & $\begin{array}{c}\text { N I-II } \\
\text { N III-VI } \\
\text { C I-V }\end{array}$ & $\begin{array}{c}88,3 \pm 13,1 \\
129,8 \pm 23,7 \\
191,5 \pm 31,7\end{array}$ & $\begin{array}{l}52,8 \pm 15,6 \\
64,5 \pm 14,1 \\
84,1 \pm 13,3\end{array}$ \\
\hline & Corycaeidae & $\begin{array}{c}\text { N III-VI } \\
\text { C I-V }\end{array}$ & $\begin{array}{c}166,8 \pm 19,2 \\
197 \pm 28,9\end{array}$ & $\begin{array}{c}80 \pm 13 \\
83,7 \pm 17,7\end{array}$ \\
\hline & Euterpina acutifrons & $\begin{array}{c}\text { N I-II } \\
\text { N III-VI }\end{array}$ & $\begin{array}{l}107,1 \pm 14,2 \\
148,7 \pm 20,4\end{array}$ & $\begin{array}{c}84 \pm 14,1 \\
101,6 \pm 13,8\end{array}$ \\
\hline & Longipedia americana & N I-II & $128,8 \pm 14,8$ & $85,9 \pm 14,97$ \\
\hline
\end{tabular}


Tabela 2.6 (continuação): Principais táxons, seus respectivos estágios de desenvolvimento em categorias e dimensões durante o período inicial dos experimentos para cada classe de tamanho de coorte.

\begin{tabular}{|c|c|c|c|c|}
\hline Coortes $(\mu \mathrm{m})$ & Táxon & Categoria & C. médio $(\mu \mathrm{m})$ & L. média $(\mu \mathrm{m})$ \\
\hline \multirow{27}{*}{$100-150$} & \multirow{3}{*}{ Acartia spp. } & N I-II & $132,4 \pm 14,9$ & $88 \pm 25,2$ \\
\hline & & N III-VI & $180,2 \pm 24,4$ & $113,9 \pm 34,2$ \\
\hline & & $\mathrm{C} \mathrm{I}-\mathrm{V}$ & $327,6 \pm 57,4$ & $127,2 \pm 21,1$ \\
\hline & \multirow{2}{*}{ Paracalanidae } & N III-VI & $177,6 \pm 27,6$ & $106 \pm 18,7$ \\
\hline & & C I-V & $309,2 \pm 57,2$ & $131,5 \pm 22,9$ \\
\hline & \multirow{3}{*}{ Parvocalanus crassirostris } & N III-VI & $139,3 \pm 25,1$ & $89,6 \pm 19,3$ \\
\hline & & C I-V & $245,8 \pm 46,8$ & $118,4 \pm 22$ \\
\hline & & $\mathrm{AD}$ & $326 \pm 31,4$ & $146,1 \pm 13,5$ \\
\hline & \multirow{3}{*}{ Temora turbinata } & N I-II & $134,2 \pm 16,5$ & $100,9 \pm 13,4$ \\
\hline & & N III-VI & $188,2 \pm 29,2$ & $120,9 \pm 18$ \\
\hline & & C I-V & $230,2 \pm 32,8$ & $139,4 \pm 25,2$ \\
\hline & \multirow{2}{*}{ T. stylifera } & N III-VI & $193,3 \pm 28,9$ & $121,5 \pm 20,3$ \\
\hline & & $\mathrm{C} \mathrm{I}-\mathrm{V}$ & $233,1 \pm 32,2$ & $127,1 \pm 16,8$ \\
\hline & \multirow{2}{*}{ Centropages velificatus } & N I-II & $168,7 \pm 15,2$ & $100,7 \pm 13,5$ \\
\hline & & N III-VI & $239,9 \pm 38,9$ & $120,9 \pm 22,9$ \\
\hline & \multirow{2}{*}{ Diothona oculata } & N III-VI & $123,5 \pm 17,2$ & $79,3 \pm 13,6$ \\
\hline & & C I-V & $293,7 \pm 39,3$ & $144,1 \pm 20,7$ \\
\hline & \multirow{3}{*}{ Oithona spp. } & N III-VI & $140,3 \pm 18,2$ & $80,4 \pm 17,5$ \\
\hline & & C I-V & $210,7 \pm 41,2$ & $100,6 \pm 20,7$ \\
\hline & & $\mathrm{AD}$ & $345,7 \pm 45,3$ & $160,5 \pm 25,2$ \\
\hline & \multirow{2}{*}{ O. plumifera } & N III-VI & $191,5 \pm 30,7$ & $96,5 \pm 26$ \\
\hline & & C I-V & $270,7 \pm 49,8$ & $105,3 \pm 21,2$ \\
\hline & \multirow{3}{*}{ Oncaeidae } & N III-VI & $163,1 \pm 32,5$ & $76,7 \pm 18,4$ \\
\hline & & C I-V & $218,1 \pm 47,8$ & $103,5 \pm 22,1$ \\
\hline & & $\mathrm{AD}$ & $278,7 \pm 21,8$ & $127 \pm 12,8$ \\
\hline & \multirow{2}{*}{ Euterpina acutifrons } & N III-VI & $151,1 \pm 33,5$ & $105,9 \pm 37,8$ \\
\hline & & C I-V & $258,3 \pm 33,9$ & $117,1 \pm 14,2$ \\
\hline \multirow{27}{*}{$150-200$} & \multirow{2}{*}{ Acartia spp. } & N III-VI & $191,2 \pm 29,9$ & $117,8 \pm 23,7$ \\
\hline & & C I-V & $361,8 \pm 59,2$ & $135,6 \pm 21,6$ \\
\hline & \multirow{2}{*}{ Paracalanidae } & N III-VI & $163 \pm 20,8$ & $98,3 \pm 18,5$ \\
\hline & & C I-V & $348,4 \pm 54,9$ & $147,8 \pm 23,9$ \\
\hline & \multirow{2}{*}{ Parvocalanus crassirostris } & C I-V & $293,9 \pm 59,4$ & $140,5 \pm 29,7$ \\
\hline & & $\mathrm{AD}$ & $356,4 \pm 43$ & $160,1 \pm 21,1$ \\
\hline & Pseudodiaptomus acutus & N III-VI & $279,9 \pm 59,1$ & $160,3 \pm 22,4$ \\
\hline & \multirow{3}{*}{ Temora turbinata } & N I-II & $134,1 \pm 13$ & $94,2 \pm 1,3$ \\
\hline & & N III-VI & $196,5 \pm 30,2$ & $118,3 \pm 17,3$ \\
\hline & & C I-V & $269,7 \pm 46,3$ & $151,1 \pm 23,8$ \\
\hline & \multirow{2}{*}{ T. stylifera } & N III-VI & $212,9 \pm 30,8$ & $123,7 \pm 17,9$ \\
\hline & & $\mathrm{C} I-\mathrm{V}$ & $268,2 \pm 28,8$ & $150,9 \pm 19,3$ \\
\hline & \multirow{3}{*}{ Dioithona oculata } & N III-VI & $186,3 \pm 23,9$ & $108,3 \pm 16,8$ \\
\hline & & C I-V & $287,3 \pm 37,6$ & $139,8 \pm 19,7$ \\
\hline & & $\mathrm{AD}$ & $361,4 \pm 42,9$ & $175,4 \pm 17,3$ \\
\hline & & N III-VI & $143,8 \pm 22,1$ & $79,6 \pm 17,6$ \\
\hline & Oithona spp. & $\mathrm{CI}-\mathrm{V}$ & $232,8 \pm 53$ & $113,8 \pm 28,7$ \\
\hline & & $\mathrm{AD}$ & $345,7 \pm 45,3$ & $160,5 \pm 25,2$ \\
\hline & & C I-V & $311,3 \pm 56,4$ & $116,3 \pm 19,6$ \\
\hline & O. plumifera & $\mathrm{AD}$ & $467,4 \pm 84,8$ & $139,2 \pm 30,1$ \\
\hline & & N III-VI & $159 \pm 41,6$ & \\
\hline & Oncaeidae & C I-V & $255,2 \pm 50$ & $122,4 \pm 27,4$ \\
\hline & & $\mathrm{AD}$ & $306,8 \pm 51,2$ & $144,8 \pm 23,2$ \\
\hline & & N III-VI & $207,2 \pm 36,7$ & $95,6 \pm 22,4$ \\
\hline & Corycaeidae & C I-V & $295,2 \pm 48,3$ & $144,1 \pm 30,8$ \\
\hline & Euterpina acutifrons & N III-VI & $177,4 \pm 29,2$ & $119,1 \pm 20,8$ \\
\hline & Euterpina acutifrons & C I-V & $302,5 \pm 54,6$ & $136,6 \pm 22$ \\
\hline
\end{tabular}




\subsubsection{Crescimento, biomassa e produção de juvenis de copépodes}

\subsubsection{Acartia spp.}

O gênero Acartia foi representado por duas espécies: A. lilljeborgii e A. tonsa, sendo a primeira dominante e muito frequente. A. tonsa ocorreu na metade das amostras quantitativas de ambas as redes $(20$ e $100 \mu \mathrm{m})$, em densidades inferiores à $A$. lilljeborgii na grande maioria dos casos. A. lilljeborgii não foi encontrada em apenas duas amostras da rede de $20 \mu \mathrm{m}$. O gênero teve densidade média de $558 \pm 625$ org.m ${ }^{-3}$ nas amostras da rede de $20 \mu \mathrm{m}$ e $627 \pm 913$ org. $\mathrm{m}^{-3}$ para a rede de $100 \mu \mathrm{m}$ durante o período estudado.

Juvenis deste gênero foram abundantes, sendo que o crescimento só não foi obtido no experimento C-2 devido ao baixo número de indivíduos (Tabela 2.4). As taxas de crescimento tiveram uma amplitude de 0,03 a $0,84 \mathrm{~d}^{-1}$, sendo os valores médios iguais à $0,38 \pm 0,29 \mathrm{~d}^{-1}$ para a coorte de $50-80 \mu \mathrm{m}, 0,34 \pm 0,19 \mathrm{~d}^{-1}$ para $80-100$ $\mu \mathrm{m}, 0,4 \pm 0,23 \mathrm{~d}^{-1}$ para $100-150 \mu \mathrm{m}$ e $0,37 \pm 0,13 \mathrm{~d}^{-1}$ para a coorte de $150-200 \mu \mathrm{m}$ (Figuras 2.6 e 2.7). Não houve uma nítida diferença de $g$ entre o verão e o inverno ou entre os anos estudados, ou ainda entre coortes de tamanhos diferentes (Tabela 2.8).

A relação entre clorofila- $a$ e feopigmentos com os valores de $g$ apresentou grande dispersão dos dados. O índice de correlação de Spearman ( $\rho$ ) indicou uma correlação negativa branda, porém significativa entre os pigmentos e $g$ (Figura 2.8). A temperatura esteve diretamente e positivamente correlacionada ao $g,(\rho=0,401 ; p<$ 0,001) (Figura 2.8). Correlações inversamente proporcionais entre $g$ medido experimentalmente e o estimado através dos modelos foram detectadas (Figura 2.9).

Tanto a biomassa quanto a produção foram maiores para os experimentos com as coortes de 100-150 e 150-200 $\mu \mathrm{m}$ para Acartia spp. (B: 0,17 $\pm 0,12 ; 0,045-0,35 \mathrm{mg}$ $\mathrm{C} \mathrm{m}^{-3}$; P: 0,066 $\pm 0,061 ; 0,025-0,169 \mathrm{mg} \mathrm{C} \mathrm{m}^{-3} \mathrm{~d}^{-1}$ ). Já as coortes de 50-80 e 80-100 $\mu \mathrm{m}$ tiveram uma variabilidade um pouco maior, porém valores médios menores (B: 0,132 \pm 0,233; 0,005-0,6 mg C.m ${ }^{-3} ;$ P: $0,04 \pm 0,032 ; 0,002-0,077 \mathrm{mg} \mathrm{C} \mathrm{m}^{-3} \mathrm{~d}^{-1}$ ). (Figura 2.10). 

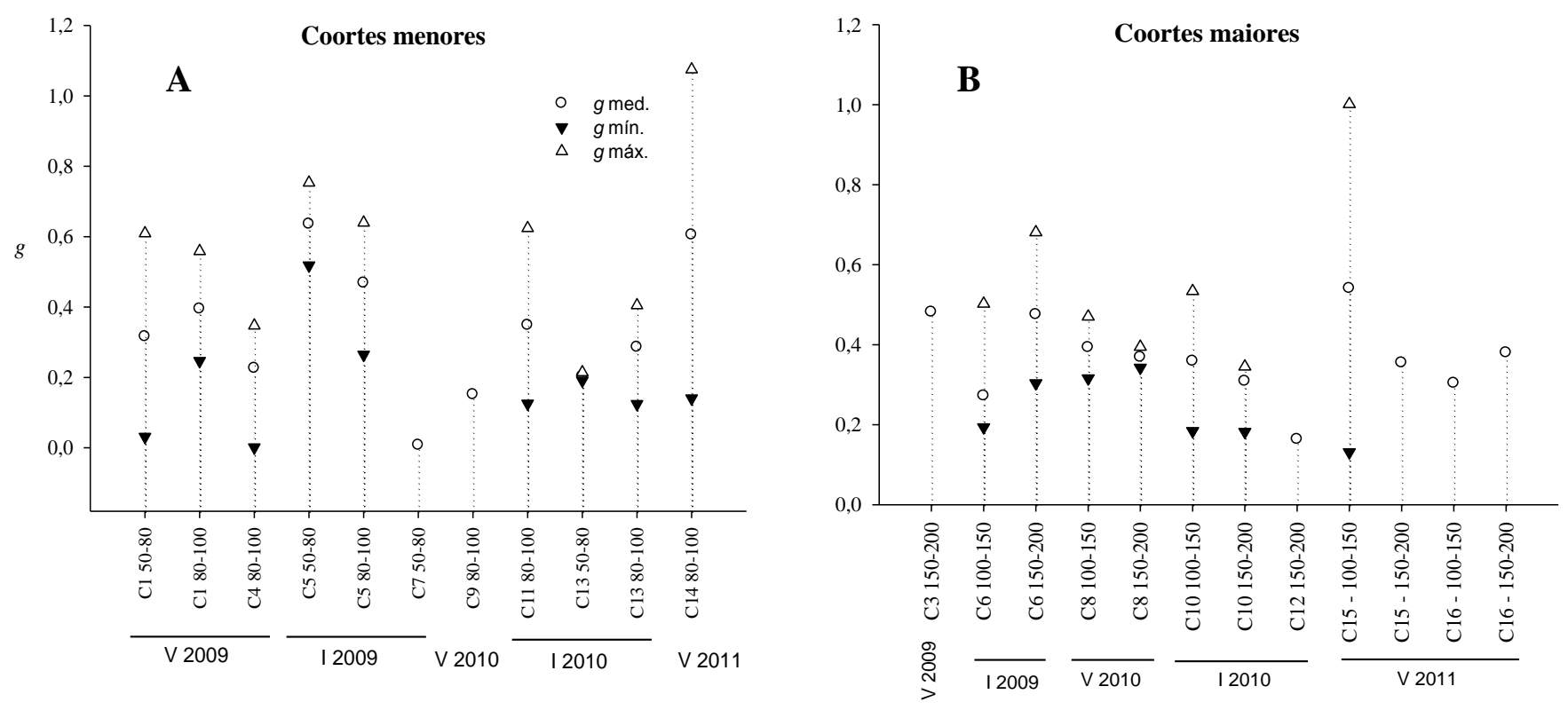

Figura 2.6: Taxas de crescimento para Acartia spp. ao longo do verão de 2009 até o verão de 2011. A: coortes menores, B: coortes maiores. $g$ mín.: mínimo; $g$ máx.: máximo e $g$ med.: mediana. Legendas do eixo x correspondem aos experimentos, conforme Tabela 2.1.
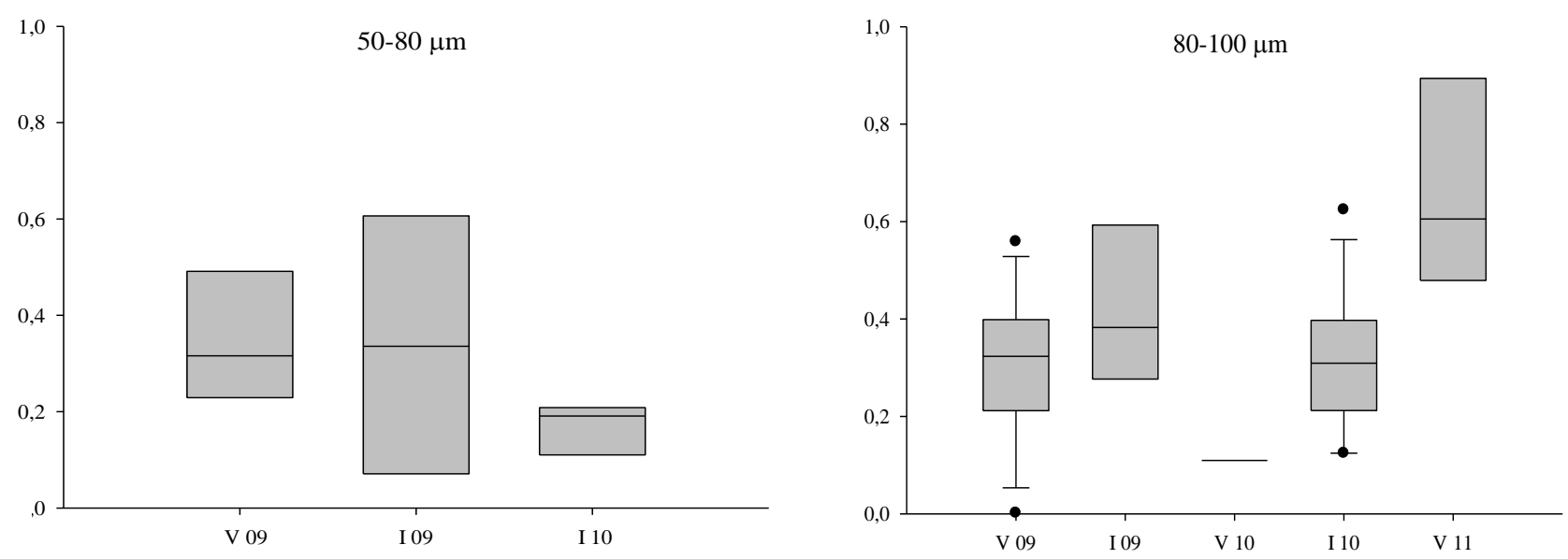

$\infty$
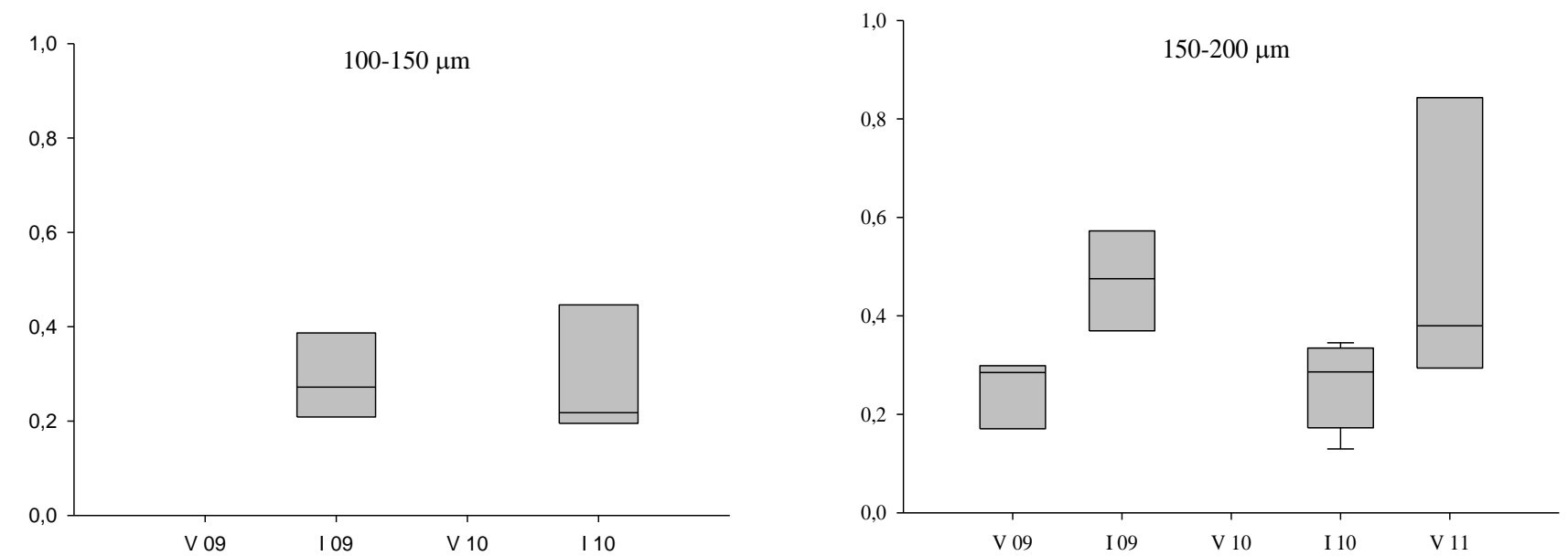

Figura 2.7: Box-plot com a variação de $g$ em cada um dos tamanhos de coortes analisados para o gênero Acartia. V: verão; I: inverno; 09,10 e 11: anos analisados. 

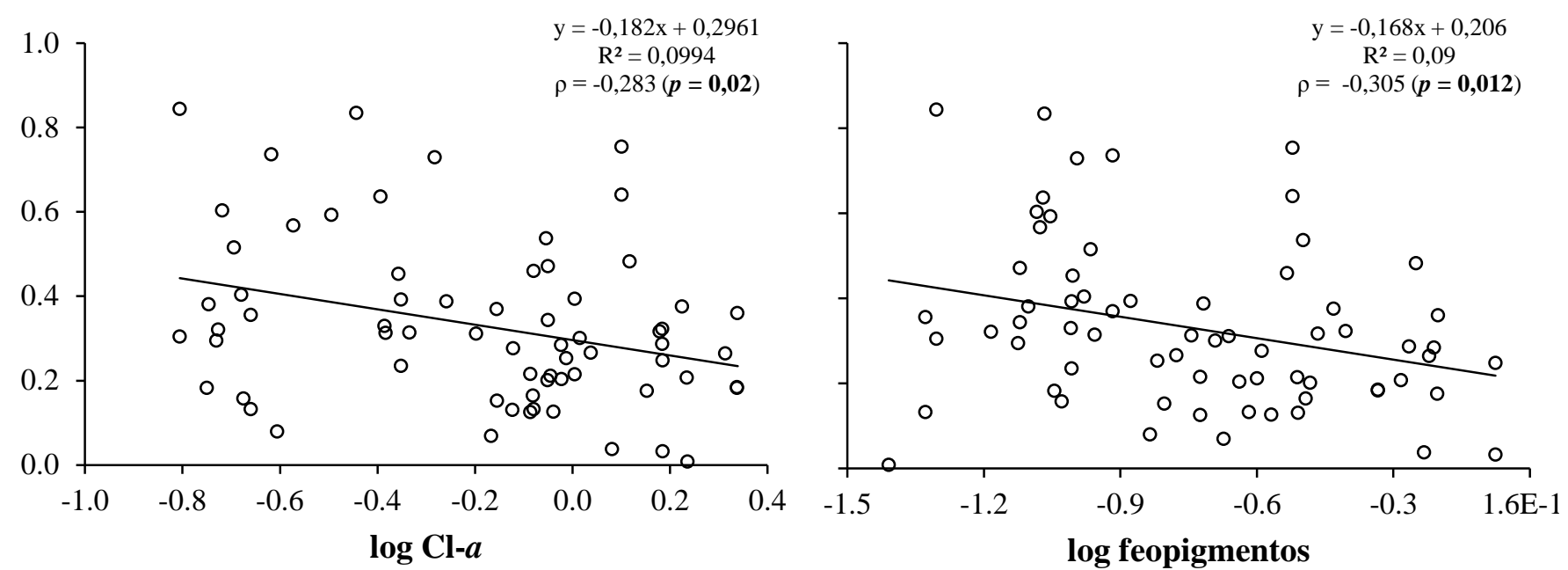

$\infty$

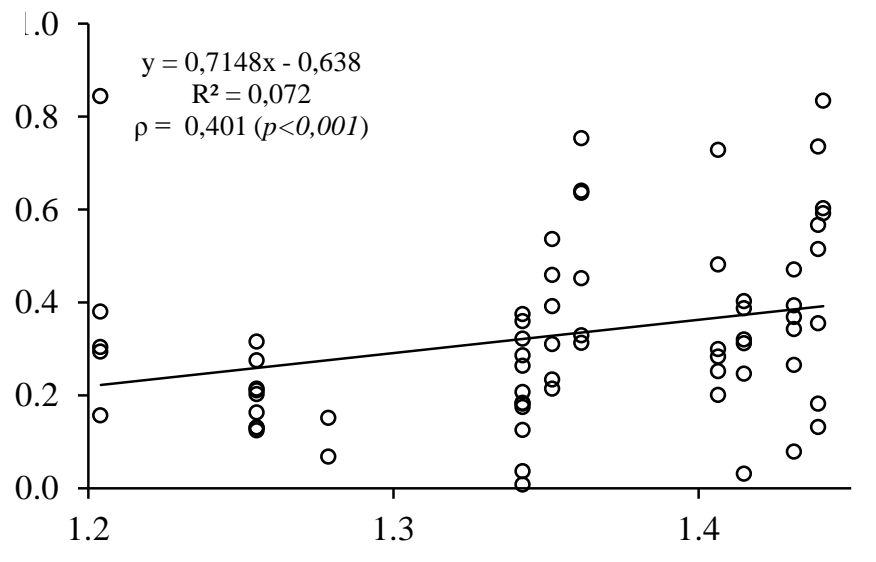

$\log$ Temperatura
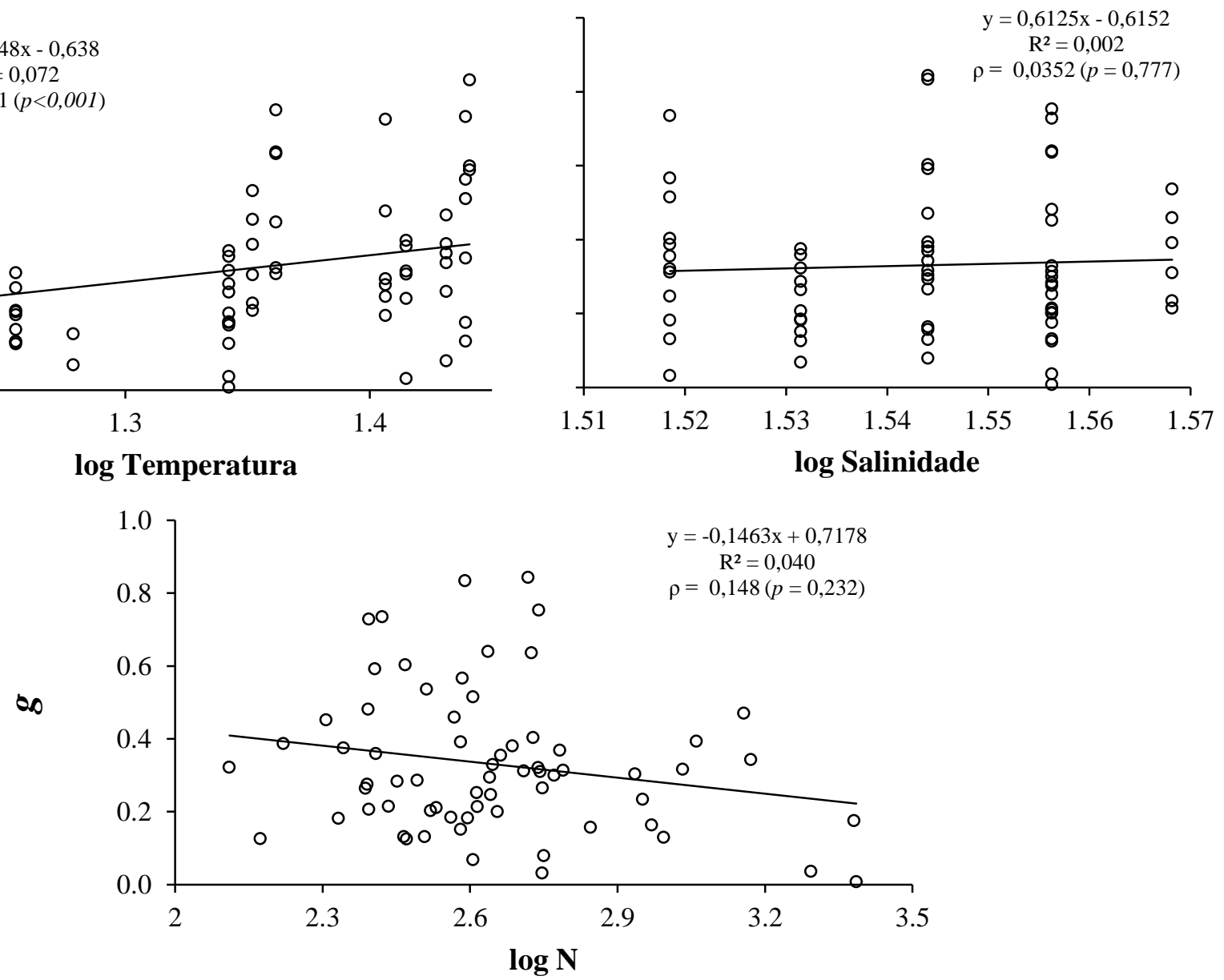

Figura 2.8: Regressão linear e correlação de Spearman ( $\rho$ ) entre as variáveis controladas e $g$ para Acartia spp. nos experimentos de coortes artificiais. O eixo y é representado por $g$ e o eixo x pelo $\log _{10}$ da variável. Clorofila- $a(\mathrm{Cl}-a)$ e feopigmentos em $\mathrm{mg} \mathrm{m}^{-3} ; \mathrm{T}$ : temperatura $\left({ }^{\circ} \mathrm{C}\right) ; \mathrm{N}$ : número de metazoários incubados. 

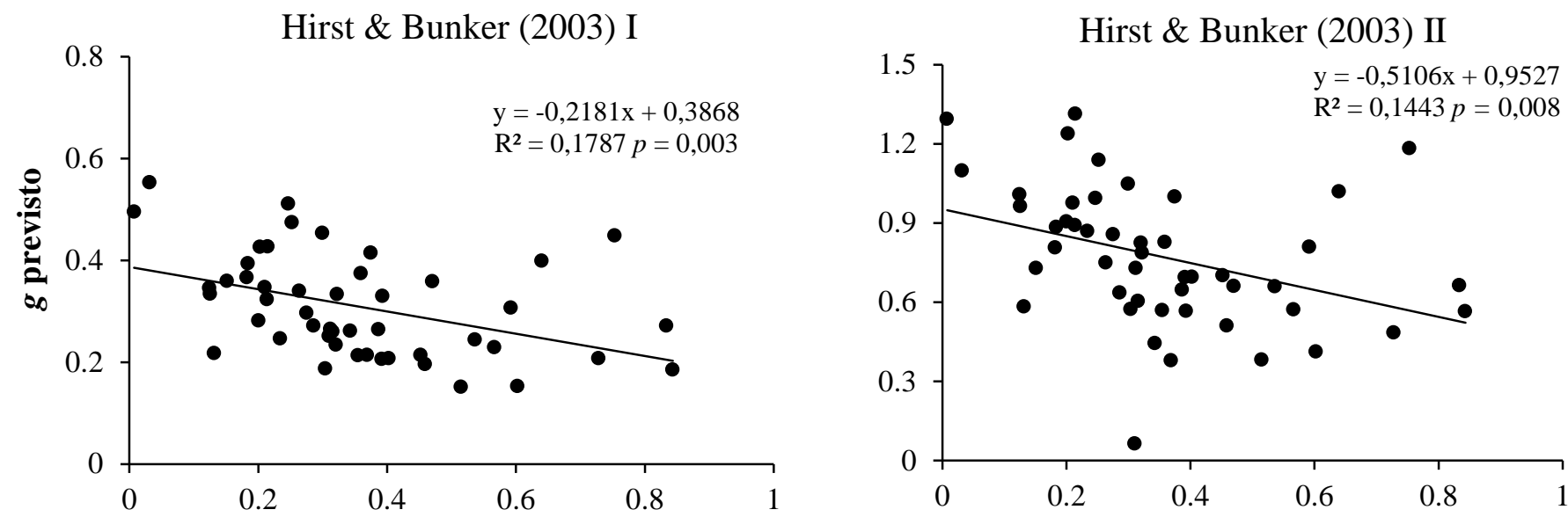

\section{$g$ medido}

Figura 2.9: Relação entre o crescimento medido experimentalmente (eixo x) e estimado para copépodes pelágicos em geral (Hirst \& Bunker 2003 I) e para juvenis de copépodes dispersores de ovos (Hirst \& Bunker 2003 II) em Acartia spp. Notar escalas diferentes no eixo y. Valores de $p$ do teste de Mann-Whitney.
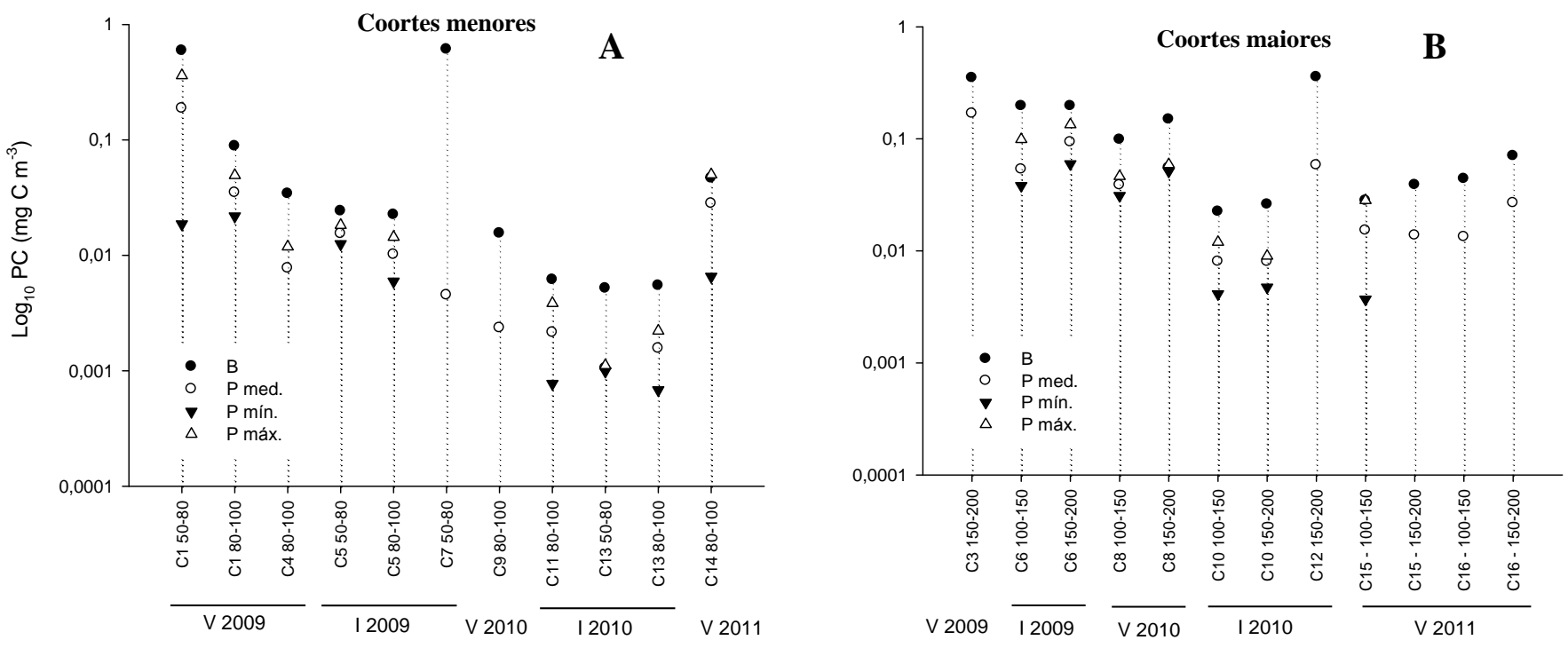

Figura 2.10: Variação da biomassa (B), produção mediana ou média (P med.), mínima (P mín.) e máxima (P máx.) para Acartia spp. do verão de 2009 ao verão de 2011. Biomassa e produção no eixo y em escala logarítmica do PC $\left(\mathrm{mg} \mathrm{m}^{-3}\right)$. A: coortes menores e $\mathbf{B}$ : coortes maiores. Legendas do eixo x correspondem aos experimentos, conforme Tabela 2.1. 


\subsubsection{Parvocalanus crassirostris}

Esta espécie de Paracalanidae é uma das menores entre os copépodes pelágicos da costa brasileira. Esteve presente em todas as amostras quantitativas e $g$ foi obtido em 14 dos 16 experimentos. A densidade foi geralmente elevada e demonstrou grande flutuação $\left(1.206 \pm 1.932\right.$ e $616 \pm 777$ org.m ${ }^{-3}$ para as amostras de 20 e $100 \mu \mathrm{m}$ respectivamente).

Foi particularmente dominante nas coortes menores (Figura 2.11) devido às pequenas dimensões dos copépodes adultos. Parte dos experimentos das coortes maiores foi eliminado ou apenas o período de 24 horas foi considerado, devido à presença de adultos durante o início ou intervalos posteriores das incubações.

Os valores de $g$ estiveram entre 0,13 e $0,68 \mathrm{~d}^{-1}\left(0,35 \pm 0,13 \mathrm{~d}^{-1}\right)$ para as coortes menores e entre 0,05 e $0,8 \mathrm{~d}^{-1}\left(0,39 \pm 0,27 \mathrm{~d}^{-1}\right)$ para as maiores. Não foi detectada diferença significativa para $g$ entre os diferentes tamanhos de coortes, entre os períodos de verão e inverno ou entre os anos analisados (Tabela 2.8). Alta variabilidade foi encontrada para as taxas de crescimento em Parvocalanus crassirostris, ilustrada na Figura 2.12 para a coorte de 50-80 $\mu \mathrm{m}$, pois a mesma possuiu maior número amostral.

Uma correlação branda e negativa $(\rho=-0,342 ; p=0,015)$ foi observada entre $g$ e a concentração de feopigmentos. O mesmo padrão foi observado para a clorofila- $a$, porém o nível de significância foi um pouco superior a $0,05(\rho=-0,277 ; p=0,051)$. As demais variáveis (temperatura, salinidade e número de animais incubados) não estiveram relacionadas ao crescimento (Figura 2.13).

Não foi possível observar uma relação nítida entre $g$ medido experimentalmente e o estimado para copépodes juvenis dispersores de ovos, porém a relação foi inversamente proporcional para a equação destinada a copépodes pelágicos em geral (Figura 2. 14).

Os valores de biomassa e produção foram cerca de uma ordem de grandeza maiores paras as coortes de 100-150 e 150-200 $\mu \mathrm{m}$, em relação às coortes de 50-80 e 80-100 $\mu \mathrm{m}$ (Figura 2. 15). A biomassa e produção para as coortes menores foram de $0,018 \pm 0,025 \mathrm{mg} \mathrm{C} \mathrm{m}^{-3}$ e $0,004 \pm 0,007 \mathrm{mg} \mathrm{C} \mathrm{m}^{-3} \mathrm{~d}^{-1}$ respectivamente, enquanto que tais valores foram de $0,164 \pm 0,173 \mathrm{mg} \mathrm{C} \mathrm{m}^{-3}$ e $0,066 \pm 0,106 \mathrm{mg} \mathrm{C} \mathrm{m}^{-3} \mathrm{~d}^{-1}$ para as coortes maiores. 

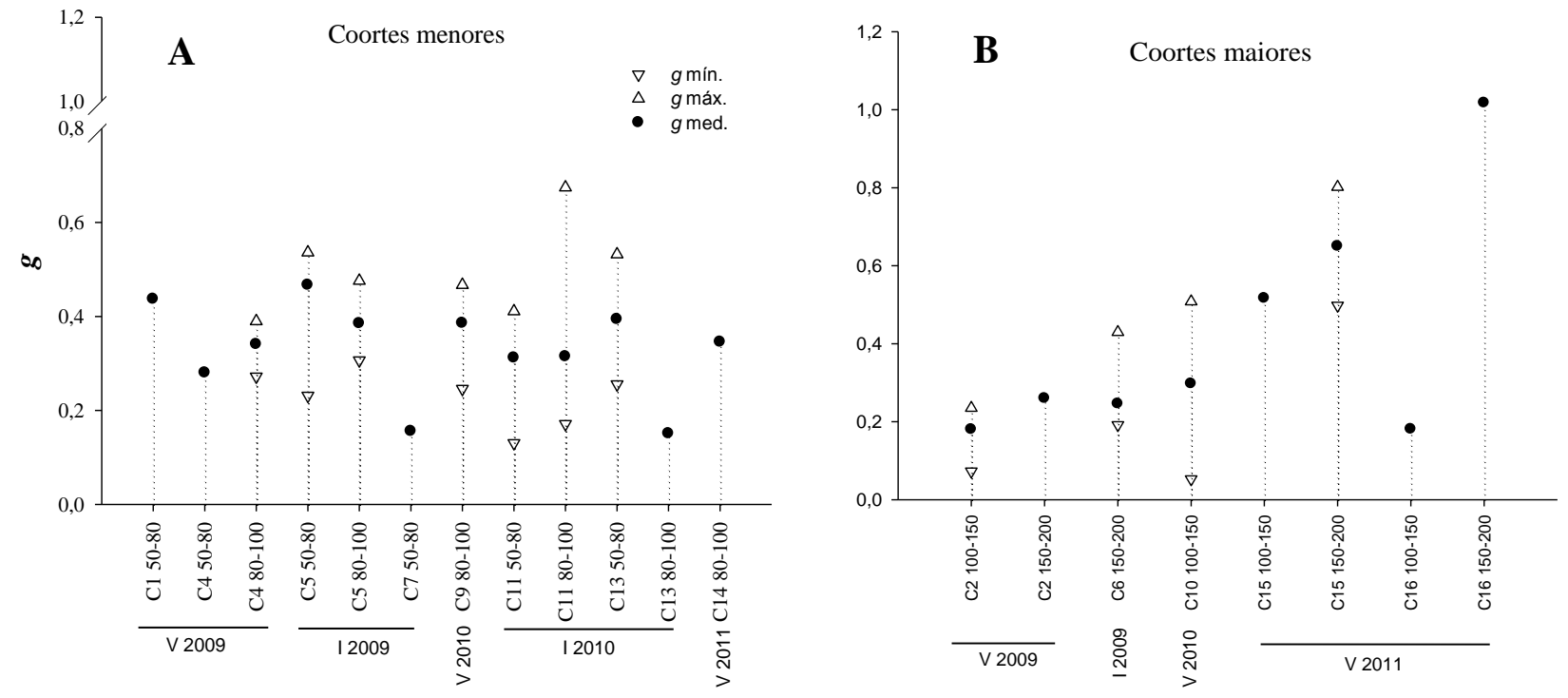

Figura 2.11: Taxas de crescimento para Parvocalanus crassirostris ao longo do verão de 2009 até o verão de 2011. A: coortes menores, B: coortes maiores. $g$ mín.: mínimo; $g$ máx.: máximo e $g$ med.: mediana. Legendas do eixo x correspondem aos experimentos, conforme Tabela 2.1.

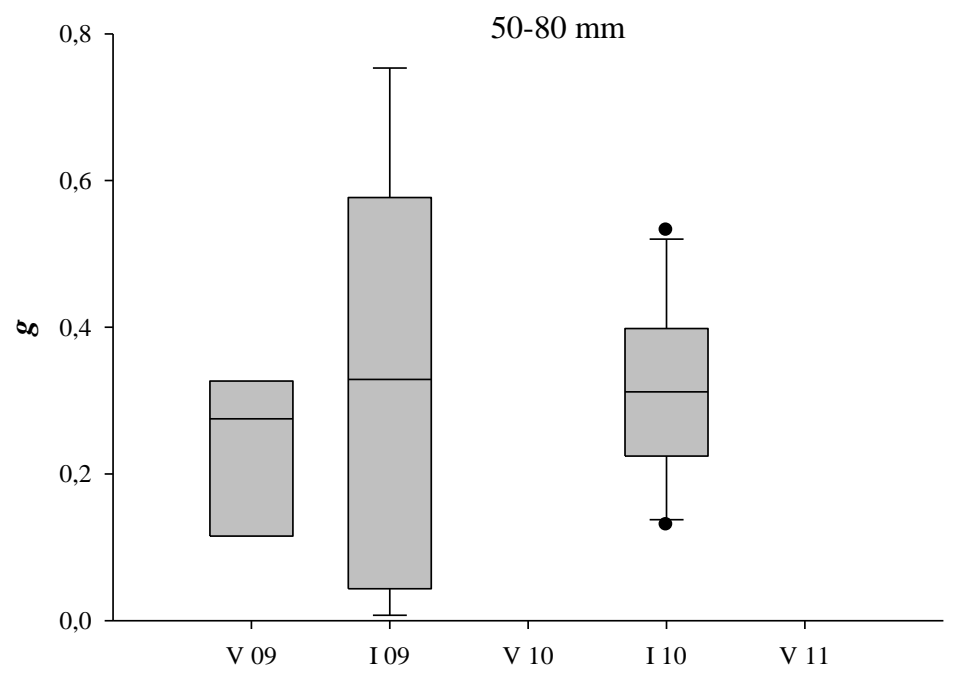

Figura 2.12: Box-plot com a variação de $g$ para Parvocalanus crassirostris, coorte de 50-80 $\mu \mathrm{m}$. O número de experimentos para as demais coortes foi insuficiente para a representação por box-plot. V: verão; I: inverno; 09,10 e 11: anos. 

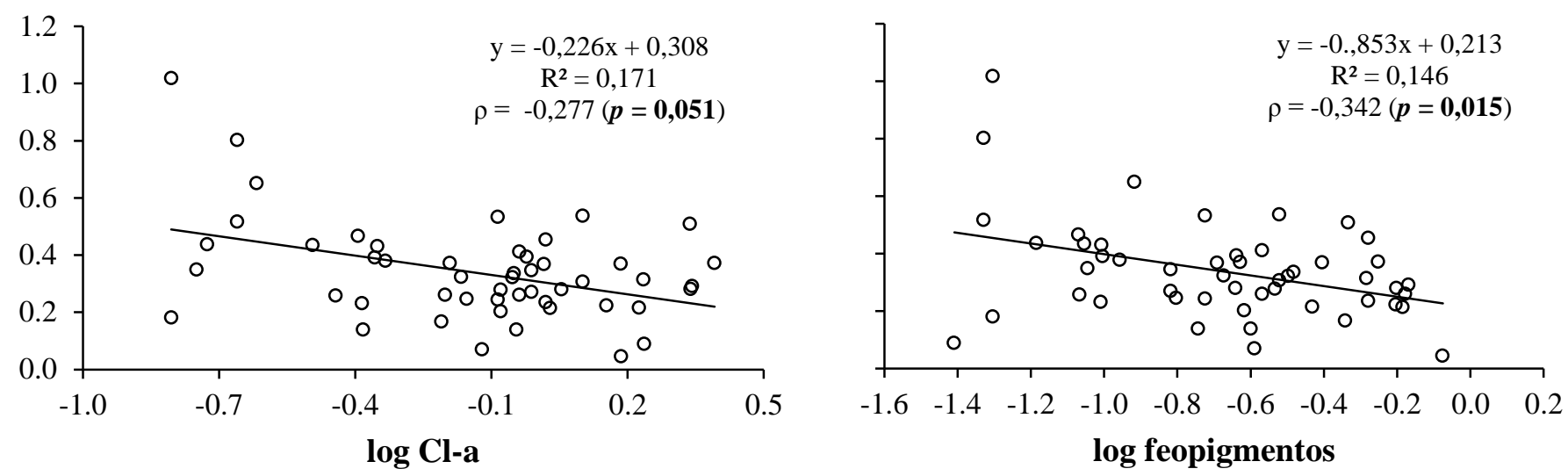

os
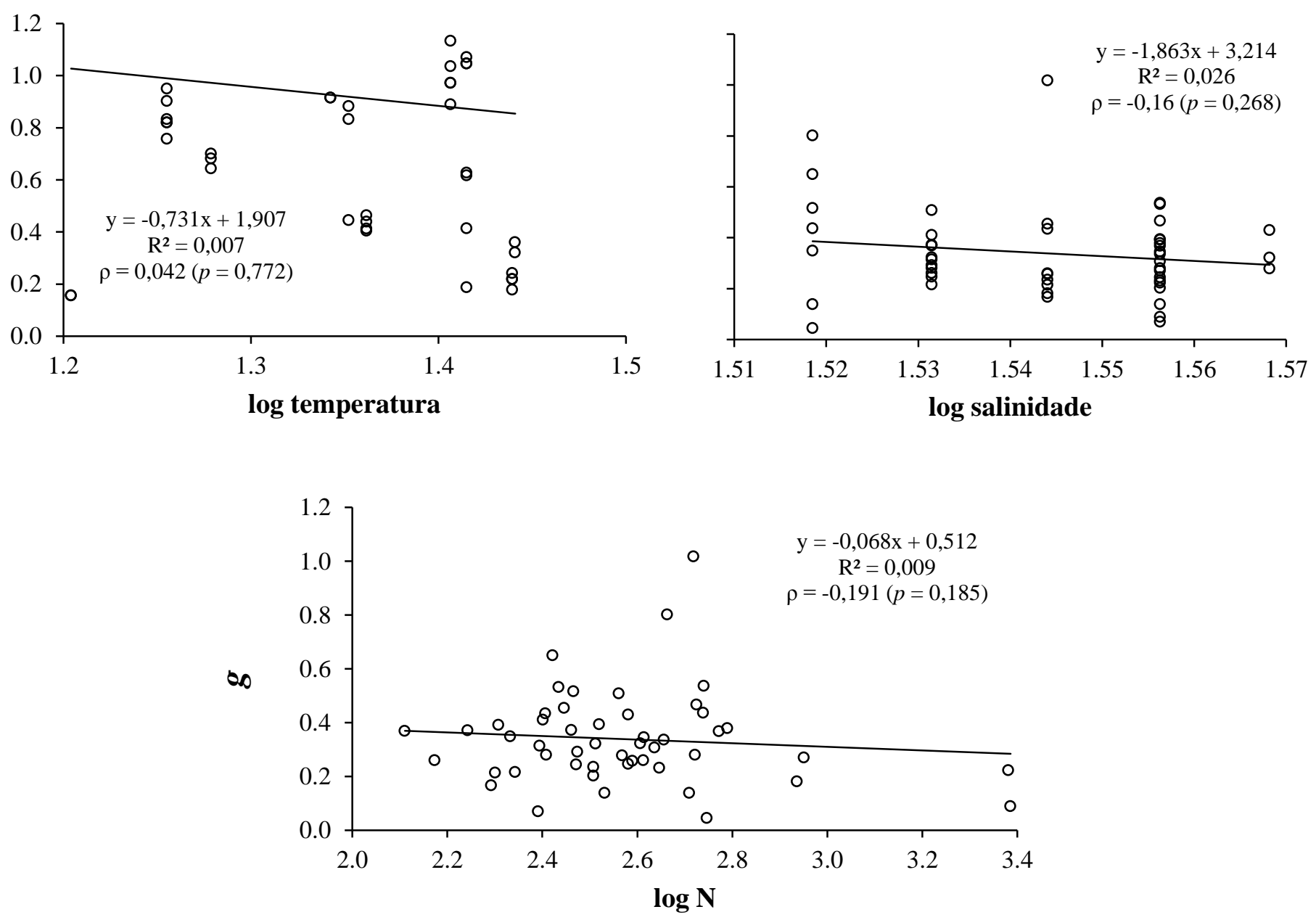

Figura 2. 13: Regressão linear e correlação de Spearman $(\rho)$ entre as variáveis controladas e $g$ para Parvocalanus crassirostris nos experimentos de coortes artificiais. $\mathrm{O}$ eixo y é representado por $g$ e o eixo $\mathrm{x}$ pelo $\log _{10}$ da variável. Clorofila- $a(\mathrm{Cl}-a)$ e feopigmentos em $\mathrm{mg} \mathrm{m}^{-3}$; T: temperatura $\left({ }^{\circ} \mathrm{C}\right)$; $\mathrm{N}$ : número de metazoários incubados. 

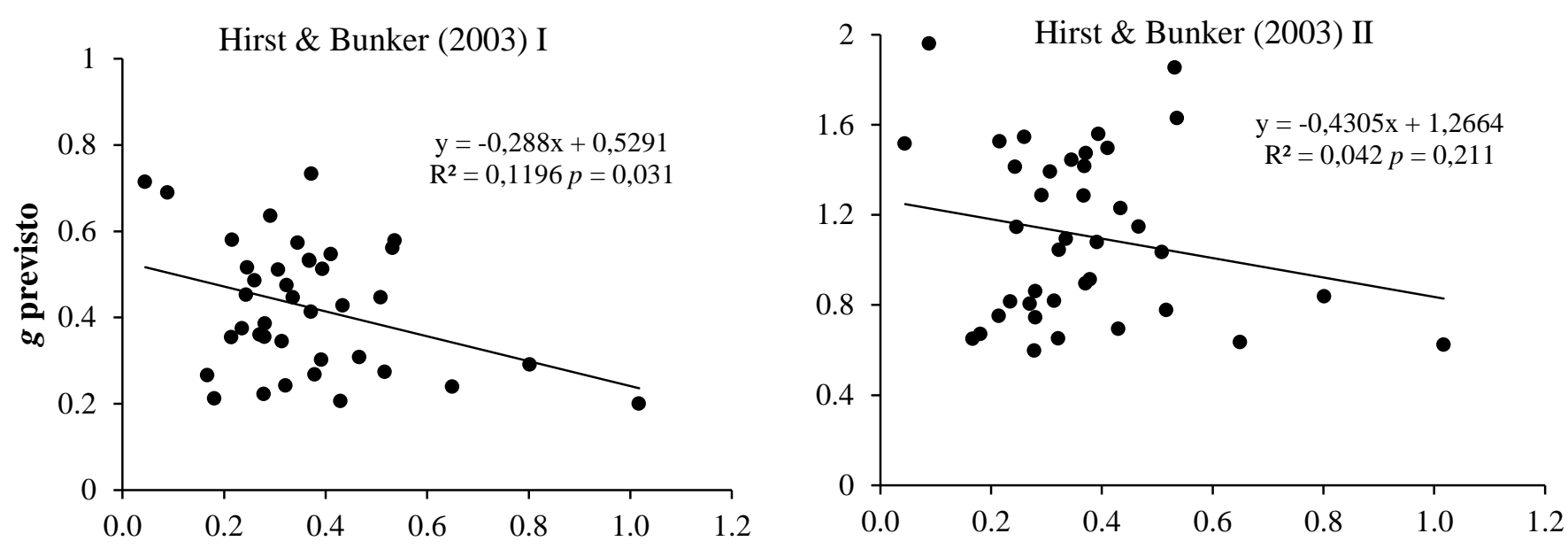

\section{$g$ medido}

Figura 2.14: Relação entre o crescimento medido experimentalmente (eixo x) e estimado para copépodes pelágicos em geral (Hirst \& Bunker, 2003 I) e juvenis de copépodes dispersores de ovos (Hirst \& Bunker, 2003 II) em Parvocalanus crassirostris. Notar escalas diferentes no eixo y. Valores de $p$ do teste de Mann-Whitney.
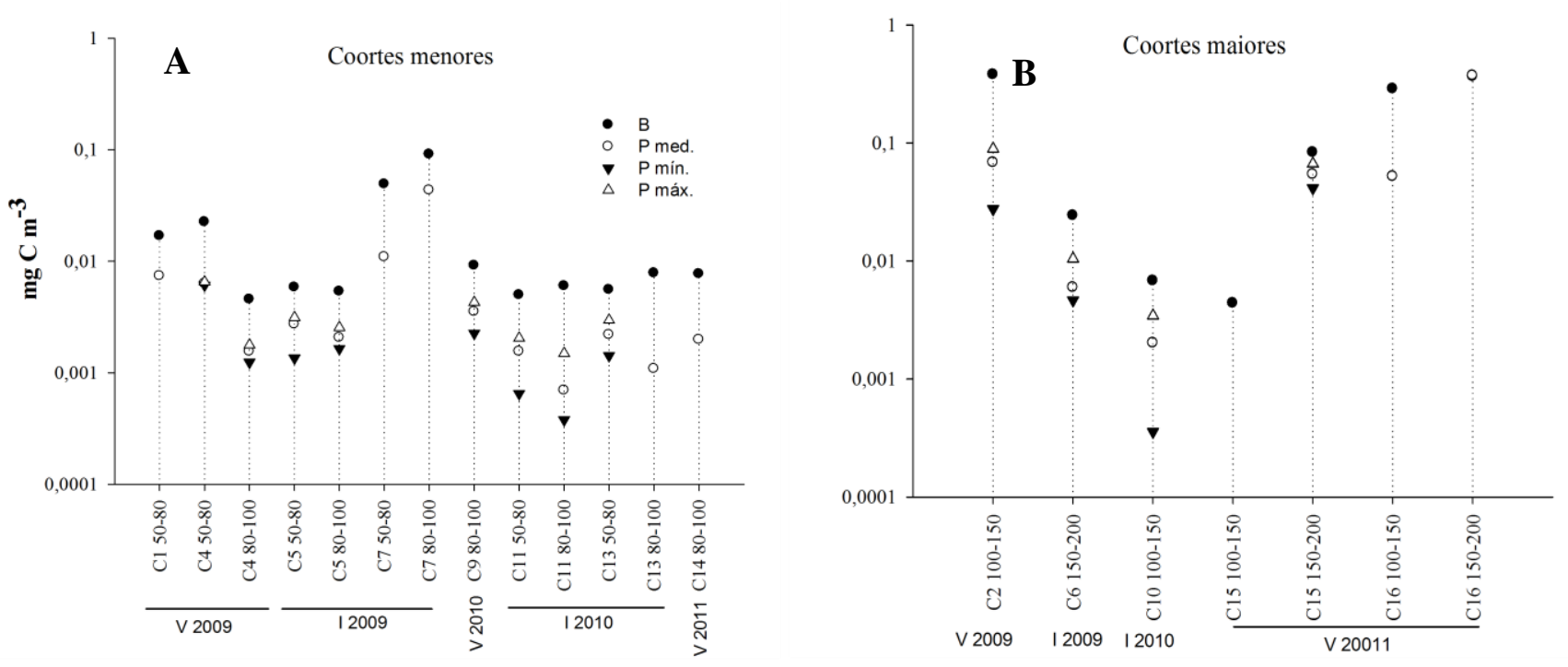

Figura 2.15: Variação da biomassa (B), produção mediana ou média (P med.), mínima (P mín.) e máxima (P máx.) para Parvocalanus crassirostris do verão de 2009 ao verão de 2011. Biomassa e produção no eixo y em escala logarítmica do PC em $\mathrm{mg} \mathrm{m}^{-3}$. Sigla dos experimentos conforme tabela 2.1. A: coortes menores e B: coortes maiores. Legendas do eixo x correspondem aos experimentos, conforme Tabela 2.1. 


\subsubsection{Paracalanus spp.}

O gênero Paracalanus foi representado pelas espécies $P$. quasimodo, $P$. aculeatus, $P$. nanus e $P$. indicus sendo $P$. quasimodo a mais comum e abundante para todo o período estudado. O gênero esteve presente durante todo o período amostral, com exceção de três amostras para a rede de $20 \mu \mathrm{m}$ e a densidade foi $\left(689 \pm 419\right.$ org. $\mathrm{m}^{-3}$ para a rede de $20 \mu \mathrm{m}$ e $553 \pm 342 \mathrm{org} \cdot \mathrm{m}^{-3}$ para a rede de $100 \mu \mathrm{m}$ ).

Foi possível mensurar o crescimento para Paracalanus spp. em todos os experimentos realizados, ao menos em uma das duas coortes de cada experimento e satisfatoriamente para as quatro classes de tamanho de coortes artificiais (Figura 2.16). Não houve diferença entre as coortes menores e maiores ou entre o verão e inverno quanto às taxas de crescimento, porém a diferença entre os anos foi significativa ( $p=$ 0,013; Tabela 2.8), sendo maiores para 2011.

Os gráficos em box-plot ilustraram a variabilidade de $g$ ao longo dos experimentos e nas diferentes classes de tamanho de coortes (Figura 2.17). O menor número de taxas de crescimento nas coortes de 150-200 $\mu \mathrm{m}$ deveu-se ao fato das incubações não atingir o terceiro dia, principalmente devido à presença de adultos impossibilitado medidas precisas de $g$. O crescimento foi de $0,4 \pm 0,25 \mathrm{~d}^{-1}$ e $0,27 \pm 0,18$ $\mathrm{d}^{-1}$ para as coortes de 50-80 e 80-100 $\mu \mathrm{m}$ e de $0,42 \pm 0,24 \mathrm{~d}^{-1}$ e $0,61 \pm 0,39 \mathrm{~d}^{-1}$ para as coortes de 100-150 e 150-200 $\mu \mathrm{m}$.

A relação entre $g$ e a concentração de clorofila- $a$ foi inversamente proporcional, $(p=0,035)$. Já a correlação entre $g$ e a temperatura foi positiva e significativa $(\rho=$ 0,506; $p<0,001$ ), enquanto que em relação à salinidade a mesma foi negativa ( $\rho=$ 0,354; $p<0,003$ ) (Figura 2.18). As correlações foram inversamente proporcionais entre o crescimento medido experimentalmente e o estimado através das equações de Hirst \& Bunker (2003) (Figura 2.19). Os valores de biomassa e produção foram ligeiramente maiores paras as coortes de maior tamanho, em relação às coortes menores (Figura 2.20). A biomassa e produção para as coortes menores foram de $0,06 \pm 0,04 \mathrm{mg} \mathrm{C} \mathrm{m}^{-3} \mathrm{e}$ $0,016 \pm 0,008 \mathrm{mg} \mathrm{C} \mathrm{m}^{-3} \mathrm{~d}^{-1}$ respectivamente, enquanto que tais valores foram de $0,114 \pm$ $0,08 \mathrm{mg} \mathrm{C} \mathrm{m}^{-3}$ e $0,052 \pm 0,042 \mathrm{mg} \mathrm{C} \mathrm{m}^{-3} \mathrm{~d}^{-1}$ para as coortes maiores. 

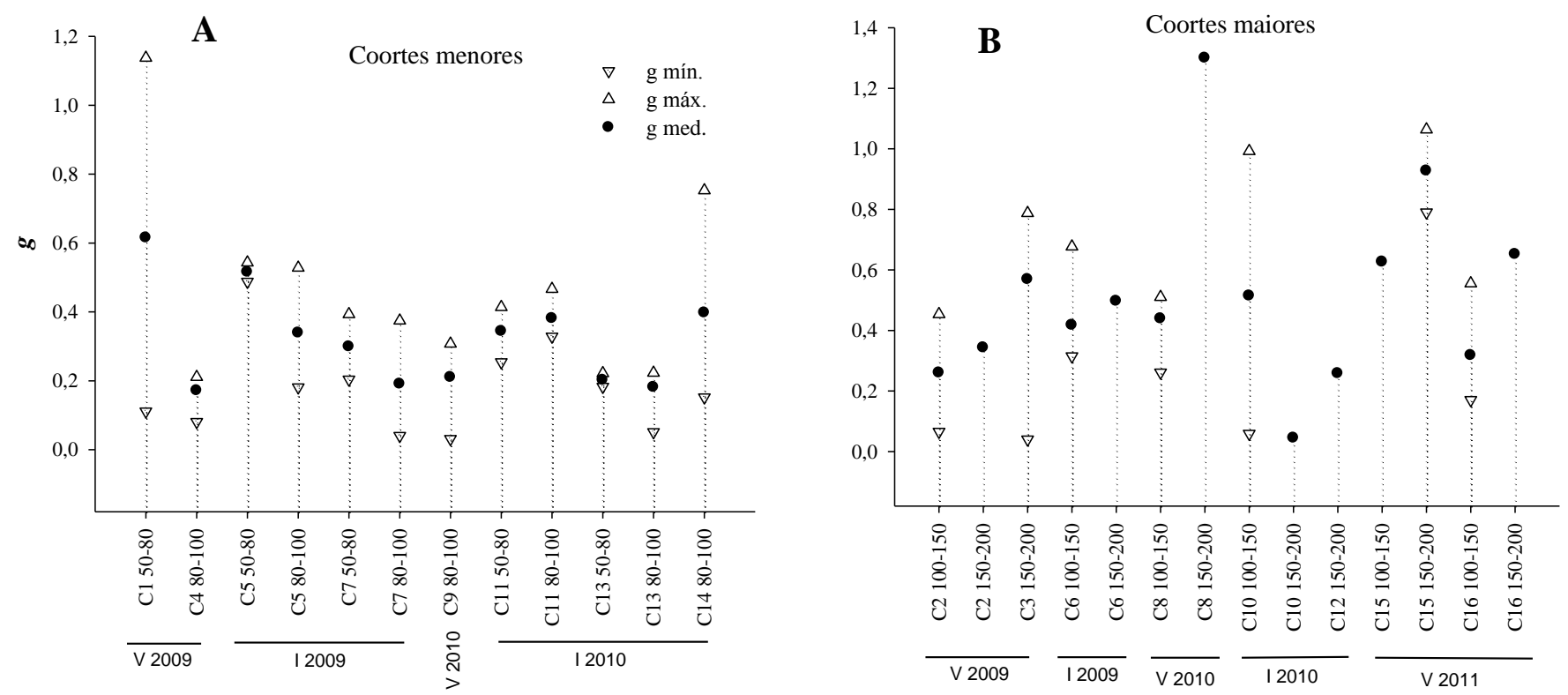

Figura 2.16: Taxas de crescimento para Paracalanus spp. ao longo do verão de 2009 até o verão de 2011. A: coortes menores, B: coortes maiores. $g$ mín.: mínimo; $g$ máx.: máximo e $g$ med.: mediana. Legendas do eixo x correspondem aos experimentos, conforme Tabela 2.1.
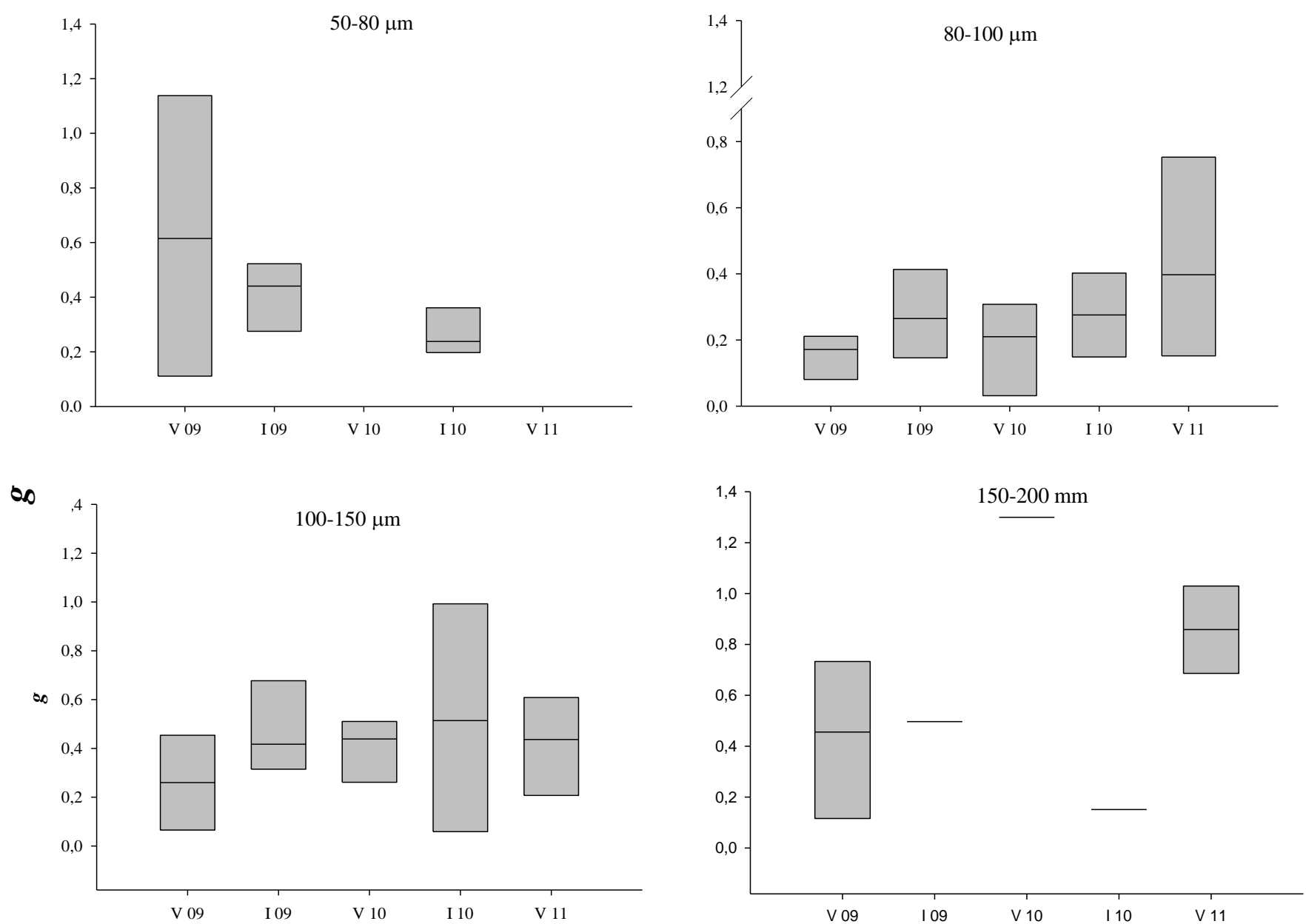

Figura 2.17: Box-plot com a variação de $g$ em cada um dos tamanhos de coortes analisados para Paracalanus spp. V: verão; I: inverno; 09,10 e 11: anos. 

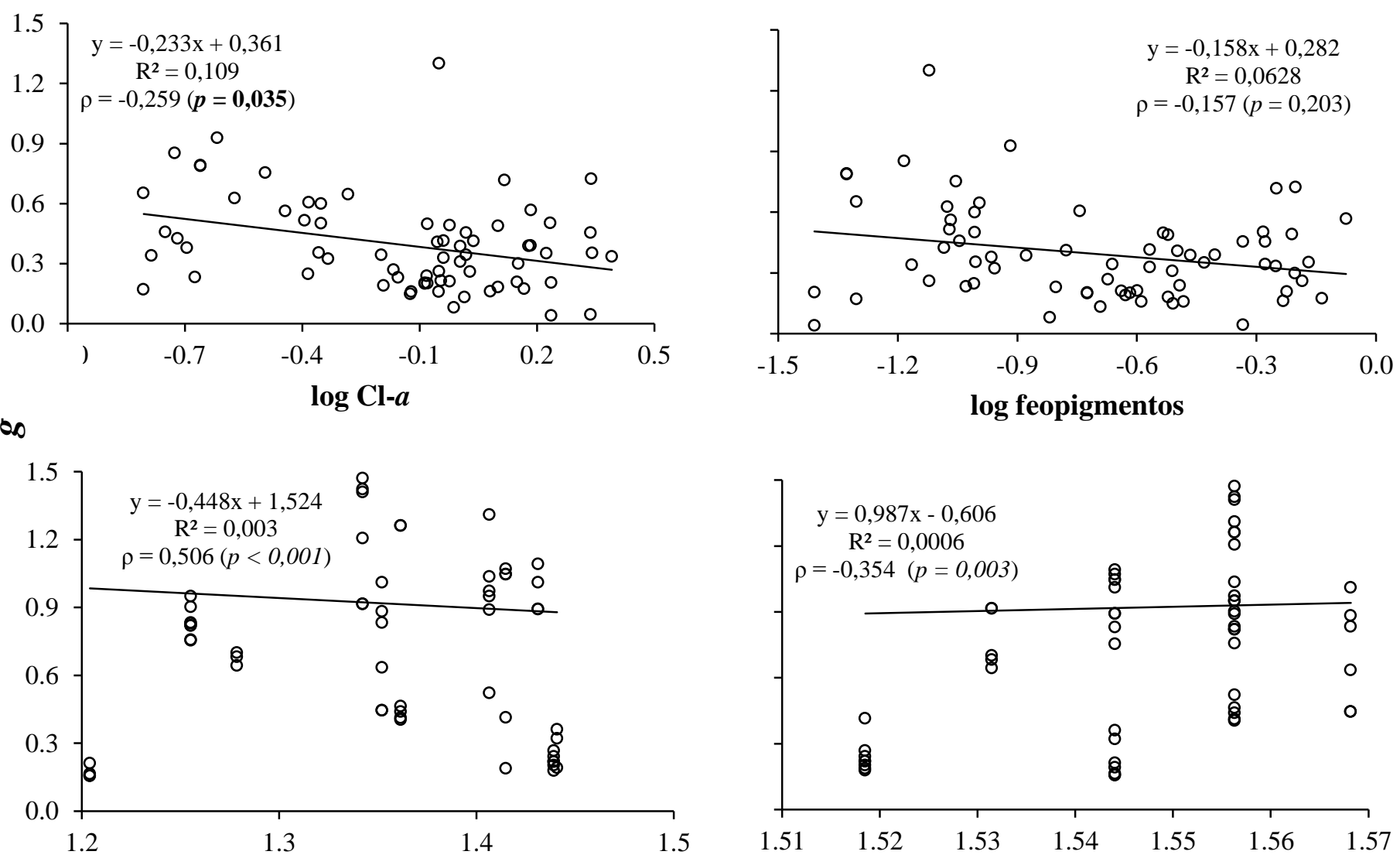

log temperatura
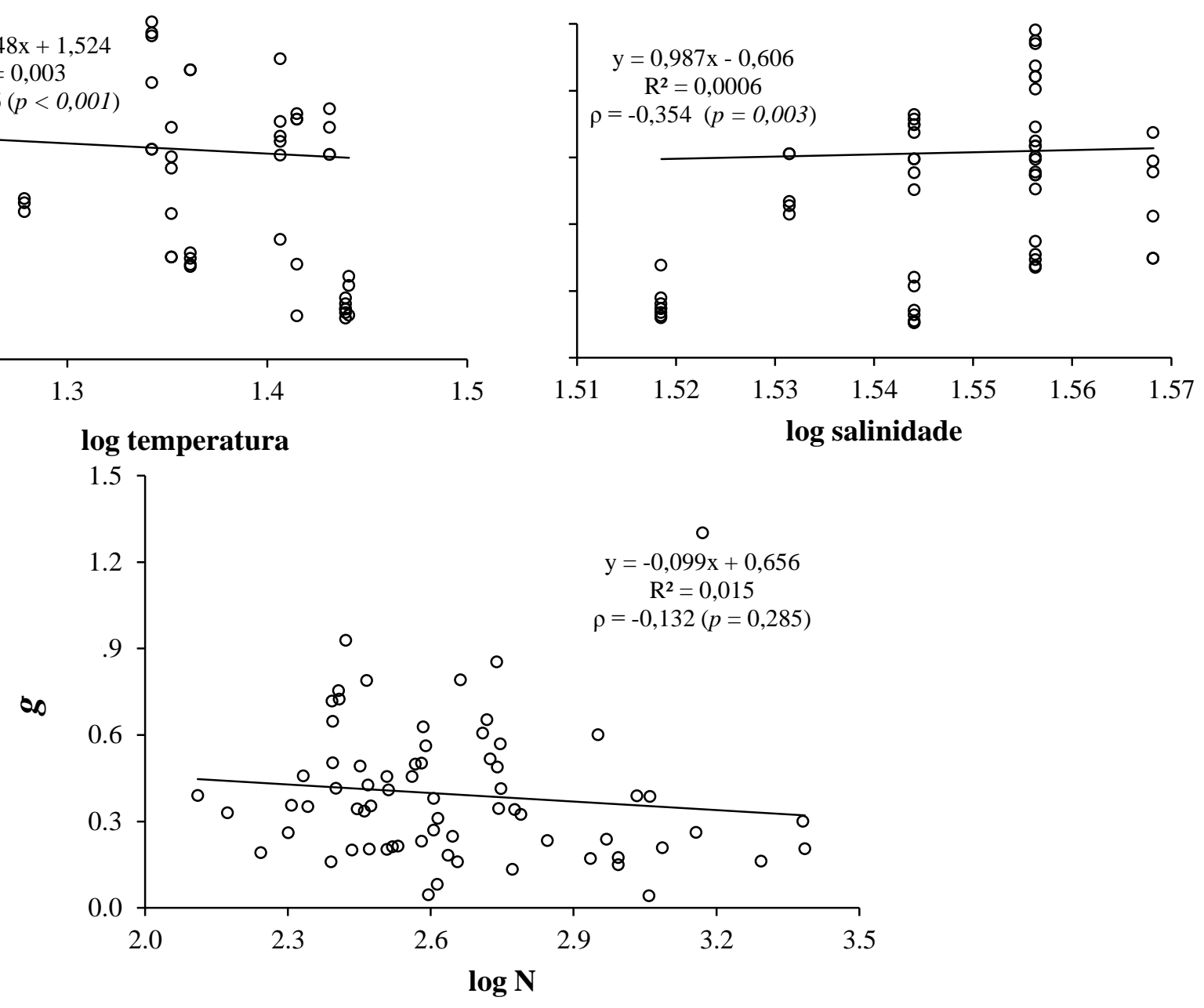

Figura 2.18: Regressão linear e correlação de Spearman $(\rho)$ entre as variáveis controladas e $g$ para Paracalanus spp. nos experimentos de coortes artificiais. O eixo y é representado por $g$ e o eixo x pelo $\log _{10}$ da variável. Clorofila- $a(\mathrm{Cl}-a)$ e feopigmentos em $\mathrm{mg} \mathrm{m}^{-3}$; $\mathrm{T}$ : temperatura $\left({ }^{\circ} \mathrm{C}\right) ; \mathrm{N}$ : número de metazoários incubados. 
Hirst \& Bunker (2003) I

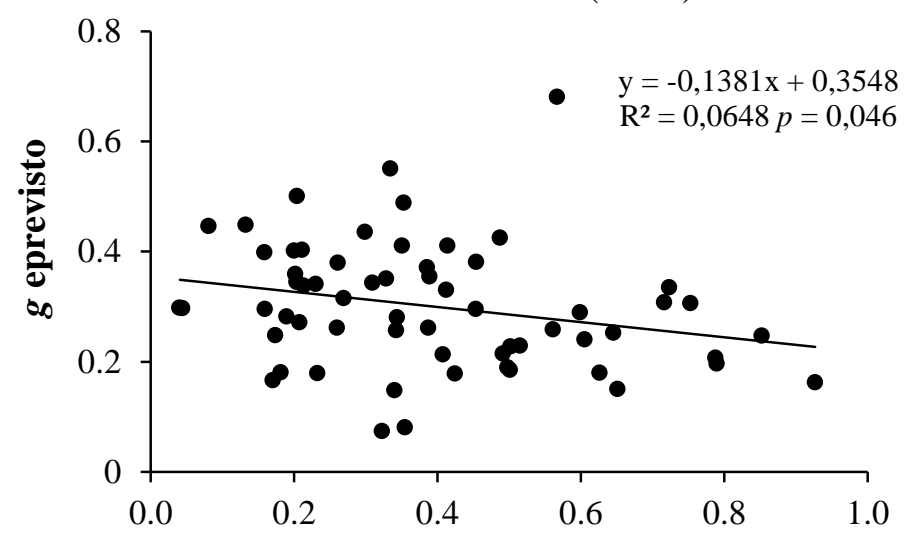

Hirst \& Bunker (2003) II

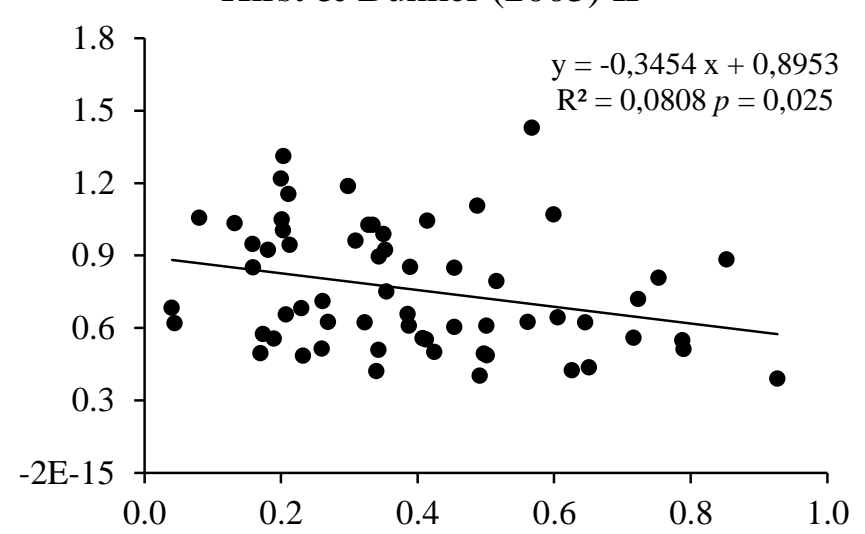

\section{g medido}

Figura 2.19: Relação entre o crescimento medido experimentalmente (eixo $\mathrm{x}$ ) e estimado para copépodes pelágicos em geral (Hirst \& Bunker, 2003 I) e juvenis de copépodes dispersores de ovos (Hirst \& Bunker, 2003 II) em Paracalanus spp. Notar escalas diferentes no eixo y. Valores de $p$ do teste de Mann-Whitney.
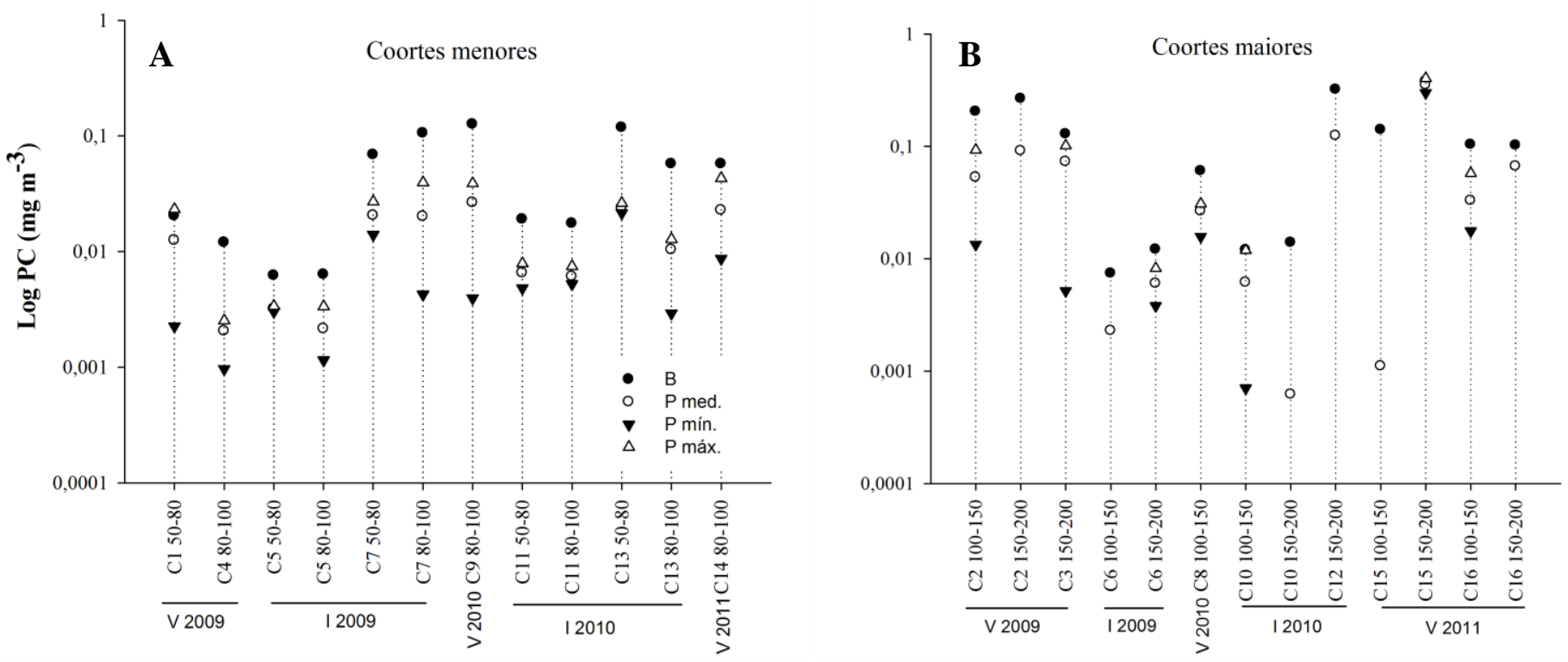

Figura 2.20: Variação da biomassa (B), produção mediana ou média (P med.), mínima (P mín.) e máxima (P máx.) para Paracalanus spp. do verão de 2009 ao verão de 2011. Biomassa e produção no eixo y em escala logarítmica do PC $\left(\mathrm{mg} \mathrm{m}^{-3}\right)$. A: coortes menores e B: coortes maiores. Legendas do eixo $\mathrm{x}$ correspondem aos experimentos, conforme Tabela 2.1 . 


\subsubsection{Temora turbinata}

A espécie Temora turbinata esteve presente em $100 \%$ das amostras quantitativas da rede de $100 \mu \mathrm{m}$ e ausente em apenas uma amostra da rede de $20 \mu \mathrm{m}$. A densidade da espécie foi moderada ao longo do período estudado $\left(649 \pm 889\right.$ e $340 \pm 373$ org. $\mathrm{m}^{-3}$ para as amostras de 20 e $100 \mu \mathrm{m}$ respectivamente).

As taxas de crescimento foram mensuradas em 9 dos 16 experimentos, sendo que nenhum resultado foi obtido para a coorte de 50-80 $\mu \mathrm{m}$ e apenas três para a coorte de 80-100 $\mu \mathrm{m}$ (Figura 2.21), uma vez que os náuplios desse gênero apresentam grandes dimensões. Para as coortes de 80-100 $\mu \mathrm{m}$, o valor médio de $g$ foi de $0,57 \pm 0,25 \mathrm{~d}^{-1}$, enquanto que para as coortes de 100-150 e 150-200 $\mu \mathrm{m}$ as médias foram de 0,46 0,37 e $0,52 \pm 0,24 \mathrm{~d}^{-1}$ respectivamente. Não houve diferença quanto ao crescimento entre os três anos amostrados ou entre as estações de verão e inverno (Tabela 2.8).

A correlação entre $g$ e a concentração de feopigmentos foi negativa $(\rho=-0,509$; $p<0,001)$. A relação entre a temperatura e $g$ foi diretamente proporcional $(\rho=0,548 ; p$ $<0,001)$, enquanto que para a salinidade a relação foi negativa $(\rho=-0,32 ; p=0,039)$ (Figura 2.22). Não houve correlação entre o crescimento medido experimentalmente e o estimado através das equações de Hirst \& Bunker (2003) (Figura 2.23).

A biomassa e produção para as coortes de 80-100 $\mu \mathrm{m}$ foram de 0,098 \pm 0,102 $\mathrm{mg} \mathrm{C} \mathrm{m}{ }^{-3}$ e $0,044 \pm 0,034 \mathrm{mg} \mathrm{C} \mathrm{m}^{-3} \mathrm{~d}^{-1}$ respectivamente, enquanto que tais valores foram de $0,1 \pm 0,103 \mathrm{mg} \mathrm{C} \mathrm{m}^{-3}$ e $0,024 \pm 0,015 \mathrm{mg} \mathrm{C} \mathrm{m}^{-3} \mathrm{~d}^{-1}$ para as coortes maiores (Figura 2.24).

\subsubsection{Temora stylifera}

A espécie Temora stylifera foi menos frequente que T. turbinata e esteve ausente em quatro períodos amostrais (25\%). A densidade da espécie foi relativamente baixa ao longo do período estudado $\left(65 \pm 96\right.$ org. $\mathrm{m}^{-3}$ para as amostras de $20 \mu \mathrm{m}$ e $103 \pm 147$ org. $\mathrm{m}^{-3}$ para as amostras de $\left.100 \mu \mathrm{m}\right)$. 

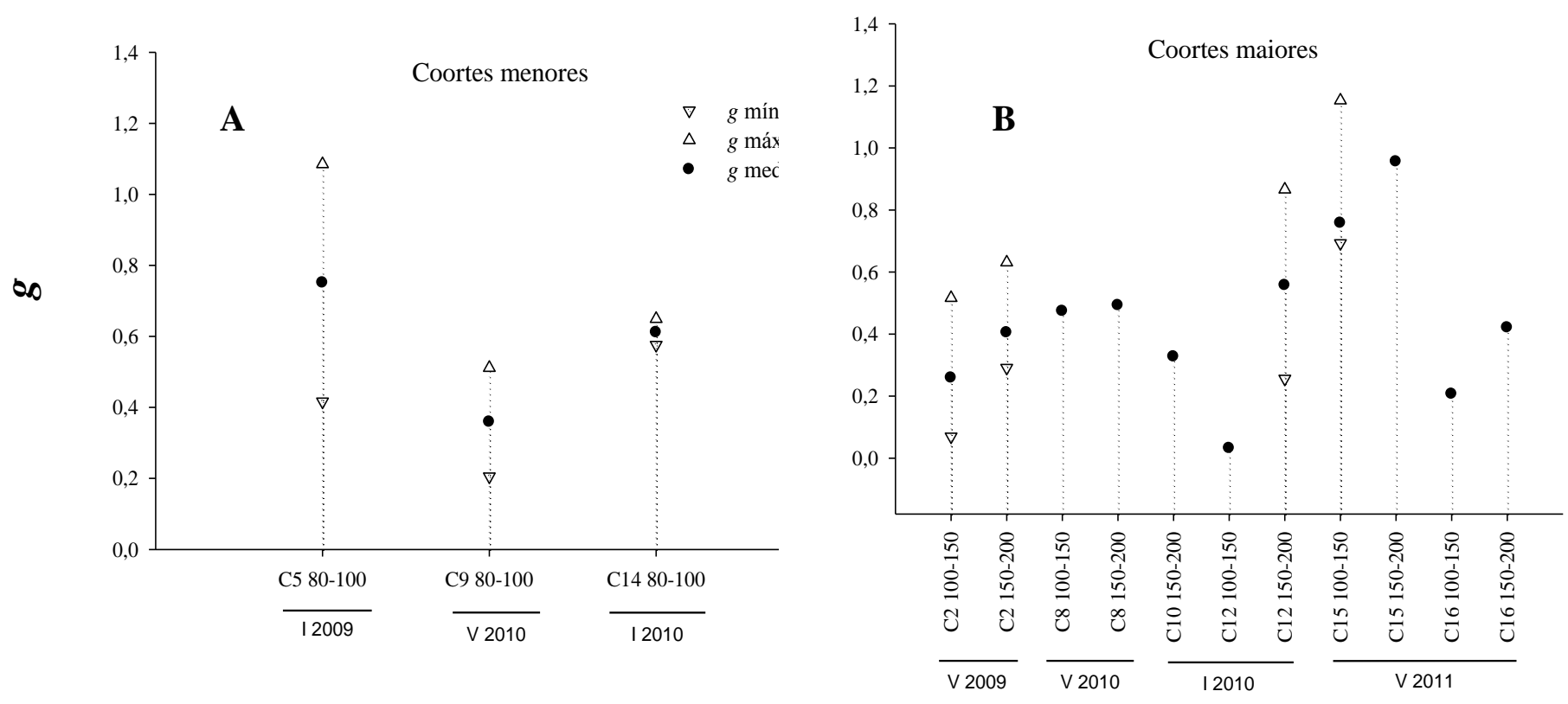

Figura 2.21: Taxas de crescimento para Temora turbinata ao longo do verão de 2009 até o verão de 2011 . A: coortes menores, B: coortes maiores. $g$ mín.: mínimo; $g$ máx.: máximo e $g$ med.: mediana. Legendas do eixo x correspondem aos experimentos, conforme Tabela 2.1.
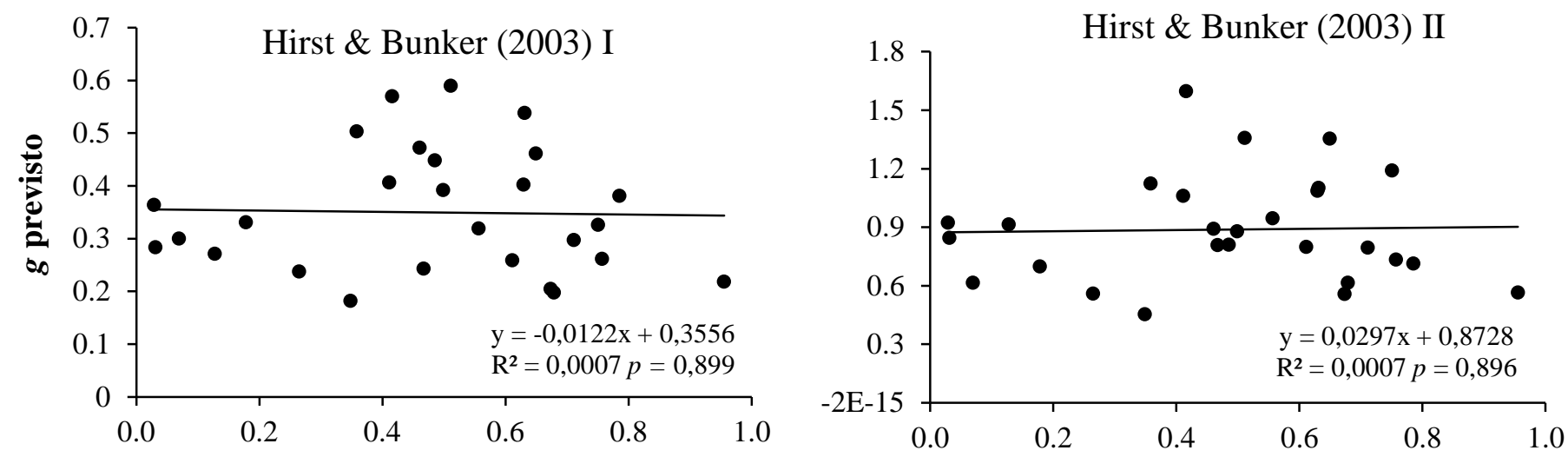

\section{$g$ medido}

Figura 2.22: Relação entre o crescimento medido experimentalmente (eixo x) e estimado para copépodes pelágicos em geral (Hirst \& Bunker, 2003 I) e juvenis de copépodes dispersores de ovos (Hirst \& Bunker, 2003 II) em Temora turbinata. Valores de $p$ do teste de Mann-Whitney. 


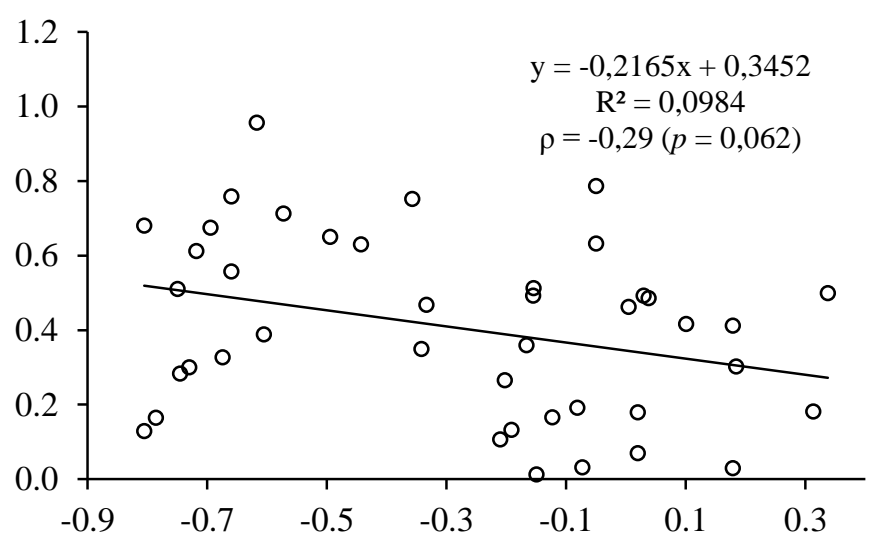

$\log$ Cl-a

$\infty$

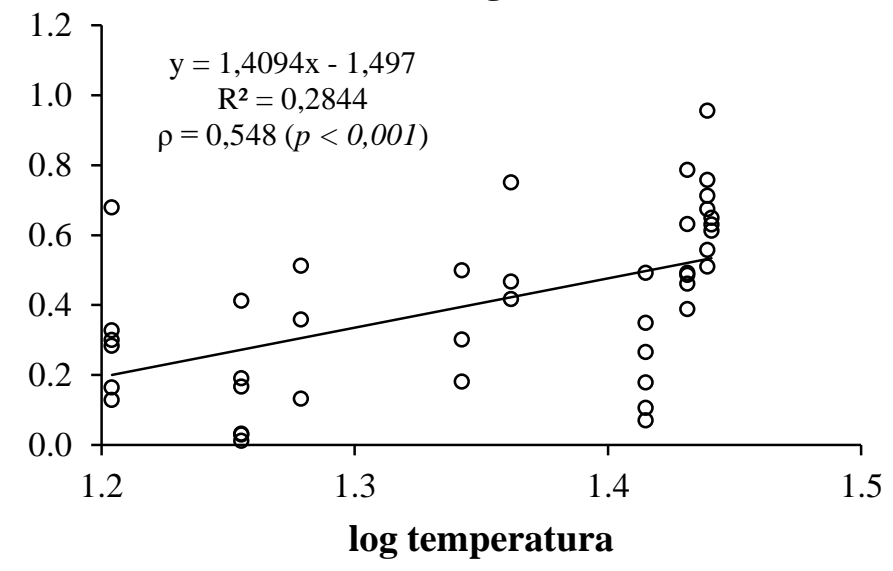

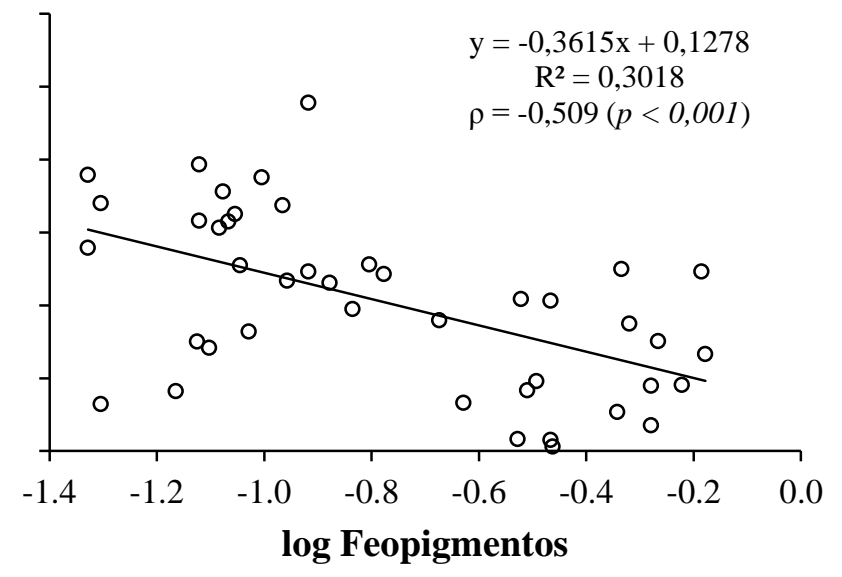
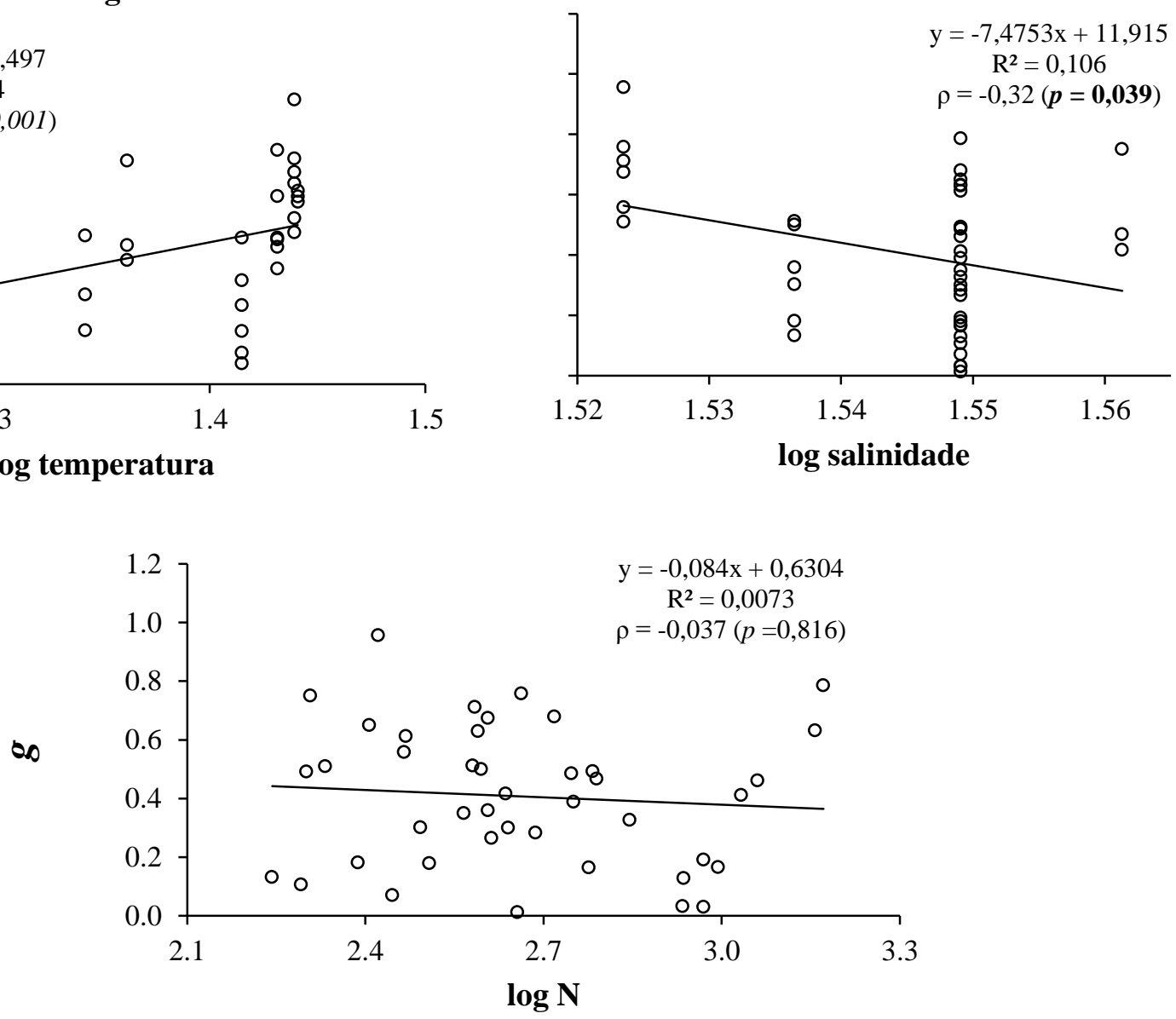

Figura 2.23: Regressão linear e correlação de Spearman $(\rho)$ entre as variáveis controladas e $g$ para Temora turbinata nos experimentos de coortes artificiais. O eixo y é representado por $g$ e o eixo x pelo $\log _{10}$ da variável. Clorofila- $a(\mathrm{Cl}-a)$ e feopigmentos em mg.m ${ }^{-3}$; T: temperatura $\left({ }^{\circ} \mathrm{C}\right) ; \mathrm{N}$ : número de metazoários incubados. 

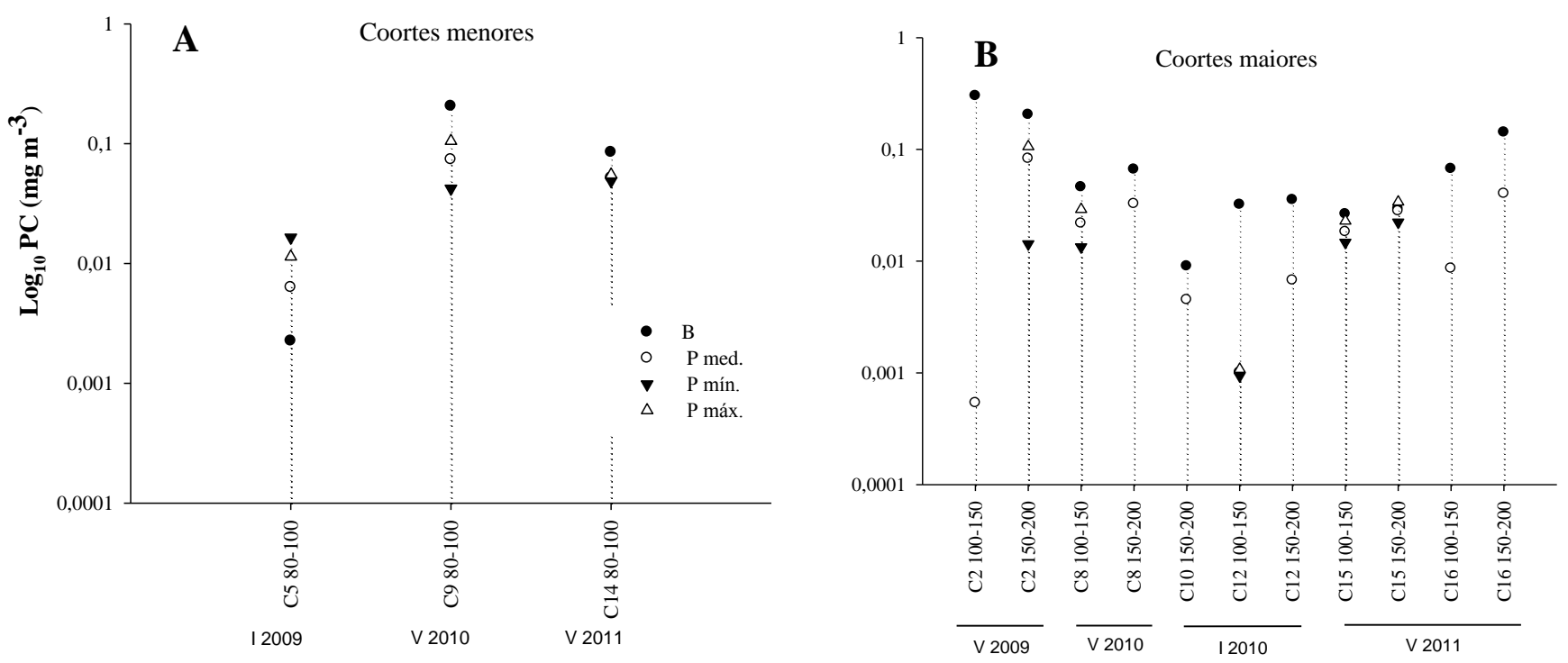

Figura 2.24: Variação da biomassa (B), produção mediana ou média (P med.), mínima (P mín.) e máxima (P máx.) para Temora turbinata do verão de 2009 ao verão de 2011. Biomassa e produção no eixo y em escala logarítmica do PC em $\mathrm{mg} \mathrm{m}^{-3}$. Sigla dos experimentos conforme tabela 2.1. A: coortes menores e B: coortes maiores. Legendas do eixo x correspondem aos experimentos, conforme Tabela 2.1.

As taxas de crescimento foram mensuradas em apenas 4 dos 16 experimentos, sendo que nenhum resultado foi obtido para a coorte de 50-80 $\mu \mathrm{m}$ e apenas um para a coorte de 80-100 $\mu \mathrm{m}$ (Figura 2.25). A média de $g$ para as coortes de 100-150 e 150-200 $\mu \mathrm{m}$ foi de $0,47 \pm 0,39 \mathrm{~d}^{-1}$. O número amostral baixo de taxas de crescimento obtidas para a espécie não permitiu a realização de testes de comparação entre grupos como verão e inverno ou entre os anos analisados.

A correlação de Spearman não foi significativa para nenhuma das variáveis controladas dos experimentos (Figura 2.28). Não foi possível também, observar relações significativas entre o crescimento experimental e o estimado através das equações para copépodes juvenis dispersores de ovos ou para copépodes pelágicos em geral (Figura 2.27). A biomassa e produção para a coorte de $80-100 \mu \mathrm{m}$ foi de $0,0012 \mathrm{mg} \mathrm{C} \mathrm{m}^{-3} \mathrm{e}$ $0,0002 \mathrm{mg} \mathrm{C} \mathrm{m}^{-3} \mathrm{~d}^{-1}$ respectivamente, enquanto que a média de tais valores foram de $0,017 \mathrm{mg} \mathrm{C} \mathrm{m}^{-3}$ e $0,002 \pm 0,001 \mathrm{mg} \mathrm{C} \mathrm{m}^{-3} \mathrm{~d}^{-1}$ para as coortes maiores (Figura 2.26). 


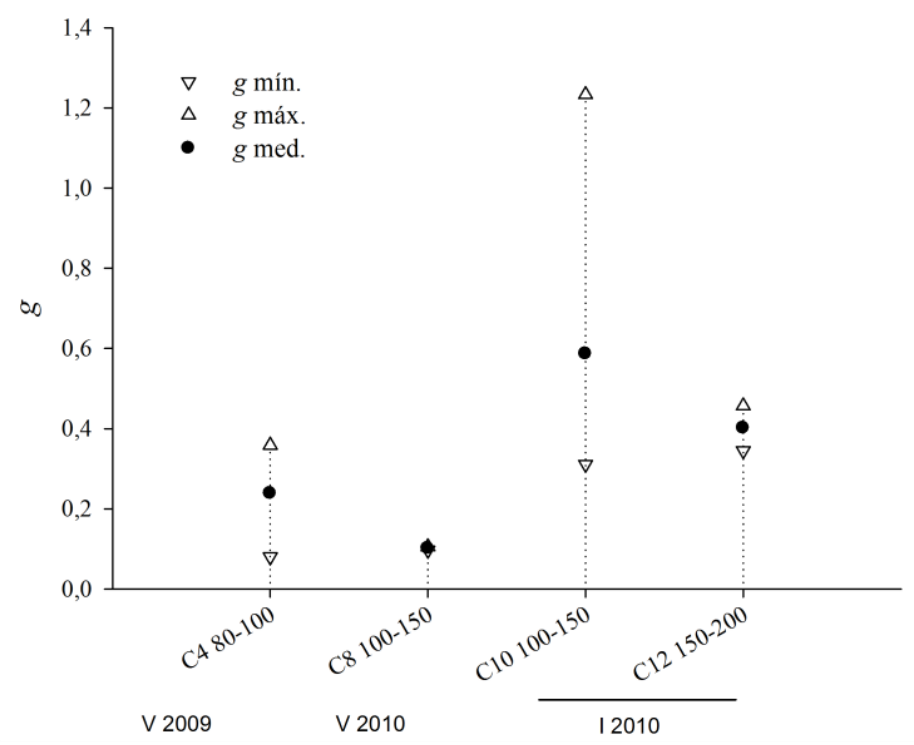

Figura 2.25: Taxas de crescimento para Temora stylifera ao longo do verão de 2009 até o inverno de 2010. $g$ mín.: mínimo; $g$ máx.: máximo e $g$ med.: mediana. Legendas do eixo $\mathrm{x}$ correspondem aos experimentos, conforme Tabela 2.1.

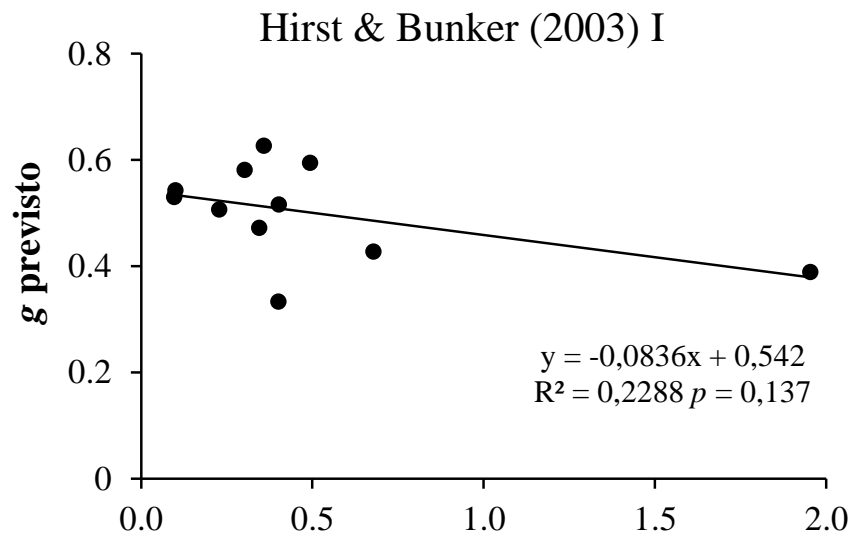

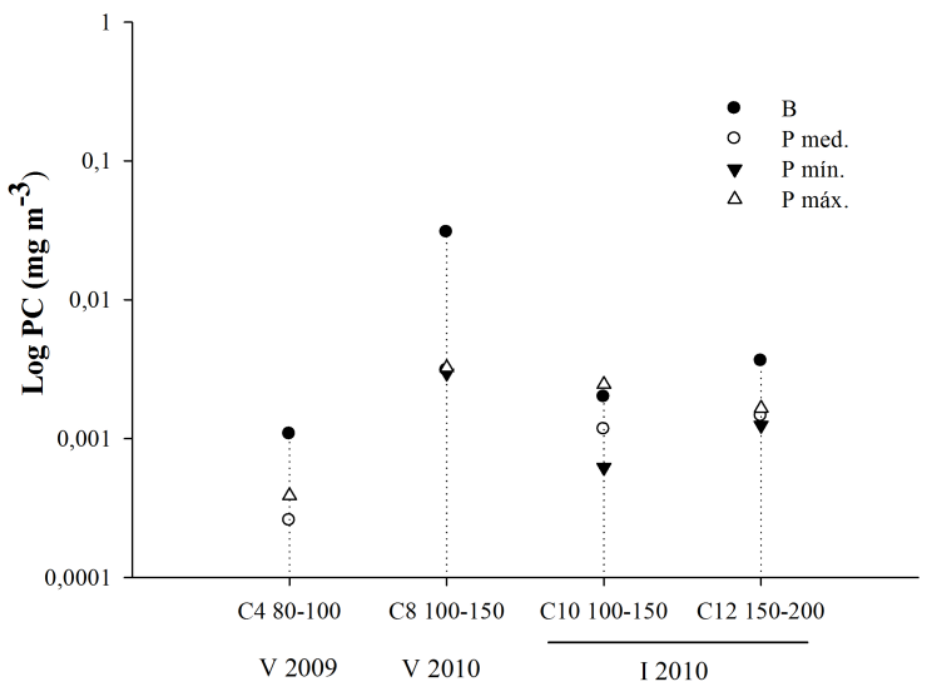

Figura 2.26: Variação da biomassa (B), produção mediana ou média ( $\mathrm{P}$ med.), mínima ( $\mathrm{P}$ mín.) e máxima (P máx.) para Temora stylifera do verão de 2009 ao verão de 2011. Biomassa e produção no eixo y em escala logarítmica do PC $\left(\mathrm{mg} \mathrm{m}^{-3}\right)$. Legendas do eixo $\mathrm{x}$ correspondem aos experimentos, conforme Tabela 2.1 .

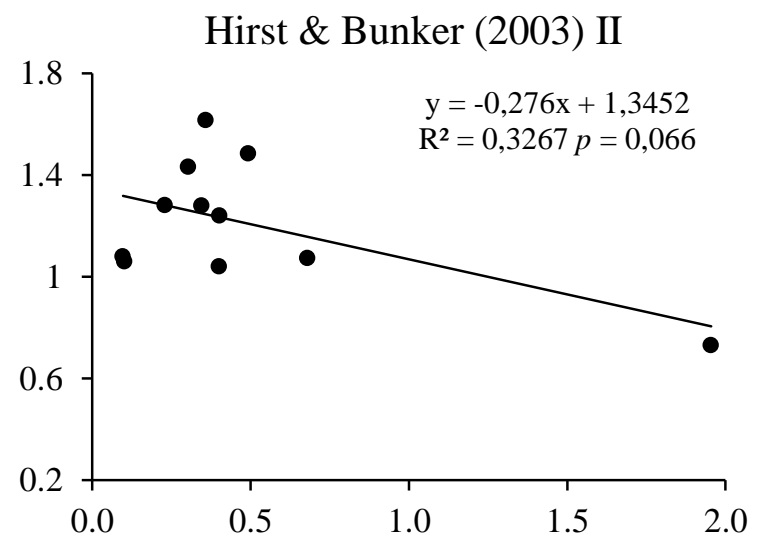

\section{$g$ medido}

Figura 2.27: Relação entre o crescimento medido experimentalmente (eixo x) e estimado para copépodes pelágicos em geral (Hirst \& Bunker, 2003 I) e juvenis de copépodes dispersores de ovos (Hirst \& Bunker, 2003 II) em Temora stylifera. Notar escalas diferentes no eixo y. Valores de $p$ do teste de MannWhitney. 


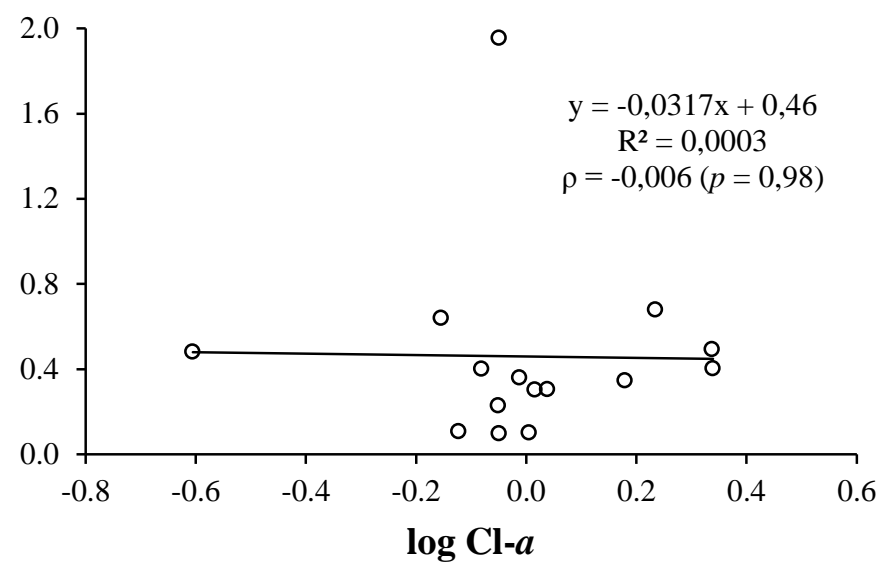

o

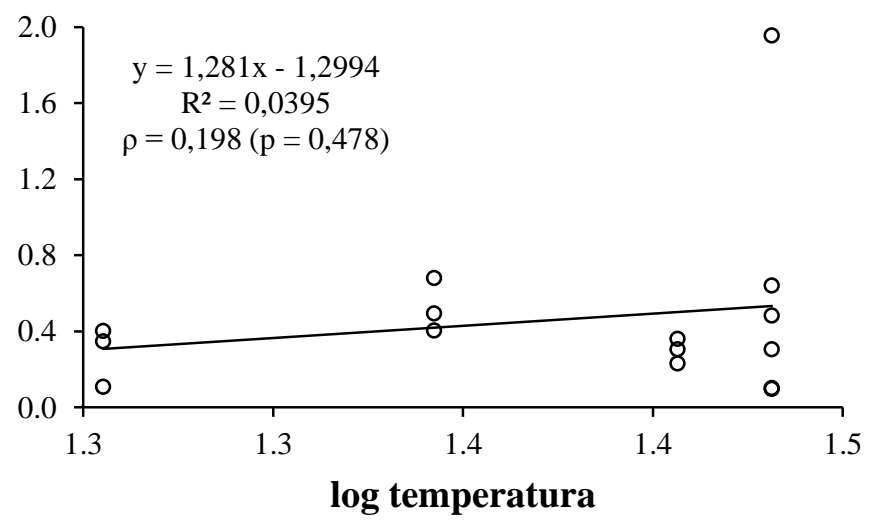

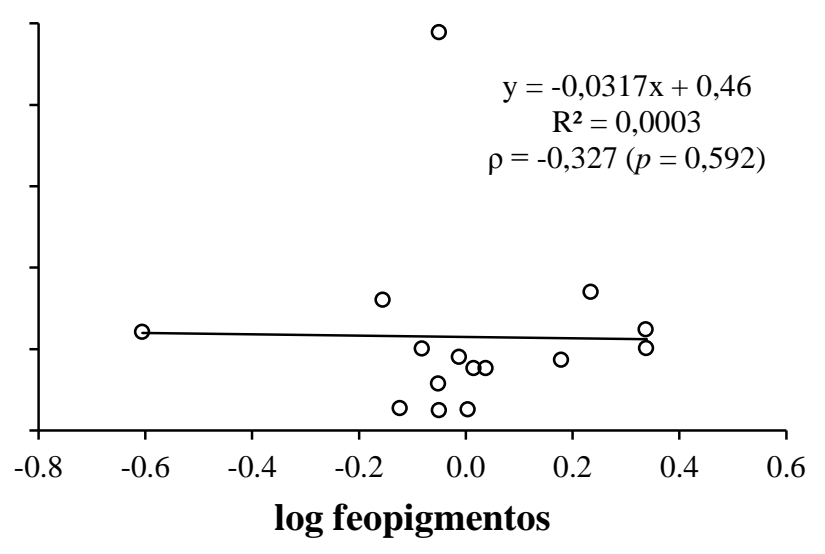

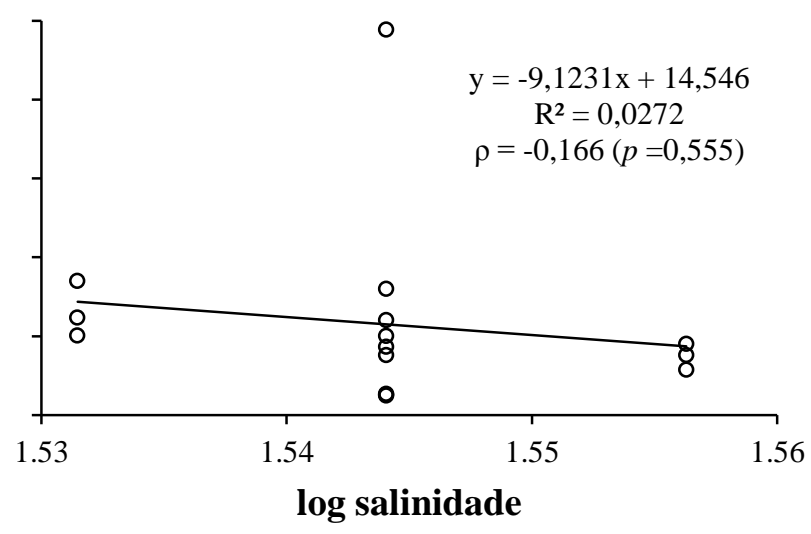

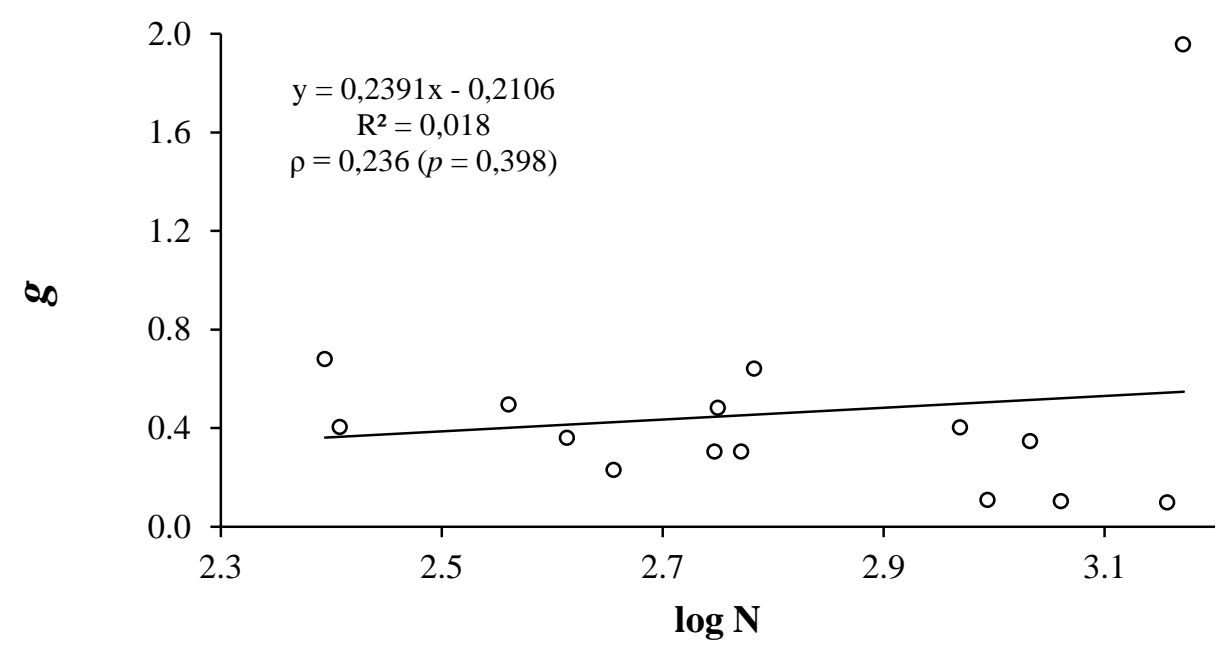

Figura 2.28: Regressão linear e correlação de Spearman $(\rho)$ entre as variáveis controladas e $g$ para Temora stylifera nos experimentos de coortes artificiais. O eixo y é representado por $g$ e o eixo x pelo $\log _{10}$ da variável. Clorofila- $a(\mathrm{Cl}-a)$ e feopigmentos em mg.m ${ }^{-3} ; \mathrm{T}$ : temperatura $\left({ }^{\circ} \mathrm{C}\right) ; \mathrm{N}$ : número de metazoários incubados. 


\subsubsection{Centropages velificatus}

Centropages velificatus esteve presente em $81,25 \%$ das amostras quantitativas. A espécie foi frequente, porém ocorreu em baixa abundância (41 \pm 47 org.m ${ }^{-3}$ e $22 \pm 25$ org. $\mathrm{m}^{-3}$ para as redes de 20 e $100 \mu \mathrm{m}$ respectivamente). A baixa densidade de indivíduos refletiu no baixo número de experimentos onde foi possível calcular $g$ : apenas três coortes em dois experimentos (Figura 2.29).

O baixo número de experimentos e taxas de crescimento obtidas impossibilitou a realização de testes de comparação e mesmo a análise das relações entre $g$ e as variáveis controladas dos experimentos. Os valores de produção variaram consideravelmente, como reflexo da variabilidade de $g$ (Figura 2.30). A biomassa e produção foram menores para o experimento $\mathrm{C}-16\left(0,01 \mathrm{mg} \mathrm{C} \mathrm{m}^{-3}\right.$ e $\left.0,006 \mathrm{mg} \mathrm{C} \mathrm{m}^{-3} \mathrm{~d}^{-1}\right)$ e maiores no experimento $\mathrm{C}-8\left(0,02 \mathrm{mg} \mathrm{C} \mathrm{m}^{-3}\right.$ e $0,014 \mathrm{mg} \mathrm{C} \mathrm{m}^{-3} \mathrm{~d}^{-1}$; Figura 2.30).

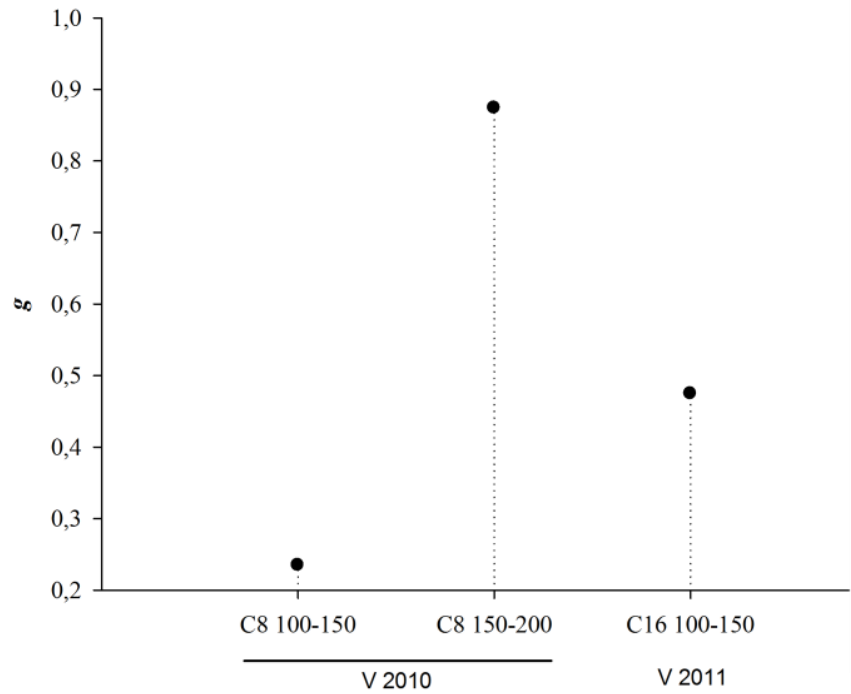

Figura 2.29: Taxas de crescimento ( $g$ médio) para Centropages velificatus durante o verão de 2010 e 2011. Legendas do eixo $x$ correspondem aos experimentos, conforme Tabela 2.1.

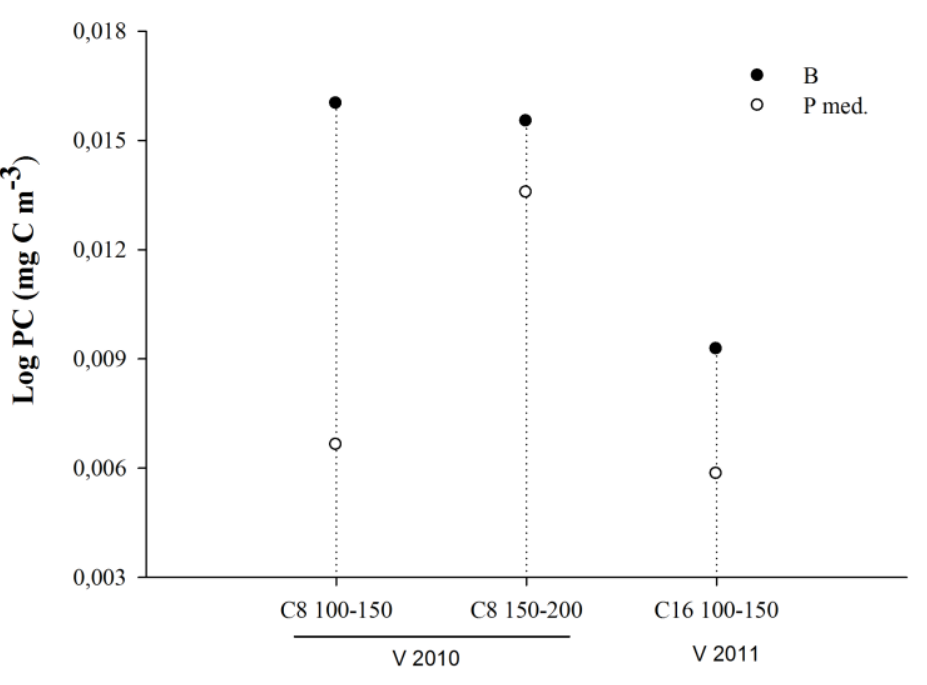

Figura 2.30: Variação da biomassa (B), produção mediana ou média (P med.) para Centropages velificatus durante o verão de 2010 e 2011. Biomassa e produção no eixo $\mathrm{y}$, em escala logarítmica do PC $\left(\mathrm{mg} \mathrm{m}^{-3}\right)$. Legendas do eixo $\mathrm{x}$ correspondem aos experimentos, conforme Tabela 2.1. 


\subsubsection{Pseudodiaptomus acutus}

A espécie Pseudodiaptomus acutus foi esporádica ao longo do trabalho, ocorrendo em apenas $50 \%$ das amostras e tendo sua ocorrência concentrada durante o inverno de 2009 e verão de 2010. A densidade média para as amostras de $20 \mu \mathrm{m}$ foi de $69 \pm 96$ org. $\mathrm{m}^{-3}$ e $81 \pm 197$ org. $\mathrm{m}^{-3}$ para as de $100 \mu \mathrm{m}$.

Valores de $g$ só foram obtidos para dois experimentos, um durante o inverno de 2009 e um para o verão de 2010 (Figura 2.31). O baixo número de experimentos e taxas de crescimento obtidas impossibilitou a realização de testes de estatísticos. A biomassa e produção foram menores para o experimento $\mathrm{C}-9\left(0,005 \mathrm{mg} \mathrm{C} \mathrm{m}^{-3}\right.$ e $0,002 \mathrm{mg} \mathrm{C} \mathrm{m}^{-3} \mathrm{~d}^{-}$ $\left.{ }^{1}\right)$ e maiores no experimento C-6 150-200 $\mu \mathrm{m}\left(0,114 \mathrm{mg} \mathrm{C} \mathrm{m}^{-3}\right.$ e 0,0184 $\mathrm{mg} \mathrm{C} \mathrm{m}^{-3} \mathrm{~d}^{-1}$; Figura 2.32).

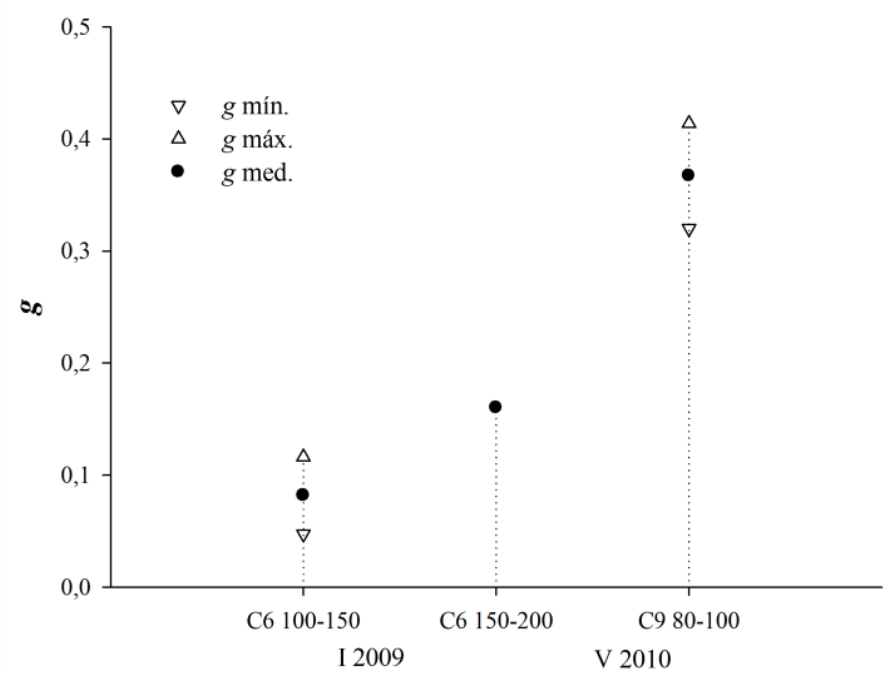

Figura 2.31: Taxas de crescimento para Pseudodiaptomus acutus durante o verão de 2009 e 2010. $g$ mín.: mínimo; $g$ máx.: máximo e $g$ med.: mediana. Legendas do eixo $\mathrm{x}$ correspondem aos experimentos, conforme Tabela 2.1.

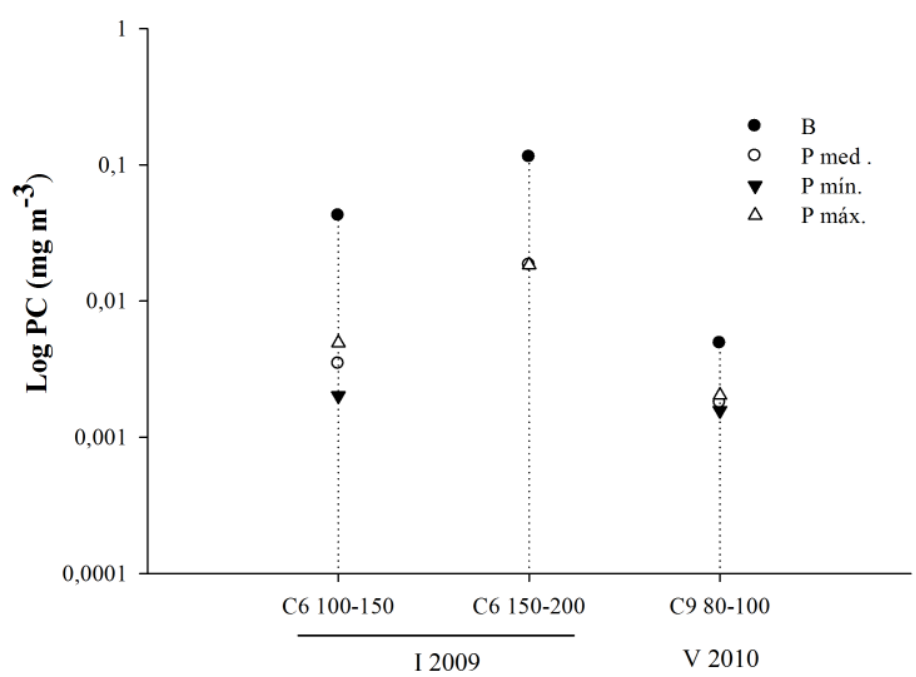

Figura 2.32: Variação da biomassa (B), produção mediana ou média ( $\mathrm{P}$ med.), mínima ( $\mathrm{P}$ mín.) e máxima (P máx.) para Pseudodiaptomus acutus durante o inverno de 2009 e verão de 2010. Biomassa e produção no eixo $\mathrm{y}$, em escala logarítmica de PC $\left(\mathrm{mg} \mathrm{m}^{-3}\right)$. Legendas do eixo $\mathrm{x}$ correspondem aos experimentos, conforme Tabela 2.1. 


\subsubsection{Oithona spp.}

As espécies Oithona hebes, O. simplex e O. nana foram agrupadas para as análises de crescimento. Os animais foram frequentes e abundantes durante todo $\mathrm{o}$ período amostral. A densidade de Oithona spp. foi elevada e raramente inferior a 300 org. $\mathrm{m}^{-3}$, sendo em média de $1.514 \pm 1.422$ org. $\mathrm{m}^{-3}$ para a rede de $20 \mu \mathrm{m}$ e $594 \pm 679$ org. $\mathrm{m}^{-3}$ para a rede de $100 \mu \mathrm{m}$. Entre as três espécies, $O$. hebes foi a mais abundante, correspondendo à cerca de $87 \%$ da abundância relativa desse agrupamento.

As taxas de crescimento foram obtidas para todos os experimentos e para quase todos os tamanhos de coortes, com exceção apenas para C-3 100-150, C-7 80-100 e C$12100-150 \mu \mathrm{m}$ (Figura 2.33). A média para as coortes de 150-200 $\mu \mathrm{m}$ foi de 0,17 \pm $0,14 \mathrm{~d}^{-1}$, já a coorte de 100-150 $\mu \mathrm{m}$ demonstrou os menores valores de $g$, em relação às demais coortes $\left(0,12 \pm 0,08 \mathrm{~d}^{-1}\right)$. A coorte de 50-80 $\mu \mathrm{m}$ apresentou a maior amplitude de valores $\left(0,4 \pm 0,36 \mathrm{~d}^{-1}\right)$ em relação à coorte de 80-100 $\mu \mathrm{m}\left(0,29 \pm 0,12 \mathrm{~d}^{-1}\right)$ (Figura 2.34).

A diferença entre as coortes menores e maiores foi significativa, sendo que $g$ foi geralmente maior para as coortes de 50-80 e 80-100 $\mu \mathrm{m}$ em relação às coortes de 100150 e 150-200 $\mu \mathrm{m}(p<0,001)$. Não houve diferença entre as coortes menores $(50-80 \mathrm{x}$ $80-100 \mu \mathrm{m})$ ou entre as maiores (100-150 x 150-200 $\mu \mathrm{m})$ isoladamente. Diferenças quanto às taxas de crescimento entre as estações de verão e inverno ou entre os anos estudados também não foram detectadas (Tabela 2.8).

Apesar do alto número de experimentos para Oithona spp., nenhuma das correlações entre $g$ e as variáveis controladas foi significativa (Figura 2.35). A relação entre o crescimento obtido experimentalmente e o estimado pelo modelo para juvenis dispersores de ovos foi diretamente proporcional (Figura 2.36).

Os valores de biomassa foram ligeiramente menores paras as coortes de 50-80 e 80-100 $\mu \mathrm{m}\left(0,165 \pm 0,109 \mathrm{mg} \mathrm{C} \mathrm{m}^{-3}\right)$, porém a produção foi mais elevada para essas coortes $\left(0,054 \pm 0,046 \mathrm{mg} \mathrm{C} \mathrm{m}^{-3} \mathrm{~d}^{-1}\right)$ em relação às coortes maiores $(\mathrm{B}: 0,179 \pm 0,086$ $\mathrm{mg} \mathrm{C} \mathrm{m}{ }^{-3}$ e P: $0,023 \pm 0,018 \mathrm{mg} \mathrm{C} \mathrm{m}^{-3} \mathrm{~d}^{-1}$ ) (Figura 2.37). 

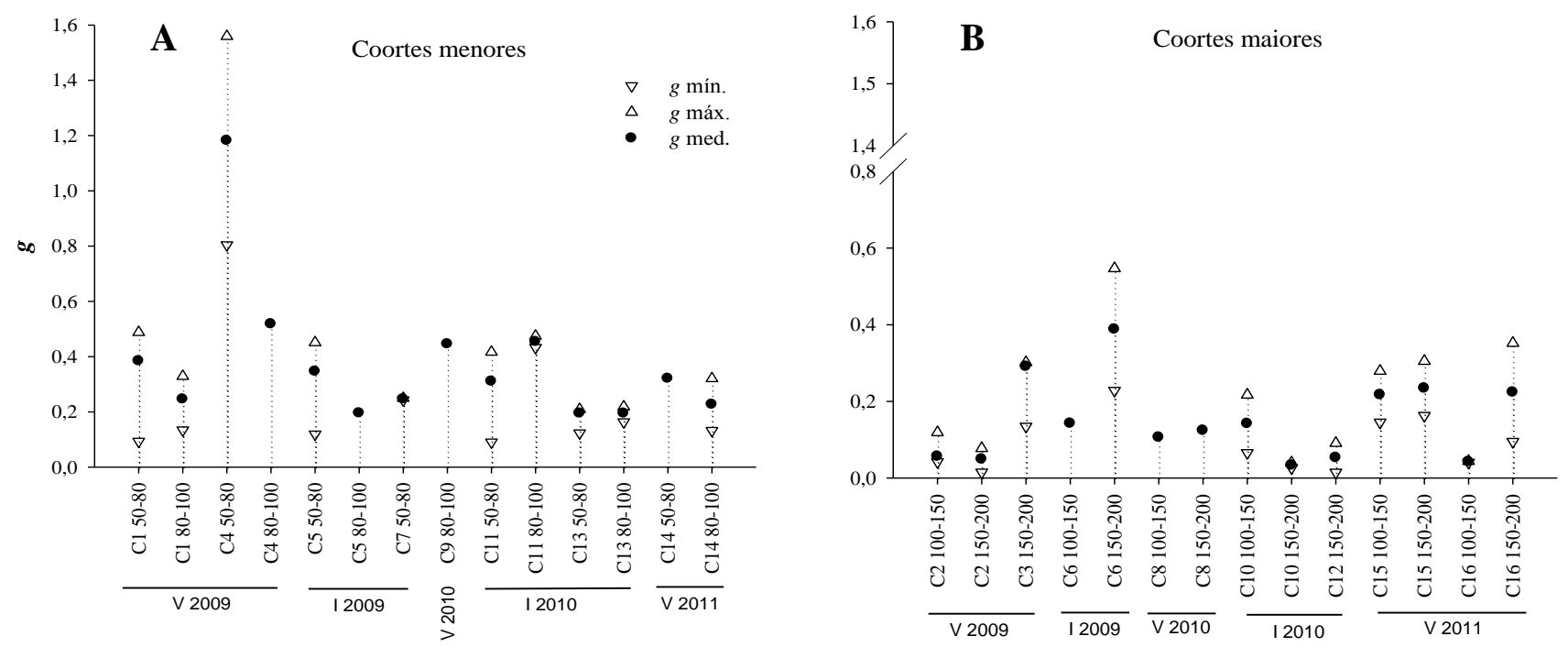

Figura 2.33: Taxas de crescimento para Oithona spp. ao longo do verão de 2009 até o verão de 2011. A: coortes menores, B: coortes maiores. $g$ mín.: mínimo; $g$ máx.: máximo e $g$ med.: mediana. Legendas do eixo x correspondem aos experimentos, conforme Tabela 2.1 .
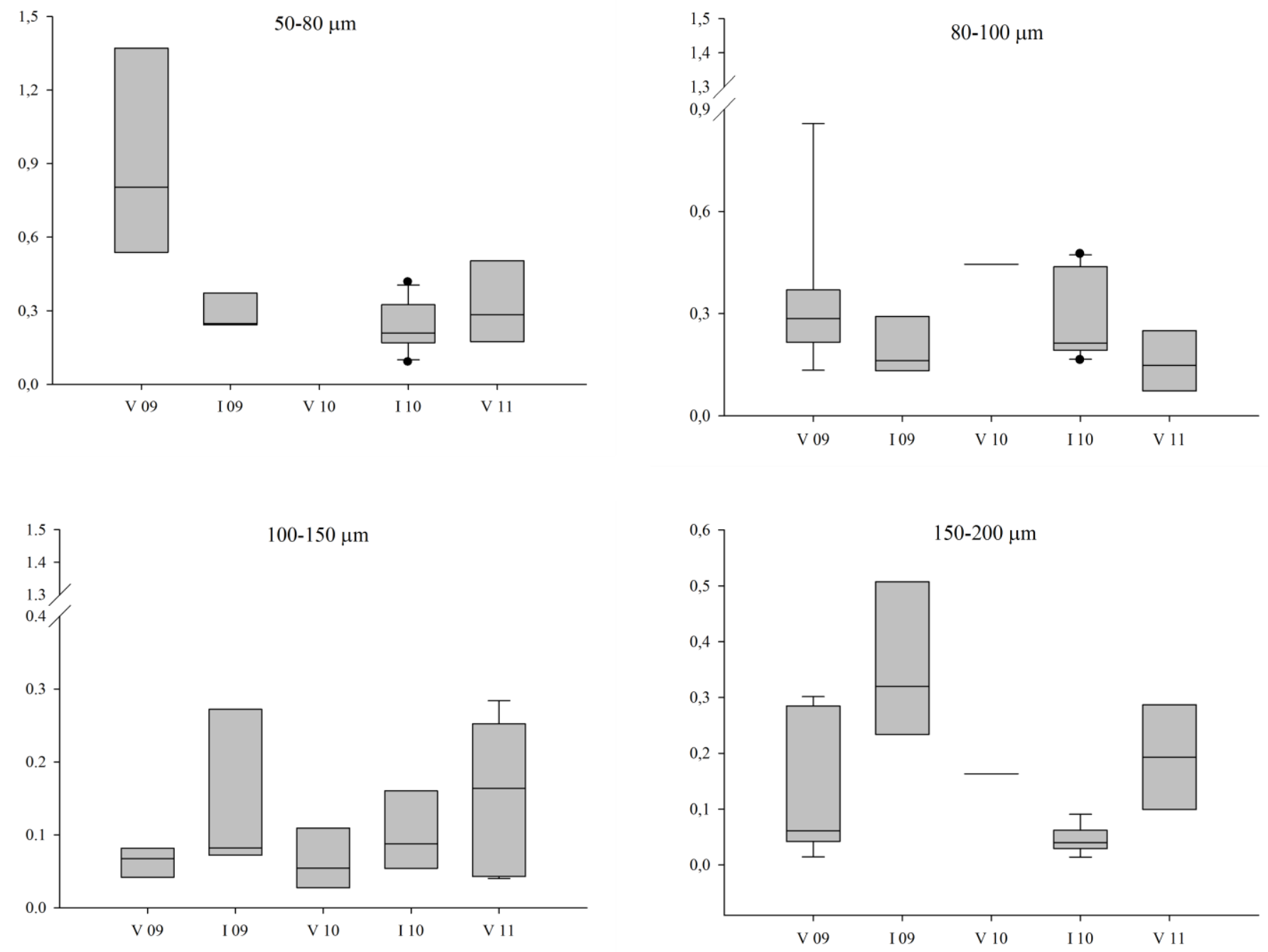

Figura 2.34: Box-plot com a variação de $g$ em cada um dos tamanhos de coortes analisados para Oithona spp. V: verão; I: inverno; 09,10 e 11: anos analisados. 


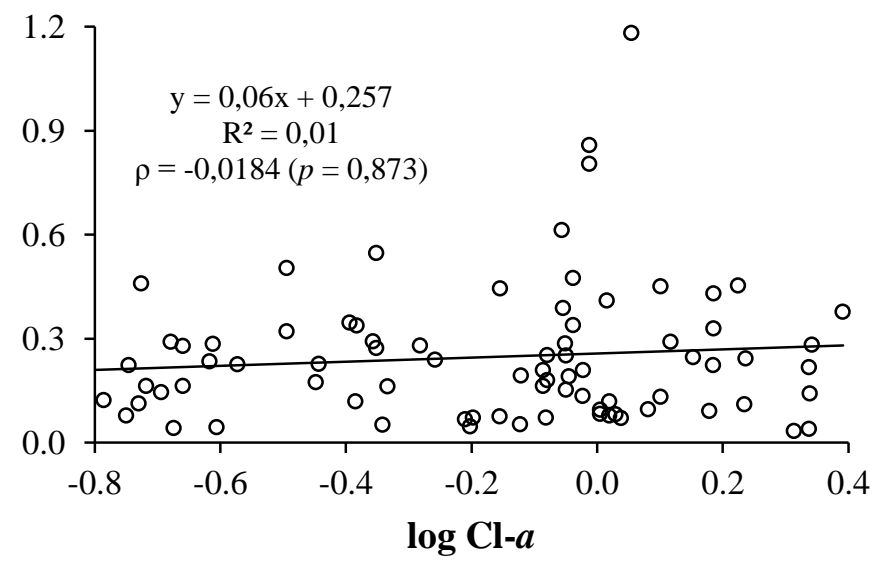

$\infty$
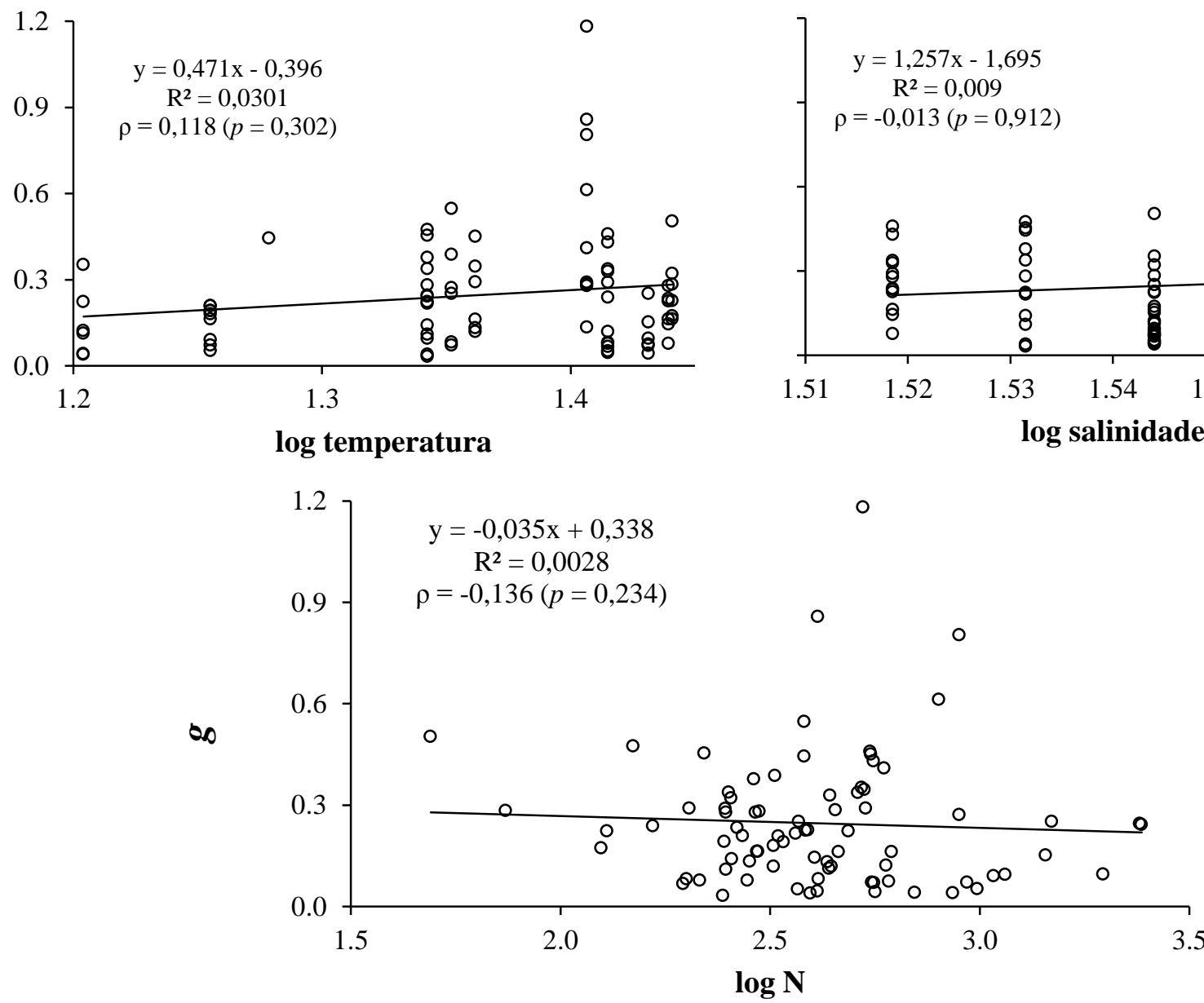

Figura 2.35: Regressão linear e correlação de Spearman ( $\rho$ ) entre as variáveis controladas e $g$ para Oithona spp. nos experimentos de coortes artificiais. O eixo y é representado por $g$ e o eixo x pelo $\log _{10}$ da variável. Clorofila- $a(\mathrm{Cl}-a)$ e feopigmentos em $\mathrm{mg} \mathrm{m}^{-3}$; T: temperatura $\left({ }^{\circ} \mathrm{C}\right)$; $\mathrm{N}$ : número de metazoários incubados. 

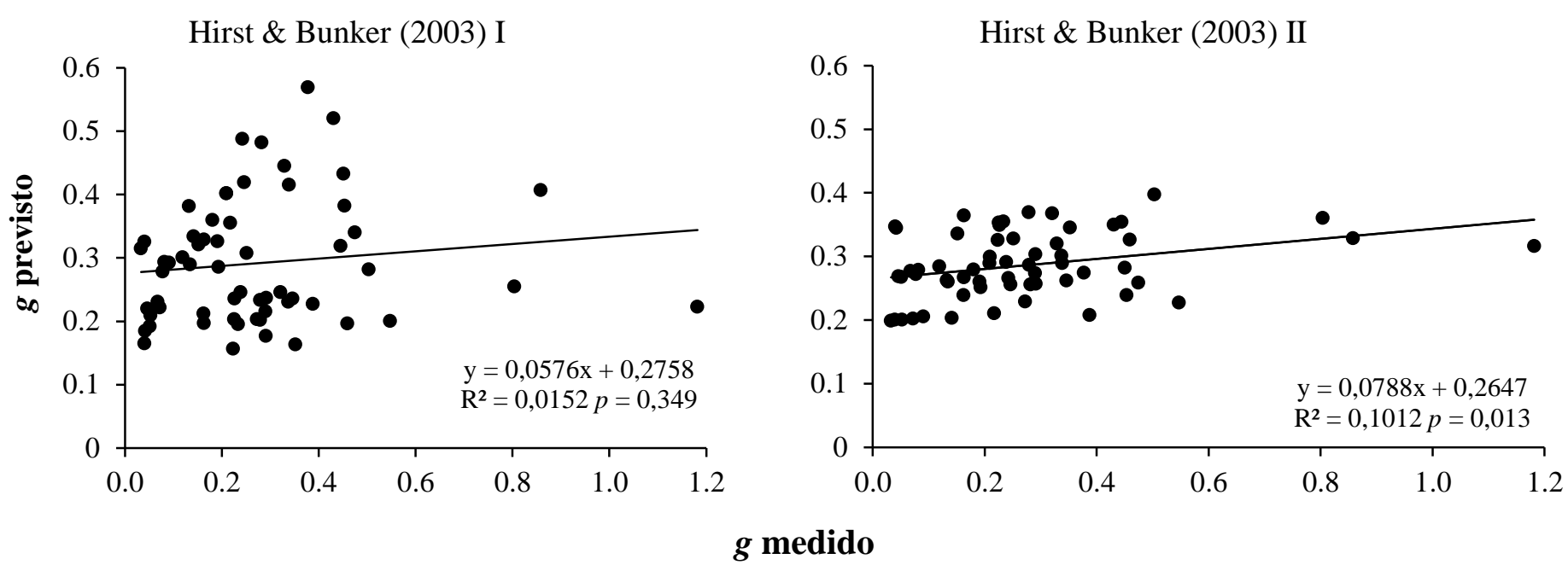

Figura 2.36: Relação entre o crescimento medido experimentalmente (eixo x) e estimado para copépodes pelágicos em geral (Hirst \& Bunker, 2003 I) e juvenis de copépodes dispersores de ovos (Hirst \& Bunker, 2003 II) em Oithona spp. Valores de $p$ do teste de Mann-Whitney.
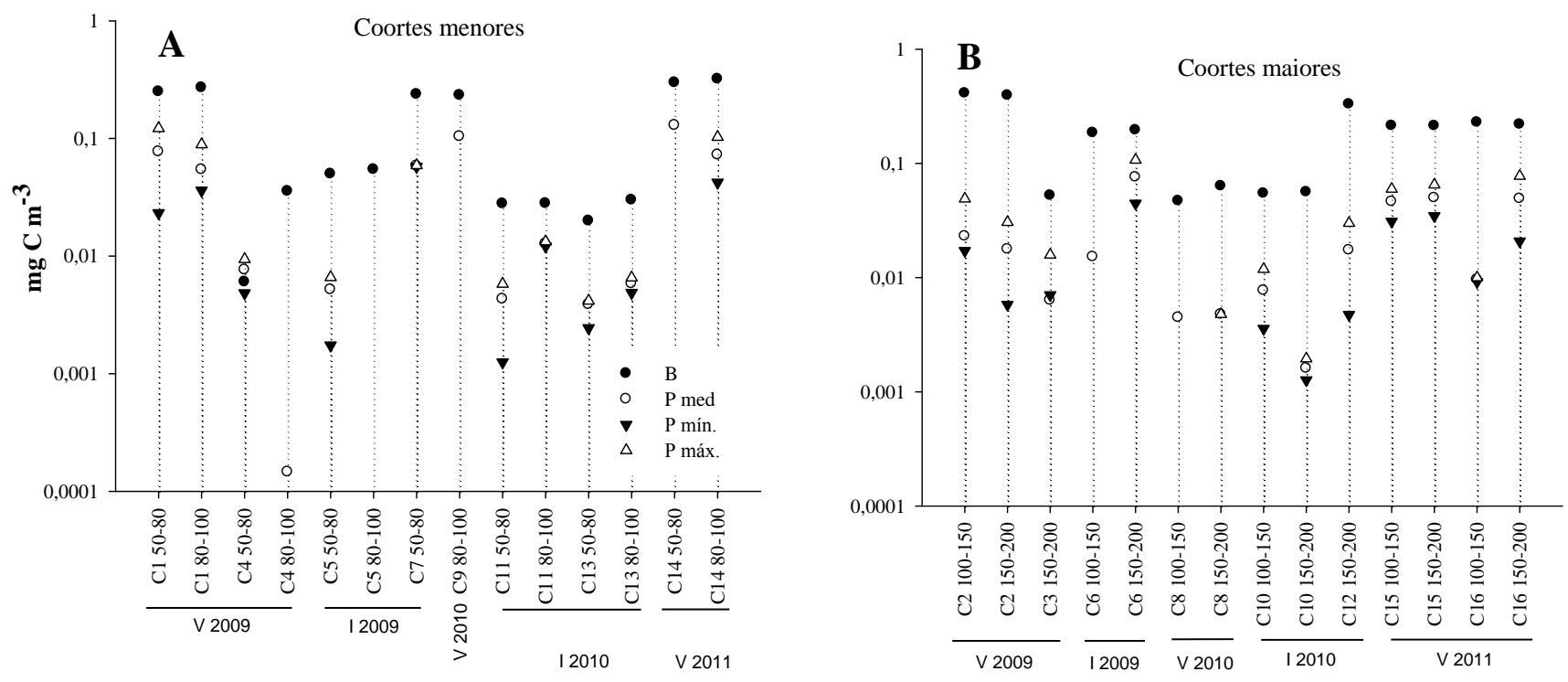

Figura 2.37: Variação da biomassa (B), produção mediana ou média (P med.), mínima (P mín.) e máxima (P máx.) para Oithona spp. do verão de 2009 ao verão de 2011. A biomassa e produção são fornecidas no eixo y na escala logarítmica do PC $\left(\mathrm{mg} \mathrm{m}^{-3}\right)$. A: coortes menores e $\mathbf{B}$ : coortes maiores. Legendas do eixo x correspondem aos experimentos, conforme Tabela 2.1. 


\subsubsection{Oithona plumifera}

A espécie é a maior entre os copépodes da família Oithonidae encontrados na região de estudo. Características morfológicas e taxonômicas facilitaram a identificação desta espécie desde os estágios naupliares. Os animais estiveram presentes em $75 \%$ das amostras quantitativas. A densidade foi relativamente baixa, sendo a média de $354 \pm$ 491 org. $\mathrm{m}^{-3}$ para a rede de $20 \mu \mathrm{m}$ e $40 \pm 66$ org. $\mathrm{m}^{-3}$ para a rede de $100 \mu \mathrm{m}$.

As taxas de crescimento foram obtidas para 6 dos 16 experimentos e foram semelhantes entre as classes de tamanho, sendo as médias iguais a 0,08 $\pm 0,06$ e 0,08 \pm $0,04 \mathrm{~d}^{-1}$ para as coortes menores e maiores respectivamente (Figura 2.38). Diferenças quanto ao crescimento entre diferentes grupos (estações de coleta, anos, tamanhos de coortes) não foram detectadas devido ao baixo número amostral para realização das comparações. Correlações entre $g$ e as variáveis controladas do experimento não foram detectadas (Figura 2.41).

Para Oithona plumifera, as regressões lineares entre o crescimento obtido experimentalmente e o estimado pelos modelos globais não foram significativas. (Figura 2.39) e o número amostral baixo pode ter contribuído para tal dispersão. A biomassa e produção para as coortes menores variaram entre 0,0184 a 0,032 (0,025 \pm $0,007) \mathrm{mg} \mathrm{C} \mathrm{m}^{-3}$ e entre 0,0001 e $0,002(0,0010 \pm 0,0008) \mathrm{mg} \mathrm{C} \mathrm{m}^{-3} \mathrm{~d}^{-1}$ respectivamente. Para as coortes maiores, a biomassa esteve entre 0,017 e 0,294 $(0,158 \pm 0,139) \mathrm{mg} \mathrm{C} \mathrm{m}^{-}$ 3 , enquanto que a produção foi de $0,01 \pm 0,01 \mathrm{mg} \mathrm{C} \mathrm{m}^{-3} \mathrm{~d}^{-1}$ (Figura 2.40). 

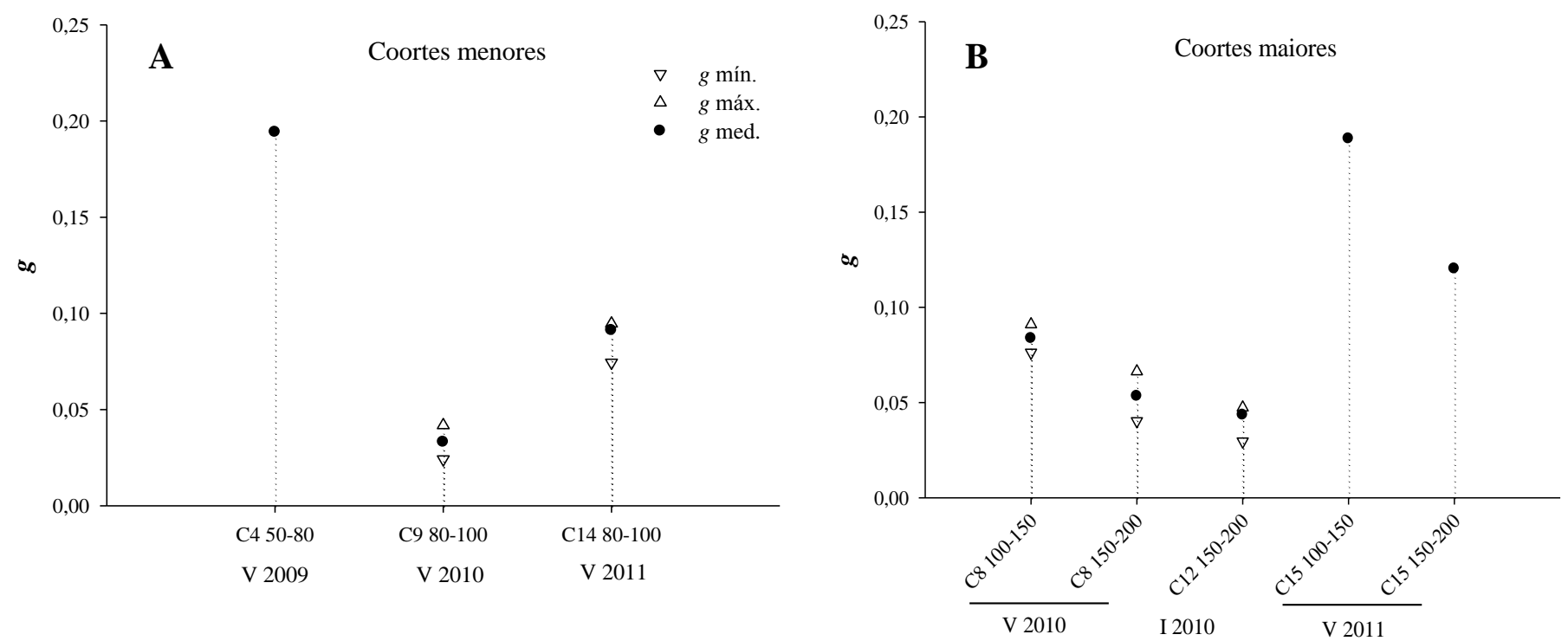

Figura 2.38: Taxas de crescimento para Oithona plumifera ao longo do verão de 2009 até o verão de 2011. A: coortes menores, B: coortes maiores. $g$ mín.: mínimo; $g$ máx.: máximo e $g$ med.: mediana. Legendas do eixo $\mathrm{x}$ correspondem aos experimentos, conforme Tabela 2.1.

Hirst \& Bunker (2003) I

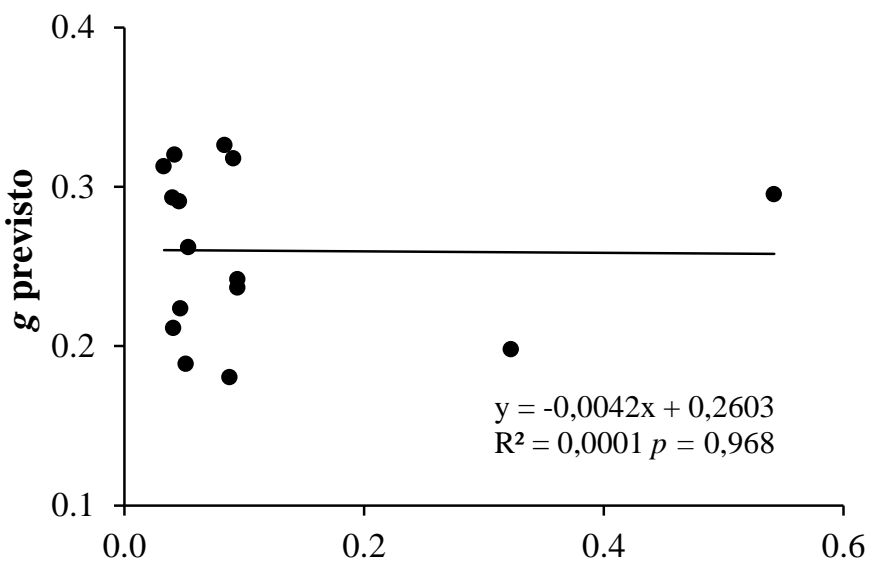

Hirst \& Bunker (2003) II

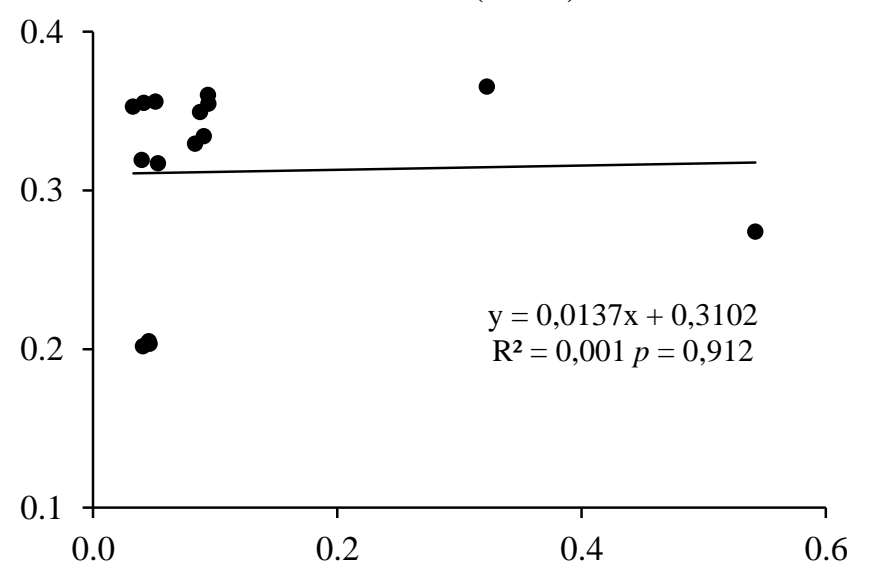

\section{g medido}

Figura 2.39: Relação entre o crescimento medido experimentalmente (eixo x) e estimado para copépodes pelágicos em geral (Hirst \& Bunker, 2003 I) e juvenis de copépodes retentores de ovos (Hirst \& Bunker, 2003 II) em Oithona plumifera. Valores de $p$ do teste de Mann-Whitney. 

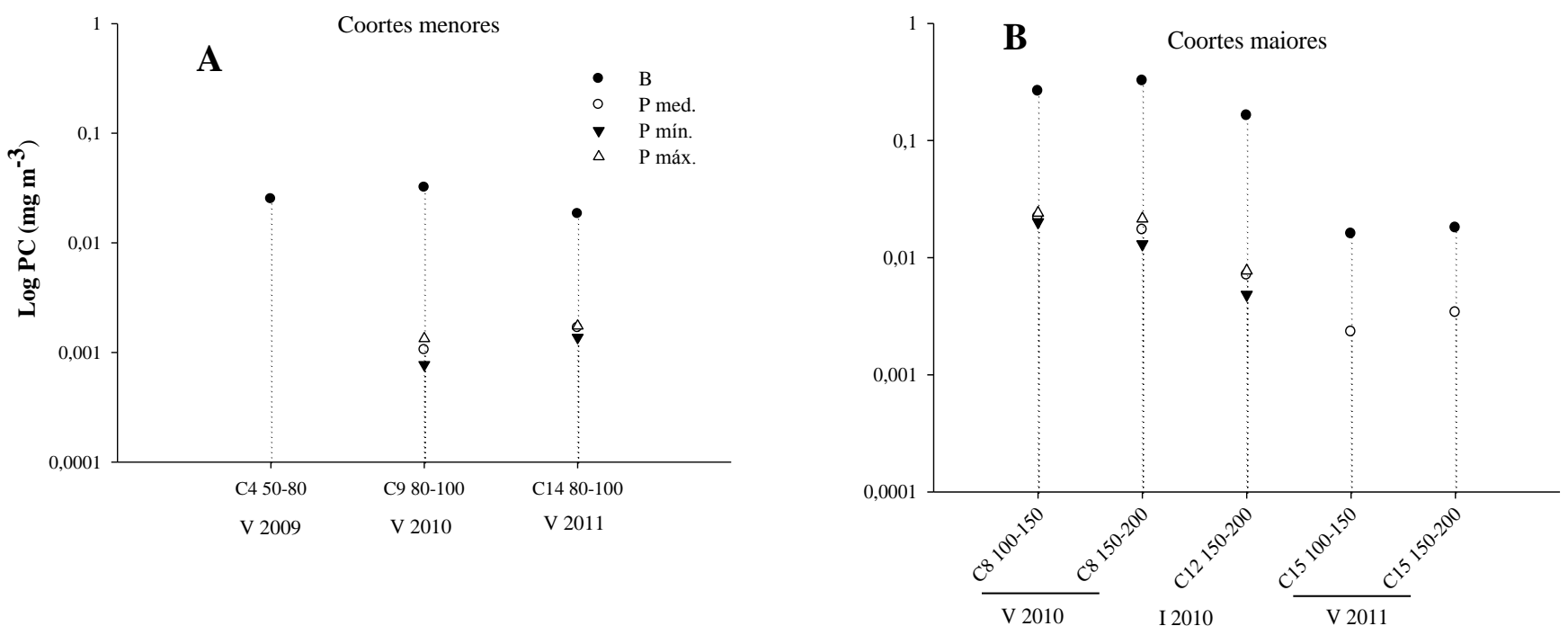

Figura 2.40: Variação da biomassa (B), produção mediana ou média (P med.), mínima (P mín.) e máxima (P máx.) para Oithona plumifera do verão de 2009 ao verão de 2011. Biomassa e produção no eixo y em escala logarítmica do PC $\left(\mathrm{mg} \mathrm{m}^{-3}\right)$. A: coortes menores e B: coortes maiores. Legendas do eixo $\mathrm{x}$ correspondem aos experimentos, conforme Tabela 2.1.

\subsubsection{Dioithona oculata}

Esta espécie ocorreu durante os três anos analisados, porém esteve presente em apenas $56,25 \%$ das amostras. As densidades foram relativamente altas nas amostras onde a espécie ocorreu $\left(759 \pm 1.968\right.$ org. $\mathrm{m}^{-3}$ e $510 \pm 1.546$ org. $\mathrm{m}^{-3}$ para as redes de $20 \mathrm{e}$ $100 \mu \mathrm{m}$ respectivamente). As taxas de crescimento foram medidas em ambas as coortes em três dos 16 experimentos e os valores médios para as coortes menores foi de 0,26 \pm $0,1 \mathrm{~d}^{-1}$, enquanto que para as maiores foi de $0,16 \pm 0,1 \mathrm{~d}^{-1}$ (Figura 2.42). Não foram encontradas relações entre o crescimento experimental e o estimado pelas equações de Hirst \& Bunker (2003) (Figura 2.44).

Para as variáveis experimentais, apenas o número de animais incubados foi correlacionada ao $g(\rho=0,74 ; p<0,001)$, sendo que a relação foi diretamente proporcional (Figura 2.45). Tanto a biomassa quanto à produção foram variáveis, sendo a média para a biomassa $0,178 \mathrm{mg} \mathrm{C} \mathrm{m}^{-3}$ e a produção $0,047 \pm 0,017 \mathrm{mg} \mathrm{C} \mathrm{m}^{-3} \mathrm{~d}^{-1}$ para as coortes menores e $0,695 \mathrm{mg} \mathrm{C} \mathrm{m}^{-3}$ e $0,325 \pm 0,017 \mathrm{mg} \mathrm{C} \mathrm{m}^{-3} \mathrm{~d}^{-1}$ para as coortes maiores respectivamente (Figura 2.43). 

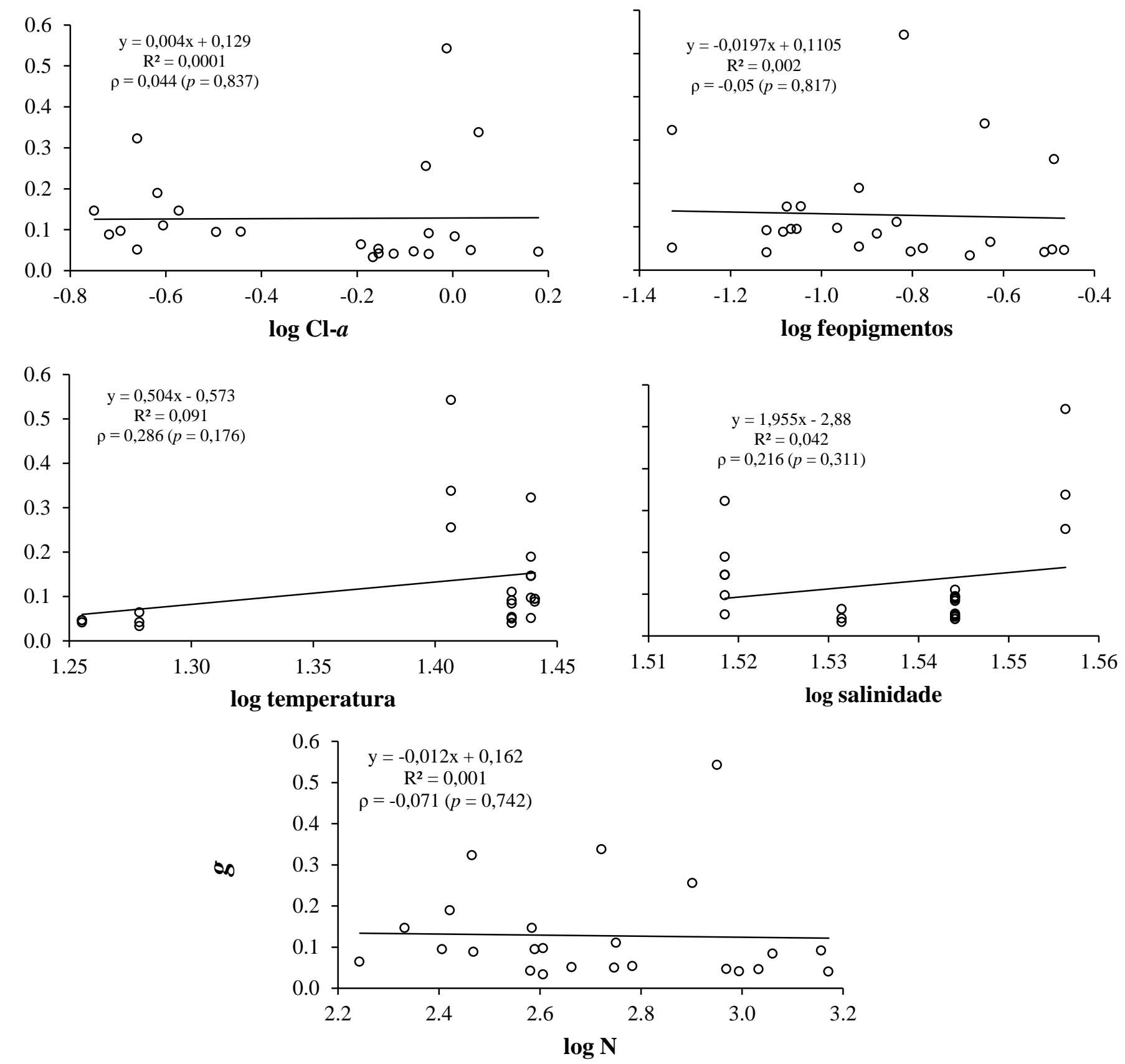

Figura 2.41: Regressão linear e correlação de Spearman ( $\rho$ ) entre as variáveis controladas e $g$ para Oithona plumifera nos experimentos de coortes artificiais. O eixo y é representado por $g$ e o eixo x pelo $\log _{10}$ da variável. Clorofila- $a(\mathrm{Cl}-a)$ e feopigmentos em $\mathrm{mg} \mathrm{m}^{-3} ; \mathrm{T}$ : temperatura $\left({ }^{\circ} \mathrm{C}\right) ; \mathrm{N}$ : número de metazoários incubados. 


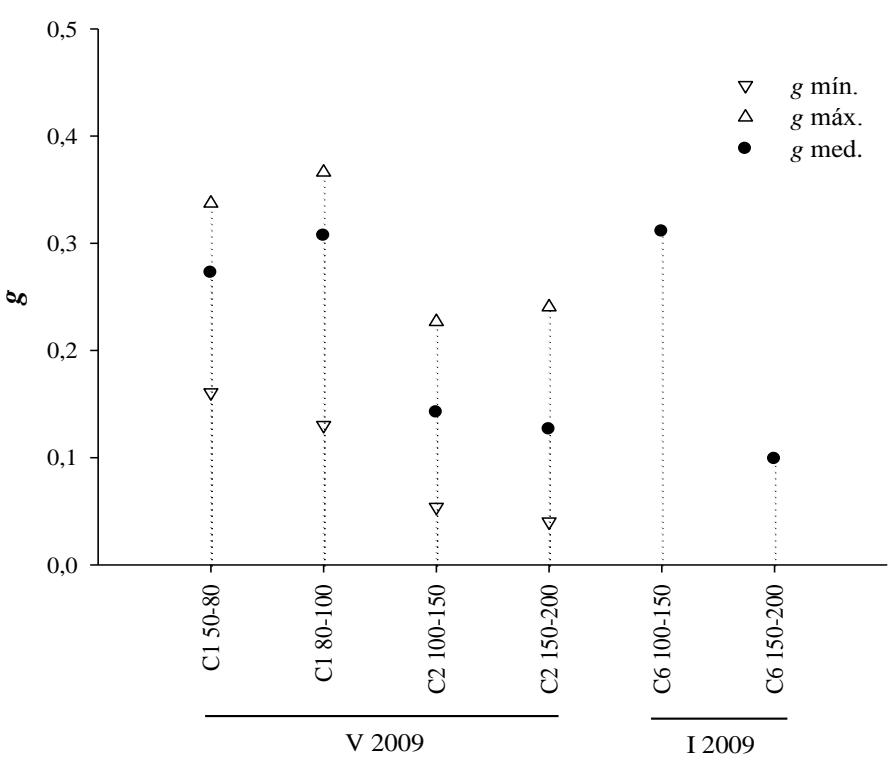

Figura 2.42: Taxas de crescimento para Dioithona oculata ao longo do verão e inverno de 2009. $g$ mín.: mínimo; $g$ máx.: máximo e $g$ med.: mediana. Legendas do eixo x correspondem aos experimentos, conforme Tabela 2.1.

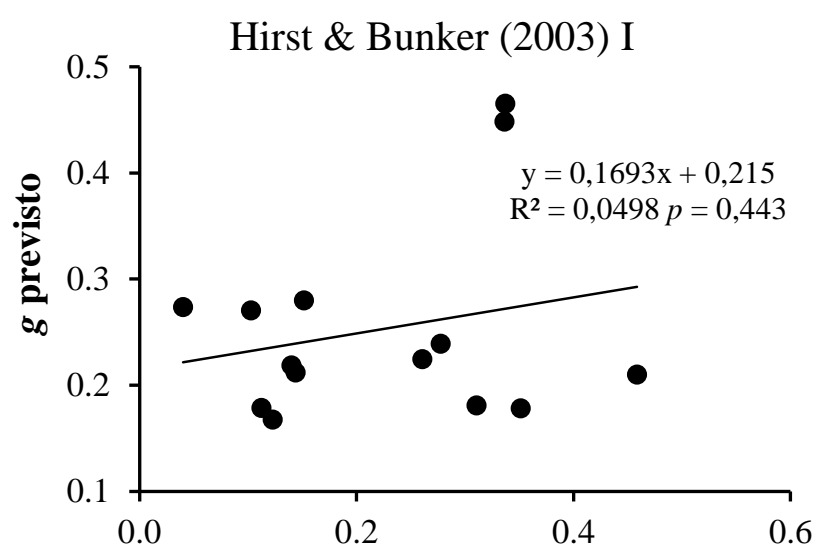

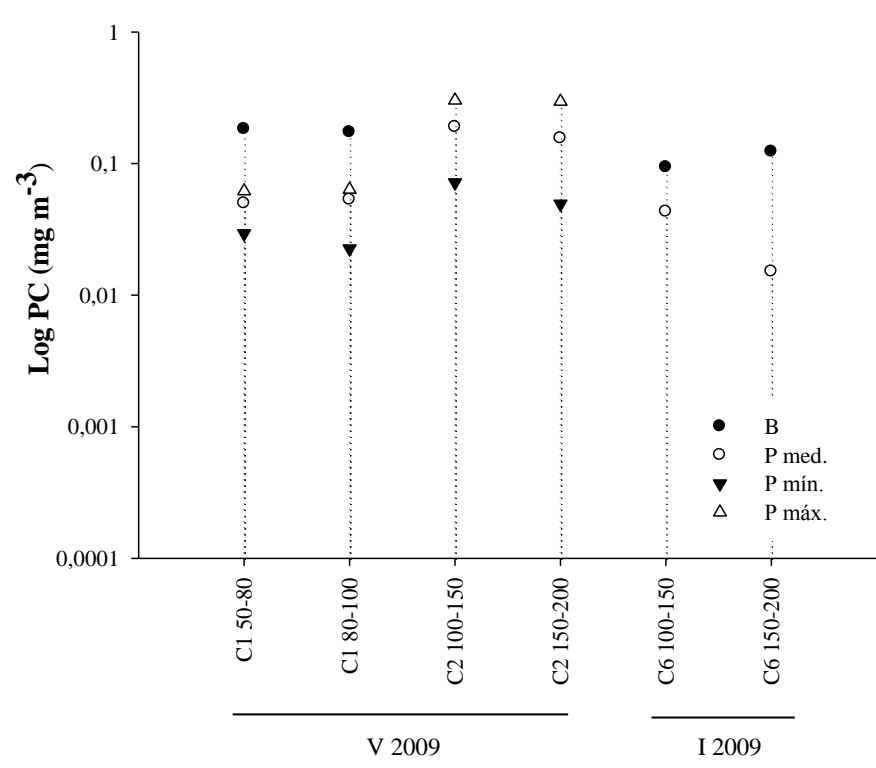

Figura 2.43: Variação da biomassa (B), produção mediana ou média ( $\mathrm{P}$ med.), mínima ( $\mathrm{P}$ mín.) e máxima (P máx.) para Dioithona oculata durante o verão e o inverno de 2009. Biomassa e produção no eixo y em escala logarítmica do PC $\left(\mathrm{mg} \mathrm{m}^{-3}\right)$. Sigla dos experimentos conforme tabela 2.1. Legendas do eixo $\mathrm{x}$ correspondem aos experimentos, conforme Tabela 2.1.

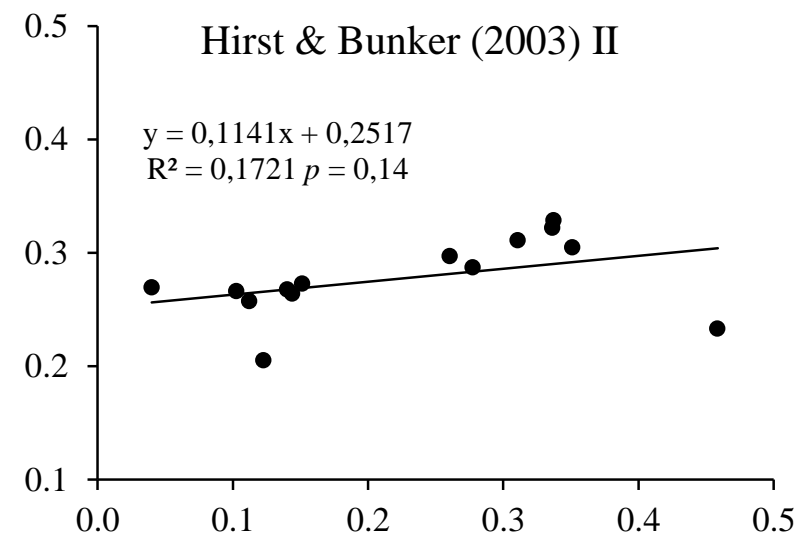

\section{$g$ medido}

Figura 2.44: Relação entre o crescimento medido experimentalmente (eixo x) e estimado para copépodes pelágicos em geral (Hirst \& Bunker, 2003 I) e juvenis de copépodes retentores de ovos (Hirst \& Bunker, 2003 II) em Dioithona oculata. Valores de $p$ do teste de Mann-Whitney. 

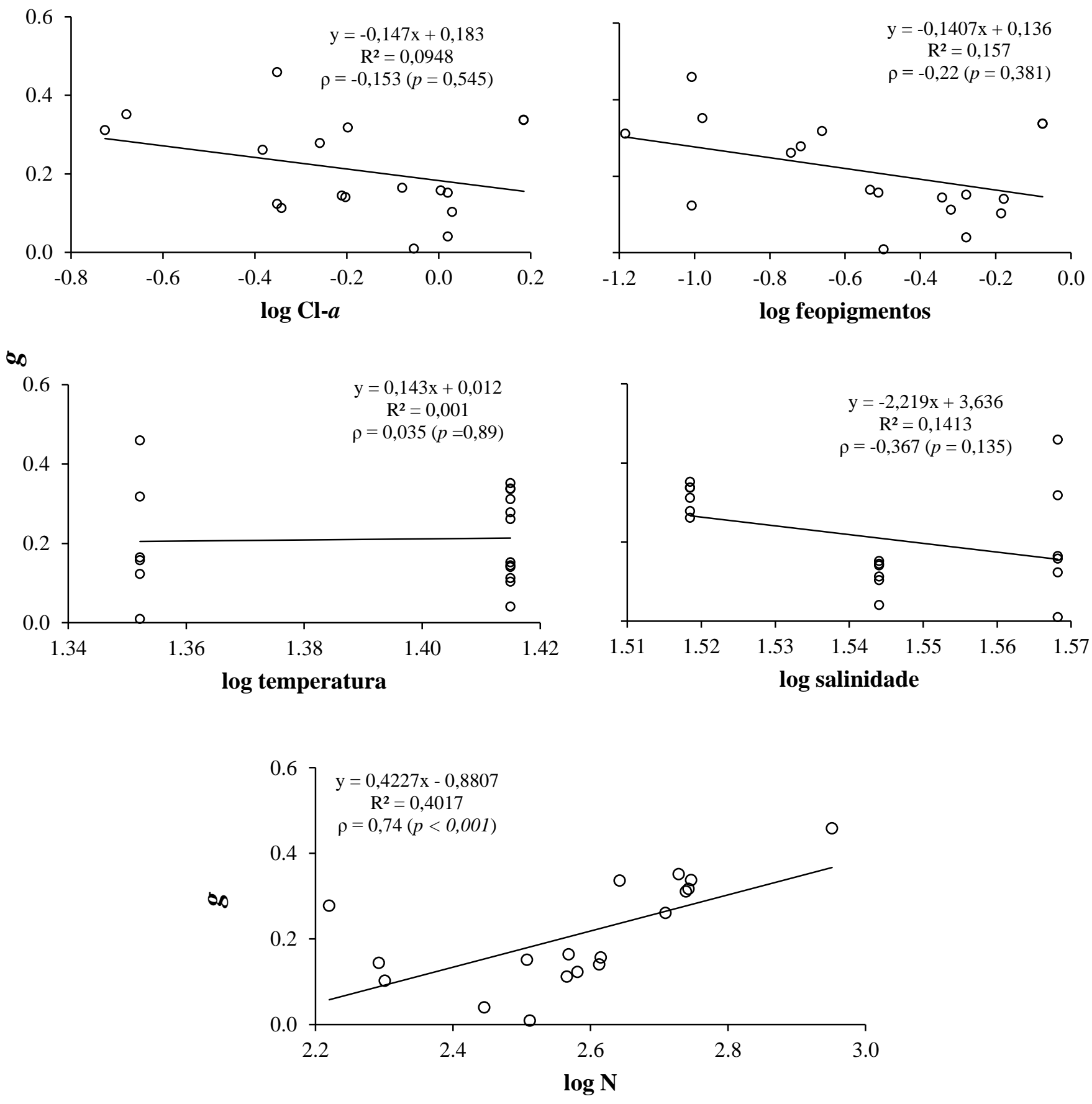

Figura 2.45: Regressão linear e correlação de Spearman $(\rho)$ entre as variáveis controladas e $g$ para Dioithona oculata nos experimentos de coortes artificiais. $\mathrm{O}$ eixo y é representado por $g$ e o eixo x pelo $\log _{10}$ da variável. Clorofila- $a(\mathrm{Cl}-a)$ e feopigmentos em $\mathrm{mg} \mathrm{m}^{-3}$; $\mathrm{T}$ : temperatura $\left({ }^{\circ} \mathrm{C}\right)$; $\mathrm{N}$ : número de metazoários incubados. 


\subsubsection{Oncaeidae}

A família Oncaeidae foi representada por espécies do gênero Oncaea, além de Monothula subtilis e Triconia conifera. Para o gênero Oncaea, foram encontradas as espécies O. minuta, O. media e O. venusta. Representantes da família foram comuns durante todo o período amostrado e estiveram presentes em 96,9\% das amostras. As espécies mais comuns foram O. venusta e O. minuta com 33 e $31 \%$ de abundância relativa da família. A densidade média para esses copépodes para as amostras da rede de $20 \mu \mathrm{m}$ foi de $485 \pm 293$ org. $\mathrm{m}^{-3}$, enquanto que para a rede de $100 \mu \mathrm{m}$ foi $619 \pm 404$ org. $\mathrm{m}^{-3}$.

As taxas de crescimento foram calculadas para 12 dos 16 experimentos e em todas as classes de tamanho. A média de $g$ para as coortes menores foi de $0,32 \pm 0,23 \mathrm{~d}^{-}$ 1 , enquanto que para as coortes maiores foi de $0,23 \pm 0,08 \mathrm{~d}^{-1}$ (Figura 2.46). Diferenças quanto às taxas de crescimento entre verão e inverno, anos de amostragem ou tamanho das coortes não foram encontradas. Não existiu uma relação entre o crescimento medido nos experimentos e o previsto através dos modelos de Hirst \& Bunker (2003) (Figura 2.47). A correlação de Spearman e regressão linear entre $g$ e as variáveis experimentais também não foram significativas (Figura 2.48).

Para as coortes menores, a média da biomassa e a produção foram de 0,087 \pm $0,054 \mathrm{mg} \mathrm{C} \mathrm{m}^{-3}$ e 0,028 $\pm 0,029 \mathrm{mg} \mathrm{C} \mathrm{m}^{-3} \mathrm{~d}^{-1}$ respectivamente. Para as coortes maiores esses valores foram de $0,151 \pm 0,108 \mathrm{mg} \mathrm{C} \mathrm{m}^{-3}$ e $0,022 \pm 0,016 \mathrm{mg} \mathrm{C} \mathrm{m}^{-3} \mathrm{~d}^{-1}$ respectivamente (Figura 2.49).

\subsubsection{Corycaeidae}

Os Corycaeidae foram compostos por Farranula gracilis, Corycaeus speciosus, Onychocorycaeus giesbrecthi e Ditrichocorycaeus amazonicus e foram frequentes durante este estudo. Representantes da família estiveram presentes em todas as amostras quantitativas. 

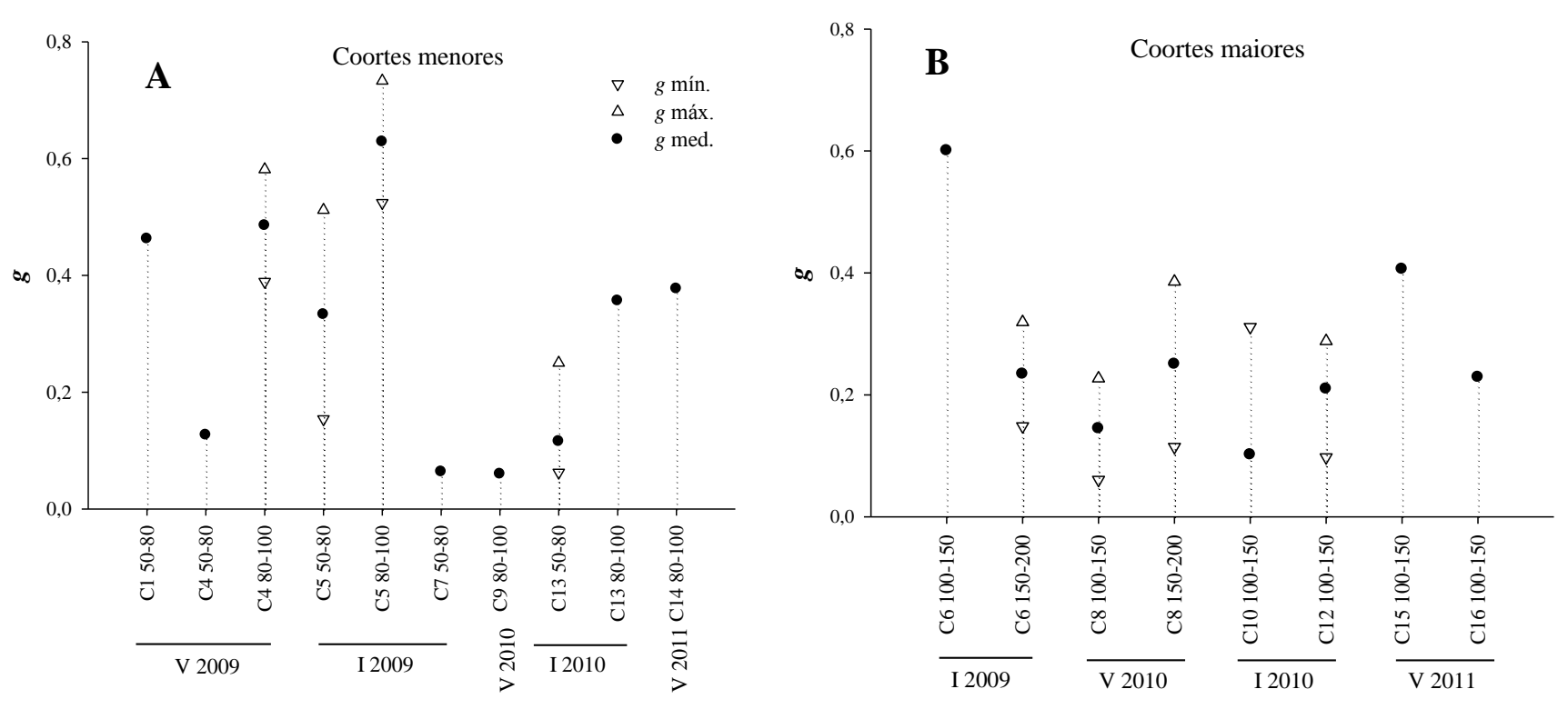

Figura 2.46: Taxas de crescimento para copépodes da família Oncaeidae ao longo do verão de 2009 até o verão de 2011. A: coortes menores, B: coortes maiores. $g$ mín.: mínimo; $g$ máx.: máximo e $g$ med.: mediana. Legendas do eixo x correspondem aos experimentos, conforme Tabela 2.1.
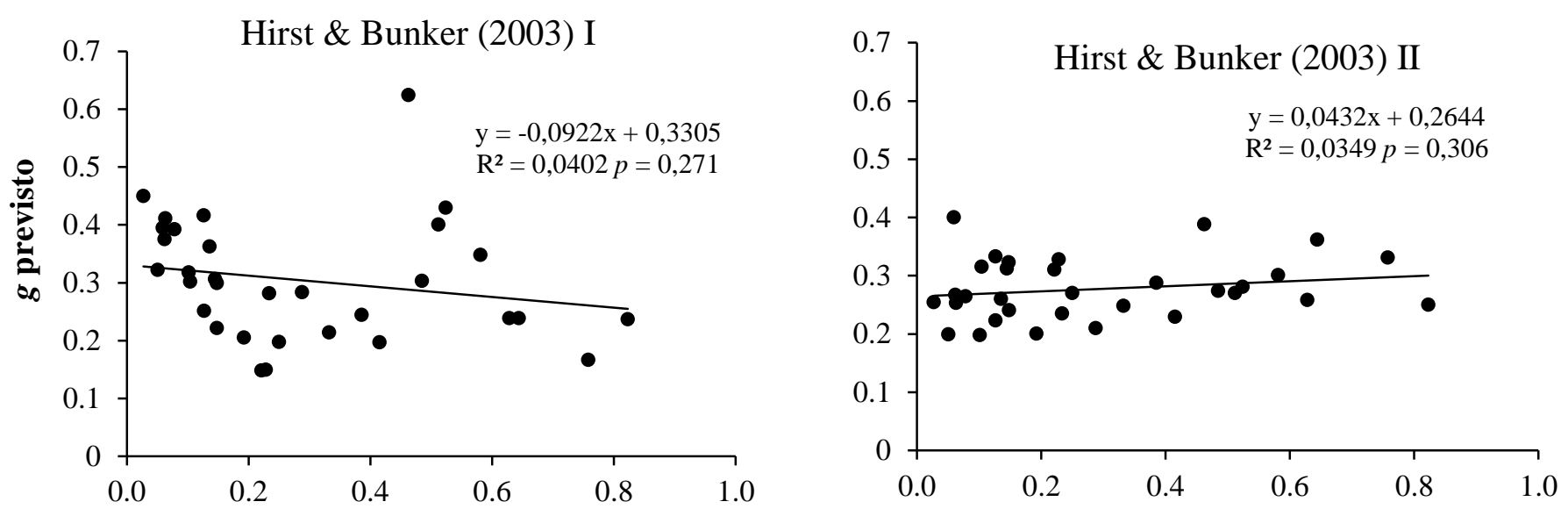

\section{g medido}

Figura 2.47: Relação entre o crescimento meaıo experımentalmente (eixo $x$ ) e estimado para copépodes pelágicos em geral (Hirst \& Bunker, 2003 I) e juvenis de copépodes retentores de ovos (Hirst \& Bunker, 2003 II) em copépodes da família Oncaeidae. Valores de $p$ do teste de Mann-Whitney. 

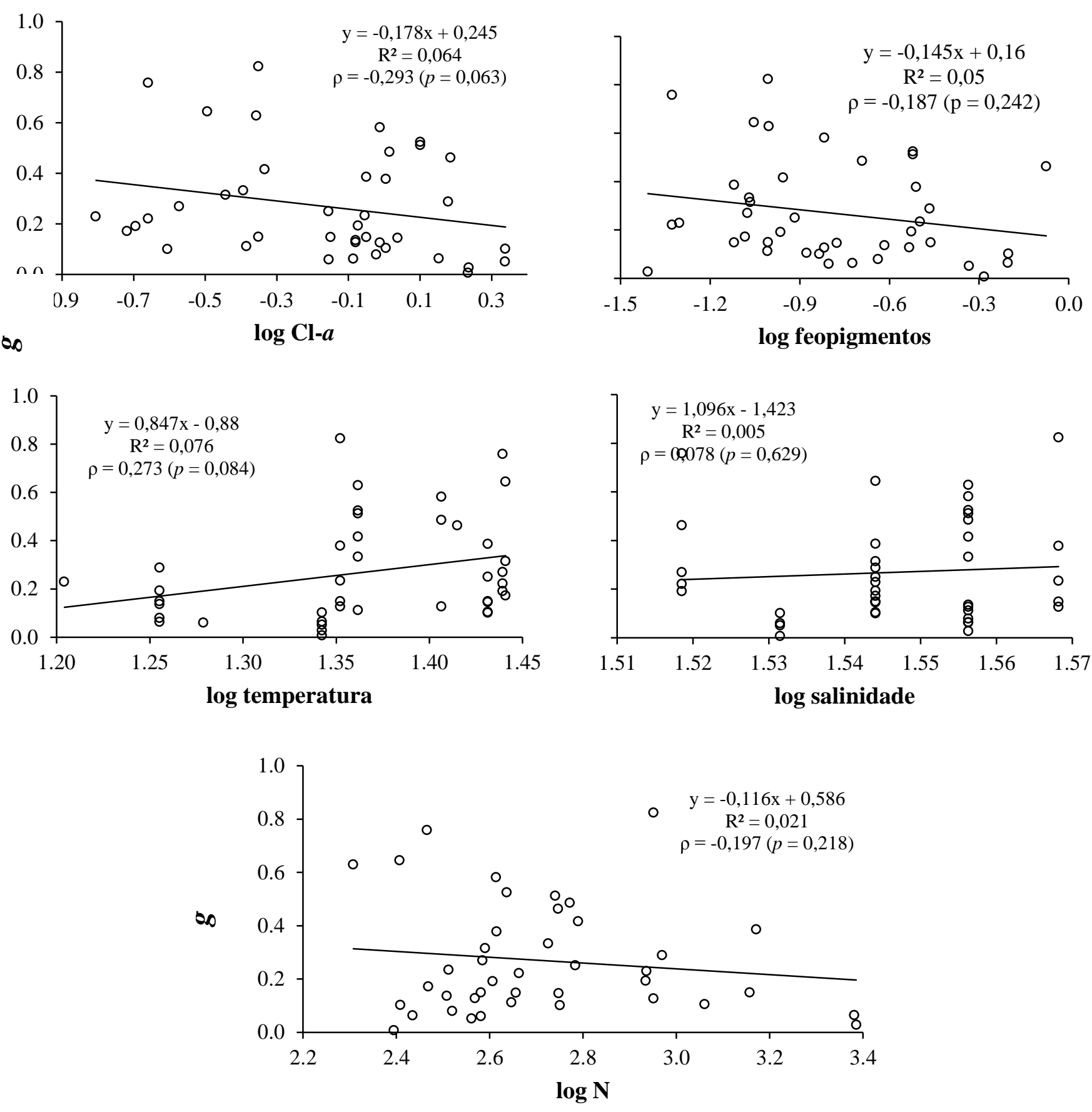

Figura 2.48: Regressão linear e correlação de Spearman $(\rho)$ entre as variáveis controladas e $g$ para copépodes da família Oncaeidae nos experimentos de coortes artificiais. O eixo y é representado por $g$ e o eixo x pelo $\log _{10}$ da variável. Clorofila- $a(\mathrm{Cl}-a)$ e feopigmentos em $\mathrm{mg} \mathrm{m}^{-3}$; T: temperatura $\left({ }^{\circ} \mathrm{C}\right)$; N: número de metazoários incubados. 

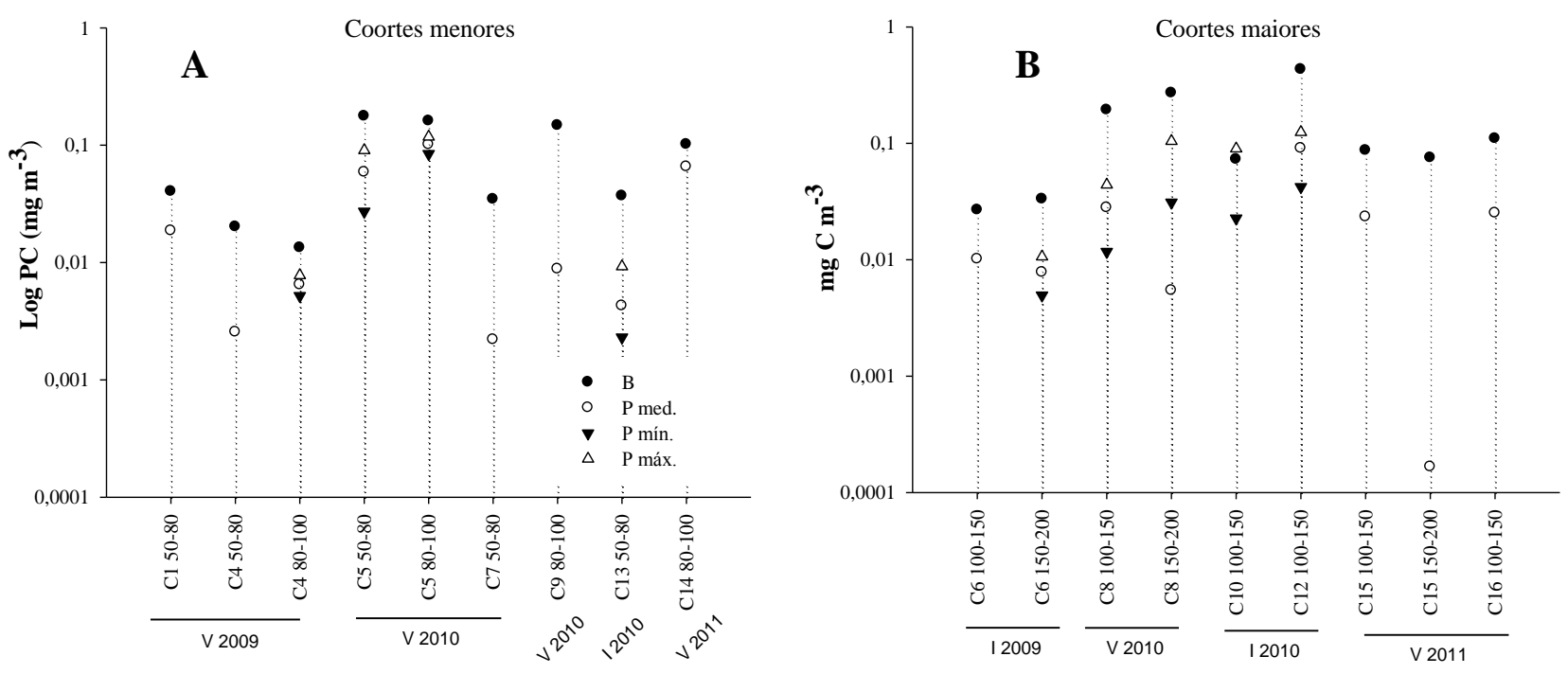

Figura 2.49: Variação da biomassa (B), produção mediana ou média (P med.), mínima (P mín.) e máxima (P máx.) para copépodes da família Oncaeidae durante o verão e o inverno de 2009. A biomassa e produção são fornecidas no eixo y na escala logarítmica do PC $\left(\mathrm{mg} \mathrm{m}^{-3}\right)$. A: coortes menores e B: coortes maiores. Legendas do eixo x correspondem aos experimentos, conforme Tabela 2.1.

A espécie $O$. giesbrechti foi a mais comum para a família, contribuindo com 33,5\% da abundância relativa dos Corycaeidae. A densidade foi considerada baixa, sendo de $78 \pm 111$ org. $\mathrm{m}^{-3}$ para a rede de $20 \mu \mathrm{m}$ e $138 \pm 119$ org. $\mathrm{m}^{-3}$ para a rede de 100 $\mu \mathrm{m}$.

O crescimento foi analisado em seis experimentos, porém nenhum resultado foi obtido para a coorte de 50-80 $\mu \mathrm{m}$ (Figura 2.50). Para as coortes de 80-100 $\mu \mathrm{m}$, a média de $g$ foi de $0,167 \mathrm{~d}^{-1}$, enquanto que para as coortes maiores esse valor foi de 0,1 $\pm 0,06$ $\mathrm{d}^{-1}$. Não foram detectadas relações entre o crescimento experimental e o estimado pelas equações e Hirst \& Bunker (2003) (Figura 2.51). Não houve correlação entre $g$ e as variáveis controladas dos experimentos (Figura 2.52). Para as coortes de 80-100 $\mu \mathrm{m}$, a média da biomassa e a produção foram de $0,026 \mathrm{mg} \mathrm{C} \mathrm{m}^{-3}$ e $0,001 \mathrm{mg} \mathrm{C} \mathrm{m}^{-3} \mathrm{~d}^{-1}$ respectivamente. Para as coortes maiores esses valores foram de $0,06 \pm 0,003 \mathrm{mg} \mathrm{C} \mathrm{m}^{-3}$ e $0,004 \pm 0,001 \mathrm{mg} \mathrm{C} \mathrm{m}^{-3} \mathrm{~d}^{-1}$ respectivamente (Figura 2.53). 

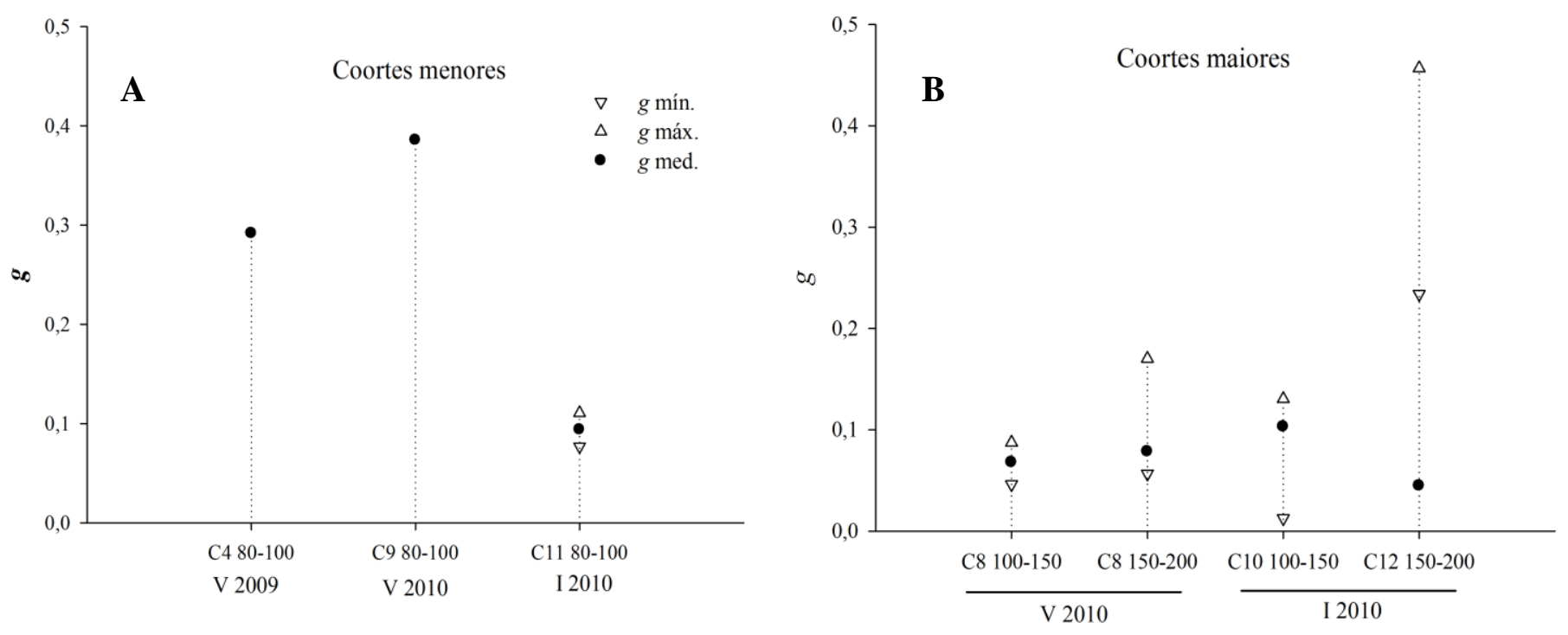

Figura 2.50: Taxas de crescimento para Corycaeidae ao longo do verão de 2009 até o inverno de 2010. A: coortes menores, B: coortes maiores. $g$ mín.: mínimo; $g$ máx.: máximo e $g$ med.: mediana. Legendas do eixo $\mathrm{x}$ correspondem aos experimentos, conforme Tabela 2.1.
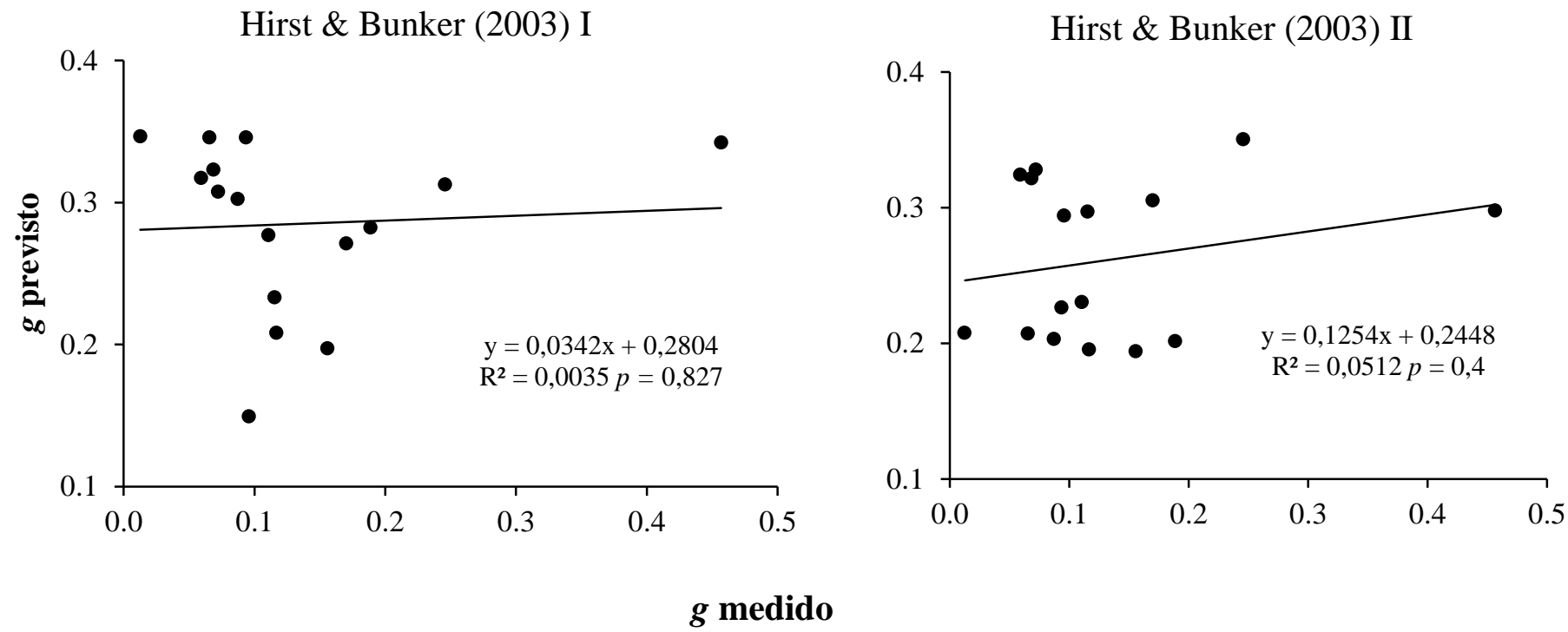

Figura 2.51: Relação entre o crescimento medido experimentalmente (eixo x) e estimado para copépodes pelágicos em geral (Hirst \& Bunker, 2003 I) e juvenis de copépodes retentores de ovos (Hirst \& Bunker, 2003 II) em Corycaeidae. Valores de $p$ do teste de Mann-Whitney. 

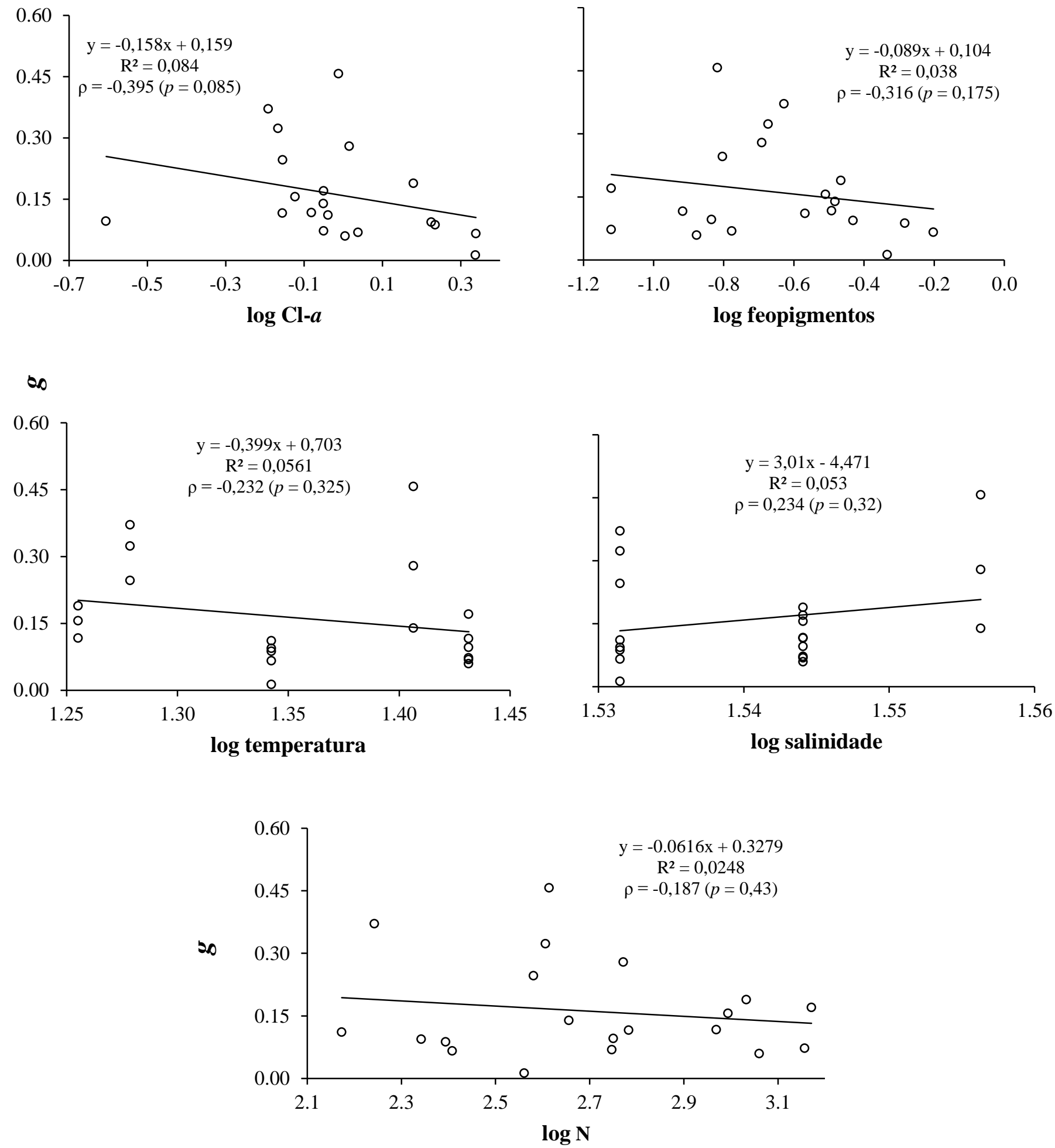

Figura 2.52: Regressão linear e correlação de Spearman $(\rho)$ entre as variáveis controladas e $g$ para copépodes da família Corycaeidae nos experimentos de coortes artificiais. $\mathrm{O}$ eixo y é representado por $g$ e o eixo x pelo $\log _{10}$ da variável. Clorofila- $a(\mathrm{Cl}-a)$ e feopigmentos em $\mathrm{mg} \mathrm{m}^{-3}$; T: temperatura $\left({ }^{\circ} \mathrm{C}\right) ; \mathrm{N}$ : número de metazoários incubados. 

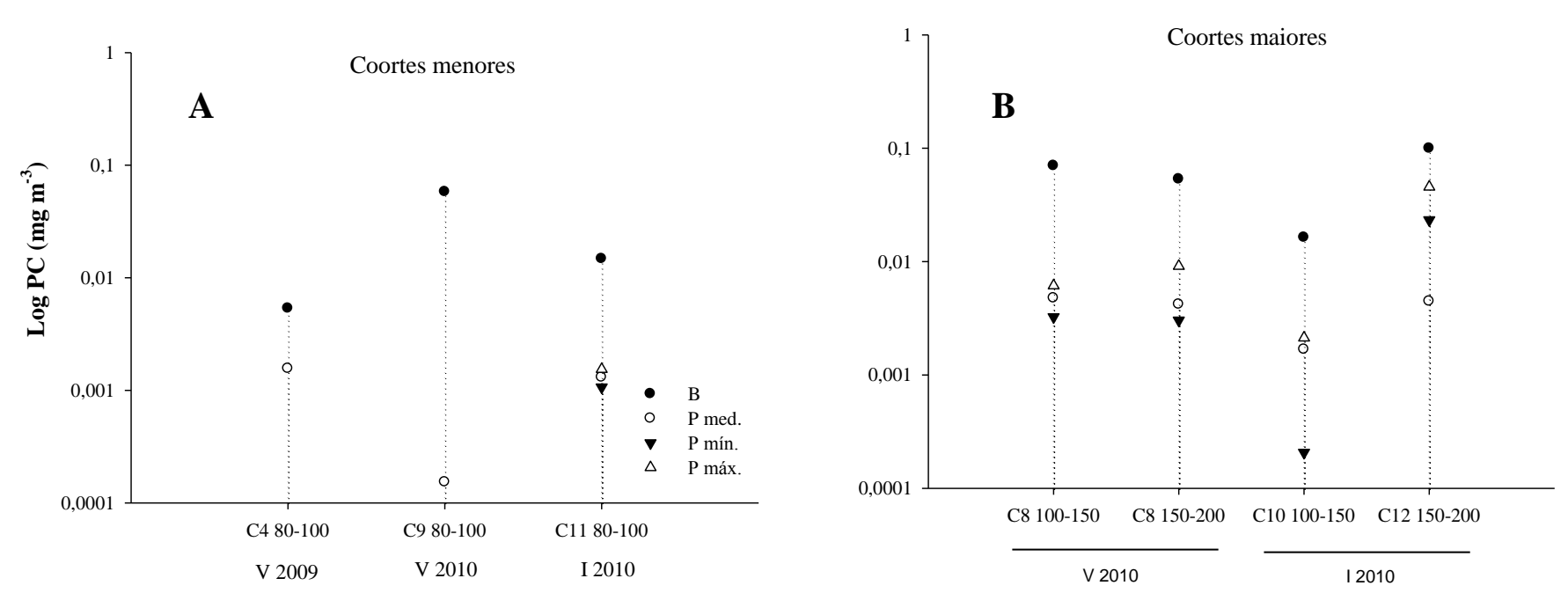

Figura 2.53: Variação da biomassa (B), produção mediana ou média ( $\mathrm{P}$ med.), mínima ( $\mathrm{P}$ mín.) e máxima (P máx.) para copépodes da família Corycaeidae durante o verão de 2009 ao inverno de 2010. A biomassa e produção são fornecidas no eixo y na escala logarítmica do PC $\left(\mathrm{mg} \mathrm{m}^{-3}\right)$. A: coortes menores e B: coortes maiores. Legendas do eixo x correspondem aos experimentos, conforme Tabela 2.1.

\subsubsection{3. $\quad$ Euterpina acutifrons e Longipedia americana}

O copépode Harpacticoida Euterpina acutifrons esteve presente em $75 \%$ das amostras quantitativas e sua densidade média foi de $123 \pm 186$ org. $\mathrm{m}^{-3}$ para a rede de 20 $\mu \mathrm{m}$ e de $92 \pm 175$ org. $\mathrm{m}^{-3}$ para a rede de $100 \mu \mathrm{m}$. Já Longipedia americana foi um copépode mais raro, ausente em 58\% das amostras quantitativas. A densidade para a espécie foi de $80 \pm 176$ e $48 \pm 131$ org. $\mathrm{m}^{-3}$ para as redes de 20 e $100 \mu \mathrm{m}$ respectivamente.

O número amostral de indivíduos de Euterpina acutifrons foi suficiente para o cálculo de $g$ em quatro experimentos e sete coortes, enquanto que em apenas uma coorte de um experimento isso foi possível para L. americana (Figura 2.54). A medida de $g$ para a coorte de $50-80 \mu \mathrm{m}$ foi de $0,16 \mathrm{~d}^{-1}$, enquanto que para as coortes maiores foi de $0,31 \pm 0,14 \mathrm{~d}^{-1}$ para E. acutifrons.

Para Euterpina acutifrons, as relações entre o crescimento medido e o estimado pelos modelos globais não foram significativas (Figura 2.56). Dentre as variáveis experimentais testadas, apenas a temperatura mostrou correlação positiva com $g$ ( $\rho=$ 
0,$44 ; p=0,046$ ) (Figura 2.57). A biomassa e produção de Longipedia americana para o único experimento calculado foi de $0,074 \mathrm{mg} \mathrm{C} \mathrm{m}^{-3}$ e $0,027 \mathrm{mg} \mathrm{C} \mathrm{m}^{-3} \mathrm{~d}^{-1}$ respectivamente. Para E. acutifrons a única coorte de 50-80 $\mu \mathrm{m}$ apresentou uma biomassa de $0,071 \mathrm{mg} \mathrm{C} \mathrm{m}^{-3}$ e produção de $0,012 \mathrm{mg} \mathrm{C} \mathrm{m}^{-3} \mathrm{~d}^{-1}$, enquanto que para as coortes maiores esses valores foram de $0,024 \pm 0,026 \mathrm{mg} \mathrm{C} \mathrm{m}^{-3}$ e $0,007 \pm 0,009 \mathrm{mg} \mathrm{C}^{-1}$ $\mathrm{m}^{-3} \mathrm{~d}^{-1}$ respectivamente (Figura 2. 55).

\subsubsection{Comparação entre o crescimento medido e o estimado}

As regressões lineares foram significativas, tanto para a equação destinada aos juvenis, quanto para os copépodes em geral apenas para Acartia spp. e Paracalanus spp. A regressão entre o crescimento medido e o estimado pela equação para copépodes gerais ainda foi significativa para Parvocalanus crassirostris. Além de Acartia spp. e Paracalanus spp., a regressão entre a equação para juvenis e o crescimento medido experimentalmente também foi significativo para Oithona spp. (Tabela 2.7).

As relações foram inversamente proporcionais para Acartia spp., Paracalanus spp. e Parvocalanus crassirostris e diretamente proporcional para Oithona spp. Entretanto, os coeficientes de correlação foram baixos, indicando uma dispersão grande dos dados e o desvio dos valores experimentais em relação aos estimados pelas equações (ver Figuras 2.9, 2.14, 2.19 e 2.36). 


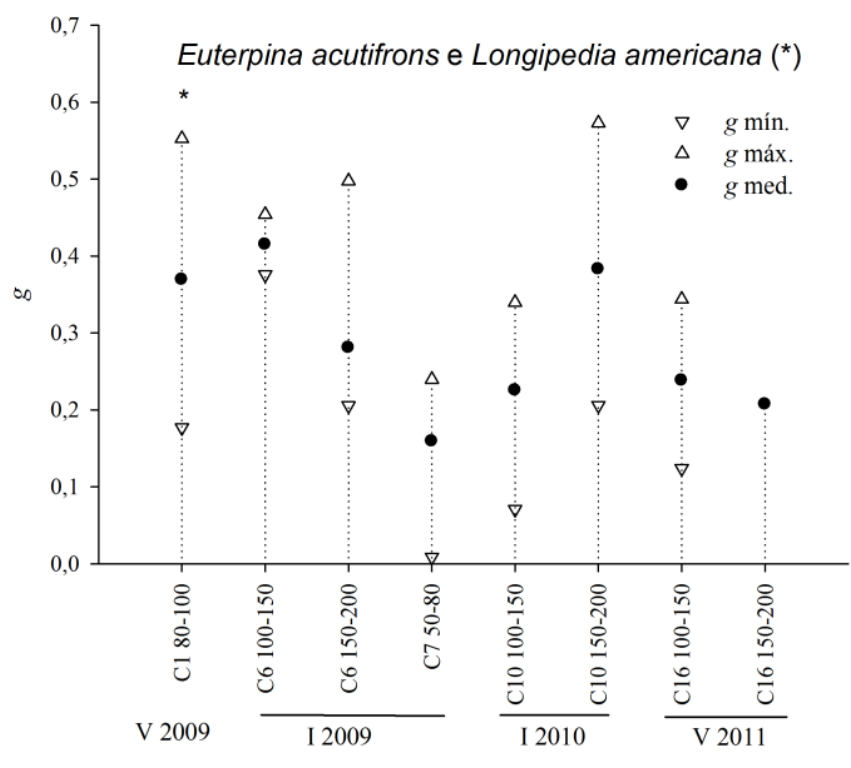

Figura 2.54: Taxas de crescimento para Euterpina acutifrons ao longo do inverno de 2009 até o verão de 2011 e para Longipedia americana (*). g mín.: mínimo; $g$ máx.: máximo e $g$ med.: mediana. Legendas do eixo $\mathrm{x}$ correspondem aos experimentos, conforme Tabela 2.1 .

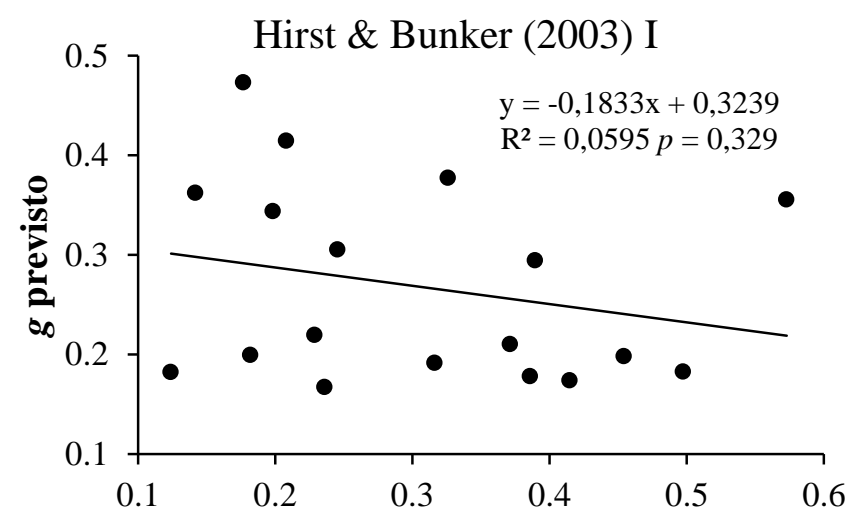

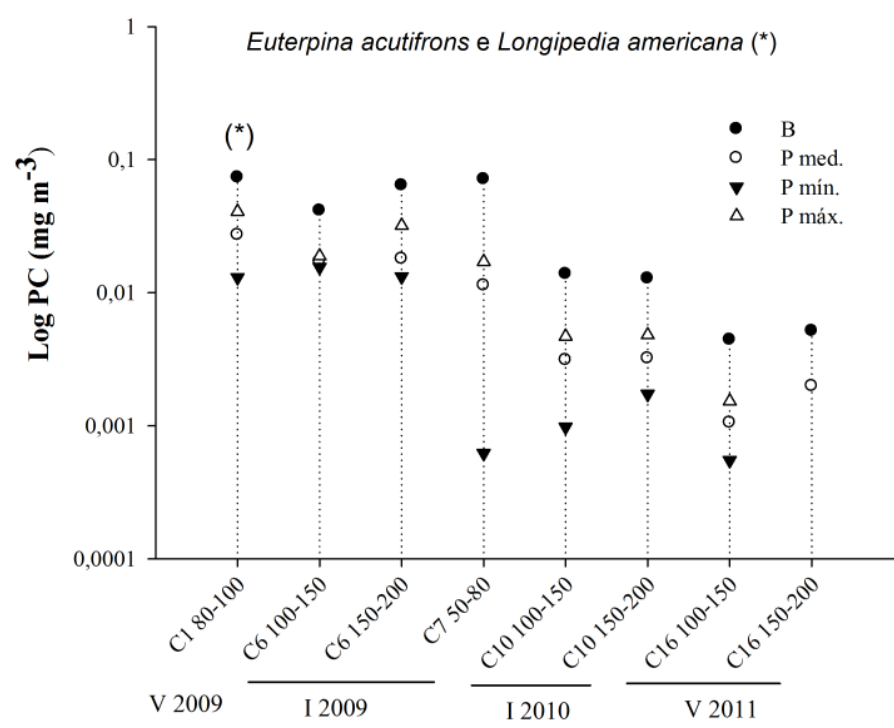

Figura 2.55: Variação da biomassa $(\mathrm{B})$, produção mediana ou média ( $\mathrm{P}$ med.), mínima ( $\mathrm{P}$ mín.) e máxima (P máx.) para Euterpina acutifrons do inverno de 2009 até o verão de 2011 e para Longipedia americana (*). A biomassa e produção são fornecidas no eixo y na escala logarítmica do PC $\left(\mathrm{mg} \mathrm{m}^{-3}\right)$. Legendas do eixo $\mathrm{x}$ correspondem aos experimentos, conforme Tabela 2.1.

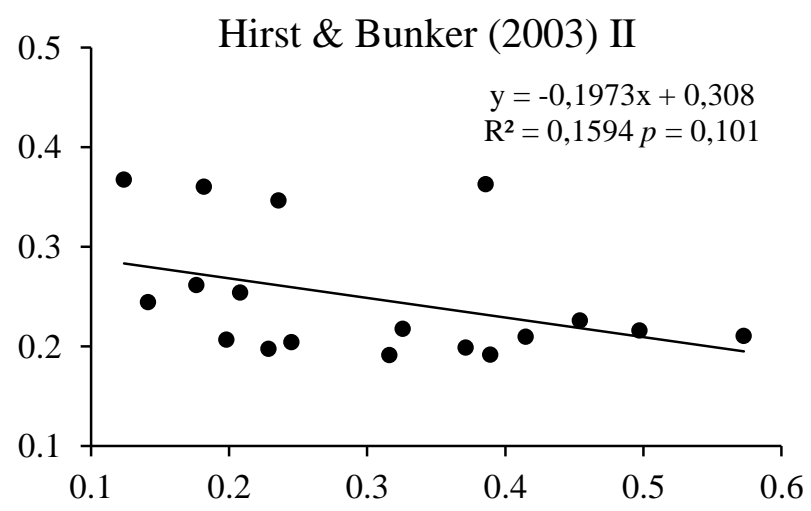

\section{$g$ medido}

Figura 2.56: Relação entre o crescimento medido experimentalmente (eixo x) e estimado para copépodes pelágicos em geral (Hirst \& Bunker, 2003 I) e juvenis de copépodes retentores de ovos (Hirst \& Bunker, 2003 II) em Euterpina acutifrons. Valores de $p$ do teste de Mann-Whitney. 

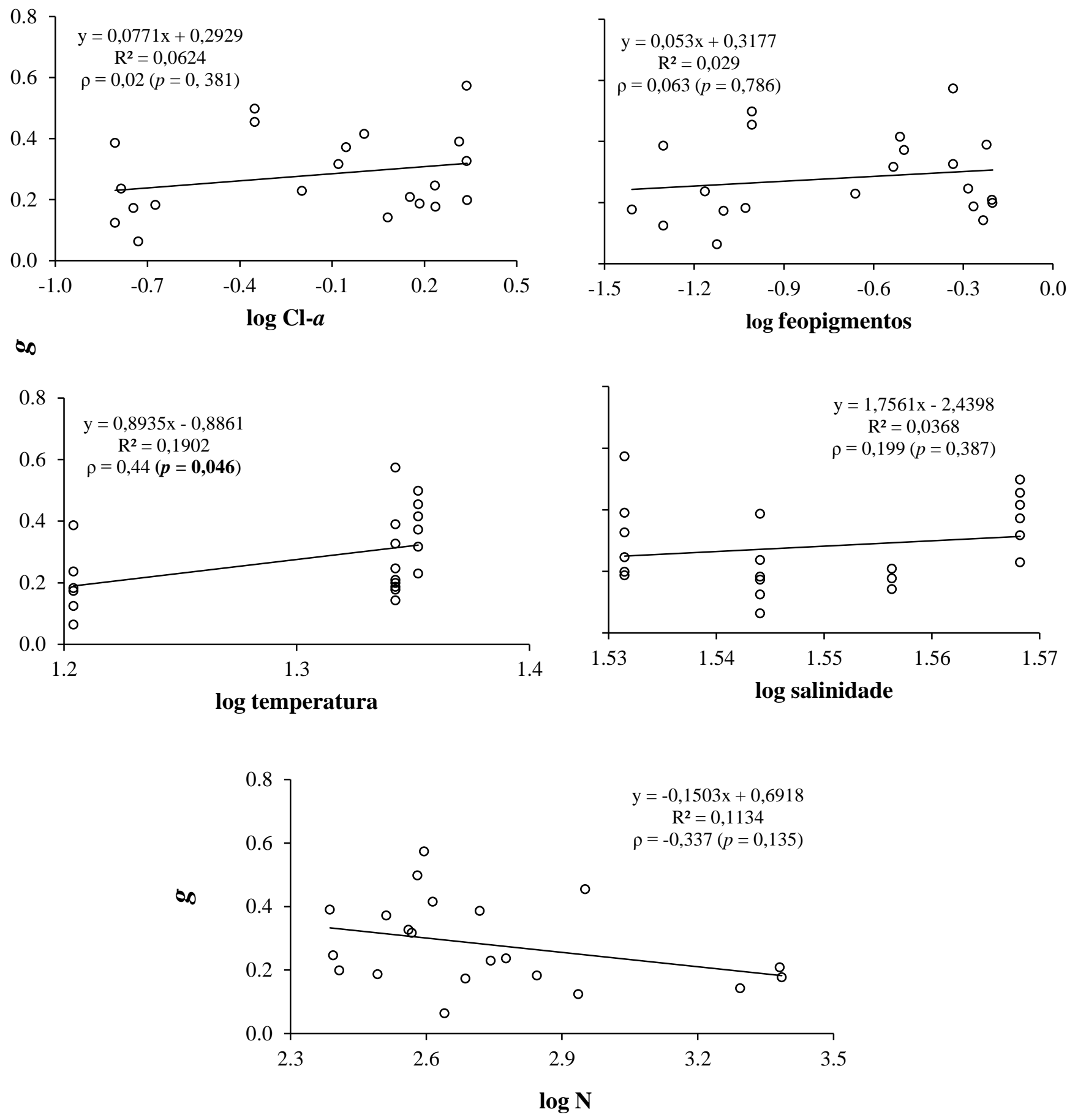

Figura 2.57: Regressão linear e correlação de Spearman $(\rho)$ entre as variáveis controladas e $g$ para Euterpina acutifrons. nos experimentos de coortes artificiais. O eixo y é representado por $g$ e o eixo x pelo $\log _{10}$ da variável. Clorofila- $a(\mathrm{Cl}-a)$ e feopigmentos em $\mathrm{mg} \mathrm{m}^{-3}$; T: temperatura $\left({ }^{\circ} \mathrm{C}\right)$; N: número de metazoários incubados. 
Tabela 2.7: valores de $p$ da regressão linear entre o crescimento medido e o estimado pelas equações de Hirst \& Bunker (2003). I: equações para copépodes em geral e II: equações para copépodes juvenis.

\begin{tabular}{ccc}
\hline Táxon & I (geral) & II (juvenis) \\
\hline Acartia spp. & $\mathbf{0 , 0 0 3}$ & $\mathbf{0 , 0 0 8}$ \\
Parvocalanus crassirostris & $\mathbf{0 , 0 3 1}$ & 0,211 \\
Paracalanus spp. & $\mathbf{0 , 0 4 6}$ & $\mathbf{0 , 0 2 5}$ \\
Temora turbinata & 0,899 & 0,896 \\
T. stylifera & 0,137 & 0,066 \\
Oithona spp. & 0,349 & $\mathbf{0 , 0 1 3}$ \\
O. plumifera & 0,968 & 0,912 \\
Dioithona oculata & 0,443 & 0,14 \\
Oncaeidae & 0,271 & 0,306 \\
Corycaeidae & 0,827 & 0,4 \\
Euterpina acutifrons & 0,329 & 0,101 \\
\hline
\end{tabular}

\subsubsection{Síntese das comparações das taxas de crescimento}

Não foi detectada diferença significativa para as taxas de crescimento entre as estações de verão e inverno para todas as espécies testadas. Em relação aos anos estudados, diferença significativa só foi encontrada para Paracalanus spp. (Tabela 2.8), onde a taxa de crescimento foi maior para o ano de 2011, em relação aos anos de 2009 e 2010.

Diferenças significativas não foram evidentes quando os valores de crescimento foram comparados quanto aos diferentes tamanhos de coortes, com a exceção apenas de Oithona spp. Para esse táxon, as taxas de crescimento obtidas para as coortes menores foi significativamente maior do que o encontrado para as coortes maiores (Tabelas $2.8 \mathrm{e}$ 29). 
Tabela 2.8: Comparações entre os valores médios de crescimento entre estações do ano agrupadas, entre os anos de coleta e entre os tamanhos de coortes. Teste de Kruskal-Wallis ou ANOVA para comparações múltiplas; ambos seguidos pelo teste de Student-Newman-Keuls de comparação entre grupos e teste $t$ ou teste de Mann-Whitney para comparação entre dois grupos. Coortes menores: 50-80 + 80-100; coortes maiores: 100-150+150-200; *: $p<0,05 \mathrm{e}^{* *}: \mathrm{p}<$ 0,001 .

\begin{tabular}{lcccccc}
\hline \multicolumn{1}{c}{ Táxon } & Estações & \multicolumn{2}{c}{ Anos } & Coortes \\
\cline { 2 - 7 } & V x I & $09 \times 10 \times$ & $09 \times 10$ & $09 \times 11$ & $10 \times 11$ & $\begin{array}{c}\text { menores x } \\
\text { maiores }\end{array}$ \\
\hline Acartia spp. & 0,378 & 0,180 & - & - & - & 0,479 \\
P. crassirostris & 0,391 & 0,484 & - & - & - & 0,899 \\
Paracalanus spp. & 0,095 & $\mathbf{0 , 0 1 3}$ & - & $<*$ & $<*$ & 0,114 \\
Temora turbinata & 0,063 & 0,482 & - & - & - & - \\
Oithona spp. & 0,728 & 0,385 & - & - & - & $>* *$ \\
Oncaeidae & 0,738 & 0,122 & - & - & - & 0,505 \\
\hline
\end{tabular}

Diferença entre os tamanhos de coortes empregadas não foi observada, mesmo considerando todos os dados de taxas de crescimento médias de todos os táxons analisados para comparação $(p=0,31)$. Os valores médios de $g$ estiveram entre 0,27 a $0,34 \mathrm{~d}^{-1}$. A mediana de $g$ entre as diferentes coortes expressou a grande similaridade entre as quatro categorias, com exceção apenas da classe de 100-150 $\mu$ m (Tabelas 2. 9 e 2.10).

Tabela 2.9: Comparação dos valores de $g$ entre as classes de tamanho de coortes artificiais.

\begin{tabular}{ccccc}
\hline Tamanho $(\boldsymbol{\mu m})$ & $\boldsymbol{n}$ & Média e desvio & Mediana & Kruskal-Wallis \\
\hline $50-80$ & 30 & $0,343 \pm 0,218$ & 0,314 & \\
$80-100$ & 43 & $0,323 \pm 0,165$ & 0,314 & $p=0,311$ \\
$100-150$ & 45 & $0,269 \pm 0,172$ & 0,238 & \\
$150-200$ & 45 & $0,341 \pm 0,253$ & 0,309 & \\
\hline
\end{tabular}


Tabela 2.10: Taxas de crescimento para os táxons estudados, em cada uma das classes de tamanho de coortes artificiais. Entre parênteses, o número amostral de experimentos em cada classe de tamanho.

\begin{tabular}{|c|c|c|c|c|c|}
\hline Táxon & $50-80 \mu \mathrm{m}$ & $80-100 \mu \mathrm{m}$ & $100-150 \mu \mathrm{m}$ & $150-200 \mu \mathrm{m}$ & Média \\
\hline Acartia spp. & $0,38 \pm 0,29(4)$ & $\begin{array}{c}0,34 \pm 0,19 \\
\text { (7) }\end{array}$ & $\begin{array}{c}0,4 \pm 0,23 \\
\text { (5) }\end{array}$ & $\begin{array}{c}0,37 \pm 0,13 \\
\text { (7) }\end{array}$ & $\begin{array}{c}0,37 \pm 0,18 \\
\text { (23) }\end{array}$ \\
\hline Parvocalanus crassirostris & $0,35 \pm 0,1(6)$ & $0,3 \pm 0,1(6)$ & $\begin{array}{c}0,29 \pm 0,16 \\
\text { (4) }\end{array}$ & $0,63(3)$ & $\begin{array}{c}0,37 \pm 0,1 \\
(19)\end{array}$ \\
\hline Paracalanus spp. & $0,4 \pm 0,25(5)$ & $\begin{array}{c}0,27 \pm 0,18 \\
\text { (7) }\end{array}$ & $\begin{array}{c}0,42 \pm 0,24 \\
\text { (6) }\end{array}$ & $\begin{array}{c}0,61 \pm 0,39 \\
\quad(7)\end{array}$ & $\begin{array}{c}0,43 \pm 0,27 \\
(25)\end{array}$ \\
\hline Temora turbinata & - & $0,57(3)$ & $\begin{array}{c}0,46 \pm 0,37 \\
(5)\end{array}$ & $\begin{array}{c}0,52 \pm 0,24 \\
\quad(6)\end{array}$ & $\begin{array}{c}0,51 \pm 0,3 \\
(14)\end{array}$ \\
\hline T. stylifera & - & $0,24(1)$ & $0,34(2)$ & $0,4(1)$ & $0,33(4)$ \\
\hline Centropages velificatus & - & - & $0,35(2)$ & $0,87(1)$ & $0,52(3)$ \\
\hline Pseudodiaptomus acutus & - & $0,37(1)$ & $0,08(1)$ & $0,16(1)$ & $0,2(3)$ \\
\hline Oithona spp. & $0,4 \pm 0,36(7)$ & $\begin{array}{c}0,29 \pm 0,12 \\
(8)\end{array}$ & $\begin{array}{c}0,12 \pm 0,08 \\
\text { (7) }\end{array}$ & $\begin{array}{c}0,17 \pm 0,14 \\
\text { (9) }\end{array}$ & $\begin{array}{c}0,24 \pm 0,17 \\
\text { (31) }\end{array}$ \\
\hline O. plumifera & $0,19(1)$ & $0,06(2)$ & $0,14(2)$ & $0,07(3)$ & $\begin{array}{c}0,1 \pm 0,07 \\
\text { (8) }\end{array}$ \\
\hline Dioithona oculata & $0,27(1)$ & $0,31(1)$ & $0,23(2)$ & $0,11(2)$ & $\begin{array}{c}0,21 \pm 0,1 \\
\quad(6)\end{array}$ \\
\hline Oncaeidae & $0,22 \pm 0,17(5)$ & $\begin{array}{c}0,38 \pm 0,21 \\
(5)\end{array}$ & $\begin{array}{c}0,28 \pm 0,19 \\
(6)\end{array}$ & $0,24(2)$ & $\begin{array}{c}0,29 \pm 0,19 \\
\quad(18)\end{array}$ \\
\hline Corycaeidae & - & $0,31(3)$ & $0,33(2)$ & $0,28(2)$ & $\begin{array}{c}0,56 \pm 0,29 \\
\text { (7) }\end{array}$ \\
\hline Euterpina acutifrons & $0,16(1)$ & - & $0,29(3)$ & $0,35(3)$ & $\begin{array}{c}0,3 \pm 0,16 \\
\text { (7) }\end{array}$ \\
\hline Longipedia americana & - & $0,37(1)$ & - & - & - \\
\hline
\end{tabular}

\subsubsection{Abundância, biomassa e produção das principais famílias de copépodes}

Neste estudo, são fornecidos dados de abundância, biomassa e produção apenas para os estágios imaturos, os adultos foram desconsiderados. Copépodes da família Oithonidae foram os mais abundantes, seguidos pelos Paracalanidae e posteriormente por Acartiidae e Oncaeidae para todo o período amostrado. Apenas para as coortes maiores durante o verão de 2009 e coortes menores durante o inverno de 2009 e verão de 2011 a família Paracalanidae foi mais abundante do que os Oithonidae (Figura 2.58).

A família Oithonidae ainda foi a que mais contribuiu em termos de biomassa, seguida posteriormente em ordem decrescente pelas famílias Paracalanidae e Acartiidae para as coortes menores e Acartiidae e Paracalanidae para as coortes maiores (Figura 2.59). 
Quanto à produção, a família Temoridae foi a segunda mais importante após os Oithonidae para as coortes menores. Para as coortes maiores, o padrão de produção por famílias foi o mesmo obtido para a biomassa (Figura 2.60).

Um domínio numérico de copépodes da família Oithonidae e Paracalanidae ocorreu durante o verão de 2009. Em termos de biomassa e produção, a família Acartiidae, mesmo sendo menos abundante, teve maior contribuição. A produção integrada para o inverno de 2009 foi menor do que o verão e a família Oncaeidae foi particularmente importante para a biomassa e produção. Os maiores valores de densidade, biomassa e produção para os juvenis de copépodes pelágicos das coortes de 100-150 e 150-200 $\mu \mathrm{m}$ também ocorreram durante o verão de 2009.

A família Temoridae apresentou uma contribuição relevante em termos de produção, embora a densidade numérica tenha sido menor: quase a metade dos Oithonidae durante o verão de 2010 e para as coortes menores. Para as coortes maiores do mesmo período, foi observada novamente a dominância numérica da família Oithonidae, sendo essa dominância diluída entre as demais famílias quanto à biomassa e produção.

Os menores valores de densidade, biomassa e produção foram observados durante o inverno do ano de 2010. As famílias Paracalanidae e Oncaeidae foram as dominantes para as coortes menores em termos de densidade, enquanto que Oithonidae e Oncaeidae foram dominantes para as coortes maiores. Os Paracalinidae apresentaram a maior contribuição para a produção neste período.

Para o verão de 2011, copépodes da família Oithonidae foram os mais importantes em termos de biomassa e produção, posição ocupada pelos Paracalanidae nas coortes maiores. A maior produção de copépodes pelágicos entre as coortes menores ocorreu durante o verão de 2011. 


\subsubsection{Abundância, biomassa e produção das ordens Calanoida, Cyclopoida e Harpacticoida}

As densidades entre os copépodes das ordens Calanoida e Cyclopoida foram semelhantes na maioria dos casos. Apenas para o verão de 2009 para as coortes maiores e o verão de 2011 para as coortes menores que a ordem Calanoida foi expressivamente dominante sobre os Cyclopoida (Figura 2.61). Para ambas as situações, a biomassa dos Cyclopoida foi maior do que a dos Calanoida, embora a densidade fosse inferior.

Em relação à biomassa e produção, os valores foram cerca de duas vezes maiores para as coortes de 100-150 e 150-200 $\mu \mathrm{m}$, em relação às coortes menores (Figuras 2.62 e 2.63). Em todas as coortes, a biomassa dos Cyclopoida foi geralmente maior em relação aos Calanoida. Já quanto à produção, esse padrão foi invertido (Figura 2.63). De maneira geral, a contribuição dos copépodes da classe Harpacticoida foi pouco expressiva e concentrada no ano de 2009. 

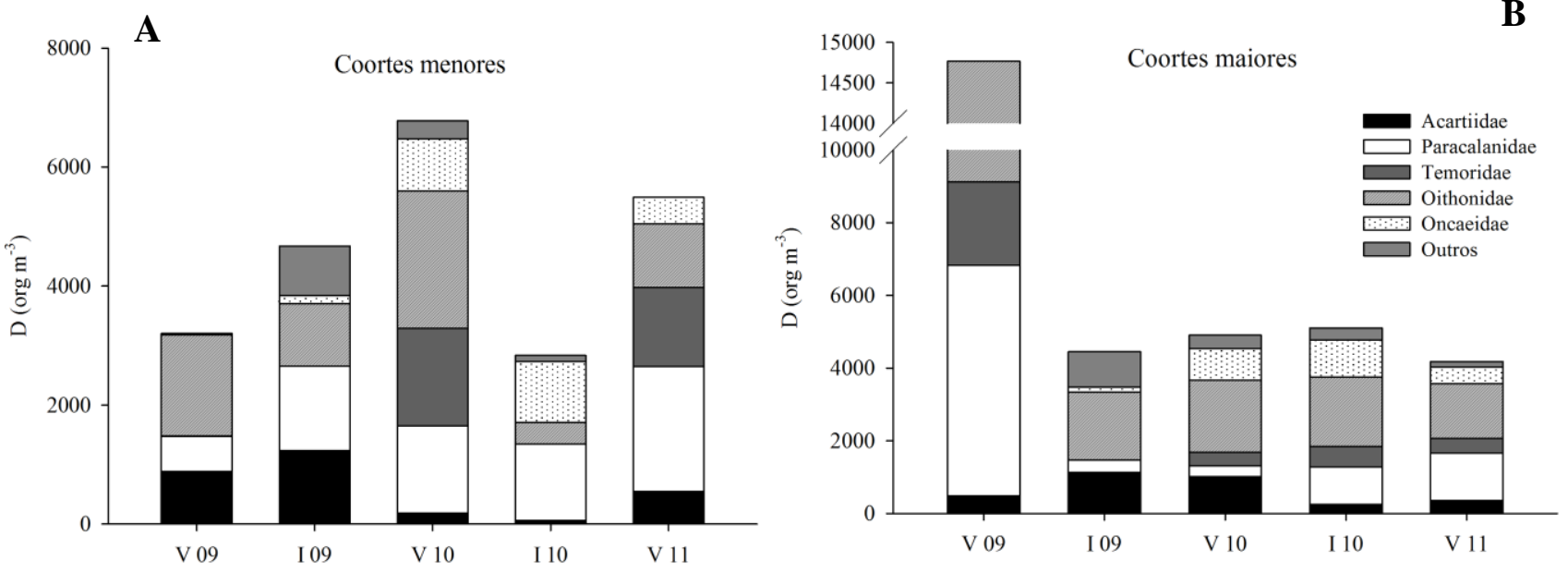

Figura 2.58: Densidade em org. $\mathrm{m}^{-3}$ de juvenis das principais famílias de copépodes pelágicos ao longo do período estudado para os animais utilizados nas coortes menores (A; capturados com rede de $20 \mu \mathrm{m}$ ) e coortes maiores (B; capturados com rede de $100 \mu \mathrm{m}$ ).
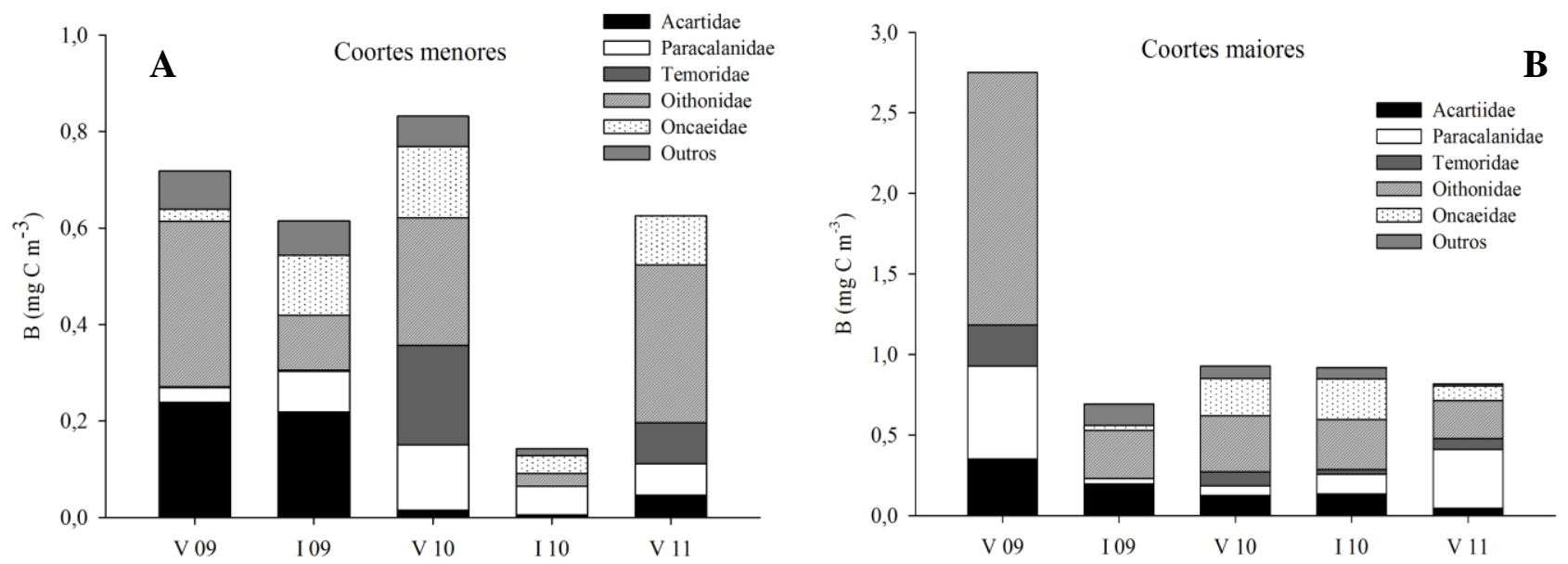

Figura 2.59: Biomassa em $\mathrm{mg} \mathrm{C} \mathrm{m}^{-3}$ de juvenis das principais famílias de copépodes pelágicos ao longo do período estudado para os animais utilizados nas coortes menores (A; capturados com rede de $20 \mu \mathrm{m}$ ) e coortes maiores (B; capturados com rede de $100 \mu \mathrm{m}$ ).
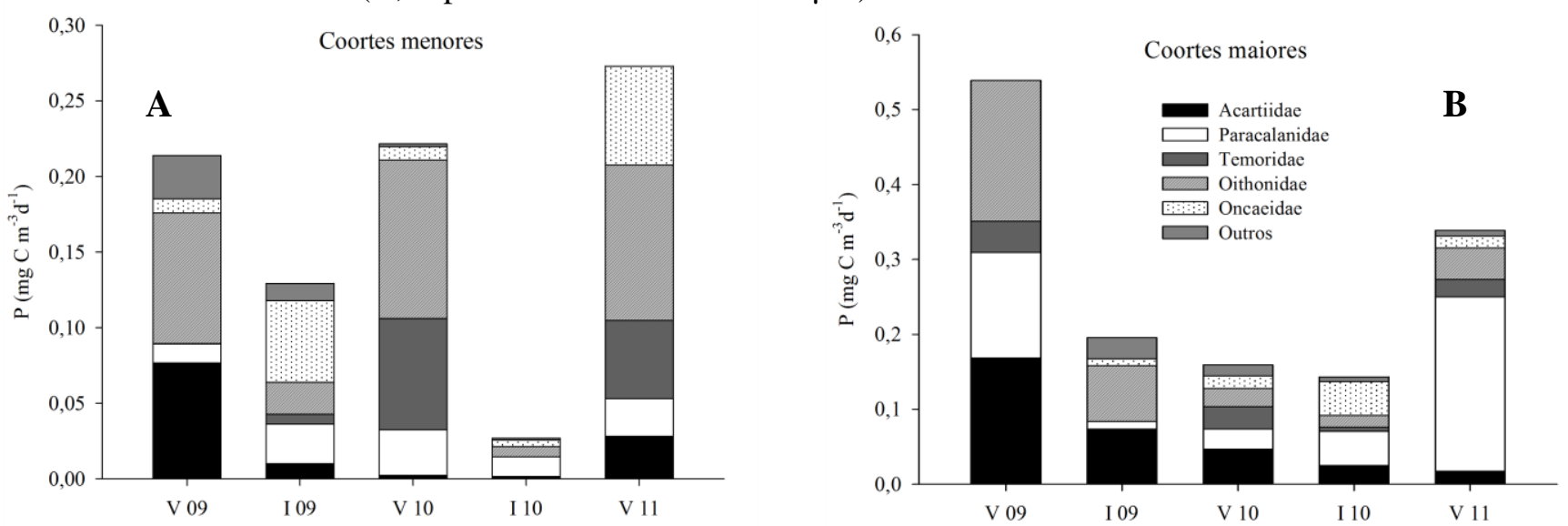

Figura 2.60: Produção em $\mathrm{mg} \mathrm{C} \mathrm{m}{ }^{-3} \cdot \mathrm{d}^{-1}$ de juvenis das principais famílias de copépodes pelágicos ao longo do período estudado para os animais utilizados nas coortes menores (A; capturados com rede de $20 \mu \mathrm{m}$ ) e coortes maiores (B; capturados com rede de $100 \mu \mathrm{m}$ ). 

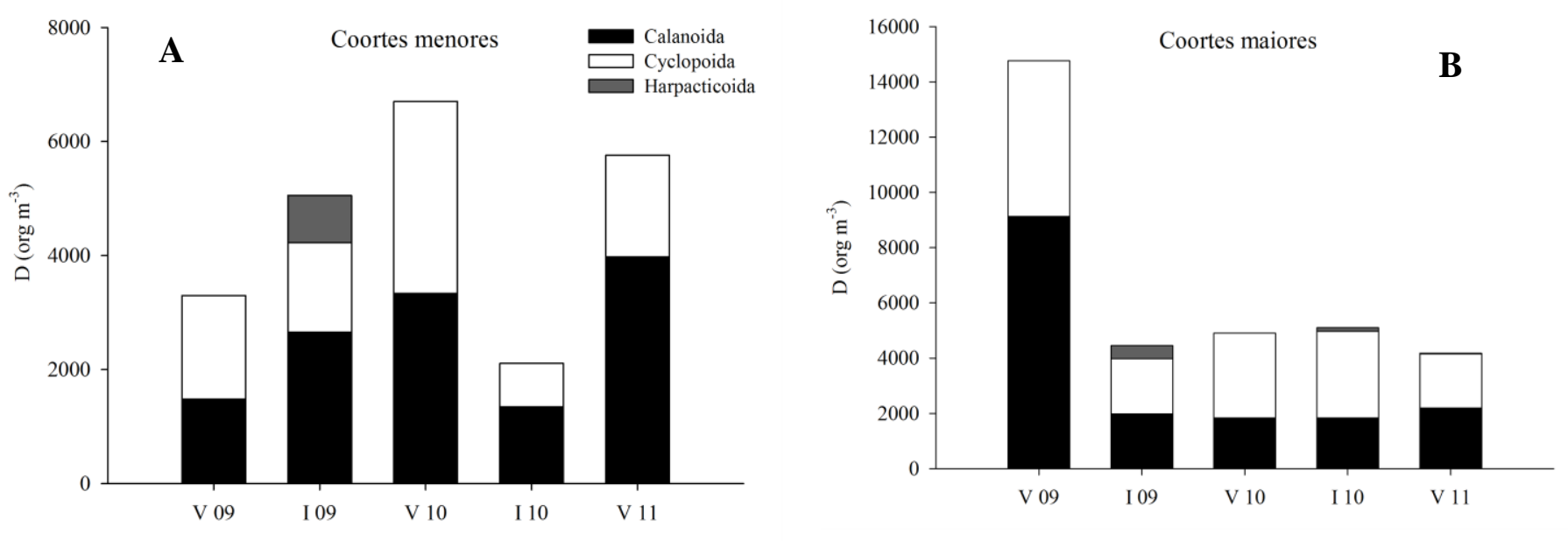

Figura 2.61: Densidade em org. $\mathrm{m}^{-3}$ de juvenis das três ordens de copépodes pelágicos ao longo do período estudado para os animais utilizados nas coortes menores (A; capturados com rede de $20 \mu \mathrm{m}$ ) e coortes maiores (B; capturados com rede de $100 \mu \mathrm{m}$ ).
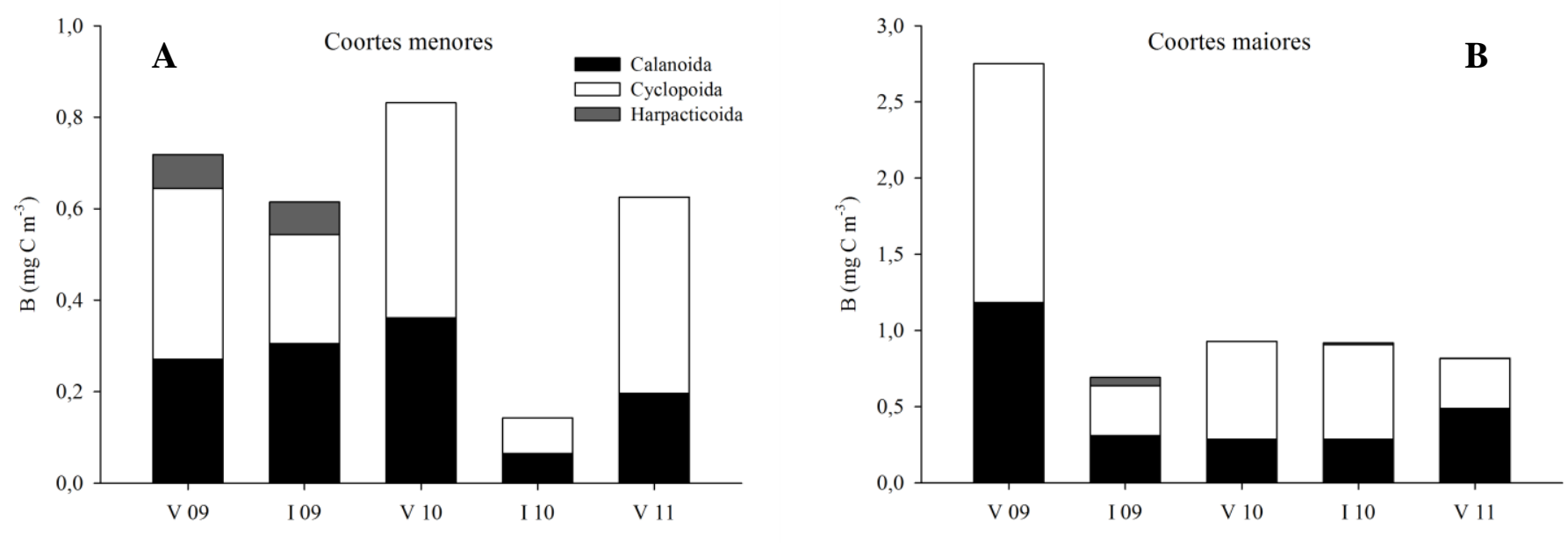

Figura 2.62: Biomassa em $\mathrm{mg} \mathrm{C} \mathrm{m}^{-3}$ de juvenis das três ordens de copépodes pelágicos ao longo do período estudado para os animais utilizados nas coortes menores (A; capturados com rede de $20 \mu \mathrm{m}$ ) e coortes maiores (B; capturados com rede de $100 \mu \mathrm{m}$ ).
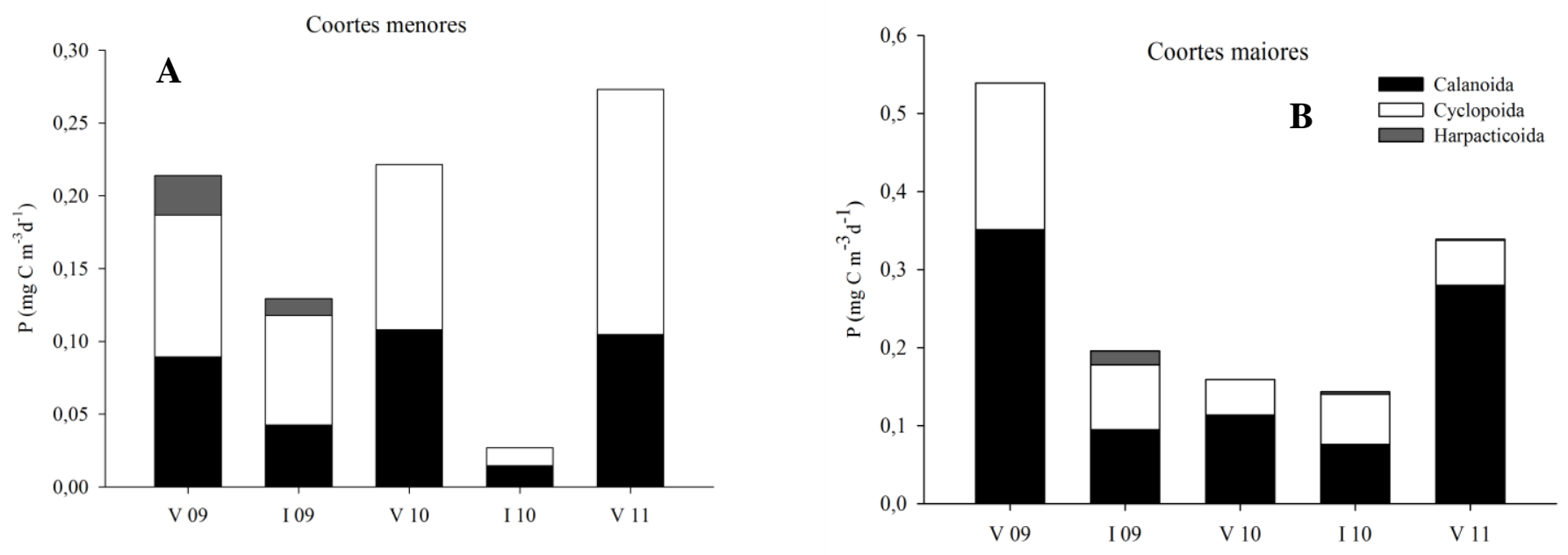

Figura 2.63: Produção em $\mathrm{mg} \mathrm{C} \mathrm{m} \mathrm{m}^{-3} \cdot \mathrm{d}^{-1}$ de juvenis das três ordens de copépodes pelágicos ao longo do período estudado para os animais utilizados nas coortes menores (A; capturados com rede de $20 \mu \mathrm{m}$ ) e coortes maiores (B; capturados com rede de $100 \mu \mathrm{m}$ ). 


\subsection{Discussão}

\subsubsection{Crescimento, biomassa e produção de estágios juvenis de copépodes no litoral brasileiro}

A densidade, biomassa, crescimento e produção de estágios juvenis de um total de 13 táxons de copépodes tropicais foram obtidos entre o verão de 2009 ao verão de 2011. Os organismos foram coletados em uma estação costeira fixa, no litoral norte do estado de São Paulo, um sistema subtropical de águas oligotróficas (Pires-Vanin, 2008).

Os dados de crescimento obtidos experimentalmente através do método de coortes artificiais para os juvenis de copépodes são inéditos para todo o litoral do Brasil, pois não existem publicações para a costa brasileira utilizando tal método (Tabela 2.11). Quanto à produção, raros trabalhos apresentaram algum resultado para estágios imaturos de copépodes de regiões tropicais (ver Tabela 2.12).

Melo-Júnior (2009) estimou a produção de copepoditos juvenis e adultos das espécies dominantes de uma estação fixa do litoral norte do estado de São Paulo, através de coletas com rede de $200 \mu \mathrm{m}$, a qual permitiu a evasão de náuplios e copepoditos de diversas espécies de menor tamanho. Para a plataforma adjacente ao complexo estuarino de Santos-Bertioga, também no estado de São Paulo, a produção dos copépodes pelágicos foi calculada através de estimativa do crescimento pelo modelo matemático de Huntley \& Lopez (1992) e Hirst \& Lampitt (1998) e equações de regressão comprimento x peso para determinação da biomassa (Miyashita et al., 2009). Foram utilizadas redes de 64 e $300 \mu \mathrm{m}$, o que possibilitou a coleta de grande parte do espectro de tamanho dos copépodes e o cálculo da produção dos estágios juvenis de copepoditos e também de alguns náuplios.

A biomassa e produção de copépodes também foram calculadas dentro do estuário supracitado por Bicalho (2010). Neste caso, a biomassa foi medida diretamente, enquanto que o crescimento foi estimado pelo modelo de Hirst \& Bunker (2003). A rede utilizada foi de $140 \mu \mathrm{m}$ de abertura da malha, coletando satisfatoriamente da maioria dos copepoditos, mas subestimando os náuplios e copepoditos I a III das famílias Oncaeidae, Oithonidae e Paracalanidae.

Magalhães et al. (2013) estimaram a variação diária da produção de Acartia tonsa e A. lilljeborgii em um estuário amazônico, mas boa parte dos copepoditos foi subestimada pelo tamanho da malha utilizada durante as coletas $(300 \mu \mathrm{m})$. Variações 
na produção da comunidade de copépodes entre estações do ano também foi avaliada pelos autores, mas novamente a maior parte dos juvenis foi descartada pelo método de coleta empregado (Magalhães et al., 2011). Ambos os trabalhos estimaram o crescimento através da equação global de Hirst \& Sheader (1997) e não calcularam dados de biomassa e produção de náuplios.

No estuário da lagoa dos Patos, no Rio Grande do Sul, a produção de copépodes também se estendeu aos estágios imaturos como copepoditos e náuplios. A produção naupliar foi considerada subestimada por Ávila et al. (2012), novamente devido ao tamanho das redes empregadas. Ainda para o sul do país, a produção de copepoditos (CI-VI) de Acartia tonsa foi monitorada durante o período de abril de 2009 a abril de 2010 (Muxagata et al., 2012), mas não foram registrados dados para os estágios naupliares.

Uma série de publicações explorou aspectos ecológicos de copépodes do estuário de Cananéia-Iguape, no litoral sul do estado de São Paulo. A variabilidade sazonal e diária da produção de Acartia lilljeborgii (Ara, 2001a), Euterpina acutifrons (Ara, 2001b), Temora turbinata (Ara, 2002) e comunidade de copépodes pelágicos em geral (Ara, 2004) foram estimadas através de métodos indiretos, tanto para determinação da biomassa por equações de regressão comprimento x peso (Ara, 2001c) quanto para o crescimento (Ikeda \& Motoda, 1978; Huntley \& Lopez, 1992; Hirst \& Sheader, 1997 ou Hirst \& Lampitt, 1998). Todos os trabalhos utilizaram rede de $150 \mu \mathrm{m}$ para a captura dos animais, subestimando os menores copepoditos.

A produção do copépode nerítico Calanoides carinatus foi estimada por Crété (2006) na plataforma continental sudeste do Brasil, entre a região de Ubatuba ao cabo de São Tomé. O trabalho utilizou equação de regressão comprimento x peso (Verheye, 1991) para estimativa da biomassa e modelos matemáticos para o crescimento (Huntley \& Lopez, 1992; Hirst \& Lampitt, 1998 e Hirst \& Bunker, 2003). Novamente, apenas os estágios de copepoditos foram considerados.

Vale ressaltar que todos esses trabalhos utilizaram modelos globais para obtenção do crescimento de copepoditos, exceto pela abordagem experimental enzimática de Ávila et al. (2011 e 2012). Os autores compararam os resultados de crescimento e produção através do método da quitobiase com os modelos tradicionais (Huntley \& Lopez, 1992 e Hirst \& Bunker, 2003) e notaram que os valores obtidos pelo método experimental foram geralmente maiores. 
Conclui-se que os dados sobre crescimento e produção de estágios naupliares ainda são escassos e foram subestimados nos dois únicos trabalhos em que foram descritos para a costa brasileira (Miyashita et al., 2009 e Ávila et al., 2012). Além disso, os dados de produção geralmente são fornecidos de maneira agrupada, impossibilitando a visualização da produção pelos estágios imaturos.

\subsubsection{Considerações sobre o método empregado}

Quaisquer métodos que requeiram a incubação do zooplâncton em micro ou mesocosmo em laboratório estão sujeitos aos efeitos da confinação e, em alguns casos, da manipulação. Em microcosmo, cuidado especial deve ser considerado quanto à disponibilidade de alimento, diminuição das taxas de grazing e crescimento bacteriano (Roman \& Rublee, 1980; Runge \& Hoff, 2000). A mortalidade também deve ser monitorada em diferentes momentos durante a incubação, sendo que experimentos ou réplicas com mortalidade elevada devem ser descartados (Kimmerer \& McKinnon, 1987).

As condições de laboratório devem ser as mais próximas possíveis do ambiente natural e o tempo de incubação estabelecido com base em observações prévias. Os experimentos realizados neste estudo foram limitados ao período máximo de 72 horas. Em alguns casos, foram considerados apenas os dados de crescimento para os períodos de 24 ou 48 horas. Tal decisão considerou como critério principal a linearidade da taxa de crescimento ao longo do período de incubação. Uma vez que o crescimento de juvenis de copépodes é considerado log-linear (Hirst et al., 2003; Kimmerer et al., 2007), desvios deste padrão foram considerados aqui como consequência do período de incubação e condições laboratoriais insatisfatórias para o crescimento normal dos copépodes.

A escolha por quatro classes de tamanho de coortes visou analisar um amplo espectro de tamanho e assim obter dados de crescimento para diversas espécies ou agrupamentos de copépodes e em diferentes estágios do desenvolvimento. Embora as coortes consistam no fracionamento dos organismos em categorias de tamanho, as mesmas podem ser eficientes para a separação dos táxons, especialmente em ambientes estuarinos ou temperados, onde a diversidade de espécies é menor (Liu \& Hopcroft, 2006 a e b). 
Neste trabalho, a diversidade de copépodes presentes nas coortes dificultou o cálculo de taxas de crescimento ao nível específico para alguns gêneros e famílias com morfologia semelhante, mas permitiu para outros onde a identificação dos estágios naupliares e primeiros copepoditos são mais evidentes morfologicamente como Temora turbinata e T. stylifera. Devido ao reduzido tamanho dos copépodes tropicais, as coortes empregadas amostraram adequadamente a diversidade de táxons e estágios de desenvolvimento. Vale ressaltar que diversas espécies estiveram presentes nas coortes (Clausocalanus furcatus, Subeucalanus pileatus e S. crassus, Candacia sp., entre outras listadas nas tabelas 1.3 à 1.5 do capítulo 1), mas o crescimento não foi calculado devido ao baixo número de indivíduos.

Os agrupamentos em gêneros ou famílias foram consequência do método empregado para obtenção do tamanho dos organismos. Todos os animais foram medidos através de fotografias, o que impede a visualização de diversos caracteres taxonômicos. Ao mesmo tempo, tais agrupamentos aceleraram a obtenção de dados morfométricos. A análise em nível específico precisa obrigatoriamente ser realizada em estereomicroscópio e microscópio, anteriormente às medições, mas consumiria um tempo excessivo para a identificação das espécies e estágios.

A técnica escolhida para estimativa da biomassa pode provocar erros ou maior variabilidade nos dados de produção. Kimmerer et al. (2007) revisaram dois métodos para o cálculo da produção zooplanctônica, com base nos dados de biomassa: a coorte artificial direta e a indireta. No primeiro caso, a biomassa média é medida diretamente, portanto eventuais diferenças nos valores são incluídas nos cálculos de produção. $\mathrm{O}$ tamanho e peso dos indivíduos, mesmo sendo todos de um mesmo estágio de desenvolvimento, são variáveis e tal método inclui essa variabilidade (Kimmerer et al., 2007).

A coorte artificial indireta estima a biomassa dos copépodes através das equações de regressão comprimento x peso, ou volume x peso. A estimativa indireta da biomassa através das regressões é amplamente utilizada, pois a variável é difícil de ser mensurada em espécies de pequeno porte, especialmente em estágios naupliares. Os indivíduos das amostras quantitativas não foram medidos neste estudo, tais medidas para estimativa da biomassa foram provenientes dos animais nos períodos iniciais dos experimentos, os quais foram submetidos pelo fracionamento de tamanho durante a elaboração das coortes.

As amostras quantitativas devem ser fracionadas nas mesmas classes de 
tamanho das coortes artificiais utilizadas nos experimentos. Após tal fracionamento, os náuplios e copepoditos das espécies que tiveram seu crescimento determinado devem ser quantificados e esses valores de densidade utilizados para o cálculo da biomassa. Tal procedimento deve ser realizado para aprimorar a estimativa, pois a densidade utilizada foi a da amostra quantitativa total e não corresponde necessariamente à densidade encontrada na fração de tamanho empregado numa determinada coorte. Em outras palavras, a densidade de náuplios ou copepoditos das amostras quantitativas pode ter sido significativamente maior e consequentemente sobrestimado a biomassa.

\subsubsection{Interações entre as variáveis controladas dos experimentos e as taxas de crescimento}

As variáveis ambientais e biológicas controladas nos experimentos neste estudo foram temperatura, salinidade, as concentrações de clorofila- $a$, feopigmentos e o número de organismos zooplanctônicos incubados. Cada uma delas foi testada quanto à relação com as taxas de crescimento para 11 táxons: Acartia spp., Paracalanus spp., Parvocalanus crassirostris, Temora turbinata, T. stylifera, Dioithona oculata, Oithona spp., O. plumifera, Oncaeidae, Corycaeidae e Euterpina acutifrons.

A temperatura é uma das principais variáveis que interfere no crescimento de animais pecilotérmicos, aumentando o consumo de oxigênio e as taxas metabólicas quando os valores de temperatura aumentam (Levinton, 2013). No caso dos copépodes a importância dessa variável é observada sobre as taxas de crescimento e tempo de desenvolvimento em inúmeras espécies (Vidal, 1980; Hart, 1990). Neste estudo, apenas três táxons resultaram em correlação positiva e significativa com a temperatura. Para as espécies onde a correlação não foi significativa, sugere-se que o baixo número amostral ou a baixa amplitude de valores de temperatura a qual o táxon foi submetido tenham gerado tal resultado.

A hipótese de que o gradiente de temperatura não tenha sido grande o suficiente para refletir nas taxas de crescimento se aplicaria a alguns táxons apenas. A temperatura testada nos diversos experimentos esteve entre 16 a $27,5^{\circ} \mathrm{C}$, o equivalente a $11,5^{\circ} \mathrm{C}$ de amplitude, o suficiente para incrementos significativos das taxas de crescimento, tempo de desenvolvimento e produção (Miller, 2004) e provavelmente resultar em diferenças significativas como as detectadas para Acartia spp., Temora turbinata e Euterpina 
acutifrons.

Contudo, algumas espécies não foram submetidas a tal amplitude de temperatura, como Pseudodiaptomus acutus e Diothona oculata, por exemplo, as quais foram medidas em poucos experimentos ou em baixa amplitude de temperatura entre esses experimentos.

Por tratar-se de uma estação costeira, a salinidade apresentou moderada variação, sendo que experimentos ocorreram em valores de salinidade entre 33 a 37 (Tabela 2.2). Porém, durante a maior parte do período amostral, a salinidade esteve entre 34 a 36, sendo que apenas um experimento foi realizado na salinidade de 33 (C15) e um na de 37 (C-6). Além dos valores extremos de 33 e 37 serem raros, as medidas foram realizadas com um refratômetro comum, um método de baixa precisão. Dessa maneira, a amplitude de valores de salinidade foi moderada a baixa, o que explica as correlações com o crescimento não serem significativas em nove dos onze táxons testados.

Correlação negativa e significativa só foi detectada em Paracalanus spp. e Temora turbinata. Este resultado pode ser explicado pela adaptabilidade às condições estuarinas por T. turbinata, uma espécie tipicamente eurihalina (Ara, 2002). A mesma hipótese pode ser aplicada para Paracalanus spp., que, embora represente um grupo de espécies, $P$. quasimodo, a dominante, é frequentemente encontrada em regiões externas de estuários e águas costeiras (Lopes, 1994; Melo-Júnior, 2009; Bicalho, 2010). Em resumo, valores mais baixos de salinidade $(<36)$ podem ter favorecido o crescimento das espécies citadas, adaptadas a tais condições.

No presente estudo, correlação significativa entre a concentração de clorofila- $a$ e o crescimento só ocorreu para Acartia spp., Paracalanus spp. e Parvocalanus crassirostris e foi sempre negativa. Uma vez que correlação positiva não foi encontrada, sugere-se que tal variável não foi um fator limitante para o crescimento dos juvenis nos experimentos. Os três casos de correlação negativa poderiam ser explicados pelo hábito alimentar das espécies: copépodes de águas tropicais ou oligotróficas possuem hábitos e modos alimentares diversificados. Os gêneros Acartia, Paracalanus e Parvocalanus podem ser considerados onívoros, fato que pode elucidar a correlação negativa entre o crescimento e a concentração de clorofila- $a$ (ver item 2.5.5 da discussão).

O nível de saturação de clorofila- $a$ para o crescimento de copépodes juvenis 
dispersores de ovos foi estimado em 0,6 mg.m ${ }^{-3}$ (Hirst \& Bunker, 2003). Esse valor é provavelmente menor para as espécies tropicais analisadas neste estudo, uma vez que a compilação dos autores é composta principalmente por copépodes da ordem Calanoida, de maiores dimensões. Todavia, optou-se por considerar tal valor para efeitos de visualização de possíveis situações onde a clorofila- $a$ pudesse ser limitante.

As concentrações médias de clorofila- $a$ dos experimentos foram inferiores a esse valor somente em C-1 (50-80 e 80-100 $\mu \mathrm{m}), \mathrm{C}-5, \mathrm{C}-8(150-200 \mu \mathrm{m})$ e C-14 a C-16 (ambas as coortes); portanto, a clorofila- $a$ só poderia ter limitado o crescimento nesses experimentos. Para o experimento $\mathrm{C}-1$, embora a concentração média do pigmento seja menor que $0,6 \mathrm{mg} \mathrm{m}^{-3}$, o valor encontrado no início da incubação foi de $1,53 \mathrm{mg} \mathrm{m}^{-3}$, possibilitando o crescimento sem prováveis restrições nutricionais, ao menos nas primeiras 24 horas da incubação. O mesmo ocorreu para o experimento C-8 (150-200 $\mu \mathrm{m})$, porém a quantidade inicial de clorofila- $a$ foi menor $\left(0,89 \mathrm{mg} \mathrm{m}^{-3}\right)$, e só atingiu valores abaixo de 0,6 $\mathrm{mg} \mathrm{m}^{-3}$ a partir do segundo dia de incubação (Figura 2.6).

Os experimentos C-14 a C-16 foram os únicos onde a concentração de clorofila$a$ sempre foi inferior ao nível de saturação. Os valores entre os tratamentos controle e experimental só foram diferentes para C-16, onde a clorofila- $a$ foi maior nos tratamentos controle (Tabela 2.5). Mesmo em casos onde a concentração de clorofila- $a$ foi menor que o nível de saturação, as taxas de crescimento da maioria dos táxons não sofreram reduções significativas. Para Acartia spp., Parvocalanus crassirostris, Paracalanus spp., Temora turbinata e T. stylifera, os menores valores médios de taxas de crescimento não estiveram relacionados com concentrações de clorofila menores que $0,6 \mathrm{mg} \mathrm{m}^{-3}$.

Ainda como exemplo de que a clorofila- $a$ não foi um fator limitante, os experimentos C-14 a C-16 apresentaram valores médios de crescimento semelhantes aos experimentos onde as concentrações dos pigmentos foram mais abundantes. Por fim, em águas tropicais na Jamaica, a clorofila- $a$ foi considerada limitante, contudo as concentrações estiveram entre 0,02 a $0,18 \mathrm{mg} \mathrm{m}^{-3}$ (Webber \& Roff, 1995), enquanto que neste estudo a amplitude foi de 0,16 a $2,77 \mathrm{mg} \mathrm{m}^{-3}$.

De maneira semelhante à clorofila- $a$, a correlação entre os feopigmentos e o crescimento só foi significativa em Acartia spp., Parvocalanus crassirostris e Temora turbinata. Os feopigmentos geralmente acompanharam o padrão de variação da 
clorofila- $a$. Em apenas um caso houve concentração crescente de feopigmentos, acompanhando o declínio da clorofila- $a$ ao longo do período de incubação (experimento C-7, Figura 2.6).

A quantidade de indivíduos incubados foi monitorada e avaliada, a fim de demonstrar se esta impôs limite ao crescimento dos organismos, ou seja, se a quantidade de animais confinados na garrafa foi alta ao ponto de causar situações como competição por alimento e mortalidade, de maneira que as taxas de crescimento diminuíssem. Tal variável só foi positivamente correlacionada para Dioithona oculata. Essa correlação foi inesperada e provavelmente causada por demais fatores externos, como uma possível cascata trófica com aumento na densidade dos protistas heterotróficos do nano- e microplâncton.

Não é possível afirmar neste estudo que a diminuição da concentração de clorofila- $a$ ocorrida em alguns experimentos seja consequência direta da predação do fitoplâncton por náuplios e copepoditos. A própria atividade alimentar e metabólica dos copépodes pode ter favorecido o crescimento do bacterioplâncton e fitoplâncton em alguns experimentos, através do sloppy feeding, excreção de compostos nitrogenados e difusão de matéria orgânica dissolvida através das pelotas fecais (Sommer et al., 2004; Møller, 2007; Perez-Aragon et al., 2011; Saba et al., 2011).

Para elucidar as interações tróficas ocorrendo durante as incubações, seria necessário controlar variáveis adicionais como a densidade de bacterioplâncton e protozooplâncton durante os intervalos experimentais, uma vez que náuplios e copepoditos podem se alimentar destes compartimentos (Turner \& Tester, 1992; Roff et al., 1995; Wu et al., 2010). Além disso, efeitos de cascata trófica entre o zooplâncton metazoário, protistas heterotróficos, fitoplâncton e bactérias deve ter sido comum durante os experimentos. Monitorar esses compartimentos tróficos poderia elucidar as relações ecológicas ocorrendo durante as incubações e o efeito das mesmas sobre o crescimento dos copépodes.

Apesar da variabilidade dos fatores controlados durante os experimentos, a linearidade do crescimento foi mantida até 72 ou 48 horas na maioria das incubações (42,8 \% até 72 horas e 30,2\% até 48 horas). Tal fenômeno poderia ser explicado por variações na duração dos estágios de desenvolvimento e tamanho dos organismos (Gusmão \& McKinnon, 2009 c). A mudança de comportamento alimentar durante o 
desenvolvimento pode aumentar a variabilidade encontrada no crescimento nos intervalos mais tardios da incubação ( $t 2$ e $t 3$ ). Os estágios de desenvolvimento mais tardios são mais limitados pela falta de alimento do que estágios anteriores (Peterson et al., 1991) cenário que pode ter ocorrido em alguns experimentos e contribuído para a falta de linearidade após o primeiro ou segundo dia.

\subsubsection{Aplicabilidade das equações globais da literatura}

Os modelos de estimativa da taxa de crescimento de Hirst \& Bunker (2003) foram utilizados e os valores obtidos comparados com os experimentais. Vale destacar que para todos os modelos globais, a maioria dos dados utilizados para a elaboração das equações advém de espécies de águas temperadas. Testar tais modelos é necessário para determinar a real aplicabilidade dos mesmos e se são representativos do crescimento in situ de copépodes de águas tropicais.

Embora os modelos de Hirst \& Bunker (2003) sejam os mais utilizados atualmente (Ara, 2004; Leandro et al., 2007; Muxagata et al., 2012), os mesmos foram considerados inadequados para os táxons e a região deste estudo. A maioria das regressões lineares não foi significativa. Mesmo nas espécies onde isso ocorreu, os coeficientes de correlação foram baixos. Em Acartia spp., Paracalanus spp. e Parvocalanus crassirostris, as relações foram inversamente proporcionais. Apenas para Oithona spp., a regressão foi diretamente proporcional entre o crescimento experimental e o estimado para a equação destinada a juvenis retentores de ovos (Hirst \& Bunker, 2003), resultado que pode ser reflexo de uma quantidade razoável de dados utilizados pelos autores para esse gênero em questão para a elaboração da equação.

A inadequação do modelo também pode ser explicada pela ausência de dados para espécies do Atlântico Sul Ocidental nos dados compilados em Hirst \& Bunker (2003). As equações foram elaboradas com base em um rico conjunto de dados, porém é representado basicamente por copépodes da ordem Calanoida de grande e médio porte. Com exceção do gênero Oithona, dados sobre outros copépodes das ordens Cyclopoida e Harpacticoida não foram utilizados na elaboração do modelo.

Quanto à estratégia alimentar, a maioria das espécies compiladas são preferencialmente herbívoras (Calanus spp., Calanoides carinatus). No presente estudo, diversos táxons da ordem Cyclopoida foram analisados, assim como diversas estratégias alimentares diferentes da herbivoria. De fato, para as espécies que possuem a dieta e 
hábitos alimentares descritos, a minoria é estritamente herbívora, um padrão já conhecido para copépodes pelágicos de águas tropicais oligotróficas (Turner, 2004).

Por exemplo, espécies da família Corycaeidae como Ditrichocorycaeus amazonicus e D. anglicus são predadores de estágios imaturos e até de adultos de outros copépodes (Turner et al., 1984; Landry et al., 1985). Os copépodes do gênero Oncaea apresentam uma gama de estratégias alimentares: utilizam matéria orgânica particulada como aparatos filtradores de apendiculários (Alldredge, 1972), neve marinha e colônias gelatinosas de fitoplâncton (Metz, 1998), pelotas fecais (Møller et al., 2011), além de que algumas espécies são predadoras de quetognátos e urocordados planctônicos (Go et al., 1998).

O modelo global leva em consideração à concentração de clorofila- $a$ como um índice da disponibilidade de alimento, porém, uma vez que tais copépodes não são herbívoros, tal variável não seria diretamente relevante para esses animais, o que explicaria a ineficácia do modelo. Representantes da família Oithonidae, por exemplo, são onívoros e importantes componentes da cadeia trófica microbiana, predando preferencialmente flagelados e ciliados heterotróficos, além dos pequenos produtores do microfitoplâncton (e.g. Castellani et al., 2005). Ainda, o gênero Oithona é considerado atualmente um dos mais importantes consumidores de pelotas fecais do zooplâncton (Registad et al., 2005; Gonzáles \& Smetacek, 1994).

A equação para juvenis retentores de ovos resultou em valores semelhantes de crescimento aos obtidos experimentalmente (Tabela 2.7). Tal resultado reforça a hipótese de que essa espécie se alimente de matéria orgânica particulada de pequeno diâmetro, uma vez que a equação para juvenis retentores de ovos não tem a concentração de clorofila- $a$ como fator limitante do crescimento (Hirst \& Bunker, 2003).

Mesmo entre os Calanoida, existem diversos exemplos de estratégias alimentares diferentes da herbivoria, o que faz com que a maioria dos táxons deste estudo seja considerada como onívora. A predação e canibalismo em copépodes da ordem Calanoida são reportados desde a década de 70 (Lonsdale et al., 1979). O gênero Temora, por exemplo, é comprovadamente onívoro, alimentando-se inclusive dos próprios ovos (Dam \& Lopes, 2003). Alguns representantes desta ordem também podem ingerir pelotas fecais desde os estágios naupliares (Green et al., 1992).

Copépodes geralmente considerados herbívoros como Parvocalanus crassirostris e o gênero Paracalanus spp., são frequentes consumidores do protista 
heterotrófico Sticholonche zanclea (Sant'Anna, 2013). O gênero Paracalanus foi recentemente classificado como onívoro, pois se alimenta preferencialmente de protistas heterotróficos durante o dia e de diatomáceas pela noite (Wu et al., 2010).

Corroborando com os resultados aqui descritos, Lopes (1997) não encontrou correlação entre as concentrações de clorofila- $a$ ambientais e nos tratos digestórios de copépodes Acartia lilljeborgii, Paracalanus quasimodo, Pseudodiaptomus acutus, Temora turbinata e $T$. stylifera. Tais resultados também indicam o comportamento onívoro desses copépodes e a alteração de hábitos alimentares relacionados com alterações no ambiente. A onivoria, considerada aqui como estratégia mais comum de alimentação para os copépodes estudados, e presença de dados de produção de ovos (crescimento reprodutivo, ao invés do somático) foram fatores que possivelmente explicam a inaplicabilidade dos modelos de Hirst \& Bunker (2003).

\subsubsection{Crescimento, biomassa e produção dos táxons considerados}

As taxas de crescimento não foram diferentes entre os quatro tamanhos de coortes empregadas, considerando todos os táxons analisados. Na maioria dos casos, as comparações não puderam ser realizadas para cada táxon isoladamente, devido ao número amostral geralmente baixo (Tabela 2.9).

As comparações entre crescimento, biomassa e produção de copépodes juvenis com outros autores foram estabelecidas quando possível. Em diversos casos, as publicações forneceram crescimento, biomassa e/ou produção apenas para adultos ou agruparam todos os estágios analisados. Já neste estudo, são fornecidos dados de juvenis, mas não dos estágios adultos. Ainda, o crescimento só foi determinado para os táxons dominantes, portanto, a produção fornecida aqui não é representativa de toda a comunidade de copépodes, pois houve a exclusão dos táxons raros ou esporádicos. Devido ao reduzido número de trabalhos sobre crescimento e produção em águas tropicais, as comparações foram realizadas com autores que utilizaram diferentes metodologias (Tabela 2.12).

O crescimento médio de Acartia spp. ao longo dos experimentos foi de $0,37 \pm$ $0,23 \mathrm{~d}^{-1}$. A produção foi estimada em $0,066 \pm 0,061 \mathrm{mg} \mathrm{C} \cdot \mathrm{m}^{-3} \mathrm{~d}^{-1}$ para as coortes de 100 150 e 150-200 $\mu \mathrm{m}$. Muxagata et al. (2012) encontraram uma produção média de 1,28 $\mathrm{mg} \mathrm{C} \mathrm{m} \mathrm{m}^{-3} \mathrm{~d}^{-1}$ para os copepoditos I a V de Acartia tonsa em estuário no litoral do Rio Grande do Sul, valor cerca de duas vezes superior à produção dos adultos. Já a produção 
de Acartia lilljeborgii (CI a C VI) para o estuário de Cananéia, litoral sul do Estado de São Paulo variou entre 0,18 a 1,05 mg C.m $\mathrm{m}^{-3} \mathrm{~d}^{-1}$ (Ara, 2001 a).

Os valores demasiadamente altos encontrados pelos autores citados em relação a este estudo possuem a seguinte explicação: as coortes empregadas aqui determinam o crescimento de estágios de desenvolvimento muito menores do que de outros estudos, desconsiderando a produção de adultos.

O crescimento obtido para Paracalanus spp. e Oithona plumifera foram semelhantes ou pouco menores do que os encontrados para copepoditos (CI-VI) de Clausocalanus/Paracalanus e O. plumifera respectivamente por Webber \& Roff (1995) em águas tropicais na Jamaica. Valores elevados de crescimento para Paracalanus spp. nas coortes de 100-150 $\mu \mathrm{m}$ deste estudo também são similares aos encontrados em Webber \& Roff (1995) para os copepoditos do gênero.

O crescimento e produção para copepoditos das espécies de pequeno porte dos Calanoida foi de $0,47 \pm 0,03 \mathrm{~d}^{-1}$ e $0,054 \mathrm{mg} \mathrm{C} \mathrm{m}^{-3}$ para a primavera e $0,5 \pm 0,08 \mathrm{~d}^{-1} \mathrm{e}$ $0,096 \mathrm{mg} \mathrm{C} \mathrm{m}^{-3}$ para o verão na plataforma adjacente à baixada santista (Miyashita $e t$ $a l ., 2009)$. Os valores de crescimento para copepoditos juvenis de Oncaea spp. também foram semelhantes aos descritos aqui, entretanto, a produção foi cerca de uma ordem de grandeza superior na baixada santista. Já para copepoditos de Oithona spp., o crescimento foi praticamente o dobro, embora a produção tenha sido inferior à metade do registrado aqui. Os valores obtidos por modelos em Miyashita et al (2009) podem ter subestimado a produção calculada na plataforma adjacente a Santos para o gênero em questão. É importante destacar que os dados fornecidos pelos autores foram para copepoditos (CI-V), enquanto que aqui foram utilizadas classes de tamanho, incluindo náuplios.

O crescimento dos estágios juvenis é geralmente maior do que de adultos. Tal tendência também é visualizada aqui, quando comparados os valores deste estudo com o crescimento reprodutivo de adultos de táxons semelhantes para a mesma região (MeloJúnior, 2009; Melo-Júnior et al., 2013). O crescimento somático dos juvenis foi cerca de uma ordem de grandeza superior (10 a 20 vezes) ao reprodutivo dos adultos de espécies dispersoras de ovos. Para as espécies retentoras, tal diferença foi menos acentuada, sendo o crescimento dos juvenis entre três a dez vezes superior ao crescimento reprodutivo de adultos.

Taxas de crescimento relativamente baixas são comuns entre os copépodes da família Oithonidae, tanto o crescimento somático, quanto o reprodutivo (Paffenhöfer, 
1993; McKinnon \& Duggan, 2003; Melo-Júnior, 2009; Gould \& Kimmerer, 2010; Temperoni et al., 2011). Os resultados do presente estudo confirmam esse padrão. A partir dos exemplos acima e dados da tabela 2.11, é provável que o crescimento de estágios imaturos de copépodes tropicais ocorra em um intervalo de valores relativamente estreito, entre 0,2 a $0,6 \mathrm{~d}^{-1}$ na grande maioria dos casos, sendo que os resultados descritos aqui estão em acordo com os encontrados na literatura para águas tropicais.

A produção de juvenis de copépodes pelágicos foi considerada baixa no presente estudo, mas foi semelhante aos valores registrados previamente para águas tropicais costeiras (Tabela 2.12). Destaca-se que espécies que foram ausentes nos experimentos, ou que estiveram presentes em quantidade muito baixa, não tiveram suas taxas de crescimento calculadas. Tais espécies não foram adicionados no cálculo da produção neste estudo e, portanto, a produção deve ser mais elevada. Acredita-se também que a produção na região possa ser maior, integrando dados de diferentes profundidades. As coletas realizadas em águas superficiais e durante o dia podem ter resultado em menores valores de densidade e biomassa no presente trabalho, por exclusão de espécies que realizem migração vertical.

Por fim, a região de Ubatuba é considerada oligotrófica a maior parte do tempo, mas a produção de copépodes foi maior do que em outras áreas tropicais com concentrações inferiores de clorofila- $a$ (Webber \& Roff, 1995; McKinnon \& Duggan, 2003). É provável que o crescimento dos estágios juvenis de copépodes não esteja limitado por recursos alimentares em Ubatuba. Além do fato das concentrações de clorofila- $a$ serem superiores ao nível de saturação do crescimento de $0,6 \mathrm{mg} \mathrm{m}^{-3}$ calculado por Hirst \& Bunker (2003) para espécies dispersoras, diversos estágios juvenis de copépodes tropicais provavelmente são onívoros (Turner \& Tester, 1992), sem depender exclusivamente dos estoques de fitoplâncton. 
Tabela 2.11: Taxas de crescimento de copépodes obtidas através do método de coorte artificial descrito por Kimmerer \& McKinnon (1987) para ambientes de águas tropicais e subtropicais. T: temperatura ambiental ou experimental de incubação. H: período de incubação em horas. Biomassa D: direta; ID: indireta.

\begin{tabular}{|c|c|c|c|c|c|}
\hline $\begin{array}{l}\text { Localização } \\
\text { Espécies }\end{array}$ & $\mathbf{T}\left({ }^{\circ} \mathbf{C}\right)$ & $\begin{array}{l}\text { Estimativa } \\
\text { da } \\
\text { Biomassa }\end{array}$ & $\begin{array}{l}\text { Taxa de } \\
\text { crescimento } \\
\quad\left(d^{-1}\right)\end{array}$ & $\mathbf{H}(\mathbf{h})$ & Fonte \\
\hline $\begin{array}{r}\text { Austrália } \\
\text { Acartia fancetti } *^{*}\end{array}$ & $11-22$ & $\mathrm{D}$ & $0,025-0,26$ & $26-50$ & $\begin{array}{c}\text { Kimmerer \& } \\
\text { McKinnon (1987) }\end{array}$ \\
\hline $\begin{array}{l}\underline{\text { Jamaica }} \\
\text { Acartia spp. }\end{array}$ & 28 & ID & $0,25-1,43$ & 120 & Hopcroft et al. $(1998 b)$ \\
\hline$\underline{\text { Jamaica }}$ & \multirow{8}{*}{28} & \multirow{8}{*}{ ID } & $0,25-1,43$ & & \multirow{8}{*}{$\begin{array}{l}\text { Hopcroft \& Roff }(1998 \\
\qquad a, b)\end{array}$} \\
\hline Centropages velificatus & & & $0,7-1,0$ & & \\
\hline Paracalanus aculeatus & & & $0,25-1,26$ & & \\
\hline $\begin{array}{l}\text { Parvocalanus } \\
\text { crassirostris }\end{array}$ & & & & 120 & \\
\hline Temora turbinata & & & $0,34-1,23$ & & \\
\hline Corycaeus spp. & & & $0,1-0,36$ & & \\
\hline Oithona nana & & & $0,4-0,91$ & & \\
\hline O. simplex & & & $0,17-0,53$ & & \\
\hline $\begin{array}{r}\text { Agulhas bank } \\
\text { Calanus agulhensis }\end{array}$ & $17-18$ & ID & $0,19-0,46$ & 24 & $\begin{array}{l}\text { Peterson \& Hutchings } \\
\quad(1995)\end{array}$ \\
\hline \multirow{3}{*}{$\begin{array}{l}\text { Oceano Índico } \\
\text { Guilda de Calanoida } \\
\text { Guilda de Cyclopoida }\end{array}$} & \multirow{3}{*}{$21-31$} & \multirow{3}{*}{ ID } & C: 0,38 & 48 & \multirow{3}{*}{$\begin{array}{c}\text { McKinnon \& Duggan } \\
\text { (2003) }\end{array}$} \\
\hline & & & $\begin{array}{l}\mathrm{N}: 0,43 \\
\mathrm{C}: 0,28\end{array}$ & $\begin{array}{l}24 \\
48\end{array}$ & \\
\hline & & & $\mathrm{N}: 0,38$ & 24 & \\
\hline $\begin{array}{l}\text { Grande Barreira de Corais } \\
\text { Guilda de Calanoida } \\
\text { Guilda de Cyclopoida }\end{array}$ & $22-30$ & ID & $\begin{array}{l}\text { C: } 0,12-0,53 \\
\text { C: } 0,16-0,48\end{array}$ & 48 & McKinnon et al. (2005) \\
\hline
\end{tabular}


Tabela 2.11 (continuação): Taxas de crescimento obtidas através do método de coorte artificial descrito por Kimmerer \& McKinnon (1987) para ambientes de águas tropicais e subtropicais. T: temperatura ambiental ou experimental de incubação. H: período de incubação em horas. N: apenas estágios naupliares; C: apenas estágios de copepoditos CI à CV. Biomassa D: direta; ID: indireta.

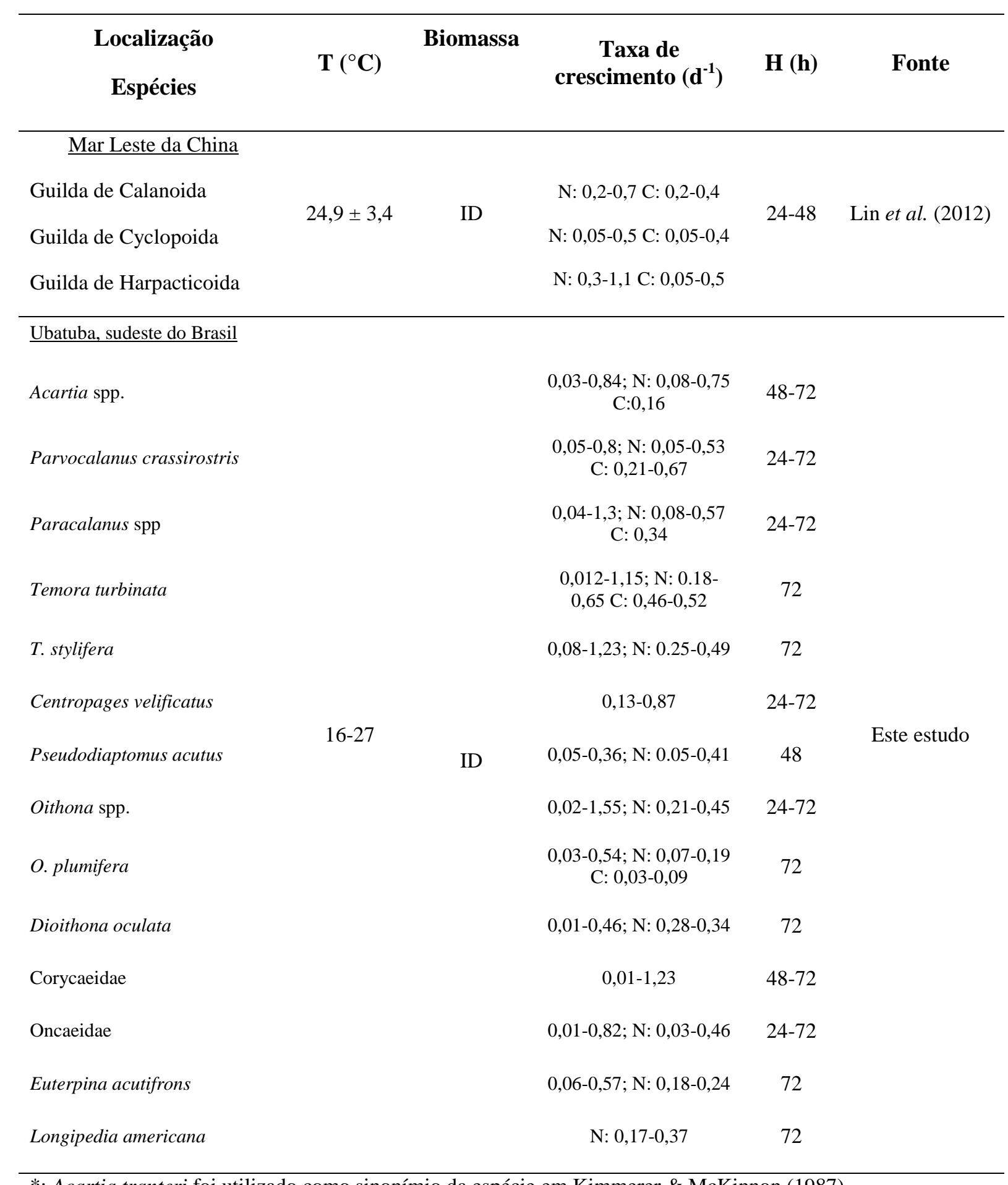

*: Acartia tranteri foi utilizado como sinonímio da espécie em Kimmerer \& McKinnon (1987). 
Tabela 2.12: Comparação entre a produção média de copépodes pelágicos imaturos para Ubatuba e demais ecossistemas tropicais e subtropicais. Métodos utilizados para determinar o crescimento: CA: coortes artificiais; C.I.: crescimento instantâneo; Enz.: métodos enzimáticos; H\&B: modelos de Hirst \& Bunker (2003); H\&L: modelo de Hirst \& Lampitt (1998); H\&Lz: modelo de Huntley \& Lopez (1992). *: dados apenas para juvenis de Oithonidae, Oncaeidae e Calanoida de pequeno porte. N.F.: dados não fornecidos isoladamente para os estágios imaturos. **: produção total do zooplâncton capturado pela rede de $90 \mu \mathrm{m}$, contando com adultos. ***: dados convertidos para $m g \mathrm{C} \mathrm{m}^{-3} \mathrm{~d}^{-1}$.

\begin{tabular}{|c|c|c|c|}
\hline Local & 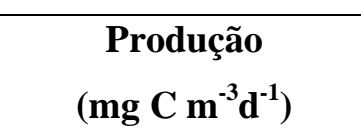 & Método & Fonte \\
\hline North West Cape, Australia & 0,42 & C.A. & $\begin{array}{c}\text { McKinnon \& Duggan } \\
\text { (2003) }\end{array}$ \\
\hline $\begin{array}{l}\text { Australia (Acrocalanus } \\
\text { gracilis) }\end{array}$ & 0,032 & C.A. & $\begin{array}{c}\text { Gusmão \& McKinnon } \\
\text { (2009 c) }\end{array}$ \\
\hline $\begin{array}{l}\text { Plataforma adjacente à } \\
\text { Santos, Brasil* }\end{array}$ & $\begin{array}{c}\text { 0,228 (primavera) } \\
0,418 \text { (verão) }\end{array}$ & H\&Lz; H\&L & Miyashita et al. (2009) \\
\hline Plataforma interna & $\begin{array}{c}0,8 \pm 0,82 \text { (dispersoras) } \\
0,08 \text { (rententoras) }\end{array}$ & $\mathrm{H} \& \mathrm{~B}$ & Melo-Júnior (2009) \\
\hline Estuário Santos-Bertioga & N.F. & $\mathrm{H} \& \mathrm{~B}$ & Bicalho (2010) \\
\hline Ubatuba, Brasil & 0,45 & C.A. & Este estudo \\
\hline Estuário Lago dos Patos** & 4,71 & Enz. & Ávila et al. (2012) \\
\hline Discovery Bay, Jamaica*** & $0,015-0,52$ & C.I. & Webber \& Roff (1995) \\
\hline Kingstor harbour, Jamaica ${ }^{* * *}$ & 3,44 & C.I. & Hopcroft et al., 1998 \\
\hline
\end{tabular}




\subsection{Conclusões}

- O método de coortes artificiais mostrou-se eficiente para a obtenção de taxas de crescimento de estágios juvenis de copépodes dominantes da comunidade, sendo que um total de 14 táxons foram estudados (Calanoida: 7; Cyclopoida: 5 e Harpacticoida: 2).

- A concentração de clorofila- $a$ não foi considerada limitante para o crescimento dos estágios juvenis de copépodes para a região de estudo, indicando a importância de outros recursos alimentares além do fitoplâncton para as espécies estudadas.

- Os valores médios para as taxas de crescimento entre os quatro tamanhos de coortes utilizados foram semelhantes, não havendo diferença significativa entre os grupos.

- Copépodes da ordem Calanoida geralmente tiveram taxas de crescimento superiores e menor variabilidade, quando comparados aos Cyclopoida e Harpacticoida.

- O crescimento obtido experimentalmente foi diferente do obtido pelos modelos globais para a maioria das espécies, sugerindo a não aplicabilidade do modelo para a região estudada.

- As taxas de crescimento dos principais táxons estudados foram semelhantes à de espécies de outras regiões tropicais, como em águas australianas e jamaicanas.

- A biomassa e a produção foram geralmente mais elevadas nas coortes maiores (100-150, 150-200 $\mu \mathrm{m})$, em relação às coortes menores $(50-80,80-100 \mu \mathrm{m})$.

- As famílias de maior contribuição para a biomassa foram Oithonidae, Paracalanidae e Acartiidae, enquanto que para a produção as famílias Oithonidae e Temoridae foram as mais importantes.

- A produção de estágios imaturos de copépodes no presente estudo $(0,45 \mathrm{mg} \mathrm{C}$ $\mathrm{m}^{-3} \mathrm{~d}^{-1}$ ) foi semelhante a de outras áreas tropicais, porém o cálculo é subestimado pois os táxons raros, ausentes nos experimentos, não foram contabilizados nesta estimativa. 
Capítulo 3

Incidência do parasita Ellobiopsis sp. (Alveolata) sobre copépodes planctônicos de uma região costeira subtropical 


\section{Capítulo 3. Incidência do parasita Ellobiopsis sp. (Alveolata) sobre copépodes planctônicos de uma região costeira subtropical}

\section{Resumo}

Em relações simbióticas, o hospedeiro é definido como o organismo provedor de recursos, enquanto que os simbiontes são os consumidores de tais recursos e podem fornecer serviços ecológicos em troca. Muitas das relações de simbiose são classificadas como parasitismo, onde os parasitas causam efeitos adversos e até mesmo a mortalidade dos hospedeiros. O presente trabalho teve como finalidade determinar a frequência relativa e estimar dados quantitativos da infecção do protista alveolado do gênero Ellobiopsis sobre as populações dos seguintes copépodes marinhos: Parvocalanus crassirostris, Paracalanus spp., Acartia lilljeborgii e Oithona spp., além de sugerir os possíveis efeitos do parasita sobre o tamanho e crescimento do hospedeiro. Amostras de plâncton foram obtidas em Ubatuba, litoral norte do estado de São Paulo, Brasil, uma área subtropical de águas predominantemente oligotróficas. O plâncton foi amostrado durante os anos de 2009 e 2010 (verão e inverno) e o verão de 2011 com rede de malha equivalente a $100 \mu \mathrm{m}$ equipada com fluxômetro e as amostras fixadas em formol $4 \%$ diluído em água do mar filtrada. Amostras quantitativas foram utilizadas para estimar a densidade do zooplâncton e amostras qualitativas para obtenção de medidas morfométricas dos parasitas e hospedeiros e das frequências relativas de copépodes parasitados em diferentes estágios de desenvolvimento e sexo (copepoditos juvenis, fêmeas e machos adultos). Foram inspecionados 7.934 exemplares de copépodes da família Paracalanidae: 4.014 Paracalanus spp. (22 indivíduos infectados) e 3.920 P. crassirostris (98 exemplares infectados). Ellobiopsis sp. também foi detectado no gênero Oithona e em A. lilljeborgii, porém essas ocorrências foram raras (cerca de $0,05 \%$ para ambas as espécies). A maior quantidade de parasitas foi observada nas peças bucais $(38,6 \%)$, seguido das antenas $(35 \%)$, sendo que até quatro protistas foram observados em um mesmo copépode. Observou-se maior quantidade de adultos infectados comparados aos copepoditos juvenis. Entre os adultos, as fêmeas foram as mais infectadas, chegando a $5 \%$ de infecção para $P$. crassirostris. É provável que o parasita influencie negativamente a taxa de crescimento dos hospedeiros, uma vez que fêmeas adultas parasitadas foram significativamente menores do que as normais. As fêmeas de copépodes calanóides geralmente são maiores e vivem por mais tempo que os machos, características que explicariam a maior frequência de infestação em fêmeas adultas.

Palavras chave: Parasitismo, Parvocalanus crassirostris, Paracalanus, Ellobiopsidae, Atlântico Sul, Ubatuba. 


\title{
Chapter 3: Incidence of Ellobiopsis sp. (Alveolata) parasites on planktonic copepods in a subtropical coastal region
}

\begin{abstract}
In symbiotic relationships, the host organism is defined as the provider of resources, while the symbionts are the consumers of such resources, and may provide ecological services in return. Many of the symbiotic relationships are classified as parasitism, where parasites may cause adverse effects in its hosts, and eventually leading to its death. The main scope of this study was to determine the relative frequency and estimate field density for Parvocalanus crassirostris, Paracalanus spp., Acartia lilljeborgii and Oithona spp. populations infected by the alveolate protist Ellobiopsis sp., and to suggest the possible effects of the parasite on the host's size and growth. Plankton samples were collected at Ubatuba, located at the north coast of the São Paulo state, Brazil, between 2009 and 2011 (summer and winter, except for 2011 sampled only during the austral summer). Plankton was collected by $100 \mu \mathrm{m}$ mesh net equipped with calibrated flowmeter and the samples were fixed by $4 \%$ formaldehyde filtered seawater solution. Zooplankton density was estimated from the quantitative samples, while relative frequencies of the infected copepods by sex and developmental stages (copepodids, female and male adults), as well as morphometric data from the hosts and parasites, obtained from the qualitative samples. From a total of 7,934 inspected paracalanid individuals, 4,014 were Paracalanus spp. (22 infected) and 3,920 were $P$. crassirostris (98 infected). Ellobiopsis sp. was also found in association with Oithona spp. and A. lilljeborgii, but these occurrences were rare (about $0,05 \%$ for both taxa). Parasites were frequently found attached to mouth appendages (38.6\%), followed by antennae (35\%), and up to four Ellobiopsis sp. were found per copepod. Adults were more infected than juvenile copepodids, as well as adult females were more infected than males, reaching 5\% for females of $P$. crassirostris. It is possible that the parasite as a negative influence on copepod growth rates, since infected females were significantly smaller than the normal ones. Females of calanoid copepods are generally bigger and live longer than males, facts that would explain the higher frequency of infection on adult females.
\end{abstract}

Keywords: parasitism, Parvocalanus crassirostris, Paracalanus, Ellobiopsidae, South Atlantic, Ubatuba. 


\subsection{Introdução}

Em relações simbióticas, o hospedeiro é definido como o organismo provedor de recursos, enquanto que os simbiontes são os organismos consumidores de tais recursos e podem fornecer ou não serviços ecológicos ao hospedeiro (Leung \& Poulin, 2008). Os simbiontes considerados como parasitas causam efeitos adversos no metabolismo do hospedeiro quando utilizam tais recursos, afetando negativamente as taxas de ingestão, respiração, crescimento, reprodução e, em última instância, causando a morte do organismo.

Os copépodes são os metazoários numericamente dominantes em ambientes marinhos (Schminke, 2007), onde são vitais para os processos de produção secundária e transferência de energia para níveis tróficos superiores (Runge, 1988). Entre as relações de simbiose envolvendo copépodes, relata-se desde a associação a bactérias como Vibrio cholerae (Huq et al., 1983; Martinelli-Filho, et al. 2011, entre outros) a diversos protistas (e.g. Alves-de-Souza et al., 2011) e até outros crustáceos, como os isópodes epicarídeos (Willians \& An, 2009).

Dentre os protistas simbiontes observados em copépodes, destacam-se as diatomáceas, ciliados, foraminíferos, protistas ameboides e coanoflagelados. Os Ciliophora e outros Alveolata são os grupos predominantes e mais diversificados de protistas associados aos crustáceos (Carman \& Dobbs, 1997).

O ciclo de vida dos copépodes é influenciado por protistas parasitas, os quais podem ser determinantes para a diferenciação sexual durante os últimos estágios de desenvolvimento (Marshall \& Orr, 1955; Conover, 1956; Turner et al. 1979). Além de efeitos como a mudança de sexo, os parasitas podem afetar as taxas reprodutivas e metabólicas dos copépodes hospedeiros (Théodoridès, 1989). Um exemplo do impacto de protistas parasitas em copépodes é o efeito negativo sobre a fecundidade dos hospedeiros (Albaina \& Irigoien, 2006). A fecundidade em fêmeas de Calanus helgolandicus foi negativamente afetada pela infecção por Ellobiopsis sp., sendo que $6,8 \%$ de fêmeas estiveram parasitadas.

O gênero Ellobiopsis é comumente encontrado parasitando copépodes e já foi classificado como um dinoflagelado aclorofilado parasita (Chatton, 1920), como um protista incertae sedis dentro dos Flagellata (Hovasse, 1926) ou ainda como um fungo 
(Jepps, 1937). O táxon possui representantes descritos para o oceano Atlântico (Steuer, 1932) e mar Mediterrâneo (Caullery, 1910; Hovasse, 1952). Apesar da ampla distribuição em ambientes e hospedeiros, apenas três espécies foram descritas até o momento: E. chattoni, E. fagei e E. elongata.

Os elobiopsídeos atualmente compõem um grupo denominado de Ellobiopsea, um agrupamento monofilético divergente dentro dos Alveolata, composto pelos gêneros Ellobiopsis e Thalassomyces (Gómez et al., 2009). O gênero Ellobiopsis parece não ter alta especificidade de hospedeiros. A espécie E. chattoni, por exemplo, foi relatada infectando pelo menos 25 espécies de copépodes pelágicos e larvas do caranguejo Portunus sp. (Shields, 1994).

Tais parasitas são organismos multinucleados onde o corpo celular é dividido em trofômero e gonômero. $\mathrm{O}$ trofômero representa a fase vegetativa da célula e possui uma raiz de absorção que penetra no tecido do hospedeiro, enquanto que o gonômero, onde ocorre a esporulação, se desenvolve distalmente ao trofômero (Jepps, 1937). Em Ellobiopsis, tanto o trofômero, quanto o gonômero crescem externamente ao corpo do hospedeiro (Shields, 1994).

O ciclo de vida de Ellobiopsis é iniciado durante a dispersão dos esporos. Alguns indivíduos se associam à base de cerdas em apêndices dos hospedeiros, onde se desenvolvem e geram o trofômero. Uma organela semelhante a uma raiz cresce externamente ao corpo do copépode e o trofômero se desenvolve na extremidade distal. Quando a célula atinge a maturidade, uma constrição celular transversal dá origem ao gonômero, de aspecto granular devido à formação de esporos. A motilidade dos esporos e os mecanismos de dispersão ainda são desconhecidos (Gómez et al., 2009).

Dados quantitativos sobre a infecção de copépodes por elobiopsídeos foram raramente obtidos. Alguns estudos em águas continentais reportaram, além do protista, a ocorrência de protusões teciduais causadas pelo parasita em adultos do copépode calanóide Eudiaptomus padanus e no ciclopóide Cyclops abyssorum (Bridgeman et al., 2000; Manca et al., 2004). A determinação das espécies que ocorrem em águas continentais ainda é incerta, mas não se tratam do gênero Ellobiopsis (Skovgaard, 2004). Tais protusões não foram observadas em copépodes marinhos infectados por elobiopsídeos, onde ao invés das lesões, foram reportadas as células do parasita 
crescendo externamente ao hospedeiro (Steuer, 1932; Skovgaard, 2004; Albaina \& Iriogoien, 2006; Konovalova, 2008; Gómez et al., 2009).

O parasita Ellobiopsis sp. foi registrado nos copépodes Parvocalanus scotii, Paracalanus quasimodo, Temora turbinata, Acartia lilljeborgii, Pseudodiaptomus acutus e Oithona hebes para o litoral sudeste do Brasil (Bicalho, 2008), porém dados quantitativos como a frequência de ocorrência de indivíduos parasitados ainda são inexistentes para a costa brasileira.

A especificidade de hospedeiros e o impacto ecológico de Ellobiopsis sobre as populações de copépodes são pouco conhecidos. Embora alguns estudos, como a própria descrição taxonômica de E. ellongata, tenha ocorrido no Atlântico Sul (Steuer, 1932), pouco se sabe sobre a distribuição, frequência de ocorrência e densidade do parasita sobre os copépodes do Atlântico Sul e em regiões tropicais e subtropicais. O presente trabalho reporta as espécies de hospedeiros de Ellobiopsis sp. e estima a frequência de ocorrência de copépodes parasitados em uma região costeira subtropical, ao largo de Ubatuba, Brasil, além de explorar as possíveis consequências do parasitismo para as populações de copépodes como a influência dos parasitas sobre o tamanho dos hospedeiros.

\subsection{Objetivo}

\subsubsection{Objetivo Geral}

Verificar a abrangência e consequência da infecção de Ellobiopsis sp. sobre os copépodes Parvocalanus crassirostris, Paracalanus spp., Acartia lilljeborgii e Oithona spp. por meio da estimativa da densidade de copépodes parasitados e influência dos parasitas sobre o crescimento, através da análise do tamanho dos hospedeiros.

\subsubsection{Objetivos específicos}

- Reportar as espécies de copépodes pelágicos infectados por Ellobiopsis sp. em Ubatuba. 
- Estimar a frequência relativa de copépodes parasitados. Dentre os paracalanídeos (Parvocalanus crassirostris e Paracalanus spp.), estimar a densidade de copépodes parasitados, de acordo com o sexo e estágio de desenvolvimento.

- Verificar a influência do parasita sobre o tamanho de P. crassirostris e Paracalanus spp., através da comparação de indivíduos infectados e normais.

- Explorar a variabilidade temporal da quantidade de copépodes parasitados, entre o verão e inverno e entre os anos de 2009 a 2011.

- Descrever as regiões preferenciais de adesão de Ellobiopsis sp. em Paracalanus spp. e em P. crassirostris e o número de parasitas por hospedeiro.

\subsection{Materiais e métodos}

\subsubsection{Obtenção das amostras de plâncton}

O zooplâncton costeiro foi coletado em uma estação fixa localizada nas coordenadas $23^{\circ} 31^{\prime} 27^{\prime}$ ' S e $45^{\circ} 04^{\prime} 54^{\prime}$ ' O, próxima à base de pesquisa Clarimundo de Jesus, do Instituto Oceanográfico da Universidade de São Paulo, no município de Ubatuba, litoral norte do estado de São Paulo, Brasil. Devido ao mau tempo, algumas coletas foram realizadas em uma segunda estação, mais próxima da base, nas coordenadas $23^{\circ} 30^{\prime} 59^{\prime \prime}$ S e $45^{\circ} 06^{\prime} 10^{\prime \prime}$ O (Figura 1, introdução geral).

As coletas foram geralmente realizadas em dias alternados, totalizando ao menos quatro (e máximo de seis) amostragens por ano, em estações de verão e inverno durante 2009 e 2010 e verão durante 2011. As amostragens foram realizadas preferencialmente no período da manhã. De um total de 12 coletas (períodos amostrais), apenas duas foram realizadas na estação interna abrigada $A$ (Tabela 3.1).

As coletas de plâncton foram realizadas através de arrastos horizontais em subsuperfície ou verticais curtos, com rede de malha equivalente a $100 \mu \mathrm{m}$ equipada com fluxômetro, poitas e copo com orifícios cobertos por malhas (para as amostras quantitativas). As redes foram arrastadas o mais lentamente possível e o zooplâncton fixado em formol $4 \%$ diluído em água do mar filtrada e neutralizado em Tetraborato de 
Sódio. O tempo de arrasto foi determinado de acordo com a concentração aparente dos organismos, obtida pela inspeção visual das amostras coletadas previamente.

Para coleta das amostras qualitativas, foram acoplados copos fechados na porção terminal da rede, pois esses minimizam o dano mecânico sofrido pelos organismos por compressão em redes que terminam em copo com orifícios (Omori \& Ikeda, 1984). As amostras qualitativas foram utilizadas para determinar as frequências relativas de copépodes parasitados, assim como as frequências de copépodes por estágios de desenvolvimento (copepoditos e adultos) e sexo. Já as quantitativas foram utilizadas na determinação da composição e densidade zooplanctônicas.

Tabela 3.1: Data, horário e profundidade local das coletas de zooplâncton. Prof.: profundidade; *: coletas realizadas na estação abrigada (Saco da Ribeira).

\begin{tabular}{llll}
\hline Campanha & Data & Horário (h) & Prof. (m) \\
\hline \multirow{2}{*}{ verão 2009 } & $26 / 01^{*}$ & $10: 20$ & 4 \\
& $29 / 01$ & $11: 00$ & 18 \\
\hline \multirow{2}{*}{ inverno 2009 } & $18 / 07^{*}$ & $09: 15$ & 3 \\
& $22 / 07$ & $15: 30$ & 18 \\
& $26 / 07$ & $09: 30$ & 18 \\
\hline \multirow{2}{*}{ verão 2010 } & $12 / 01$ & $09: 10$ & 25 \\
& $24 / 01$ & $09: 00$ & 23 \\
\hline \multirow{2}{*}{ inverno 2010 } & $21 / 07$ & $08: 45$ & 25 \\
& $26 / 07$ & $08: 45$ & 25 \\
& $30 / 07$ & $08: 40$ & 30 \\
\hline \multirow{2}{*}{ verão 2011 } & $19 / 01$ & $08: 30$ & 33 \\
& $24 / 01$ & $08: 45$ & 34 \\
\hline
\end{tabular}




\subsubsection{Análises qualitativa e quantitativa do zooplâncton}

Os valores de densidade foram obtidos através da análise das amostras quantitativas. Os copépodes, especialmente Parvocalanus crassirostris, Paracalanus spp. ( $P$. quasimodo principalmente, além de $P$. indicus e $P$. aculeatus) Oithona spp. ( $O$. hebes em sua maioria, seguido por Diothona oculata e O. plumifera) e Acartia lilljeborgii foram contados e identificados em alíquotas de tamanho variável das amostras.

A obtenção das alíquotas foi realizada utilizando um quarteador do tipo Motoda (Omori \& Ikeda, 1984). Foram contadas frações de amostras de diversos tamanhos (1/8 a 1/128) para a enumeração e identificação do zooplâncton. Numa fração de amostra, um mínimo de 30 indivíduos de cada táxon dominante foi contado, totalizando no mínimo 300 exemplares. Esse valor, estipulado por Frontier (1981), reduz a introdução de erros devido ao tamanho da subamostra. Para as espécies menos abundantes, uma alíquota maior (1/2 a 1/32) era analisada.

A densidade, registrada em organismos $\mathrm{m}^{-3}$, foi estimada através da multiplicação do número de indivíduos pelo tamanho da respectiva alíquota contada e dividindo pelo volume de água filtrada pela rede, este último obtido através do uso de um fluxômetro calibrado na boca da rede, aplicando a fórmula:

$$
\boldsymbol{V}=\text { Valor fluxômetro (final }- \text { inicial) } x A \times C
$$

Onde $\mathrm{V}$ é o volume em metros cúbicos, o valor fluxômetro corresponde a diferença entre o valor final e inicial de rotações dada pelo aparelho, $A$ representa a área da boca da rede e $C$ o fator de calibração do fluxômetro.

Os estágios de desenvolvimento considerados foram: copepoditos juvenis (CIV) e adultos (machos, CVI - M e fêmeas, CVI - F). Os náuplios não foram analisados neste estudo, uma vez que a rede de $100 \mu \mathrm{m}$ subestimou a coleta dos mesmos (ver capítulo 1). 


\subsubsection{Obtenção de imagens e dados morfométricos}

A obtenção das medidas morfométricas foi realizada através da análise de imagens. Uma máquina digital (SONY DSC W-220), montada ao estereomicroscópio sobre um acoplador foi utilizada para a obtenção das imagens. O corante rosa de bengala foi utilizado para aumentar o contraste dos organismos.

Foi verificada a ocorrência do parasita Ellobiopsis sp. em diferentes estágios de desenvolvimento (copepoditos C I-VI) e sexo em Parvocalanus crassirostris, Paracalanus spp., Acartia lilljeborgii e Oithona spp. As espécies do gênero Paracalanus e Oithona foram agrupadas, pelo fato da metodologia limitar a observação de caracteres taxonômicos, uma vez que as imagens não possuem resolução ou profundidade suficiente para visualização de estruturas reduzidas utilizadas na taxonomia destes gêneros (e.g. espinhos na perna 5 e detalhes do segmento genital). Os copépodes Oithona spp. e A. lilljeborgii também foram analisados, porém o número amostral de copépodes parasitados foi baixo em ambos.

Um total de 7.934 paracalanídeos, 19.219 Oithona spp. e 8.302 Acartia lilljeborgii provenientes das amostras qualitativas foram inspecionados. As medidas morfométricas dos copépodes e parasitas foram obtidas utilizando o Image J, programa computacional livre (freeware), que possibilita a adição de diversas ferramentas complementares (plugins) e habilitação de macros para a automatização de operações realizadas com as imagens.

O programa forneceu o comprimento, largura, perímetro e área dos organismos selecionados. O comprimento dos copépodes neste estudo corresponde ao comprimento do prossomo (Figura 3.1). Da mesma maneira, as medidas morfométricas também foram obtidas para cada Ellobiopsis sp., sendo que o pedúnculo foi desconsiderado para a obtenção do comprimento. Ainda para os protistas, foi registrada a presença do gonômero em três estágios: i) ausente; ii) em formação (constrição celular visível) e iii) gonômero maduro. 


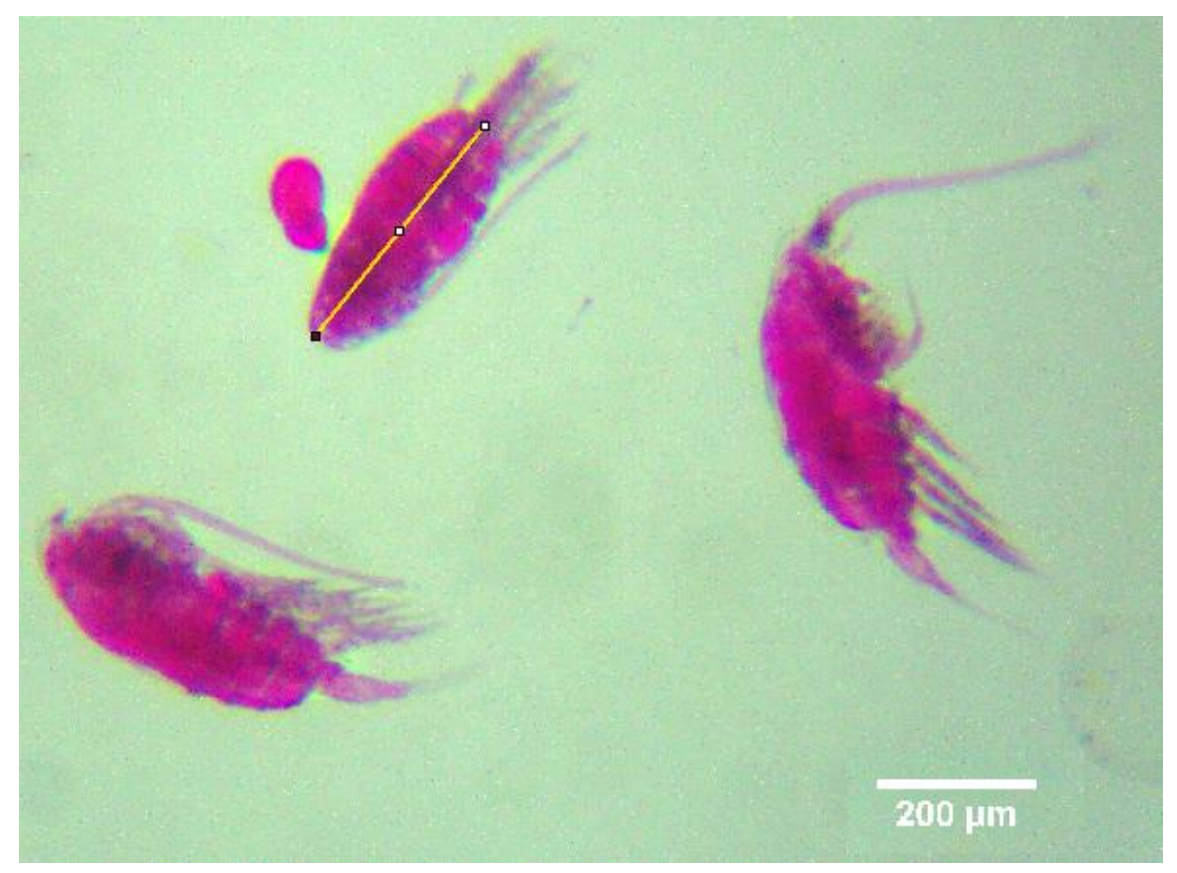

Figura 3.1: Copépodes da espécie Parvocalanus crassirostris. Um dos indivíduos encontra-se parasitado por Ellobiopsis sp. Em destaque o comprimento do prossomo, obtido utilizando o programa Image $J$.

\subsubsection{Análises de resultados e testes estatísticos}

Foram calculadas as frequências relativas de infecção (F.R.), ou seja, a proporção de indivíduos parasitados pelo total de copépodes do mesmo estágio e sexo em cada amostra como descrito abaixo:

$$
F . R .(\%)=\frac{n \text { indivíduos parasitados }}{n \text { indivíduos totais }}
$$

As frequências relativas totais do período estudado também foram fornecidas, ou seja, a média utilizando todas as amostras onde indivíduos parasitados foram encontrados e para cada categoria (copepoditos, machos e fêmeas adultos).

Os dados de densidade de Paracalanus spp. e Parvocalanus crassirostris calculados através das amostras quantitativas foram utilizados para a estimativa da quantidade de organismos parasitados, multiplicando tais valores pelas respectivas frequências de ocorrência obtidas nas amostras qualitativas.

A normalidade e homocedasticidade dos dados de estimativa da densidade foram verificadas através do teste de Lilliefors e Shappiro-Wilk. Todos os conjuntos de dados apresentaram distribuição não normal, o que levou à escolha dos testes apropriados de 
comparação entre três ou mais grupos (teste de Kruskal-Wallis, seguido em algumas ocasiões pelo teste de Student-Newman-Keuls quando $p<0,05)$ e entre dois grupos (teste de Mann-Whitney).

Comparações entre todas as categorias e também aos pares (macho x fêmea, adultos $\mathrm{x}$ copepoditos) foram realizadas para os copépodes paracalanídeos, para verificar a prevalência do parasita. Testes também foram realizados para comparar a densidade de organismos parasitados entre os anos e estações.

Os copépodes parasitados ocorreram em apenas duas amostragens durante o verão (em 2009 e 2010); já para o inverno, parasitas foram encontrados em um total de seis ocasiões (2009 e 2010). Na tentativa de comparar a diferença na quantidade dos copépodes parasitados entre o verão e o inverno, foram utilizadas as estimativas das densidades de cada estágio de desenvolvimento e sexo (juvenis, adultos machos e adultos fêmeas) para Paracalanus spp. e Parvocalanus crassirostris, em cada amostra onde o parasita foi detectado (ver Tabela 3.4).

Para cada copépode adulto parasitado, um copépode normal do mesmo sexo foi escolhido ao acaso para realização do teste de comparação entre os grupos quanto ao comprimento do prossomo. Para os copepoditos juvenis, o tratamento foi diferenciado: uma vez que os mesmos não foram separados em cada um de seus estágios de desenvolvimento isoladamente (CI a CV), uma classificação por classes de tamanho foi utilizada para separar artificialmente os estágios. Os copepoditos normais foram escolhidos aleatoriamente dentro das classes de tamanho correspondente a cada indivíduo parasitado. A diferença de tamanho entre copépodes possuindo um único parasita e aqueles com dois ou mais parasitas também foi analisada (teste de MannWhitney).

A correlação entre o biovolume corporal dos copépodes hospedeiros e biovolume dos parasitas foi realizada através do teste de Spearman. A diferença de volume dos hospedeiros carregando um e dois ou mais parasitas também foi testada. Para gerar tais comparações, o biovolume em $\mu \mathrm{m}^{3}$ de hospedeiros e simbiontes foram estimados, assumindo que tanto copépodes quanto Ellobiopsis sp. possuíssem o formato de uma elipsoide do tipo esferoide (dois eixos de igual tamanho), cujo volume pode ser descrito por: 


$$
V=\frac{4}{3} a \cdot b \cdot c
$$

Sendo o comprimento do prossomo ou comprimento do protista equivalente ao eixo $a$ e o valor da largura de ambos os organismos equivalente aos eixos $b$ e $c$.

Finalmente, a frequência de ocorrência dos parasitas por local de adesão nos copépodes foi analisado para os paracalanídeos (antenas, peças bucais, prossomo e outros). Os valores de $p$ foram obtidos para cada teste de variância, considerando o grau de liberdade $\alpha=0,05$. Foram utilizados os programas Microsoft Office Excel $2010 \mathrm{e}$ Sigma Plot 11 (Systat Software, 2008) para elaboração de gráficos e realização dos testes estatísticos, respectivamente.

\subsection{Resultados}

\subsubsection{Frequência relativa e densidade de copépodes infectados}

Do total de 4.014 Paracalanus spp. (P. quasimodo, P. indicus, P. aculeatus) observados, 3.992 eram indivíduos normais e 22 infectados. Para P. crassirostris, foi observado um total de 3.920 indivíduos, sendo 3.822 normais e 98 parasitados. Em Acartia lilljeborgii e em Oithona spp. (O. hebes, O. plumifera e Dioithona oculata) foram registrados 4 e 8 indivíduos parasitados, respectivamente. As frequências relativas de infecção para essas espécies são notadamente menores quando comparados aos paracalanídeos, cerca de 0,05\% para ambos os casos (Tabela 3.2).

Diferenças significativas foram registradas entre as espécies (Paracalanus spp. e Parvocalanus crassirostris) quanto ao número de exemplares infectados em diferentes categorias de desenvolvimento e sexo. As fêmeas adultas de Parvocalanus crassirostris foram o estágio mais afetado por parasitas (61 dos 98 indivíduos), enquanto que para Paracalanus spp. foi observada maior quantidade de copepoditos parasitados (14 de um total de 22 indivíduos infectados), seguido por machos adultos (Tabelas 3.2 e 3.3). 
Tabela 3.2: Quantidade de exemplares observados e parasitados por categoria em Paracalanus spp. e Parvocalanus crassirostris e suas respectivas frequências relativas (F.R). T: total; CVI-M: machos; CVI-F: fêmeas; CI-V: copepoditos.

\begin{tabular}{lccccccccc}
\hline \multirow{2}{*}{ amostral } & \multicolumn{3}{l}{ Parvocalanus crassirostris } & \multicolumn{7}{l}{ Paracalanus spp. } \\
\cline { 2 - 10 } & Total & CVI-M & CVI-F & CI-V & Total & CVI-M & CVI-F & CI-V \\
\hline Totais & 3.920 & 597 & 1.211 & 2.014 & 4.014 & 260 & 302 & 3.430 \\
Parasitados & 98 & 14 & 61 & 23 & 22 & 7 & 1 & 14 \\
F.R. (\%) & 2,5 & 2,4 & 5 & 1,1 & 0,6 & 2,7 & 0,3 & 0,4 \\
\hline
\end{tabular}

Tabela 3.3: Quantidade de indivíduos parasitados por amostra qualitativa (amostra total) para Paracalanus spp., Parvocalanus crassirostris, Acartia lilljeborgii e Oithona spp. V: verão; I: inverno; 09 a 11: anos de 2009 a 2011 respectivamente.

\begin{tabular}{llcccccccccc}
\hline \multirow{2}{*}{ Espécie } & Estágio & V 09 & \multicolumn{3}{c}{ I 09 } & \multicolumn{3}{c}{ I 10 } & V 11 & Soma \\
\cline { 2 - 11 } & & $\mathbf{2 6 / 0 1}$ & $\mathbf{1 8 / 0 7}$ & $\mathbf{2 2 / 0 7}$ & $\mathbf{2 6 / 0 7}$ & $\mathbf{2 1 / 0 7}$ & $\mathbf{2 6 / 0 7}$ & $\mathbf{3 0 / 0 7}$ & $\mathbf{2 4 / 0 1}$ & \\
\hline \multirow{3}{*}{ Paracalanus spp. } & C I-V & 3 & 0 & 0 & 0 & 4 & 2 & 3 & 2 & 14 \\
& CVI - & 0 & 3 & 1 & 0 & 0 & 1 & 1 & 1 & 7 \\
& CVI - F & 0 & 0 & 0 & 1 & 0 & 0 & 0 & 0 & 1 \\
\hline \multirow{3}{*}{ P.crassirostris } & C I-V & 10 & 0 & 1 & 5 & 2 & 3 & 2 & 0 & 23 \\
& CVI - & M & 3 & 0 & 1 & 2 & 4 & 2 & 2 & 0 & 14 \\
& CVI - F & 13 & 5 & 21 & 6 & 4 & 8 & 2 & 2 & 61 \\
\hline A. lilljeborgii & C I-V & 0 & 1 & 0 & 0 & 1 & 1 & 0 & 1 & 4 \\
\hline \multirow{3}{*}{ Oithona spp. } & C I-V & 1 & 0 & 0 & 1 & 0 & 0 & 0 & 1 & 3 \\
& CVI - & M & 0 & 0 & 0 & 0 & 0 & 0 & 0 & 0 & 0 \\
& CVI - F & 1 & 1 & 0 & 0 & 0 & 0 & 1 & 2 & 5 \\
\hline
\end{tabular}

A análise de variância de Kruskal-Wallis não detectou diferença significativa quanto à densidade estimada de indivíduos parasitados entre as categorias (machos, fêmeas, adultos e copepoditos) para Paracalanus spp. ( $p=0,07)$. Para Parvocalanus crassirostris, a diferença foi significativa entre os estágios de desenvolvimento ( $p=$ $0,041)$, sendo que os adultos foram mais infectados do que os copepoditos $(p=0,05)$, assim como as fêmeas apresentaram maior incidência do parasita do que os machos ( $p=$ 0,05). As demais comparações não resultaram em diferenças significativas. 
Não houve diferença na densidade de copépodes infectados entre o verão e o inverno $(p=0,075)$, embora animais parasitados tenham ocorrido em um maior número de amostras durante o inverno (Tabela 3.4). Entre os três anos analisados, o de 2009 possuiu maiores densidades de copépodes parasitados, sendo que o parasitismo foi detectado em quatro amostras durante 2009, três em 2010 e apenas uma em 2011 (Tabela 3.5).

Tabela 3.4: Estimativas da densidade de Parvocalanus crassirostris e Paracalanus spp. parasitados em org. $\mathrm{m}^{-3}$ nos respectivos períodos amostrais. $\mathrm{C}$ VI: adultos; $\mathrm{M}$. = macho; $\mathrm{F}=$ fêmea; $\mathrm{M}+\mathrm{F}=$ soma dos adultos; $\mathrm{CI}-\mathrm{V}=$ Copepoditos.

\begin{tabular}{|c|c|c|c|c|c|}
\hline Coletas & & C I-V & C VI F & C VI M & C VI M + F \\
\hline \multirow{2}{*}{ 26/01/2009 } & P. crassirostris & 9 & 84 & 19 & 103 \\
\hline & Paracalanus spp. & 8 & 4 & 25 & 29 \\
\hline \multirow{2}{*}{ 18/07/2009 } & P. crassirostris & 2 & 13 & 6 & 19 \\
\hline & Paracalanus spp. & 0 & 0 & 1 & 1 \\
\hline \multirow{2}{*}{ 22/07/2009 } & P. crassirostris & 32 & 7 & 4 & 11 \\
\hline & Paracalanus spp. & 2 & 3 & 20 & 23 \\
\hline \multirow{2}{*}{ 26/07/2009 } & P. crassirostris & 1 & 7 & 1 & 8 \\
\hline & Paracalanus spp. & 0 & 1 & 3 & 4 \\
\hline \multirow{2}{*}{ 21/07/2010 } & P. crassirostris & 0 & 2 & 0 & 2 \\
\hline & Paracalanus spp. & 0 & 0 & 1 & 1 \\
\hline \multirow{2}{*}{ 26/07/2010 } & P. crassirostris & 0 & 1 & 1 & 2 \\
\hline & Paracalanus spp. & 0 & 0 & 2 & 2 \\
\hline \multirow{2}{*}{ 30/07/2010 } & P. crassirostris & 2 & 9 & 0 & 9 \\
\hline & Paracalanus spp. & 4 & 4 & 26 & 30 \\
\hline \multirow{2}{*}{ 24/01/2011 } & P. crassirostris & 0 & 2 & 0 & 2 \\
\hline & Paracalanus spp. & 1 & 1 & 6 & 7 \\
\hline
\end{tabular}


Tabela 3.5: Resultado do teste de comparação aos pares de Student-Newman-Keuls, entre a densidade de copépodes parasitados para os três anos de amostragens.

\begin{tabular}{cccc}
\hline Comparação & Diferença de ranks & $\boldsymbol{q}$ & $\boldsymbol{P}<\mathbf{0 , 0 0 5}$ \\
\hline $\mathbf{2 0 0 9}>\mathbf{2 0 1 0}$ & 56 & 4,16 & Sim \\
$\mathbf{2 0 0 9}>\mathbf{2 0 1 1}$ & 76 & 3,8 & Sim \\
$\mathbf{2 0 1 0}=\mathbf{2 0 1 1}$ & 20 & 1,49 & Não \\
\hline
\end{tabular}

\subsubsection{Comparações morfométricas entre animais normais e infectados}

Parvocalanus crassirostris e Paracalanus spp. normais e infectados foram comparados quanto ao comprimento do prossomo entre os machos adultos, fêmeas adultas e copepoditos, com exceção apenas para fêmeas de Paracalanus spp. devido ao baixo número amostral (apenas uma fêmea parasitada). Diferença entre indivíduos normais e parasitados ocorreu entre as fêmeas de P. crassirostris, categoria com o maior número de indivíduos infectados (Tabela 3.6).

A correlação de Spearman entre o volume dos hospedeiros (Parvocalanus crassirostris) e dos parasitas foi positiva $(0,21)$ e significativa $(p=0,026)$, indicando que parasitas maiores encontram-se associados a copépodes maiores (Figura 3.2). Este resultado foi provavelmente um reflexo da distribuição de Ellobiopsis sp. em maiores proporções em fêmeas adultas, as quais possuem maior volume do que machos e copepoditos juvenis. A correlação não foi significativa para Paracalanus spp. (Figura $3.3)$.

As fêmeas de Parvocalanus crassirostris parasitadas foram significativamente menores, demonstrando prováveis efeitos negativos do parasita sobre o crescimento somático do hospedeiro. Não foram registradas diferenças entre o comprimento de machos normais e parasitados. Vale destacar que tal resultado pode ser um artefato do número reduzido de machos adultos parasitados neste estudo, apesar do esforço amostral elevado (Tabela 3.2).

Diferença entre copepoditos normais e parasitados não foi encontrada, provavelmente devido ao número amostral reduzido. Os copepoditos selecionados como controle pertenceram à mesma classe de tamanho de cada copepodito parasitado 
encontrado nas amostras qualitativas, para evitar que a variabilidade de tamanho dos estágios de copepodito pudesse mascarar o efeito do parasita sobre o comprimento do prossomo.

Tabela 3.6: Teste de Mann-Whitney para comparação entre os grupos (animais normais $\mathrm{x}$ parasitados) em machos, fêmeas e adultos de Parvocalanus crassirostris e Paracalanus spp. quanto ao comprimento do prossomo em $\mu \mathrm{m}$.

\begin{tabular}{|c|c|c|c|c|c|}
\hline Espécie & Categoria & $\begin{array}{c}\text { Média } \pm \text { D.P. } \\
\text { Normais }\end{array}$ & $\begin{array}{c}\text { Média } \pm \text { D.P. } \\
\text { Parasitados }\end{array}$ & $\begin{array}{l}\text { Número } \\
\text { amostral }\end{array}$ & Valor de $p$ \\
\hline \multirow{3}{*}{ 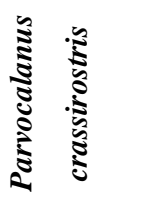 } & CI-V & $323,8 \pm 31$ & $336,9 \pm 27,2$ & 24 & 0,17 \\
\hline & CVI M & $322,2 \pm 17,6$ & $307,7 \pm 29,2$ & 14 & 0,383 \\
\hline & C VI F & $398,8 \pm 24,5$ & $381,7 \pm 22,9$ & 60 & $<0,001$ \\
\hline \multirow{3}{*}{ 离 } & CI-V & $370,9 \pm 63,5$ & $348,2 \pm 43,5$ & 14 & 0,19 \\
\hline & CVI M & $434,4 \pm 66,7$ & $376,9 \pm 26,9$ & 7 & 0,128 \\
\hline & CVI F & - & - & 1 & - \\
\hline
\end{tabular}

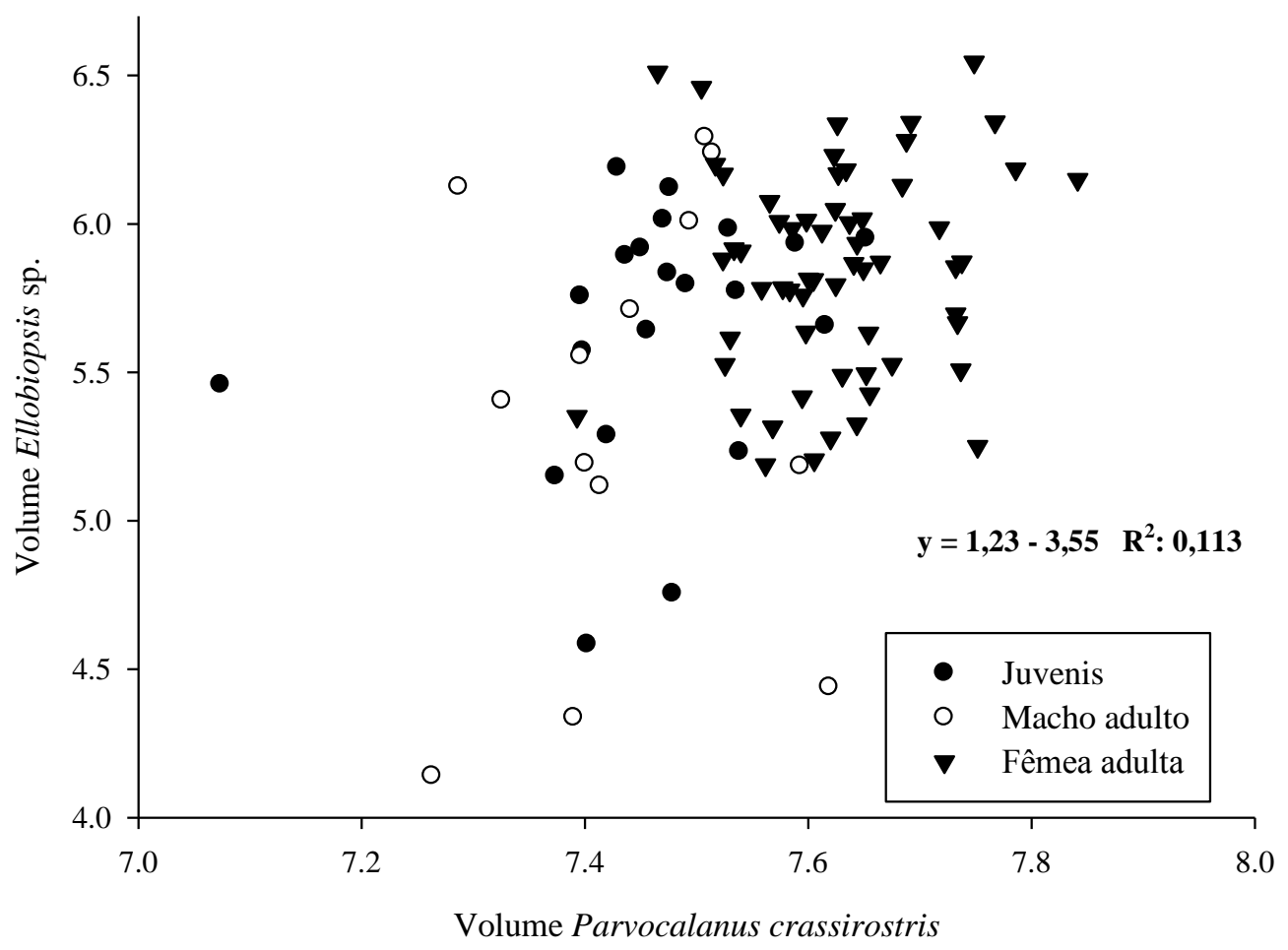

Figura 3.2: Distribuição do volume $\left(\mu \mathrm{m}^{3}\right)$ dos copépodes da espécie Parvocalanus crassirostris parasitados, em relação ao volume de seus respectivos parasitas em escala logarítmica. 


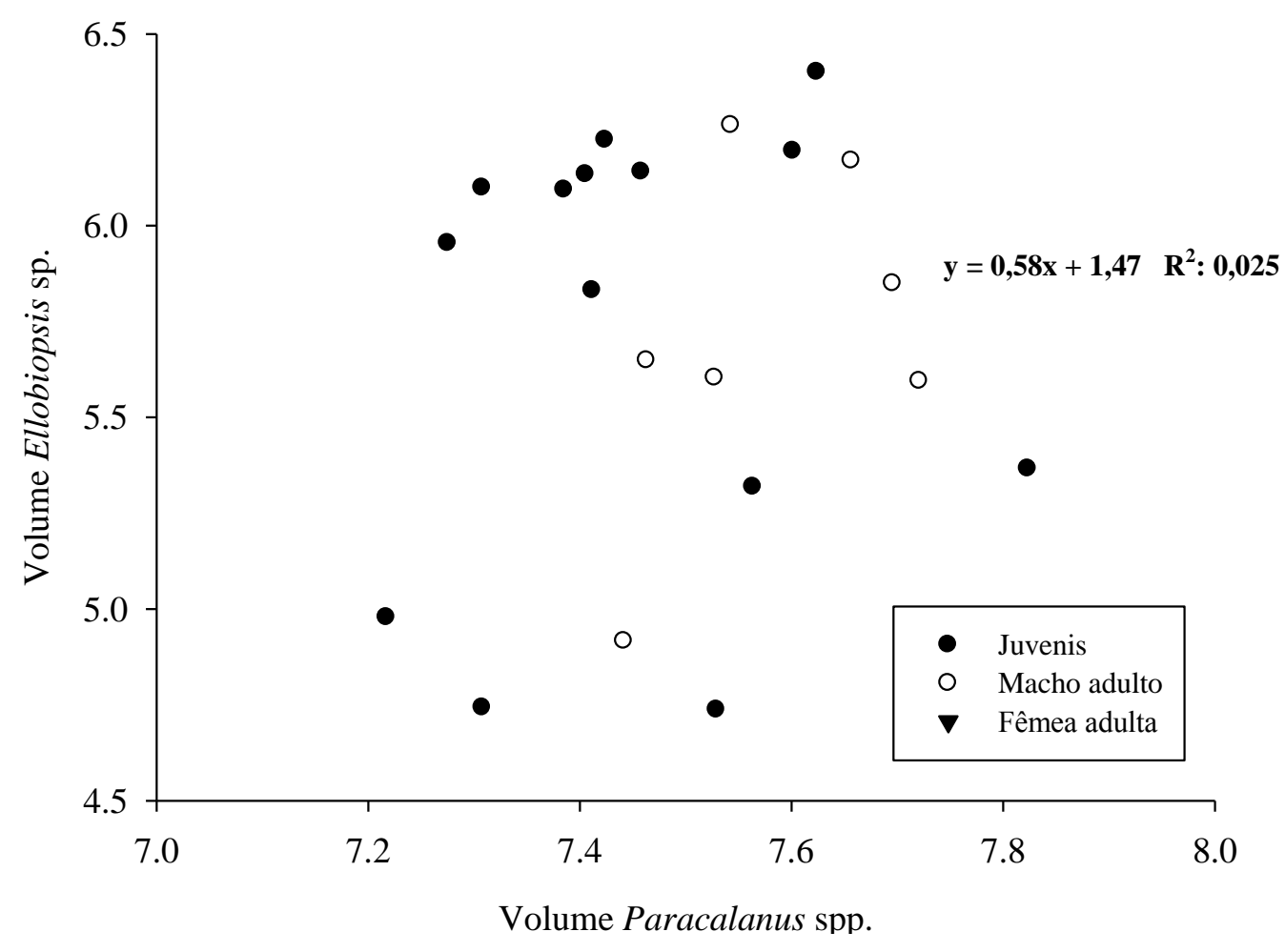

Figura 3.3: Distribuição do volume $\left(\mu \mathrm{m}^{3}\right)$ dos copépodes do gênero Paracalanus parasitados, em relação ao volume de seus respectivos parasitas em escala logarítmica.

\subsubsection{Quantidade de parasitas por hospedeiro e locais de adesão}

Dentre os paracalanídeos analisados, um total de 137 exemplares de Ellobiopsis sp. foi encontrado em 120 hospedeiros. Em alguns casos, os copépodes foram infectados por mais de um exemplar de parasita (Figura 3.4 A e C) e em locais distintos do corpo como, por exemplo, a antena 1 e articulações dos segmentos do prossomo. Cada célula observada nesses casos foi considerada como um indivíduo independente de Ellobiopsis sp.

Foram encontrados de um a quatro parasitas por paracalanídeo infectado. A grande maioria dos exemplares encontrados carregava apenas um Ellobiopsis sp. Para a espécie $P$. crassirostris foram encontrados 77 indivíduos carregando um parasita, 18 com dois e raros registros de três e quatro parasitas associados (Tabela 3.7). 
Tabela 3.7: Quantidade de parasitas por copépodes paracalanídeos e suas respectivas frequências relativas $(\%)$.

\begin{tabular}{lccccccccc}
\hline Táxon & total & $\mathbf{1}$ & $\mathbf{( \% )}$ & $\mathbf{2}$ & $\mathbf{( \% )}$ & $\mathbf{3}$ & $\mathbf{( \% )}$ & $\mathbf{4}$ & $\mathbf{( \% )}$ \\
\hline P. crassirostris & 98 & 77 & 78,6 & 18 & 18,4 & 2 & 2 & 1 & 1 \\
Paracalanus spp. & 22 & 20 & 90,9 & 1 & 4,6 & 1 & 4,6 & 0 & - \\
& & & & & & & & & \\
\hline
\end{tabular}

Outro teste realizado foi para detectar possíveis diferenças entre o tamanho de Parvocalanus crassirostris carregando um ou mais parasitas (dois a quatro). Contudo, não houve diferença de comprimento entre esses dois grupos $(p<0,194)$, sendo que o comprimento médio do prossomo de indivíduos infectados por um parasita foi de 359,7 $\pm 37,5 \mu \mathrm{m}$, enquanto que em indivíduos infectados por dois ou mais parasitas foi de $377,6 \pm 38,7 \mu \mathrm{m}$. Aparentemente não existe efeito da associação de mais de um parasita ao copépode quanto ao seu comprimento.

Os elobiopsídeos foram encontrados aderidos principalmente a peças bucais, antenas e primeiros segmentos do prossomo (Figura 3.4). Outros locais menos frequentes de adesão foram as pernas e o urossomo, os quais foram agrupados na categoria "outros" devido ao baixo número de ocorrências (Tabela 3.8). É evidente a maior ocorrência de parasitas nas peças bucais e antenas, ou seja, nos apêndices originados do cefalossomo dos copépodes, quando comparados à ocorrência nos segmentos do prossomo e outras regiões (Figura 3.4).

Tabela 3.8: Locais de adesão de Ellobiopsis sp. sobre os copépodes hospedeiros Parvocalanus crassirostris e Paracalanus spp.

\begin{tabular}{lcccccccc}
\hline & \multicolumn{4}{c}{ Parvocalanus crassirostris } & \multicolumn{3}{c}{ Paracalanus spp. } \\
\cline { 2 - 9 } & C I-V & CVI-F & CVI-M & Total (\%) & C I-V & CVI-F & CVI-M & Total (\%) \\
\hline Peças bucais & 4 & 32 & 8 & 42,7 & 6 & 1 & 5 & 46,2 \\
Antenas & 4 & 30 & 3 & 35,9 & 5 & 1 & 1 & 26,9 \\
Prossomo & 2 & 12 & 6 & 19,4 & 3 & - & 3 & 23,1 \\
Outros & - & 1 & 1 & 1,9 & - & - & 1 & 3,8 \\
\hline
\end{tabular}


A diferença foi significativa entre as quantidades de parasitas encontrados nas diferentes localidades do corpo do hospedeiro ( $p=0,013$, teste de Kruskal-Wallis), demonstrando a associação preferencial do parasita aos apêndices cefálicos (Tabela 3.8). Não foi possível identificar um local preferencial de adesão entre os apêndices do cefalossomo, sendo que tal região concentrou $90 \%$ das ocorrências dos parasitas. Não foram detectados padrões para locais de adesão, quando diferentes categorias como copepoditos e adultos ou machos e fêmeas foram testadas.

\subsubsection{Características morfológicas e dimensões dos parasitas}

A descrição mais próxima do parasita encontrado aqui é a da espécie Ellobiopsis chattoni Caullery (1910), baseado em análise da morfologia dos indivíduos (Chatton, 1920; Jepps, 1937; Boschma, 1956). Além disso, um único gonômero foi encontrado nos protistas, um caractere diagnóstico e exclusivo de E. chattoni dentro do gênero.

Grande variação foi detectada quanto às dimensões de Ellobiopsis sp., sendo o comprimento mínimo igual a $17 \mu \mathrm{m}$ e o máximo de $153 \mu \mathrm{m}$ (Figura 3.5). O comprimento, largura e volume médios foram de 75,7 $\pm 30,2 \mu \mathrm{m} ; 44,1 \pm 14 \mu \mathrm{m}$ e $804.117,2 \pm 714.671,2 \mu \mathrm{m}^{3}$ respectivamente. Vale lembrar que a quantidade de indivíduos menores do que $20 \mu \mathrm{m}$ de comprimento pode ter sido subestimada pela metodologia empregada.

Não foi detectado um tamanho mínimo celular para a formação do gonômero. De um total de 143 protistas analisados, o gonômero esteve ausente em 38,5\% dos organismos, observado em estágios diversos de formação em 39,2\% e gonômeros desenvolvidos registrados em $22,3 \%$ das células. 


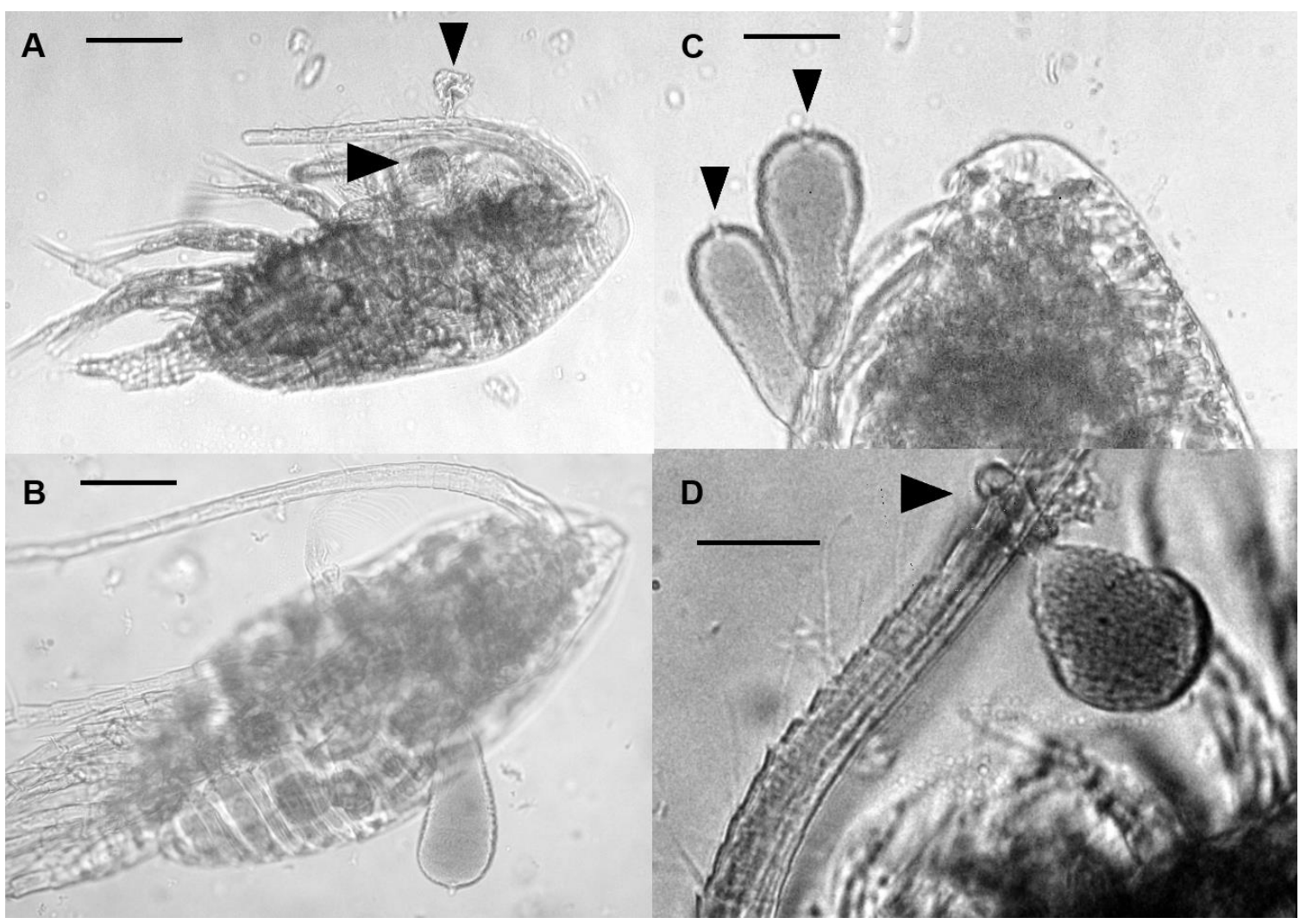

Figura 3.4: Diferentes hospedeiros parasitados por Ellobiopsis sp. A: Paracalanus quasimodo infectado por dois parasitas. B: Paracalanus sp. infectado por um Ellobiopsis sp. aderido a uma das peças bucais. C e D: Parvocalanus crassirostris com parasitas aderidos à antênula. A e B: escala $=200 \mu \mathrm{m}$; : escala $=80 \mu \mathrm{m}$ e D: escala $=60 \mu \mathrm{m}$.

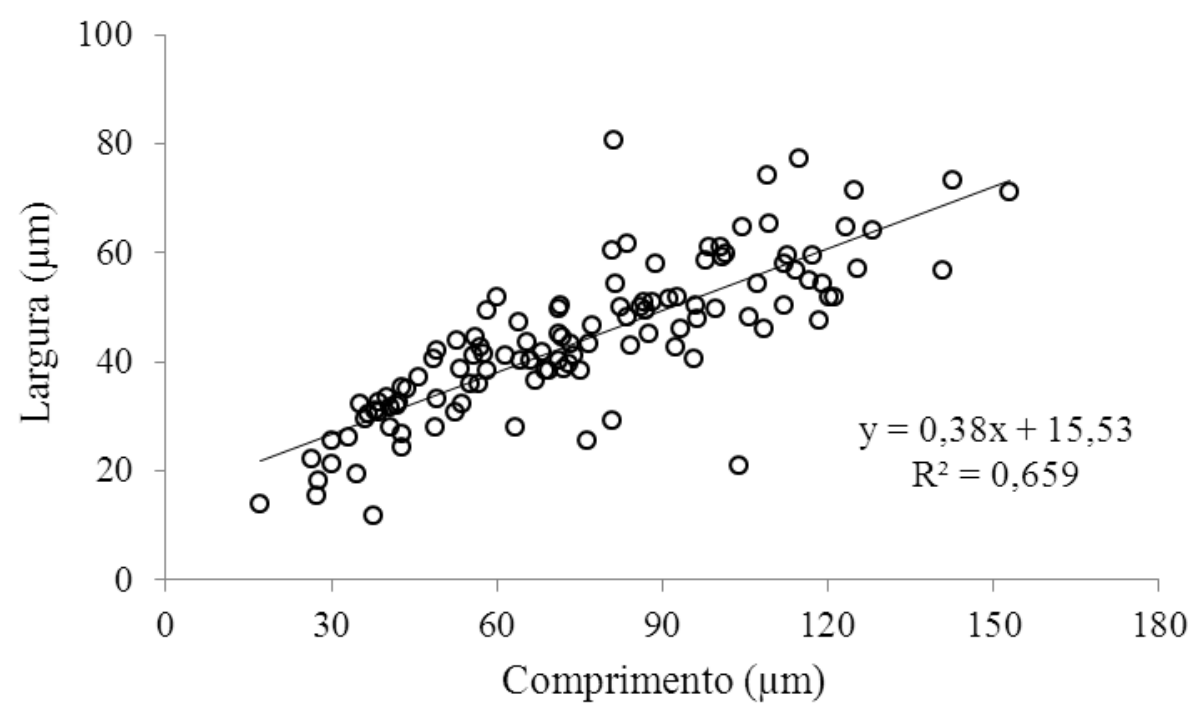

Fígura 3.5: Relação entre o comprimento e largura de Ellobiopsis sp. encontrados em copépodes paracalanídeos. $n=118$. 


\subsection{Discussão}

\subsubsection{Ocorrência de elobiopsídeos em copépodes pelágicos}

Parasitas e epibiontes em copépodes são comuns, diversificados e encontrados em uma gama de hospedeiros (Ho \& Perkins, 1985; Théodoridès, 1989; Shields, 1994). Descrições detalhadas de protistas parasitas de microcrustáceos marinhos têm sido realizadas desde o final do século XIX (Pouchet, 1884, 1885), mas poucos exemplos sobre o efeito desses simbiontes sobre os seus hospedeiros podem ser citados (Willey et al., 1990; Weissman et al., 1993; Albaina \& Irigoien, 2006; Skovgaard \& Saiz, 2006; Alves-de-Souza et al., 2011). Apesar de ser um tema relevante, o parasitismo e suas consequências ecológicas para o zooplâncton marinho é um tema ainda pouco explorado.

Em ambientes costeiros, parasitas do gênero Ellobiopsis têm sido descritos em diferentes espécies de copépodes pelágicos. Shields (1994) traz uma compilação de hospedeiros para o gênero Ellobiopsis (18 táxons), onde a maioria é de copépodes calanóides, exceto por duas citações onde o parasita ocorreu em larvas de decápodes. Posteriormente, Skovgaard \& Saiz (2006) adicionaram Calocalanus sp. e Temora stylifera à lista de hospedeiros de Ellobiopsis spp. Outras adições recentes foram registradas por Walkusz \& Rolbiecki (2007) e Gómez et al. (2009) com as espécies Calanus glacialis e Centropages typicus, respectivamente.

O copépode Calanoides carinatus também foi considerado como hospedeiro de Ellobiopsis sp. em amostras coletadas na plataforma da Namíbia (Schweikert \& Elbrächter, 2006), contudo, nenhum indivíduo infectado da espécie foi encontrado no minucioso trabalho de Albaina \& Irigoien (2006) na baía de Biscay, Espanha, onde Calanus helgolandicus foi o principal hospedeiro e as espécies raramente infectadas foram Ctenocalanus vanus, Temora longicornis e Pseudocalanus elongatus.

Além da diversidade de hospedeiros, tais registros também indicam a ampla distribuição geográfica do gênero Ellobiopsis, registradas desde o Atlântico Sul, na costa da Argentina (Steuer, 1932), ao Atlântico Norte no mar da Groelândia (Walkusz \& Rolbiecki, 2007) e mar do Norte (Jepps, 1937), além do Mediterrâneo (Hovasse, 1952), Adriático (Hoenigman, 1958) e mar Negro (Elian \& Petran, 1971). Este gênero 
também foi detectado no oceano Pacífico, no mar do Japão (Konovalova, 2008) e no oceano Índico (Santhakumari \& Saraswathy, 1979).

Ellobiopsis sp. foi registrado neste estudo para a região costeira de Ubatuba, nos seguintes hospedeiros: Parvocalanus crassirostris, Paracalanus spp. (P quasimodo, $P$. indicus e P. aculeatus); Acartia lilljeborgii, Oithona spp. (O. hebes e O. plumifera) e Diothona oculata. O parasita foi registrado na baía de Santos, estado de São Paulo, por Bicalho (2008), para as espécies Parvocalanus scotii, Paracalanus quasimodo, Temora turbinata e, em menores proporções, em A. lilljeborgii, Pseudodiaptomus acutus e $O$. hebes.

Registros para o litoral dos demais estados brasileiros não foram encontrados. É interessante notar que o presente estudo e o de Bicalho (2008) são os primeiros a reportar copépodes ciclopóides como hospedeiros de Ellobiopsis. Uma frequência de infestação relativamente alta de copépodes paracalanídeos foi observada, enquanto que outros gêneros de copépodes foram raramente infectados, padrão semelhante ao reportado por Bicalho (2008).

A grande maioria dos registros ocorreu em águas costeiras ou oceânicas. A exceção foi o levantamento realizado na baía de Santos, uma área costeira influenciada pelo estuário de Santos-Bertioga (Bicalho, 2008). Ellobiopsis sp. provavelmente é frequente em estuários e foram observados no complexo estuarino de Paranaguá, na costa do estado do Paraná (Martinelli-Filho, observação pessoal).

\subsubsection{Padrões de distribuição de Ellobiopsis sp. sobre seus hospedeiros}

Outro padrão observado foi a infecção de fêmeas adultas em maiores proporções para Parvocalanus crassirostris, o principal hospedeiro neste estudo, representado $74 \%$ do total de copépodes infectados. A proporção de fêmeas adultas parasitadas da espécie foi de 5\%, valor semelhante ao encontrado em fêmeas de Calanus helgolandicus (6,8\%, Albaina \& Irigoien, 2006). Na literatura, as proporções de copépodes infectados estiveram entre 0,06 a $26 \%$, sendo as menores para C. finmarchicus e C. glacialis em Sptisbergen, Groelândia (Walkusz \& Rolbiecki, 2007) e as maiores para Undinula vulgaris na costa da Tanzânia, África (Wickstead, 1963). 
Padrões temporais foram raramente registrados na literatura. Copépodes parasitados foram mais frequentes durante o verão para o hemisfério norte (Jepps, 1937; Konovalova, 2008). Na baía de Santos, foram mais comuns durante a primavera (Bicalho, 2008). Já para o Mediterrâneo, os parasitas foram detectados no final outono e durante o inverno (Skovgaard \& Saiz, 2006).

No presente estudo, animais parasitados foram encontrados com maior frequência e em maior número no inverno. Contudo, não houve diferença estatística para a densidade estimada de copépodes parasitados entre o verão e inverno. Vale destacar que a maior densidade de animais parasitados ocorreu em uma das amostras coletadas na estação abrigada. É possível que maiores frequências de infestação ocorram em águas costeiras, em relação a águas neríticas, uma hipótese a ser testada futuramente.

Quanto aos locais de adesão nos hospedeiros, maiores frequências foram observadas nos apêndices do cefalossomo como as antenas e peças bucais, padrão comum na literatura (Jepps, 1937; Albaina \& Irigoien, 2006). É possível que os esporos sejam aderidos aos apêndices do cefalossomo durante a atividade alimentar dos copépodes, uma vez que antenas e peças bucais são responsáveis por gerar correntes para detecção e seleção de partículas (Strickler, 1982). Os mecanismos de adesão e infecção de Ellobiopsis permanecem desconhecidos.

O número máximo de parasitas registrados por hospedeiro neste estudo foi de quatro, sendo que até 15 Ellobiopsis foram observados por Jepps (1937), com tamanhos diminutos, como $15 \mu \mathrm{m}$. A detecção dos estágios iniciais, que consistem em esporos que se instalam nas cerdas dos apêndices do hospedeiro (Gómez et al., 2009), também não pode ser realizada nas fotografias. O registro de Jepps (1937) sustenta a hipótese de que uma análise morfológica criteriosa em estereomicroscópio revelaria um maior número de hospedeiros infectados do que o método aqui empregado.

Vale ressaltar que, provavelmente, poucos protistas sobrevivam, cresçam e desenvolvam o gonômero, uma vez que os hospedeiros geralmente carregam de um a quatro Ellobiopsis desenvolvidos na maioria das observações (Chatton, 1920; Jepps, 1937; Ho \& Perkins, 1985; Albaina \& Iriogien, 2006, Walkusz \& Rolbiecki, 2007, este estudo). 
A presença do gonômero em 77,6 \% dos parasitas observados é um possível indicativo de que a produção dessa estrutura seja frequente, ou mesmo contínua em células maduras. Entretanto, não é possível afirmar que a produção de gonômeros seja responsável pela formação dos esporos exclusivamente, uma vez que a esporulação foi observada no trofômero de algumas células (Gómez et al., 2009).

A metodologia de coleta selecionou preferencialmente os estágios de copepoditos (CI a CVI). Embora os náuplios não tenham sido analisados, provavelmente Ellobiopsis sp. também ocorra nesses estágios, assim como outros elobiopsídeos foram detectados em estágios naupliares de copépodes de águas continentais (Manca et al., 2004). Outra limitação da metodologia é o fato das imagens não possuírem profundidade e o equipamento utilizado restringir a resolução. Não foi possível determinar com exatidão o local de adesão do parasita (ex: maxilípedes, maxilas e mandíbulas são todas denominadas peças bucais no presente trabalho), assim como detalhes morfológicos do copépode. O método limitou a identificação até espécie principalmente dos estágios de copepodito de Paracalanus spp. e Oithona spp.

Por outro lado, o método permitiu a análise de um elevado número de exemplares, em um prazo de tempo relativamente curto em relação às análises em microscopia. Outro ponto positivo foi a facilidade encontrada para obtenção das medidas morfométricas, pois o programa utilizado, Image $J$, fornece diversas medidas como o comprimento, largura, perímetro e área.

\subsubsection{Distribuição e taxonomia do gênero Ellobiopsis}

Provavelmente Ellobiopsis chattoni represente um complexo de espécies, devido à ampla distribuição geográfica, além da ocorrência em diversos hospedeiros (Shields, 1994). Em contrapartida, a alta variabilidade intra-individual nas sequências da subunidade SSU do rDNA em E. chattoni é um indicativo de que a espécie possui um genoma amplamente variável, diminuindo a possibilidade de que o táxon corresponda a um número muito elevado de espécies (Goméz et al., 2009). Análises moleculares serão necessárias para elucidar as relações filogenéticas entre as espécies de Ellobiopsis e principalmente para E. chattoni. 
Rayner \& King (1986) e Manca et al. (2004) e em seus respectivos trabalhos para os lagos Midmar na África do Sul e Maggiori na Itália, encontraram protistas associados a copépodes e os classificaram como Ellobiopsis chattoni. Já Bridgeman et al. (2000) no lago Paterson em Michigan, Estados Unidos, classificou os protistas como elobiopsídeos e provavelmente como membros do gênero Ellobiopsis. O mais razoável é que a classificação sugerida para os três artigos citados acima estejam erradas. Ellobiopsis spp. foram descritos e ocorrem exclusivamente em ambientes marinhos, (Caullery, 1910; Steuer, 1932; Hovasse, 1952), portanto, os elobiopsídeos encontrados em lagos continentais provavelmente representam táxons ainda não descritos ou outros gêneros de elobiopsídeos. Outros autores continuam tratando os protistas dos lagos citados como pertencentes ao gênero Ellobiopsis (Walkusz \& Rolbiecki, 2007), uma classificação provavelmente artificial.

Curiosamente, o tamanho dos Ellobiopsis encontrados aqui foi menor do que o geralmente reportado na literatura. Diversos estudos forneceram valores de comprimento entre 250 a $750 \mu \mathrm{m}$ (Chatton, 1920; Steuer, 1932; Skovgaard, 2004; Skovgaard \& Saiz, 2006; Albaina \& Irigoien, 2006; Walkusz \& Rolbiecki, 2007; Konovalova, 2008). Entretanto, duas exceções foram encontradas: Jepps (1937) registrou valores de comprimento entre 30 à $120 \mu \mathrm{m}$ e Gómez et al.. (2009) entre 50 a $250 \mu \mathrm{m}$ (estimado pelas figuras fornecidas).

Tal discrepância de tamanho deve-se ao fato do pedúnculo ser desconsiderado para a medida de comprimento no presente estudo. Além disso, os parasitas da região aqui estudada provavelmente são menores do que os descritos para o Atlântico Norte, assim como os copépodes hospedeiros são muito menores do que espécies do gênero Calanus, um dos hospedeiros mais frequentes em águas temperadas (Albaina \& Irigoien, 2006). A hipótese de que espécies maiores de hospedeiros desenvolvam parasitas maiores é sustentada pela correlação positiva e significativa entre o volume de paracalanídeos e de Ellobiopsis sp. detectada neste estudo. 


\subsubsection{Consequências do parasitismo}

Foi observada ainda uma prevalência de infecção em adultos em relação aos copepoditos juvenis, o que pode estar relacionado à idade mais avançada dos copépodes adultos, expostos por um período mais longo e sujeitos ao encontro e infecção pelo parasita por mais tempo. A correlação positiva entre o volume do hospedeiro e do parasita sustenta esta hipótese. Entre os adultos, as fêmeas foram mais infectadas em relação aos machos. Tal fenômeno provavelmente está relacionado também à longevidade, uma vez que fêmeas de copépodes calanóides sobrevivem por mais tempo, tanto em laboratório (Jacoby \& Youngbluth, 1983), quanto no campo (Parrish \& Wilson, 1978; Smith \& Lane, 1985; Drits et al., 1994). Embora a proporção de fêmeas seja maior do que de machos nos copépodes paracalanídeos (Gusmão \& McKinnon, 2009 b), o número de machos analisados neste estudo foi suficientemente alto para descartar a possibilidade de que a prevalência de parasitas sobre fêmeas estivesse relacionada à razão sexual.

Ellobiopsis sp. possivelmente interfere diretamente na natação e alimentação dos copépodes, uma vez que células com cerca de um quarto à metade do comprimento do prossomo estiveram dispostas majoritariamente na antena 1 e peças bucais. É possível também que copépodes parasitados por Ellobiopsis sejam mais susceptíveis aos predadores, como demonstrado para copépodes ciclopóides associados à euglenóides epibiontes (Willey et al., 1990), através da redução da capacidade de evasão e maior visibilidade aos predadores visuais.

Sabe-se que Ellobiopsis sp. afetam a reprodução dos hospedeiros, causando a redução da fecundidade em fêmeas da espécie Calanus helgolandicus (Albaina \& Irigoien, 2006). Uma vez que as fêmeas parasitadas foram menores do que as normais no presente estudo, sugere-se que Ellobiopsis sp. interfere negativamente sobre o crescimento somático e reprodutivo dos copépodes paracalanídeos analisados. Serão necessários experimentos com fêmeas parasitadas e não parasitadas para observar se o Ellobiopsis sp. interfere diretamente na reprodução dos paracalanídeos através da análise de produção e viabilidade de ovos, uma vez que parasitas desenvolvidos provavelmente inibem a produção de ovos nos hospedeiros (Albaina \& Irigoien, 2006). 
Os resultados aqui descritos sustentam a hipótese de que Ellobiopsis sp. afeta o estado nutricional do hospedeiro. Uma vez que a prevalência de parasitas foi maior em fêmeas adultas, chegando a 5\% para Parvocalanus crassirostris, possivelmente o parasita atua de forma significativa sobre os parâmetros reprodutivos de populações desses copépodes.

Destaca-se a importância de avaliar com maior precisão as causas e consequências do parasitismo sobre os copépodes pelágicos em níveis populacionais, analisando importantes variáveis ecológicas como o crescimento, taxas reprodutivas e produção desses microcrustáceos.

\subsection{Conclusões}

- O parasita Ellobiopsis sp. foi encontrado nos seguintes hospedeiros: Acartia lilljeborgii, Parvocalanus crassirostris, Paracalanus spp., Dioithona oculata, Oithona hebes e O. plumifera.

- As espécies Parvocalanus crassirostris, Oithona plumifera e Diothona oculata são reportadas neste trabalho pela primeira vez como hospedeiros de Ellobiopsis sp.

- Parvocalanus crassirostris foi a espécie com maiores frequências de infestação por Ellobiopsis, com 5\% das fêmeas parasitadas, seguida por Paracalanus spp. Ocorrências de copépodes infectados foram raras para as demais espécies.

- Não foram detectados padrões temporais quanto à proporção de copépodes parasitados.

- Embora menor do que o registrado na literatura, o parasita provavelmente pertence à espécie Ellobiopsis chattoni. Contudo, são necessários estudos complementares para determinação da espécie.

- Os protistas provavelmente causam a redução das taxas de crescimento dos hospedeiros, uma vez que copépodes da espécie $P$. crassirostris infectados são menores do que os normais.

- Estudos experimentais são recomendados, para elucidar os efeitos do parasita sobre parâmetros reprodutivos e populacionais dos hospedeiros. 


\section{REFERÊNCIAS BIBLIOGRÁFICAS}

ABE, D. S. 1993. Contribuição das frações do micro, ano e picofitoplâncton para a biomassa e produtividade primária do ecossistema costeiro de Ubatuba, estado de São Paulo. Dissertação de Mestrado. Instituto Oceanográfico. Universidade de São Paulo, 199 p.

ACUÑA, J. L. \& ANADÓN, R. 1992. Appendicularian assemblages in a shelf area and their relationship with temperature. J. Plankton Res., 14: 1233-1250.

AIDAR, E.; GAETA, A. S.; GIANESELlA-GALVÃO, S. M. F.; KUTNER, M. B. B. \& TEIXEIRA, C. 1993. Ecossistema costeiro tropical: nutrientes dissolvidos, fitoplâncton e clorofila $a$ e suas relações com as condições oceanográficas na região de Ubatuba, SP. Publicação especial do Instituto Oceanográfico, São Paulo, 10: 9-43.

ALBAINA, A. \& IRIGOIEN, X. 2006. Fecundity limitation of Calanus helgolandicus, by the parasite Ellobiopsis sp. J. Plankton Res., 28 (4): 413-418.

ALLDREDGE, A. L. 1972. Abandoned larvacean houses: a unique food source in the pelagic environment. Science, 177: 885-887.

ALMEDA, R.; ALCARAZ, M.; CALBET, A. \& SAIZ, E. 2011. Metabolic rates and carbon budget or early developmental stages of the marine cyclopoid copepod Oithona davisae. Limnol, Oceanogr., 56 (1): 403-414.

ALMEDA, R.; CALBET, A.; ALCARAZ, M.; YEBRA, L. \& SAIZ, E. 2010. Effects of temperature and food concentration on the survival, development, and growth rates of naupliar stages of Oithona davisae (Copepoda, Cyclopoida). Mar. Ecol. Prog. Ser., 410: 97-109.

ALMEIDA-PRADO, M. S. 1962. Sobre o plâncton da enseada do Mar Virado e os métodos de coleta. Bol. Inst. Oceanogr. São Paulo, 12 (3): 49-63.

ALMEIDA-PRADO, M. S. \& LANSAC-TÔHA, F. A. 1984. The distribution of brackish water Calanoida (Copepoda) along the coasts of Brazil.. Hydrobiologia, 113: 147-150.

ALVES-DE-SOUZA, C.; CORNET, C.; NOWACZYK, A.; GASPARINI, S.; SKOVGAARD, A. \& GUILLOU, L. 2011. Blastodinium spp. infect copepods in the ultra-oligotrophic marine waters of the Mediterranean Sea. Biogeosciences, 8: 2125-2136.

ANDERSON, J. A. 2001. A new method for non-parametric multivariate analysis of variance. Aust. Ecol., 26: 32-46.

ANDERSON, J. A. 2005. PERMANOVA: a FORTRAN computer program for permutational multivariate analysis of variance. Department of Statistics, University of Auckland, New Zealand.

APPELTANS, W.; BOUCHET, P.; BOXSHALL, G. A.; DE BROYER, C. D. E.; VOOGD, N. J.; GORDON, D. P.; HOEKSEMA, B. W.; HORTON, T.; KENNEDY, M.; MEES, J.; 
POORE, G. C. B.; READ, G.; STÖHR, S.; WALTER, T. C. \& COSTELLO, M. J. (eds). 2012. World Register of Marine Species. Disponível em: http://www.marinespecies.org.

ARA, K. 2001 a. Temporal variability and production of the planktonic copepods in the Cananeia Lagoon estuarine system, Sao Paulo, Brazil. II. Acartia lilljeborgi. Plankton Biol. Ecol. 48 (1): 35-45.

ARA, K. 2001 b. Temporal variability and production of Euterpina acutifrons (Copepoda: Harpacticoida) in the Cananéia Lagoon estuarine system, São Paulo, Brazil. Hydrobiologia 453/454: 177-187.

ARA, K. 2001 c. Length-weight relationships and chemical content of the planktonic copepods in the Cananéia Lagoon estuarine system, São Paulo, Brazil. Plankton Biol. Ecol., 48 (2): 121-127.

ARA, K. 2002. Temporal variability and production of Temora turbinata (Copepoda: Calanoida) in the Cananéia Lagoon estuarine system, São Paulo, Brazil. Scient. Mar., 66 (4): 399-406.

ARA, K.2004. Temporal Variability and Production of the Planktonic Copepod Community in the Cananéia Lagoon Estuarine System, São Paulo, Brazil. Zool. Studies 43(2): 179-186.

ARTIGAS, L. F.; VENDEVILLE, P.; LEOPOLD, M.; GUIRAL, D. \& TERNON, J.F. 2003.

Marine biodiversity in French Guiana: Estuarine, coastal, and shelf ecosystems under de influence of Amazonian waters. Gayana. 67(2): 302-326.

ATIENZA, D.; SAIZ, E. \& CALBET, A. 2006. Feeding ecology of the marine cladoceran Penilia avirostris: natural diet, prey selectivity and daily ration. Mar. Ecol. Prog. Ser., 315: 211-220.

ATIENZA, D.; CALBET, A.; SAIZ, E. \& LOPES, R. M. 2007. Ecological success of the cladoceran Penilia avirostris in the marine environment: feeding performance, gross growth efficiencies and life history. Mar. Biol., 151: 1385-1396.

ÁVILA, T. R.; MACHADO, A. A. S. \& BIANCHINI, A. 2012. Estimation of zooplankton secondary production in estuarine waters: Comparison between the enzymatic (chitobiase) method and mathematical models using crustaceans. J. Exp. Mar. Biol. Ecol., 416-417: 144-152.

ÁVILA, T. R.; MACHADO, A. A. S. \& BIANCHINI, A. 2011. Chitobiase of planktonic crustaceans from South Atlantic coast (Southern Brazil): Characterization and influence of abiotic parameter on enzyme activity. J. Exp. Mar. Biol. Ecol., 407: 323-329.

AZAM, F.; FENCHEL, T.; FIELD, J. G.; GRAY, J. S.; MEYER-REIL, L. A. \& THINGSTAD, F. 1983. The ecological role of water column microbes in the sea. Mar. Ecol. Prog. Ser., 10: 257-263.

BAKUN, A. 1996. Patterns in the Ocean. Ocean Processes and Marine Population Dynamics. California Sea Grant College System, California, p.323. 
BÅMSTEDT, U. 1986. Chemical composition and energy content. In: Corner, E. D. S. and O'Hara, S. C. M. (eds.). The Biological Chemistry of Marine Copepods. Clarendon Press, Oxford, p.1-58.

BERGGREEN, U.; HANSEN, B. \& KIØRBOE, T. 1988. Food size spectra, ingestion and growth of the copepod Acartia tonsa during development: implications for determination of copepod production. Mar. Biol., 99: 341-352.

BI, H. \& BENFIELD, M. C. 2006. Egg production rates and stage-specific development times of Clausocalanus furcatus (Copepoda, Calanoida) in the northern Gulf of Mexico. J. Plankton res. 28 (12): 1199-1216.

BICALHO, J. P. 2008. Copepoda (Crustacea) da Baía de Santos, estado de São Paulo, parasitados pelo dinoflagelado Ellobiopsis. In: IV Simpósio brasileiro de oceanografia.

BICALHO, J. P. 2010. Composição, distribuição, biomassa e produção secundária do zooplâncton do Sistema estuarino de Santos, São Paulo, Brasil. Tese de doutorado. Instituto Oceanográfico da Universidade de São Paulo, São Paulo, SP. 303 p.

BJÖRNBERG, T. K. S. 1963. On marine free-living copepods of Brazil. Bolm. Inst. Oceanogr. 13: 3-142.

BJÖRNBERG, T. K. S. 1967. The larvae and young forms of Eucalanus Dana (Copepoda) from tropical Atlantic waters. Crustaceana, 12: 59-73.

BJÖRNBERG, T. K. S. 1972. Developmental stages of some tropical and subtropical planktonic marine copepods. Studies on the fauna of Curaçao and other Caribbean islands: $\mathrm{N}^{\circ} 136$. Martinus Nijhoff, The Hague, Holanda.

BJÖRNBERG, T. K. S. 1981. Copepoda. In: Boltovskoy, D. (ed). Atlas del Zooplancton del Atlantico Sudoccidental y métodos de trabajo con el zooplancton marino. INIDEP, Mar Del Plata, Argentina, p.587-680.

BJÖRNBERG, T. K. S.; LOPES, R. M. \& BJÖRNBERG, M. H. G. C. 1994. Chave para a identificação de náuplios de copépodos planctônicos marinhos do Atlântico SulOcidental. Nauplius, 2 (1): 1-16.

BJÖRNBERG, T. K. S.; MOREIRA, M. G. S.; SILVEIRA, F. L. \& MORANDINI, A. C. 1998. Occurrence of two canuellid nauplii (Copepoda, Crustacea) in São Sebastião Channel and vicinity. Trabalhos Oceanográficos da Universidade Federal de Pernambuco, 26 (2): 63 66.

BOSCHMA, H. 1956. Ellobiopsidae, Cons. Int. Explor. Mer. Zooplankton, Sheet 65: 1-4.

BOUILLON, J. 1999. Hydromedusae. In: South Atlantic Zooplankton. Backhuys Publishers, Leiden, The Netherlands, V.1, p. 385-465.

BOUVY, M.; PAGANO, M.; M'BOUP, M.; GOT, P. \& TROUSSELlIER, M. 2006. Functional structure of microbial food web in the Senegal River Estuary (West Africa): impact of metazooplankton. J. Plankton Res., 28 (2): 195-207. 
BOXSHALL, G. A. \& HALSEY, S. H. 2004. An Introduction to Copepod Diversity. Ray Society, Londres, $966 \mathrm{p}$.

BOXSHALL, G. A. 1998. Preface. Philosophical Transactions of the Royal Society of London, B 353: 669-670.

BRADFORD-GRIEVE, J. M.; MARKHASEVA, E. L.; ROCHA, C. E. F. \& ABIAHY, B. 1999. Copepoda. In: Boltovskoy, D. (ed). South Atlantic Zooplantkon. Backhuys publishers, p.869-1098.

BRIDGEMAN, T. B.; MESSICK, G. \& VANDERPLOEG, H. A. 2000. Sudden appearance of cysts and ellobiopsid parasites on zooplankton in a Michigan Lake: a potential explanation of tumor like anomalies. Can. J. Fish. Aquat. Sci., 57: 1539-1544.

BURKILL, P. H. \& KENDALL, T. F. 1982. Production of the copepod Eurytemora affinis in the Bristol Channel. Mar. Ecol. Prog. Ser., 7: 21-31.

CALBET, A.; LANDRY, M. R. \& SCHEINBERG, R. D. 2000. Copepod grazing in a subtropical bay. Species-specific responses to midsummer increase in nanoplankton standing stock. Mar. Ecol. Prog. Ser. 193: 75-84.

CALBET, A. \& LANDRY, M. R. 2004. Phytoplankton growth, microzooplankton grazing, and carbon cycling in marine systems. Limnol. Oceanogr., 49 (1): 51-57.

CALBET, A. 2008. The trophic roles of microzooplankton in marine systems. ICES J. Mar. Sci., 65: 325-331.

CAlBET, A.; GARRIDO, S.; SAIZ, E.; ALCARAZ, M. \& DUARTE, C. M. 2001. Annual zooplankton succession in coastal NW Mediterranean Waters: the importance of the smaller size fractions. J. Plankton Res., 23(3): 319-331.

CARMAN, K. R. \& DOBBS, C. F. 1997. Epibiotic microorganisms on copepods and other marine crustaceans. Micros. Res. Tech., 37:116-135.

CASANOVA, J.P. 1999. Chaetognatha. In: South Atlantic Zooplankton. Backhuys Publishers, Leiden, The Netherlands, V.1 p. 1353-1374.

CASTELLANI,C.; IRIGOIEN, X.; HARRIS, H. P. \& LAMPITT, R. S. 2005. Feeding and egg production of Oithona similis in the North Atlantic. Mar. Ecol. Prog. Ser. 288: 173-182.

CASTRO, B. M.; LORENZZETTI, J. A. \& SILVEIRA, I. C. A. 2006. Estrutura termohalina e circulação na região entre o cabo de São Tomé (RJ) e o Chuí (RS). In: RossiWongtschowski, C. L. B. \& Madureira, L. S. P. (Eds.). O ambiente Oceanográfico da plataforma continental e do talude na região Sudeste-Sul do Brasil. São Paulo, EDUSP, p.11-120.

CASTRO-FILHO, B. M., MIRANDA, L. B. \& MYAO, S. Y. 1987. Condições hidrográficas na plataforma continental ao largo de Ubatuba: variações sazonais e em média escala. Bol. Inst. Oceanogr., 35 (2): 135-155. 
CAULLERY, M. 1910. Ellobiopsis chattoni, n. g., n. sp., parasite de Calanus helgolandicus Claus, appartenant probablement aux Péridiniens. Bulletin Scientifique de la France et la Belgique, 44: 201-214.

CHATTON, E. 1920. Les Péridiniens parasites. Morphologie, reproduction, éthologie. Archives de Zoologie Exprimentale et Générale, 59: 1-475.

CHEN, M.; LIU, H. \& LI, H. 2013. Effect of mesozooplankton feeding selectivity on the dynamics of algae in the presence of intermediate grazers - a laboratory simulation. Mar. Ecol. Prog. Ser., 486: 47-58.

CHISHOLM, L. A. \& ROFF, J. C. 1990. Abundance, growth rates, and production of tropical neritic copepods off Kingston, Jamaica. Mar. Biol., 106: 79-89.

CLARKE, K. R. \& GORLEY, R. N. 2001. PRIMER v5. User manual/tutorial. PRIMER-E, Plymouth.

CLARKE, K. R. \& WARWICK, R. M. 2001. Change in marine communities: an approach to statistical analysis and interpretation. $2^{\mathrm{a}}$ edição. PRIMER-E, Plymouth. p.148.

CONOVER, R.J. 1956. Oceanography of long Island Sound, 1952-1954. 6. Biology of Acartia clausi and A. tonsa. Bull. Bingham Oceanogr. Collect., 14:156-233.

CORNILS, A.; NIEHOFF, B.; RICHTER C.; AL-NAIJAR, T. \& SCHNACK-SCHIEL, S. B. 2007. Seasonal abundance and reproduction of clausocalanid copepods in the northern Gulf of Aqaba (Red Sea). J. Plankton Res., 29 (1): 57-70.

COSTA, K. G.; VALLINOTO, M. \& da COSTA, R. M. 2011. Molecular identification of a new cryptic species of Acartia tonsa (Copepoda, Acartiidae) from the northen coast of Brazil, based on mitochondrial COI gene sequences. J. Coastal Res. SI 64: 359-363.

CRÉTÉ, A. R. M. 2006. Distribuição e produção estimada do copépode Calanoides carinatus (Kroyer, 1849) na plataforma continental sudeste brasileira. Dissertação de Mestrado. Instituto Oceanográfico da Universidade de São Paulo, Departamento de Oceanografia Biológica, p.80.

DAGG, M. 1978. Estimated, in situ, rates of egg production for the copepod Centropages typicus (Krøyer) in the New York bight. J. Exp. Mar. Biol. Ecol. 34: 183-196.

DAGG, M. \& LITTLEPAGE, J. L. 1972. Relationships between growth rate and RNA, DNA, protein and dry weight in Artemia salina and Euchaeta elongata. Mar. Biol., 17: p.162170.

DAM, H. G. 2013. Evolutionary Adaptation of Marine Zooplankton to Global Change. Annu. Rev. Mar. Sci. 5: 349-370.

DAM, H. G. \& LOPES R. M. 2003. Omnivory in the copepod Temora longicornis: feeding, egg production and hatching rates. J. Exp. Mar. Biol. Ecol., 292: 119-137.

DE LA ROCHA, C. L. 1998. Variação temporal da comunidade zooplanctônica e produção anual do copepoda Acartia lilljeborgi na enseada da Praia do Segredo (São Sebastião - 
SP). Dissertação de mestrado. Instituto de Biociências da Universidade de São Paulo, Departamento de Ecologia, p.113.

DECELLE, J.; PROBERT, I.; BITTNER, L.; DESDEVISES, Y.; COLINI, S.; DE VARGAS, C.; GALÍ, M.; SIMÓ. R. \& NOT, F. 2012. An original mode of symbiosis in open ocean plantkon. PNAS, 109 (44): 1800-1805.

DIAS, C. O. \& BONECKER, S. L. C. 2008. Inter-annual Variability of Planktonic Copepods in a Tropical Bay in Southeastern Brazil. Braz. Arch. Biol. Technol. 51: 731-742.

DIAS, L. 1994. Siphonophora (Cnidaria, Hydrozoa) da região compreendida entre Cabo Frio, RJ (23S) e Cabo de Santa Marta Grande, SC (29S). Tese de Doutorado. Instituto de Biociências da Universidade de São Paulo, Departamento de Zoologia, p.164.

DOLAN, J. R.; LANDRY, M. R. \& RITCHIE, M. 2013. The species-rich assemblages of tintinnids (marine planktonic protists) are structured by mouth size. The ISME Journal, 7 (6): 1237-1243.

DOWNING, J. A. \& RIGLER, F. H. 1984. A manual on methods for the assessment of secondary productivity in fresh waters.Blackwell Scientific, London.

DRITS, A. V.; PASTERNAK, A. F. \& KOSOBOKOVA, K. N. 1994. Physiological characteristics of the antartic copepod Calanoides acutus during the late summer in the Weddell Sea. Hydrobiologia, 292/293: 201-207.

EGLOFF, D. A.; FOFONOFF, V. W. \& ONBÉ, T. 1997. Reproductive biology of marine cladocerans. Adv. Mar. Biol., 31: 79-168.

ELIAN, L. \& PETRAN, A. 1971. Sur la presence d' Ellobiopsis chattoni Caullery, sur quelques copépodes de la mar Noire. Rapp. P.-V. Reun. Commn. Int. Explor. Sci. Mer Mediterr. 20: 413-414.

ESCRIBANO, R.; MARIN, V. H. \& HIDALGO, P. 2001. The influence of coastal upwelling on the distribution of Calanus chilensis in the Mejillones Peninsula (northern Chile): implications for its population dynamics. Hydrobiologia 453/454: 143-151.

ESKINAZI-SANT'ANNA, E. M. 2000. Estudo da dieta natural de Parvocalanus crassirostris, Paracalanus quasimodo, Temora stylifera e Temora turbinata (Copepoda, Calanoida), no canal de São Sebastião. Tese de Doutorado. Instituto de Biociências da Universidade de São Paulo, Departamento de Ecologia, p.317.

ESKINAZI-SANT'ANNA, E. N.\& BJÖRNBERG, T. K. S. 2006. Seasonal dynamics of mesozooplankton in Brazilian coastal waters. Hydrobiologia, 563: 253-268.

ESNAL, G. 1999. Appendicularia. In: South Atlantic Zooplankton. Backhuys Publishers, Leiden, The Netherlands, V.1 p. 1375-1399.

FERNANDES, L. F. 2004 a. Tintininos (Ciliophora, Tintinnina) de águas subtropicais na região Sudeste-Sul do Brasil. I. Famílias Codonellidae, Codonellopsidae, Coxliellidae, 
Cyttarocylidae, Epiplocylidae, Petalotrichidae, Pytochocylidade, Tintinnididae e Undellidae. Rev. Bras. Zoo., 21 (3): 551-576.

FERNANDES, L. F. 2004 b. Tintininos (Ciliophora, Tintinnina) de águas subtropicais na região Sudeste-Sul do Brasil. II. Famílias Dictyocystidae, Rhabdonellidae, Tintinnidae e Xystonellidae. Rev. Bras. Zoo., 21 (3):605-628.

FERNÁNDEZ-ÁLAMO, M. A. \& FÄRBER-LORDA, J. 2006. Zooplankton and the oceanography of the eastern tropical Pacific: A review. Prog. Oceanogr., p.318-359.

FORNERIS, L. 1965. Appendicularian species groups and Southern Brazil water masses. Bol. Inst. Oceanogr. São Paulo, 14: 53-114.

FRONTIER, S. 1981. Diseño de muestros. In: Boltovskoy, D. (ed.) Atlas del zooplancton de Atlántico Sudoccidental y métodos de trabajo con el zooplancton marino. INIDEP, Mar del Plata, p.103-108.

FRYER, G. 1986. Structure, function and behaviour, and the elucidation of evolution in copepods and other crustaceans. In: Schriever, G., Schmike, H. K. \& Shih, C. Proceedings of the $2^{\text {nd }}$ international conference on Copepoda, Ottawa, Canada. Syllogeus Series 58. National Museums of Canada, Ottawa: 150-157.

GAETA, S. A.; ABE, D. S.; SUSINI, S. M.; LOPES, R M. \& METZLER, P. M. 1990. Produtividade primária, plâncton e covariáveis ambientais no Canal de São Sebastião durante o outono. Rev. Brasil. Biol., 50 (4): 963-974.

GAETA, S. A. ; RIBEIRO, S. M. S. ; METZLER, P. M. ; FRANCOS, M. S. ; ABE, D. S. 1999. Environmental forcing on phytoplankton biomass and primary productivity of the coastal ecosystem in Ubatuba region, southern Brazil. Rev. Bras. Oceanogr,, 47 (1): 11-27.

GALLIENE, C. P. \& ROBINS, D. B. 2001. Is Oithona the most important copepod in the world's oceans? J. Plankton Res., 23 (12): 1421-1432.

GIANESELlA-GALVÃO, S. M. F.; AIDAR, E.; VEGA-PÉREZ, L. A. \& SALDANHACORRÊA, F. M. P. 1997. Distribuição do plâncton na região costeira de São Sebastião. Relat. téc. inst. oceanogr., (41):5-14.

GIANESELlA-GALVÃO, S. M. F.; KUTNER, M. B. B.; SALDANHA-CORRÊA, F. M. P. \& POMPEU, M. 1999. Assessment of plankton community and environmental conditions in São Sebastião Channel prior to the construction of a produced water outfall. Rev. bras. oceanogr., 47 (1): 29-46.

GIANESElla-GALVÃO, S. M. F. \& SALDANHA-CORRÊA, F. M. P. 2008. Sistema pelagial. Características químicas. In: PIRES VANIN, A. M. S. (org). Oceanografia de um sistema tropical: plataforma de São Sebastião, SP. $1^{\text {a }}$ ed. São Paulo, EDUSP, 183-204 p.

GIANESELLA-GALVÃO, S. M. F. \& SALDANHA-CORRÊA, F. M. P. 1995. A conceptual model for primary production and phytoplankton biomass on inshore waters of Ubatuba 
region. In: International Symposium and environmental biogeochemistry, XII. Abstract. Rio de Janeiro, p.125.

GIERING, S. L. C.; STEIGENBERGER, S.; ACHTERBERG, E. P.; SANDER, R; \& MAYOR, D. J. 2012. Elevated iron to nitrogen recycling by mesozooplankton in the Northeast Atlantic Ocean. Geophys. Res. Lett., 39 (L12608): 1-5.

GO, Y. B.; OH, B-C. \& TERAZAKI, M. 1998. Feeding behaviour of poecilostomatoid copepods Oncaea spp. on chaetognaths. J. Mar. Syst., 15: 475-482.

GOMES, C. L. 2007. O mesozooplâncton da baía de Guanabara: distribuição temporal dos principais grupos e produção de duas espécies de Copepoda dominantes. Tese de Doutorado. Departamento de Ecologia. Universidade Federal do Rio de Janeiro. 130 p.

GÓMEZ, F.; LÓPEZ-GARCÍA.; P.; NOWACZYK, A. \& MOREIRA, D. 2009. The crustacean parasites Ellobiopsis Caullery, 1910 and Thalassomyces Niezabitowski, 1913 form a monophyletic divergent clade within the Alveolata. Syst. Parasitol., 74: 65-74.

GOMÉZ-ERACHE, M., NORBIS, W. \& BASTRERI, D. 2000. Wind effect as forcing factor controlling distribution and diversity of copepods in a shallow temperate estuary (Solis Grande, Uruguay). Scientia Mar., 64: 87-95.

GONZÁLES, H. E. \& SMETACEK, V. 1994. The possible role of the cyclopoid copepod Oithona in retarding vertical flux of zooplankton faecal material. Mar. Ecol. Prog. Ser. 113: 233-246.

GORRI, C. 2006. Composição, abundância e variação sazonal de copépodes capturados na zona de arrebentação da Praia do Cassino - RS, Brasil ( $\left.32^{\circ} 11^{\prime} \mathrm{S}, 52^{\circ} 05^{\prime} \mathrm{W}\right)$ com ênfase no aspecto reprodutivo e alimentar do Calanoida Parvocalanus crassirostris (Dahl, 1894). Tese de Doutorado. Departamento de Oceanografia Biológica. Fundação Universidade Federal do Rio Grande. 112 p.

GOULD, A. L. \& KIMMERER, W. J. 2010. Development, growth and production of the cyclopoid copepod Limnoithona tetraspina in the upper San Francisco estuary. Mar. Ecol. Prog. Ser., 412: 163-177.

GRAHAME, J. 1987. Plankton and fisheries. Edward Arnold (Publishers), London, p.140.

GREEN, E. P. \& DAGG, M. J. 1997. Mesozooplankton associations with medium to large marine snow aggregates in the northern Gulf of Mexico. J. Plankton Res., 19: 435-447.

GREEN, E. P.; HARRIS, R. P. \& DUNCAN, A. 1992. The production and ingestion of fecal pellets by nauplii of marine calanoid copepods. J. Plankton Res., 14(12): 1631-1643.

GUSMÃO, L. F. M. \& MCKINNON, A. D. 2009 a. The effect of food type and quantity on egg production and nucleic acid content of Acartia sinjensis. Aquaculture, 296: 71-80.

GUSMÃO, L. F. M. \& MCKINNON, A. D. 2009 b. Sex ratios, intersexuality and sex change in copepods. J. Plankton Res., 31: 1101-1117. 
GUSMÃO, L. F. M. \& MCKINNON, A. D. 2009 c. Acrocalanus gracilis (Copepoda: Calanoida) development and production in the Timor sea. J. Plankton Res., 31 (9): 10891100 .

HARRIS, R.; WIEBE, P.; LENZ, J.; SKJODAL, H. R. \& HUNTLEY, M. (eds.). 2000. ICES Zooplankton Methodology Manual. Academic Press, Londres, 684 p.

HART, R. C. 1990. Copepod post-embryonic durations: pattern, conformity, and predictability. The realities of isochronal and equiproportional development, and trends in the copepodid-naupliar duration ratio. Hydrobiologia, 206: 175-206.

HENSEN, V. 1887. Über die Bestimmung des Planktons oder des im Meere treibenden Materials an Pflanzen und Thieren. Berichte der Kommssion Wissenschaftlichen Untersuchung der Deutschen Meere in Kiel, 5: 1-107.

HERRERA, I.; YEBRA, L. \& HERNÁNDEZ-LEÓN, S. 2012. Effect of temperature and food concentration on the relationship between growth and AARS activity in Paracartia granii nauplii. J. Exp. Mar. Biol. Ecol., 416/417: 101-109.

HIRST, A. G. \& BUNKER, A. J. 2003. Growth of marine planktonic copepods: Global rates and patterns in relation to chlorophyll $a$, temperature, and body weight. Limnol. Oceanogr., 48 (5): 1988-2010.

HIRST, A. G. \& LAMPITT, R. S. 1998. Towards a global model of in situ weight-specific growth in marine planktonic copepods. Mar. Biol., 132: 247-257.

HIRST, A. G. \& MCKINNON, A. D. 2001. Does egg production represent adult female copepod growth? A call to account for body weight chages. Mar. Ecol. Prog. Ser., 223: 179-199.

HIRST, A. G.; PETERSON, W. T. \& ROTHERY, P. 2005. Errors in juvenile copepod growth rate estimates are widespread: problems with the Moult Rate method. Mar. Ecol. Prog. Ser., 296: 263-279.

HIRST, A. G.; ROFF, J. C. \& LAMPITT, R. S. 2003. A synthesis of growth rates in marine epipelagic invertebrate zooplankton. In: Southward, A. J.; Tyler, P. A.; Young, C. M. \& Fuiman, L. A. (eds). Academic Press. Adv. Mar. Biol., 44: 1-119.

HIRST, A. G. \& SHEADER, M. 1997. Are in situ weight-specific growth rates body-size independent in marine planktonic copepods? A re-analysis of the global syntheses and a new empirical model. Mar. Ecol. Prog. Ser., 154: 155-165.

HO, J.-S. \& PERKINS, P. S. 1985. Symbionts of marine copepoda: an overview. Bull. Mar. Sci. 37 (2): 586-598.

HOENIGMAN, J. 1958. Sur la decouverte de quelques especes zooplanctoniques nouvelles pour l'Adriatique, de deux epibiontes nouveaux pour les Mysidaces, et de deux especes de 
parasites nouvelles pour Ie domaine mediterraneen. Rapp. P.-V. Reun. Commn. Int. Explor. Sci. Mer Meditterr., 14: 263-264.

HOGFORS, H.; HOLMBORN, T.; HAJDU, S. \& GOROKHOVA, E. 2011. Does female RNA content reflect viable egg production in copepods? A test with the Baltic copepod Acartia tonsa. J. Plankton Res., 33 (9): 1460-1463.

HOPCROFT, R. R. \& ROFF. J. C. 1998 a. Zooplankton growth rates: the influence of female size and resources on egg production of tropical marine copepods. Mar. Biol., 132:79-86.

HOPCROFT, R. R. \& ROFF. J. C. 1998 b. Zooplankton growth rates: the influence of size in nauplii of tropical marine copepods. Mar. Biol., 132:87-96.

HOPCROFT, R. R. \& ROFF. J. C. 2001. Size paradigms in copepod communities: a reexamination. Hydrobiologia, 453/454: 133-141.

HOPCROFT, R. R.; ROFF. J. C.; WEBBER, M. K. \& WITT, J. D. S. 1998. Zooplankton growth rates: the influence of size and resources in tropical marine copepoditos. Mar. Biol., 132: 67-77.

HOVASSE, R. 1952. Ellobiopsis fagei Hovasse, Ellobiopsidé parasite, en Méditerranée, de Clausocalanus arcuicornis Dana. Bulletin de l'Institut Océanographique, Monaco, 1016: $1-12$.

HOVASSE, R. 1926. "Parallobiopsis coutieri' Collin. Morphologie, cytologie, évolution, affinités des Ellobiopsidés. Bulletin Scientifique de la France et la Belgique, 60: 409-446.

HUNTLEY, M. E. \& LOPEZ, M. D. G. 1992. Temperature-dependent production of marine copepods - a global synthesis. Am. Nat., 140 (2): 201-242.

HUQ, A.; SMALL, E. B; WEST, P. A.; HUQ, I.; RAHMAN, R. \& COLWELL, R. R. 1983. Ecological Relationships between Vibrio cholerae and Planktonic Crustacean Copepods. Appl. environ. microbiol., 45 (1): 275-283.

HUYS, R. \& BOXSHALL, G. G. 1991. Copepod evolution. The Ray Society, Londres, p.1-468.

IKEDA, T. \& S. MOTODA 1978. Estimated zooplankton production and their ammonia excretion in the Kuroshio and adjacent seas. Fish. Bull., 76: 357-366.

JACOBY, C. A. \& YOUNGBLUTH, M. J. 1983. Mating behavior in three species of Pseudodiaptomus (Copepoda: Calanoida). Mar. Biol., 76: 77-86.

JEPPS, M. W. 1937. On the protozoan parasites of Calanus finmarchicus in the Cycle Sea area. Quarterly J. of Microscop. Sci., 79: 589-658.

JIMÉNEZ-MELERO, R.; GILBERT, J. D. \& GUERRERO, F. 2013. Secondary production of Arctodiaptomus salinus in a shallow saline pound: comparison of methods. Mar. Ecol. Prog. Ser., 483: 103-116.

JÓNADOSTTIR, S. H.; KIØRBOE, T.; TANG, K. W.; JOHN, M. St.; VISSER, A. W.; SAIZ, E. \& DAM, H. G. 2000. Role of diatoms in copepod production: good, harmless or toxic? Mar. Ecol. Prog. Ser., 172: 305-308. 
KAMINSKI, S. M. \& MONTÚ, M. A. 2005. Egg production of the coastal copepods Acartia tonsa, Temora stylifera and Temora turbinata from Cassino Beach - RS, Southern Brazil. Atlântica, 27 (2): 103-111.

KARAYANNI, H.; CHRISTAKI, U.; VAN WAMBEKE, F.; DENIS, M. \& MOUTIN, T. 2005. Influence of ciliated protozoa and heterotrophic nanoflagellates on the fate of primary production in the northeast Atlantic Ocean. J. Geophys. Res., 110: C07S15.

KIMMERER, W. J. \& MCKINNON, A. D. 1987. Growth, mortality, and secondary production of the copepod Acartiatranteri in Westernport Bay, Australia. Limnol. Oceanogr., 32: 1428.

KIMMERER, W. J.; HIRST, A. G.; HOPCROFT, R. R. \& MCKINNON, A. D. 2007. Estimating juvenile copepod growth rates: corrections, inter-comparisons and recommendations. Mar. Ecol. Prog. Ser., 336: 187-202.

KIRCHNER, M.; SAHLING, G.; UHLIG, G; GUNKEL, W. \& KLINGS, K. W. 1996. Does red tide-forming dinoflagellate Noctilucas scintillans feed on bacteria? Sarsia, 81: 45-55.

KLEIN BRETELER, W. C. M.; FRANSZ, H. G. \& GONZALEZ, S. R. 1982. Growth and development of four calanoid copepod species under experimental and natural conditions. Neth. J. Sea. Res. 16: 195-207.

KONOVALOVA, G. V. 2008. Parasitic dinoflagellates and ellobiopsids (Ellobiopsidae) of the Coastal Waters of the Sea of Japan. Russian J. Mar. Biol., 34 (1): 28-37.

KUEI, H. Y. N. \& BJÖRNBERG, T. K. S. 2002. Developmental stages of Oncaea curta Sars, 1916 (Copepoda, Poecilostomatoida). Nauplius, 10 (1): 1-14.

LALLI, C. M. \& PARSONS, R. T. 1997. Biological Oceanography: an introduction. $2^{\mathrm{a}}$ ed. Elsevier, p. 337.

LAM-HOAI, T.; GUIRAL, D. \& ROUGIER, C. 2006. Seasonal change of community structure and size spectra of zooplankton in the Kaw River estuary (French Guiana). Estuarine Coastal and Shelf Sci. 68: 47-61.

LANDRY, M. R.; LEHNER-FOURNIER, J. M. \& FAGERNESS, V. L. 1985. Predatory feeding behavior of the marine cyclopoid copepod Corycaeus anglicus. Mar. Biol. 85: 163-169.

LEANDRO, S. M.; MORGADO, F.; PEREIRA, F. \& QUEIROGA, H. 2007. Temporal changes of abundance, biomass and production of copepod community in a shallow temperate estuary (Ria de Aveiro, Portugal). Estuarine, Coastal and Shelf Sci. 74: 215-222.

LEITÃO, S. N.; GUSMÃO, L. M. O.; VIEIRA, D. A. N.; SANTÁNNA, E. E.; PARANAGUÁ, M.; N.; \& SCHWAMBORN, R. 2008. Diversity and distribution of the mesozooplankton in the tropical southwestern atlantic. J. Plankton Res., 30: 795-805.

LEVINTON, J. L. 2013. Marine biology: function, biodiversity, ecology. $4^{\text {th }}$ ed. Oxford University Press. 
LEUNG, T. L. F. \& POULIN, R. 2008. Parasitism, commensalism and mutualism: exploring the many shades of symbioses. Vie. Milieu, 58 (2): 107-115.

LIANG, T. H. \& VEGA-PÉREZ, L. A. 1994. Studies on chaetognaths of Ubatuba region. I. Distribution and abundance. Bol. Inst. Oceanogr. São Paulo, 42 (1/2): 73-84.

LIANG, T. H. \& VEGA-PÉREZ, L. A. 2002. Distribution, abundance and biomass of Chaetognath of São Sebastião region, Brazil, on February 1994. Rev. Bras. Oceanogr., São Paulo, 50: 1-12.

LIN, K. Y.; SASTRI, A.; GONG, G. C. \& HSIEH, C. H. 2012. Copepod community growth rates in relation to body size, temperature, and food availability in the East China Sea: a test of metabolic theory of ecology. Biogeosciences Disscuss., 9: 16303-16346.

LIU, H. \& HOPCROFT, R. R. 2006 a. Growth and development of Metridia pacifica (Copepoda: Calanoida) in the northern Gulf of Alaska. J. Plankton Res., 28: 769-781.

LIU, H. \& HOPCROFT, R. R. 2006 b. Growth and development of Neocalanus flemingeri / plumchrus in the northen Gulf of Alaska. J. Plankton Res., 28: 769-781.

LIU, S. \& WANG, W. X. 2002. Feeding and reproductive responses of marine copepods in South China Sea to toxic and nontoxic phytoplankton. Mar. Biol., 140: 595-603.

LO, W. T.; CHUNG, C. L. \& SHIH, C. T. 2004. Seasonal distribution of copepods in Tapong Bay, southwestern Taiwan. Zool. Studies, 43: 464-474.

LONSDALE, D. J.; HEINLE, D. R. \& SIEGFRIED, C. 1979. Carnivorous feeding behavior of the adult calanoid copepod Acartia tonsa Dana. J. Exp. Mar. Biol. Ecol. 36: 235-248.

LONGHURST, A.R. 1985. The structure and evolution of plankton communities. Progress in Oceanography, 15: 1-35.

LONGHURST, A.R. 2007. Ecological geography of the sea. $2^{\mathrm{a}}$ ed. Elsevier, p.530.

LOPES, R. M. 1994. Zooplankton distribution in the Guaraú River estuary (Southeastern Brazil). Est. Coast. Shelf Sci., 39: 287-302.

LOPES, R. M. 1997. Distribuição espacial, variação temporal e atividade alimentar do zooplâncton no complexo estuarino de Paranaguá, Curitiba. Tese de Doutorado. Universidade Federal do Paraná, p.140.

LOPES, R. M. 2007. Marine zooplankton studies in Brazil - A brief evaluation and perspectives. An. Acad. Bras. Cienc., 79 (3): 369-379.

LOPES R. M.; BRANDINI, F. P. \& GAETA, S. A. 1999. Distributional patterns of epipelagic copepods off Rio de Janeiro State, Southeastern Brazil. Hydrobiologia, 411: 161-174.

LOPES, R. M.; KATSURAGAWA, M.; DIAS, J. F.; MONTÚ, M. A.; MUELBERT, J. H.; GORRI, C. \& BRANDINI, F. P. 2006 a. Zooplankton and ichthyoplankton distribution on the southern Brazilian shelf: an overview. Scientia Marina 70 (2): 189-202.

LOPES, R. M.; MONTÚ, M. A.; GORRI, C.; MUXAGATA, E.; MIYASHITA, L. K. \& OLIVEIRA, L. P. 2006 b. Diagnóstico do conhecimento atual sobre o zooplâncton 
marinho na região entre o Cabo de São Tomé (RJ) e o Chuí (RS). In: RossiWongtschowski, C. L.D.B. \& Madureira, L. (Org.). O ambiente oceanográfico de plataforma continental e do talude na região sudeste-sul do Brasil., São Paulo: EDUSP. p.265-358.

MAGAlHÃES, A. P.; NOBRE, D. S. B.; BESSA, R. S. C.; PEREIRA, L. C. C. \& COSTA, R. M. 2013. Diel variation in the productivity of Acartia lilljeborgii and Acartia tonsa (Copepoda: Calanoida) in a tropical estuary (Taperaçu, Northern Brazil). J. Coast. Res. Supplement., 2: 1164-1169.

MAGALHÃES, A.; NOBRE, D. S.B.; BESSA, R. S. C.; PEREIRA, L. C.C. \& DA COSTA, R. M. 2011. Seasonal and short-term variations in the copepod community of a shallow Amazon estuary (Taperaçu, Northern Brazil). J. Coast. Res. Supplement., 64: 1520-1524.

MACKAS, D. \& BOHRER, R. 1976. Fluorescence analysis of zooplankton gut contents and an investigation of diel feeding patterns. J. Exp. Mar. Biol. Ecol., 25: 77-85.

MALLIN, M. A. 1991. Zooplankton abundance and community structure in a mesohaline North Carolina estuary. Estuaries, 14: 481-488.

MANCA, M.; ANTONIO CARNOVALE, A. \& ALEMANI, P. 2004. Exotopic protrusions and ellobiopsid infection in zooplanktonic copepods of a large, deep subalpine lake, Lago Maggiore, in northern Italy. J. Plankton Res., 26 (11): 1257-1263.

MARQUES, S. C.; PARDAL, M. A.; MENDES, S. \& AZEITEIRO, U. M. 2011. Using multitable techniques for assessing the temporal variability of species-environment relationship in a copepod community from a temperate estuarine ecosystem. J. Exp. Mar. Biol. Ecol., 405: 59-67.

MARSHALL, S. M. \& ORR, A. P. 1955. The biology of a marine copepod. Springer - Verlag, Nova Iorque, E.U.A., p.188.

MARTINELLI FILHO, J. E.; LOPES, R. M.; RIVERA I. N. G. \& COLWELL, R. R. 2011. Vibrio cholerae $\mathrm{O} 1$ detection in estuarine and coast zooplankton. J. Plankton Res., 33: 5162 .

MARTINELLI-FILHO, J. E. 2007. A associação entre o zooplâncton e Vibrio cholerae no complexo estuarino de Santos-Bertioga e plataforma adjacente. Dissertação de mestrado. Departamento de Oceanografia Biológica, Instituto Oceanográfico da Universidade de São Paulo, São Paulo - SP, p.134.

MARTINELLI-FILHO, J. E.; STAMPAR, S. N.; MORANDINI, A. C. \& MOSSOLIN, E. C. 2008. Cleaner shrimp (Caridae: Palaemonidae) Associated with syphozoan jellyfish. Vie. Milieu, 58 (2): 133-140.

MARTINEZ, T. I. 2013. Distribuição especial e sazonal do microzooplâncton na bacia de Campos em cinco massas de água, da superfície ao batipelagial. Dissertação de mestrado. 
Instituto Oceanográfico da Universidade de São Paulo, Departamento de Oceanografia Biológica, São Paulo, SP, p.141.

MAUCHLINE, J. 1998. The biology of calanoid copepods. Academic press. San Diego, 710 p.

MCKINNON, A. D. 1996. Growth and development on the subtropical copepod Acrocalanus gibber. Limnol. Oceanogr. 41 (7): 1438-1447.

MCKINNON, A. D. \& AYUKAI, T. 1996. Copepod egg production and food resources in Exmouth Gulf, Western Australia. Mar. Freshwater Res., 47: 595-603.

MCKINNON, A. D. \& DUGGAN, S. 2003. Summer copepod production in subtropical waters adjacent to Australia's North West Cape. Mar. Biol., 143: 897-907.

MCKINNON, A. D.; DUGGAN, S. \& DE'ATH, G. 2005. Mesozooplankton dynamics in nearshore waters of the Great Barrier Reef. Estuar. Coast. Shelf Sci., 63: 497-511.

MCKINNON, A. D.; DUGGAN, S.; NICHOLS, P.D.; RIMMER, M. A.. SEMMENS, G. \& ROBINO, B. 2003. The potential of tropical paracalanid copepods as live feeds in aquaculture. Aquaculture, 223: 89-106.

MCLAREN, I. A.; TREMBLAY, J. M.; CORKETT, C. J. \& ROFF, J. C. 1989. Copepod production on the Scotian Shelf based on life-history analyses and laboratory rearings. Can. J. Fish. Aquat. Sci., 46:560-583.

MCMANNUS, G. B.; COSTAS, B. A.; DAM, H. G.; LOPES, R. M.; GAETA, S. A.; SUSINI, S. M. \& ROSETTA, C. H. 2007. Microzooplankton grazing of phytoplankton in a tropical upwellin region. Hydrobiologia, 575: 69-81.

MELO-JÚNIOR, M. 2009. Produção secundária e aspectos reprodutivos de copépodes pelágicos ao largo de Ubatuba (SP, Brasil). Tese de doutorado. Instituto Oceanográfico da Universidade de São Paulo, Departamento de Oceanografia Biológica, São Paulo, SP, p.205.

MELO-JÚNIOR, M.; MIYASHITA, L. K.; SILVA, N. J.; GAETA, S. A. \& LOPES, R. M. 2013. Reproductive traits of Euterpina acutifrons in a coastal area of southeastern Brazil. Mar. Ecol., 2013: 1-10.

MENÉNDEZ, M. C.; PICCOLO, M. C. \& HOFFMEYER, M. S. 2012. Short-term variability on mesozooplankton community in a shallow mixes estuary (Bahía Blanca, Argentina): Influence of tidal cycles and local winds. Est. Coast. Shelf Sci., 112: 11-22.

METZ, C. 1998. Feeding of Oncaea curvata (Poecilostomatoida, Copepoda). Mar. Ecol. Prog. Ser., 169: 229-235.

METZLER, P. M. 1991. Estudo da produtividade primária e características fisiológicas do fitoplâncton na região de Ubatuba, São Paulo, através de curvas de luz-fotossíntese. Dissertação de mestrado. Universidade de São Paulo, Instituto Oceanográfico. 2v.

MIAZAN, H. W. \& CORNELIUS, P. F. S. 1999. Cubomedusae and Scyphomedusae. In: South Atlantic Zooplankton. Backhuys Publishers, Leiden, The Netherlands. V.1 p. 513-559. 
MILLER, C. B. 2004. Biological Oceanograpy. Malden: Blackwell Science, p.402.

MILSTEIN, A. 1979. Vertical distribution of Paracalanus crassirostris (Copepoda: Calanoida), analysis by the general linear model. Bol. Inst. Oceanogr. São Paulo, 28 (2): 65-78.

MIYASHITA, L. K.; MELO-JÚNIOR, M. \& LOPES, R. M. 2009. Estuarine and oceanic influences on copepod abundance and production of a subtropical coastal area. J. Plankton Res., 31 (8): 815-826.

MIYASHITA, L. K.; POMPEU, M,; GAETA, S. A. \& LOPES, R. M. 2010. Seasonal contrasts in abundance and reproductive parameters of Penilia avirostris (Cladocera, Ctenopoda) in a coastal subtropical area. Mar. Biol., 157: 2511-2519.

MIYASHITA, L. K. \& LOPES, R. M. 2011. Larvacean (Chordata,Tunicata) abundance and inferred secondary production off southeastern Brazil. Est. Coast. Shelf Sci. p.367-375.

MIYASHITA, L. K.; GAETA, S. A. \& LOPES, R. M. 2011. Life cycle and reproductive traits of marine podonids (Cladocera, Onychopoda) in a coastal subtropical area. J.Plankton Res., 33 (5): 779-792.

MIYASHITA, L. K.; BRANDINI, F. P.; MARTINELLI FILHO, J. E.; FERNANDES, L. F. \& LOPES, R. M. 2012. Comparison of zooplankton community structure between impacted and non-impacted areas of Paranaguá Bay Estuarine Complex, south Brazil. J. Natural History, 46: 1557-1571.

MØLLER, E. F. 2007. Production of dissolved organic carbon by sloppy feeding in the copepods Acartiatonsa, Centropagestypicus, and Temoralongicornis. Limnol. Oceanogr., 52 (1): 79-84.

MØLLER, E. F.; BORG, C. M.A.; JÓNASDÓTTIR, S. H.; SATAPOOMIN, S.; JASPERS, C. \& NIELSEN, T. G. 2011. Production and fate of copepod fecal pellets across the Southern Indian Ocean. Mar. Biol., 158: 677-688.

MONTI, M.; MINOCCI, M.; MILANI, L. \& UMANI, S. F. 2012. Seasonal and interannual dynamics of microzooplankton abundances in the Gulf of Trieste (Northern Adriatic Sea, Italy). Est. Coast. Shelf Sci., 115: 149-157.

MORANDINI, A. C. \& SILVEIRA, F. L. 2001. Sexual reproduction of Nausithoe aurea (Scyphozoa, Coronate). Gametogenesis, egg release, embryonic development, and gastrulation. Sci. Mar., 65(2): 139-149.

MORANDINI, A. C.; ASCHER, D.; STAMPAR, S. N. \& FERREIRA, J. F. V. 2005. Cubozoa e Scyphozoa (Cnidaria: Medusozoa) de águas costeiras do Brasil. Iheringia, Série Zoologia, 95 (3): 281-294.

MOREIRA, G.S.; MCNAMARA, J.C. \& MOREIRA, P. S. 1982. The Combine Effect of Temperature and Salinity on the Survival of Euterpina Acutifrons (Dana) (Copepoda, Harpacticoida) from the New Zealand and Brazilians Coasts. J. Plank. Res., 4: 85-91. 
MUXAGATA, E;. AMARAL, W. J. A. \& BARBOSA, C. N. 2012. Acartia tonsa production in the Patos lagoon estuary, Brazil. ICES J. Mar. Sci., 69 (3): 475-482.

MUXAGATA, E;. WILliAMS, J.A. \& SHEADER, M. 2004. Composition and temporal distribution of cirripede larvae in Southampton Water, England, with particular reference to the secondary production of Eliminius modestus. ICES J. Mar. Sci. 61: $585-595$.

NEUMANN-LEITÃO, S. \& MATSUMURA-TUNDISI, T. 1998. Dynamics of a perturbed estuarine zooplanktonic community: Porto f Suape, PE, Brazil. Verh. Internat. Verein. Limnol. 26: 1981-1988.

NICHIBE, Y.; HIROTA, Y. \& UEDA, H. 2009. Community structure and vertical distribution of oncaeid copepods in Tosa Bay, southern Japan. J. Mar. Biol. Ass. U. K. 89 (3): 491498.

OLIVEIRA, A. J. F. C. 2000. Regeneração de nutrientes por alguns componentes da alça microbiana. Tese de doutorado, Instituto Oceanográfico da Universidade de São Paulo, Departamento de Oceanografia Biológica, São Paulo, SP, p.94.

OLIVEIRA, O. M. P. \& MIGOTTO, A. E. 2006. Pelagic ctenophores form the São Sebastião Channel, southeastern Brazil. Zootaxa, 1183: 1-26.

OLIVEIRA, O. M. P.; MIAZAN, H.; MIGOTTO, A. E. \& MARQUES, A. C. 2007. Chave de identificação dos Ctenophora da costa brasileira. Biota Neotropica, 7(3): 341-350.

OMORI, M. \& HAMNER, W. M. 1982. Patchy distribution of Zooplankton: Behavior, Population assessment and Sampling Problems. Mar. Biol., 72: 193-200.

OMORI, M. \& IKEDA, T. 1984. Methods in marine zooplankton ecology. John Wiley \& sons, Nova Iorque, p.332.

ONBÉ, T. 1999. Ctenopoda and Onychopoda (Cladocera). In: South Atlantic Zooplankton. Backhuys Publishers, Leiden, The Netherlands, V.1 p.797-813.

OOSTERHUIS, S.S.; BAARS, M. A. \& KLEIN BRETELER, W. C. M. 2000. Release of the enzyme chitobiase by the copepod Temora longicornis: characteristics and potential tool for estimating crustacean biomass production in the sea. Mar. Ecol. Prog. Ser. 196: 195206.

PAFFENHÖFER, G. 1993. On the ecology of marine cyclopoid copepods (Crustacea, Copepoda). J. Plankton Res., 15 (1): 37-55.

PARRISH, K. K. \& WILSON, D. F. 1978. Fecundity studies on Acartia tonsa (Copepoda: Calanoida) in standardized culture. Mar. Biol., 46: 65-81.

PARSONS, T. R.; TAKAHASHI, M. \& HARGRAVE, B. 1984. Biological oceanographic processes. $3^{\circ}$ edição. Ed. Pergamon, Nova Iorque, E.U.A. 
PÉREZ-ARAGÓN, M.; FERNANDEZ, C. \& ESCRIBANO, R. 2011. Nitrogen excretion by mesozooplankton in a coastal upwelling area: Seasonal trends and implications for biological production. J. Mar. Exp Biol. Ecol., 406: 116-124.

PETERSON, W. T. 2001. Patterns in stage duration and development among marine and freshwater clanoid and cyclopoid copepods: a review of rules, physiological constraints, and evolutionary significance. Hydrobiologia 453/454: 91-105.

PETERSON, W. T.\& HUTCHINGS, L. 1995. Distribution, abundance and production of the copepod Calanus agulhensis on the Agulhas Bank in relation to spatial variations in hydrography and chlorophyll concentration. J. Plankton Res., 17: 2275-2294.

PETERSON, W. T.; TISELIUS, P. T. \& KIORBOE, T. 1991. Copepod egg production, molting and growth rates, and secondary production, in the Skagerrak in August 1988. J. Plankton Res., 13: 131-154.

PIELOU, E. C. 1977. Mathematical Ecology. New York, John Wiley \& Sons, p.385.

PINESE, J. F. 1983. Distribuição Vertical e Variação sazonal do Copepoda Acartia lilljeborgi na Enseada do Flamengo, Ubatuba-SP. Dissertação de mestrado. Instituto Oceanográfico da Universidade de São Paulo, São Paulo - SP.

PIRES-VANIN, A. M. S. 2008. Oceanografia de um Ecossistema Subtropical: Plataforma de São Sebastião, SP. Editora da Universidade de São Paulo EDUSP. São Paulo, SP, p.462.

PIRES-VANIN, A. M. S.; ARASAKI, E. \& MUNIZ, P. 2013. Spatial pattern of benthic macrofauna in a sub-tropical shelf, São Sebastião Channel, southeastern Brazil. Lat. Am. J. Aquat. Res., 41 (1): 42-56.

PIRES-VANIN, A. M. S., GIANESELLA, S. M. F. \& SOARES, L. S. H. 2008. O Ecossistema da plataforma de São Sebastião e os principais fatores que regem seu funcionamento. In: Pires-Vanin, A. M. S. (org.). 2008. Oceanografia de um Ecossistema Subtropical: Plataforma de São Sebastião, SP. Editora da Universidade de São Paulo EDUSP. São Paulo, SP, p.449-462.

PIRES-VANIN, A.M.S.; ROSSI-WONGTSCHOWSKI, C. L. B.; AIDAR, E.; MESQUITA. H. S. L.; SOARES, L. S. H.; KATSURAGAWA, M. \& MATSUURA, Y. 1993. Estrutura e função do ecossistema de plataforma continental do Atlântico Sul brasileiro: síntese dos resultados. Publicação especial do Instituto Oceanográfico 10: 217-231.

POMBO, M. \& MARTINELLI-FILHO, J. E. 2012. New non-sexual skeletal abnormalities in Acartia lilljeborgii Giesbrecht, 1889 (Copepoda, Calanoida). Crustaceana, 85 (2): 249255 .

POMEROY, L. R. 1974. The ocean's food web, a changing paradigm. Bioscience, 24: 499-504.

POMPEU, M. 1998. Microzooplâncton - Tintinnina da Região de Abrolhos ( $16^{\circ}$ a $21^{\circ} \mathrm{S}$ e $36^{\circ}$ a $41^{\circ}$ ). Dissertação de Mestrado. Instituto Oceanográfico, Universidade de São Paulo. São Paulo, p.84. 
POUCHET, G. 1885. Nouvelle contribution à l'histoire des Péridiniens marins. J. Anat.phys. XXI: 28-88.

POUCHET, G. 1884. Sur un Péridinien parasite. C. R. Acad. Se. XCVIII, 1345-1346.

POULET, S. A.; IANORA, A.; LAABIR, M. \& KLEIN BRETELER, W. C. M. 1995. Towards the measurement of secondary production and recruitment in copepods. ICES. J. Mar. Sci., 52: 359-368.

RAYNER, A. N. \& KING, E. M. 1986. First record of a freshwater calanoid Tropodiaptomus spectabilis (Kiefer, 1929) (Crustacea, Copepoda) as host of an ellobiopsid parasite. J. Plankton Res., 8: 837-840.

REGISTAD, M.; RISER, C. W. \& SVENSES, C. 2005. Fate of copepod faecal pellets and the role of Oithona spp. Mar. Ecol. Prog. Ser. 304: 265-270.

RICHARDSON, A. J. 2008. In hot water: zooplankton and climate change. ICES. J. Mar. Sci., 65: 279-295.

RICHTER, G. \& SEAPY, R. R. 1999. Chapter 14. Heteropoda. In: Boltvoskoy, D. (ed.). South Atlantic Zooplankton. Leiden, Backhuys Publishers. XX-YY p.

RIGLER, F. H. \& DOWNING, J. A. 1984. The calculation of secondary productivity . In: RIGLER, F. H. \& DOWNING, J. A. A manual on methods for the assessment of secondary productivity in fresh waters, p. 19-58. Blackwell Scientific, Oxford.

RIMOLDI, D. C. 2008. Estudo comparativo dos copépodes Temora stylifera e Temora turbinata na plataforma continental sudeste do Brasil no verão e inverno de 2002. Dissertação de mestrado.Instituto Oceanográfico da Universidade de São Paulo, Departamento de Oceanografia Biológica, São Paulo, SP, p.134.

ROCHA, C. E. F. 1986. Copepods of the Genus Oithona Baird, 1843 from mangrove areas of Central and South America. Hydrobiologia, 135: 95-107.

ROCHA, G. R. A.; ROSSI-WONGTSCHOWSKI, C. L. D. B.; PIRES-VANIN, A. M. S. \& JARRE-TEICHMANN, A. 2003. Seasonal budgets of organic matter in Ubatuba shelf system, SE Brazil. I. Planktonic and benthic components. Oceanologica Acta, 26: 487495 .

ROFF, J. C.; TURNER, J. T.; WEBBER, M. K. \& HOPCROFF, R. R. 1995. Bacterivory by tropical copepod nauplii: extent and possible significance. Aquat. Microbiol. Ecol., 9:165-175.

ROMAN, M. R. \& RUBLEE, P. A. 1980. Containment effects in copepod grazing experiments: A plea to end the black box approach. Limnol. Oceanogr. 25 (6): 982-990.

RUNGE, J. A. 1988. Should we expect a relationship between primary production and fisheries? The role of copepod dynamics as a filter of trophic variability. Hydrobiologia, 167/168: 61-71. 
RUNGE, J.A. \& ROFF, J. C. 2000. The measurement of growth and reproductive rates. In: HARRIS, R.P.; WIEBE, P.; LENZ, J.; HUNTLEY, M. \& SKJOLDAL, H. R. (eds.) ICES Zooplankton Methodology Manual. Academic Press. 401-454 p.

SABA, G. K. STEINBERG, D. K. \& BRONK, D. A. 2011. The relative importance of sloppy feeding, excretion, and fecal pellet leaching in the release of dissolved carbon and nitrogen by Acartia tonsa copepods. J. Exp. Mar. Biol. Ecol., 404: 47-56.

SAIZ, E. \& CALBET, A. 2011. Copepod feeding in the ocean: scaling patterns, composition of their diet and the bias of estimates due to microzooplankton grazing during incubations. Hydrobiologia, 666: 181-196.

SAIZ, E., CALBET, A., FARA, A. \& BERDALET, E. 1998. RNA content of copepods as a tool for determining adult growth rates in the field. Limnol. Oceanogr., 43, 465-470.

SALDANHA-CORRÊA, F. M. P. \& GIANESELLA, S. M. F. 2008. Produção primária e fitoplâncton. In: A.M.S. Pires-Vanin. (Org.). Oceanografia de um Ecossitema Subtropical: Plataforma de São Sebastião. $1^{\text {a }}$ ed.São Paulo: Editora da Universidade de São Paulo- EDUSP p. 223-251.

SANT'ANNA, E. E. 2013. Remains of the protozoan Sticholonche zanclea in the faecal pellets of Paracalanus quasimodo, Parvocalanus crassirostris, Temora stylifera and Temora turbinata (Copepoda, Calanoida) in Brazilian coastal waters. Braz. J. Oceanogr., 61 (1): 73-76.

SANTHAKUMARI, V. \& SARASWATHY, M. 1979. On the Ellobiopsidae, parasitic protozoa from zooplankton. Mahasagar-Bull. Nat. Inst. Oceanogr., 12: 83-92.

SARTORI, L. P. \& LOPES, R. M. 2000. Seasonal variability of pelagic coppepod assemblages on the inner continental shelf off Paraná, Brazil. Nauplius, 8 (1): 79-88.

SASTRI, A. R. \& DOWER, J. F. 2006. Field validation of an instantaneous estimate of in situ development and growth for marine copepod communities. Can. J. Fish. Aquat. Sci., 63: 2639-2647.

SCHMINKE, H. K. 2007. Entomology for the copepodologist. J. Plankton Res. 29 (supplement 1): $49-62$.

SCHMOKER, C.; HERNÁNDEZ-LEÓN, S. \& CALBET, A. 2013. Microzooplankton grazing in the oceans: impacts, data variability, knowledge gaps and future directions. J. Plankton. Res., 35 (4): 691-706.

SCHWAMBORN, R.; BONECKER, S. L. C.; GALVÃO, I. B.; SILVA, T. A. \& LEITÃO, S. N. 2004. Mesozooplankton grazing under conditions of extreme eutrophication in Guanabara Bay, Brazil. J. plankton Res., 26 (9): 983-992.

SCHWEIKERT, M. \& ELBRÄCHTER, M. 2006. First ultrastructural investigations on Ellobiopsis spec. (incertae sedis) a parasite of copepods. Endocytobiosis Cell Res., 17: 73. 
SHANNON, C. E. 1948. A mathematical theory of communication. The Bell System Tech. J. 27: $379-423$.

SHERR, E. B. \& SHERR, B. F. 1991. Planktonic microbes: tiny cells at the base of the ocean's food webs. Trends Ecol. Evol., 6 (2): 50-54.

SHIELDS, J. D. 1994. The parasitic dinoflagellates of marine crustaceans. Ann. Rev. Fish Dis., 4: $241-271$.

SHMELEVA, A. A. 1965. Weight characteristics of the zooplankton of the Adriatic Sea: Bull. Inst. Oceanogr. Monaco 65 (n1351): 1-24.

SHREEVE, R. S.; WARD, P. \& MURRAY, A. W. A. 1998. Moulting rates of Calanus helgolandicus: an inter-comparison of experimental methods. J. Mar. Exp. Biol. Ecol. 224: 145-154.

SILVA, N. J. 2012. Influência da ingestão de microalgas potencialmente nocivas na alimentação e reprodução de copépodes: uma abordagem experimental. Dissertação de mestrado. Instituto Oceanográfico da Universidade de São Paulo, Departamento de Oceanografia Biológica. SP, p.163.

SKOVGAARD, A. 2004. Tumour-like anomalies on copepods may be wounds from parasites. J. Plankton Res. 26 (9): 1129-1131.

SKOVGAARD, A. \& SAIZ, E. 2006. Seasonal occurrence and role of protistan parasites in coastal marine zooplankton. Mar. Ecol. Prog. Ser., 327: 37-49.

SMITH, S. L. \& LANE, P. V. Z. 1985. Laboratory studies of the marine copepod Centropages typicus: egg production and development rates. Mar. Biol., 85: 153-162.

SOMMER, U.; SOMMER, F.; FEIUCHTMAYR, H. \& HANSEN, T. 2004. The Influence of Mesozooplankton on Phytoplankton Nutrient Limitation: A Mesocosm Study with Northeast Atlantic Plankton. Protist, 155: 295-304.

STEUER, A. 1932. Über Ellobiopsis elongata n. sp. aus dem Südatlantik. Note dell Instituto Italo-Germanico de Biologia Marina de Bovigno Distria, 5: 1-6.

STØTTRUP, P. J. \& COHEN, P. P. 1990. Influence of algal diet on feeding and egg production of the calanoid copepod Acartia tonsa. J. Exp. Mar. Biol. Ecol., 141: 87-105.

STRICKLER, J.R. 1982. Calanoid copepods, feeding currents, and the role of gravity. Science, 218, 158-160.

STROM, S. L.; MACRI, E. L. \& OLSON, M. B. 2007. Microzooplankton grazing in the coastal Gulf of Alaska: Variations in top-down control of phytoplankton. Limnol. Oceanogr., 52 (4): $1480-1494$.

SUCHY, K. D.; DOWER, J. E.; SASTRI, A. R. \& NEIL, M. C. 2013. Influence of diet on chitobiase-based production rates for the harpacticoid copepod Trigiopus californicus. J. Plankton Res., 35 (3): 657-667. 
TANG, K. W. 2005. Copepods as microbial hotspots in the ocean effects of host feeding activities on attached bacteria. Aquat. Microb. Ecol., 38: 31-40.

TANG, K. W.; GLUD, R. N.; GLUD, A.; RYSGAARD, S. \& NIELSEN, T. G. 2011. Copepod guts as biogeochemical hotspots in the sea: Evidence from microelectrode profiling of Calanusspp. Limnol. Oceanogr., 56 (2): 666-672.

TEIXEIRA, C.; TUNDISI, J. \& KUTNER, M. B. 1965. Plankton studies in a mangrove environment.II. The standing-stock and some ecological factors. Bol. Inst. Oceanogr. São Paulo, 14 (1): 13-41.

TEMPERONI, B.; VIŇAS, M. D. DIOVISALVI, N. \& NEGRI, R. 2011. Seasonal production of Oithona nana Giesbrecht, 1893 (Copepoda: Cyclopoida) in temperate coastal waters off Argentina. J. Plankton Res., 33 (5): 729-740.

THÉODORIDÈS, J. 1989. Parasitology of Marine Zooplankton. Adv. Mar. Biol., 25: 117-177.

THOMPSON, G. A.; ALDER, V. A. \& BOLTOVSKOY, D. 2001. Tintinnids (Cilliophora) and other net microzooplâncton (> $30 \mu \mathrm{m}$ ) in Southwestern Atlantic shelf break waters. Mar. Ecol. 22 (4): 343-355.

TRONOLONE, V. B. 2007. Estudo faunístico e da distribuição das hidromedusas (Cnidaria, Hydrozoa) da região compreendida entre Cabo Frio (RJ) e Cabo de Santa Marta Grande (SC), Brasil. Tese de doutorado. Instituto de Biociências da Universidade de São Paulo, Departamento de Zoologia, São Paulo, SP, p. 209.

TUNDISI, T. M. 1970. On the seasonal occurrence of appendicularians in waters off the coast of São Paulo state. Bol. Inst. Oceanogr. São Paulo 19: 131-144.

TUNDISI, J.; TEIXEIRA, C.; MATSUMURA-TUNDISI, T.; KUTNER, M. B. \& KINOSHITA, L. 1978. Plankton studies in a mangrove environment. IX. Comparative investigations with coastal oligotrophic waters. Rev. Bras. Biol. 38 (2): 301-320.

TUNDISI, J. G. \& TUNDISI, T. M. 1968. Plankton studies in mangrove environment. V. Salinity tolerances of some planktonic crustacean. Bol. Inst. Oceanogr. São Paulo, 17 (1): $57-65$.

TURNER, J. T. \& TESTER, P. A. 1992. Zooplankton feeding ecology - bacterivory by metazoan microzooplankton. J. Exp. Mar. Biol. Ecol., 160: 149-167.

TURNER, J. T. 2004. The importance of small planktonic copepods and their roles in pelagic marine food webs. Zool. Stud., 43 (2): 255-266.

TURNER, J. T.; POSTEK, M. T. \& COLLARD, S. B. 1979. Infestation of the estuarine copepod Acartia tonsa with the ciliate Epistylis. Trans. Am. Microsc. Soc., 98:136-138.

TURNER, J. T.; TESTER, P. A. \& CONLEY, W. J. 1984. zooplankton feeding ecology: predation by the marine cyclopoid copepod Corycaeus amazonizcus F. Dahl upon natural prey. J. Exp. Mar. Biol. Ecol. 84: 191-202. 
UNDERWOOD, A. J. 1997. Experiments in Ecology: their logical design and interpretation using Analysis of Variance. Cambridge University Press, Cambridge.

VALENTIN, J. L. 1984 a. Analyse des paramètres hydrobiologiques dans la remontée de Cabo Frio (Brésil). Mar. Biol., 82: 259-276.

VALENTIN, J. L. 1984 b. Spatial structure of the zooplankton community in the Cabo Frio region (Brazil) influenced by coastal upwelling. Hydrobiologia 113: 183-199.

VALENTIN, J. L. \& MONTEIRO-RIBAS, W. 1993. Zooplankton community structure on the east-southeast Brazilian continental shelf (18-23ㅇ S latitude). Cont. Shelf Res. 13 (4): 407424.

VAN DER SPOEL, S. \& DADON, J. R. 1999. Chapter 15. Petropoda. In: Boltvoskoy, D. (ed.). South Atlantic Zooplankton. Leiden, Backhuys Publishers. XX-YY p.

VANNUCCI, M. 1957. Distribuição de Scyphozoa nas costas do Brasil. Anais Acad Bras. Ciências, 29 (4): 593-598.

VEGA-PÉREZ, L. A. 1993. Estudo do zooplâncton da região de Ubatuba, Estado de São Paulo. Publicação especial do Instituto Oceanográfico, 10: 65-84.

VEGA-PÉREZ, L. A. 2008. Zooplâncton. In: Pires-Vanin, A. M. S. (Org.). Oceanografia de um Ecossistema Subtropical. Plataforma de São Sebastião, SP. 1ªd.São Paulo: edusp, 2008, p. 253-272.

VERHEYE, H. S. 1991. Short-term variability during an anchor station study in the southern Benguela upwelling system: Abundance, distribution and estimated production of mesozooplankton with special reference to Calanoides carinatus (Krøyer, 1849). Prog. Oceanogr. 28: 91-119.

VIDAL, J. 1980. Physioecology of zooplankton. I. Effects of phytoplankton concentration, temperature, and body size on the growth rates of Calanus pacificus and Pseudocalanus sp. Mar. Biol., 56:111-134.

WAGNER, M.; DURBIN, E. \& BUCKLEY, L. 1998. RNA:DNA ratios as indicators of nutritional condition in the copepod Calanus finmarchicus. Mar. Ecol. Prog. Ser. 162: $173-181$.

WAGNER, M.; CAMPBELL, R. G.; BOUdREAU, C. A. \& DURBIN, E. G. 2001. Nucleic acids and growth of Calanus finmarchicus in the laboratory under different food and temperature conditions. Mar. Ecol. Prog. Ser. 221: 185-197.

WALKUSZ, W. \& ROLBIECKI, L. 2007. Epibionts (Paracineta) and parasites (Ellobiopsis) on copepods from Spitsbergn (Kongsfjorden area). Oceanologia, 49 (3): 369-380.

WALTER, T.C. \& Boxshall, G.A. 2008.World of Copepods database. Available online at http://www.marinespecies.org/copepoda.

WEBBER, M. K. \& ROFF, J. C. 1995. Annual biomass and production of the oceanic copepod community off Discovery Bay, Jamaica. Mar. Biol. 123: 467-479. 
WEISMMAN, P.; LONSDALE, D. J.\& YEN, J. 1993. The effect of peritrich ciliates on the production of Acartia hudsonica in Long Island Sound. Limnol. Oceanogr. 38 (3): 613622.

WELSCHMEYER, N. A \& LORENZEN, C. J. 1985. Chl budgets: Zooplankton grazing and phytoplankton growth in a temperate fjord and the Central Pacific Gyres. Limnol. Oceanogr., 30: 1-21.

WELSCHMEYER, N. A. 1994. Fluorometric analysis of chlorophyll $a$ in the presence of chlorophyll $b$ and pheopigments. Limnol. Oceanogr., 39(8): 1985-1992.

WICKSTEAD, J. H. 1963. A new record of Ellobiopsis chattoni (Flagellata incertae sedis) and its incidence in a population of Undinula vulgaris var. major (Crustacea, Copepoda). Parasitology, 53: 293-296.

WIEBE, P. H. \& BENFIELD, M. C. 2003. From the Hensen net toward four-dimensional biological oceanography. Prog. Oceanogr., 56: 7-136.

WILLEY, R. L.; CANTRELL, P. A.THREKELD, R. T. 1990. Epibiotic euglenoid flagellates increase the susceptibility of some zooplankton to fish predation. Limnol. Oceanogr., 35 (4): 952-959.

WILLIANS, J. D. \& AN, J. 2009. The cryptogenic parasitic isopod Orthione griffenis Markham, 2004 from the eastern and western Pacific. Integr. Comparative Biol., 49: 114126.

WINBERG, G. G. 1971. Methods for the estimation of production of aquatic animals. Academic Press, London.

WU, C. J.; CHIANG, K. P. \& LIU, H. 2010. Diel feeding pattern and prey selection of mesozooplankton on microplankton community. J. Exp. Mar. Biol. Ecol. 390: 134-142.

YEBRA, L.; BERDALET, E.; ALMEDA, R.; PÉRES, V. CALBET, A. \& SAIZ, E. 2011. Protein and nucleic acid metabolismo as proxies for growth and fitness of Oithona davisae (Copepoda: Cyclopoida) early developmental stages. J. Exp. Mar. Biol. Ecol., 406: 87-94.

YEBRA, L.; HARRIS, R. P. \& SMITH, T. 2005. Comparison of five methods for estimating growth of Calanus helgolandicus later developmental stages (CV-CVI). Mar. Biol. 147: 1367-1375.

YEBRA, L. \& HERNÁNDEZ-LEÓN, S. 2004. Aminoacyl tRNA synthetase activity as a growth index in zooplankton. J. Plankton Res. 26 (3): 351-356.

ZAR, J. H. 1999. Biostatistical Analysis. Prentice Hall, Upper Saddle River. 663 p. 
ANEXOS 
Anexo A: Valores de precipitação em milímetros, para as estações de verão e inverno dos anos de 2009 a 2011. Dados obtidos da estação meteorológica da base de pesquisa Clarimundo de Jesus, Ubatuba.

\begin{tabular}{cc|cc|cc|cc|cc|cc}
\hline \multicolumn{2}{c|}{$\begin{array}{c}\text { Verão } \\
2009\end{array}$} & \multicolumn{2}{c|}{$\begin{array}{c}\text { Inverno } \\
\mathbf{2 0 0 9}\end{array}$} & \multicolumn{2}{c|}{$\mathbf{2 0 1 0}$} & \multicolumn{2}{c|}{$\mathbf{2 0 1 0}$} & $\mathbf{2 0 1 1}$ & \multicolumn{2}{c|}{$\mathbf{2 0 1 1}$} \\
\hline $09 / 01$ & 4,2 & $9 / 07$ & 0 & $3 / 01$ & 0,1 & $9 / 07$ & 0 & $6 / 01$ & 0 & $2 / 07$ & 0 \\
\hline $10 / 01$ & 45 & $10 / 07$ & 0 & $4 / 01$ & 0 & $10 / 07$ & 0 & $7 / 01$ & 3,8 & $3 / 07$ & 0 \\
\hline $11 / 01$ & 0 & $11 / 07$ & 0 & $5 / 01$ & 0 & $11 / 07$ & 0 & $8 / 01$ & 0,1 & $4 / 07$ & 0 \\
\hline $12 / 01$ & 0 & $12 / 07$ & 0 & $6 / 01$ & 0 & $12 / 07$ & 0 & $9 / 01$ & 0 & $5 / 07$ & 10,6 \\
\hline $13 / 01$ & 0 & $13 / 07$ & 0 & $7 / 01$ & 0 & $13 / 07$ & 0 & $10 / 01$ & 2,4 & $6 / 07$ & 0 \\
\hline $14 / 01$ & 0,8 & $14 / 07$ & 0 & $8 / 01$ & 0 & $14 / 07$ & 0 & $11 / 01$ & 32,9 & $7 / 07$ & 12,4 \\
\hline $15 / 01$ & 0 & $15 / 07$ & 0 & $9 / 01$ & 1,1 & $15 / 07$ & 62,1 & $12 / 01$ & 54 & $8 / 07$ & 0 \\
\hline $16 / 01$ & 0 & $16 / 07$ & 0 & $10 / 01$ & 0 & $16 / 07$ & 71 & $13 / 01$ & 10,4 & $9 / 07$ & 3,5 \\
\hline $17 / 01$ & 17,2 & $17 / 07$ & 0 & $11 / 01$ & 0 & $17 / 07$ & 24,7 & $14 / 01$ & 1 & $10 / 07$ & 0 \\
\hline $18 / 01$ & 0 & $18 / 07$ & 0 & $12 / 01$ & 0 & $18 / 07$ & 50 & $15 / 01$ & 12,2 & $11 / 07$ & 0 \\
\hline $19 / 01$ & 0 & $19 / 07$ & 0 & $13 / 01$ & 0 & $19 / 07$ & 0 & $16 / 01$ & 26,4 & $12 / 07$ & 0 \\
\hline $20 / 01$ & 4,9 & $20 / 07$ & 0 & $14 / 01$ & 0 & $20 / 07$ & 0 & $17 / 01$ & 2 & $13 / 07$ & 0 \\
\hline $21 / 01$ & 38,2 & $21 / 07$ & 0 & $15 / 01$ & 168 & $21 / 07$ & 0 & $18 / 01$ & 0 & $14 / 07$ & 0 \\
\hline $22 / 01$ & 1,9 & $22 / 07$ & 0 & $16 / 01$ & 0,3 & $22 / 07$ & 0 & $19 / 01$ & 0 & $15 / 07$ & 0 \\
\hline $23 / 01$ & 0,3 & $23 / 07$ & 0 & $17 / 01$ & 0 & $23 / 07$ & 0 & $20 / 01$ & 0 & $16 / 07$ & 0 \\
\hline $24 / 01$ & 4,9 & $24 / 07$ & 0 & $18 / 01$ & 0 & $24 / 07$ & 0 & $21 / 01$ & 17,7 & $17 / 07$ & 0 \\
\hline $25 / 01$ & 0 & $25 / 07$ & 25,4 & $19 / 01$ & 0 & $25 / 07$ & 0 & $22 / 01$ & 0 & $18 / 07$ & 0 \\
\hline $26 / 01$ & 0 & $26 / 07$ & 26,6 & $20 / 01$ & 0 & $26 / 07$ & 0 & $23 / 01$ & 0 & $19 / 07$ & 0 \\
\hline $27 / 01$ & 2,3 & $27 / 07$ & 0 & $21 / 01$ & 0 & $27 / 07$ & 0 & $24 / 01$ & 0 & $20 / 07$ & 0 \\
\hline $28 / 01$ & 0 & $28 / 07$ & 0 & $22 / 01$ & 16 & $28 / 07$ & 0 & $6 / 01$ & 0 & $21 / 07$ & 0 \\
\hline $29 / 01$ & 0,6 & $29 / 07$ & 0 & $23 / 01$ & 0,1 & $29 / 07$ & 0 & - & - & $22 / 07$ & 0 \\
\hline $30 / 01$ & 3,4 & $30 / 07$ & 0 & $24 / 01$ & 0,9 & $30 / 07$ & 0 & - & - & $23 / 07$ & 59 \\
\hline $31 / 01$ & 0,4 & - & - & - & - & $31 / 07$ & 0 & - & - & - & - \\
\hline $01 / 02$ & 0 & - & - & - & - & $1 / 08$ & 0 & - & - & - & - \\
\hline $02 / 02$ & 6,1 & - & - & - & - & - & - & - & - & - & - \\
\hline & & & & & & & & 0 \\
\hline
\end{tabular}

